Université de Szeged - Université Rennes 2

\title{
Pál Gyöngyi:
}

LE DISPOSITIF PHOTO-LITTERAIRE EN FRANCE DANS LA SECONDE MOITIE DU XX' SIECLE

Analyse de l'œuvre de François-Marie Banier, Jean-Loup Trassard, Lorand Gaspar et Denis Roche

Thèse en co-tutelle présentée et soutenue

le 2 avril 2010

à l'Université de Szeged

Directeurs de thèse :

\section{Gyimesi Timea}

Jean-Pierre Montier

Rapporteurs :

Danièle Méaux

Beke László 
Pal, Gyöngyi. Le dispositif photo-littéraire en France dans la seconde moitie du XXe siècle Analyse de l'oeuvre de François-Marie Banier, Jean-Loup Trassard, Lorand Gaspar et Denis Roche - 2010 
« chacun peut y lire autre chose et aussi la même chose. »

(Lorand Gaspar, Approche de la parole) 
Pal, Gyöngyi. Le dispositif photo-littéraire en France dans la seconde moitie du XXe siècle Analyse de l'oeuvre de François-Marie Banier, Jean-Loup Trassard, Lorand Gaspar et Denis Roche - 2010 
Je tiens avant tout à remercier mes deux directeurs de thèse, dr. Gyimesi Timea à l'Université de Szeged et M. Jean-Pierre Montier à l'Université Rennes 2 pour leur assistance accordée tout au long de ce travail.

Mes remerciements vont aussi au Service de Bourse de l'Ambassade de France pour m'avoir accordé la Bourse de cotutelle sans laquelle ce travail n'aurait pas pu avoir lieu.

Merci aussi à Camille Tauveron pour la correction minutieuse et pour le canapé qui m'a toujours accueilli pour que je puisse compléter mes recherches à Paris.

Je tiens également à exprimer ma profonde reconnaissance pour Jean-Loup Trassard pour m'avoir chaleureusement accueilli chez lui, pour avoir répondu à mon questionnaire, et pour m'avoir accordé l'autorisation de reproduction de ses images dans ma thèse.

Je remercie au même titre Lorand Gaspar et Denis Roche pour l'autorisation des reproductions de leurs œuvres.

Et bien entendu, ma gratitude va à Christian Barkow, à ma famille et à mes amies (Tóth Júlia et Kovàcs Teréz) qui m'ont supportée avec beaucoup d'affection et de patience pendant ces années d'études. 
Pal, Gyöngyi. Le dispositif photo-littéraire en France dans la seconde moitie du XXe siècle Analyse de l'oeuvre de François-Marie Banier, Jean-Loup Trassard, Lorand Gaspar et Denis Roche - 2010 


\section{Sommaire}

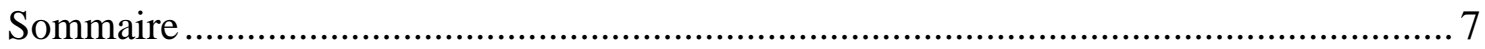

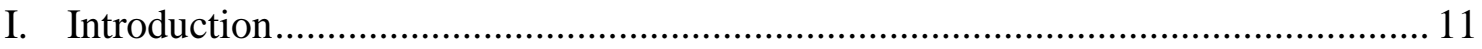

\section{Partie : Panorama photographique et photo-littéraire de la} deuxième moitié du XXe siècle ...................................................21

II. L'évolution de la théorie de la photographie - la vérité en question....................... 24

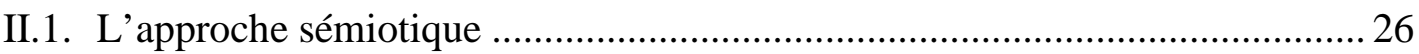

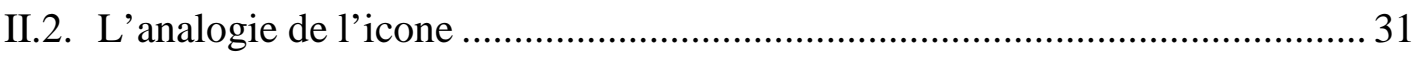

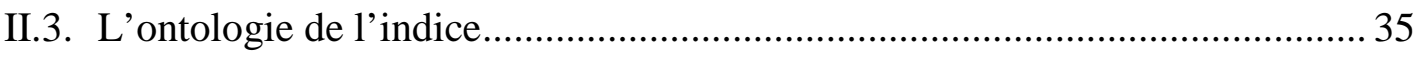

II.4. La deuxième moitié du $\mathrm{XX}^{\mathrm{e}}$ siècle : contextes et changements ...................... 38

II.5. Le paradoxe de l'empreinte ….............................................................. 47

II.6. La photographie comme dispositif .......................................................... 53

II.7. Le sens sensible de la photographie............................................................56

II.8. La pluralité du sens et la pluralité de l'usage.................................................59

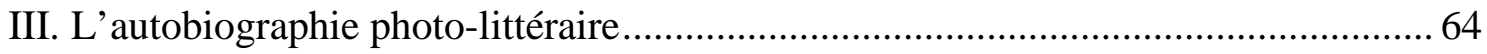

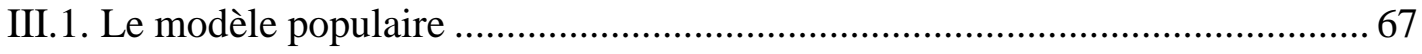

III.2. Le modèle des arts plastiques, l'approche conceptuelle ............................... 72

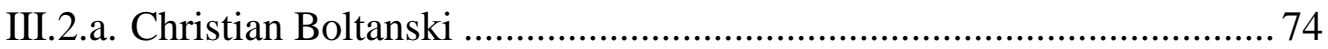

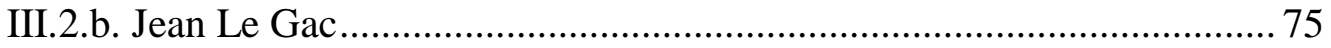

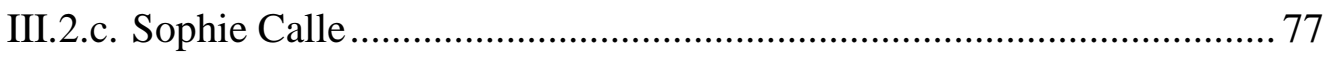

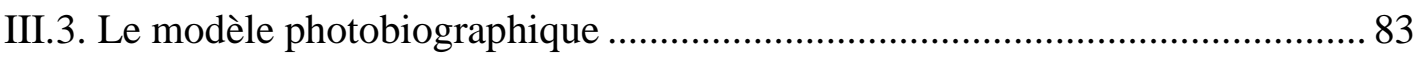

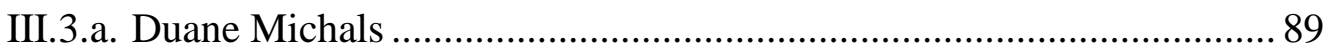

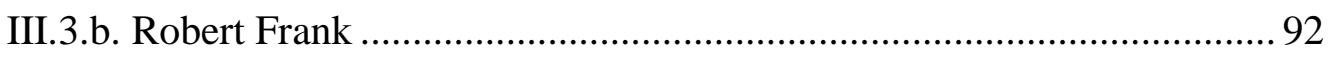

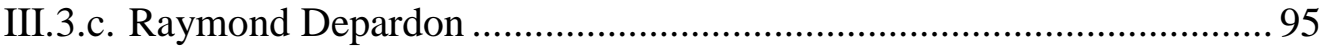

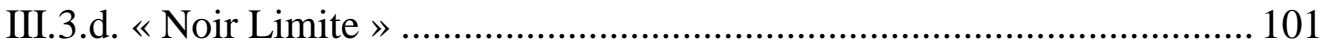

III.3.e. La dissolution du clivage entre extériorité et intériorité .................... 106 
III.4. Le modèle littéraire .113

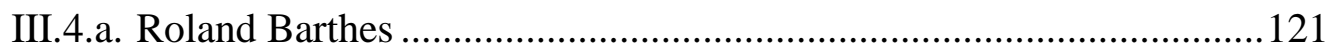

III.4.b. L'entre-deux dans les récits autobiographiques ..................................125

III.4.c. L'autofiction chez l'écrivain photographe Hervé Guibert ...................128

III.4.d. L'identité dynamique du désordre....................................................133

III.5. Photographie et fiction - la pluralité et la dissolution des frontières ..............142

\section{Partie : Zoom sur l'œuvre photo-littéraire de quelques} écrivains photographes.........................................................153

IV. Zoom sur l'œuvre photo-littéraire de quelques écrivains photographes ...................154

V. François-Marie Banier - la passion de la vie ..........................................................157

V.1. La famille universelle - le portraitiste de son temps........................................159

V.1.a. Les portraits d'écrivain - la photo intertextuelle ................................162

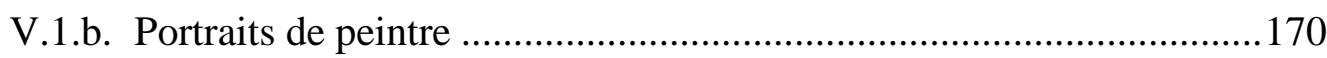

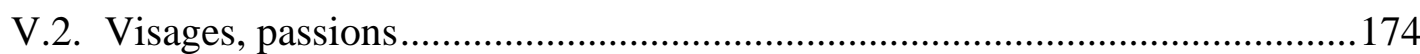

V.3. Photographie et théâtre................................................................................181

V.4. Iconotextes ou pratiques transversales ..............................................................

V.4.a. Les photographies écrites ................................................................186

V.4.b. Les photographies peintes ……………………………………….........190

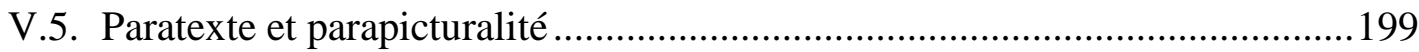

V.6. La construction des livres et le récit visuel .......................................................205

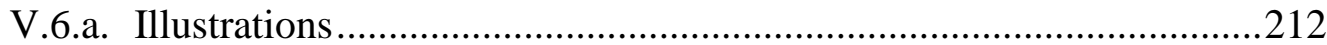

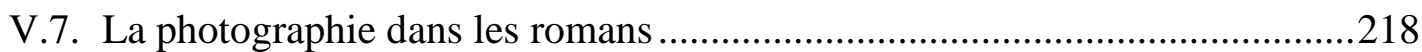

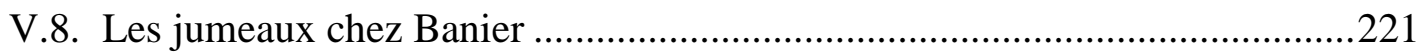

V.9. François-Marie Banier - Conclusion …………………………………….......227

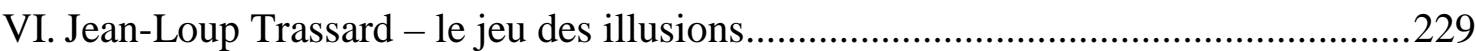

VI.1. L'espace habité par les souvenirs...................................................................232

VI.1.a. Tardifs instantanés - les multiples facettes du modèle photographique 
VI.1.b. Dormance - la photographique comme schème

VI.1.c. Au-delà des genres.

VI.2. La phautofiction

VI.3. Les récits de voyage.

VI.4. L'énigme photographique ou l'espace intime de l'entre-deux 260

VI.5. Les rapports texte/image 267

VI.5.a. Inventaire des outils à main dans une ferme - la poétique de l'empêchement. 267

VI.5.b. Archéologie des feux - une trace de lumière 269

VI.5.c. Territoire - la surface plane fragmentée 270

VI.5.d. Ouailles - le récit en image. 273

VI.5.e. Tumulus - le crépuscule des civilisations. 276

VI.5.f. Nuisibles - le labyrinthe de la pensée. 277

VI.5.g. La Composition du jardin - la sonate visuelle. 280

VI.5.h. Sanzaki - la ronde des saisons 283

VI.5.i. Les livres illustrés par des dessins 285

VI.6. La transparence de la photographie 288

VI.7. Jean-Loup Trassard - Conclusion. 291

ANNEXE $n^{\circ} 1$ : Comparaison des livres hybrides de Jean-Loup Trassard. 292

ANNEXE n² : Questionnaire adressé à Jean-Loup Trassard 294

VII. Lorand Gaspar - poète de la lumière 301

VII.1. Le caractère autobiographique de son oeuvre 303

VII.2. Paysage de lumière 307

VII.3. Parallèles photographiques : pierre, archéologie, érosion, langage, silence 312

VII.4. Une approche spinoziste. 318

VII.5. Au-delà des apparences 321

VII.6. La représentation vivante 326

VII.7. Idéogrammes 330 
VII.8. Les livres d'artiste et les lectures d'images .340

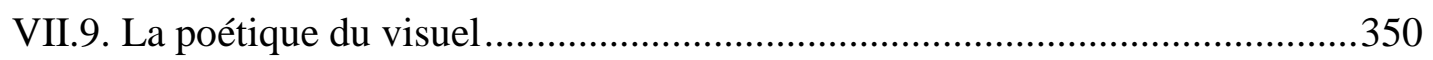

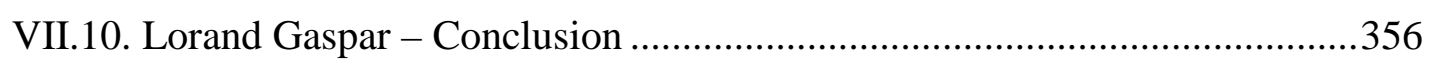

ANNEXE n³ : Exemples du cheminement des œuvres de Lorand Gaspar à travers

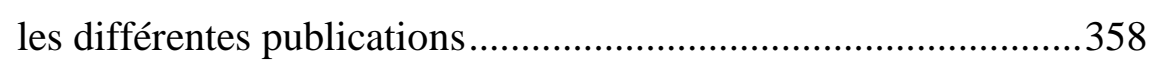

ANNEXE $n^{\circ} 4$ : Ouvrages de Lorand Gaspar rassemblant textes et images ............359

VIII. Denis Roche - les allers et retours entre littérature et photographie ....................363

VIII.1. L'approche critique d'une œuvre en construction......................................365

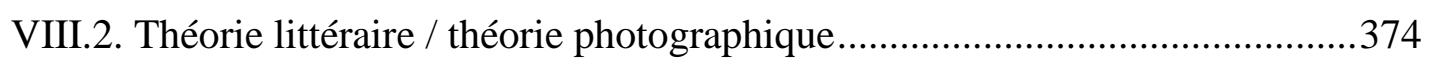

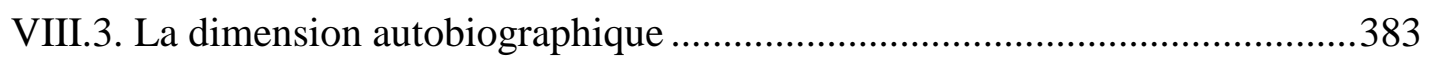

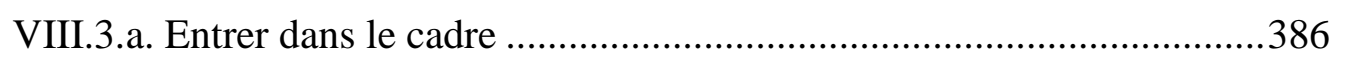

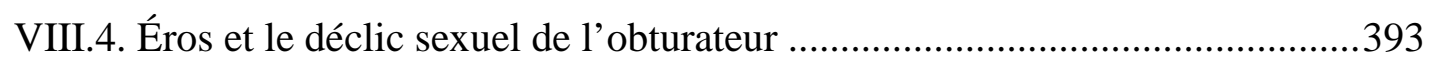

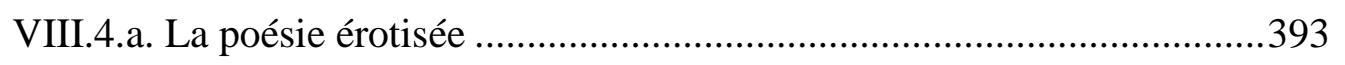

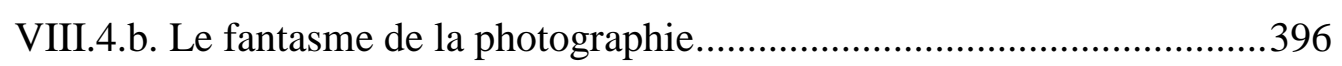

VIII.4.c. La photographie comme chant d'amour ........................................401

VIII.4.d. Analogies théorique et thématique ...............................................404

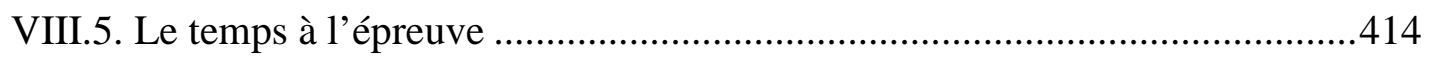

VIII.6. Poésie et photographie en mouvance ......................................................423

VIII.7. Denis Roche - Conclusion ............................................................431

ANNEXE n 5 : L'évolution vers l'iconicité de recueil en recueil........................434

ANNEXE $n^{\circ} 6$ : Structure temporelle du livre Les Preuves du Temps ....................438

IX. La convergence dans les pratiques des écrivains photographes ...........................440

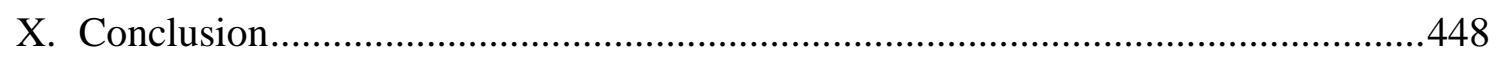

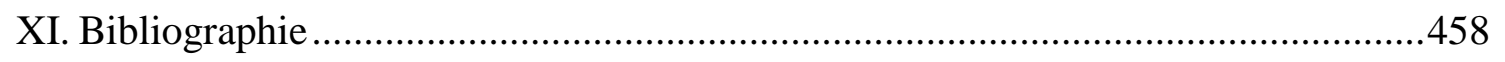

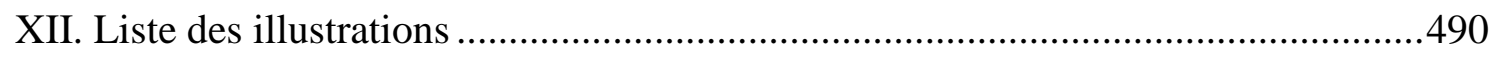




\section{Introduction}

La photographie est omniprésente dans la littérature depuis l'invention du procédé au $\mathrm{XIX}^{\mathrm{e}}$ siècle. Cependant son influence et sa présence dans la littérature restèrent longtemps inaperçus, comme le démontre Philippe Ortel dans son livre La Littérature à l'ère de la photographie ${ }^{1}$. Pourtant, ces deux formes d'art se sont mutuellement influencés : la littérature contribua à l'invention de la photographie, selon Jérôme Thélot ${ }^{2}$, en la modelant, en construisant son imaginaire, en développant sa théorie entre autres à travers des œuvres de fiction; de manière réciproque, la photographie renouvela la littérature. Depuis les années 1990, une nouvelle discipline voit le jour aux États-Unis, une branche des «Cultural Studies » intitulée «Visual Studies » ou «Visual Culture $^{3}$ », qui s'intéresse de manière générale à l'image. En même temps en France, plusieurs études commencèrent à explorer plus spécifiquement le domaine «photolittéraire ${ }^{4} \gg$. Cette thèse s'intègre dans de ces recherches et poursuit le même but : éclairer l'influence réciproque entre la littérature et la photographie en analysant les dispositifs photo-littéraires en France dans la seconde moitié du $\mathrm{XX}^{\mathrm{e}}$ siècle.

Il faut toutefois mentionner, que la tâche n'est pas simple car les classements par sujets dans les bibliothèques ne contiennent que depuis peu la mention «photographie et littérature » et «photographie ---- Dans la littérature »- et encore ces entrées ne fontelles référence qu'à la littérature secondaire traitant de ce sujet, et non pas aux œuvres primaires. Les rayons des librairies et les maisons d'édition elles-mêmes ne font pas la distinction entre les dispositifs où la photographie apparaît dans le livre en tant qu'illustration ou ceux où elle joue le rôle d'un élément narratif actif. La constitution de notre corpus primaire se base donc sur la littérature secondaire photo-littéraire publiée, ainsi que sur une recherche personnelle menée par tâtonnement à cause de la non visibilité des œuvres.

\footnotetext{
${ }^{1}$ ORTEL, Philippe, La Littérature à l'ère de la photographie, Nîmes, Jacqueline Chambon, 2002.

${ }^{2}$ THELOT, Jérôme, Les inventions littéraires de la photographie, Paris, PUF, 2003.

${ }^{3}$ Voir l'article « visual culture » : http://en. wikipedia.org/wiki/Visual_culture (consulté le : 07/11/2009).

${ }^{4}$ Ce terme est proposé par Jean-Pierre Montier dans l'ouvrage : Littérature et photographie, (sous la dir. de Jean-Pierre Montier; Liliane Louvel ; Danièle Méaux ; Philippe Ortel, Rennes, PUR, 2008, p. 11). Pour une liste des études menées à bien dans ce domaine voir dans la bibliographie la rubrique : Théorie photo-littéraire.
} 


\section{L’hypothèse de départ}

Pour restreindre le champ de notre étude, nous avons adopté dans notre hypothèse de départ la distinction que propose Michel Tournier ${ }^{5}$ sur les écrivains photographes. Tournier est lui-même photographe amateur et promoteur de la photographie ${ }^{6}$, mais c'est en tant que préfacier de certains livres de ses amis photographes qu'il conclut qu'il y a toujours un rapport de force et de domination entre le texte et l'image, et que dans la majorité des cas l'écriture apposée au cliché influence l'interprétation de ce dernier. Tournier expose cette problématique dans un livre de photos conçu avec le photographe Edouard Boubat :

Le mariage de l'écriture et de la photographie a toujours été l'une de mes préoccupations. Est-il possible ? N'est-ce pas vouloir mêler l'eau et le feu ? Les meilleurs dessins humoristiques sont «sans paroles », et ce mot même de «légende» dont on désigne le texte bref qui prétend expliquer une image paraît le dénuer a priori de tout fondement. [...] Il s'agit en somme d'un problème de préséance. De son côté la photographie a peu de chances de pouvoir rejoindre un texte imposé, ou alors elle l'accompagnera de loin, vaguement, plus par l'esprit qu'à la lettre.

Tournier conclut ensuite que la solution pour éviter ce rapport de force serait que le photographe et l'écrivain soient une seule et même personne, mais il ajoute : «l'oiseau doit être bien rare car on le cherche encore ${ }^{8} »$. Il fait alors la distinction entre la photographie créatrice et la photographie prédatrice que pratiquent tous les photographes amateurs9 ${ }^{9}$ L'écrivain photographe serait, selon lui, celui qui développe un style propre à la fois en photographie et en littérature. La thèse examine donc, à l'intérieur du domaine photo-littéraire l'œuvre des écrivains photographes et la relation du texte/photographie.

\footnotetext{
${ }^{5}$ Ce travail de recherche se situe donc dans la suite logique d'une étude de Master 2 sur le rôle de la photographie dans l'œuvre de Michel Tournier : PAL, Gyöngyi, Les mille et une faces de la photographie dans l'œuvre de Michel Tournier, Mémoire de Master 2, 2005, Paris III. - Sorbonne Nouvelle sous la direction de M. Jean-Louis Leutrat.

${ }^{6}$ Avant de commencer sa carrière littéraire, Tournier travailla entre 1960 à 1965 à une série télévisée, Chambre noire, consacrée à la popularisation de la photographie ; il contribua également à fonder, avec Jean-Marie Rouquette, conservateur de musée, et Lucien Clergue, photographe, les Rencontres internationales de Photographie d'Arles. Il devient promoteur de la photographie en publiant de nombreuses préfaces de livre de photographie, mais le médium intervient également comme modèle et repoussoir dans son œuvre romanesque.

7 BOUBAT, Edouard, Miroirs autoportraits, Paris, Denoël, 1973, livre sans pagination (préface de Michel Tournier).

${ }^{8}$ Ibid.

9 TOURNIER, Michel, «Création et prédation », Les Cahiers de la photographie, édition du colloque de Paris I - Panthéon Sorbonne, 1982, p. 84-90.
} 


\section{Une approche historique}

Selon Tournier, les romanciers accepteraient bien «qu'on illustre leurs œuvres », mais ils ne se prêteraient pas volontiers au rôle de commentateurs. Sa remarque fait écho à celle de Denis Roche, qui constate à son tour dans les années 1980 :

[...] Il faut tout de même s'étonner de la relation amoureuse établie depuis des siècles entre la littérature et la peinture et s'étonner encore plus, que depuis l'invention de la photographie, cette relation n'ait fait que croître tandis qu'il ne vient quasiment jamais à l'idée d'un écrivain d'écrire sur la photographie. En d'autres termes : d'où vient que l'écrivain soit si préfacier de peinture et jamais de photographie (affaire de classe ?). ${ }^{10}$

Dans le dialogue entre l'écriture et la photographie, la hiérarchie joue donc un rôle important. Le changement du statut de la photographie et son institutionnalisation entraînent justement un bouleversement à la fin du $\mathrm{XX}^{\mathrm{e}}$ siècle dans le rapport texte/photographie, ce qui justifie notre approche historique. En effet, à partir des années 1990 apparaissent progressivement nombre d'œuvres hybrides ${ }^{11}$ et de dispositifs hétérogènes mêlant de manière très variée la photographie et le texte. Certaines maisons d'édition se spécialisent même dans l'édition d'œuvres photo-littéraires en promouvant la collaboration entre les écrivains et les photographes. Parallèlement, le critère que nous avons posé au départ - à savoir d'examiner les œuvres des écrivains photographes pour éviter le rapport hiérarchique entre la photographie et le texte - ne semble plus pertinent. Car les œuvres hybrides ne se soucient plus si l'un des médiums infléchit le sens de l'autre, leur objectif est au contraire de déformer mutuellement leur sens premier en les juxtaposant.

La photographie en tant que première image technique, bouleverse non seulement la littérature, mais plus généralement la société, la manière de vivre, de connaître et d'évaluer le monde et nous-même. En 1994, deux professeurs indépendamment l'un de l'autre introduisent la notion du «tournant iconique ${ }^{12} »$ pour rendre compte du passage à la société de l'information où les images, avant tout techniques (photographie, télévision, Internet), prennent le pas sur la communication

${ }^{10}$ ROCHE, Denis, La disparition des lucioles (réflexions sur l'acte photographique), Paris, l'Etoile, 1982, p. 52.

${ }^{11}$ Nous empruntons ce terme à Chloé Conant qui l'introduit dans sa thèse intitulée La littérature, la photographie, l'hétérogène : étude d'interactions contemporaines (C. Boltanski, W. Boyd, S. Calle, G. Davenport, J. Roubaud, W.G. Sebald), thèse soutenu à l'Université de Limoges en 2003.

${ }^{12}$ Il s'agit de W. J. T. Mitchell, (« The Pictorial Turn », The Art Forum, 1994.) et de Gottfried Boehm («Die Wiederkehr der Bilder» (Le retour des images), dans G. Boehm (éd.), Was ist ein Bild? (Qu'est-ce qu'une image?), Munich, Wilhelm Fink Verlag, 1994, p. 11-38. 
langagière. Selon Vilem Flusser, il s'agit alors d'un retour à l'état d'avant l'invention de Gutenberg, d'avant le règne de l'écriture ${ }^{13}$.

La première partie de notre travail tente ainsi de retracer ces changements très complexes en proposant un aperçu panoramique et théorique aussi vaste que possible pour comprendre les mutations qui ont vu le jour autour des productions photolittéraires.

\section{Problématiques fondamentales}

Le rapport de force entre le texte et la photographie que Tournier mentionne cache avant tout un problème de référent: la valeur de vérité d'une photographie est toujours problématique. Nous examinerons alors au sein de cette première partie théorique, l'évolution de la théorie de la photographie dans la deuxième moitié du $\mathrm{XX}^{\mathrm{e}}$ siècle. Les théoriciens de la photographie n'aboutissent qu'à décrire le médium comme paradoxal : elle est en même temps intentionnel et mécanique, art et non-art. Cette problématique autour de la valeur de vérité des clichés influence à son tour les productions photolittéraires, et plus précisément les autobiographies photo-littéraires. Dans son rôle documentaire de support à la mémoire visuelle, la photo redéfinit l'appréhension de l'identité. Dans le second sous-chapitre, nous analyserons alors les diverses facettes de cette influence de la photographie sur la littérature.

Il faut voir toutefois, que les questionnements qui apparaissent autour de l'hypothèse de départ sont très nombreux à cause de l'utilisation et du rôle multiple de la photographie. Les questions que nous allons évoquer ici se présentent en arrière-plan dans la thèse, mais restent invisibles dans la structuration de l'ensemble.

La photographie sert de support à la mémoire visuelle mais aussi à la communication visuelle; elle joue, à l'ère des appareils numériques, à l'illusion de pouvoir communiquer ce que l'on voit avec la même immédiateté que la communication orale. La fixité de l'image photographique pose toutefois un problème, car elle s'oppose à l'image de la perception, à la mémoire visuelle (l'enregistrement des

\footnotetext{
${ }^{13}$ FLUSSER, Vilem, La civilisation des médias, Paris, Circé, 2006. Le texte est disponible en hongrois sur Internet : http://www.artpool.hu/Flusser/Univerzum/00.html (consulté le : 20/10/2009).
} 
choses vues) et aux images mentales (les rêves et fantasmes suscités, entre autres, par la lecture). C'est ce que Baudelaire ${ }^{14}$ reprochait déjà à l'image mécanique : que l'image concrète, puisqu'elle ne fait que «copier la nature », ne puisse pas refléter «l'âme de l'homme », «l'impalpable», «l'imaginaire » et le «Beau ». La photographie s'oppose aux images traditionnelles qui fonctionnent comme des synthèses de l'image perçue, leur transcription codée.

L'œil toujours en mouvement déchiffre l'environnement, il sélectionne et intègre les informations dans un système de signification. L'image perçue ne ressemble que peu à une photographie, même si le principe de leur fonctionnement est similaire. La vue n'est pas fixe et concrète comme un cliché. On peut se demander par exemple si en lisant on voit le livre et la typographie ou bien ce qu'on imagine à partir du texte ? Dans la rue en marchant, est-ce le paysage devant nous ou les souvenirs auxquels on pense qui occupent la vision?

René Laloux, La planète sauvage $e^{15}$
Dans le dessin animé La planète sauvage (ci-contre) un appareil à vocation pédagogique récitant la leçon génère automatiquement des images concrètes dans le cerveau de celui qui écoute. Mais comment peut-on imaginer dans les détails quelque chose qu'on n'a jamais vu?

Notre travail repose donc sur la conviction qu'une image ne peut être tout à fait décrite, elle doit être vue, car l'image au-delà du contenu provoque un effet visuel au lecteur, un effet inconscient et indescriptible. C'est pour cela que les illustrations occupent une place importante dans la thèse et que nous avons cherché à les insérer à côté du texte. Si un récit fait référence implicitement ou explicitement à une image (photographique ou autres) le lecteur doit avoir vu l'image pour réanimer l'image mentale de l'image réelle, ce qui demanderait une culture visuelle commune. La thèse s'inscrit donc sur ce terrain amovible où les mots voudraient maîtriser les images, mais elle utilise aussi leur sens inconscient et fuyant.

\footnotetext{
${ }^{14}$ BAUDELAIRE, Charles, «Le public moderne et la photographie », Euvres complètes, (textes présenté et annoté par Claude Pichois) Paris, Gallimard, col. "La Pléiade", 1976, p. 614-619.

${ }^{15}$ Voir des extraits du film sur le site de strimoo : http://www.strimoo.com/video/16271272/PlantasticFanet-Vimeo.html (consulté le : 06/06/2009).
} 
Comme l'image de la perception, la mémoire visuelle semble en soi problématique. Le décalage entre l'objet de la vision et ce qu'en retient la mémoire est déjà visible entre le temps de quelques secondes du trajet que l'œil d'un dessinateur effectue entre son modèle et le papier. La reconstitution des portraits-robots qu'utilise la police, démontre aussi que l'image perçue reste d'autant plus vive dans la mémoire, qu'est forte la charge émotive, le choc de l'instant vécu ${ }^{17}$. Mais autant de témoins interrogés, autant de portraits réalisés; la mémoire visuelle paraît instable et de nombreux facteurs peuvent l'altérer ${ }^{18}$. Les représentations mentales, ou vues imageantes ${ }^{19}$ que le lecteur élabore en lisant, paraissent d'ailleurs tout aussi floues, elles sont un mélange de formes et de sens, une image «en performance ${ }^{20} »$ et en constante évolution pendant la lecture, et même en dehors de la lecture, pendant les poses quand le lecteur continue à fantasmer l'histoire.

Elles ressembleraient en quelque sorte, selon nous, à une image réalisée par surimpression comme cette image cicontre réalisée par Philippe de Jonckheere, une combinaison d'images qui laisse entrevoir les traits constitutifs au-delà du flou qui le marque. Encore faudraitil animer cette image, et de ce flou sortirait momentanément une partie plus nette pour retourner ensuite dans le flou de la surimpression. Mais comme le note François Vanoosthuyse, cet espace de représentation

Philippe de Jonckheere, Surimpression médiatique $e^{16}$

\footnotetext{
${ }^{16}$ L'image est réalisée dans un contexte de critique des médias, mais nous nous y référons simplement pour l'effet visuel qu'elle met en place. Voir la photographie sur le site de l'auteur (consulté le : 06/06/2009) : http://www.desordre.net/photographie/numerique/campagne/surexpose/index.htm.

${ }^{17}$ Voir à ce sujet l'article de Frank Arnould « Mémoire, émotion et témoignage » sur le site de la CNRS : http://psychotemoins.veille.inist.fr/spip.php?article134 (consulté le : 20/09/2009).

${ }^{18}$ Voir à ce propos les autres articles du même site (consulté le : 20/09/2009) : http://psychotemoins.veille.inist.fr/spip.php?rubrique1.

${ }^{19}$ Voir à ce sujet : Fiction et vues imageantes : typologies et fonctionnalités, sous la dir. de Bérengère Voisin, (Actes du colloque qui s'est tenu à Tartu le 4 et 5 avril 2008, publiés dans Studia Romanica Tartuensia VII.) Disponible sur Internet (consulté le : 20/09/2009) : http://www.fl.ut.ee/orb.aw/class=file/action=preview/id=445799/SRT+VII+-+Vues+imageantes.pdf SARTRE, Jean-Paul, L'imaginaire, Paris, Gallimard, col. "Folio Essais", 1986.

ISER, Wolfgang, L'acte de lecture. Théorie de l'effet esthétique, Bruxelles, Pierre Madraga, col.

"Philisophie et langage", (1976), 1985. Disponible partiellement sur googlebooks : http://books.google.com/books?id=vgcRvVE27BsC\&lpg=PP1\&ots=WEci4aMXX\&dq=wolfgang\%20iser\%20l'acte\%20de\%20lecture \&hl=fr\&pg=PP1\#v=onepage \&q=\&f=false (consulté le : 20/09/2009).

${ }^{20}$ BERENGERE, Voisin, « Avant propos », in Fiction et vues imageantes : typologies et fonctionnalités, Ibid., p. 8.
} 
vague, instable et dynamique, qui se crée dans l'imagination du lecteur, tisse un ensemble inséparable avec le texte. L'image mentale constitue comme une trace du texte et elle apparaît déjà dans un réseau de signification ${ }^{21}$.

On pourrait soutenir que la fixité de la photographie, qui l'opposerait aux images perçues, à la mémoire visuelle ou aux vues imageantes, est aussi trompeuse, déjà parce que l'œil doit effectuer un parcours de lecture pour l'interpréter. La lecture de l'image doit d'ailleurs s'apprendre, mais elle est moins enseignée que la lecture et l'interprétation des textes. Michel Tournier évoque ce problème dans un entretien radiophonique : il y a un problème de base, selon lui, qui résulte du fait que l'initiation à la photographie commence par l'apprentissage de la technique, c'est «comme si on demandait d'écrire tout de suite des poèmes aux enfants. [...] Les gens ne savent pas reconnaître une photo créatrice, et c'est par manque d'éducation de l'œil ${ }^{22}{ }^{2}$.

Mais la lecture et l'interprétation de l'image soulèvent encore une autre problématique, la question cruciale dans l'œuvre de Denis Roche, celle de l'autorité de la pensée autonome de l'image. Denis Roche soutient que «la littérature de la photographie c'est la photographie elle-même ${ }^{23}$ », et il publie plusieurs livres de photographies présentés comme des œuvres littéraires ${ }^{24}$. Mais communique-t-on de la même manière avec ou sans les mots ? La communication visuelle existe-t-elle en soi ? $\mathrm{Ne}$ prend-elle pas toujours corps dans les mots? L'image est dérangeante, car à l'opposée du langage, elle est une entité difficilement divisible en constituants inférieurs ${ }^{25}$. Kibédi Varga affirme d'ailleurs que la communication visuelle et la communication verbale ne peuvent être séparées qu'au niveau philosophique : «La communication intentionnelle et consciente ne peut jamais se passer des deux sens

${ }^{21}$ VANOOSTHUYSE, François, «Dispositif et temporalité », in Fiction et vues imageantes : typologies et fonctionnalités, Ibid., p. 53.

${ }^{22}$ Radioscopie de Jacques Chancel avec Michel Tournier, diffusée sur France-Inter le 11/02/1981.

${ }^{23}$ ROCHE, Denis, La disparition des lucioles (réflexions sur l'acte photographique), Paris, Etoile, 1982, p. 5 .

${ }^{24}$ ROCHE, Denis, Ellipse et laps, Paris, Maeght, 1991 ; ROCHE, Denis, Douze photographies publiées comme du texte, Paris, Orange Export Ltd, 1984.

${ }^{25}$ Il faut noter tout de même que plusieurs recherches sont menées dans cette perspective, sans donner de résultats convaincants pour le moment. Voir par exemple : SZILÁGYI Gábor, elemi KÉPTAN elemei. Az álló és mozgó fényröl ( Les éléments d'une science élémentaire de l'image»), Budapest, Magyar filmintézet, 1999. 
privilégiés, mais ceux-ci ne se présentent pas toujours simultanément ${ }^{26} »$. L'œuvre de Denis Roche joue sur ce lien par les incessants allers-retours entre les deux médiums.

Dans le rapport entre l'écriture et la photographie il y a aussi la question de l'acte qui favorise la relation hiérarchique qui s'établit entre les deux. On ne peut pas écrire et photographier en même temps. Les deux actes créateurs se succèdent nécessairement, même s'ils s'influencent l'un et l'autre. Pourtant les écrivains photographes tendent justement à faire se confondre les deux pratiques qui paraissent à première vue tellement dissemblables.

\section{Nouvelles pratiques photo-littéraires - nouvelles approches méthodologiques}

La deuxième partie de la thèse revient sur l'hypothèse de départ et analyse en détails l'œuvre de quelques écrivains photographes choisis pour la dissemblance de leur parcours. Mais l'objectif dans l'étude de leurs œuvres n'est plus de surmonter le problème de référent que suggérait Michel Tournier, mais de rendre compte de nouvelles pratiques qui émergent par l'interaction des deux médiums. François-Marie Banier, Jean-Loup Trassard, Lorand Gaspar et Denis Roche emploient ainsi diverses stratégies pour nouer la pratique de la photographie avec celle de l'écriture. Ils aboutissent à des usages très différents, ce qui permet de rendre compte de la pluralité du champ photo-littéraire, mais nous trouvons également certains points communs. Malgré leur différence d'âge, nos quatre auteurs ont commencé à publier dans les années 1960, et leur activité s'épanouit à une période clef, témoin de transformations essentielles dans le statut de la photographie (le paradigme pragmatiste, la montée des mythologies individuelles, l'évolution vers l'autofiction, etc.) que nous évoquons dans la première partie dans l'approche historique.

Dans notre étude sur les écrivains photographes choisis, nous ne nous contenterons pas d'analyser seulement leurs œuvres en rapport avec la photographie, mais parcourrons aussi leur production en profondeur, en l'étudiant dans son intégralité sous l'angle du rapport qu'elles entretiennent avec les images en général. Nous

\footnotetext{
${ }^{26}$ KIBÉDI VARGA, Áron, Discours, récit, image, Liège - Bruxelles, Pierre Mardaga, 1989, p. 91.
} 
considérerons ainsi également les avant-propos rédigés pour des catalogues d'exposition d'autres artistes ou les œuvres issues de la collaboration avec d'autres artistes.

Nous explorerons les livres dans leurs totalités, suivant la méthode d'analyse de l'énonciation éditoriale élaboré par Emmanuel Souchier ${ }^{27}$, qui inclut l'examen de la mise en page, de la typographie, ainsi qu'en marge des œuvres : la relation entre les photos ou dessins des auteurs qui se trouvent sur la couverture du livre et le récit, la relation entre la photographie et le titre, ou encore les menus changements qui se mettent en place dans les republications d'un livre à l'autre; en bref : le sens sousjacent qui naît de la matérialité du support. Catalogues d'exposition ou albums photographiques seront alors analysés comme des œuvres, car s'y manifeste une prise de conscience de l'importance de la mise en page et de la construction du livre chez les auteurs concernés ${ }^{28}$.

Mais c'est avant tout une envie d'image qui sous-tend ce travail ; elle apparaîtra dans l'insertion récurrente des images évoquées et l'exploitation de leur effet sensible, mais aussi dans l'élaboration d'outils méthodologique analysant, découpant, ou coloriant les textes comme des images. Dans la deuxième partie nous avons également ajouté en marge des chapitres nos propres photos en hommage aux écrivains photographes dans le but de lancer la question si la critique photo-littéraire ne pouvaitelle, comme la littérature, communiquer par les images.

\section{Un dispositif soumis aux changements}

La loi sur la reproduction empêche de reproduire librement les images d'un tiers malgré la facilité technique. Dans la version de la thèse destinée à la diffusion sur Internet la majorité des images a été enlevée et remplacée par un cadre vide pour expliciter l'absence et le manque. Toutefois nous avons cherché à nous référer aux images à l'aide

27 SOUCHIER, Emmanuel, «L'image du texte, pour une théorie de l'énonciation éditoriale », Les Cahiers de médiologie, 6 (1998), p. 137-145. Disponible sur Internet en fichier Pdf: (consulté le : 10/09/2009). http://www.mediologie.org/collection/06_mediologues/souchier.pdf.

${ }^{28}$ Denis Roche a travaillé dans l'édition : il était directeur littéraire aux éditions Tchou de 1964 à 1970 ; il a créé et dirigé la collection «Fiction et Cie » au Seuil jusqu'en 2005 ; il a également fondé, avec Gilles Mora, Bernard Plossu et Claude Nori, Les Cahiers de la photographie. Chez François-Marie Banier, un entretien avec Martin d'Orgeval, son ami et principal éditeur, laisse supposer la même prise de conscience. Mais les propos de Jean-Loup Trassard laissent entrevoir que le choix des photos se fait avec l'éditeur (Le Temps qu'il fait) d'un commun accord. 
de liens hypertextes, qui invite donc le lecteur à cliquer sur les liens en bas de page dans les références. Dans ce but, nous avons choisi de ne pas faire de distinction entre la nature des sites: il s'agit tout aussi bien de galeries, de maison de vente, de sites personnels, que de blogs d'amateurs. Cette recherche nous à menés toutefois à faire une cartographie du Web, à explorer les textes et les images accessibles à ce jour, créant par le réseau d'hyperlien intégré à la thèse un dispositif éphémère soumis aux changements et à l'évolution d'Internet.

Selon l'équipe de recherche «Lettres, langages et Arts» de l'université de Toulouse, «il n'est plus possible aujourd'hui d'envisager la représentation comme un objet dont le statut épistémologique serait stable et donné29 ${ }^{9}$. L'introduction de la notion de «dispositif », promue par la même équipe de recherche, veut faire face à l'instabilité et l'hétérogénéité de la consommation esthétique, en favorisant justement les frontières floues et en intégrant le changement dans le temps. Il s'agit alors de tenter de comprendre comment la photographie, qui a modifié notre appréhension du temps et de l'espace, contribue à cette évolution et comment les changements autour de la photographie influencent-ils les pratiques photo-littéraires de la deuxième moitié du $\mathrm{XX}^{\mathrm{e}}$ siècle.

\footnotetext{
${ }^{29}$ LOJKINE, Stéphane, Dispositif, texte diffusé sur le site de l'équipe de recherche «Lettres, langages et Arts » de l'Université de Toulouse (consulté le : 10/10/2009) : http://galatea.univ-tlse2.fr/pictura/UtpicturaServeur/AideRecherche.php?numero=15
} 
I $^{\mathrm{e}}$ Partie : Panorama photographique et photo-littéraire de la deuxième moitié du XXe siècle 
Pal, Gyöngyi. Le dispositif photo-littéraire en France dans la seconde moitie du XXe siècle Analyse de l'oeuvre de François-Marie Banier, Jean-Loup Trassard, Lorand Gaspar et Denis Roche - 2010 


\section{Contenu du chapitre :}

II. L'évolution de la théorie de la photographie - la vérité en question........................2 24

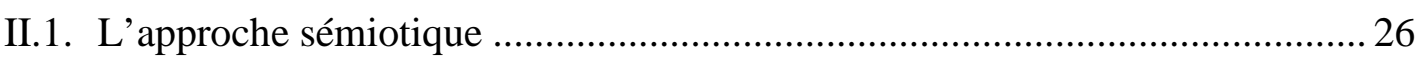

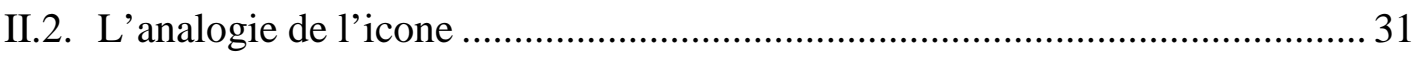

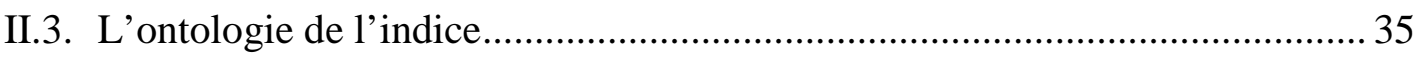

II.4. La deuxième moitié du $\mathrm{XX}^{\mathrm{e}}$ siècle : contextes et changements ...................... 38

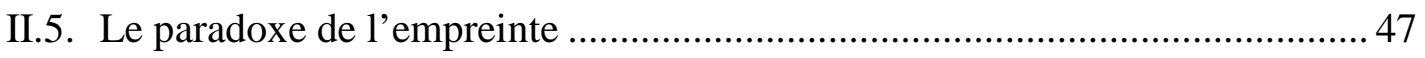

II.6. La photographie comme dispositif .......................................................... 53

II.7. Le sens sensible de la photographie......................................................... 56

II.8. La pluralité du sens et la pluralité de l'usage...............................................59 


\section{L'évolution de la théorie de la photographie - la vérité en question}

Historiquement, le discours concernant l'essence du médium photographique s'articulait toujours autour de la valeur de vérité de l'image, du rapport entre l'image et son référent. Le doute s'instaure petit à petit dans l'image comme miroir de la réalité, ce qui influencera la relation du texte à l'image.

Les réévaluations récentes ${ }^{1}$ démontrent à quel point l'évolution de la théorie de la photographie est complexe et comment, dès l'apparition de l'invention, plusieurs approches coexistaient déjà sur le concept du médium - présentes et décelables dans la littérature de l'époque. Néanmoins, ces premières approches même une fois dépassées ne disparaissent pas tout à fait.

Selon Philippe Ortel, une double posture caractérise l'influence de la photographie sur la littérature au $\mathrm{XIX}^{\mathrm{e}}$ siècle, à savoir que la photographie va être considérée comme modèle, pour ce qui est du procédé, ou repoussoir, pour ce qui est de son produit : l'image photographique ${ }^{2}$. Dans la littérature contemporaine, le procédé en tant que concept - la captation, l'analogie et l'immédiateté de l'image, la sensation de présence - convoite la littérature, il est un facteur qui influence l'apparition de nouvelles formes littéraires ; tandis que l'image photographique reste un catalyseur des problèmes de représentation et du fonctionnement de la mémoire ${ }^{3}$.

Paul Edwards distingue à son tour quatre discours théoriques prédominants sur la photographie, au $\mathrm{XIX}^{\mathrm{e}}$ siècle et au tournant du $\mathrm{XX}^{\mathrm{e}}$ siècle, qu'il nomme : Nature, Science, l'Homme, le Devenir ${ }^{4}$. Le premier, un discours néoplatonicien, s'appuie sur la métaphysique de la lumière. La photographie est identifiée à une surface sensible dans une boîte qui capte la «lumière », l'essence divine, qui est à l'origine de Tout. La

${ }^{1}$ EDWARDS, Paul, Soleil Noir. Photographie \& Littérature des origines au surréalisme. France \& Royaume-Uni, Rennes, PUR, 2008. Voir aussi: SNYDERS, Joel, «Pouvoir de l'équivoque. Fixer l'image de la camera obscura », Études photographiques $\mathrm{n}^{\circ}$ 9, mai 2001. L'article est accessible en ligne : http://etudesphotographiques.revues.org/index240.html (consulté le : 13/07/2009).

${ }^{2}$ ORTEL, Philippe, La littérature à l'ère de la photographie. Enquête sur une révolution invisible, Nîmes, Edition Jacqueline Chambon, 2002.

${ }^{3}$ Nous reprenons ici les termes que propose Jean-Pierre Montier, pour qui la photographie est à la fois un facteur, un catalyseur et un analyseur privilégié qui transforme la littérature. MONTIER, Jean-Pierre, « Préface », in Littérature et photographie, (sous la dir. de Jean-Pierre Montier ; Liliane Louvel ; Danièle Méaux ; Philippe Ortel) Rennes, PUR, 2008, p. 11.

${ }^{4}$ EDWARDS, Paul, Op. cit. 
photographie est confondue alors avec le procédé : «Il s'agissait moins d'une invention de l'homme que d'une merveille de la nature, voire de Dieu ${ }^{5} »$. Puis, avec la popularisation de la daguerréotypie, et une pratique plus répandue de la prise de vue, la dimension scientifique devient importante. La photographie est confondue avec l'appareil, la technique, comme si l'intervention de l'homme n'était pas nécessaire. Elle est considérée comme un outil scientifique qui permet de capter des images objectives, reflets de la réalité. À partir du pictorialisme, selon Edwards, la photographie subit cependant l'influence du monde de l'art, et l'on reconnaît que l'image obtenue dépend également de l'homme; elle peut donc atteindre le statut d'œuvre d'art. Puis la créativité des photographes fait basculer le statut de la photo - ce qu'Edwards nomme la phase du devenir, où l'on reconnaît qu'il reste à inventer les thèmes et les moyens de représentation propres à la photographie. Nous pouvons discerner, dans ces quatre phases, une évolution vers la prise de conscience du rôle de l'homme dans la fabrication des images, sans pour autant mettre en cause la valeur objective de l'image.

Ces premières approches continuent à alimenter notre imaginaire concernant la photo. Ainsi on retrouve l'assimilation de la photographie à la lumière chez Lorand Gaspar, ou la reconnaissance de la part de l'homme dans le courant photobiographique auquel Denis Roche est lié.

Nous allons donc esquisser brièvement l'histoire ${ }^{6}$ de la théorie de la photographie de la deuxième moitié du $\mathrm{XX}^{\mathrm{e}}$ siècle, pour montrer quelles idées se sont formées autour du médium et quelles notions ont à leur tour eu un impact sur les œuvres photo-littéraires.

\footnotetext{
${ }^{5}$ Ibid.

${ }^{6}$ Nous ne prétendons pas à une description complète, car un recensement exhaustif de l'histoire des idées de la photographie demanderait une thèse entière.
} 


\section{II.1. L'approche sémiotique}

Dans la deuxième moitié des années 1960, c'est l'approche sémiotique basée sur la linguistique qui influence les théories photographiques. La question fondamentale consiste à décrire de manière scientifique l'effet de réalisme que provoque la photographie.

Rappelons que la science de la sémiologie, promu par Ferdinand de Saussure, est basée sur un système binaire, du signifiant (l'image acoustique d'un mot) et du signifié (le concept, la représentation mentale d'une chose). Grâce à cette théorie du signe, la langue peut être décrite comme un système clos dans lequel la relation des éléments sert à déterminer et à décrire la structure de l'ensemble. Selon cette théorie de Saussure, ce n'est pas le référent extérieur qui détermine le sens des mots, mais justement à l'inverse, ce sont les signes linguistiques qui donnent une structure aux pensées désordonnées en organisant les suites phoniques inarticulées. Cette description systématique de la langue basée sur des oppositions fournit un modèle aux sciences humaines et c'est ainsi qu'on retrouve l'approche structuraliste, entre autres, dans la philosophie, la théorie littéraire, l'anthropologie (Claude Lévi-Strauss), la psychanalyse (Jacques Lacan) ou dans la théorie des religions (Jean-Pierre Vernant).

Roland Barthes en tant que sémiologue est considéré comme une figure majeure du structuralisme, qui employa cette approche dans la théorie littéraire mais aussi aux productions de la culture populaire. Ainsi il analysa la mode, la publicité ou la photographie. On distingue d'habitude trois phases dans l'œuvre de Roland Barthes : dans un premier temps, il cherche à démystifier les messages en exposant leurs codes, puis il développe une méthodologie structuraliste plus systématique; enfin, dans une dernière période de son œuvre, selon les termes de Jean-Michel Rabaté, Barthes serait plus concerné par la recherche des « extases personnelles ${ }^{1} »$.

\footnotetext{
1 RABATE, Jean-Michel, «Introduction», Writing the image after Roland Barthes, Philadelphia, University of Pennsylvania Press, 1997, p. 4. Jean Michel Rabaté souligne toutefois une continuité entre La chambre claire, son dernier livre, et les premières œuvres, via la référence à L'imaginaire de JeanPaul Sartre. Le livre est partiellement disponible sur google books : http://books.google.com/books?id=2V 4eBK6klMC\&lpg=PP1\&dq=writing\%20the\%20image\%20after\% 20roland\%20barthes\&hl=fr\&pg=PP1\#v=onepage \&q=\&f=false (consulté le : 10/09/09).
} 
Dans Le message photographique en 1961, Roland Barthes analyse la photographie de presse par le biais du modèle linguistique et constate que l'image se comporte comme un «message sans $\operatorname{code}^{3} »$, elle est une transposition littérale de la scène, son «analogon » parfait. A la différence de la communication langagière, lors du passage de l'objet perçu à l'image photographique, il n'y a pas de processus d'encodage. L'image qui se crée ne passe pas par un découpage du réel en unités et une réorganisation en signes: «[...] dans la photographie, le message dénoté étant absolument analogique, c'est-à-dire privé de tout recours à un code, c'est-à-dire encore :

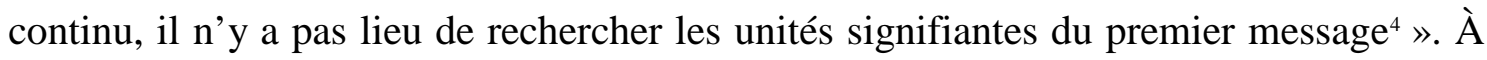
partir de ce message sans code se développe pourtant un «message connoté », un message supplémentaire «qui renvoie à une certaine "culture" de la société qui reçoit le message ${ }^{5} \gg$. Parmi les procédés de connotation, Barthes distingue le trucage, la pose, les objets photographiés, la photogénie, la mise en série (tout ce que Philippe Dubois placera dans les années 1980 en dehors de l'acte photographique).

Dans la Rhétorique de l'image 6 , Barthes cherche à comprendre comment le sens vient à l'image en examinant non plus les photographies de presse mais la photo publicitaire. Il délimite alors trois types de message : un message linguistique, un message iconique codé, et un message iconique non codé ${ }^{7}$ Le message iconique non codé (le signe dénoté) opère au niveau de la perception par la simple reconnaissance des objets, et suppose «un état adamique » de l'image où aucun sens codé et culturel ne contamine la réception contrairement au «message iconique codé ». Cependant Roland

2 BARTHES, Roland, «Le message photographique », Euvres complètes, t. 1, 1942-1965, édition présentée par Éric Marty, Seuil, 1993, p. 939 (article publié d'abord dans la revue Communications en 1961, n¹, p. 127-138).

${ }^{3}$ Ibid

${ }^{4}$ Ibid., p. 941. Barthes emprunte ici les notions du linguiste Louis Hjelmslev du «message dénoté » et du «message connoté ». Voir sur ce dernier: http://fr.wikipedia.org/wiki/Dénotation_et_connotation (consulté le : 10/09/09).

${ }^{5}$ Ibid., p. 939.

${ }^{6}$ BARTHES, Roland, « Rhétorique de l'image », Euvres complètes, t. 1, 1942-1965, édition présentée par Éric Marty, Seuil, 1993, p. 1417-1429 (paru initialement dans la revue Communications en novembre $\mathrm{n}^{\circ} 4,1964$, p. 40-51.) Le texte est également accessible sur Internet :

http://www.oasisfle.com/doc_pdf/roland_barthes_rhetorique_image.pdf (consulté : le 06/10/2009).

${ }^{7}$ Ces catégories font penser à la catégorisation d'Ervin Panofsky (dans Essais d'iconologie, publié à l'origine en 1939 chez Oxford University Press, 1967 pour l'édition française chez Gallimard, p. 31), ce qui rapproche cette déconstruction du signe photographique, la recherche de la signification minimale, des recherches semblables sur l'image non photographique. Les analyses de Panofsky sur l'iconologie chrétienne (axées sur la production du Moyen Âge) cherchent justement à retrouver, dans les textes contemporains de la production des images, les significations «évidentes » dont l'interprétation ne s'offre plus naturellement à l'ère de la disparition massive d'une culture religieuse. 
Barthes insiste sur le fait que les deux types de messages, le message iconique non codé et le message iconique codé, sont inséparables, «le spectateur de l'image reçoit en même temps le message perceptif et le message culturel» et «le message littéral apparaît comme le support du message symbolique ${ }^{8} »$. Toutefois, à la fin de l'article, Barthes revient sur la distinction entre le dessin et la photographie pour souligner la capacité de cette dernière à transmettre l'information de manière littérale. Le paradoxe de la photographie, selon Barthes, est qu'elle installe une conscience de l'«avoir été là », « une conjonction illogique entre l'ici et l'autrefois », idée qu'il reprendra dans $L a$ Chambre claire sous la forme du «ça a été », l'identifiant en tant qu'essence ou noème de la photographie ${ }^{9}$. Cependant dans la Rhétorique de l'image, revenant aux images spécifiques de la photographie publicitaire, il affirme que l'image photographique «correspondrait à une mutation capitale des économies d'information»car «elle fournit les moyens de masquer le sens construit sous l'apparence du sens donné ${ }^{10} \gg$.

Le message connoté s'inscrit invisiblement dans le signe, mais en déployant sa signification, on peut retrouver son contenu symbolique. Les Mythologies ${ }^{11}$ de Roland Barthes cherchent ainsi à démasquer le sens secondaire des produits de la culture populaire pour révéler l'idéologie bourgeoise dont ils sont imprégnés. Dans le chapitre final, «Le mythe aujourd'hui », il donne un cadre théorique à son étude. Il désigne le mythe comme un signe double où le système signifiant/signifié est entraîné dans un nouveau signifiant.
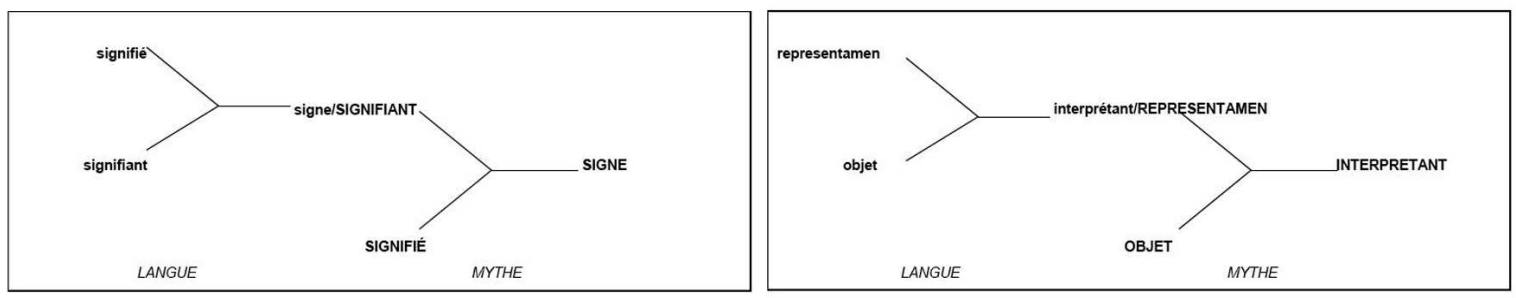

Selon Robert Marty ${ }^{12}$, comme il le représente dans le tableau ci-dessus, cette définition annonce déjà le système dynamique de Peirce, même si Barthes, comme la plupart de ses sémiologues contemporains, aurait manqué l'essence de la sémiotique peircienne, ne

\footnotetext{
${ }^{8}$ BARTHES, Roland, « Rhétorique de l'image », Op. cit., p. 1420.

${ }^{9}$ BARTHES, Roland, La Chambre claire, Paris, Cahiers du cinéma/Gallimard/Seuil, 1980, p. 176.

${ }^{10}$ BARTHES, Roland, « Rhétorique de l'image », Op. cit., p. 1425.

${ }^{11}$ BARTHES, Roland, Mythologies, Paris, Seuil, 1957.

${ }^{12}$ MARTY, Robert, La dimension perdue de Roland Barthes. Disponible sur Internet en format Pdf: http://robert.marty.perso.cegetel.net/semiotique/dimension-perdue.pdf (consulté le : 11/07/2009). Nous reproduisons ici la figure 5 et 6 .
} 
retenant que les notions : icone, index et symbole. L'œuvre de Peirce fut revalorisée au tournant du $\mathrm{XXI}^{\mathrm{e}}$ siècle par la philosophie pragmatiste, mais il importe de le mentionner ici, car une partie de sa théorie eut une influence sur la théorie de la photographie et les productions photo-littéraires des années 1980.

Charles Sanders Peirce ${ }^{13}$, à l'opposé de la structure binaire de Saussure, organise les signes dans un système tertiaire comprenant l'objet, l'interprétant et le representamen.

Un signe ou representamen, est quelque chose qui tient lieu pour quelqu'un de quelque chose sous quelque rapport ou à quelque titre. Il s'adresse à quelqu'un c'est-à-dire crée dans l'esprit de cette personne un signe équivalent ou peut-être un signe plus développé. Ce signe qu'il crée, je l'appelle interprétant du premier signe. Ce signe tient lieu de quelque chose : de son objet. ${ }^{14}$

C'est-à-dire qu'un signe est entraîné de manière dynamique dans une cascade de signification, il ne cesse de se développer par l'intermédiaire du nouveau signe (l'interprétant) qu'il crée. Mais Peirce souligne aussi que le signe « tient lieu pour quelqu'un de quelque chose sous quelque rapport ou à quelque titre », donc il valorise le côté de la réception et le contexte qui influencent la signification du signe. En même temps, il suppose un lien entre l'objet et le signe, qu'il classe selon les trois notions déjà mentionnées : l'icone, l'index et le symbole.

L'icone signifie ce qu'elle représente par analogie, par ressemblance de principe (ainsi les diagrammes, ou certaines images, peintures, dessins, figurent dans cette catégorie). Le symbole est un signe qui indique le référent par le biais d'un système conventionnel (comme le langage ou la peinture). L'icone et le symbole ne sont pas liés à l'existence réelle de l'objet auquel ils réfèrent. L'index suppose en revanche un contact physique entre le signe et le référent et montre la trace ou l'effet que ce contact a produit (comme la fumée qui signale le feu, la girouette qui indique la direction du vent). Peirce évoque lui-même la photographie en tant que signe indiciel. Son système n'exclut pas pour autant qu'un signe puisse figurer dans plusieurs catégories, car il ne cesse de se développer en créant de nouveaux signes. Même la langue, de nature symbolique et conventionnelle, contient des éléments iconiques (les onomatopées) ou

\footnotetext{
${ }^{13}$ Une partie des manuscrits de Peirce fut rassemblée après sa mort et publiée dans les années 1960 dans plusieurs volumes sous le titre Collected Papers 1931-1935 (Cambridge, Harvard University Press, 196065). La traduction française paraît en 1978 (Écrits sur le signe, Paris, Seuil, col. "L'ordre Philosophique", 1978), mais une grande partie de ses manuscrits reste même de nos jours inédite. Le décalage dans la parution de la traduction française explique alors la reconnaissance tardive de son œuvre.

${ }^{14}$ PEIRCE, Charles Sanders, Écrits sur le signe, Op. cit., p. 121.
} 
des mots indiciels (les noms propres). Les théories photographiques apparues au cours des années 1980 se disputent pourtant à quel type de signe correspond réellement la photographie, et s'il est possible de décrire par ces notions l'essence même du médium. Les théories recherchent à définir la photographie en la réduisant à un seul aspect, ce qui est peut-être lié au contexte des années 1980, car c'est environ à cette époque-là que la photographie cesse d'être considérée comme le parent pauvre des arts plastiques, et sa raison d'être exige qu'elle ait une base théorique qui la distingue de tous les autres médiums visuels. 


\section{II.2. L'analogie de l'icone}

Le signe iconique que décrit Peirce, paraît très pertinent pour rendre compte de l'effet du réel que provoque la photographie. On interprète de manière similaire une photographie que l'objet perçu, elle provoque un effet semblable. L'icone entre en relation analogique avec l'objet auquel il se réfère comme le signe dénoté. L'analogie de l'icone démontre comment on utilise les photos souvenirs dans les albums photos, ou la photographie de presse, où ce qui importe en premier lieu, c'est ce qui est visible sur l'image. Le regardeur est capable de se projeter dans l'image comme s'il était présent à la prise de vue.

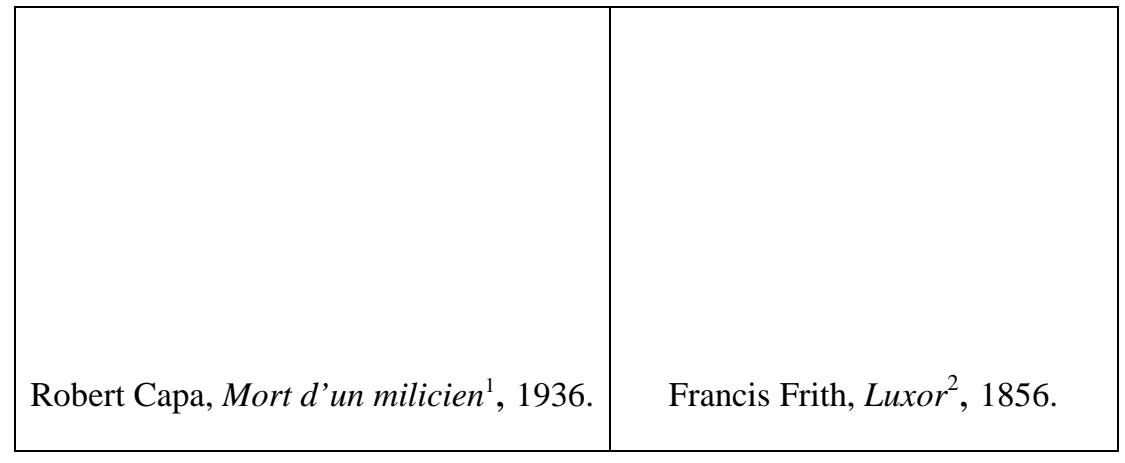

D’ailleurs le procédé de la chambre noire repose sur le même principe que le fonctionnement de l'œil : la loi physique de la lumière naturelle. La lumière est une onde électronique de propagation rectiligne, elle est absorbée et réfléchie par les

Emile Zola, ses enfants et Jeanne Rozerot ${ }^{3}$. objets $^{4}$ (dans des proportions diverses). Cette spécificité de la lumière permet d'obtenir, dans une chambre close dont un des murs est percé d'un petit trou, une image inverse de la réalité extérieure projetée sur le mur d'en face. L'œil humain fonctionne selon le même principe. Par le trou de la pupille nous percevons la lumière réfléchie sur les objets, qui se projette au fond de l'œil sur la rétine sous la forme d'une image réduite et inversée, qui sera successivement renversée par le cerveau. Le procédé de la chambre

\footnotetext{
${ }^{1}$ http://expositions.bnf.fr/capa/grand/002.htm (consulté le : 13/07/2009).

2 http://www.shafe.co.uk/crystal/images/lshafe/Frith_Luxor_Egypt_1856.jpg (consulté le : 13/07/2009).

${ }^{3}$ http://fr.wikipedia.org/wiki/Fichier:ZOLA_Jeanne_Enfants.jpg (consulté le : 13/07/2009).

${ }^{4}$ J. P. MATTHIEU, A. KASTLER, P. FLEURY, Dictionnaire de physique, Paris, Masson-Eyerolles, 1991, s.v : « lumière ».
} 
noire était connu déjà depuis l'Antiquité, et l'invention de la photographie reposa sur la fabrication de plaques photosensibles qui, par le biais de la chimie, fixaient l'image obtenue dans la chambre noire. La photographie qui, à l'aide de la lumière, semble créer mécaniquement une image de la réalité a été donc inventée pour reproduire analogiquement le fonctionnement de l'œil humain 5 .

Mais l'analogie n'est pas la seule particularité de l'icone. Jean-Christophe Blaser $^{6}$ en rappelant l'usage religieux du terme souligne la différence fondamentale qui sépare l'icone de l'index :

Alors que la notion d'icone s'introduisait dans la littérature photographique, elle entraînait dans son sillage celle de l'icône - avec circonflexe - sans que les deux notions fissent la plupart du temps l'objet d'aucune distinction. Il existe, dans le domaine de la réflexion historique, une «communauté d'intérêts» entre spécialistes de l'icône byzantine, et spécialistes de la photographie. Elle se noue autour de problématiques comparables. L'opposition entre image naturelle et image artificielle, qui permettait de rendre compte de la différence entre image transfiguration de la chair - et icône - image faite de la main de l'homme - présente ainsi des analogies avec l'opposition entre index et icone de Peirce. ${ }^{7}$

Le rapprochement du terme d' «icône » (l'image religieuse) et d' «icone » (type de signe chez Peirce) permet également de rendre compte du pouvoir de fascination que peut exercer la photo et du culte qui l'entoure. Blaser mentionne la série d'Andy Warhol intitulée «Icônes », série de portraits de célébrités qui symbolisent par leur magnétisme la réussite sociale ; le mot icône s'est ensuite banalisé dans le domaine de la mode, du cinéma et dans le monde «people ». Si la photographie participe à la création des stars, en retour elle sera également assimilée à un outil qui fige en une seule image l'objet ou

\footnotetext{
5 Cette conception d'une vision mécanique est à la base de nombreuses croyances concernant la photographie. Paul Edwards analyse ainsi le phénomène de l'optogramme qui a alimenté la littérature au tournant $\mathrm{du} \mathrm{XX}^{\mathrm{e}}$ siècle. Ce procédé consistait à reproduire la dernière image qui se projette et se fixe sur la rétine des personnes assassinées au moment de la mort, et qui s'annonçait (au moins dans les romans policiers) comme un outil révolutionnaire dans les enquêtes de meurtre. (Edwards, Soleil Noir, Op. cit.).

${ }^{6}$ Nous suivrons ici l'analyse diachronique qu'en propose Jean-Christophe Blaser. BLASER, JeanChristophe, «Sur les traces de l'icône: vers un nouveau concept critique? », in Art architecture en Suisse (Revue de la Société de l'histoire de l'art en Suisse), n 4, hiver 2000, consulté sur le site Web du Musée de l'Elysée de Lausanne, Suisse, le 19/01/2009: http://www.elysee.ch/index.php?id=120\&tx ttnews[pS]=1232373229\&tx ttnews[tt_news $]=20 \& t x$ ttnew s[backPid] $=119 \& \mathrm{cHash}=644 \mathrm{~d} 62 \mathrm{fdd} 0$.

Parmi les sources mentionnées par Blaser, nous retiendrons deux œuvres importantes, celle de Régis Debray (Vie et mort de l'image. Une histoire du regard en Occident, Paris, 1992) et celle de Marie-José Mondzain (Image, icône, économie. Les sources byzantines de l'imaginaire contemporain, Paris, 1996). On retrouve également cette notion dans les œuvres théoriques en Hongrie. Voir, entre autres : SZILÁGYI Gábor, Elemi KÉPTAN elemei. Az álló és mozgó fényröl. (Élément d'une science élémentaire de l'image. Sur les lumières stagnantes et mobiles) Budapest, Magyar filmintézet, 1999.

${ }^{7}$ BLASER, Jean-Christophe, Op. cit.
} 
la personne représentée. Le processus pétrifiant permet toutefois que l'image soit retenue et passe sauvée dans la mémoire collective ${ }^{8}$.

Cependant la transformation en icône ne touche pas seulement les stars, elle concerne également les gens ordinaires. JeanChristophe Blaser mentionne à ce titre la photographie intitulée «Migrant Mother» de Dorothea Lange" , réalisée pour une enquête de la FSA (Farm Security Administration) sur les effets de la crise dans les campagnes américaines lors de la Grande Dépression des années trente. La photo semble

Dorothea Lange, Migrant Mother, 1936. ainsi participer à un processus de démocratisation, elle transforme tout un chacun en objet culte. Encore faudrait-il ajouter que dans le cas des gens ordinaires, la transformation en icône ne traduit pas une fascination, mais fige les individus dans une activité, les assimilant au caractère type de leur classe sociale.

L'œuvre d'August Sander ${ }^{10}$ illustre bien ce propos. La photographie sociale, avec ses thèmes de prédilection (travailleurs dans les mines, les hauts fourneaux ou les usines, asiles, prisons ou maisons de retraite) réduit les gens représentés à une seule image, à un point de vue extérieur, souvent loin de l'image qu'ils ont d'eux-mêmes ${ }^{11}$. Le pouvoir de fixation de la photographie peut alors être ressenti comme asphyxiant, ne proposant qu'un point de vue parmi les milliers

August Sander, Vernisseur, 1936.

\footnotetext{
${ }^{8}$ Jean-Christophe Blaser mentionne notamment un livre de photo sur l'histoire de la photographie au $\mathrm{XX}^{\mathrm{e}}$ siècle, présentant sur chaque double page un cliché d'un photographe avec sa description en vis-àvis, publié en Angleterre sous le titre Icons of photography (London, Prestel, 2005). La version hongroise choisit de reprendre également le même titre : KOETZELE, Hans-Michael, Fotóikonok, Budapest, Vincze kiadó, 2003.

${ }^{9}$ LANGE, Dorothea, Migrant Mother (Mère migrante), 1936 ; voir l'image sur le site de Wikipedia : http://fr.wikipedia.org/wiki/Dorothea Lange (consulté le : 03/03/2009).

${ }^{10}$ L'œuvre la plus connue d'August Sander comprend des portraits de gens de tous les milieux et classes sociales (plus de 500 clichés) qui a d'abord donné lieu à un livre, Antlitz der Zeit Sechzig Aufnahmen deutscher Menschen des 20. Jahrhunderts (Le Visage de ce temps. Un choix de soixante photographies des Hommes du XX $X^{e}$ siècle) Kurt Wolff/Transmare Verlag, Erstausgabe Munich 1929. L'originalité de ce travail tient à son ampleur, à sa méthode de classification rigoureuse, et à son style à la fois artistique et documentaire. Voir la photo insérée : http://www.elangelcaido.org/fotografos/sander/asander06.html (consulté le : 03/03/2009).

${ }^{11}$ Voir notamment à la page 87 comment une enquête sur le livre Let us Now Praise Famous Men, dévoile la colère des gens photographiés par Walker Evans pour les avoir réduit en icône de la misère.
} 
possibles. C'est bien à l'origine contre cette caractéristique du cliché que la loi du « droit à l'image » a été mise en place le 6 janvier 1978, protégeant en premier lieu les gens célèbres contre l'abus des paparazzi, mais rendant de plus en plus difficile la photographie sociale et le photojournalisme. C'est au sein de ce dernier qu'est utilisé dernièrement le terme $d^{\prime}$ '«icône » avec une connotation péjorative. Selon JeanChristophe Blaser, l'expression se serait récemment transmutée pour désigner les menaces qui guettent aujourd'hui l'image documentaire, notamment l'excès poussant à glorifier certaines photographies jusqu'à en faire des objets cultes aux dépens des autres points de vue. 


\section{II.3. L'ontologie de l'indice}

László Moholy-Nagy ${ }^{1}$, photogramme, Mains et pinceaux, 1926.
Harold E. Edgerton, Photographie d'une goutte de lait $^{2}, 1936$.

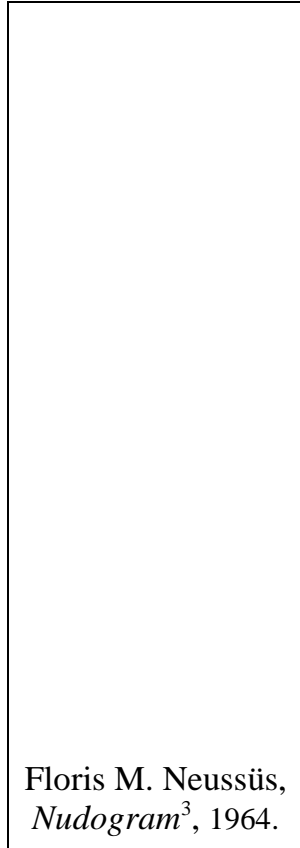

Nudogram ${ }^{3}, 1964$.

Dans les années 1980, l'indicialité reconnue comme essence de la photographie ouvre un champ de réflexion et de polémique très vaste, qui influencera également la littérature. La photographie semble être un signe indiciel car elle est une empreinte lumineuse, si on tient compte de sa fabrication. Selon Philippe Dubois ${ }^{4}$, la notion peircienne $^{5}$ de l'index valorise l'acte photographique, le moment précis où nous appuyons sur le bouton de l'appareil. Pendant ce temps, l'obturateur s'ouvre pour une durée déterminée afin de laisser s'infiltrer la lumière réfléchie sur les êtres et les choses; la lumière s'imprime ainsi sur le support photosensible et l'obturateur se referme. Pendant l'acte s'instaure une réelle connexion, par le biais de la lumière, entre la chose et sa représentation. Dubois précise que «l'important dans l'index, c'est que l'objet existe réellement et qu'il soit contigu au signe qui en émane - que celui-ci

${ }^{1}$ http://exponto.spavia.com/2008/08/20/moholy-nagy-ratapint/ (consulté le : 03/03/2009).

2 http://straightphotography.ifrance.com/artistesharoldedgerton.html (consulté le : 03/03/2009).

${ }^{3}$ Voir sur le site des éditions Lumas : http://eu.lumas.com/ $\mathrm{id}=1305$ \&artist=71\&wid=40\&version=3\&ed $=$ (consulté le : 03/03/2009).

${ }^{4}$ DUBOIS, Philippe, L'Acte photographique, Paris-Bruxelles, Nathan \& Labor, 1983. Il faut remarquer toutefois que Dubois, comme il l'indique d'ailleurs, n'entre pas en détail dans l'analyse du système de Peirce, il ne reprend que ce qui est en rapport avec la détermination du photographique. Son analyse puise en premier lieu dans l'article de Rosalind Krauss, qui la première introduit le terme «index » en France : « Notes sur l'index, L'art des années 1970 aux États-Unis », Macula, 5/6, 1979, p. 172 (L'article sera ensuite repris plus tard dans son livre : KRAUSS, Rosalind, Le Photographique, Paris, Macula, 1990).

${ }^{5}$ PEIRCE, Charles S., Écrits sur le signe, Paris, Seuil, 1978, p. 147-166. Nous reprendrons ici les extraits que choisit Philippe Dubois. 
ressemble ou non à $l^{1}$ objet $^{6} »$. De ce point de vue, les photogrammes ${ }^{7}$ peuvent être considérées comme des photographies, car le contour des objets se dessine grâce à la connexion directe entre la lumière, l'objet et le support photosensible. Même si l'image ne ressemble pas à l'objet, le principe même prouve l'existence de l'objet.

Le système de Peirce n'exclut pas - à l'inverse, il favorise - qu'un signe puisse entrer dans plusieurs catégories et Dubois n'exclut pas non plus la possibilité de pouvoir trouver une analogie ou un fond symbolique entre le signe et son référent; mais il ramène cette inscription symbolique ou iconique au-delà de l'acte photographique, aux choix qui précèdent ou suivent cet acte. La phase antérieure à l'acte présuppose un certain nombre de décisions que prend consciemment ou inconsciemment le photographe (choix de l'appareil, de la pellicule, choix du lieu et de l'instant, du thème, du cadrage, etc.), de même qu'après l'acte le photographe intervient au cours de la révélation du négatif et de l'agrandissement, en choisissant son révélateur, la température de la révélation, le papier photographique, les manipulations postérieures (le recadrage, la retouche), tout autant que la présentation des photos (dans une exposition, un livre, un journal, etc.).

Michael Snow, Authorization, 1969.

Il est d'ailleurs intéressant que la production théorique sur la photographie s'élabore en parallèle avec les pratiques des artistes. Ainsi, la photographie ci-contre $^{8}$ est, pour Philippe Dubois, l'illustration parfaite de l'acte photographique, car la photo exhibe la manière dont elle a été fabriquée. Le photographe se place avec sa caméra devant une glace et prend une première photo, qu'il développe et colle sur la glace ; puis il prend une deuxième photo pour la mettre à son tour sur la glace et ainsi de suite, jusqu’à ce que les

\footnotetext{
${ }^{6}$ DUBOIS, Op. cit., p. 62.

${ }^{7} \mathrm{La}$ «photographie directe » ou «photogramme », technique inventée parallèlement par Man Ray (la rayographie) et Christian Shad (la shadowgraphie), fut perçue comme une image vraie, car aucun appareil ne s'interpose entre l'objet et l'image, même si les traces n'offrent aucune ou peu de ressemblance avec leur objet. Les surréalistes y voyaient alors l'équivalent de l'écriture automatique. GATTIONI, Christian, Les mots de la photographie, Paris, éd. Belin, 2004, s.v. «photogramme ».

${ }^{8}$ SNOW, Michael, Authorization, 1969, 54,5 x 44,5 cm, Musée des Beaux Arts du Canada. Voir l'image sur la galerie virtuelle du musée :

http://cybermuse.gallery.ca/cybermuse/search/artwork_e.jsp?mkey=7852 (consulté le : 03/03/2009). Il existe toutefois plusieurs versions de la même photo avec un arrière-plan différent.
} 
images fixées sur la glace couvrent totalement le reflet du photographe ; le photographe sera donc absent de la photo finale. Les quatre photos exhibant le processus prennent la place de l'appareil et de l'auteur, ils sont à la fois l'appareil et l'image, qui est mise en abyme en plus petit, dans le coin gauche en haut du cliché. On retrouvera les notions d'acte photographique et de mise en abyme, appliquées à la fois à la littérature et à la photographie, dans l'œuvre de Denis Roche, et le caractéristique indiciel, en tant qu'ancrage temporel, aura un impacte sur les autobiographies photo-littéraires ou photobiographies. 


\section{II.4. La deuxième moitié du $X X^{e}$ siècle : contextes et changements}

Progressivement au cours de la deuxième moitié du $\mathrm{XX}^{\mathrm{e}}$ siècle apparaissent les premiers écrits théoriques sur le médium. Cette période correspond également à l'institutionnalisation de la photographie'.

Des photographes créent des agences de presse $^{2}$ en vue de garder un contrôle total sur les droits de leurs photos, ce qui entrainera la mise en place d'une valeur marchande des clichés et une certaine esthétique et éthique des photos de presses.

C'est à cette période qu'apparaissent des galeries spécialisées dans la photo (le musée Nicéphore Niepce ${ }^{3}$ de Chalon-sur-Saône en 1972, la galerie Agathe Gaillard ${ }^{4}$ en 1975, Contrejour en 1975 - à la fois galerie, journal et maison d'édition -, la galerie municipale du Château d'eau à Toulouse ${ }^{5}$ en 1974, la Maison Européenne de la Photographie $^{6}$ en 1982), et plusieurs musées ${ }^{7}$ se dotent d'un fonds photographique.

Divers journaux spécialisés voient le jour, des revues techniques ( $L e$ Photographe, Magazine des professionnels photo-video), ou accessibles à un large public (Caméra, Photo, Photo-revue, Photographie Magazine), mais aussi des revues plus théoriques (Les Cahiers de la Photographie (1981-1995), Photographies (1983-

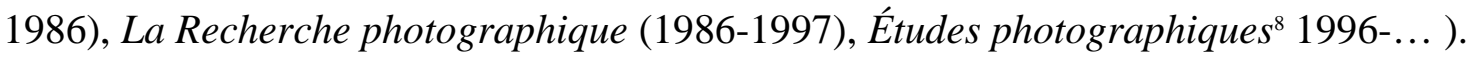

Aussi faut-il encore mentionner le premier festival consacré à la photographie, «Les Rencontres d'Arles », créé en 1969 à l'initiative de l'écrivain Michel Tournier, du photographe Lucien Clergue, et du conservateur de musée Jean Rouquette. C'est au même moment que naissent des écoles spécialisées visant à faire entrer la photographie

\footnotetext{
${ }^{1}$ Un livret publié par le Ministère de Culture en 1992, recense justement les institutions qui ont été créées pour la valorisation et la conservation de la photographie. (Sans mention de l'auteur, La Photographie, Paris, La Documentation française, col. «État et culture », 1992.)

${ }^{2}$ Rapho (1933), Magnum (1947), Gamma (1966), Viva (1972), Sipa (1973), Sygma (1973), Vu (1986), Métis (1989).

${ }^{3}$ Voir le site du musée : http://www.museeniepce.com/ (consulté le : 10/10/2009).

${ }^{4}$ Voir le site de la galerie : http://www.agathegaillard.com/ (consulté le : 10/10/2009).

${ }^{5}$ Voir le site de la galerie : http://www.galeriechateaudeau.org/ (consulté le : 10/10/2009).

${ }^{6}$ Voir le site du musée : http://www.mep-fr.org/default_test_ok.htm (consulté le : 10/10/2009).

${ }^{7}$ Le livret «État et culture » mentionne, entre autres : le cabinet des Estampes de la Bibliothèque Nationale, La BHVP, le Musée Carnavalet, la Bibliothèque du Musée des Arts Décoratifs, l'École Nationale Supérieure des Beaux-Arts, la Bibliothèque centrale du Musée d'Histoire Naturelle et le Musée Guimet.

${ }^{8}$ Une version en ligne est disponible sur Internet depuis $1997:$ http://etudesphotographiques.revues.org/ (consulté le : 10/10/2009).
} 
dans les programmes scolaires, de l'école primaire à l'Université. Une politique de conservation, d'enrichissement, de mise en valeur et de diffusion s'instaure alors, soutenue par plusieurs organisations.

Ces changements progressifs aboutissent ainsi, à la fin du $\mathrm{XX}^{\mathrm{e}}$ siècle, à l'entrée de la photographie dans le marché de l'art: désormais sa valeur artistique n'est plus mise en doute. Les théories de la photographie qui se développent pendant cette période d'institutionnalisation du médium visent donc à légitimer la photo en lui assignant une fonction (l'analogie ou la preuve), une essence qui pourrait la distinguer de tous les autres arts visuels.

Vers les années 1990 s'opère pourtant un nouveau changement de paradigme dans la théorie de la photographie. La valeur documentaire des clichés (basée justement sur le caractère analogique et révélateur de la photo) se trouve progressivement mise en doute, ainsi que la possibilité de trouver une caractéristique qui rendrait compte de toutes les pratiques existantes.

La remise en cause de la valeur documentaire de la photographie est en partie liée à la crise du photojournalisme. La crise s'est développée à cause de la concurrence des chaînes de télévision dans la diffusion de l'information. La photo en tant que document objectif et porteur d'information est progressivement questionnée par les photographes mêmes en remettant en cause, entre autres, le rapport du texte avec l'image. Plusieurs photographes, comme par exemple Gisèle Freund, témoignent comment la signification de leurs images a été détournée par les journaux; la photographe en conclut que «l'objectivité de l'image n'est qu'une illusion. Les légendes qui la commentent peuvent en changer du tout au tout ${ }^{9} »$.

Selon André Rouillé, la crise du photojournalisme était déjà visible en 1972 avec la suppression du journal Life ${ }^{10}$, et dans le changement significatif qui s'est opéré dans les images de guerre. La guerre du Viêt-Nam (1959-1975) a attiré l'attention de l'armée sur le rôle manipulateur de la photographie. Pendant cette guerre, les photographes étaient encore libres et l'atrocité de certaines images dépassait le seuil de ce qu'un

\footnotetext{
${ }^{9}$ FREUND, Gisèle, Photographie et société, Paris, Seuil, 1974, p. 153. Voir aussi le cas de Raymond Depardon à la page 96.

${ }^{10}$ Le magazine paraît en 1936 et devient vite l'un des plus grands illustrés de l'époque. Il s'arrête en 1972, mais récemment les archives photos ont été mises en ligne sur un site Internet, ce qui permet de faire des recherches à but pédagogique ou de revendre les photos en dehors de leur premier contexte : www.life.com (consulté le 03/03/2009).
} 
lecteur moyen d'un magazine illustré pouvait supporter ${ }^{11}$. Selon André Rouillé, la guerre des Malouines constitue un tournant dans la photographie de guerre: les troupes britanniques n'admirent que deux photographes, et commencèrent à contrôler le choix des images. Depuis, très peu d'images sont réellement diffusées, et au lieu de montrer les combats réels et les morts, on choisit plutôt de montrer des images vues d'avion ou des satellites : «la guerre devenait ainsi abstraite et acceptable, sinon acceptée ${ }^{12} »$.

Yan Morvan, dans un album sur le photojournalisme en 2007, résume ainsi la situation actuelle :

La disparition progressive d'un photojournalisme prétendant montrer une «certaine réalité », a été programmée au profit d'une image fabriquée, mondialisée, où tout le monde peut croire à un monde unique voué au culte du profit et de la consommation.

Le message journalistique a été supplanté par les messages publicitaires ou ceux d'un modèle de société idéalisée par la beauté, la richesse, l'immortalité, la santé, la virilité... ${ }^{13}$

La crise du photojournalisme fait écho à la crise de ses institutions. Les agences photographiques tendent à se regrouper en monopole (Getty, AFP, Reuters) pour pouvoir assurer grâce aux technologies coûteuses la course avec le temps et surmonter le défi que pose la télévision - ce qui laisse de moins en moins de liberté aux photographes qui ne sont plus propriétaires de leurs photos. Les photos retenues ne sont plus choisies par les photographes et les agences sont désormais gérées par des managers qui ne viennent plus du milieu photographique ${ }^{14}$. Le droit de l'homme à l'image rend d'ailleurs de plus en plus difficile la liberté d'action des photographes. Le photographe Laurent van der Stockt parle ainsi de la difficulté à ne pas être manipulé :

À notre époque, même les hommes des pays les moins développés ont compris le rôle de l'image, et il faut constamment être sur ses gardes. Par exemple, au cours d'un voyage au plus profond du Sud-Soudan (...), dans un camp de déplacés, le chef du groupe m'a expliqué ce que je devais faire et ne pas faire. Il a tenu à ce que je sois accompagné, parce qu'il savait pertinemment quelles images peuvent influencer la distribution des aides humanitaires. Pire! Dans un conflit, les différentes parties peuvent mettre tout en œuvre pour contrôler les accès. Le photographe peut se faire manipuler, et les images à leur tour manipuler l'opinion. ${ }^{15}$

\footnotetext{
${ }^{11}$ Michel Frizot mentionne les images de Don Mc Cullin, qui dépassent le seuil du supportable. (FRIZOT, Michel - DELPIRE, Robert, Histoire de voir. De l'instant à l'imaginaire (1930-1970), Paris, Nathan, Collection Photo Poche n42, 2001, p. 11).

${ }^{12}$ ROUILLÉ, André, La photographie, Paris, Gallimard, 2005, p. 182.

${ }_{13}^{13}$ MORVAN, Yan, «Introduction », Photojournalisme, Paris, Victoires, 2007, hors pagination.

${ }^{14}$ Voir à ce sujet les films de Raymond Depardon et le commentaire en supplément sur le DVD : Numéros zéro naissance d'un journal, reproduit par ARTE France, 2007 ; Reporters, produit en 1981 et reproduit par SEPT Vidéo, 1993.

${ }^{15}$ VAN DER STOCKT, Laurent, «Jusqu'au bout du témoignage », entretien publié dans : MORVAN, Yan, Photojournalisme, Paris, Victoires, 2007, p. 71.
} 
Pour Michel Poivert, l'œuvre d'Alfredo Jaar Real Pictures (1994) symbolise la mise à mort du photojournalisme ${ }^{16}$. Les 550 images prises par le photographe lors des massacres au Rwanda sont enfermées dans des boîtes hermétiques sur lesquelles figure la description de chacune des épreuves. Exposée en 1995 au musée de la Photographie contemporaine de $\mathrm{Chicago}^{17}$, la présentation prend la forme d'une installation qui évoque les monuments commémoratifs, les fosses communes dédiées aux disparus inconnus.

Alfredo Jaar Real Pictures, 1994.

Cette installation montre que nous n'avons pas besoin de voir les images pour qu'elles aient un impact sur nous, d'autres images présentes dans notre esprit et le texte descriptif venant combler le manque et produisant un effet semblable à celui des images. En même temps, elles sont le signe qu'il s'agit là de quelque chose d'indicible, d'inmontrable, qui dépasse ce qui peut être montré. En retour, ce qui est montré ne peut plus atteindre son but - faire changer les choses : on les regarde, choqué peut-être, terrifié sans doute, puis on tourne la page.

Le changement qui s'opère au tournant du siècle vis-à-vis de la valeur de vérité de la photographie s'articule donc autour d'une problématique très vaste, celle du pouvoir de communication des clichés. L'image entre en compétition avec d'autres média (télévision, Internet, téléphone portable) dans la course accélérée de la diffusion de l'information ${ }^{18}$. Rappelons que Barthes évoquait déjà dans la Rhétorique de l'image, que l'image photographique «correspondrait à une mutation capitale des économies

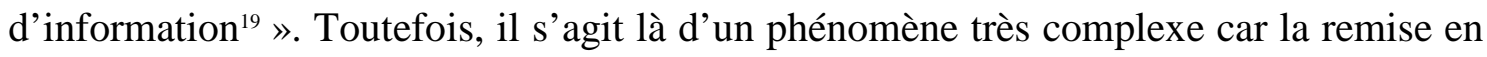
cause de la valeur de vérité est en partie aussi liée à la fin des grandes utopies

\footnotetext{
${ }^{16}$ POIVERT, Michel, La photographie contemporaine, Paris, Flammarion, 2002, p. 68-69.

${ }^{17}$ Voir le lien du musée de Chicago d'où provient l'image insérée : http://www.mocp.org/collections/permanent/jaar_alfredo.php (consulté le : 03/03/2009).

${ }_{18}$ Yan Morvan cite, à propos de l'invention de la photographie numérique, le livre Trafic des nouvelles d'Olivier Boyd-Barrett et de Michel Palmer, qui formulaient déjà en 1981 la thèse que « dans l'histoire de l'information et de la communication, depuis l'imprimerie et la gravure, toute technologie permettant d'accélérer la diffusion des informations s'était inexorablement imposée ». MORVAN, Yan, «Introduction », Op. cit., hors pagination. Voir aussi : La fin de l'information?, Entretien avec Bernard Poulet et Vincent Giret par Thierry Pech, 18-04-2008, http://www.laviedesidees.fr/La-fin-de-1information.html (consulté le : 03/03/2009).

${ }^{19}$ BARTHES, Roland, « Rhétorique de l'image », Op. cit., p. 1425.
} 
idéologiques. Suite à Zaki Laïdi, nous pourrions même dire que s'opère un changement général dans notre approche de la vérité :

Dans cette nasse de présent, la vérité n'a de sens que dans l'ici et maintenant, un peu à l'image des marchés financiers où la valeur des choses ne fait sens qu'aujourd'hui. Non seulement la vérité n'a de sens que dans l'ici et maintenant, mais elle est toujours susceptible d'être révisée par une perception ultérieure car la vérité d'aujourd'hui ne court pas le danger d'être probablement démentie demain ; en effet, elle sera devenue la vérité d'hier et c'est le fait d'être une vérité d'hier qui la rend inexorablement obsolète aujourd'hui. Autrement dit, le sens et la valeur de la vérité ne se trouve que dans le seul présent. ${ }^{20}$

Nous trouvons donc dans l'histoire des idées de la photographie une évolution qui va de la photographie objective, miroir de la réalité, vers la prise de conscience de son mécanisme en tant que générateur de réalités. Toutefois, ce bouleversement ne signifie pas que la croyance en la vérité de l'image ait tout à fait disparu.

Même si la valeur de document et l'objectivité de la photographie sont remises en cause dans les années 1990, Michel Poivert souligne que nous voulons croire à l'utopie du document comme on "glosait jadis sur le "dernier tableau" face aux expériences radicales de l'abstraction ${ }^{21} »$.

Selon André Rouillé, le fait d'avoir considéré la photographie comme une image objective de la réalité s'explique par des raisons historiques et sociales. On pourrait voir dans l'invention de la photographie le symbole de la société industrielle, puisqu'elle reflète le positivisme, la croyance que l'évolution de la science sert l'amélioration de nos conditions de vie. Dans cette approche, la vérité et l'exactitude augmenteraient proportionnellement avec l'exclusion de l'homme dans la production de l'image ${ }^{22}$. Avec les images «exactes » et «objectives », c'est l'utopie de l'encyclopédie de Diderot qui renaît, c'est-à-dire que le monde pourrait être décrit, interprété et classé en catalogues ${ }^{23}$. Selon Rouillé, la valeur documentaire de la photographie est avant tout une question de croyance. Elle s'apparente à l'utilisation de l'argent, qui suppose une croyance commune en sa valeur, et demande un système d'équivalence.

C'est en renouvelant le régime de la vérité, en nourrissant la croyance que ses images sont «l'exactitude, la vérité, la réalité elle-même », que la photographie a pu supplanter le dessin et la gravure dans leurs fonctions documentaires. ${ }^{24}$

\footnotetext{
${ }^{20}$ LAÏDI, Zaki, « Le sacre du présent », in Figures du temps (sous la dir. de Spyros, Théodorou), Paris, Parenthèse, 2003, p. 94-95. Le parallèle avec le marché financier paraît d'autant plus parlant que la crise financière actuelle est due aux spéculations avec des valeurs fictives.

${ }^{21}$ POIVERT, Michel, Op. Cit., p. 142.

${ }^{22}$ ROUILLÉ, André, Op. cit., p. 76.

${ }^{23}$ Ibid., p. 41.

${ }^{24}$ Ibid., p. 59.
} 
Nous retrouvons la remise en cause de l'objectivité de la photographie dans plusieurs ouvrages théoriques à la fin du $\mathrm{XX}^{\mathrm{e}}$ siècle. Ainsi par exemple, le philosophe Henri Van Lier souligne le processus d'abstraction qu'opère une photo à plusieurs reprises depuis le moment de la prise de vue jusqu'au développement du clichée ${ }^{25}$. Le cadrage produit déjà un écart entre la réalité et l'image, selon Van Lier : non seulement il prélève un fragment d'un espace-temps continu et indivisible mais, déjà, sa forme carré ou rectangulaire produit un effet de sens (avec la coupe aiguë de ses bords perpendiculaires et non ronds, par exemple). Une autre abstraction se produit au niveau de la focalisation. Même sur l'image la plus riche en détail il reste toujours un espace où les photons ne seront réfléchis que partiellement, à cause de la distance qui sépare l'appareil de la source de lumière. Se produit également une perte d'information lors des différentes manœuvres à effectuer pour obtenir une image photographique. Ainsi la qualité et la sensibilité du négatif influence la marge de réaction du support à la lumière, mais l'information (en terme de photon et de détail) se perd également lors des manipulations de développement et d'agrandissement. En même temps, selon Van Lier, l'image photographique amène à la fois une perte d'information et un surplus d'information car, dans l'image immobile, notre œil toujours en mouvement peut capter plus d'éléments que ce qui s'offre à la vue directe.

Vilém Flusser ${ }^{26}$ attire l'attention sur une autre problématique par rapport à l'objectivé du médium : le conditionnement de l'appareil. Ce dernier délimite les possibilités de l'image produite. Le photographe ne peut créer ses images qu'au sein des contraintes qu'impose la machine, en fusionnant avec la machine. L'acquisition du regard photographique passe par l'apprentissage de la technique et l'acquisition de réflexes inconscients, de manières de regarder, jusqu'à aboutir à une fusion avec l'appareil :

Le photographe est à l'intérieur de son appareil, il lui est lié d'une autre façon que l'artisan entouré de ses outils et que le travailleur à sa machine. Voilà une fonction d'un nouveau genre, où l'homme n'est ni constante ni variable, mais où l'homme et l'appareil se confondent pour ne plus faire qu'un. ${ }^{27}$

${ }^{25}$ VAN LIER, Henri, Philosophie de la photographie, Paris - Bruxelles, Les Impressions Nouvelles, 1983, p. 16-21.

${ }^{26}$ FLUSSER, Vilém, Pour une philosophie de la photographie, Paris, Circé, 2004.

${ }^{27}$ Ibid., p. 29. 
Vilém Flusser ajoute toutefois que malgré ce conditionnement de l'appareil, les contraintes techniques peuvent être dépassées et que l'appareil est capable de transmettre des idées, un sens, car il est un «jouet simulant la pensée ${ }^{28} »$.

L'homme se soumet aux contraintes de l'appareil, tandis que ce dernier est à son tour soumis aux enjeux de l'industrie photographique et aux attentes (ou appareils) économiques et sociales. Françoise Denoyelle fournit par exemple une analyse très pertinente de l'évolution technique qui eut lieu dans les années 1930 et de son influence sur l'esthétique photographique de l'école de Paris ${ }^{29}$. Nous retrouvons le même type de changement avec le passage des appareils analogiques aux appareils numériques. Comme la pratique photographique de masse se fait désormais en numérique, les usines qui produisaient des équipements, des accessoires, des produits pour la photographie analogique ont dû fermer leur porte ou fusionner avec d'autres entreprises, gardant la production analogique en marge de leur activité. Les appareils numériques permettent de créer d'autres types d'image, engendrent un autre aspect visuel que l'analogique, ce qui va également bouleverser en retour la réception des images et la théorie de l'idée de la photographie.

L'analogie que souligne le terme d'icone ne semble plus un critère absolu de la photographie, certaines pratiques cherchent justement à explorer les capacités spécifiques de l'appareil (dérèglements ${ }^{30}$, distorsions, pixellisation, procédés numériques, etc.) qui peuvent dépasser celles de l'œil ou s'en différencier. Aussi la photographie contemporaine, qui exploite l'invisible sur l'image ne peut plus recourir ni à la notion d'index ni à la notion d'icone. L'avènement du numérique et des programmes de traitement d'images ouvre le champ à la profusion des manipulations postérieures en bouleversant l'indicialité de la photographie, ainsi que les caractéristiques qui distinguaient jusqu'à présent la photographie de la peinture.

\footnotetext{
${ }^{28}$ Ibid., p. 69 et 86.

${ }^{29}$ DENOYELLE, Françoise, Le marché de la photographie, 1919-1939, Paris, l'Harmattan, 1997.

${ }^{30}$ Voir à ce propos le livre de Clément Chéroux (CHEROUX, Clément, Fautographie, Petite histoire de l'erreur photographique, Paris, Yellow Now, 2003) ou le catalogue d'exposition : Réels, fictions, virtuel, catalogue publié à l'occasion des Rencontres internationales de la Photographie d'Arles, Actes Sud, 1996.
} 


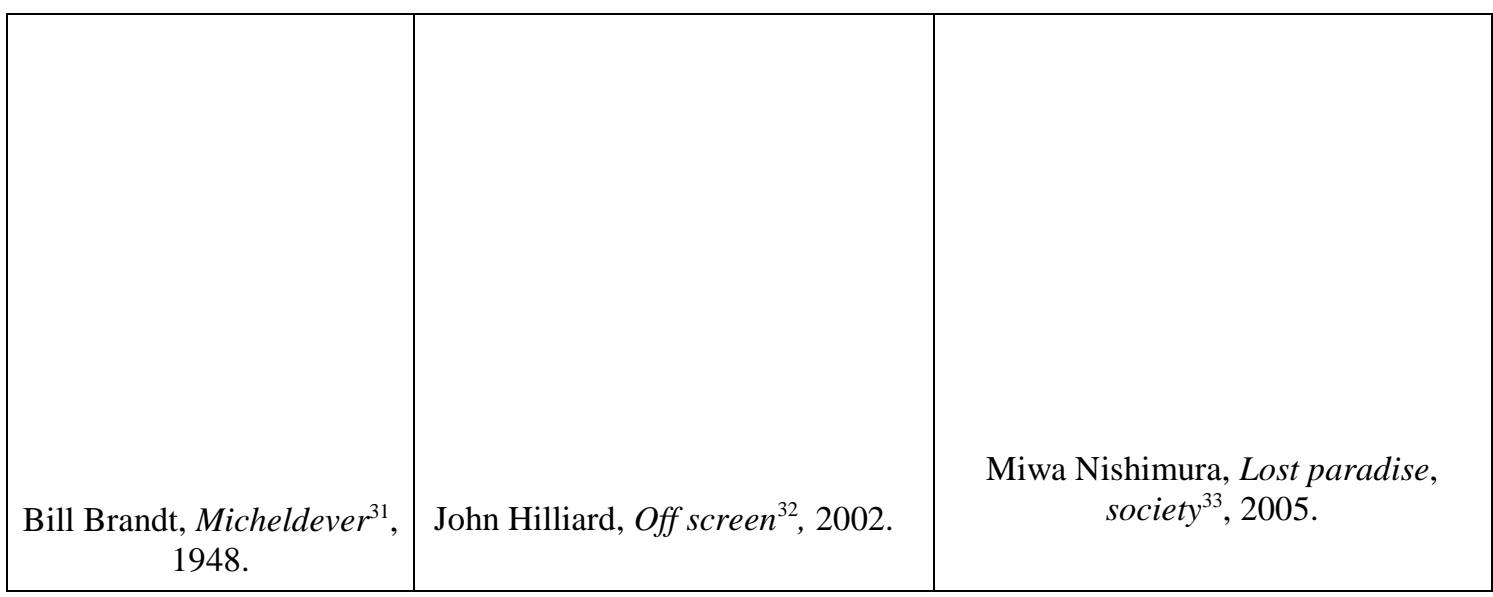

Contrairement aux définitions essentialistes qui caractérisent l'approche analytique de la période de l'institutionnalisation du médium, dans les années 1990 se répand le courant pragmatiste $^{34}$, qui se base sur l'usage. L'approche pragmatique, qui trouve son origine dans les écrits de Peirce, démontre l'insuffisance de la définition de la photographie comme «acte», car elle ne prend pas en compte l'image qui implique entre autres la participation d'un photographe (ou, selon le terme de Barthes, d'un «Operator ») qui fait des choix volontaires ou involontaires (des choix techniques et personnels), et néglige aussi le spectateur (comme corps subjectif, social, etc.) consommateur de l'image qui va devoir choisir diverses stratégies de lecture pour comprendre l'image.

L'esthétique pragmatiste évalue à titre égal la culture populaire et la haute culture. Elle refuse «les catégories ontologiques et les essences supra-historiques ${ }^{35}$ » dans la définition de l'art, et rejette le fait que l'art serait « détaché de toute fonction, de toute récupération pratique ${ }^{36} »$. Richard Shusterman intègre ainsi à son analyse la musique rap et les graffitis. Mais on trouve déjà le même intérêt pour la culture populaire dans les Mythologies de Roland Barthes (1957) et c'est aussi le caractère populaire de la photographie qu'analyse Pierre Bourdieu ${ }^{37}$ du point de vue de la sociologie en 1965. Certaines caractéristiques de la photographie amateur semblent même gagner de

\footnotetext{
${ }^{31} \mathrm{http}: / /$ www.artnet.com/Galleries/Artists_detail.asp?gid=480\&aid=2968 (consulté le : 16/07/2009).

${ }^{32}$ http://www.staedtische-galerie-erlangen.de/seiten/6_sammlung/bilder/diverse/hilliard_off_screen.jpg (consulté le : 16/07/2009).

${ }^{33}$ Voir sur le site personnel de l'artiste : http://www.miwanishimura.com/ (consulté le : 16/07/2009).

${ }^{34}$ C'est Richard Shusterman qui applique en premier cette notion linguistique à l'art. SHUSTERMAN, Richard, L'art à l'état vif : la pensée pragmatiste et l'esthétique populaire, traduit de l'américain par Christine Noille, Paris, Minuit, 1991.

${ }^{35}$ Ibid., p. 18.

${ }^{36}$ Ibid. p. 26.

${ }^{37}$ BOURDIEU, P. ; BOLTANSKI, L. CASTEL, R. ; CHAMBOREDON, J.-C., Un art moyen, essai sur les usages sociaux de la photographie, Paris, Minuit, col. "Le sens commun", 1965.
} 
l'intérêt dans les années 1970 et 80, telles la mauvaise mise au point qui produit un flou à l'image, ou le mauvais cadrage qui fournit des images inattendues ${ }^{38}$.

Dans la photographie contemporaine la production amateur apparaît en tant qu'utopie de l'automatisme et de l'objectivité. Selon Michel Poivert, la valeur documentaire se trouverait aujourd'hui dans la neutralité d'une photographie, dans une distance «juste» prise par rapport à l'image, entre le retrait et l'implication de l'auteur ${ }^{39}$. Les «photographies neutres » ne cherchent plus l'évènement, le moment décisif, les couleurs et les lumières qui attirent l'œil. Elles cherchent le «temps faible » quand il ne se passe rien. Dans son livre en parallèle au texte décrivant la photographie contemporaine se trouvent, entre autres, des clichés de Jean-Marc Bustamante ${ }^{40}$, Thomas Ruff, William Eggleston ${ }^{41}$, ou Valéry Jouve ${ }^{42}$. Poivert n'analyse pas toutes les images insérées, mais le style des images parle de soi. Si la photographie peut fonctionner comme document neutre, selon Poivert, c'est parce qu'elle incarne un paradoxe, celui d'être à la fois artistique et l'anti-modèle artistique, à la fois fiction et document. Le visuel recherché se place alors entre les réalisations amateurs et la recherche de la belle image. De plus, dans le document neutre, le spectateur de la photo n'est plus un consommateur potentiel, il devient impliqué. L'information n'est plus donnée, mais elle exige une connaissance préalable, un investissement de la part du spectateur $^{43}$.

\footnotetext{
${ }^{38}$ Le flou et le cadrage aléatoire sont fréquemment utilisés par Robert Frank dans Les Américains (Paris, Delpire, 1958) et il gagne une popularité en France grâce à l'œuvre de Bernard Plossu. GATTINONI, Christian - VIGOUROUX, Yannick, La photographie contemporaine, Paris, Scala, 2005, p. 25.

${ }^{39}$ POIVERT, Michel, Op. cit., p. 156.

${ }^{40}$ Voir quelques exemples des images de Jean-Marc Bustamante et Thomas Ruff sur le site de la Tate Galery à Londre : http://www.tate.org.uk/modern/exhibitions/ubsphotography/left.shtm (consulté le : 25/05/2009).

${ }^{41}$ Voir le site Web de William Eggleston : http://www.egglestontrust.com/ (consulté le : 25/05/2009).

${ }^{42}$ Voir le site Web de Valéry Jouve: http://www.valeriejouve.com/\# (consulté le : 25/05/2009).

${ }^{43}$ POIVERT, Michel, Op. Cit., p. 162.
} 


\section{II.5. Le paradoxe de l'empreinte}

À l'encontre de l' «icône » ou de l' « index », la notion d' «empreinte » ou de «trace » est désormais fréquemment employée dans le discours sur la photographie au tournant du XXI ${ }^{\mathrm{e}}$ siècle. La notion d'empreinte favorise l'indicialité de la photographie et renoue en même temps avec les débuts de l'invention du procédé photographique. Les premiers essais de Henri Fox Talbot consistaient justement à trouver une formule chimique par laquelle des plaques sensibilisées à la lumière, après exposition, conserveraient les empreintes de feuilles et autres objets placés dessus. De même, le procédé du photogramme capte les contours et les traces des objets. Cette notion de l'empreinte est alors particulièrement apte à éveiller l'imagination, et l'envol littéraire. Elle permet de comparer la photographie aux traces naturelles laissées dans le sable, la neige, traces éphémères que le temps et l'érosion font disparaître. C'est par la notion d'empreinte que la photographie est assimilée à «l'image vraie » qui s'est imprimée sur le voile de Véronique ou à la «vaporographie ${ }^{1} » d u$ Saint Suaire. Elle permet également d'insérer et de penser la photographie dans la tradition des arts plastiques et, encore une fois, de la légitimer. Philippe Dubois évoque ainsi l'œuvre d'Yves Klein en faisant sentir que Klein «joue aux effets photographiques par la peinture ${ }^{2} »$. Yves Klein, dans un premier temps utilise des corps de femmes nues enduits de peinture comme des pinceaux vivants pour inscrire les traces colorées de leurs corps sur des toiles. Puis, dans un second temps, à l'aide de peintures au lance-flammes, il obtenait la forme négative des corps. Des photographes exploreront d'ailleurs en photographie la technique d' « empreinte » : ainsi les Nudogrammes de Floris M. Neussüs ${ }^{3}$ rappellent les images d'Yves Klein. Mais

\footnotetext{
${ }^{1}$ Paul Vignon, dans son étude de 1902 intitulée Le linceul du Christ. Étude scientifique, considère le Saint Suaire de Turin comme une vaporographie. L'étude du suaire photographié en 1898 par Secondo Pia a révélé que l'image était en négatif. Selon Vignon, ce phénomène aurait pu se produire grâce aux lumières ou aux vapeurs émises par le corps du Christ. GEIMER, Peter, «L'autorité de la photographie, Révélation d'un suaire », Études photographiques, n6, mai 1999, p. 67-99:

http://etudesphotographiques.revues.org/index189.html (consulté le : 03/03/2009).

${ }^{2}$ DUBOIS, Philippe, Op. cit., p. 240-243.

${ }^{3}$ Voir l'image insérée à la page 35 qui provient du site des éditions Lumas : http://eu.lumas.com/?id=1305\&artist=71\&wid=40\&version=3\&ed= (consulté le : 03/03/2009). Michel Tournier fait d'ailleurs référence implicitement au Nudogrammes de Neussüs dans son récit intitulé $L e$ voile de Véronique (TOURNIER, Michel, «Les suaires de Véronique », Le Coq de bruyère, Paris, Gallimard, 1978, p. 139-159).
} 
François Rouan ${ }^{4}$ place à son tour des femmes nues sur des papiers photographiques pour prélever des empreintes de corps, qu'il réutilisera dans sa méthode particulière de tressage pour évoquer le morcellement du corps.

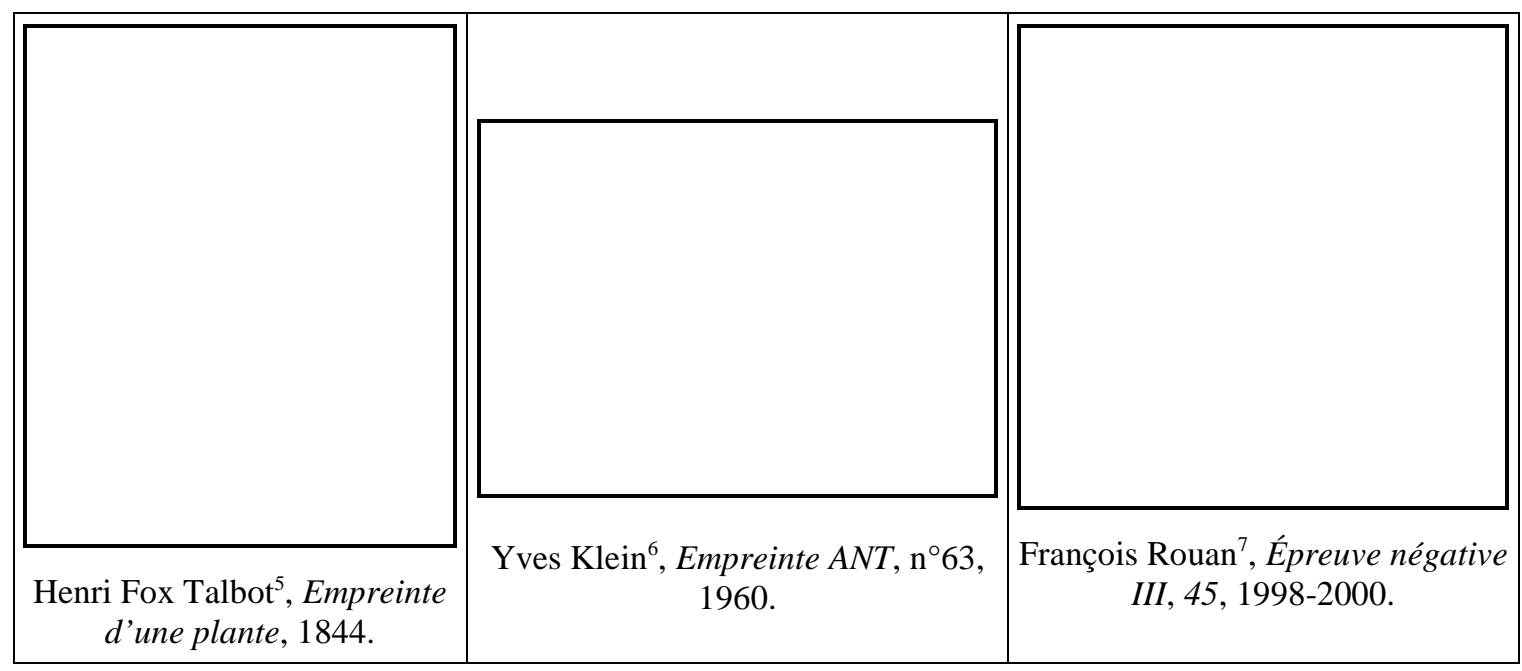

François Soulage invite également à interpréter la photographie comme trace, mais il écarte la valeur de preuve qu'implique l'indicialité. La photographie serait selon lui une trace essentiellement énigmatique : «[...] une photo est une trace, mais une trace de quoi $^{8}$ ? » se demande-t-il.

Une photo n'est pas une preuve mais une trace à la fois de l'objet à photographier qui est inconnaissable et inphotographiable, du sujet photographiant qui est aussi inconnaissable, et du matériel photographique; c'est donc l'articulation de deux secrets, celui de l'objet et celui du sujet. Voilà pourquoi la photographie est intéressante : elle ne donne pas une réponse, mais pose et impose ce secret de secret qui fait passer le récepteur d'un désir de réel à une ouverture sur l'imaginaire, d'un sens à une interrogation sur le sens, d'une certitude à une inquiétude, d'une solution à un problème. La photographie est énigme : elle convoque le récepteur à interpréter, à interroger, à critiquer, bref à créer et à penser, mais de façon inachevable. ${ }^{9}$

\footnotetext{
${ }^{4}$ Voir sur son œuvre le livre : MARTIN, Jean-Clet, Le corps de l'empreinte, Paris, Kimé, col. "Le collège en acte", 2004.

${ }^{5}$ TALBOT, Henri Fox, The Pencil of nature, Longman, Brown, Green \& Longmans, London 1844, planche VII, voir l'image (consulté le : 03/03/2009) à la page suivante : http://www.cs.waikato.ac.nz/oldcontent/cbeardon/dcollage/collage2/images/FoxTalbot/photogenic.jpg ${ }^{6}$ Voir l'image insérée : http://www.laboratoiredugeste.com/spip.php?article28. Pour d'autres œuvres, voir les archives Yves Klein: http://www.yveskleinarchives.org/works/works1_fr.html (consulté le : 03/03/2009).

${ }^{7}$ Voir une image de la même série : http://www.paris-art.com/img/oeuvre/DT-Rouan-2N.jpg ou encore à la galerie Daniel Templon, sous le nom de l'artiste et parmi les expositions de 2003: http://www.danieltemplon.com/ (consulté le : 03/03/2009).

${ }^{8}$ SOULAGE, François, «La trace ombilicale», in Traces photographiques, traces autobiographiques, (dir.) MÉAUX, Danièle, VRAY, Jean-Bernard, Saint-Étienne, Publication de l'Université Saint-Étienne, 2004, p. 21.

${ }^{9}$ Ibid. p. 23 .
} 
Le propre de la photographie est qu'elle s'ouvre facilement à la polysémie car le cliché est conditionné par son usage. Dans l'Esthétique de la photographie Soulage note :

La photographie domestique, artistique ou publicitaire révèle le véritable usage possible de la photographie : on peut toujours lui donner un autre sens ; mieux, son destin social et historique est même d'acquérir d'autres sens ; ainsi la photo de Newton, qui servit d'abord pour la publicité des parfums Rochas, puis pour la couverture du livre de Tisseron L'érotisme du toucher des étoffes, est exposée dans un musée et peut être une photo domestique pour le mannequin photographié. ${ }^{10}$

La personne qui regarde va toujours interpréter l'œuvre selon le contexte, mais aussi selon son imagination et son inconscient investissant l'image. Le paradoxe de la photographie pour Soulage, mais aussi son intérêt, découle du fait que l'acte est irréversible, mais son interprétation est inachevable.

Selon Didi-Huberman, «l'empreinte » introduit un anachronisme fondamental, un défi au temps et à la mémoire, dans la mesure où elle peut être prélevée et dupliquée et instaure un paradoxe entre la singularité d'une emprise corporelle et son caractère universel en tant que reproduction sérielle ${ }^{11}$. Considérer l'empreinte comme une expérience artistique fondamentale équivaut à contester le modèle de l'imitation (la mimesis) en promouvant, dans la lignée de Walter Benjamin, le modèle, tactile et technique, du travail en acte.

Rappelons que Walter Benjamin dans L'euvre d'art à l'époque de sa reproductibilité technique, soutient que le caractère technique de la photographie, qui permet sa reproductibilité, transforme foncièrement notre rapport à l'œuvre d'art. La reproduction supprime l'unicité de l'œuvre et détruit son authenticité. À l'origine, selon le raisonnement de Benjamin, les œuvres d'art servaient un culte, un rituel, et l'unicité de l'œuvre lui conférait les caractéristiques lointaines et inapprochables de l'objet culte qui se trouvait dans un endroit précis. Avec la possibilité d'une reproduction à « l'infini », l'objet est démultiplié, il se retrouve en même temps à plusieurs endroits et finalement perd sa valeur historique ancrée dans sa durée matérielle :

${ }^{10}$ SOULAGES, François, Esthétique de la photographie, Paris, Nathan, 1998, p. 229. On pourrait tout aussi citer Susan Sontag qui décrit la même idée dans son livre Sur la photographie: «Du fait que chaque photographie n'est qu'un fragment, sa charge morale et émotive dépend de son point d'insertion. Une photographie n'est pas la même suivant les contextes dans lesquels elle est vue... » SONTAG, Susan, Sur la photographie, Paris, Union Générale, 1983. p. 131-132.

11 DIDI-HUBERMAN, Georges, La ressemblance par contact, Paris, Minuit, 2008. Ce livre est une réédition du texte que Didi-Huberman écrivit pour le catalogue de l'exposition intitulée « Empreinte » qui avait lieu au Centre Georges Pompidou entre le 19 février et le 12 mai 1997. L'exposition retraçait, dans une visée chronologique, la fascination pour l'empreinte depuis la préhistoire jusqu'aux œuvres d'art postmodernes. 
Ce qui fait l'authenticité d'une chose est tout ce qu'elle contient de transmissible de par son origine, de sa durée matérielle à son pouvoir de témoignage historique. Comme cette valeur de témoignage repose sur sa durée matérielle, dans le cas de la reproduction, où le premier élément la durée matérielle - échappe aux hommes, le second - le témoignage historique de la chose - se trouve également ébranlé. Rien de plus assurément, mais ce qui est ainsi ébranlé, c'est l'autorité de la chose.

Tout ces caractères se résument dans la notion d'aura, et on pourrait dire : à l'époque de la reproductibilité technique, ce qui dépérit dans l'œuvre d'art, c'est son aura. ${ }^{12}$

La reproductibilité, en abolissant l'authenticité de l'œuvre et son utilisation comme objet culte, instaure une nouvelle fonction à l'œuvre d'art. Elle provoque d'un côté l'apparition de la notion d' «art pour l'art », selon Benjamin, et fonde non plus l'autorité de l'image sur le culte, mais sur la politique :

[...] dès lors que le critère d'authenticité n'est plus applicable à la production artistique, toute la fonction de l'art se trouve bouleversée. Au lieu de reposer sur le rituel, elle se fonde désormais sur une autre pratique : la politique. ${ }^{13}$

Cette dernière remarque est intéressante, car, comme on l'a vu, l'institutionnalisation de la photographie joue un rôle dans son acceptation comme objet d'art et dans le changement qui s'opère dans l'approche théorique de la photographie. L'œuvre de Walter Benjamin, tout comme celui de Charles Sanders Peirce valorise les contextes dans la signification de l'image ou du signe (le support, la technicité, la diffusion, la réception, le contexte économique et social, etc.) et développent un modèle dynamique de la signification. Ce n'est pas un hasard que l'œuvre de tous les deux soit revalorisée par les théoriciens post-modernes et ce non seulement dans la théorie de la photographie mais dans la théorie littéraire ${ }^{14}$.

On retrouve également l'influence de Benjamin et de Peirce dans L'image précaire, livre synthétique de Jean-Marie Schaeffer, qui décrit encore l'empreinte

\footnotetext{
12 BENJAMIN, Walter, L'œuvre d'art à l'époque de sa reproductibilité technique, traduit de l'allemand par Maurice de Gandillac, Paris, Allia, 2006, p. 16 (rédigé en 1935, l'essai subit plusieurs corrections et ne sera publié que de façon posthume en 1955. La dernière version de 1939 est traduite en français par Maurice Gandillac en 1959, revue par Rainer Rochlitz dans Euvres III, Paris, Gallimard, version que reprend l'édition Allia de 2006).

13 Ibid., p. 26. Cette fonction politique de l'art un peu énigmatique se manifesterait dans l'effet que l'œuvre produit sur les masses et la société en l'éduquant à la «perception tactile». Cette dernière ne demande plus d'effort ni de concentration pour la contemplation de l'œuvre mais se base sur l'usage, l'habitude et le divertissement. Benjamin cite comme exemple le cinéma et l'architecture, des formes d'art souvent consommées sans réflexion. Rappelons encore que les deux livres théoriques sur la photographie de Walter Benjamin parurent dans les années 1930, période de l'âge d'or du photojournalisme, des magazines illustrés, mais c'est aussi la période de la Nouvelle Objectivité en Allemagne.

${ }^{14}$ Voir notamment les actes du colloque La littérature à l'ère de la reproductibilité technique. Réponses littéraires au nouveau dispositif représentatif créé par les médias modernes. Penser la représentation 1. textes réunis par Pierre Piret, Paris, L’Harmattan, col. "Champs visuels", 2007.
} 
comme «l'arché » de la photographie ${ }^{15}$. C'est l'enregistrement de la trace d'un corps physique sur un autre corps physique et sensible qui confère à l'image photographique sa spécificité, selon Schaeffer, et c'est donc l'indicialité qui la distingue de toutes les autres images. Il ajoute toutefois qu'admettre l'indicialité de la photographie nécessite un savoir : il faut connaître le fonctionnement de l'appareil et avoir appris son usage. Il apporte comme preuve et exemple le cas décrit par l'ethnologue René Lindenkens ${ }^{16}$ : un autochtone de Mélanésie n'aurait pas réussi du premier coup à déchiffrer son portrait photographique, puis, après un certain temps, aurait commencé à reconnaître les fragments de l'anatomie humaine, mais non pas son propre portrait.

Mais Schaeffer ne s'arrête pas à ce retour à l'indicialité, et précise que la «spécificité qui permet de distinguer l'indice photographique d'autres empreintes photoniques réside dans la fonction analogique de sa réalisation iconique ${ }^{17} \gg$. Le caractère indiciel et iconique de la photographie se trouve pourtant conditionné par l'usage, selon Schaeffer. Nous retrouvons l'approche pragmatique chez lui car dans son analyse figure la photographie dans ses utilisations très variées : photo scientifique (photos téléguidées de sous-marins ou photos prises sur la surface de Mars), photo de presse (Henri Cartier Bresson) ou photo artistique (Edward Weston). Schaeffer distingue ainsi plusieurs fonctions communicationnelles dans l'usage de la photographie: le souvenir, la remémoration, la présentation, la description, le témoignage, la monstration et la trace. Ces différentes fonctions, dont Schaeffer précise que la liste n'est pas exhaustive, lui permettent d'aboutir à un diagramme assez abstrait, qui montre que les différents usages exigent la reconnaissance indicielle et/ou la reconnaissance iconique de la photographie à des degrés divers ${ }^{18}$.

${ }^{15}$ SCHAEFFER, Jean-Marie, L'image précaire, Du dispositif photographique, Paris, Seuil, 1987, p. 1358.

${ }^{16}$ LINDENKENS, René, Essai de sémiotique visuelle, Paris, Kliensieck, 1976, p. 45, cité par SCHAEFFER, L'image précaire, p. 42.

${ }^{17}$ SCHAEFFER, Op. cit., p. 59.

${ }^{18} \mathrm{Ibid}$, p. 128-156. Figure tirée de la p. 139. 


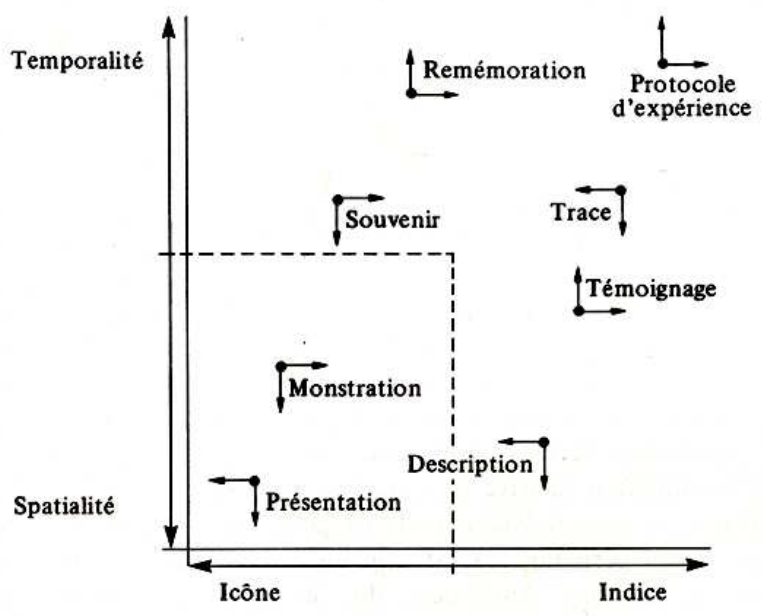

SCHAEFFER, L'image précaire, p. 139.

Contrairement à l'esthétique pragmatiste, Schaeffer classe à part la photographie d'art, car cette dernière «vaut en tant que telle et non pas comme moyen pour quelque stratégie communicationnelle transcendante ${ }^{19} »$. Mais comme François Soulage, il souligne que même si, par la fonction indicielle, une photo ne correspond qu'à une seule conjoncture spatio-temporelle, dans son utilisation, elle peut faire intervenir différentes intentionnalités communicationnelles.

Le signe photographique reste en grande partie sauvage, intermittent : signe (éventuellement) pour le photographe, puis signe, toujours autres et inédit, pour chaque récepteur. [...] Lorsque le signe photographique est désolidarisé de l'environnement communicationnel à l'intérieur duquel il circule, il devient un signe parfaitement erratique et qui pourtant garde toute sa puissance sémiotique. $^{20}$

C'est dans ce sens que Schaeffer considère la photographie comme précaire, au signifiant flou, soumise aux normes communicationnelles dans lesquelles elle se trouve impliquée. L'approche pragmatique parcourt le livre de Schaeffer, sans pour autant vouloir renoncer à une définition essentialiste de l'empreinte comme «arché » de la photographie.

\footnotetext{
${ }^{19}$ Ibid., p. 157.

${ }^{20}$ Ibid., p. 103-104.
} 


\section{II.6. La photographie comme dispositif}

Dans le sous-titre de son livre, Jean-Marie Schaeffer associe la notion du dispositif à la photographie sans pour autant l'approfondir. L'utilisation philosophique de l'expression $\mathrm{du}$ «dispositif » remonte à Michel Foucault et c'est en commentant Foucault que Deleuze $^{1}$ se l'approprie. Il s'agit d'un terme qui fut revalorisé par l'équipe de recherche «Lettres, langages et Arts » de l'université de Toulouse ${ }^{2}$ et appliqué à la littérature en vue de donner un cadre théorique commun pour rapprocher la littérature des médiums visuels, et traiter les œuvres hybrides ou hétérogènes.

La polysémie du mot «dispositif » et son emploi très varié lui confèrent un statut de fourre-tout théorique très pertinent à l'image de l'instabilité des signes. On retrouve ce mot fréquemment utilisé dans les journaux, ou des textes officiels, ce que note Bernard Vouilloux en remarquant que le dispositif «véhicule avec lui l'affairement et le sérieux technocratique qui s'attachent à toute "mise en place" $"$ " .

Dans son emploi le plus courant le dispositif désigne une catégorie générale à laquelle appartiennent plusieurs éléments de nature différente (ce qu'indique aussi le préfixe « dis $\left.^{4} \gg\right)$. Il peut ainsi signifier les mesures prises dans un objectif spécifique. En écrivant «dispositif » dans le moteur de recherche Google, on reçoit par exemple la phrase suivante (le titre d'une info publiée par AFP) : «Mise en place d'un dispositif de sécurité pour le 14 juillet à Paris ${ }^{5} »$. Dans ce cas, on peut y comprendre toutes les démarches qui sont mises en place pour assurer la sécurité à partir de la planification jusqu'à la réalisation (comprenant des éléments aussi disparates que l'installation d'un fonds financier ou la mobilisation des unités de sécurité - police, sapeurs-pompiers).

Le dispositif est orienté par son utilisation, comme le note Bernard Vouilloux, il est : « un agencement actualisant et intégrant des éléments en vue d'un objectif ${ }^{6}$ ». Il n’a

\footnotetext{
${ }^{1}$ DELEUZE, Gilles, «Qu'est-ce qu'un dispositif ? », 1988, réédité dans : Deux régimes de fous. Textes et entretiens 1975-1995, éd. par D. Lapoujade, Paris, Minuit, 2003 ; Voir encore l'analyse de AGAMBEN, Giorgio, Qu'est-ce qu'un dispositif ?, Paris, Rivage poche, 2007. Un résumé du livre est disponible sur le site de François Bon : http://remue.net/spip.php?article2257 (consulté le : 13/07/2009).

${ }^{2}$ ORTEL, Philippe (sous la dir. de), Discours, image, dispositif, Paris, L'Harmattan, 2008.

${ }^{3}$ VOUILLOUX, Bernard, « Du dispositif », in Discours, image, dispositif, Op. cit., p. 15.

${ }^{4}$ ORTEL, Philippe, « Avant-propos », in Discours, image, dispositif, Op. cit., p. 6.

${ }^{5}$ http://www.google.com/hostednews/afp/article/ALeqM5g-psW2HZnMJgO1IzgDhMc6U8dXpA (consulté le : 13/07/2009).

${ }^{6}$ VOUILLOUX, Bernard, Op. cit., p. 24.
} 
de sens que dans son utilisation, son fonctionnement, et il implique une généalogie et un devenir ${ }^{7}$. De ce point de vue, il répond aux exigences du pragmatisme qui est centré sur l'usage.

Le dispositif a aussi une connotation technique et il peut être utilisé dans certaines phrases en tant que synonyme de la photographie, de l'appareil ou de l'image. Cette technicité rappelle l'analyse de Vilém Flusser, qui révèle une sorte de soumission de l'homme aux appareils techniques, conditionnés à leur tour par les mécanismes économiques et sociaux.

Si on considère le dispositif en tant que catégorie générale et philosophique, comme Foucault et Deleuze, et on l'applique à l'œuvre d'art ou littéraire, on élargit alors les frontières de l'œuvre au-delà de sa réalisation matérielle jusqu'à sa réception, en comprenant aussi le contexte dans lequel il apparaît.

La question n'est plus de savoir ce que « dit » un texte mais ce qu'il « fait » concrètement, de sorte que l'analyse poétique s'élargit en amont et en aval du message littéraire : en amont parce que l'efficacité du message tient à des éléments non discursifs, comme les stratégies éditoriales et le support sur lequel l'œuvre est diffusée ; on croise alors les préoccupations de la médiologie. En aval, parce que l'effet du texte sur l'imaginaire et la mémoire du lecteur s'ajoute à l'effet du sens. ${ }^{8}$

Une œuvre en tant que dispositif, n'est pas seulement ouverte, ayant autant de significations que de lecteurs comme l'insinue Umberto Eco9 ${ }^{9}$, mais elle se définit dans la transformation qu'opère l'œuvre sur le lecteur, dans l'objectif qu'elle atteint.

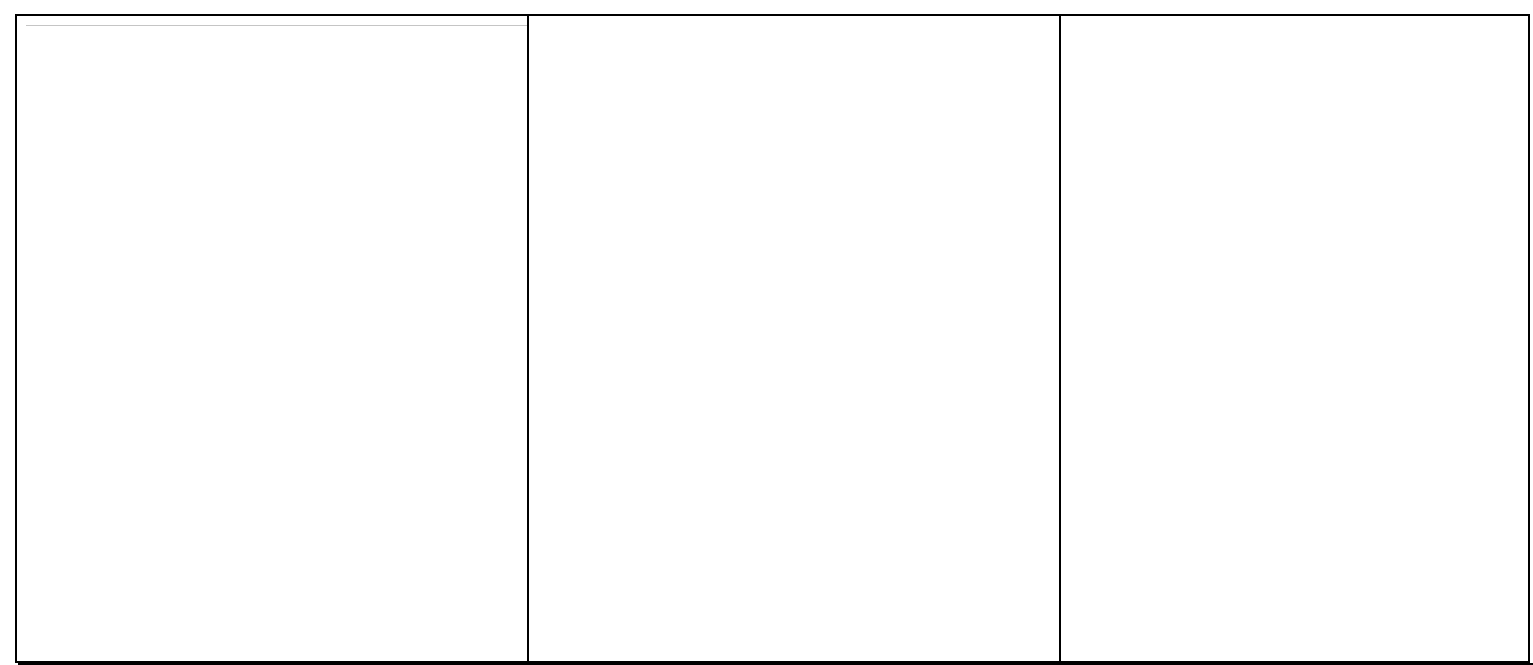

Sophie Calle, Les aveugles ${ }^{10}, 1986$.

\footnotetext{
${ }^{7}$ Ibid., p. 20.

${ }^{8}$ ORTEL, Philippe, « Avant-propos », in Discours, image, dispositif, Op. cit., p. 6.

${ }^{9}$ ECO, Umberto, L'œuvre ouverte, Paris, Seuil, 1965.
} 
Pour prendre un exemple, la série de Sophie Calle sur les Aveugles est un dispositif où le contexte de l'œuvre joue un rôle important. La photographe a réalisé cette série suite à une enquête, dans laquelle elle a questionné des aveugles de naissance, sur leur «vision » de la beauté. Dans le dispositif exposé elle juxtapose ainsi leur réponse sous forme de texte et sous forme d'image, ainsi que le portrait de la personne questionnée. Ce sont donc des éléments hétérogènes. La série provoque un effet sur le regardeur en tant que voyant, il se retrouve presque face à face avec la personne aveugle grâce au portrait et au texte, mais aussi face à une image qui transmet l'expérience esthétique que l'autre ne verra jamais. La question implicite, à savoir quel est le rapport entre la vue et la beauté, retombe sur le regardeur et l'invite à se remettre en question. L'objectif de l'œuvre est en premier lieu de faire entamer la réflexion, mais par rapport aux arts conceptuels, il importe que l'idée soit transmise par l'actualisation matérielle de l'image.

L'effet de sens que l'œuvre provoque dans le lecteur/regardeur est pris en compte, ce qui fait que la signification s'étend au-delà du descriptible, et comprend aussi le sens sensible.

10 Voir les images sur le site du centre Georges Pompidou et le blog de Magali Nachtergael : http://www.centrepompidou.fr/education/ressources/ENS-calle/popup07.html, http://viperenoire.free.fr/oeuvresC.htm (consulté le 13/07/2009). 


\section{II.7. Le sens sensible de la photographie}

Un colloque organisé le 19 et 20 mai 2009 intitulé "L'image, le sensible et le photographique » cherchait justement à démontrer le rapport de la photographie contemporaine au sensible ${ }^{1}$. Mais cette notion est déjà employée par Walter Benjamin qui soutient d'un côté que l'invention de l'instantané de la photographie efface $l^{1}$ « aura ${ }^{2} »$ des choses ou personnes photographiées (qui était encore présent à l'âge d'or de la photographie dans des œuvres comme ceux de Hill, Cameron Hugo ou Nadar). D'un autre côté, il est le premier à insister sur l'inconscient optique que mobilise le médium. De manière paradoxale, si la photographie paraît instaurer le manque d'aura, son originalité se trouve, selon Benjamin, dans le fait qu'elle est prompte «à saisir des images fugaces et cachées, dont le choc éveille les mécanismes d'association du spectateur ».

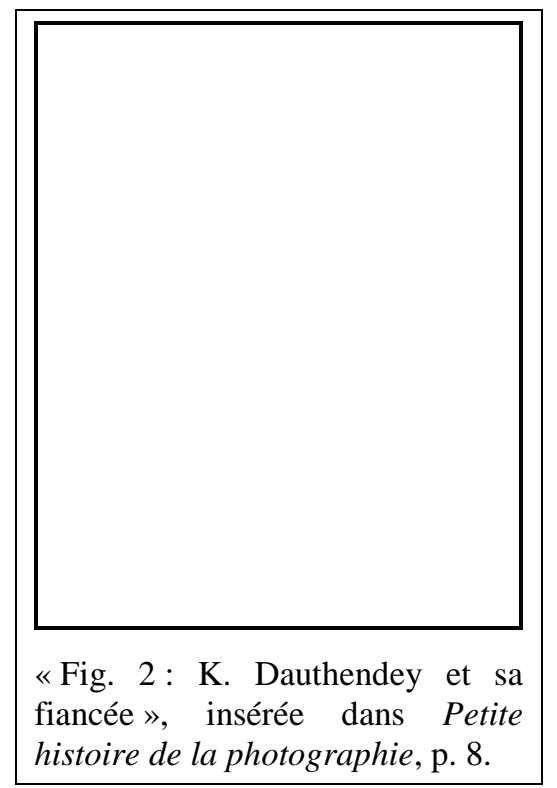

Il ajoute aussi que la légende participe à ce jeu d'association: «la légende qui engrène dans la photographie la littéralisation des conditions de vie, et sans laquelle toute construction photographique demeure incertaine ${ }^{3} »$. Selon lui, la photographie nous fait découvrir l'inconscient optique, comme la psychanalyse révèle l'inconscient des pulsions ${ }^{4}$. Dans une de ses analyses de photo, il en développe même un exemple. La photo ci-contre montre un couple, K. Dauthendey et sa fiancée. Cette dernière a un regard distant dirigé vers le hors cadre, ce que Benjamin interprète comme un signe susceptible d'annoncer son futur suicide - Benjamin

1 Les interventions ne sont pas encore publiées, voir l'annonce du colloque sur Fabula: http://www.fabula.org/actualites/article24158.php, ainsi que le programme détaillé : http://www.univmlv.fr/lisaa/actualites/Colloque-19_et_20_mai_Programme.pdf (consulté le : 09/10/2009).

${ }^{2}$ BENJAMIN, Walter, «Petite histoire de la photographie », Die Literarische Welt, $\mathrm{n}^{\circ}$ 38, 1931, traduit en français en 1971 par Maurice de Gandillac, (rééd. 1983, 1996, 1998, 2005) ; la version à laquelle nous nous référons est parue en édition spéciale dans Études photographiques, ${ }^{\circ}{ }^{\circ}$, novembre 1996. Disponible sur Internet le texte seul : http://etudesphotographiques.revues.org/index99.html ou avec les images : http://www.lhivic.org/sources/divers/benjamin-1931.pdf (consulté le : 10/07/2009).

${ }^{3}$ Ibid., p. 29.

${ }^{4}$ Ibid., p. 12. 
confondant ici la première et la deuxième femme de Dauthendey à cause d'un passage du livre de souvenirs de ce dernier ${ }^{5}$. Ce glissement de sens est révélateur de la manière dont le texte investit la photo et comment l'inconscient optique peut devenir un lieu d'investissement propice aux fantasmes. Si chez Benjamin «l'aura »'efface par la reproduction mécanique, elle paraît refaire surface dans la photographie contemporaine, et elle est notamment revalorisée par la critique qui démontre le sacré ${ }^{6}$, le sublime ${ }^{7}$ et l'effet sensible que peut propager un cliché8.

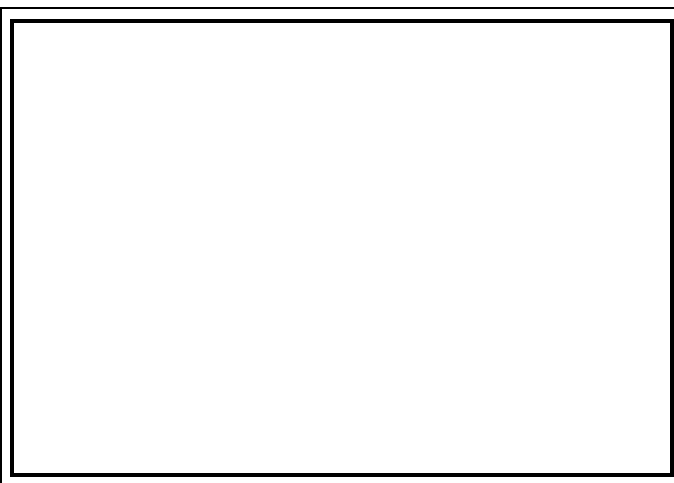

Evgen Bavčar, Nude with hands ${ }^{9}$.

Ainsi par exemple le photographe aveugle, Evgen Bavčar fait confondre la vue avec le touché dans ses images qui sont des reconstructions de représentations mentales. La méthode de Bavčar consiste à prendre les clichés dans le noir absolu, et construire l'image à l'aide d'une torche électrique qui rend visible ce qu'il a parcouru et touché par la torche dans sa main ${ }^{10}$. Pour lui « la cécité est un problème universel ${ }^{11}$ » qui est lié entre autre à l'hégémonie accordée au regard aux dépens des autres sens. La lumière dans ses photos donne à voir le touché, et il ne s'agit jamais d'une inscription littérale, mais d'une évocation de souvenirs, de rêves, de désir et de volupté, son œuvre est donc ancrée dans une dimension autobiographique et subjective.

Le sensible et le subjectif se rejoignent également dans la notion du « punctum » proposée par Roland Barthes. Le punctum, c'est l'élément « qui part de la scène, comme

${ }^{5} \mathrm{Ibid}$., la remarque est faite par le rédacteur, dans les Notes qui suivent l'ouvrage, note ${ }^{\circ} 16$, p. 32 .

${ }^{6}$ ALMIRON, Miguel, «Le sacré et le sensible », intervention au colloque L'image, le sensible et le photographique organisé le 19 et 20 mai 2009. http://www.univ-mlv.fr/lisaa/actualites/Colloque19 et 20_mai_Programme.pdf (consulté le : 09/10/2009).

${ }^{7}$ FRANGNE, Pierre-Henry, «Photographie et littérature de montagne ou le sublime contemporain », in Littérature et photographie, Op. cit., p. 153-165.

${ }^{8} \mathrm{La}$ (re)valorisation du sensible coïncide avec les premières approches de la photographie qui voyaient le procédé comme une surface sensible révélant la métaphysique de la lumière. Comme nous l'avons déjà mentionné on retrouvera notamment chez Lorand Gaspar le sens sensible lié à la lumière ou dans l'approche du rythme/ancrage spatiotemporel chez Denis Roche.

${ }^{9}$ Voir sur le site personnel du photographe : http://www.zonezero.com/exposiciones/fotografos/bavcar/bavcar21.html (consulté le : 09/10/2009).

${ }^{10}$ Son œuvre fait écho à la série des Nocturnes de Michel Séméniako, dans laquelle il éclaire également par ses lampes des paysages qui sont des lieux de mémoires. Voir sur le site personnel du photographe : http://www.michel-semeniako.com/gal_1.html (consulté le : 09/10/2009).

11 Présentation du photographe sur le site du CNRS: http://www2.cnrs.fr/presse/journal/337.htm (consulté le : 09/10/2009). 
une flèche, et qui vient me percer ${ }^{12}{ }^{\prime}$, comme l'écrit Barthes, un détail de l'image (toujours subjectif) qui en modifie entièrement la lecture. Le punctum s'oppose à la connotation culturelle du studium qui relève d'une «sorte d'intérêt général» de l'image, qui peut provoquer de l'émotion chez le spectateur «par le relais raisonnable d'une culture morale et politique ${ }^{13} \gg$. Avec la notion du punctum Barthes dépasse alors la définition de la photographie comme signe dénoté sur lequel se fixe le signe connoté. D'ailleurs le choix des images insérées dans La Chambre claire, montre selon Denis Roche, un rapport subjectif à l'image. Par exemple, il n'y a presque pas de figures féminines représentées sur les clichés (sauf vieille ou déformée) à l'encontre des figures masculines, jeunes et belles ${ }^{14}$. Il n'est pas non plus anodin que Barthes aurait découvert le noème de la photographie grâce à une photographie de sa mère. Denis Roche soutient que le plus important dans les écrits de Barthes sur la photographie serait d'avoir montré le caractère affectif du dispositif ${ }^{15}$.

L'affection et la fascination pour les images ${ }^{16}$ (insinuée par le terme «icône »), en outre de l'économie du temps dans la transmission de l'information, serait un des motifs de la montée des images, et c'est ce qui fait dire à Walter Benjamin que l'analphabète de demain ne sera pas celui qui ignore l'écriture, mais celui qui ignore la photographie, l'effet de sens qu'elle produit ${ }^{17}$.

\footnotetext{
${ }^{12}$ BARTHES, Roland, La Chambre claire, Op. cit., p. 49.

${ }^{13}$ Ibid., p. 48.

${ }^{14}$ Voir par exemple la photo de Mapplethorpe dans le livre de Barthes : http://www.nd.edu/ jmontgom/ti/GraphicArchive/Scans/Original\%20Files/Ch9-

PicTheoryPhoto/RMapplethorpe.jpg ou le cliché réalisé par Alexander Gardner sur un condamné à mort : http://www.desordre.net/textes/bibliotheque/barthes.html (consulté le : 13/07/2009).

${ }^{15}$ ROCHE, Denis, «Un discours affectif sur l'image », Magazine littéraire, numéro Roland Barthes, n³14, octobre 1993, p. 65-67.

${ }^{16}$ Comme exemple pour cette affection que partage les photographes amateurs et professionnels nous reproduisons ici les mots de Jean-Sébastien Stehli, qui se veut spécialiste amateur d'image et qui écrit sur son blog intitulé « le sensible »: «Ce n'est pas, comme on le dit trop souvent, pour arrêter le temps et ainsi éloigner la mort que l'on photographie. Pour moi, la photographie est un moyen d'être attentif au monde qui nous entoure, d'être "présent au monde", comme disent les bouddhistes. Avec ce blog, je souhaite faire partager ma passion, mes découvertes, entraîner les lecteurs dans ma boulimie d'images [...] » http://blog.madame.lefigaro.fr/stehli/ (consulté le : 09/10/2009).

${ }^{17}$ BENJAMIN, Walter, Petite histoire de la photographie, Op. cit, p. 29. La phrase est empruntée à László Moholy Nagy (1928) p. 5.
} 


\section{II.8. La pluralité du sens et la pluralité de l'usage}

Le sens d'une photographie n'est pas seulement actualisé et réactualisé par le contexte, par des éléments en dehors du signe, mais comme on l'a vu des effets de significations inconscientes et sensibles viennent s'ajouter à son emprise tirant le médium vers la région floue de l'indescriptible. A l'image de la photographie, la notion du dispositif est elle aussi floue. En effet, on retrouve ce terme au sein des études littéraires dans des emplois tout à fait dissemblables. Il peut ainsi désigner : des schèmes de représentation (la scène dans les pièces de théâtre ou les romans ${ }^{1}$, le pantomime ${ }^{2}$ ); des formes de récit (le dialogue ${ }^{3}$, la parodie ${ }^{4}$ ); des techniques narratives (l'ellipse ${ }^{5}$, le concept de l'entredeux de l'image et du texte ${ }^{6}$ ); ou encore les images mentales ou vues imageantes ${ }^{7}$.

La pluralité semble régner dans l'utilisation de la notion du dispositif, comme dans l'utilisation de la photographie (photographie amateur, photo souvenir, photo d'identité, photojournalisme, photographie dans la publicité, dans l'illustration, photographie de mode, photographie plasticienne, photographie dans la littérature, etc.). Suivant l'approche pragmatique, il ne paraît plus possible de définir l'essence de la photographie, car sa multitude d'emplois tend à rendre impossible une définition ontologique.

Lors d'une conférence sur la théorie de la photographie organisée en 2006, Sabine T. Kriebel, après avoir esquissé une brève histoire de la théorie de la

${ }^{1}$ ORTEL, Philippe, «Une poétique des dispositifs », in Discours, images, dispositifs, Op. cit., p. 33-58. ; Voir également le site Internet de l'équipe de recherche «Lettres, langues et arts » de l'Université de Toulouse : http://galatea.univ-tlse2.fr/pictura/UtpicturaServeur/AideRecherche.php?numero=15 (consulté le : 03/03/2009).

${ }^{2}$ RYKNER, Arnaud, «La pantomime comme dispositif fin de siècle », in Discours, images, dispositifs, Ibid., p. 161-173.

${ }^{3}$ LOJKINE, Stéphane, «Discours du maître, image du bouffon, dispositif du dialogue : Le Neveu de Rameau », in Discours, images, dispositifs, Ibid., p. 97-125.

${ }^{4}$ DOUSTEYSSIER-KHOZ, Catherine, « Notes sur un dispositif fin de siècle : pub, parodie, poésie », in Discours, images, dispositifs, Ibid., p. 221-231.

5 BUIGNET, Christine, «De la narration à l'ellipse : nouveaux dispositifs photographique dans la photographie contemporaine », in Discours, images, dispositifs, Ibid., p. 201-219.

${ }^{6}$ BOCQUILLON, Michel, «Le dispositif : concept de l'entre-deux ou ligne de partage entre discours et image ?», in Discours, images, dispositifs, Ibid., p. 69-83.

${ }^{7}$ VANOOSTHUYSE, François, « Dispositif et temporalité », in Fiction et vues imageantes : typologies et fonctionnalités, sous la dir. de Bérengère Voisin, (Actes du colloque qui s'est tenu à Tartu le 4 et 5 avril 2008, publiés dans Studia Romanica Tartuensia VII.). 
photographie, arrive à la même conclusion ${ }^{8}$ : il est impossible de déterminer la nature de la photographie, tant pour la variété des procédés qu'on regroupe sous ce nom (la daguerréotypie entre dans cette catégorie autant que les photogrammes, les polaroïds ou les images numériques), que pour les changements qu'a connus sa perception culturelle. Parmi les références anglophones qu'elle évoque, plusieurs théoriciens (Joel Snyder, Victor Burgin, Abigail Solomon-Godeau, William J. Mitchell et Lev Manovich) parlent également du caractère conventionnel de la photographie, comme les théoriciens français que nous avons cités.

Les écrits théoriques sur la photographie se sont démultipliés et diversifiés depuis les années 1980, en partie par l'influence de l'œuvre de Roland Barthes. De nos jours on trouve des approches théoriques très variées et non seulement dans des livres et actes de colloques, mais sur des blogs de théoriciens sur Internet, ou des forums de discussion animés par des professionnels ou amateurs.

En même temps il existe un courant inverse, qui conteste la pluralité des théories. Geoffrey Batchen accuse ainsi les théoriciens de la photographie de rester essentialistes et d'avoir seulement déplacé la nature inchangeable du médium par une détermination soumise aux changements culturels ${ }^{9}$. Jan Baetens remarque aussi que le fait que ce soient des académiciens, des spécialistes en théorie de la photographie qui déterminent le discours théorique dominant, conduit la théorie à un enfermement dans une perspective de l'histoire de l'art qui se cantonne aux mêmes questions et problématiques $^{10}$.

Le terme du «dispositif » tente aussi de réduire tout le processus de création à une notion, même s'il a la vertu d'être assez flou pour désigner des éléments dissemblables et juxtaposés qui cohabitent le même espace. Suivant l'exemple géométrique de Robert Marty ${ }^{11}$ qu'il applique pour distinguer le structuralisme du pragmatisme, on peut imaginer cette évolution dans la théorie de la photographie selon un modèle tridimensionnel. Le structuralisme, comme système clos s'étendrait alors en surface (2D), tandis que le pragmatisme peircien s'approfondirait par la troisième

\footnotetext{
8 KRIEBEL T., Sabine, «Theories of photography. A short history», in ELKINS, James (dir.), Photography Theory, New York, Routledge, 2007, p. 3-49.

${ }^{9}$ Cité par Sabine T. Kriebel, Ibid., p. 37.

${ }^{10}$ «The Art seminar », discussion entre les participants du colloque, Ibid., p. 172-173.

${ }^{11}$ MARTY, Robert, La dimension perdue de Roland Barthes. Disponible sur Internet en format Pdf: http://robert.marty.perso.cegetel.net/semiotique/dimension-perdue.pdf (consulté le : 2009/07/11).
} 
dimension avec l'inclusion du sujet, qui interprète et utilise le signe (comme la géométrie de Monge qui suppose que l'utilisateur puisse replier mentalement la représentation plane de la projection orthogonale d'une figure donnée sur le plan horizontal et frontal). Le dispositif intègrerait aussi le temps à cette structure tridimensionnelle. C'est une «structure qui ouvre sur la conjecture ${ }^{12} »$, selon les mots de Bernard Vouilloux, ou un agencement d'hétérogénéités qui se réorganise constamment en réseaux ${ }^{13}$. Par la dimension temporelle, le dispositif permet de prendre en compte les possibilités du devenir du signe, son actualisation et sa mise à jour constante, à l'image de la définition du signe de Peirce ou de la définition du mythe de Barthes.

C'est aussi dans une perspective historique (donc intégrant la dimension temporelle) que ce chapitre sur l'évolution de la théorie de la photographie veut démontrer comment sont déconstruite l'objectivité du médium et sa valeur de vérité en parcourant l'approche sémiotique de la photographie, l'institutionnalisation du médium, la crise du photojournalisme, et le changement de paradigme de l'esthétique pragmatiste. Mais dans cette évolution qui va d'une définition essentialiste vers une définition basée sur l'usage qui accepte la pluralité, les «anciennes » notions d'icone, d'index, de l'acte photographique se trouvent réintégrées dans les «nouvelles » notions d'empreinte et de trace. La notion d'empreinte comprenait déjà l'instabilité du signe, mais la notion du dispositif ouvre l'œuvre sur l'infini de son devenir.

${ }^{12}$ VOUILLOUX, Bernard, « Du dispositif », Op. cit., p. 18.

${ }^{13}$ Ibid., p. 27. 
Pal, Gyöngyi. Le dispositif photo-littéraire en France dans la seconde moitie du XXe siècle Analyse de l'oeuvre de François-Marie Banier, Jean-Loup Trassard, Lorand Gaspar et Denis Roche - 2010 


\section{Contenu du chapitre :}

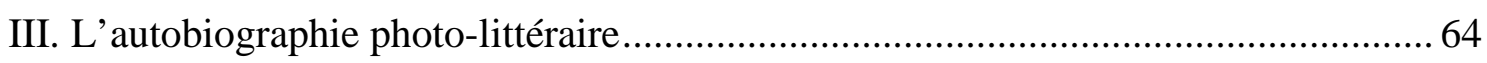

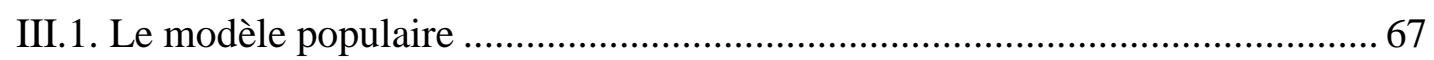

III.2. Le modèle des arts plastiques, l'approche conceptuelle ................................... 72

III.2.a. Christian Boltanski ........................................................................... 74

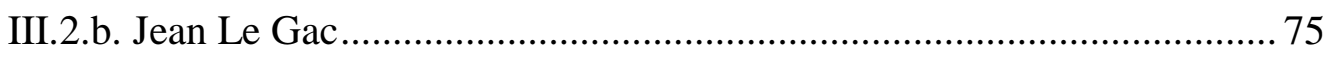

III.2.c. Sophie Calle ………………………………………………………. 77

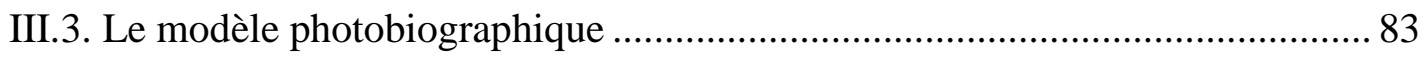

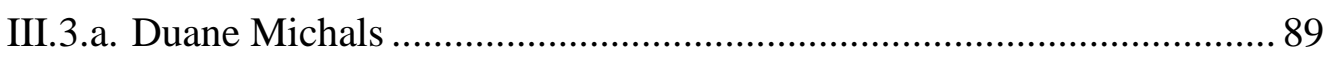

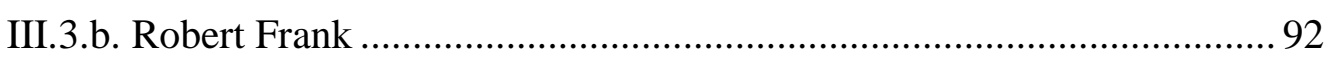

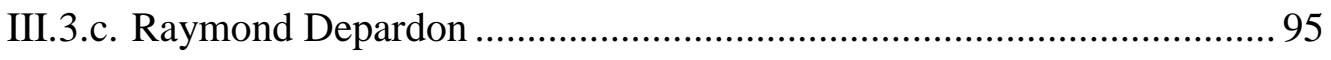

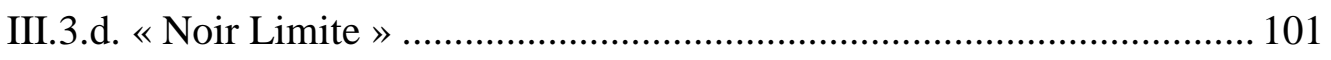

III.3.e. La dissolution du clivage entre extériorité et intériorité ..................... 106

III.4. Le modèle littéraire ........................................................................................... 113

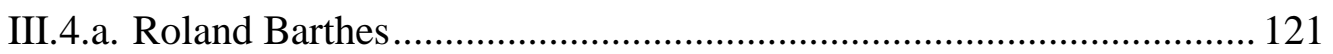

III.4.b. L'entre-deux dans les récits autobiographiques.................................. 125

III.4.c. L'autofiction chez l'écrivain photographe Hervé Guibert.................. 128

III.4.d. L'identité dynamique du désordre ....................................................... 133

III.5. Photographie et fiction - la pluralité et la dissolution des frontières.............. 142 


\section{L’autobiographie photo-littéraire}

Parmi les champs de croisement entre la littérature et la photographie, le domaine autobiographique fut l'un des plus prospères dans les œuvres de la deuxième moitié du $\mathrm{XX}^{\mathrm{e}}$ siècle; c'est aussi le plus étudié ${ }^{1}$. La remise en question de la vérité de la photographie et de son interprétation indicielle semble avoir influencé celle de la valeur de vérité des autobiographies littéraires. Cette question est toutefois très complexe, elle touche à l'identité, et dépasse le champ de recherche photo-littéraire. Plusieurs disciplines de sciences humaines (la sociologie, l'anthropologie, la psychologie, la philosophie tout comme les arts visuels ${ }^{2}$ ) s'y intéressent en effet parallèlement. Au cours des années 1960, le corps, qui reste à plusieurs égards un tabou, est considéré comme un ultime mystère pour l'homme. Selon Hans Belting, les corps incarnent l'idée que chaque époque se forme de l'être humain, et en cela le corps de l'homme est naturellement le lieu d'images, une sorte d'organe vivant qui les stocke, les transmet et les interprète ${ }^{3}$.

Les images tout autant que les récits de vie deviennent une matière première ouverte à l'exploration de l'homme et de son identité. En littérature, les écrits autobiographiques se démultiplient et deviennent un genre à succès au cours de la deuxième moitié du $\mathrm{XX}^{\mathrm{e}}$ siècle, mouvement suivi d'une forte théorisation, comme le note Francine Dugast-Portes ${ }^{4}$. Le genre tient son succès en partie de par ses aspects subversifs qui questionnent le corps et l'identité sexuelle, en offrant une possibilité d'aveu, d'acceptation et de rémission qui aboutit en fin de compte à la transgression et à la transformation progressive des tabous dans le domaine de la sexualité et de l'image du corps. Mais c'est de la transformation à volonté et d'un contrôle absolu de l'image de soi que l'on rêve au début du $\mathrm{XXI}^{\mathrm{e}}$ siècle, avec les identités parallèles, ou l' «identité numérique » et la vie virtuelle qu'offrent plusieurs programmes d'Internet (blog, facebook, myspace, etc.).

\footnotetext{
${ }^{1}$ Voir les références dans la bibliographie et au long du chapitre.

${ }^{2}$ Puisqu'il s'agit d'une question très vaste nous ne prétendons donc pas à décrire tous ses aspects, seulement quelques facettes.

${ }^{3}$ BELTING, Hans, Pour une anthropologie des images, Paris, Gallimard, 2004.

${ }^{4}$ Voir le chapitre « Développement de l'autobiographie » dans Histoire de la littérature française du XX ${ }^{e}$ siècle, (sous la dir. de Michèle Touret), t. 2, Rennes, PUR, 2008, p. 358-368.
} 
Selon Magali Nachtergael ${ }^{5}$ l'intérêt porté au récit de vie dans toutes ses formes est en rapport avec la montée des mythologies individuelles, tandis que cette dernière est indirectement liée à l'invention de la photographie au $\mathrm{XIX}^{\mathrm{e}}$ siècle. L'avènement du nouveau médium a eu un impact direct sur la peinture au point que les thèmes historiques et mythologiques sont abandonnés au profit de l'impressionnisme. Ce fut le premier indicateur d'une tendance qui s'est généralisée au cours du $\mathrm{XX}^{\mathrm{e}}$ siècle, qui a vu éclipser les grands mythes fondateurs des collectivités. Cette transformation s'accompagne de l'apparition d'un nouveau sujet qui se donne par défaut, celui de l'auteur ou de l'artiste, comme le note Magali Nachtergael en se référant à l'analyse de Michel Servière :

$\mathrm{Au}$ « sujet de l'art » se substitue une subjectivité dont l'émergence entraîne dans son sillage une redéfinition du statut d'artiste et de ses productions. Les œuvres qui ne réfèrent plus à des mythes ou des histoires collectifs nécessitent alors une documentation nouvelle, basée sur l'expérience et la démarche originale de son auteur. ${ }^{6}$

Il s'agit d'un changement qui ne s'opère pas seulement au niveau de l'art, mais trouve un fondement dans les transformations de la société et dans la montée de l'individualisme.

L'individu moderne dans la France des années cinquante se trouve aux prises avec deux forces qui conditionnent à la fois son appartenance à une collectivité qui se nourrit de petites mythologies et la nécessité de se créer une altérité singulière au sein même de cette mise en conformité massive. Ces forces le poussent donc, d'une part, vers un modèle petit-bourgeois véhiculé par des traditions et habitus sociaux et d'autres part, vers une singularisation, justement à travers la chronique familiale qui se matérialise dans les albums photographiques et les collections d'objets personnels. Les espaces privés et publics, bien qu'ils se mélangent et communiquent de plus en plus, imposent en fait un plus fort repli sur soi, puisque le moi seul reste le lieu ultime de la singularité. Le rapport qui lie alors le sujet moderne aux objets constitutifs de cet environnement problématise ses propres productions historiques. ${ }^{7}$

L'histoire que chaque individu se construit est nourrie de documents visuels et d'objets personnels, ce qui influencera les arts plastiques et la littérature qui questionnent l'identité. Ce phénomène aura également un impact sur l'apparition d'œuvres hybrides constituées d'éléments hétérogènes tels l'image et l'écriture. Toutefois, selon Nachtergael, la mythologie se définit dès son origine par un «polymorphisme

5 NACHTERGAEL, Magali, Esthétiques des mythologies individuelles, thèse sous la direction d'Eric Marty soutenue à l'Université Paris 7 en 2008. Dans ce chapitre «Photographie et autobiographie » nous suivrons à plusieurs égards la thèse de Magali Nachtergael, pour la compléter et examiner la question d'un autre point de vue : celui d'une évolution de l'identité vers un modèle dynamique.

${ }^{6}$ Ibid., p. 40. Pour l'œuvre de Michel Servière, dont Nachtergael reprend le principe : SERVIERE, Michel, Le Sujet de l'art, précédé de «Comme s'il y avait un art de la signature » de Jacques Derrida, Paris, L'Harmattan, col. "La Philosophie en commun", 1997, p. 27.

${ }^{7}$ NACHTERGAEL, Magali, Ibid., p. 219. 
médiatique » et elle «se constitue donc tout autant par l'image que par le récit, et peutêtre même plus par un choc séminal des images ${ }^{8} »$. Cette évolution qui tend vers la montée des mythologies individuelles se développe sous l'influence réciproque de plusieurs usages de la photographie (voir le diagramme ci-dessous), l'utilisation populaire, celle des médias et des produits de la culture de masse, et finalement l'usage de diverses disciplines artistiques. Ces différents usages s'influencent les uns et les autres, mais ils sont également soumis à une évolution dans le temps, et conditionnés par les techniques de captation et de diffusion, qui rendent possible l'apparition de nouveaux dispositifs.

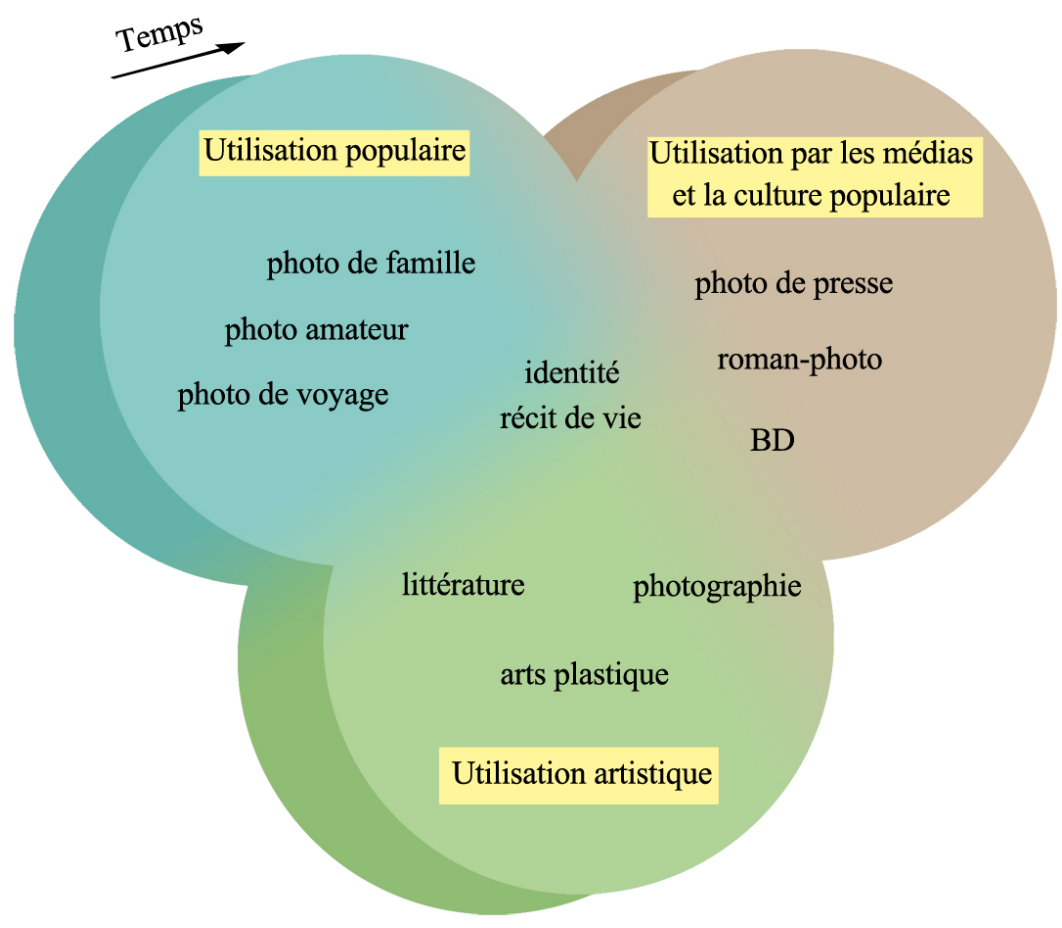

Nous allons donc analyser suivant l'approche pragmatiste les différents usages de la photographie en rapport avec l'identité : l'utilisation populaire, sa place dans les arts plastiques, dans la photographie artistique, pour revenir ensuite à son emploi plus étroitement lié à la littérature et au champ photo-littéraire.

${ }^{8}$ Ibid., p. 227. 


\section{III.1. Le modèle populaire}

Dès l'invention du procédé, c'est le portrait photographique qui assure le succès du médium, comme le note avec ironie Baudelaire :

«Puisque la photographie nous donne toutes les garanties désirables d'exactitude (ils croient cela, les insensés !), l'art c'est la photographie. » À partir de ce moment, la société immonde se rua, comme un seul Narcisse, pour contempler sa triviale image sur le métal. Une folie, un fanatisme extraordinaire s'empara de tous ces nouveaux adorateurs du soleil. ${ }^{1}$

Le portrait photographique était l'outil assouvissant le désir narcissique de la bourgeoisie de se voir figurer et d'accéder à son image, privilège que ne pouvait se permettre auparavant que l'aristocratie. Mais les clichés dépassent cette fonction sociale par le rôle ambigu qu'ils entretiennent avec la mémoire et la construction de l'identité.

La photographie nous accompagne dès la naissance. On pourrait même avancer l'hypothèse que le stade du miroir dans la construction de l'identité de l'enfant est complété par une phase photographique. Lors de cette phase du miroir, l'enfant apprend à se reconnaître dans son image et à différencier son image de celle des autres, mais aussi à faire la distinction entre l'image (au sens de tout ce qui est vu) et la représentation - l'image qui est mise à la place de ce qu'elle figure ${ }^{2}$. Grâce aux affirmations des parents lors du feuilletage de l'album photo, l'enfant retrouve également dans les multiples images figées les principaux constituants de sa propre image, qu'il associe assez vite à la prise de vue qui précède la fabrication du cliché. Si le miroir lui apprend l'unité de son corps, les photographies juxtaposées dans un album ou diffusées sur un écran conduisent à l'expérience du dédoublement du corps, où la verbalisation de l'Autre joue un rôle primordial pour certifier l'unité, tandis que dans le cas du miroir l'identification se fait et par le regard et par la verbalisation de l'Autre.

L'enfant construit son identité dans son rapport à l'Autre et de fait l'album de famille constitue un document important dans l'appréhension de soi. Selon Anne-Marie Garat, les photos de familles et leur feuilletage constituent avant tout un rituel qui

\footnotetext{
${ }^{1}$ BAUDELAIRE, Charles, «Le public moderne et la photographie », in : Cuvres complètes, (textes présenté et annoté par Claude Pichois) Paris, Gallimard, coll. «La Pléiade », 1976, p. 617.

2 «stade du miroir», Wikipedia: http://fr.wikipedia.org/wiki/Stade_du_miroir ainsi que «Jacques Lacan »: http://fr.wikipedia.org/wiki/Jacques_Lacan\#L.27inconscient_est_structur.C3.A9_comme_un_la ngage (consulté le : 13/07/2009).
} 
prouve et renforce l'unité de la famille ; il est un manuel pratique, voire initiatique pour l'enfant, « une affaire de secret partagé ${ }^{3} »$.

La consultation de l'album est une cérémonie. Pour que quelqu'un s'avise d'aller le chercher dans l'armoire, pour qu'on ouvre l'album sur la table ou qu'on y répande en vrac des boîtes, avec les souvenirs pieux, les menus fêtes, les faire part, il faut un événement. Un départ, une absence. Il faut que le fil ordinaire de la vie soit menacé, rompu, pour que se célèbre le feuilletage. Quelquefois solitaire, le plus souvent collectif. ${ }^{4}$

Le rituel du feuilletage devient un support au récit de vie, et pour cela, selon Anne-

Marie Garat, l'album de famille est comparable à un roman.

C'est que le livre de photographies familiales est un vrai livre, dont les pages d'images, même éparses, se feuillettent comme un roman. Roman des origines, chronique, récit de vie, autobiographie, légende tout ensemble. [...] Il se consulte comme un roman, mais sans titres, sans chapitres, ni dialogue, ni narration précise. Il est surtout fait d'ellipses et de beaucoup de lacunes. ${ }^{5}$

En plus d'être d'emblée incomplet et imprécis, l'album photo peut bloquer ou remplacer les vrais souvenirs. La photographie est considérée tantôt comme un support, tantôt comme un obstacle dans les récits de vie. Sa consultation certes ravive la mémoire, mais l'image figée a tendance à se superposer aux images mentales fragiles et éphémères, et à bloquer l'accès à la remémoration d'instants et de passages de vie non enregistrés.

En réalité, la photographie se superpose à la vraie mémoire, elle s'y oppose et l'efface. Tandis que nous accédons au souvenir mental par effraction, secousse, illumination, ou par le labeur douloureux de l'archéologie individuelle, l'image en souvenir impose sa permanence, son évidence. ${ }^{6}$

La mémoire involontaire, qui fait revivre les instants vécus comme s'ils arrivaient à ce moment-là, est déclenchée comme son nom l'indique de manière inconsciente et incontrôlable. Elle n'est donc que rarement liée au feuilletage de photographies, et si c'est le cas, elle peut tout aussi bien se déclencher à partir d'un détail insignifiant, ravivant un souvenir qui n'a aucun rapport avec ce que montre le cliché.

Un lien plus étroit lie la photo à la mémoire volontaire, mais dans ce cas le cliché fonctionne avant tout comme un document attestant d'un état ou d'un événement de la vie de la personne photographiée. Encore faut-il que la personne reconnaisse ou ait appris ce que montre l'image (par exemple on ne reconnaît sa propre image bébé que grâce aux affirmations des parents). Anne-Marie Garat en vient alors à mettre en doute en fin de compte la possibilité de fixer l'instant par la photographie :

\footnotetext{
${ }^{3}$ GARAT, Anne-Marie, Photos de famille, Paris, Seuil, 1994, p. 23.

${ }^{4}$ Ibid., p. 22-23.

${ }^{5}$ Ibid., p. 24-25.

${ }^{6}$ Ibid., p. 41-42.
} 
A force de faire des images en souvenir, pour après, nous pensons prendre une assurance contre l'oubli, et nous nous en remettons à elles pour garantir qu'au moins ceci n'est pas perdu. Au moment de déclencher, nous conjuguons déjà au futur antérieur le présent de cet instant que va saisir la photographie. Ainsi captons-nous des reflets en fragments, en faisons-nous des signes, sauvés du grand brouillage nébuleux. Nous nous donnons les marques, repères et mesures, d'une mémoire future, stable, explorable à loisir, croyons-nous. ${ }^{7}$

Cependant ce qui est fixé, ce n'est pas la réalité de l'instant, ce n'est qu'une image, qui renvoie avant tout à elle-même : «La photographie n'est la preuve, le souvenir de rien sinon d'elle-même ${ }^{8} \gg$.

Deux approches de la photographie que distingue Serge Tisseron ${ }^{9}$ semblent se profiler derrière cette attitude positive ou négative à l'égard du rôle de la photographie dans le processus du souvenir. L'une considère la photographie comme un médium nostalgique, qui vise à arrêter le défilement du temps et à figer la représentation, l'autre accompagne et anticipe le mouvement du monde.

La première, qui suite à La Chambre claire Roland Barthes a largement influencé la réflexion sur le médium, est une approche mélancolique, qui voit seulement dans la photo la nostalgie du passé. Rappelons que Barthes définit dans ce livre la photographie comme un «ça a été », et que le deuil de sa mère marque l'ensemble de l'ouvrage. Cette approche de la photographie met l'accent sur le fait que dès la prise de vue, dès que le moment se trouve fixé, l'instant est irrévocablement perdu à jamais.

Tandis que l'autre approche est centrée sur le procédé, et considère la photographie comme une action posée sur le monde pour l'organiser et l'orienter. En regardant dans le viseur, en appuyant sur le déclencheur, en développant ou non une photo, en la considérant réussie ou ratée, en lui conférant une importance particulière sur les autres, on organise nos souvenirs, nos récits de vie et on prend ainsi un certain contrôle sur notre histoire.

L'identité demande constamment une reconstruction et une recomposition du passé à partir du présent. L'évidence qu'offre le cliché photographique peut alors poser problème si le cliché ne correspond plus avec l'identité du présent et si le travail de relativisation du passé n'est pas mené à bien. Anne-Marie Garat apparente l'album de

\footnotetext{
${ }^{7}$ Ibid., p. 42.

${ }^{8}$ Ibid., p. 43.

9 TISSERON, Serge, Le mystère de la chambre claire. Photographie et inconscient, Paris, Les Belles Lettres, 1996.
} 
famille à un roman, mais le récit de vie ne peut à son tour correspondre tout à fait avec la réalité puisque l'identité est soumise à une constante réévaluation.

À plusieurs égards, les récits autobiographiques littéraires démontrent au cours de la deuxième moitié du $\mathrm{XX}^{\mathrm{e}}$ siècle l'impossibilité de faire correspondre le récit de soi avec la réalité, ce qui entraîne l'émergence du genre de l'autofiction que nous analyserons en détail dans le chapitre «Le modèle littéraire»). Mais on peut déjà projeter que c'est le même rapport autofictionnel qui lie les utilisateurs aux identités virtuelles fabriquées sur Internet ${ }^{10}$ (Myspace, facebook, blog, etc.). Même si ces programmes permettent de créer une identité tout à fait fictive (on peut choisir par exemple de prendre l'identité du sexe opposé, de tricher sur l'âge ou sur nos préférences), les choix renvoient toujours à la personne qui a créé cette identité fictive ${ }^{11}$, même s'il faut le prendre au second degré, comme témoignage d'un goût pour le travestissement ou pour la farce. D'ailleurs des personnages de bande dessinée ou des héros fictifs peuvent aussi avoir leur propre profil, et il y a des gens qui créent une identité virtuelle à leur chien ou autre animal chéri. Ces identités virtuelles de personnages fictifs fonctionnent à l'intérieur du programme comme l'identité virtuelle d'une personne réelle, créant l'illusion qu'ils existent réellement.

La particularité de ces programmes est de permettre de se construire une identité multimédiatique (mélangeant texte, image, son, vidéo), mais aussi de mettre en place un espace interactif qui favorise l'échange entre les internautes. Leur popularité, selon Peeters, s'explique d'une part par un besoin de se projeter dans une identité créée sans contrainte et contrôlée, face à l'identité réelle qui peut paraître désolante tout comme la vie quotidienne peut sembler trop restreinte ou fade. D'autre part cette popularité s'inscrit dans la lignée du phénomène des stars, qui ne sont plus considérées au $\mathrm{XX}^{\mathrm{e}}$ siècle comme lointaines et inatteignables, mais donnent l'illusion d'être à la portée de chacun. Le succès semble être seulement le fruit d'un travail de création de soi.

L'usage de la photographie dans ces identités virtuelles est révélateur du goût de la personne, qu'il s'agisse d'une identité entièrement réelle ou fictive (on peut tout aussi

\footnotetext{
${ }^{10}$ Voir à ce sujet : PEETERS, Heidi. «The Networked Self : Autofiction on MySpace.» (Le «je »du réseau : autofiction sur Myspace), Image [\&] Narrative, ${ }^{\circ} 19$ (2007). Journal électronique disponible sur : http://www.imageandnarrative.be/autofiction/peeters.htm (consulté le : 30/05/2009).

${ }^{11}$ En outre, la liberté de ces programmes n'est que relative car le programme lui-même n'est que relativement maniable avec des modules préfabriqués, de même que la dépendance technologique empêche une partie de la société d'y avoir accès.
} 
bien choisir d'utiliser la photo d'un tiers (jeune et beau) ou choisir la photo d'un objet pour se représenter). Les photos de profil peuvent être retirées et remplacées par d'autres clichés, ce qui permet de reconstruire son identité en fonction du ressenti du présent $^{12}$, selon un modèle dynamique. Il en résulte une démultiplication des identités et la transformation des récits de vie en un dispositif multimédiatique.

Les récits de vie littéraires et artistiques suivent la même évolution. Ainsi l'album photo elliptique et fragmentaire influencèrent dans la deuxième moitié du $\mathrm{XX}^{\mathrm{e}}$ siècle les récits autobiographiques littéraires qui deviennent à leur tour elliptiques, fragmentaires, composés d'éléments juxtaposés sans ordre hiérarchique, voir faussant la chronologie. Mais l'album photo constitue depuis l'avènement de la photographie numérique un modèle en voie de disparition, qui laisse sa place à un système de dossiers et sous-dossiers organisés dans un ordre ou désordre dont seul l'utilisateur possède la véritable clé. Ce modèle, comme on va le voir aura de même un impact sur la littérature. Les photos digitales sont produites en plus grand nombre, elles permettent, par le choix de clichés retenus ou non, un plus grand contrôle de l'image de soi, mais leur virtualité et la dépendance à une technologie changeant à un rythme accéléré leur confèrent également un statut plus éphémère. Le rituel du feuilletage laisse désormais sa place à l'échange et au partage quasi immédiat via Internet et les programmes spécialisés. On retrouve ce modèle basé sur la constante reconstruction et le dispositif multimédiatique dans les œuvres autobiographiques littéraires qui prennent des formes dérivées du journal intime (c'est le cas des blogs par exemple).

On peut toutefois se demander si c'est la conscience que l'homme moderne a de son hétérogénéité psychologique qui le fait s'exprimer dans un art composite ou bien à l'inverse, si ce n'est pas l'éclatement des genres, et les progrès technologiques qui autorisent à se représenter facilement par différents médiums (un déterminisme technologiques ?), et qui provoquent alors un dédoublement de la personnalité et une identité éclatée. L'utilisation populaire de la photographie démontre toutefois une interdépendance entre la technologie et l'image de soi.

12 Toutefois Serge Tisseron attire l'attention au danger que représente les nouveaux sites de communication ouverts sur Internet où « rien n'est jamais effacé, et tout diffuse très vite, souvent à l'insu des usagers eux-mêmes » http://squiggle.be/serge-tisseron/nouveaux-reseaux-le-danger.html (consulté le : 13/07/2009). 


\section{III.2. Le modèle des arts plastiques, l'approche conceptuelle}

Selon la thèse de Magali Nachtergael, qui relie l'apparition des œuvres hybrides à la montée des mythologies individuelles, le phénomène de recyclage du quotidien populaire apparaît déjà chez les avant-gardes du début du $\mathrm{XX}^{\mathrm{e}}$ siècle. Face au déclin des grands mythes collectifs et religieux, les surréalistes élevaient au niveau du merveilleux et du sacré la vie quotidienne et les objets banals, s'inspirant des cubistes qui utilisaient des objets ordinaires dans leurs collages, ainsi que des ready-mades de Marcel Duchamp. Il s'opère en même temps un détournement de la mimesis, car dans les collages l'objet n'est plus représenté, mais déplacé de son contexte original et intégré dans l'œuvre. Dans la lignée de ces artistes qui se tournent vers les objets banals et populaires pour les transformer en œuvres d'art, Nachtergael cite également, après les surréalistes, le Pop Art et l'hyperréalisme1. Dans les années 1960 et 1970, les artistes du Narrative $A r t^{2}$ intègrent, à leur tour, des dispositifs hétérogènes à leurs œuvres, mais la particularité de leur production se trouve dans le fait que c'est la fiction qui relie les différents éléments. Ils combinent à la fois les modèles artistiques reconnus comme l'art abstrait, mais aussi le modèle des mass médias.

Une influence importante revient également à quelques artistes de la scène parisienne des années 1970. Issus de l'art conceptuel, mais sans former un groupe cohérent, ils travaillent les uns et les autres en parallèle, collaborant parfois, sur la question de l'identité et mêlent dans leurs œuvres des dispositifs divers: textes, photographies, peintures, objets banals. Parmi ces artistes, Magali Nachtergael, reprenant l'analyse de Jean-Marc Poinsot, cite Christian Boltanski, Bernard Borgeaud, André Cadere, Paul Amrand Gette, Jean Le Gac, Anette Messager, Gina Pane et Sarkis ${ }^{3}$.

\footnotetext{
${ }^{1}$ NACHTERGAEL, Magali, Op. cit., p. 350.

2 Ibid., p. 366. Magali Nachtergael cite les artistes suivants : aux États-Unis, David Askevold, John Baldessari, Bill Beckley, Robert Cumming, Peter Hutchinson ou William Wegman ; en Allemagne, Jochen Gerz et Joseph Beuys et en France, Didier Bay, Christian Boltanski et Jean Le Gac. Elle remarque toutefois que ce regroupement s'était fait sur le mode de « l'après-coup » par le galeriste new-yorkais John Gibson en 1973. Voir aussi l'article de Perin Emel Yavuz, «Photographie, séquence et texte. Le Narrative art aux confins d'une temporalité féconde », Image and narrative, n²3 nov. 2008, disponible sur le site : http://www.imageandnarrative.be/Timeandphotography/yavuz.html (consulté le : 13/07/2009). ${ }^{3}$ Ibid. p. 355. Pour l'œuvre paraphrasée : POINSOT, Jean-Marc (dir.), Une Scène parisienne, 1968-1972, Rennes, Archives de la critique d'art, Centre d'histoire de l'art contemporain, 1991.
} 
En 1972, Harald Szeemann, le concepteur de l'exposition Documenta 5, à Kassel, regroupe l'œuvre de plusieurs artistes (entre autres Christian Boltanski et Jean Le Gac) dans une catégorie qu'il nomme les «mythologies individuelles », terme que reprendra à son tour Magali Nachtergael pour désigner les autobiographies photo-littéraires.

Les œuvres d'art sont non seulement envahies par des objets, mais aussi par le langage ce qui dénote à partir des années 1960 une dématérialisation progressive de l'art, et qui trouve son aboutissement dans l'art conceptuel, notamment dans l'œuvre du groupe nommé Art\&Language qui s'est formé autour de l'artiste anglais Terry Atkinson en 1968 à Coventry, au Royaume-Uni ${ }^{4}$ et dont Joseph Kosuth était membre.

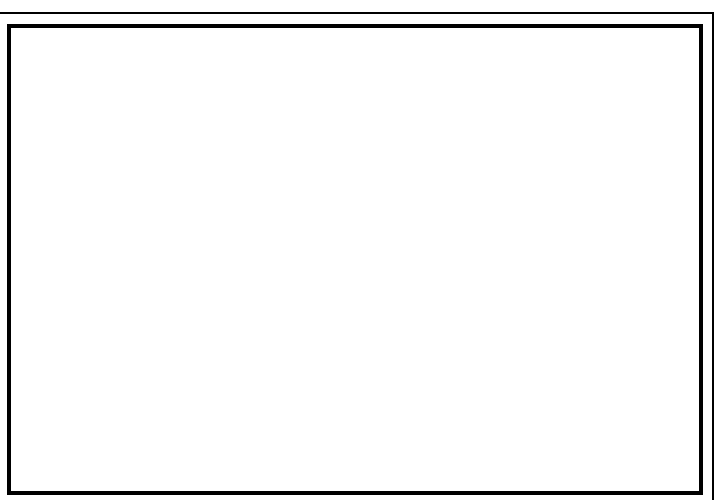

Joseph Kosuth Une et trois chaises, 1965.
La série de Joseph Kosuth intitulée Dictionnaire de synonymie remet en cause nos modes de représentation en comparant justement le langage à la photographie. L'artiste dans son œuvre Une et trois chaises $^{5}$, place ainsi dans l'espace de l'exposition l'article «chaise» d'un dictionnaire, une photo de la chaise, ainsi qu'une vraie chaise. Les deux modes de

représentation, le texte et l'image, sont confrontés avec la présence de l'objet, et leur incomplétude se voit accentuée. En quelque sorte, l'objet lui-même ne recouvre que partiellement la notion de «chaise », car en tant qu'objet d'exposition il est dépourvu de sa fonction primaire (permettre aux gens de s'asseoir).

L'insuffisance des deux modes de représentation (langage et photographie) saute aux yeux grâce à leur juxtaposition, et c'est cette même technique, la juxtaposition d'éléments hétérogènes, qu'utilise Christian Boltanski pour questionner l'identité.

\footnotetext{
4 Pour une histoire détaillée du mouvement voir la page web «Blurting in Art \& Language »: http://blurting-in.zkm.de/e/home (consulté le : 03/06/2009).

${ }^{5}$ KOSUTH, Josef, Une et trois chaises, 1965, 200x271x44 cm, MNAM, Paris. Voir l'image sur le site du Centre Georges Pompidou : http://www.centrepompidou.fr/education/ressources/ENSArtConcept/image03.htm (consulté le : 03/06/2009).
} 


\section{III.2.a. Christian Boltanski}

L'œuvre de Christian Boltanski est ainsi exemplaire de la façon dont un dispositif hétérogène vient questionner l'identité de l'artiste. Dans son premier livre ${ }^{6}$, Recherche et présentation de tout ce qui reste de mon enfance, 1944-1950, il rassemble une photographie de classe, une rédaction scolaire et d'autres documents. Le but de cette quête est de préserver quelque chose de l'oubli et de la mort grâce à une autodocumentation. Le texte qui accompagne le petit livret d'artiste précise :

[...] se conserver tout entier, garder une trace de tous les instants de notre vie, de tous les objets qui nous ont côtoyés, de tout ce que nous avons dit et de ce qui a été dit autour de nous, voilà mon but. La tâche est immense et mes moyens sont faibles. Que n'ai-je commencé plus tôt ? Presque tout ce qui avait trait à la période que je me suis d'abord prescrit de sauver (6 septembre 1944-24 juillet 1950) a été perdu, jeté, par une négligence coupable. Ce n'est qu'avec une peine infinie que j'ai pu retrouver les quelques éléments que je présente ici. Prouver leur authenticité, les situer exactement, tout cela n'a été possible que par des questions incessantes et une enquête minutieuse. $^{7}$

Il procède à la manière d'une fouille archéologique pour reconstituer les objets de son enfance. Ainsi dans Vitrine de référence (ci-dessous), il rassemble des fragments, censés provenir de son enfance - un « morceau de pull-over porté par Christian Boltanski en 1949 » et une «mèche de cheveux de Christian Boltanski - 1949 » - qui constituent pourtant les fausses reliques d'une enfance que l'artiste ne parvient pas à retrouver.

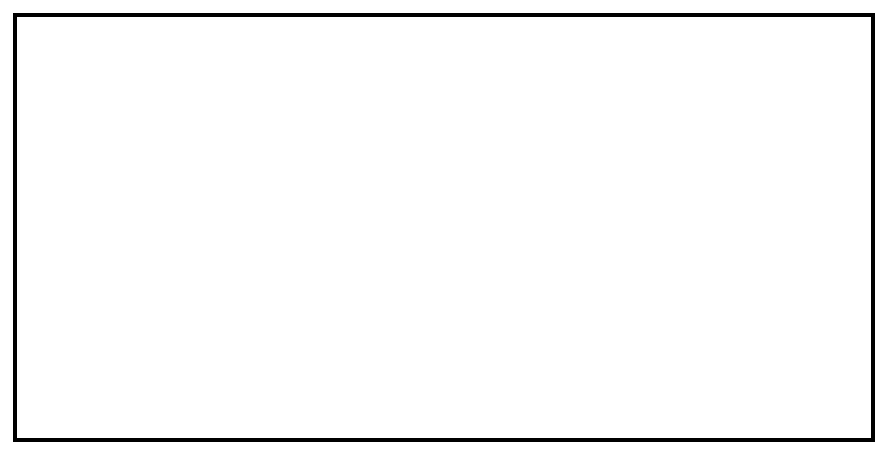

Christian Boltanski, Vitrine de référence ${ }^{8}, 1971$.

\footnotetext{
${ }^{6}$ BOLTANSKI Christian, Recherche et présentation de tout ceaui reste de mon enfance, 1944-1950, livre d'artiste, 1969.

${ }^{7}$ Ibid., texte disponible sur le site du Centre Georges Pompidou (consulté le : 03/06/2009) : http://www.centrepompidou.fr/education/ressources/ENS-boltanski/ENS-boltanski.htm\#textes

${ }^{8}$ BOLTANSKI, Christian, Vitrine de référence, 1971. Boîte en bois peinte sous plexiglas et contenant : photos, cheveux, bribes de vêtements de l'artiste, échantillon de son écriture, page de son livre de lecture, entassement de 14 boulettes de terre, un piège composé de trois objets faits de morceaux de tissu, fil de fer, épingles 59,6 x 120 x 12,4 cm. L'image provient du site du Centre Georges Pompidou (consulté le : 03/06/2009) : http://www.centrepompidou.fr/education/ressources/ENS-boltanski/popup01.html.
} 
Que les objets soient authentiques ou non n'a pas d'importance, ce sont les questions que soulève cette quête qui importent et dans ce questionnement tout le monde peut se reconnaître. C'est d'ailleurs l'une des caractéristiques communes de mythologies individuelles : même si elles impliquent des représentations personnelles, un récit de vie d'un sujet concret, l'œuvre acquiert une valeur collective.

Avec Vitrine de référence, Boltanski parodie également l'institution des musées, notamment le Musée de l'Homme, où des objets à l'origine sans vocation esthétique sont présentés dans des vitrines «un peu poussiéreuses ». Les musées ôtent ainsi aux objets leur valeur d'usage ; pour Christian Boltanski, ce sont « des lieux sans réalité, des lieux hors du monde, protégés, où tout est fait pour être joli ${ }^{9}{ }$. En présentant son autoarchivage sous la forme d'une vitrine d'un musée, l'artiste soumet sa propre vie à ce processus à la fois conservateur et mortifère ${ }^{10}$.

Les premières œuvres de Christian Boltanski emploient délibérément un style amateur, pour ce qui est des photos, ce qui renforce l'effet documentaire, à la manière des artistes conceptuels, mais on pourrait trouver la même esthétique dans les premières œuvres de Jean Le Gac, ou de Sophie Calle.

\section{III.2.b. Jean Le Gac}

Jean Le Gac, dans ses fragments narratifs, met en scène un personnage-écran, un alter ego qu'il dénomme le Peintre, personnage joué par lui-même (désigné tantôt par «cet homme », tantôt par «il », «vous », « on » ou «je ») qui a pour rôle de replacer la peinture dans sa dimension mythique, comme il la fantasmait enfant ${ }^{11}$. Sa première œuvre, Les Cahiers de 1970, évoque la forme du journal intime et mêle des textes et des photographies.

\footnotetext{
${ }^{9}$ Ibid.

${ }^{10}$ Ibid.

${ }^{11}$ Anne Dagbert cite les œuvres suivantes : Le peintre (1973), Le professeur de dessin (1975), Le décor (1972), La cabane (1973), Les images bavardes (1973), Les vues (1973), L'excursion (1974) DAGBERT, Anne, Jean Le Gac, Paris, Fall édition 1998, p. 38.
} 


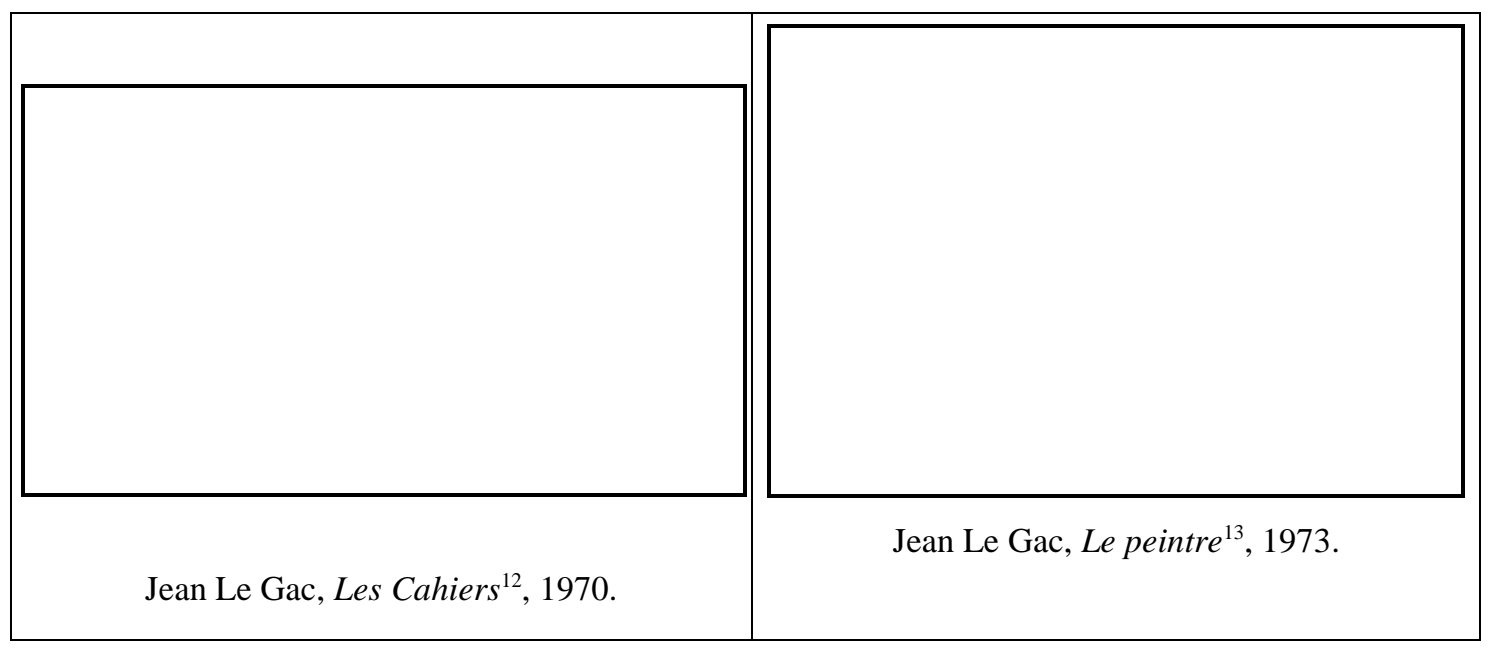

À la manière dont il présenterait un journal d'écolier, Le Gac recense ses activités dans la nature. Les photos montrent l'artiste pendant ses vacances, au bord de la mer, s'adonnant à des actions énigmatiques, comme la plantation de piquets sur la plage ou l'alignement de galets. Un texte explicatif est accolé à l'image, mais il ne révèle pas davantage le sens des actions photographiées, laissant le lecteur/regardeur perplexe. L'énigme de ce dispositif phototextuel veut témoigner de la complexité indéchiffrable du réel ${ }^{14}$.

Au texte et à la photographie, se mêlent aussi des peintures. Dans ses tableaux, Jean Le Gac reproduit au fusain, au pastel, ou à la gouache des illustrations empruntées à la littérature populaire, à des livres qu'il a aimés dans sa jeunesse, auxquelles il juxtapose des photos et des textes (voir ci-dessous à gauche). Puis dans un second temps, il installe au sein des expositions des appareils (machine à écrire, appareil photo, projecteur de cinéma) devant les tableaux, qu'il photographie ensuite comme trace documentaire, mais qui évoquent aussi une fiction qui n'en finit pas de mettre en abyme ses procédés. Notons déjà qu'on retrouvera chez Denis Roche la mise en scène de l'appareil photographique qui enregistre l'image.

12 L'image provient du site de la galerie Daniel Templon où l'auteur expose régulièrement : http://www.danieltemplon.com/ (consulté le : 13/07/2009).

${ }^{13}$ L'image est reproduite dans le livre d'Anne Dagbert, Op. cit., p. 14-15.

${ }^{14}$ DAGBERT, Anne, Op. cit., p. 12. 


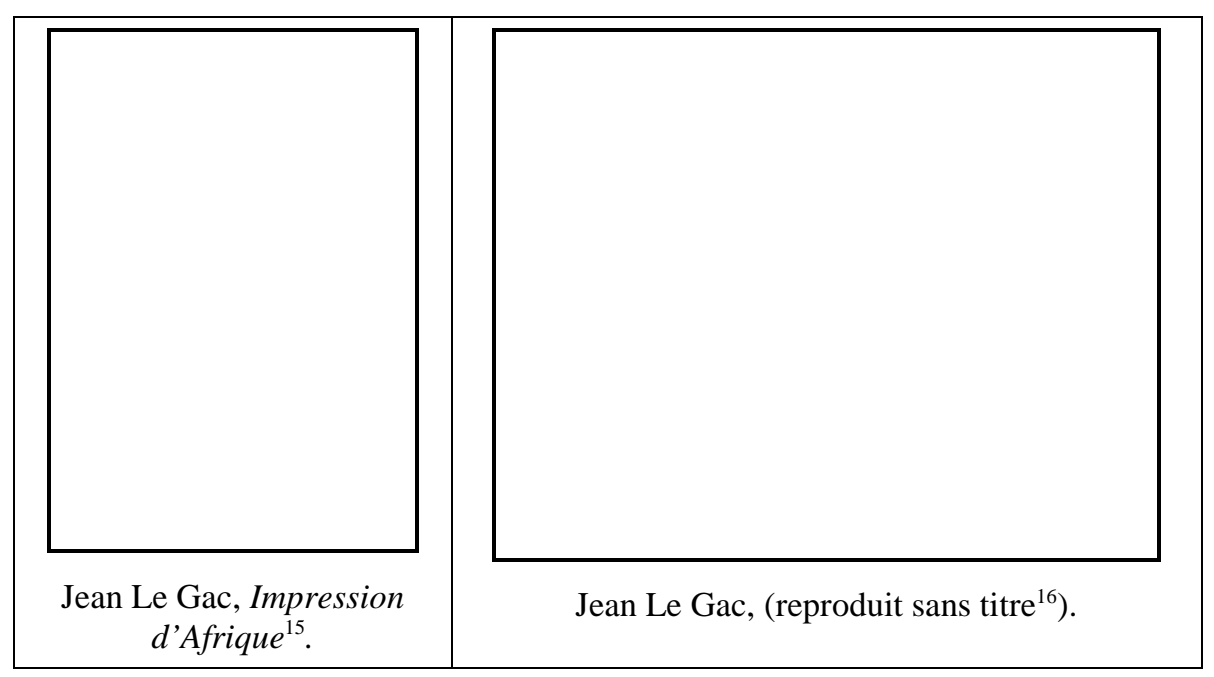

Jean Le Gac annonçait dès le début de sa carrière : «Le compte à rebours du projet sans fin est commencé... ${ }^{17} \gg$. Par ce message de détresse, il projette toute son œuvre à venir, mais aussi sa technique de réinterprétation des illustrations de jeunesse et l'emboîtement des images qui permet la réinterprétation «sans fin» de l'œuvre (à l'image de l'inachèvement du signe chez Peirce).

\section{III.2.c. $\quad$ Sophie Calle}

L'œuvre de Sophie Calle, selon Magali Nachtergael, se construit autour de l'angoisse de la disparition, dans la lignée barthésienne du médium nostalgique.

L'absence et la mise en scène du vide ont surgi très tôt dans ses travaux mais ce n'est que la publication des récits en petits livres qui a permis de rendre ce phénomène visible : cimetières, disparitions, fantômes, souvenirs, clients invisibles d'un hôtel fantôme et même cadeaux d'anniversaire figés dans le temps font partie d'un paysage callien lacunaire et désolé. ${ }^{18}$

${ }^{15}$ Jean Le Gac, Impression d'Afrique, 70x50 cm, 1989. La photo provient du site www.aresarts.com http://www.aresarts.com/catalog/impressiondafrique-pi-1331.html?osCsid=722869cae8bb1cfe500f7e7a (consulté le : 06/06/2009). Le titre fait peut être référence au livre de Raymond Roussel, très populaire à dans les années 1970-80 (ROUSSEL, Raymond, Impressions d'Afrique, Paris, J-J. Pauvert, 1963). Sur Roussel voir notamment Michel Foucault « Dire et voir chez Raymond Roussel », Dits et ecrits I., Paris, Gallimard, 1994, p. 205-228. Voir aussi l'article de Jean-Pierre Montier, «Et vint La Vue », in Littérature et photographie, Op. cit., p. 413-430.

16 Jean Le Gac, reproduit sans titre sur le site: http://www.artpointfrance.org/Diffusion/legac.htm (consulté le : 06/06/2009).

${ }^{17}$ Le fragment figure parmi les 24 Messages Personnels adressés par voie postale à 200 destinataires en octobre 1970. Cité par Anne Dagbert, Op., cit., p. 7.

${ }^{18}$ NACHTERGAEL, Magali, Op., cit., p. 418. 
Non seulement les photos utilisées donnent une impression d'amateurisme (surtout dans ses premiers travaux) par le recours au flou, le mauvais cadrage, qui ont pour effet de faire croire à leur authenticité, mais le style du texte juxtaposé à l'image est aussi volontairement simple, du point de vue syntaxique, et présente des informations en apparence objectives et dénuées d'affect. L'œuvre de Sophie Calle est tantôt classée parmi celle des écrivains, tantôt parmi celle des plasticiens ou encore parmi celle des photographes, ce qui témoigne encore une fois de l'effacement des frontières dans l'art contemporain. On note toutefois une évolution dans son œuvre, qui abandonnera l'effet amateur au profit de belles images dont la réalisation est parfois même confiée à des professionnels ${ }^{19}$.

Les mythologies individuelles de Sophie Calle jouent sur le couple vérité et fiction. La suite Vénitienne ${ }^{20}$, Histoires Vraies + dix $^{21}$, Doubles-jeux ${ }^{22}$, le film sur sa liaison avec Greg Shephard Double - Blind ${ }^{23}$ sont des reconstructions que le lecteur non averti pourrait prendre pour de vrais fragments autobiographiques. Dans des entretiens, l'auteur dévoile les circonstances de la genèse de ses œuvres. La Suite Vénitienne par exemple selon un entretien avec Johnnie Gratton ${ }^{24}$, est une reconstitution réalisée à l'aide d'un ami, de l'expérience originale de Calle, qui avait suivi un homme à Venise, comme un paparazzi. Mais le livre ne révèle rien du caractère reconstruit de la série et de cette mise en scène. L'auteur jette même le doute puisqu'elle donne plusieurs versions de l'histoire dans ses entretiens. Selon Magali Nachtergael ${ }^{25}$, Calle explique cela par sa très mauvaise mémoire mais aussi par le plaisir qu'elle ressent à « refaire l'histoire». Savoir s'il s'agit de fiction ou de réalité perd de son importance, car

${ }^{19}$ D'après la présentation de Sophie Calle de son œuvre dans la série Contacts, DVD, volume 2, Réalisation : Jean-Pierre Krief, Arte, 1992-2000.

${ }^{20}$ CALLE, Sophie. Suite Vénitienne suivi de BAUDRILLARD, Jean. «Please follow me », Paris, L’Étoile, col. "Écrit sur l'image", 1983.

${ }^{21}$ CALLE, Sophie, Des histoires vraies + dix, Arles, Actes sud, 2002.

${ }^{22}$ CALLE, Sophie, Doubles-jeux, Arles, Actes sud, 1998.

${ }^{23}$ CALLE, Sophie, Double - Blind, [1992] Paris, CNC, DVD, 2007.

${ }^{24}$ Entretien avec Johnnie Gratton, Paris, 3 juin 2007. Selon Magali Nachtergael l'auteur serait plus enclin à dévoiler les secrets de la construction mythique dans des entretiens à l'étranger : Lecture by Sophie Calle at the Keio University, Hara Museum review, $n^{\circ}$ 47, « Sophie Calle : Exquisite Pain », hiver 2000 (exp. 20 nov. 1999 au 27 février 2000), 15 novembre 2000, Tokyo ; ou les articles de la presse étrangère comme William Leith, «A Quick Calle », Observer Life, 17 janvier 1999. Cité par Magali Nachtergael, Op. cit., p. 405.

${ }^{25}$ D'ailleurs au lieu de donner une interview à Magali Nachtergael, Sophie Calle l'incite à écrire une interview fictive à sa place «Magali, ne le prenez pas mal, mais je suis dégoûtée des interviews. La répétition... le récit des mêmes choses depuis trop d'années. Mes propres réponses m'ennuient, sauf quand je « refais » l'histoire. [...] Faites un faux, sans cacher le fait, à partir de ce que vous trouverez ici et là ? Sophie. » Magali Nachtergael, Ibid., p. 459. 
l'identité contient toujours une part de fiction. Selon Jean Arrouye, la photographie dans le projet autobiographique de Sophie Calle est à la fois «douloureuse et délicieuse ». Elle constitue un échec du point de vue de la reconstitution de l'histoire personnelle de l'auteure-photographe, mais le mélange du texte et de l'image, qui rend compte de l'imagination fabulatrice de Calle, séduit le lecteur ${ }^{26}$.

Dans plusieurs de ses séries, telles Douleur Exquise ${ }^{27}$, Disparitions ${ }^{28}$, et Fantômes $^{29}$, le texte est utilisé comme une image. Le livre Douleur Exquise est un journal photographique tenu pendant les 90 jours de sa bourse au Japon. Les photos accompagnées d'un texte explicatif sont disposées jours après jours, page après page. $\mathrm{Au}$ bout des trois mois auraient dû avoir lieu les retrouvailles avec son ami en Inde, mais elle apprend la rupture le jour des retrouvailles, de manière très douloureuse. Son ami laisse un message annonçant qu'il ne peut pas venir à cause d'un accident. Sophie Calle passe alors la nuit à l'hôtel où ils devaient se revoir, pleine d'angoisse et sans dormir, pour apprendre le lendemain qu'il ne s'agissait que d'une blessure anodine,

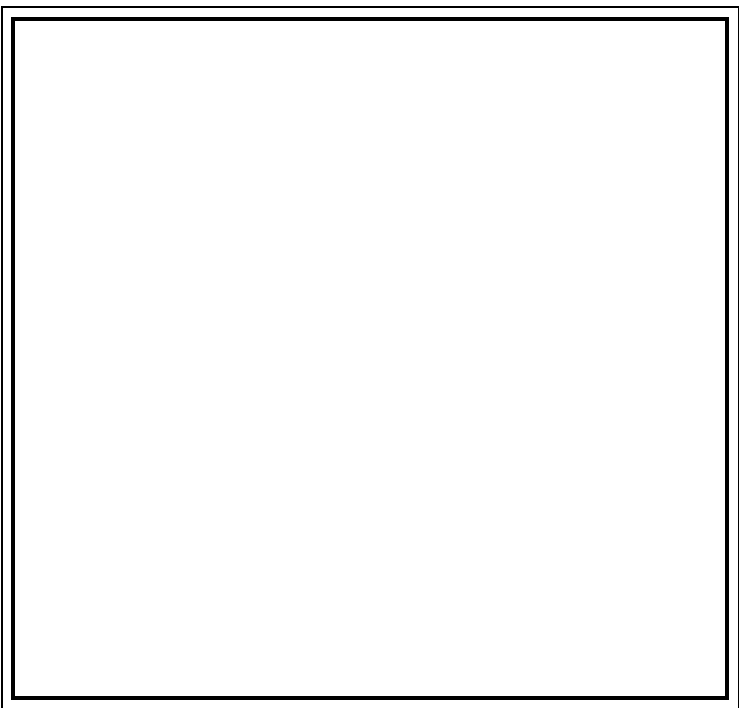

Sophie Calle, Douleur Exquise, p. 224-225. ayant servi de prétexte pour ne pas la rejoindre. Il s'agit là du point pivot du livre ; la date fatidique est suivie alors de 92 jours placés sous le signe de cette rupture. À chaque double page on retrouve le récit de la rupture avec la même image de la chambre d'hôtel où Calle a attendu l'appel toute la nuit. À côté du texte de l'auteur se trouvent annexés d'autres textes accompagnés de photos. Les clichés et le texte sont réalisés suite à une enquête et décrivent des moments douloureux vécus par d'autres personnes, relativisant ainsi la douleur de l'auteur. Pendant les 92 jours la

${ }^{26}$ ARROUYE, Jean, « Des histoires vraies + 10 de Sophie Calle », in MEAUX, Danièle - VRAY, JeanBernard (sous la direction de), Traces photographiques, traces autobiographiques, Saint-Étienne, Publications de l'Université de Saint-Étienne, 2004, p. 65-71.

27 CALLE, Sophie, Douleur exquise, Arles, Actes sud, 2003. L'image ci-dessous provient du site : http://thematique.wordpress.com/2009/05/20/douleur-exquise-adaptee-au-theatre-fta/ (consulté le : 13/07/2009).

${ }^{28}$ CALLE, Sophie, Disparitions, Arles, Actes Sud, 2000.

${ }^{29}$ CALLE, Sophie, Fantômes, Arles, Actes Sud, 2000. 
même image sert à cristalliser la douleur de Sophie Calle, mais le texte lui aussi se trouve reproduit presque à l'identique, sauf qu'il devient au fil des jours de plus en plus court et transparent, comme une image qui s'efface jusqu'à se fondre dans la couleur noire de la page. Le dispositif mis en place dans le livre témoigne de l'attente du jour des retrouvailles, d'une montée de tension, puis de l'effacement progressif du souvenir et l'apaisement de la douleur.

Le texte est donc bien utilisé comme une image, comme il le sera dans la série intitulée Disparitions. Il s'agit d'une enquête menée par l'auteur sur des tableaux dérobés dans plusieurs musées. Ces derniers sont alors remplacés par les récits et les souvenirs qu'en font les employés du musée. La description prend littéralement la place des tableaux, ce qui est souligné par la mise en forme encadrée dans le livre (ci-dessous à gauche). Une photographie accompagne la description, montrant l'emplacement originel de chaque œuvre resté vide ou comblé par d'autres œuvres. Dans la série Fantômes, le principe est presque identique, le personnel du musée se voit invité à décrire et à dessiner les œuvres prêtées temporairement à d'autres musées, leur texte et leur dessins étant exposés à la place des œuvres absentes (ci-dessous à droite).

Sophie Calle, Disparitions, p. 62-63.

Sophie Calle, Fantômes, p. 24-25.

Les expériences de Sophie Calle tendent à faire disparaître les frontières entre l'art et la vie, et sous la forme d'un recyclage constant, elles s'ouvrent sur des enjeux collectifs et sur une réflexion à l'échelle sociale. Ainsi plusieurs séries, L'Hôtel ${ }^{30}$, Les dormeurs ${ }^{31}$, la

\footnotetext{
${ }^{30}$ CALLE, Sophie, L'Hôtel, Paris, Étoile, col. "Écrit sur l'image", 1984. Pour cette série Sophie Calle se
} fait engager comme remplaçante d'une femme de chambre dans un hôtel vénitien, et elle photographie les 
série sur Les Aveugles ${ }^{32}$ déjà mentionnée, ou plus récemment, Prenez soins de $v_{\text {vous }}{ }^{33}$, prennent la tournure d'une pseudo enquête sociologique.

Le privé et le public semblent même se fondre dans Souvenirs de Berlin-Est ${ }^{34}$, et L'Erouve de Jérusalem ${ }^{35}$. Dans ce dernier, la mise en page du livre elle-même renforce cette imbrication du public et du privé. Il s'agit d'une recherche menée à Jérusalem, composée de deux séries de photos.

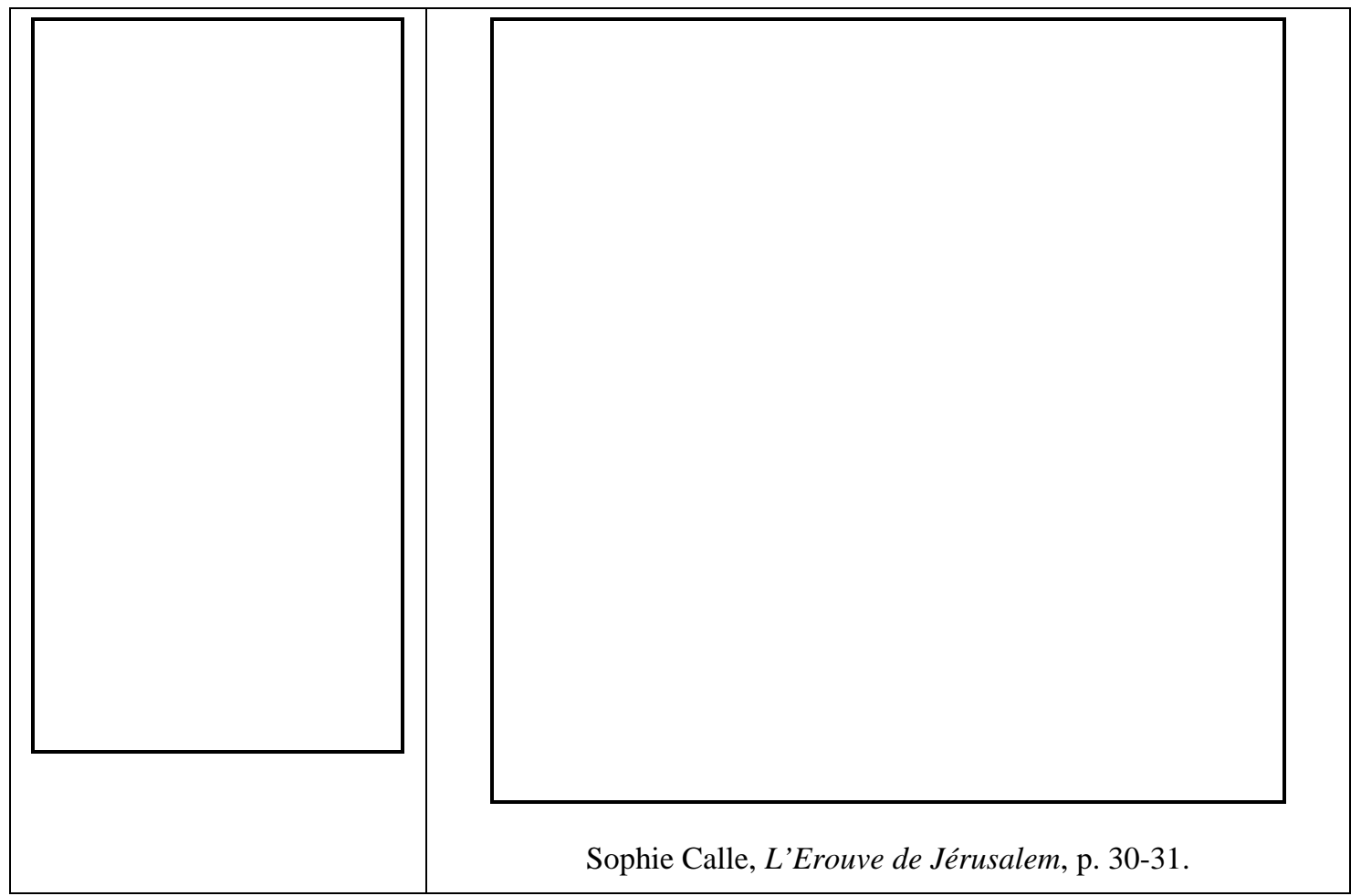

traces du passage des clients (lits défaits, serviettes laissées dans la salle de bain, poubelles pas encore vidées, etc.).

${ }^{31}$ CALLE, Sophie, Les dormeurs, Arles, Actes sud, 2000. Dans cette série Sophie Calle invite des gens pris au hasard à venir dormir quelques heures dans son lit, à tour de rôle, vingt-quatre heures sur vingtquatre pendant huit jours. Elle prend une photo chaque heure et note à l'aide d'un questionnaire les habitudes de dormir des gens, comment se déroule l'arrivée et le départ des personnes. Voir le dossier pédagogique sur l'œuvre de Sophie Calle sur le site du Centre Georges Pompidou :

http://www.centrepompidou.fr/education/ressources/ENS-calle/popup02.html (consulté le : 12/06/2009).

${ }^{32}$ Voir à la page 54.

${ }^{33}$ CALlE, Sophie, Prenez soins de vous, Arles, Actes sud, 2007. Dans cette série Sophie Calle, ayant reçu un mail de rupture et ne pouvant répondre, donne le texte à analyser à 107 femmes choisies en fonction de leur métier, leur talent, pour interpréter la lettre sous un angle professionnel. Elle photographie ou filme leurs productions. Voir certaines photos sur le site Internet de la Galerie Perrotin : http://www.galerieperrotin.com/artiste-Sophie_Calle-18.html\# (consulté le : 07/06/2009).

${ }^{34}$ CALLE, Sophie, Souvenirs de Berlin-Est, Arles, Actes sud, 1999. Dans cette série l'auteur s'intéresse aux monuments (statuts, plaque mémorative) qui ont été enlevés suite à la chute du mur de Berlin. Elle juxtapose les anciennes photos des monuments avec l'image du lieu tel qu'elle se présente aujourd'hui, ainsi que la transcription des souvenirs que les passants et les habitants du quartier lui confient.

${ }^{35}$ CALLE, Sophie, L'Érouve de Jérusalem, Arles, Actes sud, 2002. 
La première série montre des «érouves », des poteaux à la limite des villes ou des quartiers reliés par un fil (ci-dessus à gauche). En Israël, pendant le Shabbat, aucun travail n'est autorisé en dehors des espaces privés (l'interdit est pris au sens strict, car le transport de n'importe quel objet - même un sac ou les clés de la maison - est interdit). Les érouves ont la fonction de transformer la ville en espace privé pour que les gens puissent se déplacer le jour du Shabbat. Les photos d'érouves placées au début et à la fin du livre encerclent à leur tour une autre série de photo-textes, mettant en scène le témoignage d'habitants, et leurs souvenirs personnels et intimes liés à un endroit précis de la ville. Ce dispositif rend compte à la fois de la démarche de Sophie Calle, qui soumet sa vie à la réalisation de l'œuvre rendant public ce qui est privé, mais aussi d'une caractéristique inhérente à la photographie, qui est d'osciller entre subjectivité et objectivité, intériorité et extériorité.

Un cercle de photographe, qui s'est constitué autour des Cahiers de la photographie dans les années 1980, revendique pour la photographie la même position double d'intériorité et d'extériorité. Sophie Calle est proche de ce cercle tout autant que du cercle de Christian Boltanski ${ }^{36}$. Elle publie en effet sa première série de photo, Suite Vénitienne $^{37}$, dans «Écrits sur l'image» aux éditions de l'Étoile et des Cahiers du cinéma $^{38}$, série dirigée par Alain Bergala et où parut également le Manifeste photobiographique $^{39}$. Selon Magali Nachtergael, ce cercle d'artistes est bien un cercle de photographes et non plus de plasticiens, qui s'emparent de la photographie dans un objectif autobiographique, institutionnalisant et reprenant à leur compte les démarches artistiques des auteurs-plasticiens qui ont lancé les mythologies individuelles.

\footnotetext{
${ }^{36}$ Magali Nachtergael rapporte que Robert Calle, le père de la photographe, fut, dès 1969, l'un des premiers collectionneurs de l'œuvre de Christian Boltanski. Nachtergael, Op. cit., p. 373.

${ }^{37}$ CALLE, Sophie. Suite Vénitienne suivi de BAUDRILLARD, Jean. « Please follow me », col. "Écrit sur l'image", Paris, Étoile, 1983.

${ }^{38}$ C'est en collaboration entre les Cahiers du cinéma, Gallimard et Seuil que parait La Chambre claire de Roland Barthes en 1980. Il faut noter encore que Denis Roche travaille à cette époque au Seuil dirigeant la collection «Fiction et Cie ».

${ }^{39}$ MORA, Gilles ; NORI, Claude, L'été dernier. Manifeste photobiographique, Paris, Étoile/Cahiers du cinéma, col. "Écrits sur l'image" 1983.
} 


\section{III.3. Le modèle photobiographique}

La publication dans les années 1980 du Manifeste photobiographique ${ }^{1}$ de Gilles Mora et de Claude Nori a eu un impact considérable sur la production photographique au service de la construction de soi par l'image - où l'image est un élément actif de la création de soi et non plus un élément nostalgique. Les Cahiers de la photographie, également fondés par Gilles Mora, Claude Nori et Denis Roche en 1981, fournit le cadre théorique de ce courant ${ }^{2}$. Il faut rappeler que c'est dans les années 1980 que se répand la théorie de l'indicialité de la photographie, suite à la parution de L'acte photographique de Philippe Dubois (1983) et il y eut aussi un colloque fondateur en 1982 à la Sorbonne et qui parut dans Les Cahiers de la photographie sous le titre «L'acte photographique ${ }^{3}$ ». Mettre l'accent sur le caractère indiciel de la photographie et accorder une importance majeure à l'acte photographique pour expliquer l'ontologie de la photographie revient à soutenir la part essentiellement autobiographique de toutes les photos. La prise de vue est nécessairement liée à un lieu et un moment précis, elle forme donc un ancrage spatiotemporel pour la personne qui prend la photo. L'acte est un moment vécu par la personne et ses choix reflètent sa personnalité. Denis Roche note à ce propos que « de toute façon on se photographie soi-même quand on prend une photo. On photographie ce qu'on a regardé, donc on se photographie soi-même ${ }^{4} \gg$.

Le Manifeste photobiographique définit la photographie comme «amplificateur d'existence », où l'intensité de l'acte est semblable à l'«expérience littéraire », où l'on ne sait plus «s'il convient de vivre pour photographier ou l'inverse ${ }^{5} »$.

La photographie, à l'encontre de toutes les blagues à la mode, n'est pas liée à la mort mais bien au contraire, et fondamentalement, à la vie: la nôtre, celle des autres, toutes celles qui nous concernent et font que chaque instant, si nous n'y prenons garde, échappe constamment. La

\footnotetext{
${ }^{1}$ Le Manifeste fut publié à l'origine en 1983 dans la collection "Écrits sur l'image" mentionnée ci-dessus. Cependant nous nous référerons à sa réédition sans les photos dans l'ouvrage : MEAUX, Danièle VRAY, Jean-Bernard (sous la direction de), Traces photographiques, traces autobiographiques, SaintÉtienne, Publications de l'Université de Saint-Étienne, 2004, p. 103-106.

2 Notamment le numéro 13 de la revue qui s'intitule «Photobiographie » (Les Cahiers de la photographie, $\mathrm{n}^{\circ} 13,1^{\mathrm{er}}$ trim. 1984).

${ }^{3}$ Les Cahiers de la photographie, «L'acte photographique », n8 et nº́cial 2, 1983. Le colloque s'est déroulé du 5 au 7 novembre 1982 à la Sorbonne.

4 ROCHE, Denis, La disparition des lucioles (réflexions sur l'acte photographique), Paris, Etoile, col. "Écrits sur l'image", 1982, p. 73.

${ }^{5}$ MORA, Gilles ; NORI, Claude, Manifeste photobiographique, Op. cit., p. 103.
} 
photographie constitue donc pour nous, et avant tout autre préalable, un amplificateur d'existence. Elle seule peut boucler dans un même mouvement qui nous fascine et nous sauve la révélation du présent et celle de sa conservation. Nous refusons tous les alibis culturels, sociaux ou esthétiques, ayant jusqu'à maintenant tenu le photographe plus ou moins à l'écart de cette vérité essentielle qui est de l'ordre de l'expérience privée. En photographiant, nous ne sommes pas les spectateurs passifs d'un grand film en dolby stéréo et relief compressé se déroulant devant nous, jusqu'à ce que nous n'en retenions que les instants simplement décisifs. Tout, dans la photographie, ramène inexorablement à manifester sa présence sur les choses et les êtres du dehors comme, enfants, nous rêvions d'être à la fois dans le film et de le regarder ${ }^{6}$.

La photographie participe à une quête de soi, à la recherche des «crêtes de [son] l'existence » ou des moments d' «épiphanie », mot emprunté à James Joyce, que Mora identifie à «ces accélérations du présent où s'engouffrent et se résolvent nos attentes, notre passé, nos nostalgies et nos désirs ${ }^{7} »$, moment intense qui sera ensuite transposé visuellement dans le cliché. Il faut ajouter que le projet de Claude Nori, de Gilles Mora, et des Cahiers de la photographie, coïncide avec la période de la promotion du livre photographique et photo-littéraire ${ }^{8}$, qui permet d'explorer par la linéarité imposée de la mise en page un récit visuel semblable aux récits écrits.

Gilles Mora, dans son texte Photobiographies', propose de recenser l'histoire des œuvres photobiographiques, et son analyse dévoile la multiplicité de ce qu'on peut ou pourrait regrouper sous cette appellation, car lui-même écarte les exemples les uns après les autres. Il commence son analyse par l'histoire de l'autoportrait photographique qui remonte à l'époque de l'invention du procédé. Plusieurs possibilités s'offrent à un photographe pour se prendre en image : il peut recourir à un miroir, à un câble qui permet de déclencher à distance, à un déclencheur à retardement, ou encore enregistrer son ombre en s'affichant dans le cadre. Parmi les réalisations contemporaines des années 1980, Gilles Mora ${ }^{10}$ souligne que la fonction des autoportraits dépasse le simple but autobiographique pour laisser la place à l'exploration psychologique (Claude Cahun $^{11}$, Pierre Molinier ${ }^{12}$, Robert Mapplethorpe $\left.{ }^{13}\right)$, à la revendication de nouveaux rôles sociaux (Florence Henri) ou à la critique sociale (Cindy Sherman $\left.{ }^{14}\right)$.

\footnotetext{
${ }^{6}$ Ibid. (En italique dans l'original.)

${ }^{7}$ Ibid., p. 105.

${ }^{8}$ Voir à ce sujet le chapitre «Photographie et fiction - la pluralité et la dissolution des frontières » à la page 142.

${ }_{9}$ Publié initialement dans RITM, n²0: Récits de vie et médias, pp. 183-189, et republié dans Traces photographiques, traces autobiographiques, p. 107-113.

${ }^{10}$ MORA, Gilles, Photobiographies, Op. cit, p. 108.

${ }^{11}$ Voir le site du photographe : http://www.connectotel.com/cahun/ (consulté le : 13/07/2009) ainsi qu'un article de Julie Hétu, Voyage entre les genres, l'entre-deux de Claude Cahun : (consulté le : 13/07/2009) http://www.chass.utoronto.ca/french/SESDEF/entredeux/juliehetu.htm
} 
Le projet que le Manifeste soutenait se place plutôt dans une approche littéraire, comme Mora le remarque lui-même. Faisant appel à la définition de Philippe Lejeune, il souligne la différence entre le pacte autobiographique appliqué à la photographie et celui utilisé par la littérature. Sa définition renvoie avant tout à l'approche indicielle de la photographie : «toute photographie fonde clairement, pour le spectateur, l'identité entre l'opérateur technique et l'auteur de l'image [...] toute photographie s'affirme surtout comme authentiquement «vécue » par celui qui l'a prise, et pour celui qui la regarde $^{15} \gg$. Écartant la prise de vue subjective qu'inaugure Les Américains de Robert Frank paru en 1958 et qui influencera entre autres la production de Bernard Plossu ${ }^{16}$, la définition de Gilles Mora reste floue et ambiguë sur ce qu'il entend réellement par «photobiographie ». Aussi cite-il avec réticence l'ouvrage d'Anny Duperey «à textualité dominante », ainsi que la série Tulsa de Larry Clark ${ }^{17}$, qui témoigne de son adolescence liée à la drogue et aux dérives sexuelles, ou encore l'œuvre de Nan Goldin $^{18}$, qui expose également sa vie intime mêlée à des cercles marginaux, ses amis homosexuels ou travestis, consommant de la cocaïne, ou frappés tragiquement par le sida.

La déception de Gilles Mora sera totale en 2003, lorsqu'il publie Pour en finir avec la photobiographie, dans lequel il accuse les photobiographies de n'offrir qu'un « spectacle-réalité » pareil à ce que les médias proposent du réel. Dans ce texte il fait le point sur les productions photobiographiques de la période des vingt dernières années, qui se sont écoulées depuis la publication du Manifeste. Le mot inventé par lui est devenu courant, mais son sens s'est élargi, et il en arrive désormais à désigner toutes sortes de biographies illustrées par des photos à l'exemple du magazine Life ${ }^{19}$, ou même

\footnotetext{
${ }^{12}$ Voir quelques image sur le site de la galerie Ubu à New York : http://www.ubugallery.com/phpwcms/?id=34,149,0,0,1,0 (consulté le : 13/07/2009)

${ }^{13}$ Voir le site du photographe : http://www.mapplethorpe.org/ (consulté le : 13/07/2009)

${ }^{14}$ Voir le site du photographe : http://www.cindysherman.com/ (consulté le : 13/07/2009)

${ }^{15}$ Ibid., p. 109. Pourtant comme nous l'avons déjà montré le caractère analogique de la photo est démenti par l'usage (voir notamment les exemples à la page 47.

${ }^{16}$ Voir quelques image sur le site : http://www.documentsdartistes.org/artistes/plossu/repro.html (consulté le : 13/07/2009).

${ }^{17}$ Voir quelques clichés sur le site de la Maison Européenne de la Photographie à Paris, qui lui a consacré une exposition en 2007. http://www.mep-fr.org/actu/lc.htm\# (consulté le : 13/07/2009).

18 Voir les pages qui lui sont consacrées sur le site du Centre Georges Pompidou (consulté le : 13/07/2009) : http://www.centrepompidou.fr/expositions/nangoldin/.

${ }^{19}$ Le photojournalisme, mais surtout la presse à sensation voit l'apparition du genre du photoreportage ou photo-essay en anglais, dont un des emblèmes fut le journal Life paru en 1936. Il s'agit d'un récit fragmentaire illustré de photographies, qui peut présenter à part les actualités, des «biographies
} 
des textes quelconques adjoints à des photos. «En finir avec la photobiographie, c'est accepter l'étroitesse et la difficulté des limites et des ambitions que nous lui avions initialement dévolues ${ }^{20} \gg$ - écrit Mora. En fait, loin d'un emploi à des fins narcissiques, le manifeste prônait une expérience de la photographie, non pas tournée uniquement vers l'exploration du moi profond, mais tournée vers le monde, dans un dialogue de l'intime et de l'extime. «Photographier reviendra dès lors, pour nous, à rechercher ces coïncidences essentielles où s'imbriquent intérieur-extérieur, in-out ${ }^{21} »$. En fin de compte, selon Mora, l'échec de la photobiographie, est dû au fait que la photographie, pour être à la fois intime et extime, ne peut se passer de l'écriture ${ }^{22}$. Sans le texte qui devient ancrage retranscrivant les circonstances des prises de vue, la photographie reste une trace « précaire », comme le note Jean-Marie Schaeffer ${ }^{23}$.

Rappelons que le premier cliché qui exploite le caractère fictionnel de l'image était un autoportrait. Hippolyte Bayard suite au rejet de son invention du procédé du négatif sur papier, qui n'a pas été retenu face à celui de Daguerre, réalisa un autoportrait en noyé, au dos duquel il ajouta le texte suivant :

\begin{tabular}{|c|c|}
\hline $\begin{array}{l}\text { Hippolyte Bayard, Autoportrait } \\
\text { en noyé, } 1840 .\end{array}$ & $\begin{array}{l}\text { Le cadavre du Monsieur que vous voyez ci-derrière est celui de M. } \\
\text { Bayard, inventeur du procédé dont vous venez de voir ou dont } \\
\text { vous allez voir les merveilleux résultats. À ma connaissance, il y a } \\
\text { à peu près trois ans que cet ingénieux et infatigable chercheur } \\
\text { s'occupait de perfectionner son invention. L'Académie, le Roi et } \\
\text { tous ceux qui ont vu ces dessins que lui trouvait imparfaits les ont } \\
\text { admirés comme vous les admirez en ce moment. Cela lui fait } \\
\text { beaucoup d'honneur et ne lui a pas valu un liard. Le gouvernement } \\
\text { qui avait beaucoup trop donné à M. Daguerre a dit ne rien pouvoir } \\
\text { faire pour M. Bayard et le malheureux s'est noyé. Oh! instabilité } \\
\text { des choses humaines! Les artistes, les savants, les journaux se sont } \\
\text { occupés de lui depuis longtemps et aujourd'hui qu'il y a plusieurs } \\
\text { jours qu'il est exposé à la morgue personne ne l'a encore reconnu } \\
\text { ni réclamé. Messieurs et Dames, passons à d'autres, de crainte que } \\
\text { votre odorat ne soit affecté, car la figure du Monsieur et ses mains } \\
\text { commencent à pourrir comme vous pouvez le remarquer. }{ }^{24}\end{array}$ \\
\hline
\end{tabular}

C'est bien le texte qui nous permet de voir dans l'image le portrait d'un noyé, plutôt que celui d'un homme endormi. Bayard joue à détourner le sens de l'image faisant passer la

expresses » de célébrités. En quelques pages les photos et les légendes retracent la vie d'une célébrité, simplifiée à l'extrême, offrant un idéal du succès de l'icône représenté, un rêve avec lequel tout le monde peut s'identifier. NACHTERGAEL, Magali, Ibid., p. 193-198.

20 MORA, Gilles, Pour en finir avec la photobiographie, in Traces photographiques, traces autobiographiques, Op. cit., p. 116.

${ }^{21}$ MORA, Gilles, Manifeste photobiographique Op. cit., p. 106.

${ }^{22}$ MORA, Gilles, Pour en finir avec la photobiographie, Op. cit., p. 115.

${ }^{23}$ SCHAEFFER, Jean-Marie, L'image précaire, Du dispositif photographique, Paris, Seuil, 1987, p. 104.

${ }^{24}$ Voir l'image sur Wikipédia : http://fr.wikipedia.org/wiki/Hippolyte Bayard (consulté le : 27/05/08). 
différence de ton des mains et du visage bronzés comme preuve de la décomposition du corps, dans le but d'augmenter la compassion du regardeur.

Sans le texte le cliché semble insuffisant, mais la sincérité du texte peut également être problématique. Gilles Mora cite comme seul exemple de production photobiographique qui lui parait satisfaisant, un livre qui est le fruit d'une collaboration entre l'écrivain et poète James Agee et le photographe Walker Evans, Let us Now Praise famous Men. Dans ce livre, le texte et la photographie témoignent, selon Gilles Mora, « d'une expérience commune en préservant d'une façon rare, devant un même champ de réel, leurs différences autant que leur complémentarité ${ }^{25} »$. Ce livre fut réalisé suite à une commande du journal Fortune en 1936, à l'époque de la Grande Dépression aux États-Unis, et présente trois familles de fermier qui vivaient dans une très grande pauvreté $^{26}$. On voit dans le choix de Mora une sorte de nostalgie pour la photographie qui s'impose le devoir moral de témoigner de la réalité, où le texte souligne à quel point les mots sont insuffisants. Toutefois le choix dans Let us Now Praise famous Men de remplacer les vrais noms de famille par des noms fictifs aurait dû déjà susciter la méfiance : un reportage réalisé 69 ans plus tard révèle que les membres des familles décrites dans le livre portaient un tout autre regard sur leur situation ${ }^{27}$.

Nous retrouvons chez Gilles Mora les deux tendances que démontre Serge Tisseron dans la photographie. Dans le Manifeste photobiographique on reconnaît l'approche positive qui anticipe la perte de l'instant par une action dont le résultat pourra être reconsidéré et devenir révélateur. Vingt ans plus tard en revanche, à la suite d'une déception générale vis-à-vis du caractère authentique de la photographie (comme nous l'avons vu dans le chapitre «L'évolution de la théorie de la photographie - La vérité en question »), il se mettra à déplorer l'incapacité de la photographie à rendre compte de la réalité dans sa totalité, ne pouvant désigner qu'un signifiant flou et précaire qui, sans le texte, se perd. Quoique ce qu'il rejette en mentionnant la biographie

\footnotetext{
${ }^{25}$ Ibid., p. 116.

${ }^{26} \mathrm{http}$ ://en.wikipedia.org/wiki/Let_Us_Now_Praise_Famous_Men (consulté le : 13/07/2009)

${ }_{27}$ http://money.cnn.com/magazines/fortune/fortune_archive/2005/09/19/8272885/index.htm (consulté le : 13/07/2009). Il s'agit d'un reportage réalisé par Fortune, le magazine où devait apparaître à l'origine l'œuvre d'Agee et d'Evans. Le présent article détaille les circonstances de la genèse du reportage réalisé à l'époque, et le met en parallèle avec la situation de la région aujourd'hui. Les familles et leurs descendants interviewés 69 ans plus tard (notamment Charles Burroughs et Laura Tingle apparaissant en tant qu'enfant sur les images d'Evans), confirment en effet qu'ils vivaient dans la pauvreté telle qu'elle était décrite par le livre, mais expriment leur colère pour l'image qui les a représenté en tant qu'ignorant, paresseux et misérable.
} 
illustrée par des photos (comme la «photobiographie » du Che), ce n'est peut-être pas le genre même, mais son utilisation à des fins uniquement commerciales. La photographie mythologise en effet la vie de personnages publics après leur mort (car les mythes captent la fascination, ce qui est distant et inatteignable offrant une dimension de rêve et d'évasion), créant une fausse identité par les images, participant à la fabrication d'une idole, belle et touchante ${ }^{28}$.

La notion même de photobiographie reste toutefois problématique. Si nous essayons de transposer la définition de Philippe Lejeune à la photographie, nous nous heurtons à plusieurs problèmes. Selon Lejeune, l'autobiographie est un récit rétrospectif écrit à la première personne du singulier dans lequel l'auteur s'engage à parler sincèrement de sa propre vie.

L'œuvre de Jacques-Henri Lartigue ${ }^{29}$ pourrait pourtant être un exemple de récit visuel autobiographique réalisé rétrospectivement. Lartigue pratiquait la photographie amateur et il enregistrait les évènements de sa vie, mais avec une sensibilité artistique qui produisit des images remarquables. Ses clichés classés dans des albums photo (comprenant 14500 pages) et annotés ont servi rétrospectivement de base pour la réalisation de livres «autobiographiques", tels Un album de famille de la belle époque $e^{30}$, ou Instants de ma vie ${ }^{31}$. Toutefois, dans le cas de la photo, on ne peut choisir rétrospectivement qu'à partir des images, des moments de notre vie qui ont été enregistrés, ce qui restreint le récit visuel.

La reconstitution (que pratique Christian Boltanski ou Sophie Calle) pourrait être une alternative pour réaliser une photobiographie, mais alors l'ancrage indiciel et la dimension de preuve de la photographie se perdent.

La photobiographie telle que Mora la décrit dans le Manifeste correspondrait plutôt à un enregistrement immédiat, selon nous, elle serait semblable à une sorte de journal intime, qui ne se soucie que de la vérité du moment, ce qui serait en accord avec la définition de Philippe Lejeune, qui a évolué en intégrant dans son corpus les journaux intimes non littéraires; mais cette forme photobiographique dépasse probablement

\footnotetext{
${ }^{28}$ Le gonflement médiatique autour de la mort de Michael Jackson pourrait être un autre exemple...

${ }^{29}$ Voir la page de la Donation Jacques Henri Lartigue : http://www.lartigue.org/index.html (consulté le : 20/08/2009).

${ }^{30}$ LARTIGUE, Jacques-Henri, Un album de famille de la belle époque, Lausanne, Ami Guichard Editeur et Edita S.A., 1966.

${ }^{31}$ LARTIGUE, Jacques-Henri, Instants de ma vie, Paris, Sté Nlle des Éditions du Chêne, 1973.
} 
«l'étroitesse » de la définition initiale. Nous prendrons néanmoins comme exemple quelques œuvres qui proposent des récits visuels autobiographiques combinés ou non en une œuvre hybride pour démontrer quels sont les dispositifs spécifiques que mettent en place les photographes dans le questionnement de l'identité et comment ces dispositifs déconstruisent l'identité dans une autofiction où l'intériorité et l'extériorité semblent se dissoudre.

\section{III.3.a. Duane Michals}

C'est à la fin des années 1950 que Duane Michals ${ }^{32}$ commence à assembler des photographies en séquence pour créer des histoires. Comme le note Magali Nachtergael $^{33}$, ses premières œuvres, qui sont des saynètes composés de deux-trois photos avec un titre ou une légende courte, se complexifieront progressivement, et à partir des années 1970 plusieurs de ses «photo-story » traitent de questionnements autobiographiques.

Le titre de son livre Vraies rêves ${ }^{34}$ fait référence à la tension s'installant entre la véracité de l'image photographique et l'univers onirique chargé de symboliques, qui caractérisent son univers photographique ${ }^{35}$. La réalité des prises photographiques est décomposée dans plusieurs séquences, telles Le miroir d'Alice ${ }^{36}$ ou Things are queer ${ }^{37}$ (Les choses sont bizarres), créant par les reflets dans le miroir ou par le zoom arrière un effet de mise en abyme infini.

32 Duane Michals, certaines œuvres sont visibles sur le site de la galerie Fahey/Klein (consulté le : 04/08/2009) : http://www.faheykleingallery.com/featured_artists/michals/michals_frames1.htm

${ }^{33}$ Voir le sous-chapitre «La mécanique du récit photographique en mutation : le cas de Duane Michals, NACHTERGAEL, Op. cit., p. 189-192.

${ }^{34}$ MICHALS, Duane, Vraies Rêves, Histoires photographiques de Duane Michals, Chêne, Paris, 1977, (sans pagination).

${ }^{35}$ Duane Michals a été beaucoup influencé par l'œuvre de René Magritte, pour les thèmes, la remise en cause de la réalité visuelle, ainsi que l'utilisation et la mise en rapport du texte et de l'image. Voir les séquences : L'ange déchu (1968) ainsi que Take one and see Mt. Fujiyama (1970), disponible sur Internet sur le site de Christie's : (consulté le : 05/06/2009)

http://www.christies.com/LotFinder/ZoomImage.aspx?image=/LotFinderImages/D51652/D5165273

${ }^{36}$ MICHALS, Duane, Le miroir d'Alice, 1974 : (consulté le : 04/08/2009).

http://www.re-title.org/exhibitions/archive_nohrahaimegallery290.asp

37 MICHALS, Duane, Things are queer, 1973 : http://www.momentism.com/processthis/DM-QueerProcessTHIS.pdf (consulté le: 04/08/2009). 
Duane Michals, Things are queer, 1973

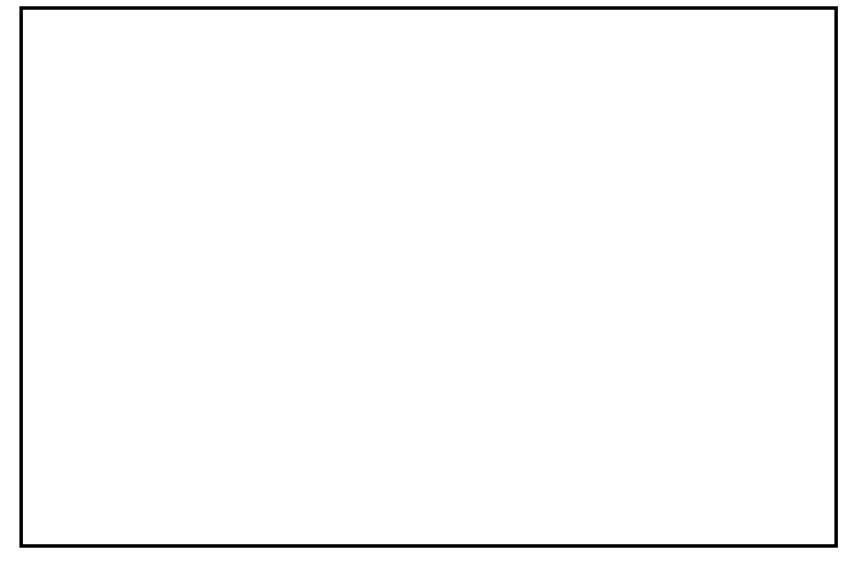

La troisième et la quatrième image sont particulièrement intéressantes, car le texte raconte la fin d'un conte mettant en scène un géant. En examinant de près l'image, qui devient l'illustration du conte, on découvre l'artifice du miroir qui cache une seconde image d'un

bâtiment. Le pouce cache par ailleurs le reflet insolite du seau sur la troisième image. Le miroir, comme l'image photographique, ne reflète pas la réalité, de plus, d'autres images se dissimulent et s'impriment sur elles. Il n'est pas non plus anodin, que dans cette salle de bain lilliputienne on retrouve une carte à gauche sur le mur, et l'inscription « exit ». La carte est une représentation abstraite et codée de l'espace, dont la fonction principale est de faciliter l'orientation. Avec la photographie, on pense sortir vers le monde extérieur, pourtant l'image n'est en fin de compte qu'abstraite comme la carte. La photographie abolit la frontière entre la réalité et l'imaginaire, de même que l'opposition entre le visible et l'invisible. 
Dans plusieurs des séquences de Duane Michals, c'est ainsi le texte qui met en doute le visuel ou l'inscrit dans un autre registre. Dans les photos à thème autobiographique, le texte vient également remettre en cause l'identité et le fonctionnement de la mémoire dans une série de questions qui interrogent jusqu'à la date de naissance du photographe ${ }^{38}$ : « ça a existé, 1954 ? Qu'est-ce que je faisais en juin 1971 ? Que s'est-il passé en 1945 ? Je pense qu'il y a eu un 1932 ». Ces inscriptions remettent en cause la possibilité de témoignage de la photographie.

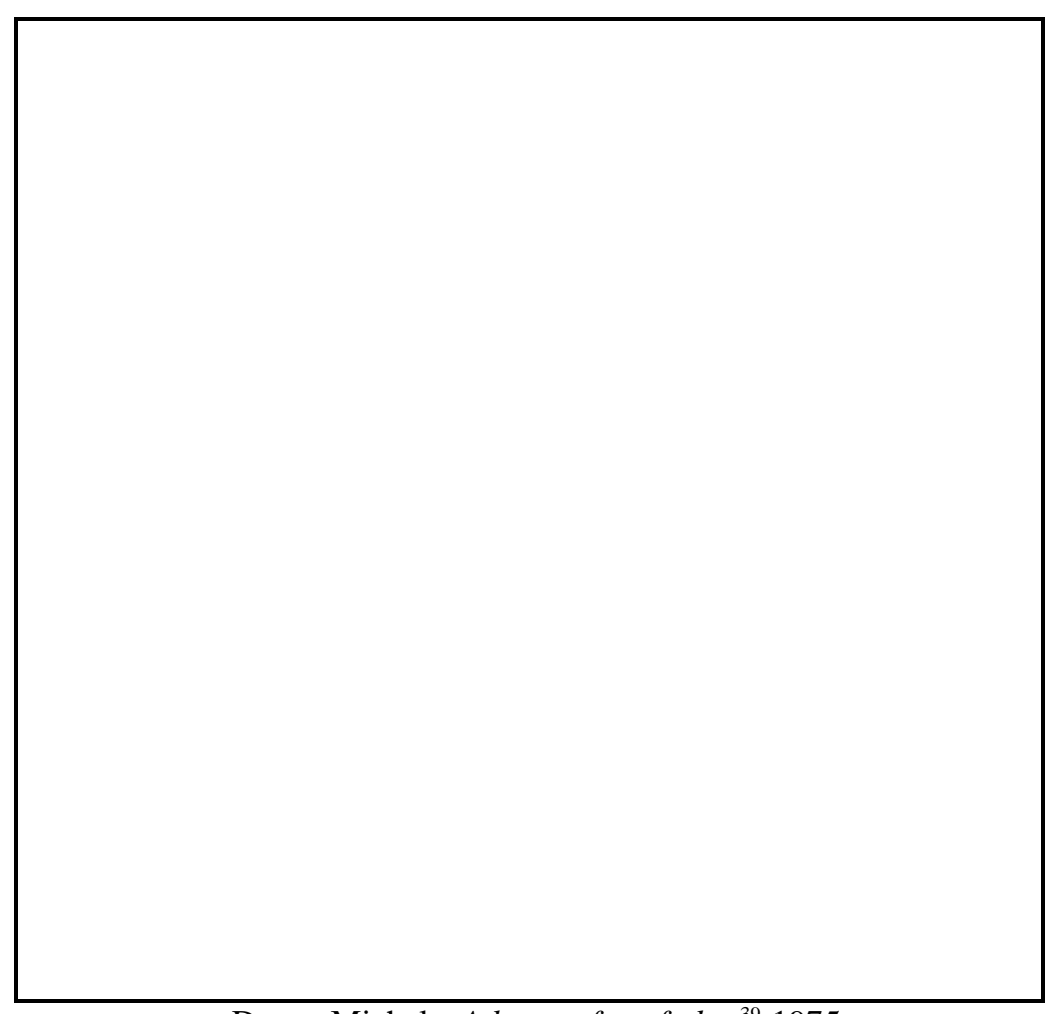

Duane Michals, A letter of my father ${ }^{39} 1975$.

L'écriture manuscrite (titres, légendes ou textes brefs) sur le bord des photos semble prendre une revanche sur l'indicialité du cliché authentifiant et garantissant la touche personnelle de l'auteur. Le texte peut également renforcer ce que l'image ne fait que suggérer, ainsi dans l'image intitulée «A letter from my Father », l'écriture transcrit la dimension psychologique du rapport entre le photographe et ses parents.

Dans ce dernier, le texte écrit à la première personne fait part d'une confidence : le père aurait promis au narrateur une lettre, qu'il ne lui aurait jamais remise. Il relate sa

\footnotetext{
${ }^{38}$ Cité par Magali Nachtergael, Op. cit., p. 191.

${ }^{39}$ La photo provient du site : http://www.flickr.com/photos/christopheducamp/3436725523/ (consulté le : 21/07/2009).
} 
déception d'avoir attendu en vain, la lettre d'une part mais aussi un signe d'affection de son père. La photo suggère ce manque d'affection en mettant en scène le fils dans le flou du premier plan s'effaçant presque au profit des parents à l'arrière plan, qui regardent dans sa direction. L’image est dominée par la figure du père, dont le geste, les bras sur les hanches, traduit une impatience ou un mécontentement à l'égard du fils. La figure de la mère, qui porte sur son fils un regard plutôt protecteur et inquiet, est en retrait derrière son image, comme si le rôle maternel rivalisant avec celui de l'épouse au côté de son mari ne pouvait s'exprimer.

Comme le note Magali Nachtergael, ce dispositif particulier que Duane Michals élabore subit l'influence du photo-essay journalistique, mais son œuvre influencera à son tour plusieurs écrivains photographe, tels Hervé Guibert (dans son roman photo Suzanne et Louise ${ }^{40}$ ), Denis Roche ${ }^{41}$, les romans-photos de Benoît Peeters réalisés en collaboration avec Marie-Françoise Plissart ou encore le livre Surbanalisme ${ }^{42}$ de Bernard Plossu.

\section{III.3.b. Robert Frank}

Le livre Les Américains ${ }^{43}$ de Robert Frank inaugure en 1952 le courant de la photographie subjective. Son reportage photographique montre les États-Unis tels qu'il les voit, loin des représentations de la presse fortement idéologiques reflétant la grandeur et la splendeur du pays ${ }^{44}$. Sa démarche pourrait correspondre à celle prônée par

\footnotetext{
${ }^{40}$ GUIBERT, Hervé, Suzanne et Louise (Roman-photo), Paris, Hallier, 1980. Nous y reviendrons à la page 130 .

${ }^{41}$ Denis Roche élabore à son tour un dispositif dans lequel il ajoute un texte écrit à la main sur le cadre des photographies, mais ce qui lui est propre est qu'il transpose cette technique à l'écriture retranscrivant le cadre et les circonstances de l'écriture. Voir à la page 424.

${ }^{42}$ PLOSSU, Bernard, Surbanalisme, séquences photographiques de Bernard Plossu, préface de Sergio Leone, éd. du Chêne, Paris, 1972.

${ }^{43}$ FRANK, Robert, Les Américains, Paris, Delpire, 1958. Dans notre analyse nous nous appuyons sur l'étude de Philippe de Jonckheere qui a mis en ligne son mémoire de maîtrise sur Robert Frank. Voir sur le site du désordre : http://www.desordre.net/photographie/photographes/robert_frank/robert_frank.html (consulté le : 26/07/2009)

${ }^{44}$ Il faut toutefois remarquer que si Robert Frank peut faire ce reportage subjectif, c'est grâce à la bourse de la fondation Guggenheim, qui lui assure une certaine liberté, et qui témoigne en même temps du rôle des institutions dans le changement à l'égard de la photographie qui s'est produit à la deuxième moitié du $\mathrm{XX}^{\mathrm{e}}$ siècle.
} 
Gilles Mora, car elle est une œuvre tournée à la fois vers l'extérieur et l'intérieur ; pourtant Mora l'écarte des œuvres photobiographiques. Il ne mentionne pas non plus The Lines of my hands ${ }^{45}$, cette œuvre explicitement autobiographique, parue vingt ans après Les Américains, après une période de pause où Frank délaisse la photographie pour faire du cinéma. Selon Philippe de Jonckheere, le dispositif autobiographique particulier que Frank mettra en place dans The Lines of my hand est déjà présent en germes dans ses films :

A Mabou, en Nouvelle-Ecosse, au Canada, Robert Frank filme des éléments de son existence, celle de son fils Pablo et de sa deuxième femme, June Leaf. Il utilise pour ce faire une caméra vidéo et achève ainsi la bande Home improvements, en filmant sa propre image, elle-même filmant sa propre image, dans le reflet d'une vitre ; il dit alors, enregistré par le micro de sa caméra : "je fais toujours la même image, je regarde à l'intérieur, de l'extérieur et je regarde à l'extérieur de l'intérieur", Le champ de la caméra allant en s'élargissant, le spectateur comprend que Robert Frank filme une fenêtre de l'extérieur vers l'intérieur, l'image produite en raison de la forte différence de luminosité, est en fait une image de l'extérieur, où se trouve Robert Frank, filmant. Il pousse alors la métaphore : "J'essaye de dire quelque chose qui s'approcherait de la vérité, mais ceci n'est probablement pas vrai"46

Dans The Lines of my hands, Robert Frank associe des images en séquence auxquelles il ajoute des mots, utilisant et combinant plusieurs procédés ${ }^{47}$ (grattage sur la pellicule, inscription ou peinture manuelle sur le tirage, inscription sur les objets photographiés, typographie présente sur les objets photographiés ou encore filtres de lumière. Ces messages énigmatiques pour le regardeur témoignent d'un sentiment éprouvé lors de la prise de vue et ils parlent avant tout au photographe. C'est le cas du cliché cicontre $^{48}$, qui associe deux vues de fenêtre prises à partir

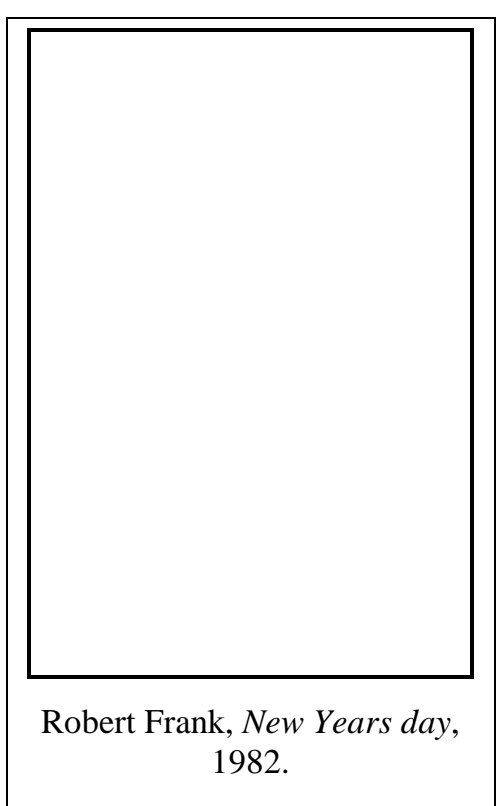

${ }^{45}$ FRANK, Robert, The Lines of my hand, Zurich/New York, Alltag/Parkett, 1989. Le livre connaîtra deux éditions publiées sous le même titre, la première en 1972, la seconde en 1989 augmentée des clichés réalisés après 1970.

${ }^{46}$ Cité par Philippe de Jonckheere : http://www.desordre.net/photographie/photographes/robert_frank/wor ds.html : (consulté le : 27/07/2009). En tant qu'écrivain-photographe Philippe de Jonckheere élabore à son tour une œuvre singulière sur le principe autobiographique. Voir à la page 133.

${ }^{47}$ Voir des exemples sur le site de Philippe de Jonckheere (consulté le : 27/07/2009) :

grattage sur le négatif et typographie sur un objet tel un poste de télé http://www.desordre.net/photographi e/photographes/robert_frank/wake_up.html; inscription sur un objet qui est ensuite photographié : http://www.desordre.net/photographie/photographes/robert_frank/mother_nature.html ; peinture sur l'image : http://www.desordre.net/photographie/photographes/robert_frank/zoe.html ou encore écrit à l'aide de filtres de lumière :

http://www.desordre.net/photographie/photographes/robert_frank/moving_out2.html.

${ }^{48}$ FRANK, Robert, New Year's Day, Mabou, 1981, (consulté le : 27/07/2009) :

http://www.desordre.net/photographie/photographes/robert frank/be happy.html 
d'un intérieur. Sur la première, dans le cadre de la fenêtre apparaît une forme qui pourrait être un masque, vestige d'une fête, qui serait donc un accord iconique avec le texte du deuxième cliché, explicitant l'ancrage temporelle «New Years day, 1981 ». La vue minimaliste de l'image traduit une solitude qui contraste avec le message écrit. Le noir domine le cliché et ce que donne à voir le cadre de la fenêtre reste flou ; on y distingue à peine un paysage hivernal aride, jalonné de poteaux (selon Jonckheere ce dernier est un motif récurrent chez Frank, symbolisant la communication avec le monde « extérieur »). L'emplacement identique du poteau, que met en évidence la juxtaposition des clichés, permet de comprendre qu'il s'agit d'une porte vitrée qui se referme sur l'intérieur, sur l'intimité du photographe et l'intimité des mots. Reste néanmoins incertain le destinataire de cette phrase à l'impératif, qui invite à être heureux.

Sur certains clichés apparaît partiellement ou entièrement le photographe. On voit son ombre ; une partie de son corps (son bras par exemple, comme sur le cliché ci-contre) ; ou la caméra est entièrement tournée vers lui, devenant ainsi celui qui est pris et non plus celui qui prend le cliché. Sick of good bys ${ }^{49}$ (marre des adieux) combine les surfaces transparente (le vitre de la fenêtre) et réfléchissante (miroir), qui sont également des motifs récurrents chez Frank. Ils deviennent les symboles de l'enchevêtrement de l'extérieur et de l'intérieur, qui résonne aussi avec l'idée de Denis Roche pour qui la verrière c'est la «métaphore de l'esprit. [...] Elle n'est là

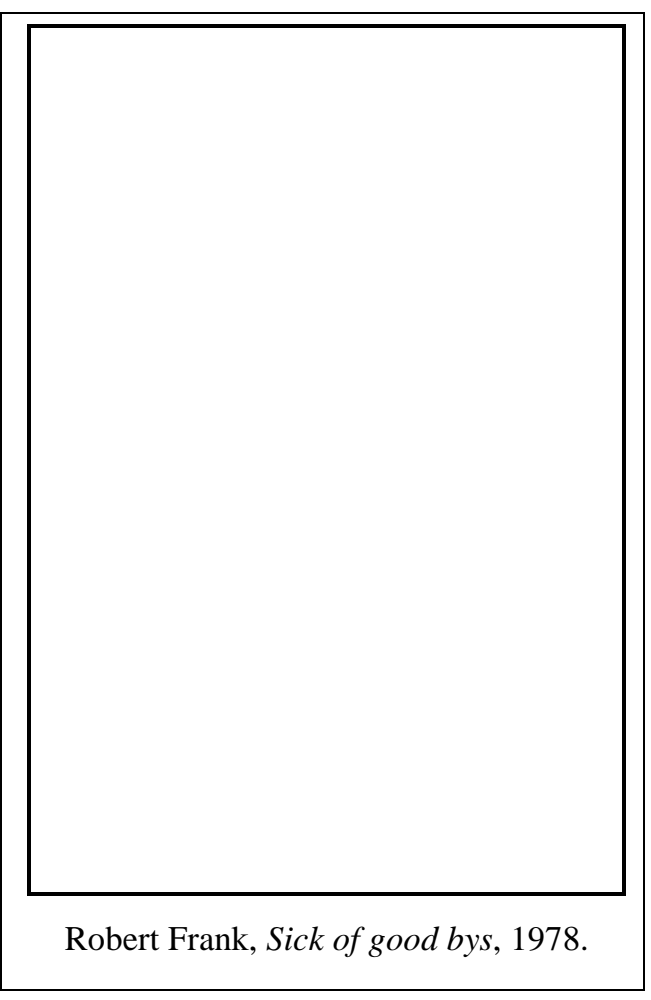
que pour signifier le monde visuel et pour faire voir cette signification ${ }^{50} »$.

La particularité du dispositif qu'élabore Robert Frank par ses expérimentations formelles consiste en l'assemblage ou collage de photos (ou d'autres documents tels une

\footnotetext{
${ }^{49}$ FRANK, Robert, Sick of good bys, 1978 (consulté le : 27/07/2009) : http://www.desordre.net/photographie/photographes/robert frank/sick of goodbyes.html ${ }^{50}$ ROCHE, Denis, Photolalies, Paris, Argraphie, 1988, p. 36.
} 
lettre $^{51}$ ), où le texte devient également un élément formel suggérant un sens sensible (comme l'aigu du grattage, la coulée de la peinture qui déforme les mots expriment le sentiment de malaise). Toutefois, selon Philippe de Jonckheere, parfois le texte ne fait que dérouter ou désinformer, le message reste énigmatique et ne témoigne que d'un être au monde : «[...] j'ai décidé d'exprimer dans ces photos instantanées, un sentiment tout simple, celui d'être au monde. Exister, être là, et rien d'autre ${ }^{52} »$.

\section{III.3.c. Raymond Depardon}

Raymond Depardon, comme Duane Michals et Robert Frank, est issu d'un milieu journalistique, mais tandis que ces deux derniers ont délaissé le métier pour se consacrer à leur propre œuvre liée au projet autobiographique, Raymond Depardon continue, même si c'est pour son propre compte à faire, entre autres, des documentaires. En 1979, Depardon publie Notes $^{53}$, un livre où il juxtapose des photos de reportage de guerre avec les textes de son journal, alignant ainsi le monde extérieur et son univers intime. Curieusement c'est un éditeur de poésie qui publie cet ouvrage ${ }^{54}$. Depardon relate ainsi l'expérience :

Quand ils m'ont contacté je rentrais d'Afghanistan après être passé à Beyrouth et au Pakistan. C'était une désillusion sentimentale qui m'avait poussé à faire ce voyage, à quitter Paris... À partir à la guerre et à écrire un journal pour prouver mon désir et mon attachement tout au long de ce reportage que personne ne m'avait commandé ! ${ }^{55}$

L'usage abusif dont est victime une des photos pousse également Depardon à privilégier le support du livre et l'œuvre mixte de photographie et écriture :

${ }^{51}$ Voir l'exemple sur le site de Philippe de Jonckheere (consulté le : 27/07/2009) : http://www.desordre.net/photographie/photographes/robert frank/mailbox.html

${ }^{52}$ Cité par Philippe de Jonckheere (consulté le : 27/07/2009) : http://www.desordre.net/photographie/photographes/robert frank/words.html

${ }_{53}$ Pour l'édition originale : DEPARDON, Raymond, Notes, Paris, Arfuyen, 1979.

${ }^{54}$ Il s'agit d'une édition expérimentale qui avait pour objectif d' «inventer une nouvelle forme, qui permette de sortir du style insupportable des albums de photos pleine page sur papier glacé, alors en grande vogue », selon l'éditeur. Ce premier livre photo-littéraire n'a eu de suite qu'un ouvrage en 1987 : Hivers, comprenant également des textes et photographies de Depardon. Voir à ce propos le site de l'éditeur : http://www.arfuyen.fr/html/domaines.asp?id_dom=39 (consulté le : 10/09/2009).

55 DEPARDON, Raymond, La solitude heureuse du voyageur. Précédé de Notes, Paris, Points, 2006, p. 10 . 


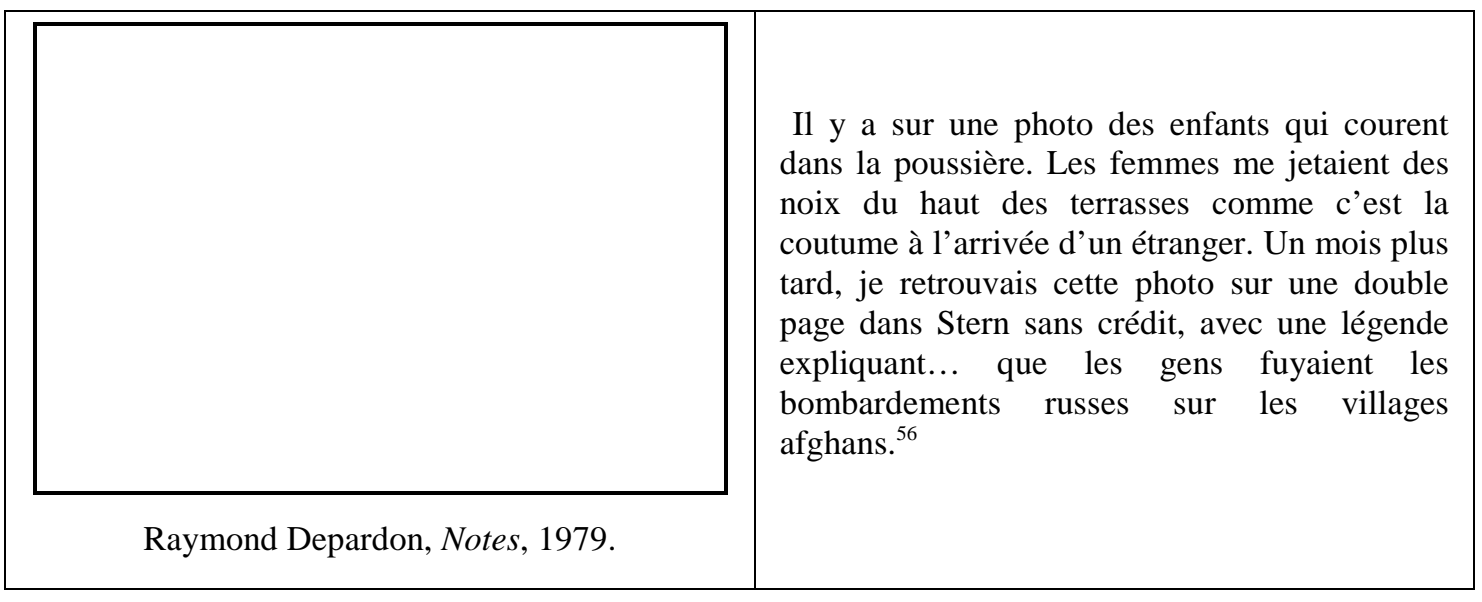

Cette première expérience de cocréation de 1979 est suivie en 1981 par Correspondance new-yorkaise, qui paraît cette fois-ci au sein du quotidien Libération et qui introduit une nouveauté dans la pratique de la presse. Le principe de cette correspondance est semblable à celui de Notes: le photographe prend des photos pendant une période d'un mois et en choisit une tous les jours à laquelle il ajoute un texte. La Correspondance bouleverse les valeurs journalistiques, en refusant d'une part de couvrir les évènements, de faire des images «fortes » comme l'on a coutume de voir dans la presse, et en proposant d'autre part un texte qui ne relate pas toujours ce qui est visible sur l'image et crée ainsi un décalage (comme pour l'image ci-dessous ${ }^{57}$ ).

\begin{tabular}{|l|l|}
\hline \multicolumn{1}{|c|}{} & $\begin{array}{l}\text { 24 juillet 1981, New York. Toilettes « dames » } \\
\text { du magazine américain Géo, 450 Park Avenue. } \\
\text { J'ai envie de faire des photos à la «chambre ». } \\
\text { J'ai envie de faire ma famille dans la Dombes. Je } \\
\text { pense à la campagne... ça doit être la moisson } \\
\text { maintenant ! (Paru le } 28 \text { juillet). }{ }^{58}\end{array}$ \\
\hline Depardon, Correspondance new-yorkaise, 1981. & \\
\hline
\end{tabular}

Depardon note à propos de cet écart :

Je suis rentré, j'ai développé la photo et - je ne sais pas ce qui m'a pris dans la tête ce soir-là, un jour de juillet -, j'ai pensé aux foins à la ferme du Garet. J'ai choisi [la] cette photo et j'ai écrit :

\footnotetext{
${ }^{56}$ Ibid., p. 18.

${ }^{57}$ Voir l'image sur le site de Magnum (consulté le : 27/07/2009) : http://www.magnumphotos.com/Archive/C.aspx?VP3=ViewBox\&ALID=2TYRYD1K0FR4\&IT=Thumb Image01_VForm\&CT=Album

${ }^{58}$ DEPARDON, Raymond, Correspondance new-yorkaise, (textes et photographies). BERGALA, Alain, Les absences du photographe, Paris, Étoile/Cahiers du cinéma, col. "Écrits sur l'image", 1986.
} 
«Je pense aux foins qui se font en ce moment à la ferme du Garet. » Donc, on avait la ferme du

Garet et l'avenue la plus chic des Etats-Unis. Voilà, c'est un peu comme ça, le décalage. ${ }^{59}$

Depardon se réfère à l'article Rhétorique de l'image pour distinguer à la suite de Roland Barthes deux types de relation possible entre les mots et les images : «Les mots qui viennent avec une photo, soit ils sont ancrage, soit ils sont relais ${ }^{60} »$. Ancrage signifie légende qui explique ce qui se voit sur l'image, et relais se rapporte aux mots qui disent autre chose et déplacent ainsi le sens de l'image : « je pense à quelque chose, je pense à autre chose que ce qu'il y a sur la photo, sous la photo ${ }^{61} »$. Même si cette constatation est simpliste et ne rend pas justice à la complexité du rapport entre la photographie et le texte $^{62}$, ces propos attirent l'attention sur la dichotomie intime et extime qui intervient dès la prise de vue. En effet, le sentiment qu'éprouve le photographe au moment de la prise peut influencer ce qu'il prend en photo, et lors de la contemplation des clichés, d'autres images mentales peuvent surgir et altérer le sens de l'image.

La photographie qui peut évoquer ce qui ne se voit pas sur l'image devient ainsi similaire à l'écriture : «Si l'écriture permet à l'écrivain d'évoquer l'ailleurs ou l'absent, c'est qu'il est dans la nature même du langage que l'on puisse y faire surgir ce qui n'a pas besoin d'être là où l'écriture a lieu pour être présent dans l'écriture ${ }^{63} \gg$. Les légendes de Depardon témoignent de ces ailleurs, de ces rêveries : "sous cette chaleur la ville a un côté Beyrouth » (9 juillet) ; «je pense au désert » (15 juillet) ; mais avant tout selon Bergala, elles «nous parlent du photographe comme sujet aux prises avec l'acte photographique, en tant que cet acte, comme tout acte véritable, engage aussi bien ses pensées, ses désirs, ses angoisses du moment, et jamais seulement, de toute évidence, sa sensibilité à capter les apparences ${ }^{64} \gg$. Cette expérience montre néanmoins qu'on ne peut ontologiquement réduire la photographie à l'acte photographique, puisqu' « on n'évalue une réalité qu'en la filtrant à travers une autre ${ }^{65}$ » et les images mentales viennent

\footnotetext{
${ }^{59}$ DEPARDON, Raymond, L'être photographe, entretiens avec Christian Caujolle, Paris, L'Aube, 2007, p. 55.

${ }^{60}$ Ibid., p. 52. Pour l'œuvre de Roland Barthes déjà citée voir notamment sur Internet : http://www.oasisfle.com/doc_pdf/roland_barthes_rhetorique_image.pdf (consulté : le 06/10/2009).

${ }^{61}$ Ibid.

${ }^{62}$ La notion de légende pose déjà en-soi un problème en voulant retranscrire « objectivement » ou «tautologiquement » ce qui est visible sur l'image.

${ }^{63}$ DEPARDON, Raymond, Les absences du photographe, Op. cit., p. 30.

${ }^{64}$ Ibid., p. 44.

${ }^{65}$ Ibid., p. 42.
} 
« contaminer » la prise de vue ${ }^{66}$, mais nous pourrions également ajouter que les images mentales, les pensées, l'expérience vécue «contaminent» tout aussi la (re)lecture de l'image, qu'il s'agisse du photographe qui contemple ses propres images ou d'un quelconque regardeur. «[T] oute photographie est une image mentale ${ }^{67}$ » car l'acte est toujours une expérience aussi bien intérieure qu'extérieure.

Plusieurs livres et films de Depardon trouvent leur source dans des thèmes qui lui sont proches et qu'on pourrait qualifier d'autobiographiques à cause du choix de thèmes personnels ${ }^{68}$. Quoi qu'il en soit, son livre intitulé La ferme du Garet naît explicitement d'un projet autobiographique :

[...] pour ne pas perdre le souvenir de cette enfance que j'ai écrit relativement tôt, il y a une dizaine d'année, La ferme du Garet - pour ne pas perdre ces impressions. ${ }^{69}$

Le livre est composé d'un texte écrit à la première personne, de photos puisées dans ses archives familiales, de ses premières images faites à la ferme et de photographies en couleurs réalisées en 1984 pour la mission de la DATAR ${ }^{70}$ (les photos sont consultables sur le site de l'agence Magnum photos $\left.{ }^{71}\right)$. Le projet constitue une quête d'identité, où le photographe cherche à retracer ses souvenirs en même temps qu'à se remémorer la ferme, le paysage qui a complètement changé depuis son enfance suite à l'urbanisation. «Quand j'ai pris conscience de cette ferme, - écrit Depardon - tout avait déjà disparu $^{72} . »$

Selon Laurence Perrigault, la photographie peut de fait servir à évoquer le souvenir face à un paysage méconnaissable :

La photographie vient donc combler l'absence de souvenirs - elle permet aussi de réveiller des souvenirs enfouis. [...] Souvent, la photographie suscite d'autres souvenirs que ceux qu'elle représente, elle permet des rapprochements avec d'autres moments vécus. ${ }^{73}$

\footnotetext{
${ }^{66}$ Bergala pense reconnaître d'autres clichés de New York qui hantent les vues de Depardon, les photos d'Evans, Weegee, Robert Frank, Harry Callahan, Lee Friedlander, Diane Arbus... Ibid., p. 58.

${ }^{67}$ Ibid., p. 52.

${ }^{68}$ Par exemple : DEPARDON, Raymond, Errance, (Paris, Seuil, 2003) ou les films documentaires Profils paysans I-III, (Palmeraie et désert/Canal+ 2008)

${ }^{69}$ DEPARDON, Raymond, L'être photographe, Op. cit., p. 7.

${ }^{70}$ L'abréviation DATAR signifie : la Délégation à l'Aménagement du Territoire et à l'Action Régionale.

${ }^{71} \mathrm{http}$ //www.magnumphotos.com/Archive/c.aspx?VP=XSpecific_MAG.BookDetail_VPage\&pid=2K7O 3R180FIW (consulté le : 13/07/2009).

${ }^{72}$ DEPARDON, Raymond, La ferme du Garet, Paris, Actes Sud, 1997.

${ }^{73}$ PERRIGAULT, Laurence, «La photographie comme déclencheur de la mémoire dans Le royaume des voix d'Antonio Muñoz Molina et La ferme du Garet de Raymond Depardon », in Littérature et photographie, Op. cit., p. 403.
} 
Les photos en noir et blanc suivent chronologiquement la vie de l'auteur, mais elles sont mises en abyme tout au long du livre par les photos en couleur réalisées pour la DATAR. Nous retrouvons parfois les mêmes lieux, comme la cour, la cuisine, l'escalier où le lierre gagne progressivement de l'espace, et l'écoulement du temps s'affiche alors visiblement sur les images. Mais un écart se crée entre les photos en noir et blanc et celles en couleur. Ces dernières sont vides, ce sont des paysages ou des vues d'intérieur, des grands formats, à la recherche esthétique très marquée. Il se peut que ce vide ne soit dû qu'à un choix d'objectif différent de celui des photos NB - la mission de la DATAR voulait témoigner du territoire, mais le fait de les avoir juxtaposées aux autres photos souvenirs accentue l'écart d'atmosphère et de temps, que le texte souligne également. Dans un entretien, Depardon explique :

Aujourd'hui, la ferme est ceinturée d'autoroutes, de zones industrielles. Elle a été totalement transformée, bousillée, par rapport à il y a trente ans. C'est ce contraste entre mes souvenirs et la réalité que je voudrais montrer. ${ }^{74}$

La remémoration joue sur le décalage, que le texte souligne à son tour. Ce dernier s'organise en petits paragraphes indépendants les uns des autres, restituant le désordre des souvenirs. Plusieurs paragraphes commencent par «Je me souviens... ${ }^{75} »$, et la description met face à face l'évocation du passé et du présent : «Aujourd'hui, là où j'avais pris cette photo, à la place des chevaux Fanfan et Bijou, il y a l'autoroute et le centre commercial avec un Géant Casino et un Mc Donald's ${ }^{76}{ }^{2}$. Le texte évoque les évènements qui l'ont marqué dans son enfance, fête, mariage, mais aussi les travaux agricole : les foins, les moissons, les vendanges ${ }^{77}$. Il décrit la ferme et la vie à la ferme, mais sans l'idéaliser en mentionnant également la dureté du travail et le manque de confort.

Au-delà de la remémoration de l'enfance et du souvenir d'un monde rural disparu, les photos et le texte relatent comment il est devenu photographe, et l'œuvre prend l'allure d'une quête d'identité qui tente de raccorder le métier choisi avec ses

74 ROEGIERS, Patrick, Écoutez voir. Neuf entretiens avec des photographes, Paris, Paris Audiovisuel, 1989.

${ }^{75} \mathrm{La}$ formule fait peut-être référence au livre du même titre de Georges Perec (Je me souviens, Paris, Hachette, 1978). Il s'agit d'un recueil de bribes de souvenirs, forme que Perec emprunte à Joe Brainard, et qui aura une influence sur nombre d'œuvres autobiographiques. Voir notamment sur Wikipedia quelques références : http://fr.wikipedia.org/wiki/Je_me_souviens_\%28livre\%29 (consulté le : 10/09/2009) ou sur le site du Désordre auquel nous reviendrons à la page 133.

${ }^{76}$ DEPARDON, Raymond, La Ferme du Garet, Op. cit., p. 64.

${ }^{77}$ Ibid., p. 39. 
origines paysannes. Le devoir de photographier se confond avec une éthique du monde rural. On retrouve constamment, dans tous les textes de Depardon, le rapprochement entre les photographes et les paysans : l'attachement à leur travail, le souci constant de la récolte, la production, leur besoin de liberté et l'impossibilité d'être dans une situation professionnelle, une position subordonnée ${ }^{78}$. Son identité de photographe s'associe à l'évocation du giron maternel, qui est à son tour identifié au mode de vie rural : «Sept ans après mon père, à soixante-dix-huit ans, [...], ma mère disparaissait elle aussi. Et, avec elle, un certain monde rural $^{79}{ }^{\prime}$. S'il y a nostalgie pourtant, c'est avant tout de n'avoir pas fait assez de photos sur la réalité de la ferme et de ses parents :

Il m'arrive de regretter de ne pas être venu plus souvent quand mes parents exploitaient cette ferme [...] Il y avait des photographies encore plus belles à faire ici [...] je vivais à côté d'un trésor inestimable, devenu aujourd'hui rare et, en fait, peu photographié. ${ }^{80}$

Pourtant ce n'est pas le deuil d'un monde révolu qui caractérise l'ensemble de son œuvre, plutôt l'émerveillement. Dans L'être photographe, Depardon raconte qu'on vient de lui demander pourquoi il photographie un café, ce à quoi il aurait répondu : «"Parce qu'il est formidable et que peut-être un jour il disparaîtra...". Ce n'est pas seulement une nostalgie, - commente-t-il - c'est aussi du présent. Il faut photographier $^{81} »$.

Le livre se termine d'ailleurs sur l'évocation du futur, avec une photo de ses enfants sur l'escalier entièrement couvert de lierre.

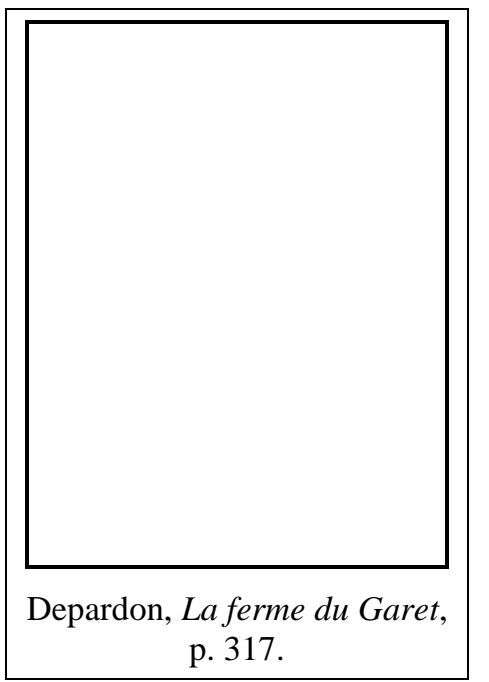

Je photographie mes fils sur l'escalier de pierre pour qu'ils gardent ensuite quelques souvenirs de ce lieu. Ils sont encore trop jeunes pour que je leur explique tout. Mais peut-être ont-ils déjà compris... ${ }^{82}$

Le photographe se projette ainsi dans la possibilité que le présent puisse devenir un souvenir grâce aux photos, que quelque chose puisse être sauvé de sa disparition possible. L'image témoigne aussi du regard attentif et de l'amour paternel du photographe.

\footnotetext{
${ }^{78}$ DEPARDON, Raymond, L'être photographe, Op. cit., p. 16.

${ }^{79}$ DEPARDON, Raymond, La Ferme du Garet, Op. cit., p. 302.

${ }^{80}$ Ibid., p. 304.

${ }^{81}$ DEPARDON, Raymond, L'être photographe, Op. cit., p. 62.

${ }^{82}$ DEPARDON, Raymond, La Ferme du Garet, Op. cit., p. 318.
} 
Depardon en tant que photographe participe alors plutôt au courant positif qui définit la photographie comme «être au monde». La particularité de ce livre qui tente de retracer de manière rétrospective sa vie, est de mêler non seulement le texte à l'image, mais aussi deux séries d'images faites dans des buts différents, et selon une esthétique différente, ce qui fait surgir visuellement l'écart entre le passé et le présent, dans l'univers du sensible.

III.3.d. 《Noir Limite»

L'univers du sensible est également au cœur des travaux du groupe d'artiste « Noir limite » fondé en 1985 par Yves Trémorin, Florence Chevallier et Jean-Claude Bélégou. Comme le nom choisi l'indique, leurs travaux photographiques explorent les limites de ce qui est montrable. Les «limites du dehors et du dedans, de la peau et des entrailles », « là où ça fond entre le nous et le monde » comme l'explique le texte du $1^{\text {er }}$ manifeste du groupe ${ }^{83}$.

Ils examinent les limites de l'intimité en proposant un point de vue qui ne cherche pas à embellir la vision du corps, mais à en donner une image plus directe. L'exposition

\footnotetext{
${ }^{83}$ Voir le manifeste d'où provient l'image insérée : http://www.belegou.org/PDF\%20LIBRES/MANIFESTESNL.pdf (consulté le : 28/07/2009).
} 
Corps à $\operatorname{corps}^{84}$ en 1987 prévue à la Maison de la Culture de Bourges provoqua un scandale et elle fut interdite à cause de l'érotisme cru de leurs clichés. Leur dernière exposition commune - non moins provocante - intitulée La Mort ${ }^{85}$ fut mise en place aux anciens abattoirs du Havre en 1991. Le groupe se dissout officiellement en 1992, date après laquelle chaque photographe poursuivra l'exploration de sa propre voie, mais sans pour autant se départir de leur volonté de donner une vision plus directe dans leurs images. Yves Trémorin et Jean-Claude Bélégou s'intéresseront à des thèmes autobiographiques, mais chacun recourant à des topoï et un style personnels.

Ainsi chez Yves Trémorin c'est le quotidien qui fait surface dans la représentation de ses proches dans la série Tribu, Poupig ou Neonboy (sa mère, sa femme ou son enfant), et d'objets quotidiens dans la série Nature morte (voir les images ci-dessous $\left.^{86}\right)$.

Ce qui caractérise ces images, selon Jean-Marc Huitorel, est qu'elles révèlent la beauté et le naturel de la souillure :

Splendeur du pain et des légumes, noire brillance des poissons, nudité royale des peaux et jusqu'aux écorchés, le séduisant mystère des objets. C'est par cet amour féroce et absolu de la vie et de ses éclats que l'artiste, via la souillure, transfigure ses sujets, comme l'amant le fait de l'amante, et les hisse jusqu'à cette beauté supérieure que seul permet le sentiment constant de la mort. $^{87}$

Il y a de l'humour noir et cru à exposer les excréments, le bébé bavant à côté de la viande saignante ou d'un œuf au plat dont le jaune commence à se répandre sur l'assiette.

\footnotetext{
${ }^{84}$ Voir les photos d'Yves Trémorin sur son site : http://tremorin.wunderblock.com/Pages/BlackWhite/CAC/CacMenu.htm ainsi que les photos de JeanClaude Bélégou sur son site : http://www.belegou.org/francais/GALERIES\%20WEB/CORPS\%20A\%20CORPS\%20GALERIE\%20W EB/index.htm.

${ }^{85}$ Voir la série d'Yves Trémorin sur son site : http://tremorin.wunderblock.com/Pages/BlackWhite/MORT/MortMenu.htm ainsi que les photos de JeanClaude Bélégou sur son site : http://www.belegou.org/francais/GALERIES\%20WEB/LA\%20TERRE\%20GALERIE\%20WEB/index.ht

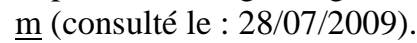

${ }^{86}$ Les images proviennent du site de l'auteur : http://tremorin.wunderblock.com/Pages/1992_1995.htm (consulté le : 28/07/2009).

87 HUITOREL, Jean-Marc, Nous Autres, http://tremorin.wunderblock.com/Pages/NousAutres.htm (consulté le : 28/07/2009).
} 
Yves Trémorin, D’Ar Ger, 1999.

Il s'agit d'une sorte de transformation en icône, d'un face-à-face avec l'objet qu'il poursuit au-delà de l'univers du quotidien dans ses séries plus récentes (Blasons ${ }^{88}$, Numériques $\left.{ }^{89}\right)$. Cependant ses séries s'apparentent dans leur forme plus à un inventaire qu'à un vrai récit.

L'œuvre de Jean-Claude Bélégou, d'après ses propres mots, prend la forme d'une autofiction photographique plutôt que de photobiographie, puisque les menus détails du quotidien qu'il représente sont des mises en scènes et non pas des vues prises sur le vif. Il en va ainsi surtout des séries en noir et blanc réalisées entre 1989 et 2000 (date après laquelle il passe à la photographie couleur ${ }^{90}$ ). L'œuvre intitulée Visages (1989) et publiée dans Les Cahiers de la photographie ${ }^{91}$ se compose de deux séries imbriquées l'une dans l'autre dans l'espace du livre, une série d'autoportraits et une série sur le visage de son amante, complétées par quelques autoportraits à deux.

${ }^{88} \mathrm{http} / /$ tremorin.wunderblock.com/Pages/BlasonsFigures/Blasons/Blasons_FiguresMenu.htm (consulté le : 28/07/2009).

${ }^{89} \mathrm{http} / / /$ tremorin.wunderblock.com/Pages/DigitalIndex.htm (consulté le : 28/07/2009).

${ }^{90}$ Pour la série photobiographique : http://www.belegou.org/francais/series19892000.html; pour la série «La revanche de la chair»: http://www.belegou.org/francais/series19892000.html (consulté le : 28/07/2009).

${ }^{91}$ BÉLÉGOU, Jean-Claude, Visages suivi de Les Amants, Les Cahiers de la photographie, n²6, ACCP, 1992. Les photos ci-dessous sont disponibles sur le site du photographe: (consulté le : 28/07/2009) http://www.belegou.org/francais/GALERIES\%20WEB/VISAGES\%20GALERIE\%20WEB/index.htm. 


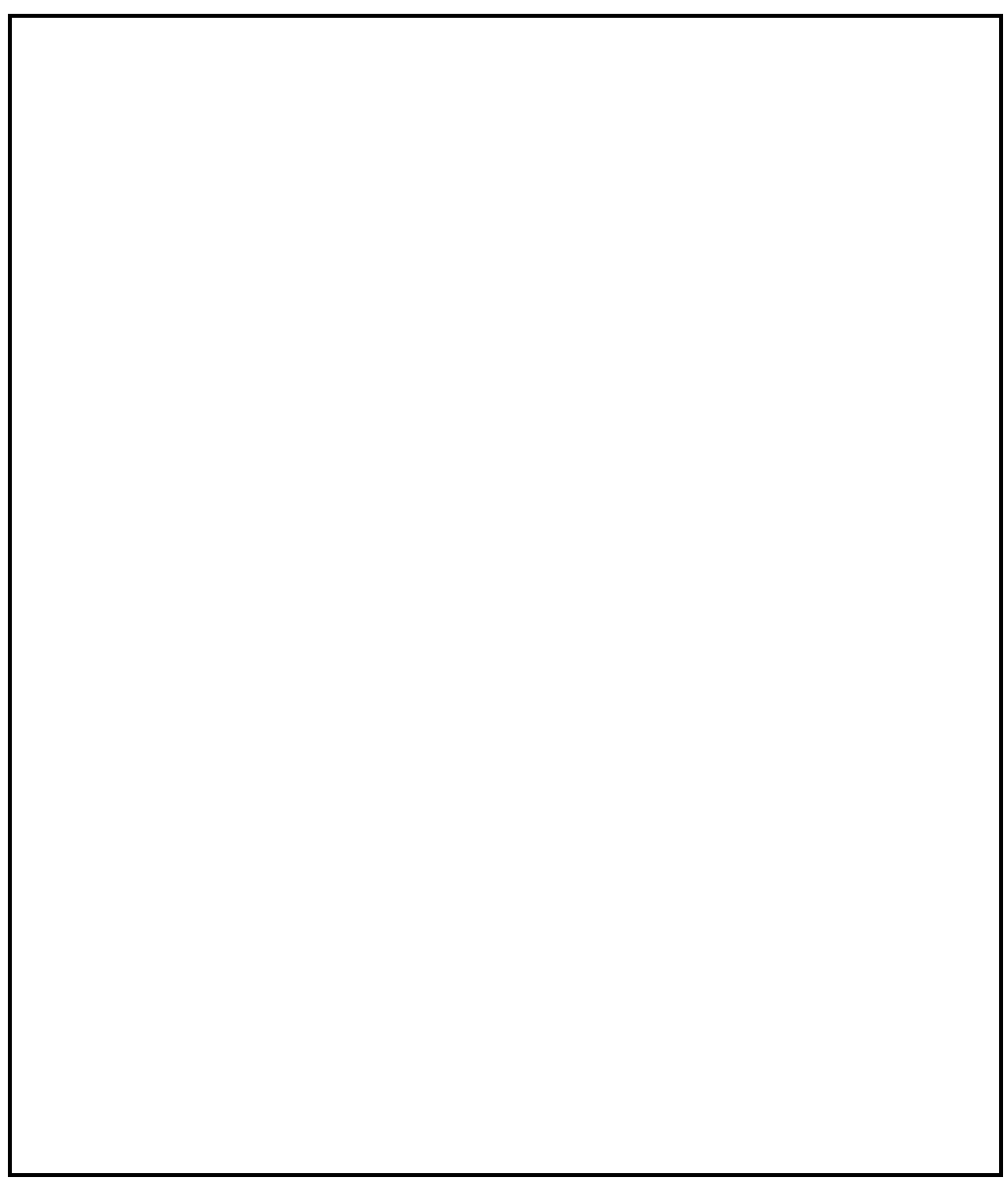

Jean-Claude Bélégou, Visages, 1989/90.

Toutefois son but n'est pas de se connaître par les autoportraits ou de connaître l'autre, mais de «pénétrer l'être, pénétrer l'intériorité ». Il refuse la dimension autobiographique dans la mesure où celle-ci veut donner un sens à l'existence, donner un sens à quelque chose qui fondamentalement n'en a pas :

La tentative de donner sens est une tentative complètement absurde, une tentative complètement compulsionnelle, obsessionnelle et désespérée mais je crois qu'on entre dans cette folie là, qui serait de donner sens à la fois au réel et à la fois à ce que l'on vit, parce qu'il est évident que ce que l'on vit ne ressemble ni à un film, ni à un livre, ni à une série de photographie ; ça ressemble plutôt à une espèce de purée de pois décousue où les moments sans aucun sens abondent bien plus que d'autres. ${ }^{92}$

Les clichés témoignent avant tout du rapport à l'autre, de «la confrontation de sa propre existence à l'existence de l'autre ${ }^{93} \gg$. Il en résulte un sentiment d'étrangeté, provoqué par la recherche d'une esthétique poussée et par la mise en scène, qui place le regardeur en confrontation avec la pluralité de l'être.

92 BÉLÉGOU, Jean-Claude, Ma vie et la photographie, in MEAUX, Danièle - VRAY, Jean-Bernard (sous la direction de), Traces photographiques, traces autobiographiques, Op. cit., p. 169.

${ }^{93}$ Ibid., p. 167. 
C'est également le rapport à l'autre qui est le thème principal de la série De tous les jours ${ }^{94}$ (voir des extraits ci-dessous). Cette série représente une femme dans ses activités quotidiennes, s'adonnant à des tâches ménagères (épluchage de pomme, vaisselle, lavage de vitre, repassage), se reposant, ou lisant un livre, sortant de la douche, prenant ses repas, ou se masturbant.

Jean-Claude Bélégou, De tous les jours, 1999.

L'œuvre, qui contient 240 clichés, est présentée selon les lieux de la maison (salle de bain, salon, cuisine, terrasse...), sous la forme de 17 séries. Plus que la banalité du quotidien, ces images révèlent l'intimité, celle du rapport entre le photographe et la femme, mais aussi «l'intimité du corps dans sa nudité. L'intimité de l'individu dans une posture impudique. L'intimité de l'espace habité, gardien des secrets ${ }^{95} »$. Le regard de l'homme y est à la fois présent et absent, on sent la solitude du modèle ou à l'inverse la présence de l'autre.

C'est la subjectivité et la sensibilité que le photographe érige en matière première d'être au monde, «du plus-intérieur, du lieu habité d'une vie, d'un corps habité d'un

\footnotetext{
${ }^{94}$ Voir un extrait sur le site du photographe : (consulté le : 28/07/2009) http://www.belegou.org/francais/GALERIES\%20WEB/DTLJ\%20GALERIE\%20WEB/index.htm\#18

${ }^{95}$ GAU, Olivier, « Jean-Claude Bélégou : intime conviction », L'opinion indépendante, Toulouse, 22/1/99. Article disponible sur le site du photographe : (consulté le : 28/07/2009) http://www.belegou.org/PDF\%20LIBRES/FORTUNE\%20CRITIQUE.pdf.
} 
langage, et livré dans un frottement au monde et au regard de l'autre. L'attention à une $v^{2} e^{96} »$. C'est la sensibilité et une approche poétique qui transparaissent également dans les textes de Bélégou, par lesquels il accompagne ses photos depuis sa série Erres (1994). Ses textes sont comme ses clichés de petits fragments de pensées, un questionnement sur l'existence. Il ajoute d'ailleurs volontiers à ses œuvres des textes théoriques sur la photographie pour expliquer sa démarche conceptuelle et philosophique. Dans ces textes, il prend de la distance avant tout avec les théoriciens des années 1980, avec l'indicialité de la photographie et avec un certain discours critique sur le réalisme et sur la photo comme preuve de l'existence. Il explique :

[...] le réalisme s'effectue dans une mise à jour du sens. En cela mes photographies sont réalistes et pourtant elles sont toujours construites, il ne s'agit ni d'accident, ni d'une quête de hasards ou de rencontres. ${ }^{97}$

Il se démarque en cela de l'approche photobiographique de Gilles Mora, même si cette dernière a été floue dès le départ.

\section{III.3.e. La dissolution du clivage entre extériorité et intériorité}

Les photographes dont nous avons analysé l'œuvre jusqu'ici, Duane Michals, Robert Frank, Raymond Depardon, Yves Trémorin ou Jean-Claude Bélégou pressentent tous comme Gilles Mora un rapport plus étroit entre l'intériorité et l'extériorité. Cependant ce lien entre intériorité et extériorité ne concerne pas forcément la photobiographie, en tout cas pas en tant que « récit » visuel de notre propre vie. Il traduit plutôt une manière d'être au monde, une sorte d'ouverture vers le monde. L'appareil ainsi que le cliché fonctionnent comme une interface mobilisant un champ de force allant dans deux directions opposées. Le photographe agit sur le monde en prenant une image, son acte est semblable à celui de nommer les choses, et les tire vers l'existence ; il s'agit, comme le dit l'expression de Paul Klee «non pas [de] rendre le visible mais [de] rendre

\footnotetext{
${ }^{96}$ Photonouvelles, ${ }^{\circ} 11$, Mars-Avril 2001, Claude Nori La rencontre : Jean-Claude Bélégou. Entretien disponible sur le site de l'auteur (consulté le : 28/07/2009) : http://www.belegou.org/PDF\%20LIBRES/FORTUNE\%20CRITIQUE.pdf

${ }^{97}$ BÉLÉGOU, Jean-Claude, Auto entretien, disponible sur son site (consulté le : 28/07/2009) : http://www.belegou.org/PDF\%20LIBRES/BELEGOU\%20ECRITS\%20SUR\%20LA\%20PHOTO.pdf
} 
visible $^{98}{ }$. C'est dans le même sens que Michel Tournier définit la photographie comme l'«Art extraverti par excellence, [qui] se lance à la conquête du monde ${ }^{99} »$. Il fait d'ailleurs le rapprochement entre l'extériorité et «l'existence» en passant par l'étymologie du mot «exister» qui équivaut à «être dehors, sistere ex $x^{100}$ ». La photographie attire alors à l'existence en mobilisant l'être vers le dehors. Cela implique un mouvement du devenir ou « une mise à jour du sens », selon les mots de Bélégou et à l'image du signe de Peirce ou de la notion du «dispositif ». L'appareil pousse le photographe à explorer le monde en faisant appel à sa sensibilité et à sa personnalité, elle mobilise sa conscience et son inconscient. C'est l'écrivain qui fait l'œuvre tout comme c'est l'œuvre qui fait l'écrivain, constatation qu'on peut transposer également à la photographie. L'image tout comme le texte, puisqu'ils demandent une « recréation », aura le même double effet : le lecteur/regardeur tire vers l'existence l'œuvre et l'œuvre en revanche transforme son recréateur. Dans ce sens tout acte de création peut devenir un «amplificateur d'existence», pour reprendre l'expression du Manifeste photobiographique, ainsi que toute photographie qui invite à un investissement personnel.

Melanie Wiora, Stream ${ }^{101}, 2002$.

En ce qui concerne l'intériorité et l'extériorité, l'intime et l'extime dans la formation de l'identité, traditionnellement la distinction se base sur l'expérience du corps physique comme limite, la peau étant une surface/interface par laquelle entrent en interaction le dehors et le dedans ${ }^{102}$. Melanie Wiora traduit ce caractère d'interface dans ses photos en gros plans de l'œil, évoquant par le reflet de l'image extérieure se projetant sur la pupille le pouvoir de la vision à être à la fois intérieure et extérieure.

${ }^{98}$ KLEE, Paul, Théorie de l'art modern, Paris, Denoël-Gonthier, 1980, p. 34.

99 TOURNIER, Michel, Le Crépuscule des masques : photos et photographes, Paris, Hoëbeke, 1992, p. 148.

100 TOURNIER, Michel, Vendredi ou les limbes du Pacifique, Paris, Gallimard, collection Folio plus $\mathrm{n}^{\circ} 12,1967$, p. 149.

${ }^{101}$ Voir l'image : http://www.melaniewiora.de/e/eye1_10.htm (consulté le : 29/07/2009).

${ }^{102}$ Nous reviendrons à ce thème d'image/surface dans le chapitre sur Denis Roche à la page 376. 
Cependant l'identité ou le «moi »se forme tout autant par l'identité psychique (conscient et inconscient) que par l'identité sociale, et elles sont soumises tout comme le corps biologique aux changements, demandant une réappropriation et une réidentification constante au cours de notre vie. La photographie, en tant qu'acte que l'on peut toujours et facilement recommencer, peut favoriser le processus de réappropriation, dans la mesure où l'on peut faire ultérieurement le choix de ce que l'on retient. Comme le note Serge Tisseron : avec la photographie «nous ne sommes plus réductibles à aucune image qui nous représente parce que nous n'avons plus une image, mais plusieurs ${ }^{103} »$. Plusieurs photographes utilisent d'ailleurs la photographie comme moyen thérapeutique pour réconcilier les gens avec leur image ${ }^{104}$.

C'est le cas par exemple de Michel Séméniako qui a réalisé plusieurs séries «négociées » avec les gens portraiturés (voir les images ci-dessous ${ }^{105}$ ). Le travail est préparé ensemble et il demande de la part du client une réflexion sur sa propre identité : qu'aime-t-il, que veut-il montrer de lui-même?

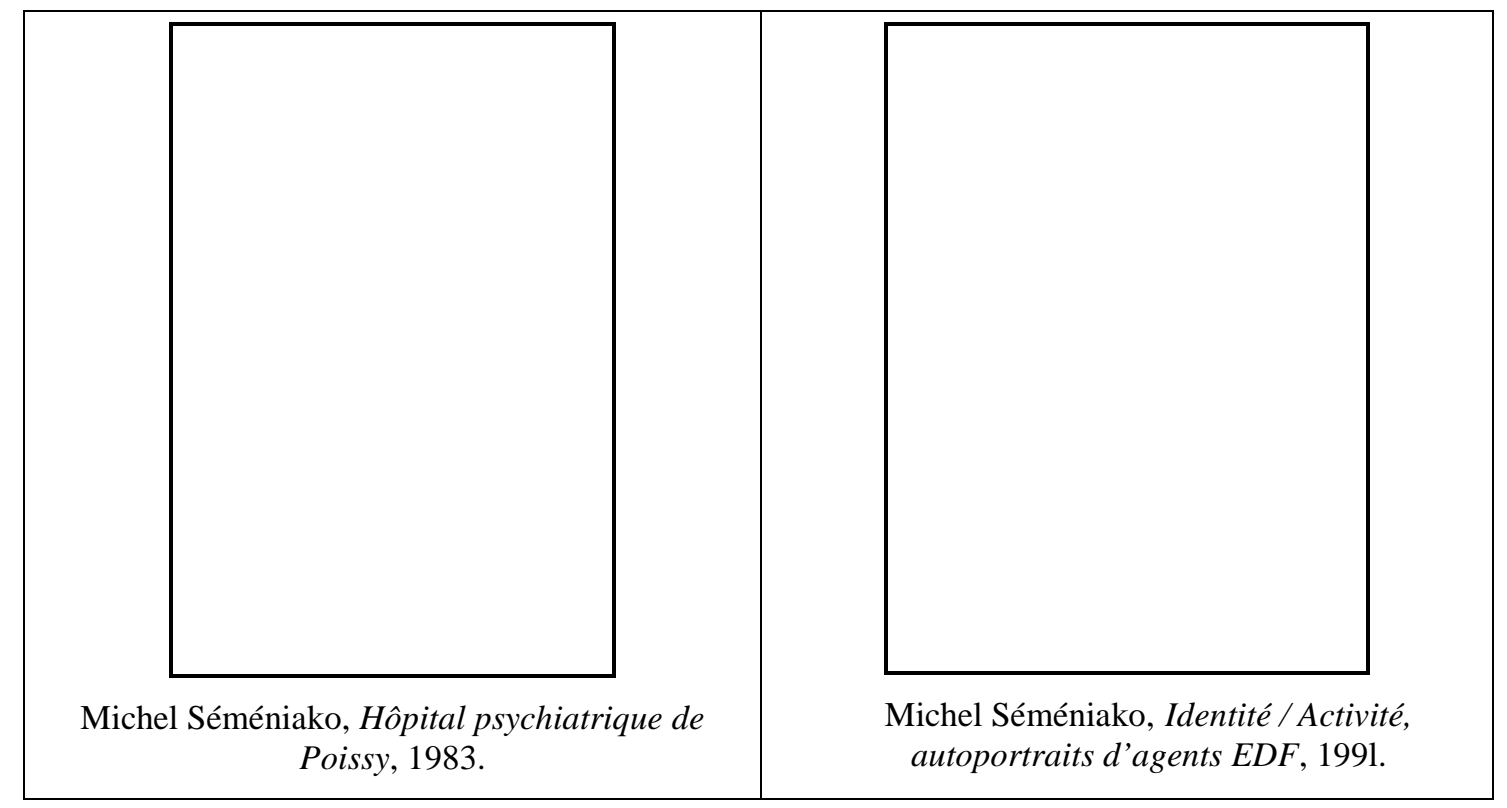

L'objectif est de construire une image dans laquelle les gens se reconnaissent et se revalorisent par la réflexion que demande la conception de l'image. Ce travail

\footnotetext{
103 TISSERON, Serge, « Désir de jumeau, angoisse du double », in L'ère du double, sous la dir. de Patrick Roegiers, Paris, Marval, 1998, p. 95.

104 Voir notamment le travail des photographes Patrick Wecksteen et Gérard Machot http://phototherapie.fr/ ou le site anglais consacré à la photo-thérapie (consulté le : 31/07/2009) : http://www.phototherapy-centre.com/home.htm.

${ }^{105}$ Les images sont disponibles sur le site du photographe (consulté le : 31/07/2009) : http://www.michelsemeniako.com/gal 5.html.
} 
identitaire peut passer par la mise en scène d'objets personnels, telle la série menée à bien à l'hôpital psychiatrique de Poissy. Ces images dissimulent des histoires intimement liées à la personne. Dans le cas des autoportraits négociés avec des agents EDF, chacun devait se représenter avec des outils familiers de son environnement de travail. La photographie finale est une photographie construite, un photomontage à l'aide de Photoshop. Les phases de négociation et de réflexion sur soi sont tout aussi importantes que le plaisir de créer. Le fait de travailler avec des groupes en consacrant du temps individuellement à chaque personne, même s'il s'agit d'un travail personnel, consolide le groupe.

D'autres travaux de Michel Séméniako s'inspirent d'une expérience vécue, et s'apparentent ainsi à une œuvre autobiographique, même s'il s'agit d'une reconstitution à l'aide d'acteurs. C'est le cas de la série Exil ${ }^{106}$, qui rend compte d'une expérience personnelle mais qui la dépasse pour devenir celle de tous les exilés, en se faisant la transcription du sentiment de la fuite. Les prises de vues sont faites à l'aide d'un matériel militaire qui permet de capter et fixer les émissions infrarouges, la chaleur des corps pendant la nuit et la traversée de lieux abandonnés. La série se divise en trois chapitres : La fuite, L'errance, Demain tout va changer..., dont le message est renforcé par le choix des couleurs qui se succèdent : vert, bleu, rouge.

L'histoire personnelle peut dépasser l'individu, et d'ailleurs l'un des objectifs de l'écriture autobiographique, comme le note Bruno Blanckeman, est de réaliser un objet d'identification possible pour autrui ${ }^{107}$. Selon l'approche du sociologue Norbert Elias, l'intériorité n'est en définitive que du social incorporé ce qui conduit également à désamorcer la dialectique intériorité/extériorité. Selon lui, le lien entre l'individu et la société s'inscrit dans un rapport récursif : «la société produit des individus qui produisent la société ${ }^{108} \gg$. Il pense l'individu comme un être autonome et déterminé, qui est le produit et le producteur de la société, irréductiblement singulier et pourtant semblable à tous les autres. Les travaux de certains photographes vont dans ce sens.

\footnotetext{
106 SEMENIAKO, Michel, Exil, textes de Louise L. Lambrichs, Paris, Éd. Trans Photographic Press, 2004. Voir quelques images sur le site personnel du photographe (consulté le : 13/07/2009) : http://www.michel-semeniako.com/gal_3.html

107 A. Mura-Brunel \& F. Schuerewegen (éds.), L'Extime/L'Intime, CRIN (Cahiers de Recherches des Instituts Néerlandais de Langue et Littérature Française), 41, Amsterdam - New York, 2002. Voir le résumé sur Fabula : http://www.fabula.org/actualites/article3683.php (consulté le : 13/07/2009).

${ }^{108}$ Cité par Vincent de Gaulejac, «L'ego Sociologicus », Cahiers internationaux de sociologie, $\mathrm{n}^{\circ} 113$, 2002. Disponible sur Cairn: http://www.cairn.info/revue-cahiers-internationaux-de-sociologie-2002-2page-347.htm (consulté le : 18/07/2009). Voir également : http://fr.wikipedia.org/wiki/Norbert Elias
} 
Ainsi les clichés de Martin Parr, qui à l'aide de son humour anglais très singulier met en scène des comportements humains communs. Il s'intéresse entre autres aux habitudes d'utilisation des appareils photographiques. Les photos souvenirs qui devraient assurer l'histoire personnelle de chaque individu, dévoilent une utilisation extrêmement codée comme le démontre déjà Pierre Bourdieu dans son analyse sociologique de la photographie ${ }^{109}$.

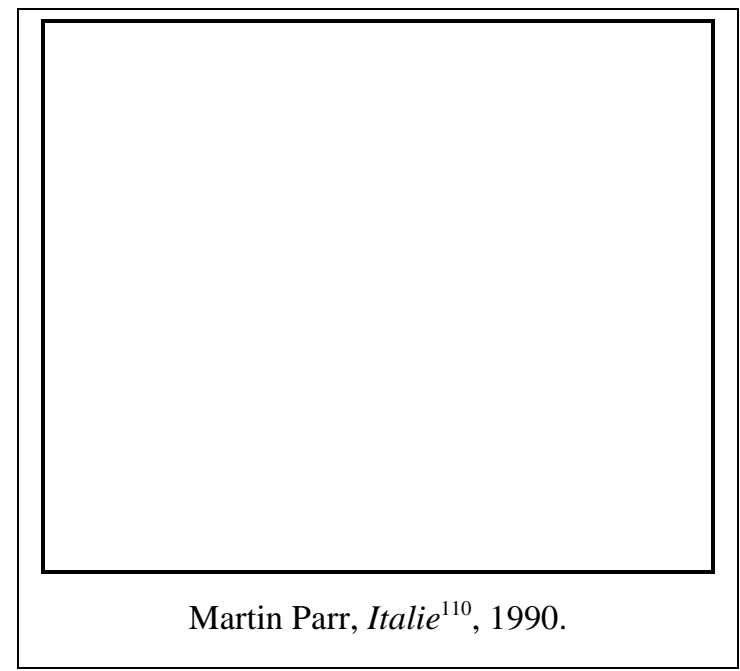

Ainsi l'image ci-contre montre comment plusieurs gens jouent en même temps à prendre une photo comme s'ils tenaient la tour de Pise. Autre motif récurrent dans le travail de Matin Parr, les habitudes alimentaires : par exemple des clichés de gens se goinfrant d'un gros sandwich tout en téléphonant, ou des mangeurs de glaces qui luttent avec la crème qui fond de tous les côtés. Une autre série de Martin Parr intitulée Signes $d u$ Temps $^{111}$ pourrait illustrer sous un angle ironique les propos de Gaston Bachelard dans La poétique de l'espace ${ }^{112}$. Dans ce texte, Bachelard recherche le sens de la «maison », la «coquille initiale » : en quoi reflète-t-elle notre vie intérieure, comment vient-elle habiter nos souvenirs et peupler notre imaginaire ? Mais aussi de quelle manière tout espace habité sincèrement tient-il lieu de «maison » pour nous, comment le dehors et le dedans s'imbriquent-ils par l'investissement d'un lieu ? La série intitulée Signes du Temps, fut réalisée sur le tournage du documentaire de Nicholas Barker pour la chaîne BBC. Cette série télévisée du même nom que l'œuvre de Parr consistait en une enquête sur les goûts de la classe moyenne britannique. Les personnes sélectionnées parlaient chez elles de leurs propres goûts. Le livre que Martin

\footnotetext{
${ }^{109}$ BOURDIEU, P. ; BOLTANSKI, L. CASTEL, R. ; CHAMBOREDON, J.-C., Un art moyen, essai sur les usages sociaux de la photographie, Paris, Minuit, col. "Le sens commun", 1965. Les images analysées dans le livre de Bourdieu sont disponibles sur Flicrk: http://www.flickr.com/photos/gunthert/sets/72157615403627432/detail/ (consulté le : 17/07/2009).

${ }^{110}$ PARR, Martin, Small world, London, Dewi Lewis Publishing, 1995. Voir sur le site de Magnum : http://www.magnumphotos.com/Archive/C.aspx?VP3=ViewBox\&ALID=29YL53G7RT3\&IT=ThumbIm age01_VForm\&CT=Album (consulté le : 17/07/2009).

${ }_{111}$ PARR, Martin, Signs of the Times, Manchester, Cornerhouse, 1992. Voir sur le site de Magnum : http://www.magnumphotos.com/Archive/c.aspx?VP=XSpecific_MAG.BookDetail_VPage\&pid=29YL53 GUDGH.

${ }^{112}$ BACHELARD, Gaston, La poétique de l'espace, Paris, PUF, (1957) 1998.
} 
Parr sortit suite à cette expérience rapproche les photos ${ }^{113}$ qu'il a réalisées des personnes dans leur maison et des détails de la décoration, ainsi qu'un extrait significatif de la conversation révélant leurs goûts.

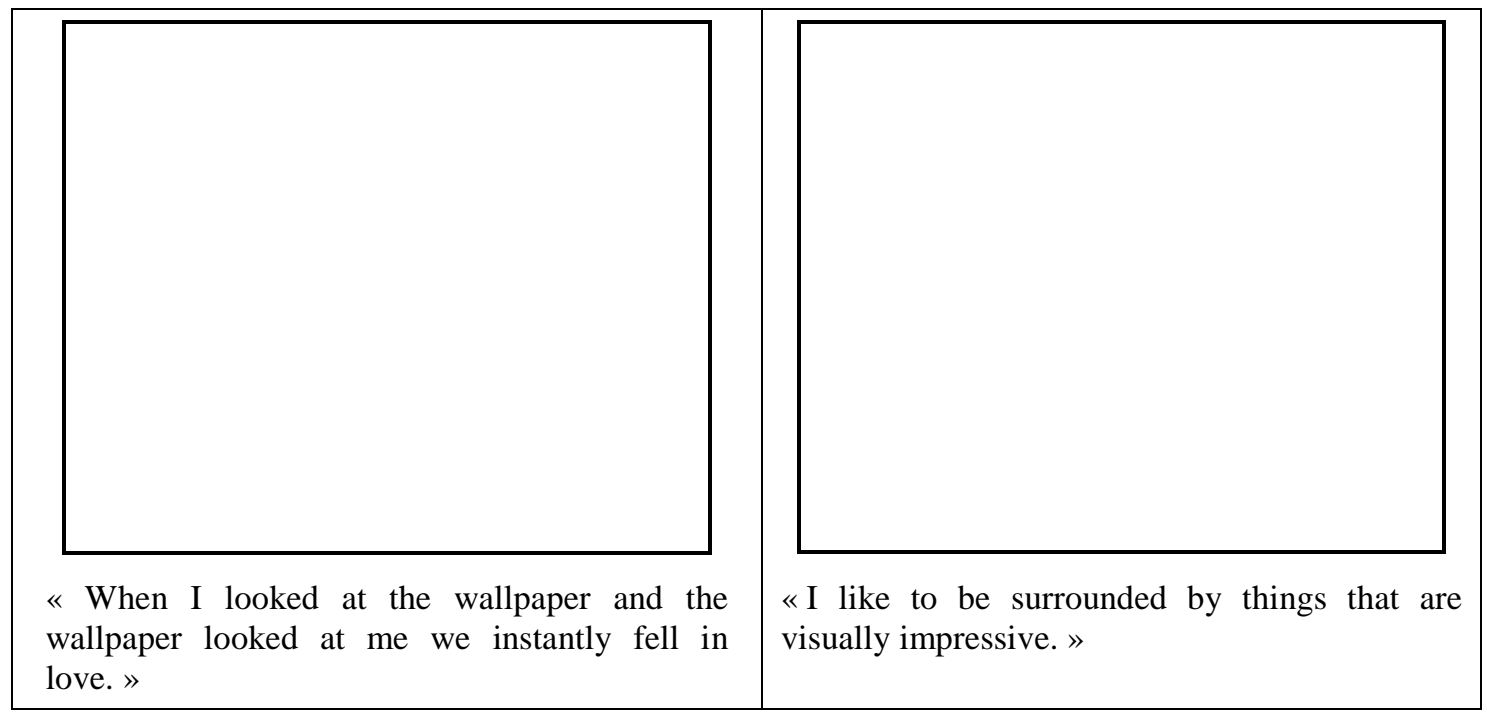

Le choix des textes et la présentation concentrée au sein d'un même livre de ces lieux habités confèrent aux images ce ton humoristique propre au photographe.

On ne retrouve pas ce ton particulier dans le travail de Joachim Schmidt, qui révèle pourtant lui aussi des habitudes liées à l'utilisation de la photographie. Schmidt cherche notamment sur le programme Flickr, un programme d'échange d'image sur Internet, des images faites par des amateurs, qui sans se connaître, aux quatre coins du monde produisent des images semblables (voir cicontre). En juxtaposant des prises de vue similaires, Schmidt tente de dresser un inventaire du langage contemporain Joachim Schmidt, Reloaded, 2008. commun de la photographie ${ }^{114}$.

${ }^{113}$ Voir la série sur le site de magnum, d'où proviennent les photos : http://www.magnumphotos.com/Archive/c.aspx? VP=XSpecific MAG.BookDetail VPage\&pid=29YL53 $\underline{\text { GUDGH }}$ 
Le projet de Joachim Schmidt fait écho à l'ADaM Project ${ }^{115}$ lancé par Timothée Rolin, invitant, à la suite de sa propre pratique d'autoarchivage par la photographie numérique, des personnes volontaires à partager leur vie en images, selon des contraintes clairement définies ${ }^{116}$. La juxtaposition de ces archives met également à jour un langage commun de la photographie, elle rend compte des habitudes sociales mais, selon les mots de Rolin participe aussi « à la représentation d'un modeste morceau de réalité ». Toutefois, les œuvres mentionnées dans ce sous-chapitre «La dissolution du clivage entre l'extériorité et l'intériorité » ne nient pas en cela la subjectivité de l'individu, mais soulignent plutôt le caractère multiple du «moi », et la complexité de la construction de l'identité.

Si l'histoire de la photographie et de ses théories démontre la remise en cause de la valeur de vérité de l'image, l'utilisation populaire du médium révèle que l'identité est pensée à l'image de la technologie comme multiple et dynamique. Le modèle des arts plastiques montre à son tour, comment la photographie amateur devient matière artistique et participe au questionnement de la vérité de l'image et des récits de vie. Par contre, si les photographes doutent aussi de la valeur objective des clichés, leur position est quelque peu différente, car ils sont non seulement les utilisateurs passifs des images, mais les créateurs d'images et créateurs de leur propre identité par les images. En fusionnant avec l'appareil, leurs images se confondent avec leur vie en faisant disparaître la séparation entre l'intériorité et l'extériorité, ce qui démontre encore une fois à quel point l'identité est complexe. Les modèles que nous venons de retracer à l'aide de quelques exemples ont à leur tour un impacte sur le modèle littéraire et photolittéraire.

\footnotetext{
${ }^{114}$ Voir la série sur le site de l'auteur : http://schmid.wordpress.com/works/2008-reload/ (consulté le : 03/08/2009).

${ }^{115} \mathrm{http}: / /$ www.adamproject.net/ (consulté le : 03/08/2009).

${ }^{116}$ Il s'agit des contraintes suivantes : 1 . se prendre en photo au lever du lit; 2 . prendre en photo une vue du lieu où l'on a dormi depuis la fenêtre ; 3 . prendre en photo tout être vivant et les interactions avec ce dernier ; 4. prendre en photo tout acte d'écriture manuscrite ; 5 . prendre en photo tout objet avec lequel il y a interaction ; 6. prendre en photo chaque lieu visité ; 7. se prendre en photo dans chaque lieu visité ; 8. prendre en photo tout événement inhabituel ; 9. prendre le plus de photos possible; 10 . ne pas faire de photo esthétisante; 11 . une tierce personne peut prendre des photos (voir la description du projet: http://www.adamproject.net/fr/concept/ (consulté le : 03/08/2009).
} 


\section{III.4. Le modèle littéraire}

Paul Ricœur propose de dépasser grâce à la «narration » la distinction entre une conscience de soi basée sur l'identité (au sens d'«identique ») et un modèle dynamique de soi, modèle qui depuis l'avènement du numérique et d'Internet, comme on l'a vu, est désormais insurpassable. Dans Temps et Récits, Ricœur écrit :

Sans le secours de la narration, le problème de l'identité personnelle est en effet voué à une antinomie sans solution [...]. Le dilemme disparaît si, à l'identité comprise au sens d'un même (idem), on substitue l'identité comprise au sens d'un soi-même (ipse) ; la différence entre idem et ipse n'est autre que la différence entre une identité substantielle ou formelle et l'identité narrative. ${ }^{1}$

Le caractère indiciel de la photographie (sa qualité de preuve et d'attestation) serait alors lié à l'idem, tandis que l'ipséité intègrerait par la narrativité le temps et le devenir (à l'image du dispositif qui implique aussi le devenir d'une œuvre).

L'utilisation d'éléments hétérogènes dans les écrits autobiographiques au cours de la deuxième moitié du $\mathrm{XX}^{\mathrm{e}}$ siècle démontre que l'ipséité n'a pas nécessairement besoin d'une manifestation verbale pour se produire, elle peut tout aussi bien être implicite et comprendre des éléments non verbaux, comme des images ou des sensations. Il importe donc de comprendre la narrativité dont parle Ricoeur au sens large, comme la narration filmique qui peut produire un sens par une suite discontinue d'images sans paroles et sans texte.

La déconstruction de la valeur de vérité absolue des photographies s'est opérée, entre autres, grâce à l'interaction des textes juxtaposés aux images ; en retour la valeur de vérité de l'écriture sera remise en cause, notamment dans les écrits autobiographiques. Il s'agit cependant d'une influence inconsciente de l'un sur l'autre comme le suggère Jean-Pierre Montier :

Aussi bien [...] est-il possible que l'évolution sémantique qui a fait passer de la catégorie traditionnelle d' «autobiographie » à la notion d' «autofiction », soit, subrepticement, davantage qu'une réaction aux thèses et aux œuvres de «l'ère du soupçon », un effet secondaire et souterrain de la photographie sur nos modèles mimétiques, nos schèmes de représentation. ${ }^{2}$

Tout comme la photographie dont le rapport avec la réalité est mise en question au cours de la deuxième moitié $\mathrm{du} \mathrm{XX}^{\mathrm{e}}$ siècle, les récits de vie sont considérés comme une

\footnotetext{
${ }^{1}$ RICOEUR, Paul, Temps et Récits, « Le Temps raconté », t. 3. Paris, Seuil 1985, p. 355.

${ }^{2}$ MONTIER, Jean-Pierre, «Traces de soi en régime totalitaire: Josef Koudelka », in Traces photographiques, traces autobiographiques, Op. cit., p. 121.
} 
autofiction, car ils impliquent nécessairement une sélection à partir d'une opinion ou d'un point de vue qui peut changer avec le temps, comme nous l'avons évoqué à propos des albums photos de famille. En plus de cela, l'identité ne se construit pas uniquement à partir d'événements réels, mais l'imagination et la fiction contribuent à titre égal à sa formation. En revanche la fiction peut être également considérée comme contenant nécessairement une part autobiographique, car l'imagination constitue une part importante de l'identité, comme le remarque Heidi Peeters ${ }^{3}$. Pour illustrer son propos, Heidi fait le rapprochement avec la théorie du simulacre de Jean Baudrillard ${ }^{4}$. Ce dernier explique l'évolution du rapport à l'idole et au simulacre.

Dans la première période qu'il définit, l'idole est prise pour la vraie image de Dieu, on l'adore comme si elle était la divinité elle-même. Elle est un signe iconique de son apparence et de son existence. L'image est alors « le reflet d'une réalité profonde ${ }^{5} »$. Dans la seconde phase, le caractère divin de l'idole et la croyance en la véracité de la représentation de Dieu sont remis en cause, ce qui entraîne un mouvement iconoclaste et destructeur. L'image «masque et dénature [alors] une réalité profonde ${ }^{6} »$. À la troisième étape, le doute ne concerne plus seulement la véracité de la représentation de Dieu, mais il s'agit également de savoir si l'idole représente quelque chose. Il est possible que Dieu n'existe pas et que l'idole ne soit là que pour masquer sa nonexistence. Dans un esprit iconoclaste, on détruirait alors l'image pour démontrer qu'elle n'est qu'une simulation. En fin de compte, dans une dernière phase post-iconoclaste, l'idole ne représente plus rien d'autre qu'elle-même, mais cela n'empêche pas de ressentir le besoin de l'adorer, et alors l'idole deviendrait Dieu. L'image est alors « sans rapport à quelque réalité que ce soit : elle est son propre simulacre pur ${ }^{7} \gg$.

\footnotetext{
${ }^{3}$ PEETERS, Heidi. «The Networked Self : Autofiction on MySpace. » (Le «je » du réseau : autofiction sur Myspace), Image [\&] Narrative [journal électronique], ${ }^{\circ} 19$ (2007).

Disponible sur : http://www.imageandnarrative.be/autofiction/peeters.htm (consulté le : 30/05/2009).

${ }^{4}$ Ibid. La description de Heidi Peeters se base sur le livre anglais «Selected writings" de Jean Baudrillard (Stanford, Stanford Univerity Press, 2001), voir aussi les pages de Wikipedia (consulté le : 30/05/2009) sur Baudrillard : http://fr.wikipedia.org/wiki/Jean_Baudrillard\#.C5.92uvres (en français) et http://en.wikipedia.org/wiki/Simulacra_and_Simulation (en anglais).

${ }^{5}$ BAUDRILLARD, Jean, Simulacres et simulations, Paris, Galilée, 1981, p. 17.

${ }^{6} \mathrm{Ibid}$.

${ }^{7}$ Ibid.
} 
Selon Peeters ${ }^{8}$, il est possible de tracer un parallèle entre cette évolution du rapport à l'icône et celle de la croyance en la véracité des récits autobiographiques. Dans une première phase, le lecteur croirait en une équivalence associant l'auteur (le niveau extradiégétique), le narrateur et le personnage du roman (le niveau intradiégétique), donc en l'identité d'une construction verbale infra-médiatique et son référent extra-médiatique ${ }^{9}$. Le pacte autobiographique tel que Philippe Lejeune ${ }^{10}$ le définit dans sa première version de 1975, comme nous l'avons déjà évoqué, décrit l'existence d'un contrat entre le lecteur et l'auteur et l'engagement de ce dernier à dire la vérité, et correspondrait donc à cette première phase. Les récits autobiographiques de la fin du $\mathrm{XX}^{\mathrm{e}}$ siècle mettent en doute cette équivalence et on voit émerger le genre de l'autofiction. Dans ce dernier, le lecteur est mis en garde sur le fait que le récit relaté contient une partie fictive élaborée par l'imagination de l'auteur, et/ou qu'il emprunte des techniques narratives inspirées par la fiction ${ }^{11}$. Le lecteur est donc averti (par les allégations péritextuelles - titre, quatrième de couverture...) que le récit ne coïncide pas forcément avec la vie de l'auteur. La fiction masquerait comme dans la deuxième phase de l'image, la réalité profonde. Dans la troisième phase, le lecteur peut remettre en cause le lien entre le narrateur de l'autofiction et l'auteur extra-médiatique. Le nom même de l'auteur qui figure sur la couverture se vide de sens, ne désigne plus que l'auteur, et non l'entité extra-médiatique auquel il fait référence ${ }^{12}$. Dans un quatrième temps, le lecteur ne se soucierait plus de savoir si l'auteur renvoie ou non à une entité extra-médiatique pour pouvoir jouir du plaisir du texte et il prendrait alors le narrateur

\footnotetext{
${ }^{8}$ Peeters applique le schéma de Baudrillard sur la notion d'autofiction en ne prenant pas en compte l'émergence de cette notion à la fin du $X^{\mathrm{e}}$ siècle, au même moment où la vérité de la photographie est aussi remise en cause. Nous appliquons plutôt ce schéma à l'autobiographie dont la possibilité de rendre compte du réel et de l'identité de l'auteur est questionnée également dans les œuvres photo-littéraires.

${ }^{9}$ Nous faisons ici la différence entre le narrateur extradiégétique, qui correspond à l'auteur désigné par le nom sur la couverture (une identité qui passe encore par le médium) et la personne réelle dans sa complexité de l'être, entité extra-médiatique, qui ne peut pas être réduite à l'identité d'écrivain.

${ }^{10}$ LEJEUNE, Philippe, Le Pacte autobiographique, Paris, Seuil, 1975. Voir aussi sur le site de Philippe Lejeune : http://www.autopacte.org/pacte_autobiographique.html (consulté le : 18/07/2009).

${ }^{11}$ Il existe en effet plusieurs définitions du terme « autofiction » introduit par Serge Doubrovsky dans son roman Fils (1977), ce qui rend le genre problématique ou selon les expressions respectives de Michel Contat, Marie Darrieussecq et Jacques Lecarme «litigieux », «pas sérieux », ou « mauvais genre ». Ce sens multiple et flou de l'autofiction rappelle l'usage varié du terme « dispositif », mais nous l'appliquons ici dans la mesure où il reflète justement dans son emploi divers le caractère problématique et la complexité de l'identité. Pour les différentes définitions de l'autofiction voir : http://www.autofiction.org et la page «autofiction» de Wikipedia: http://fr.wikipedia.org/wiki/Autofiction (consulté le : $13 / 07 / 2009)$.

${ }^{12}$ Le texte «La mort de l'auteur » de Roland Barthes de 1968 décrit ce rapport de non correspondance entre l'auteur extra-médiatique et l'auteur infra-médiatique (repris dans : Le bruissement de la langue, Paris, Seuil, 1984, p. 61-67.)
} 
intradiégétique pour le vrai auteur. Une équivalence se crée alors entre l'auteur et le narrateur, même si c'est au second degré, car c'est tout autant l'auteur qui fait l'œuvre que l'œuvre qui fait l'auteur, les deux se trouvant dans une interdépendance, même s'il s'agit d'une œuvre de fiction. Cette évolution serait donc en rapport avec l'utilisation de la photographie dans la littérature.

La photographie, par son rapport ambigu avec la réalité, intervient avant tout comme schème dans la littérature et son utilisation ainsi que son intégration ont été longtemps freinées à cause de son caractère populaire, «d'art-moyen ». C'est ce que remarque Jacques Lecarme dans son livre intitulé L'autobiographie :

Au XIX ${ }^{\mathrm{e}}$ siècle, comme au nôtre, il s'attache au livre illustré quelque chose de primaire, de populaire ou de pédagogique. [...] La présence ou l'abondance d'image est en proportion inverse du niveau de l'œuvre dans la hiérarchie littéraire. ${ }^{13}$

Il ajoute alors que les mémoires pouvaient faire exception, car on y trouve plus souvent le portrait de l'écrivain, sous forme de gravure jusqu' au $\mathrm{XIX}^{\mathrm{e}}$ siècle, puis sous forme de photographie :

Les mémoires s'ouvrent parfois sur le portrait de l'écrivain, et se déroule sans rien de visuel. Ce portrait initial joue le rôle d'un embrayage automatique du récit de vie référentiel. Au XXe siècle, l'édition originale de l'autobiographie est presque toujours vierge d'image; en revanche, quand on passe dans l'édition moins coûteuse, mais réputée moins noble du livre de poche, il y a presque toujours, sur la couverture, une photo du protagoniste au moment des faits évoqués. ${ }^{14}$

La photo insérée permet de renforcer l'identification du texte comme biographique ou autobiographique. Selon Lecarme, au tournant du XXI ${ }^{\mathrm{e}}$ siècle, en opposition avec la hiérarchie littéraire qui refusait l'utilisation de l'image, nous sommes dans une période d'excès du portrait photographique :

Il était réservé à notre époque d'imposer l'image photographique de l'auteur à tel point que s'il est dépourvu de «visibilité », il est dépourvu d'existence : il faut se faire une image et non seulement un nom. ${ }^{15}$

Ou pourrait-on ajouter, il faut non seulement une image, mais une présence sur Internet.

Si l'utilisation de la photographie dans la littérature a été freinée par son statut d'art moyen, de nos jours elle est freinée par la loi sur la reproduction des œuvres et des droits d'auteur ${ }^{16}$. Le statut «d'art moyen » de la photographie a eu pour conséquence

${ }^{13}$ LECARME Jacques, LECARME-TABONE, Éliance, L'autobiographie, Paris, Armand Colin, 1997, rééd. 2004, p. 255.

${ }^{14}$ Ibid.

${ }^{15} \mathrm{Ibid}$.

${ }^{16}$ Voir sur la loi Hadopi : http://www.laquadrature.net/ (consulté le : 13/07/2009). 
une revalorisation tardive des photographies de certains écrivains ${ }^{17}$, montrant le rapport qui se tisse inconsciemment avec l'œuvre. Ainsi les photographies de Claude Simon ${ }^{18}$ ont été exposées seulement vers la fin de sa vie en 1992. Il se considère d'ailleurs luimême comme un photographe amateur, mais à la fin du $\mathrm{XX}^{\mathrm{e}}$ siècle, comme on l'a vu, cela n'a plus une valeur péjorative. Irène Albers montre pourtant que la photographie sous-tend son œuvre, car elle devient la métaphore de la perception et du souvenir en influençant son style d'écriture; dans plusieurs de ses livres sont évoquées implicitement ou explicitement des photographies ou des cartes postales réelles. La publication des photos de l'auteur alimente alors l'imaginaire du lecteur, elle ouvre une piste de jeu où le lecteur doit utiliser sa sensibilité, sa mémoire visuelle pour retracer les liens avec l'œuvre.

La photographie est utilisée comme métaphore du souvenir par plusieurs écrivains, même s'ils ne pratiquent pas eux-mêmes la photographie. Les albums photos, comme nous l'avons déjà développé, offrent un récit discontinu, fragmentaire et lacunaire, ce qui semble aller de pair avec la prise de conscience du fait que la remémoration fonctionne de la même manière, se déclenchant involontairement, sans ordre apparent, toujours fragmentaire et discontinue. Nous retrouvons cette métaphore, entre autres, chez Marcel Proust ${ }^{19}$, Jacques Roubaud ${ }^{20}$ ou Jean-Loup Trassard ${ }^{21}$.

\footnotetext{
${ }^{17}$ Il en va ainsi des photos de Claude Simon (1913-2005) : sa première exposition fut organisée en 1992 ; de Georges Simenon (1903-1989) : la première rétrospective fut organisée 1999; ou de Nicolas Bouvier (1929-1998) : sa première exposition a lieu en 1995, voir la liste sur un site consacré à son œuvre : http://www.peregrin-genevois.net/1bouvier/expobouvier.html (consulté le : 13/07/2009).

${ }^{18}$ Une première exposition lui est consacrée à la Galerie Maeght, à Paris en 1992 au mois de mars, puis une deuxième exposition a lieu la même année en avril à Toulouse à la Galerie municipale du Château d'Eau. Voir le catalogue : Claude Simon, Photographie 1937-1970 (avec une préface de Denis Roche), Paris, Maeght, 1992. Sur les liens entre l'œuvre de Claude Simon et la photographie voir: CALLEGRUBER, Mireille, Claude Simon, chemins de la mémoire, Grenoble, PUG, 1993 ; ALBERS, Irene, Claude Simon, Moments photographiques, Villeneuve d'Asq, Presses Universitaire de Septentrion, 2007. Disponible partiellement sur Google books :

$\underline{\mathrm{http}} / / /$ books.google.com/books?id=qOKOvWozKGgC\&printsec=frontcover $\& \mathrm{hl}=\mathrm{fr} \# \mathrm{v}=$ onepage $\& \mathrm{q}=\& \mathrm{f}=\mathrm{fa}$ lse (consulté le 03/09/2009).

${ }^{19}$ Voir à ce sujet : MONTIER, Jean-Pierre, La photographie « ... dans le Temps. » De Proust à Barthes et réciproquement. Mis en ligne le 20 avril 2003. http://pierre.campion2.free.fr/montier_proustbarthes.htm (consulté le : 01/08/2009).

${ }^{20}$ Voir à ce sujet: PUFF, Jean-François, «L'écriture photographique de Quelque chose noir », Les Cahiers de La Licorne, Les Cahiers Roubaud, Cahiers $n^{\circ} 1,2007$. Disponible en ligne : http://edel.univpoitiers.fr/licorne/document.php?id=3956 (consulté le : 01/08/2009).

${ }^{21}$ Voir le chapitre sur l'œuvre de Jean-Loup Trassard à la page 229.
} 
Comme le note Philippe Ortel $^{22}$, la photographie est déjà présente dans la littérature au $\mathrm{XIX}^{\mathrm{e}}$ siècle en tant que schème, en tant qu'idée d'un procédé mimétique réaliste, mais ce qui change à partir du $\mathrm{XX}^{\mathrm{e}}$ siècle c'est qu'elle est juxtaposée au texte dans les œuvres et devient un élément narratif actif.

Sylvie Jopeck, dans son anthologie, intitulée La photographie et l'(auto)biographie ${ }^{23}$, analyse à travers de courts extraits (avant tout littéraires) le rôle du dispositif dans les récits d'enfance, dans les biographies ${ }^{24}$ et dans l'œuvre de quelques photographes. Elle montre dans son analyse que dans la plupart des cas, la photographie se charge de plusieurs rôles et fonctions dans la narration (à caractère autobiographique) indépendamment du fait si la photographie est intégrée ou non. Sylvie Jopeck distingue ainsi quatre fonction : se remémorer le passé ; réactiver le pacte autobiographique grâce à sa valeur documentaire; fixer l'image de soi au présent (aspect démonstratif) ; et interroger l'identité (objectif connotatif) ${ }^{25}$. Ces fonctions peuvent se combiner dans les œuvres.

Aussi Sylvie Jopeck constate-t-elle que les photos d'enfance sont celles qui sont les plus souvent convoquées dans les récits autobiographiques. Elles sont intrigantes parce qu'elles obligent rétrospectivement à retrouver le rapport avec ce moi enfant dont témoigne la photo, exhumant des «moi » anciens, méconnaissables, voire oubliés. Les photos d'enfance fonctionnent comme une identité dédoublée - un double qui peut engendrer un dialogue, mettre en place une relation critique et distanciée ou à l'inverse une bonne relation émue et proche ${ }^{26}$.

Parallèlement, la description des photos des autres et même la description des objets personnels peuvent également fonctionner comme double ou révélateur de

\footnotetext{
${ }^{22}$ ORTEL, Philippe, La littérature ía l'ère de la photographie. Enquête sur une révolution invisible, Nîmes, Edition Jacqueline Chambon, 2002.

${ }^{23}$ JOPECK, Sylvie, La photographie et l'(auto)biographie, Anthologie et lecture accompagnée, Paris, Gallimard, 2004. Le livre a pour but de construire un outil pédagogique pour les enseignants du lycée et collège, mais ses analyses restent une bonne base pour aborder ce sujet.

${ }^{24}$ Les biographies illustrées par des photographies entrent dans le champ de réflexion, mais Sylvie Jopeck ne fait que brièvement allusion aux dispositifs hétérogènes qui questionnent l'identité, comme l'œuvre de Sophie Calle.

${ }^{25}$ JOPECK, Sylvie, Op. cit., p. 41.

${ }^{26}$ Ibid., p. 44. Sylvie Jopeck cite des œuvres des écrivains tels qu'André Gide ; Si le grain ne meurt, 1924 ; Simone de Beauvoir, Mémoires d'une jeune fille rangée, 1958 ; Jean-Paul Sartre, Les Mots, 1964 ; Georges Perec ; W ou le souvenir d'enfance, 1975 ; Marguerite Duras, L'amant, 1984 ; Annie Ernaux, La Place, 1983 ; La Honte, 1997 ; ou Anny Duperey, Le voile noir, 1992. Mais cette liste reste sommaire, et analyser les différents rapports que les écrivains ont avec leurs photos d'enfance pourrait faire l'objet d'une thèse à part entière.
} 
l'identité. Selon Sylvie Jopeck, commenter les photos des autres c'est aussi se comparer à d'autres. Ainsi les photos des proches, les photos de la famille sont utilisées pour comprendre le lien, la filiation qui les unit à l'écrivain ${ }^{27}$. Il est sans doute plus facile de parler de ses proches et des autres ${ }^{28}$ que de soi-même, ce qui explique selon Jopeck qu'il y a plus de biographies qui ont recours aux photos que d'autobiographies. On pourrait tout autant encore une fois faire le lien avec le stade du miroir où la construction de l'identité passe par le regard de l'Autre, ce qui justifie également l'emboîtement de l'intime et de l'extime ${ }^{29}$. La description d'objets anodins, de choses quotidiennes peuvent tout aussi bien être révélatrice de la personnalité de son propriétaire, tout en étant les témoins de souvenirs liés aux objets ${ }^{30}$. Un double mouvement est lié à ces autobiographies, biographies ou descriptions d'objets personnels, notamment parce qu'elles demandent un travail «d'archéologie », d'enquête pour faire remonter une histoire familiale, l'histoire d'une vie, mais en même temps l'écriture sert à archiver et conserver la mémoire pour des générations futures ${ }^{31}$.

Dans le processus de remémoration, la photographie a une valeur avant tout pour l'auteur, et il se peut qu'il recoure alors simplement à sa description (sans la reproduire), comme le fait Roland Barthes dans La Chambre claire avec la photo de sa

\footnotetext{
${ }^{27}$ Elle cite à part les auteurs déjà mentionnés : Colette, Étoile Vesper, 1946 ; Albert Cohen, Le livre de ma mère, 1954 ; Marguerite Yourcenar, Souvenirs pieux, 1974 ; Louis Aragon, Le Mentir-Vrai, 1980 ; Hervé Guibert, L'image fantôme, 1981 ; Nina Berberova, C'est moi qui souligne, 1989 ; Anne Wiazemsky, Album de famille, 1992 ; Andreï Makine, Le testament français, 1995 ; Isabelle Allende, Portrait sépia, 2001.

${ }^{28}$ Parmi les biographies d'autres personnes Sylvie Jopeck mentionne le livre d'Emmanuel Carrère, L'adversaire (2000), qui raconte à partir de son album de famille la biographie de Jean-Claude Romand, qui a tué toute sa famille et puis a voulu se suicider. Les photos permettent à l'auteur de se projeter dans son personnage et d'essayer de le comprendre. Mais il faudrait encore ajouter les livres de Pierre Michon. ${ }^{29}$ Notons que le mot extime a été proposé par Michel Tournier dans son Journal extime, qui, en opposition avec le journal intime, rassemble des « découvertes, observations, anecdotes » réparties sur les douze mois de l'année, et est construit d'après le modèle du « livre de saison où les modestes hobereaux de jadis notaient les récoltes, les naissances, les mariages, les décès et les sautes de la météorologie ». (TOURNIER, Michel, Journal extime, Paris, La Musardine, 2002, p. 11). Tournier avoue que son but avec ce journal était de lutter contre l'intimité du genre, mais le choix des événements racontés révèle tout autant la personnalité de l'auteur.

${ }^{30}$ Sylvie Jopeck fait mention du livre de Georges Perec, Je me souviens, qui contient 480 micros souvenirs liés entre autres à des objets anodins, ainsi que le livre de Philippe Delerm, La Première Gorgée de bière et autres plaisirs minuscules, qui est composé de trente-cinq récits sur de petites choses. Sylvie Jopeck évoque également les photos de Sophie Calle et d'Alain Fleischer, mais nous pourrions ajouter les livres photo-littéraires de Jean-Loup Trassard (Objets de grande utilité, 1995) ou un ouvrage récent né d'une collaboration: Constance Villeroy, (photographe) et Gérard Prémiel, (écrivain), Petits trésors restés dehors, Paris, Factory Editions, 2005. (Voir un extrait de ce dernier sur le site de l'éditeur: http://www.linternaute.com/sortir/livre/beaux-livres/petits-tresors-restes-dehors/diaporama/1.shtml ainsi que sur le site de Constance Villeroy : http://www.constancevilleroy.com/ ; consulté le : 01/08/2009).

${ }^{31}$ JOPECK, Sylvie, La photographie et l'(auto)biographie, p. 90.
} 
mère. Comme il le précise, la photo de sa mère dans le jardin d'hiver ne peut avoir la même signification pour le lecteur que pour lui. Toutefois, la présence ou l'absence effective du cliché dans le corps du livre est significative, car la photo juxtaposée au texte permet aux écrivains de jouer sur la connivence avec le lecteur. Les photos mobilisent le regard et l'imaginaire scopique, elles prennent en compte l'envie et le plaisir du lecteur, elles convoquent son jugement, mais elles transforment en même temps le livre en un dispositif particulier.

En effet, les biographies et les autobiographies, en recourant à la photographie et plus particulièrement aux photos des albums de famille, deviennent fragmentaires dans leur forme, comme nous l'avons déjà mentionné.

L'évolution de l'autobiographie confirme cette attirance du genre pour la fragmentation, soit dans le traitement de la structure narrative en chapitres, soit dans la prise en compte de l'oubli ou de l'approximation du souvenir en interrompant le récit, soit dans le choix de formes spécifiques. ${ }^{32}$

Ainsi par exemple l'œuvre de Georges Perec se fait puzzle, récit à la forme mosaïque et éclatée du souvenir qui est consubstantielle à la photographie.

Dans la brièveté réside le fantasme de l'automatisme et de l'objectivité. Plus la forme autobiographique choisie est lapidaire, plus elle semble se rapprocher d'une saisie nette, rapide et précise de ce moment évoqué. Tout comme la figure rhétorique de «l'hypotypose », le but de la forme brève est de provoquer un effet de réel, de donner à voir au lecteur, de faire partager l'émotion. La juxtaposition des souvenirs sans liaison, comme une structure en parataxe, imite le fonctionnement de la remémoration. La brièveté de la forme et la juxtaposition libèrent l'autobiographie du poids de la contrainte du récit rétrospectif. C'est aussi pourquoi ce genre a pu être apparenté avec la forme poétique selon Sylvie Jopeck. Chaque poème d'un recueil peut être considéré comme des fragments d'une autobiographie en morceaux ${ }^{33}$. Cette fragmentation et cette brièveté évoquent également la forme poétique des haïkus ${ }^{34}$.

Selon Magali Nachtergael, Nadja d'André Breton ${ }^{35}$ serait la première autobiographie moderne, élaborant un dispositif particulier : un récit discontinu à l'aide de l'intégration des images ${ }^{36}$. Loin de faire simplement l'économie de la description par

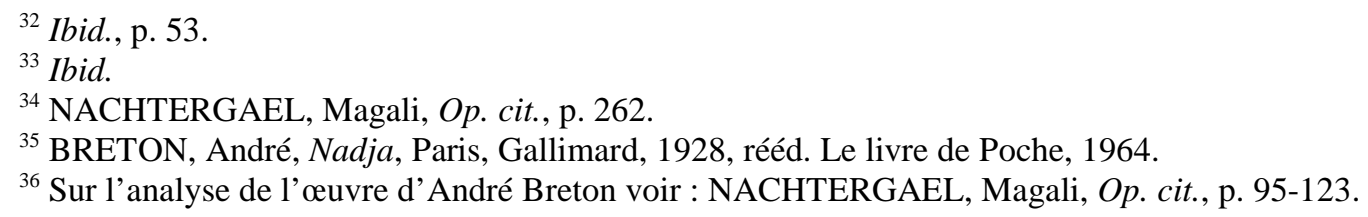


les photos, comme l'insinue Breton, les documents iconiques dans Nadja travestissent et déplacent le vrai sujet du récit, le récit de soi.

La figure la plus absente et la plus désirée revient toujours et à la fin de son texte dans l'édition originale, son portrait par Henri Manuel indique clairement qu'il était le seul et véritable sujet du livre et son point d'arrivée ${ }^{37}$.

La photographie et les dessins insérés provoquent un effet d'arrêt dans la lecture, tout comme le collage textuel (évocation d'une revue théâtrale, de réflexions philosophiques, une dépêche de journal, etc.), et les changements dans les types de narration $^{38}$. Par ces éléments hétéroclites l'auteur inaugure une «poétique de la discontinuité » marquée par «l'esthétique du hasard et de l'intermittence ${ }^{39} \gg$. Les photos insérées dans le livre créent des œuvres hybrides photo-littéraires, un dispositif qui a pour objectif de créer un effet de lecture particulier.

\section{III.4.a. Roland Barthes}

Après Nadja d'André Breton, il semble y avoir un vide, selon Nachtergael, dans l'utilisation de la photographie incorporée dans l'œuvre littéraire, et ce jusqu'à l'œuvre de Roland Barthes $^{40}$. Ce dernier aura un impact important sur l'apparition des «mythologies individuelles ${ }^{41} »$ dans les œuvres littéraires tout comme dans les œuvres d'arts plastiques - d'une part, grâce à son livre Mythologies, dans lequel il dévoile les constructions mythiques modernes (c'est-à-dire les fables fondatrices d'une bourgeoisie dominante) et surtout par sa réédition en livre de poche en 1970 qui rend le livre accessible à un public plus large ; d'autre part, par ses livres où il explore et compose lui-même des œuvres hybrides, L'Empire des signes ${ }^{42}$, Roland Barthes par Roland

\footnotetext{
${ }^{37}$ NACHTERGAEL, Magali, Op. cit., p. 119.

${ }^{38}$ La structure de Nadja se compose selon Magali Nachtergael, d'un prologue qui évoque le quotidien surréaliste d'André Breton et prépare l'entrée en scène de la jeune femme, puis à son arrivée la narration prend la forme d'un journal daté, forme qui sera abandonnée dans l'épilogue qui dresse un bilan après l'internement et la disparition de l'hérö̈ne. Ibid., p. 104.

${ }^{39}$ Ibid., p. 118.

${ }^{40}$ Voir le chapitre consacré à Roland Barthes, NACHTERGAEL, Magali, Op. cit, p. 253-339.

${ }^{41}$ Magali Nachtergael qualifie ainsi toutes les œuvres autobiographiques composées de matériaux hétéroclites, nous trouvons toutefois que l'expression a une connotation narcissique, tandis que la quête de l'identité est dans la plupart des œuvres une condition pour explorer le monde extérieur.

42 BARTHES, Roland, L'Empire des signes, Genève, Skira, col. "Les sentiers de la créations", 1970, (réédition en livre de poche, Flammarion, 1980). Magali Nachtergael relate que certaines images de
} 
Barthes $^{43}$ et La Chambre claire $^{44}$, œuvres qui mêlent des images à l'analyse critique et à l'autobiographie. Barthes n'y prend jamais la position de l'Operator, du photographe, il est seulement le collectionneur et le sélectionneur d'images, mais selon Magali Nachtergael, on peut à titre égal analyser ses œuvres hybrides comme une praxis photographique, car elle s'intègre dans la «tradition duchampienne qui veut que le choix de l'artiste constitue le geste élémentaire et originel de toute œuvre d'art ${ }^{45} \gg$. La sélection demande aussi l'habile association d'un texte à une image, qui va faire mûrir la prise de conscience de la matérialité du livre, de l'importance de «l'image » du livre.

Les photos sélectionnées et la mise en page de L'Empire des signes deviennent révélatrices de toute l'esthétique de Barthes, selon Magali Nachtergael. Ce livre est le premier où Barthes ne se présente pas en tant que scientifique et théoricien, mais plutôt comme «l'écrivain au voyage » décrivant ses impressions en vrac. Le Japon, dans son altérité foncière, se révèle un système de signe inouï. À l'instar de sa définition du mythe, le signe au Japon ne paraît jamais stable, il est tiré vers d'autres significations, ce qu'illustre une des images du livre et sa légende.

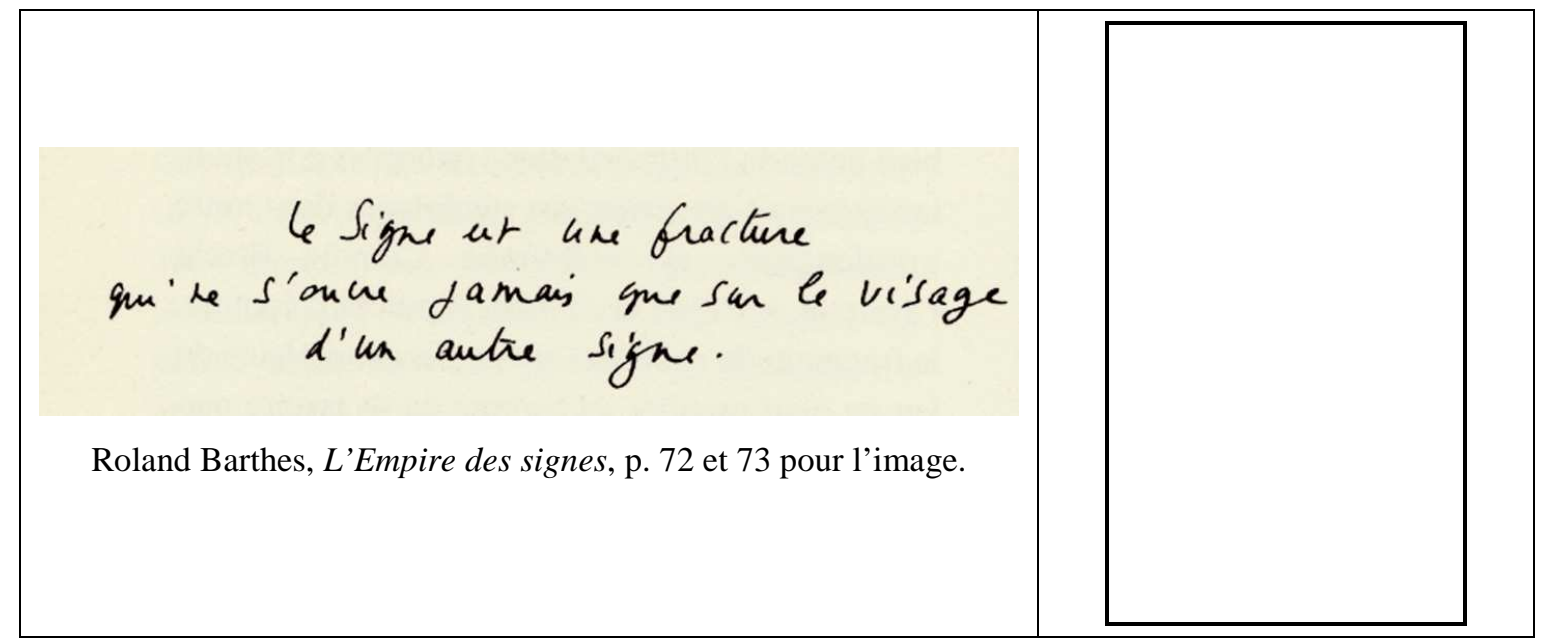

Le montage du livre se fait sur le modèle des compositions musicales tout en étant influencé par la philosophie extrême-orientale du vide (signifié par le mu japonais) et de

L'Empire des signes ont été empruntées à l'écrivain-voyageur et photographe Nicolas Bouvier, qui travaillait également comme iconographe. C'est lui qui initie Barthes à cette technique singulière de composition développée dans ses propres livres de voyage illustrés. NACHTERGAEL, Magali, Op. cit., p. 269.

43 BARTHES, Roland, Roland Barthes par Roland Barthes, Paris, Seuil, col. "Écrivains de toujours", 1976.

${ }^{44}$ BARTHES, La Chambre claire, Cahiers du cinéma, Paris, Gallimard, Le Seuil, 1980.

${ }^{45}$ NACHTERGAEL, Magali, Op. cit., p. 278. 
la «perte du sens » (le satori $)^{46}$. Les fragments et les images sont traités comme des unités génératrices d'interstice et sont disposés de manière à créer une «rythmique visuel minimal et sériel ${ }^{47} »$.

Les photos d'architectures ${ }^{48}$ insérées dans le livre traduisent cette esthétique rythmique de la perte du sens. Ainsi cette photo où Barthes écrit : «Renversez l'image, rien de plus, rien d'autre, rien ${ }^{49} \gg$.

Corridor de Shikidai - Château Nijo, Kyoto, construit en 1603

Les deux photos de l'acteur japonais Kazuo Funaki, reprises presque à l'identique au début et à la fin du livre, renforcent également cette lecture.

D'une photographie à l'autre, rien ne change sur le visage, si ce n'est que la bouche de l'acteur s'est légèrement entr'ouverte, dans un mouvement qui esquisse autant une parole qu'un possible baiser. Car sous cette évocation ambiguë du désir, l'écart entre les deux photographies fait de tout le texte un interstice, un moment : en un bref instant, comme un battement de cil, lorsque les paupières font se rouvrir les yeux, seules les lèvres ont, mais à peine, bougé. ${ }^{50}$

${ }^{46}$ Ibid., p. 256-257.

47 « Cette esthétique joue de l'écart et des vides, une oscillation qui traverse tous ses écrits et qui trouvera un point d'équilibre sous l'appellation de neutre. »Ibid., p. 265.

48 «Les machines à sous décrites par Barthes et appelées Pachinko (p. 375) mais aussi des barils de saké qui font face au regard, comme un mur opaque (p. 384) montrent des objets alignés qui se répètent sur une image dont le cadrage serré donne l'impression que la série continue infiniment en hors-champ. L'architecture inspire aussi à Barthes trois clichés qui se rapprochent très nettement de toiles abstraites géométriques et dont la rythmique procède d'une répétition d'un même motif minimal. C'est le cas notamment du corridor de Shikidai (p. 391), de la «Poutraison » photographiée par Daniel Cordier (p. 432) ou encore de «L'alcôve dite tokonoma » (p. 436) à la fin du livre. » Ibid. p. 258.

${ }^{49}$ BARTHES, Roland, L'Empire des signes, Op. cit., p. 64-65. L'image provient d'un blog, qui prend Barthes au mot en juxtaposant l'image renversée à l'original : (consulté le : 10/09/2009) http://www.eternalnetwork.org/jcl/index.php?art=790.

${ }^{50}$ NACHTERGAEL, Magali, Op. cit., p. 266-267. 


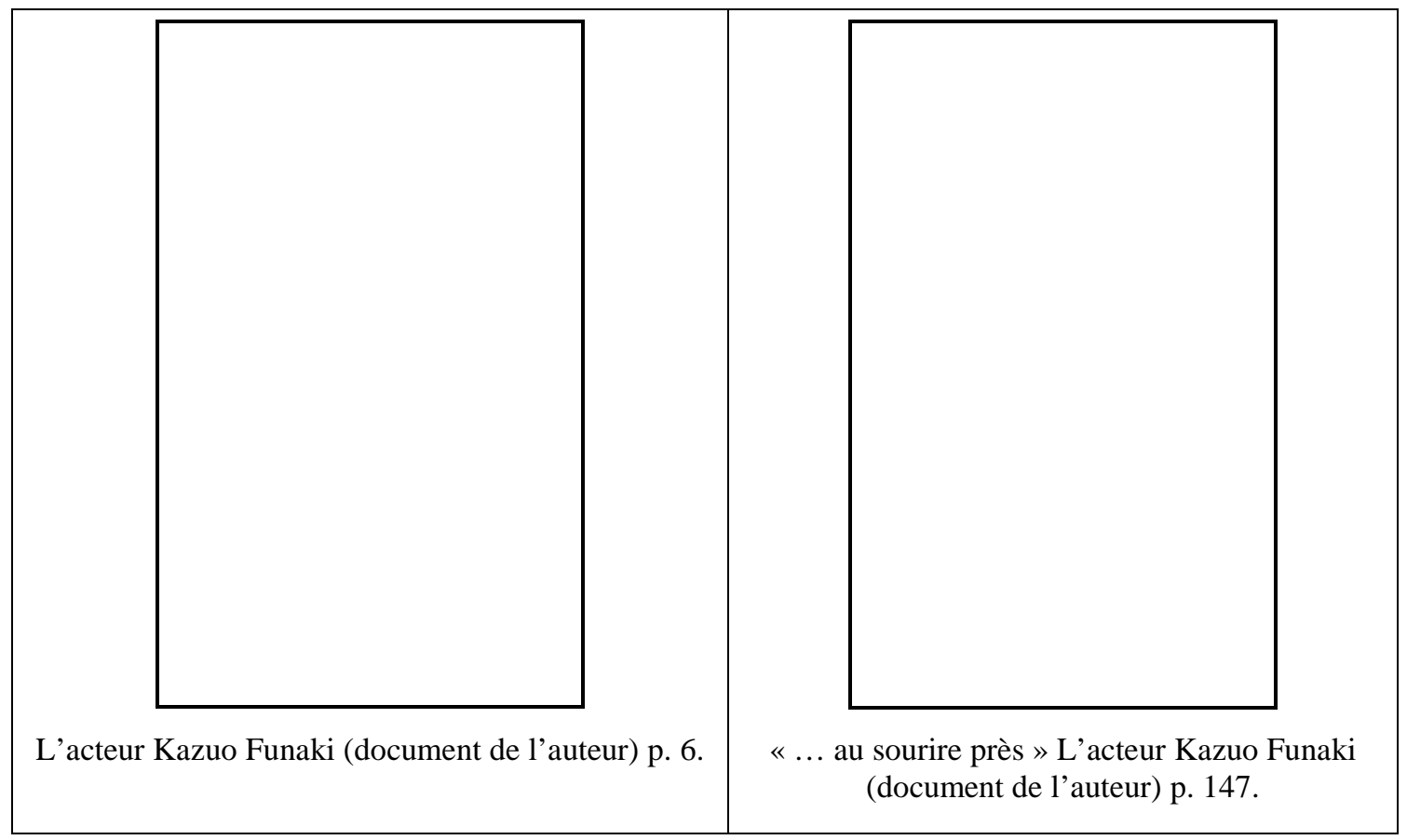

Magali Nachtergael montre dans sa thèse que la photographie est exploitée de la même manière dans les deux autres livres photo-littéraires de Barthes, le sens s'inscrit invisiblement dans et par l'image. Les photos insérées dans Roland Barthes par Roland Barthes, constituent avant tout des «biographèmes ${ }^{51}$ » de l'auteur, révélateurs de la subjectivité, des «détails, goûts et inflexions ». Ces unités minimales prennent la place du récit de vie qui désormais ne peut plus contenir l'intégralité de l'être. À ce titre, les clichés de La Chambre claire, choisis pour ce qui «pointe » et affecte Barthes, peuvent également constituer ses biographèmes.

Dans Roland Barthes par Roland Barthes, un des biographèmes de l'auteur serait l'ennui ${ }^{52}$, qui assure une continuité entre l'enfant et l'adulte Barthes. La juxtaposition des images cherche à expliciter ce lien visuellement, l'expression sur le visage qui confirmerait l'identités3. La mise en page feint un récit chronologique,

51 Roland Barthes définit dans l'introduction de son livre Sade, Fourier et Loyola, la notion de «biographème » qui, par l'anecdote biographique, en dehors de la vie de l'auteur relatée de manière chronologique, témoigne de sa subjectivité. Barthes écrit : «Si j'étais écrivain, et mort, comme j'aimerais que ma vie se réduisît, par les soins d'un biographe amical et désinvolte, à quelques détails, à quelques goûts, à quelques inflexions, disons : des «biographèmes ». BARTHES, Roland, Sade, Fourier, Loyola, Euvres complètes, éd. revue, corrigée et présentée par Éric Marty, t. 3, Paris, Seuil, 2002, p. 706.

${ }^{52}$ Voir l'image scannée à partir du livre en anglais sur le site suivant : (consulté le : 10/08/09) http://3.bp.blogspot.com/_7y8Jhm8GiGw/RtNZROT5P4I/AAAAAAAAALI/jvIMBDDSPE0/s1600h/Panic+boredom.JPG.

${ }^{53}$ Dans La chambre claire, Barthes parle ainsi de l'air du sujet sur le cliché, évoquant la photo de sa mère au Jardin d'hiver : «L'air exprime le sujet, en tant qu'il ne se donne pas d'importance. Sur cette photo de vérité, l'être que j'aime, que j'ai aimé, n'est pas séparé de lui-même : enfin il coöncide. Et, mystère, cette 
montrant le lieu de l'enfance, les ancêtres, la famille, ses portraits d'enfance et de sa jeunesse, en s'arrêtant à «l'entrée de la vie productive ${ }^{54}$, et en laissant la place à l'écriture. Cependant, le choix des images a eu lieu après l'achèvement du texte ${ }^{55}$, inscrivant le récit dans une boucle, un retour à soi, qui rappelle la mise en page des photos de l'acteur Kazuo Funaki dans L'Empire des signes. La phrase mise en exergue «Tout ceci doit être considéré comme dit par un personnage de roman » devient la métaphore de la photographie, selon Magali Nachtergael ${ }^{56}$, puisqu'elle est écrite à la main en blanc sur une page noire, devenant une image / trace en négatif.

Reprenant une analyse de Raimar Stange, Nachtergael souligne que Barthes aurait redéfini l'«ego » comme un changement constant, comme le signale cette constatation : «mon "moi" ne coïncide jamais avec mon image ${ }^{57} »$.

Ce dispositif global renvoie donc à une fiction de soi. En effet, le centre vide, cet espace blanc de la page où l'identité doit se constituer en discours ou en représentation, est celui où le sujet s'installe et prend sa place et sa forme, à partir de rien. ${ }^{58}$

Avec ce vide, surface sensible en devenir, Barthes se place dans la tradition poétique de Mallarmé et de Maurice Blanchot, mais aussi dans la tradition visuelle orientale, reprise également par les peintres occidentaux ${ }^{59}$.

\section{III.4.b. L'entre-deux dans les récits autobiographiques}

Le dispositif particulier, construit sur l'écart et l'entre-deux du texte et de la photographie, est largement exploité pour affirmer la complexité de l'identité par des écrivains qui, à l'instar de Barthes, ne pratiquent pas eux-mêmes la photographie.

coïncidence est comme une métamorphose. Toutes les photos de ma mère que je passais en revue étaient un peu comme des masques ; à la dernière, brusquement, le masque disparaissait : il restait une âme, sans âge mais non hors du temps, puisque cet air, c'était celui que je voyais, consubstantiel à son visage, chaque jour de sa longue vie », La Chambre claire, Op. cit., p. 168.

${ }^{54}$ Roland Barthes par Roland Barthes, Op. cit., p. 6.

${ }_{55} \mathrm{Au}$ tout début du livre Barthes écrit : «Voici pour commencer, quelques images : elles sont la part du plaisir que l'auteur s'offre à lui-même en terminant son livre. » Ibid., p. 5.

${ }^{56}$ NACHTERGAEL, Magali, Op. cit., p. 279.

${ }^{57}$ Ibid. p. 386.

${ }^{58}$ Ibid. p. 291.

59 Voir sur le vide et le creux dans les arts visuels, l'exposition à Beaubourg en mars 2009. http://www.centrepompidou.fr/education/ressources/ENS-klein-EN/ENS-klein-EN.htm (consulté le : 03/08/2009). 
Il en est ainsi du livre Le voile noir ${ }^{60}$ d'Anny Duperey. Dans ce récit autobiographique, l'auteure tente de faire remonter les souvenirs de ses parents décédés lorsqu'elle avait l'âge de huit ans grâce aux descriptions des photographies familiales prises par son père. Le projet est pourtant un échec, car l'auteure ne réussit à extirper aucun souvenir, le voile noir persiste sur son enfance. Le livre se construit sur cet entredeux, sur les photographies et leur description. Le récit reste désormais une fiction sans dénouement, la vraie signification des images reste du domaine du non-dit et du non accessible. La description des photos ouvre toutefois une voie pour l'auteur, lui permettant d'exprimer sa douleur refoulée de la perte et son sentiment de culpabilité pour avoir désobéi ce jour-là à ses parents (elle ne les avait pas suivis dans la salle de bain où elle les a retrouvés plus tard morts asphyxiés au monoxyde de carbone). Comme le montre Véronique Montémont ${ }^{61}$, le texte permet à l'auteure à la fois d'exprimer ses sentiments et de les analyser et, même si aucun souvenir ne lui revient, l'enquête menée à l'aide des images permet d'écrire une biographie des parents et d'entamer par l'autobiographie une reconstruction de soi.

Les photos insérées dans le livre permettent au lecteur de s'identifier partiellement avec le narrateur, puisque le lecteur se trouve dans la même position en face de photos dont la signification lui échappe. Elles invitent également à suivre les fantasmes de l'auteur, à essayer d'imaginer comment la scène a pu avoir lieu, à prolonger les clichés.

Le livre L'usage de la photo ${ }^{62}$, livre à deux voix d'Annie Ernaux et Marc Marie, se base également sur l'entre-deux, sur le vide et l'absence. Le livre est structuré par les quatorze photographies prises par l'auteure et son compagnon (sans que la distinction soit marquée) et les descriptions respectives qu'ils en font. Les images dévoilent notamment leurs vêtements jetés par terre précipitamment la veille et témoignent du désir de leur étreinte. La prise de vue devient un rituel entre eux qui prolonge le désir dans une curiosité presque enfantine de savoir à quoi la scène de la veille ressemble, de redécouvrir et de revivre les moments vécus. L'écriture à deux voix laisse la place à une deuxième découverte: l'écriture de l'autre, la verbalisation parallèle d'un vécu

\footnotetext{
${ }^{60}$ DUPEREY, Anny, Le voile noir, Paris, Seuil, 1992.

${ }^{61}$ MONTEMONT, Véronique, « Anny Duperey, Le Voile noir », mis en ligne le 19 janvier 2007. Disponible sur : http://www.item.ens.fr/index.php?id=27105 (consulté le : 03/08/2009).

${ }^{62}$ ERNAUX, Annie, MARIE, Marc, L’usage de la photo, Paris, Gallimard, 2005.
} 
identique mais perçu et dit d'une manière forcément différente. Toutefois le texte ne transcrit pas de souvenirs. Les descriptions donnent un sens après coup à la scène qui s'est formée de manière involontaire, le texte dépasse l'image ; ainsi par exemple la chaussure au premier plan dressée sur les vêtements féminins qui devient le symbole de la domination masculine. Selon Isabelle Roussel-Gillet ${ }^{63}$ les descriptions exhibent les modes de lecture des images, la lecture sémiologique, sociocritique ou littéraire. «C'est un imaginaire qui déchiffre la photo non la mémoire ${ }^{64}$. $\gg$ En creux de la photographie et du texte se place la thématique du cancer de sein de l'auteure, le vécu sensible dont les mots n'arrivent pas à transcrire l'émotion. Comme le remarque Isabelle Roussel-Gillet les photos de vêtements évoquent l'absence du corps mais aussi une double intrusion, celle du partenaire dans l'acte sexuel et celle du cancer dans le corps. Les dédoublements mettent en place une esthétique de l'entre-deux, qui comme chez Barthes donne accès sur un vide, un espace de flottement et de devenir.

[..] l'entre-deux n'est aucun des deux : il est vide - ou l'espace, ou le temps [...], ou le sens - qui rapporte en ne rassemblant pas, ou qui rassemble sans unir, ou qui unit sans achever, ou qui achève sans porter à la fin. ${ }^{65}$

Mais cet «usage» de la photo participe également à la reconquête et à la réappropriation du corps, comme les photos sont la trace du désir suscité par le corps, ou comme le linceul qui est signe à la fois de la mort et de la résurrection ${ }^{66}$.

Sylvie Jopeck attire l'attention sur le fait que la photographie à la fois renforce le pacte autobiographique en tant que document, et le problématise. Elle peut constituer non pas une aide mais un écran supplémentaire entre le vécu raconté et les images (ce que note également Anne-Marie Garat à propos des photos de famille). L'écart entre le texte et la photo devient ainsi significatif dans le livre Crybaby! de Janice Williamson ${ }^{67}$. Le livre se base sur l'incompatibilité entre les images prises par le père de la narratrice il la montre souriante, menant une enfance normale, insouciante -, et ses propres souvenirs que le texte retranscrit. Il s'agit de souvenirs douloureux et très intimes sur le rapport sexuel que son père avait avec elle à cet âge-là. C'est en fin de compte le silence de la photographie et ce qu'elle ne montre pas qui devient significatif. Le décalage entre

${ }^{63}$ ROUSSEL-GILLET, Isabelle, «Les paradoxes de la photographie chez Ernaux et Le Clézio », in Littérature et photographie, Op. cit., p. 283.

${ }^{64}$ ERNAUX, Annie, MARIE, Marc, L'usage de la photo, Op. cit., p. 24.

${ }^{65}$ ROUSSEL-GILLET, Isabelle, Op. cit., p. 288.

${ }^{66}$ Ibid., p. 283.

${ }^{67}$ WILLIAMSON, Janice, Crybaby!, Edmonton, Ne West, 1998. Voir l'analyse de Nancy Pedri, «Le silence photographique, un geste provocateur », in Littérature et photographie, Op. cit., p. 391-397. 
le texte et les clichés remet en cause l'objectivité de la photographie, mais en retour questionne également le texte, non pas sa sincérité ou la validité du pacte, mais sa vérité absolue. «Le moi réel, extratextuel, n'a pas une forme fixe en dehors de sa narration. Mais une fois narré, le moi n'est plus qu'une version des autres "mois" autobiographiques $^{68} »$. De par la relation ambiguë que la photo entretient avec la réalité, son insertion dans l'œuvre autobiographique fonctionne également comme un catalyseur des questions d'écriture, du rapport entre l'écriture et la réalité ${ }^{69}$.

\section{III.4.c. L'autofiction chez l'écrivain photographe Hervé Guibert}

Le doute jeté sur la possibilité d'une authenticité du récit autobiographique est, comme on l'a vu, à l'origine de l'émergence de la notion d'autofiction. Toutefois, selon Bruno Blanckeman, le recours à la fiction dans les récits de vie, tout en semant un doute sur l'authenticité, constitue aussi une stratégie de la part de l'auteur pour pouvoir partager et communiquer l'expérience intime :

[...] l'usage de la fable permet d'énoncer l'intime sans le révéler et de l'écrire pour ce qu'il est: une vie secrète, soustraite à la place publique, en retrait des réalités extérieures, un for intérieur de langue et de fiction. A l'opposé, caler la narration au plus près de l'expérience vécue, c'est en faire un objet d'identification possible pour autrui, l'instituer en figure de connaissance commune, cultiver le lien interpersonnel qui déplace l'intime hors les murs. ${ }^{70}$

Comme nous l'avons vu chez les photographes mentionnés dans le chapitre sur «Le modèle photobiographique », la distinction entre l'intime et l'extime s'efface. Malgré le recours à l'autofiction, les auteurs ne cessent pourtant de déclarer dans les entretiens qu'ils donnent que ce qui est raconté s'est réellement déroulé et qu'il serait possible de le vérifier.

Hervé Guibert, écrivain et photographe, réclame ce statut fictionnel en choisissant pour ses livres l'appellation «roman»; pourtant sa démarche consiste à aller jusqu'au bout «du dévoilement de soi et de l'énoncé de l'indicible ${ }^{71}$ », de révéler

\footnotetext{
${ }^{68}$ Ibid., p. 393.

${ }^{69}$ JOPECK, Sylvie, Op. cit., p. 161.

${ }^{70}$ MURA-BRUNEL A. ; SCHUEREWEGEN F. (éd.), L'Extime/L'Intime, CRIN (Cahiers de Recherches des Instituts Néerlandais de Langue et Littérature Française), 41, Amsterdam - New York, 2002. Voir le résumé sur fabula : http://www.fabula.org/actualites/article3683.php (consulté le : 08/08/2009).

${ }^{71}$ GUIBERT, Hervé, À l'ami qui ne m’a pas sauvé la vie, Paris, Gallimard, 1990, p. 247.
} 
au plus près la "vérité ", comme il l'indique dans son premier livre, La Mort propagande $^{72}$. Comme le démontrent Arnaud Genon et Guillaume Ertaud, Guibert crée son personnage de roman à partir de lui-même et de sa vie.

Guibert avait fait de lui-même son propre personnage par le prisme de l'écriture autofictionnelle, il était devenu cet autre " moi-même " littéraire, alter ego au sens premier de l'expression latine. Bien sûr, derrière le narrateur, Guibert se livrait on ne peut plus, mais il restait toujours ce filtre fictionnel qui résidait dans la mise en fiction de soi, c'est-à-dire dans la mise en texte, en personnage, dans la composition, la recréation de certains moments vécus à des fins romanesques. ${ }^{73}$

Écrire sur soi, comme se prendre en photo, demande une prise de distance par rapport à soi, pour pouvoir atteindre une certaine objectivité, écrire sur soi comme un autre $^{74}$. L'expérience de se voir sur les photos prises par d'autres renforce cette relation à soi-même. Ainsi, Guibert note, à propos des photos de Hans Georg Berger publiées dans le livre L'Image de soi ou l'injonction de son beau moment :

Ne ménageons pas plus longtemps un faux secret de polichinelle : cet individu c'est bien moi, je suis forcé de me reconnaître en ses faces et ses silhouettes, je suis bien l'acteur de toutes ces fantaisies, et pourtant il me dépasse, il me surprend, et je peux parler de lui comme un personnage de roman, et peut-être d'un roman que moi-même j'aurais écrit, il y a entre lui et moi toute la distance accomplie dans le passage d'un je à un $i l$, et bien d'autres distances. ${ }^{75}$

Les photographies prises par d'autres permettent de se voir comme on ne se voit pas, par les yeux de l'autre devenant un étranger-familier à nous-mêmes, qui permet d'observer sa vie à la loupe.

Dans ce projet autofictionnel, l'écriture et l'image s'enchevêtrent à plusieurs degrés. Après la publication de son premier roman, La Mort propagande, Hervé Guibert fait paraître un dispositif photo-textuel en 1980, Suzanne et Louise ${ }^{76}$, étiqueté comme « roman-photo ». Toutefois, ses photographies annotées à la main semblent être inspirées avant tout par l'œuvre de Duane Michals ${ }^{77}$.

${ }^{72}$ GUIBERT, Hervé, La mort propagande, Paris, Régine Deforges, 1977.

${ }^{73}$ GENON, Arnaud ; ERTAUD, Guillaume, «Entre textes et photographies: L'autofiction chez Hervé Guibert », Image [\&] Narrative, $\mathrm{n}^{\circ}$ 19, 2007. Journal électronique disponible en ligne sur: http://www.imageandnarrative.be/autofiction/genon_ertaud.htm (consulté le : 08/08/2009).

${ }^{74}$ Nous retrouvons les mêmes pensées chez Dominique Viart: «Ecrire "je suis", c'est commencer à se dire autre que soi, à dire l'autre que l'on porte en soi. [...] l'individu ne constitue son identité que par le truchement de médiations. "Il y a de l'autre en moi" continuent d'affirmer les écrivains à la suite de la formule radicale de Rimbaud "Je est un autre". » TDC n 853, L'autoportrait, avril 2003. Disponible en ligne : http://www.sceren.fr/RevueTDC/853-65992.htm (consulté le : 08/08/2009).

${ }^{75}$ GUIBERT, Hervé ; BERGER, Hans Georg, L'Image de soi, ou l'injonction de son beau moment, Bordeaux, William Blake \& Co., 1988, p. 5. Certaines photos sont disponibles sur le site de Hans Georg Berger, voir : http://www.hansgeorgberger.de/page/herve/herve_photo.html (consulté le : 08/08/2009).

${ }^{76}$ GUIBERT, Hervé, Suzanne et Louise (Roman-photo), Paris, Hallier, 1980.

${ }^{77}$ Dans leur article Arnaud Genon et Guillaume Ertaud évoquent le lien multiple qui lie Hervé Guibert à Duane Michals. Déjà Guibert décrivait le dispositif particulier de Michals dans un article publié en 1978 


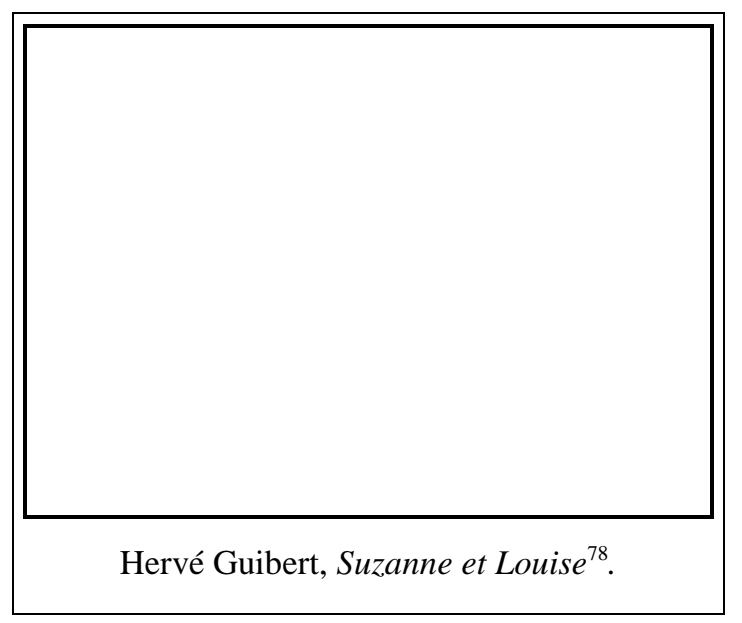

La suite d'images et de textes ne compose pas une narration visuelle continue à la manière des romans-photos, elle s'apparente plutôt à un journal intime, avec des entrées accompagnées d'une photo, qui parlent du rapport du narrateur Guibert avec ses tantes Suzanne et Louise. Selon Genon et Ertaud, l'avant-dernière photographie, qui présente Hervé Guibert assis sur un fauteuil avec ses tantes, souligne la théâtralité de la prise de vue, qui est toujours une mise en scène, feignant la transparence de la présence du photographe et l'instantanéité. Il en va de même du genre de l'autofiction qui se construit lui aussi dans un entre-deux, entre le factuel et le fictionnel, soumis à la fois au pacte romanesque et au pacte autobiographique ${ }^{79}$.

La relation entre le texte et la photographie ne se tisse pas uniquement à l'intérieur d'un même ouvrage. Les expositions et les catalogues d'exposition ${ }^{80}$ construisent un palimpseste visuel de ses romans, en montrant les personnages qui y sont évoqués. Dans Le Seul Visage $e^{81}$, Guibert pose cette question sur la quatrième de couverture : « un livre avec des figures et des lieux, n'est-ce pas un roman ?». L'auteur invite alors le regardeur à poursuivre la fabulation, de la même manière que Roland Barthes dans La chambre claire écrit à propos de la photo d'Ernest prise par André Kertész : «Il est possible qu’Ernest, jeune écolier photographié en 1931 par Kertész, vive encore aujourd'hui (mais où ? comment? Quel roman!) $82 »$. A propos de la photographie qui donne son titre au catalogue, Guibert explique qu'il s'agissait d'une photo prise en Yougoslavie, où il se trouvait avec Henri Cartier-Bresson, dans un

dans Le Monde, et repris dans La photographie inéluctablement, (Gallimard, Paris, 1999, p. 40-45). De plus, Guibert a contribué à une série de Michals intitulée : Changements, et une photographie représentant Guibert à Venise réalisée par Michals est mentionnée dans la liste des effets appartenant à Guibert vendus aux enchères en 2002. GENON, Arnaud; ERTAUD, Guillaume, «Entre textes et photographies: L'autofiction chez Hervé Guibert », Op cit.

${ }^{78}$ Voir l'image sur un blog : http://www.intexte.net/docenligne/suzannelousie_interieur.jpg (consulté le : 08/08/2009).

${ }^{79}$ GENON ; ERTAUD, Op. cit.

${ }^{80}$ Voir la liste des expositions d'Hervé Guibert sur le site consacré à l'auteur : www.herveguibert.net (consulté le : 08/08/2009).

${ }^{81}$ GUIBERT, Hervé, Le seul visage, Paris, Minuit, 1984.

${ }^{82}$ BARTHES, Roland, La chambre claire, Op. cit., p. 131. 
auditorium rempli de gens. En regardant Cartier-Bresson prendre une image de la foule et puis jeter un «regard d'une mise à mort, d'un abandon après la mise à mort ${ }^{83}$ », Guibert prend conscience que pour lui, prendre quelqu'un en photographie est un acte d'amour. Alors soudain un visage apparaît dans la foule, qui attire son attention :

Instantanément j'aimais follement ce visage. C'était pour moi un instant proprement photographique : programmé par le hasard et la configuration de l'espace, un coup de foudre photographique. $^{84}$

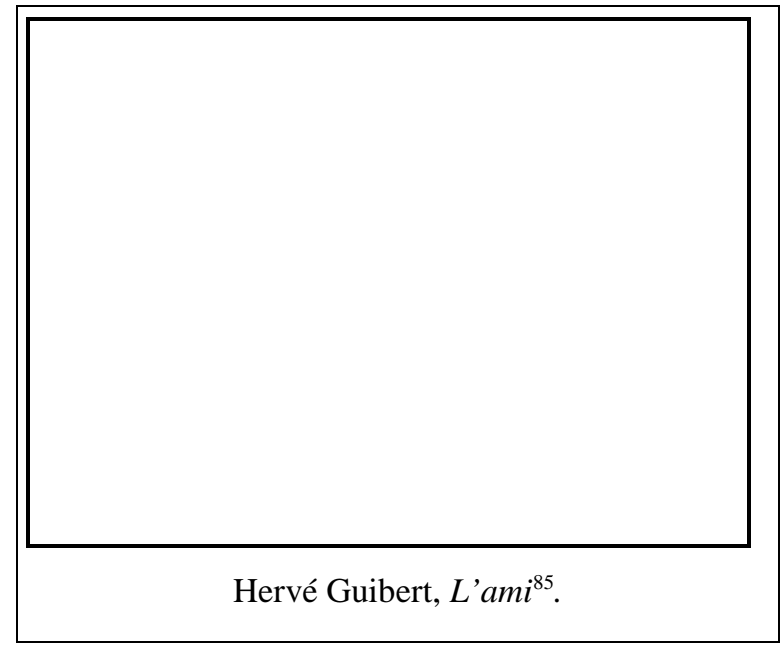

Derrière les images du livre, on trouve cet amour, cette relation intime qui se dévoile en creux, entre le photographe et son modèle. Le catalogue s'ouvre d'ailleurs sur la photo intitulée L'ami (cicontre), qui montre sa propre main tendue pour toucher l'autre, une image qui symbolise aussi le désir.

La posture d'Hervé Guibert n'est pas nostalgique, tournée vers le passé, mais prospective, même si, selon Frédérique Poinat, par l'image c'est sa propre disparition qu'il met en scène ${ }^{86}$. La posture est la même, peuplée d'ombres, de vide et d'absence, qu'il s'agisse de vraies photographies, de photographies décrites dans L'image fantôme ${ }^{87}$, ou du film La Pudeur ou l'Impudeur ${ }^{88}$ qu'il réalisa sur le SIDA peu avant sa mort à l'âge de trente-six ans.

${ }^{83}$ GUIBERT, Hervé, Le seul visage, Op. cit., p. 6.

${ }^{84}$ Ibid.

${ }^{85}$ Voir l'image sur un blog: http://www.intexte.net/docenligne/guibert_1_ami_zoom.jpg (consulté le : 08/08/2009).

${ }^{86}$ POINAT, Frédérique, «" Un certain chaos résolu " : les derniers choix photographiques et littéraires d'Hervé Guibert », La Chouette, 2001. Disponible en ligne sous format PDF (consulté le : 03/08/2009) : http://www.bbk.ac.uk/lachouette/chou32/Poinat32.PDF

${ }^{87}$ GUIBERT, Hervé, L'Image fantôme, Paris, Minuit, 1981. Le chapitre qui donne son titre au livre, qui décrit une séance photo avec sa mère réalisée à blanc, est disponible sur le site Internet consacré à Hervé Guibert sous forme de lecture audio par Guibert. Le moment partagé perdu à jamais, sur lequel l'écriture prend le pas en le transcrivant, est réanimé par la voix de Guibert. La voix enregistrée, comme la photo, rend alors cette impression de présence par l'ancrage indiciel. Disponible sur le site consacré à l'œuvre d'Hervé Guibert : http://www.herveguibert.net/index.php?2006/10/11/54-lectures-par-herve-guibert (consulté le : 06/08/2009).

${ }^{88}$ GUIBERT, Hervé, La Pudeur ou l'Impudeur, vidéo, diffusé sur TF1, 30 Jan. 1992. 
L'image photographique guibertienne est celle des petits riens, des objets familiers, de la proximité du corps des autres, et d'un certain autoportrait de l'absence, des ombres, des vides laissés par la lumière. ${ }^{89}$

Comme chez Roland Barthes, le vide et l'entre-deux caractérisent la représentation de soi, l'absence qui invite le lecteur à la fabulation.

Toutefois, selon Bruno Blanckeman, le recours à la fiction de soi n'a pas pour objectif la remise en cause de l'authenticité du récit, mais plutôt de démontrer la complexité de l'identité.

L'autofiction représente [...] une pratique d'écriture entremêlant la relation phénoménologique brute, qui permet l'étude du corps et de la conscience, et l'acte de fabulation, qui tente celle de l'imaginaire et de l'inconscient. Elle ne se résume donc pas, comme un usage parfois malencontreux le supposerait, à la peau neuve du très vieil et honorable débat selon lequel tout récit autobiographique appelle nécessairement la recomposition du réel, sa trahison, et pour lequel l'authenticité est un mythe... Elle correspond à la volonté d'étendre, au-delà des zones de la conscience claire, la tentative autobiographique. ${ }^{90}$

La photographie, par le sensible qu'elle mobilise, par la lecture affective qu'elle demande, par son ouverture à la fabulation, participe à la représentation de cette identité complexe, qui dépasse l'exprimable et le récit verbal.

La position du photographe, de «l'Operator », permet de répéter aisément par l'acte photographique la prise de distance par rapport à soi-même, d'extérioriser et de relativiser le vécu, de regarder les choses en face avec une certaine curiosité - savoir à quoi « ça » ressemble, à quoi « on » ressemble de l'extérieur - qui aboutit chez Guibert à une certaine acceptation de la maladie et de la mort, notamment dans A l'ami qui ne m’a pas sauvé la vie ${ }^{91}$.

L'acte répété de la photographie, tout comme la quête toujours reprise d'un livre à l'autre de l'écriture de soi chez Guibert, inscrivent l'identité dans un modèle dynamique, en constant changement à l'image de l'ipséité. La photographie s'apparente alors au journal intime, dans la mesure où elle est projective, elle enregistre le présent pour qu'il puisse être revisité et réinvesti ultérieurement et non pas pour figer l'instant.

Il y a d'ailleurs un nombre considérable de blogs sur Internet, qui à la manière des journaux intimes retracent et archivent en images les événements quotidiens,

\footnotetext{
${ }^{89}$ POINAT, Frédérique, Op. cit., p. 37.

${ }^{90}$ BLANKCEMAN, Bruno, « Nouvelle et Autofiction : le cas Guibert », in La nouvelle aux frontières des autres genres, du Moyen-Âge à nos jours (Tome II, sous la direction de V. Engel et M. Guissart, Academia Bruylant, Bruxelles, 2001) disponible sur www.herveguibert.net (consulté le : 09/06/2008).

${ }^{91}$ Voir sur ce sujet l'article de Michel Braudeau, « Ecrire contre la mort », Le Monde, 2 mars 1990 disponible sur le site consacré à Guibert: http://www.herveguibert.net/index.php?2006/05/13/21litterature-a-lami-qui-ne-ma-pas-sauve-la-vie (consultées le : 10/08/2009).
} 
intimes ou non, selon les goûts. Il existe des photoblogs accompagnés d'un titre ou d'une légende plus ou moins longue, mais aussi des sites qui mêlent l'image et le texte de manière plus complexe. On trouve une grande variété allant des images artistiques, comme le photoblog de Louise Merzeau ${ }^{92}$, aux clichés explicitement amateurs du site $A D a M$ Project ${ }^{93}$ déjà mentionné. Ce qui est commun en revanche à ces réalisations c'est le retour cyclique de mêmes types d'image et d'imagerie, de mêmes cadrages ou le retour de sujets semblables. Parmi les réalisations littéraires, on pourrait mentionner le blog de François Bon ${ }^{94}$ ou le site du désordre de Philippe de Jonckheere.

\section{III.4.d. L’identité dynamique du désordre}

Le site intitulé «désordre» de Philippe de Jonckheere ${ }^{95}$ constitue un dispositif particulier qui fonctionne sur le principe de la mémoire, n'offrant pas une lecture linéaire, mais un système d'hyperliens labyrinthique dans lequel le lecteur/internaute peut se perdre. Plusieurs renvois d'une page à l'autre fonctionnent sur le mode aléatoire, faisant surgir de manière incontrôlable une image, un texte, ou un enregistrement sonore, comme la mémoire involontaire. L'auteur nous met en garde sur l'une des pages d'accueil : «Vous n'y trouverez pas toujours ce que vous cherchez en revanche vous trouverez parfois ce que vous ne cherchiez plus. Bon voyage ${ }^{96}$. » À chaque entrée dans le site, se dessine une nouvelle trajectoire, un autre fil de lecture, où des pages déjà lues, une mise en page similaire, des icônes semblables donnent un rythme toujours nouveau au parcours. Le site est composé de plusieurs éléments : des pages d'accueil ; des blocs ;

\footnotetext{
92 Voir le blog de Louise Merzeau tenu pendant une année, disponible sur son site personnel: http://www.merzeau.net/photo/gal/jour/0009.html (consulté le : 10/08/2009).

${ }^{93} \mathrm{http}: / /$ www.adamproject.net/ (consulté le : 03/08/2009).

94 http://www.tierslivre.net/spip/ (consulté le : 03/08/2009) La partie blog de son site est composée de différentes sous-parties rangées thématiquement, alignant une photo à un texte plus ou moins long, ou simplement quelques lignes avec plusieurs images rassemblées (dans «images \& petit journal »). Même s'il y a une sous-partie intitulée «autobiographies \& tentatives », ce qui intéresse l'auteur c'est moins de se connaître, qu'une ouverture vers le monde, dont le dispositif photographique, comme le note Danièle Méaux, sert de modèle à l'écriture. Ce journal en ligne participe principalement à la construction de l'identité littéraire de son auteur. Voir l'article de Danièle Méaux, «L'écriture à l'épreuve de l'image enregistrée », in Littérature et photographie, Op. cit., p. 311-324.

95 www.désordre.net (Nous ne détaillerons pas à chaque citation mais les pages du désordre ont été toutes consultées le : 13/08/2009).

${ }^{96}$ http://www.desordre.net/accueil.htm.
} 
des liens vers l'œuvre d'autres artistes ou écrivains ; des œuvres hybrides mêlant textes et images de l'auteur, des textes (récit ou roman) sans images ou des images sans textes ; des œuvres hybrides réalisées avec d'autres artistes ; pour finir, des jeux.

Les pages d'accueil sont comme des carrefours de liens hypertextuels qui permettent de repartir dans plusieurs directions. Le site lui-même est soumis au changement constant, ce dont témoigne un «historique ${ }^{97} »$ qui recense les étapes antérieures du site en ligne depuis 2001, en présentant des pages d'accueil qui restent opérationnelles, sauf qu'elles ne figurent plus à la page initiale.

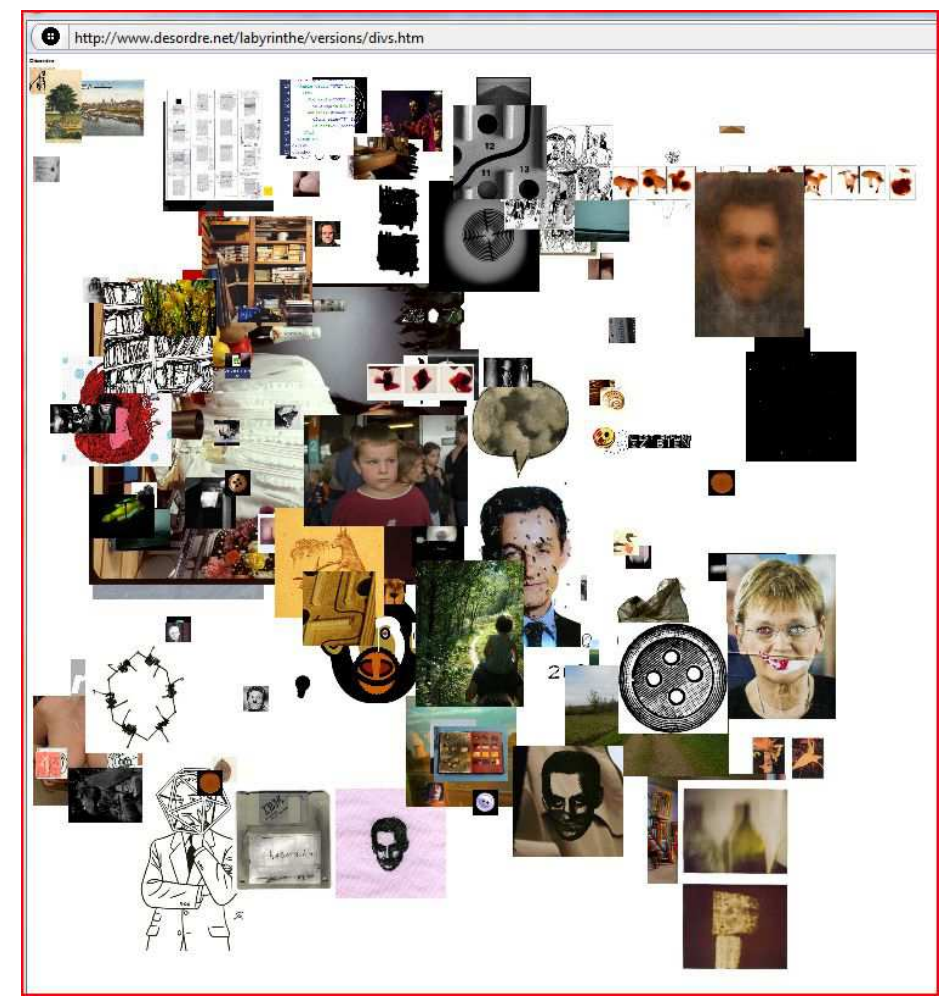

Exemple de la page initiale du désordre.

La page d'accueil actuelle ${ }^{98}$ (depuis mai 2009 - voir ci-dessus) est composée d'un collage à base des images, disposées de façon aléatoire et tirées des pages intérieures (voir ci-dessus). La disposition et certaines icônes changent donc à chaque fois qu'on atteint de nouveau la page initiale. On atteint la page concernée en cliquant sur l'icône, mais il se peut qu'au prochain démarrage on ne retrouve plus la même image. Ce mode aléatoire fait tout autant référence au hasard qui opère en photographie, qu'au mode aléatoire des écrans de veille des ordinateurs.

\footnotetext{
${ }^{97} \mathrm{http}: / /$ www.desordre.net/labyrinthe/versions/versions_du desordre entier.html.

${ }^{98}$ http://www.desordre.net/.
} 
Les pages de blocs constituent un enregistrement du quotidien sous plusieurs formes : mélange de texte et de photographie (Bloc-notes ${ }^{99} ; 22042003 . t x t^{100}$; aeiou fluctuat $^{101}$, Le petit journal ${ }^{102}$ ), photographies juxtaposés $\left(\right.$ La vie ${ }^{103}$, Adèle $^{104}$; Exercice de style ${ }^{105}$; Pola Journal $\left.{ }^{106}\right)$, ou «roman » $\left(\right.$ La cible $\left.^{107}\right)$. À plusieurs égards, le projet du « désordre s’inspire de l'œuvre de Georges Perec, par la description du quotidien, par le goût pour le jeu, et plusieurs pages lui sont explicitement dédiées : «Tentative d'épuisement ${ }^{108} »$, ou encore «Je me souviens de Je me souviens de Georges Perec ${ }^{109} »$. Dans un texte intitulé «Pourquoi », Philippe de Jonckheere rapproche son travail de l'expérience du Petit Poucet :

Tenir son journal en ligne (blog) n'est-ce pas semer des cailloux dans ce qui s'amoncelle en espérant que ces derniers n'auront pas été emportés entre temps par quelque accident géologique et dans l'espoir également que retrouvant ces cailloux on puisse en fait acquérir la certitude de tourner en rond. ${ }^{110}$

Il ne s'agit pour autant de croire en l'illusion de sauver quoi que ce soit de l'oubli ou d'offrir une image vraie du quotidien. Même l'exercice journalier consistant à noter et à photographier sa vie ne constitue qu'une fiction :

Lorsque j'écris dans le bloc-notes, je ne dis pas tout, loin s'en faut. Et je n'écris qu'à propos de ce qui plait à mes yeux, en somme je ne mentionne que ce que je voudrais retenir des jours [...] en fait, je peux bien l'écrire : j'écris ma vie rêvée. ${ }^{111}$

${ }^{99} \mathrm{http}: / / \mathrm{www} \cdot \mathrm{des}$ ordre.net/blog/.

${ }^{100}$ http://www.desordre.net/bloc/adam_project/index.htm Ce bloc est la contribution de Philippe de Jonckheere à l'AdAM Project déjà cité, qu'il reproduit sur le site en le rendant plus souple et en l'enrichissant de liens aléatoires; il a ensuite proposé à un de ses amis de refaire librement les images. Voir : http://www.le-terrier.net/desordre/adam_project/.

${ }^{101} \mathrm{http}: / / \mathrm{www} \cdot \mathrm{des}$ ordre.net/bloc/fluctuat/index.htm.

$102 \mathrm{http}: / /$ www.desordre.net/bloc/petit_journal/index.htm.

${ }^{103} \mathrm{http}: / / \mathrm{www} \cdot d$ esordre.net/bloc/vie/reprise/index.htm.

$104 \mathrm{http} / / / \mathrm{www}$. desordre.net/bloc/cachette/adele/index.htm.

${ }^{105} \mathrm{http} / / / \mathrm{www}$. desordre.net/bloc/adam_project02/index.htm.

$106 \mathrm{http}: / /$ www.desordre.net/photographie/polaroid/pola journal/pola journal.html.

${ }^{107} \mathrm{http} / / / \mathrm{www}$. desordre.net/textes/romans/cible/index.htm.

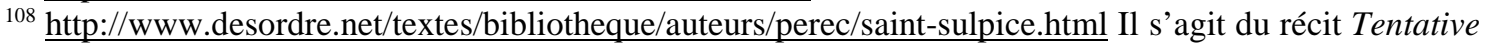
d'épuisement d'un lieu parisien de Georges Perec, mise en abyme par des liens hypertextuels. Le texte perecquien, décrit les petits détails d'un lieu, que personne ne remarque et les liens très divers font fusionner les mots avec leur référent. Par exemple la mention du mot «nuage » dans le texte ouvre en cliquant dessus sur un portail éducatif présentant les types de nuages avec des photos.

109 http://www.desordre.net/textes/bibliotheque/auteurs/perec/je_me_souviens.html Ce texte reprend un autre principe du récit perecquien, l'inventaire de souvenirs, de petits détails, mais pris dans un entrelacement de texte, d'hyperliens qui pointent cette fois-ci vers les pages internes du site.

${ }^{110} \mathrm{http} / / / \mathrm{www}$. desordre.net/bloc/pourquoi.html Nous retrouvons cette sensation de tourner en rond sur soi-même déjà chez Nadar, mais aussi chez Denis Roche. Voir à la page 409.

${ }^{111}$ http://www.desordre.net/bloc/2004_06_20_archive.htm\#108815479765208108. 
L'enregistrement automatique du quotidien est en soi un leurre, car il demande la transparence du médium (écriture ou photographie) qui transcrit les gestes, les sentiments, ou les pensées.

En 1990, je tentais pareillement de dicter tout au long d'une journée les différentes actions qui composaient une journée, mais las, le projet tourna court puisque je tombais dans la chausse-trappe prévisible qui voulut que je commençais en énonçant à mon dictaphone que je venais de l'allumer et de presser sur la touche d'enregistrement et que ce que j'étais en train de faire était d'enregistrer mon action d'enregistrement, laquelle se reprenait en charge, ce qui donnait quelque chose comme ceci: "je suis en train de parler dans mon dictaphone décrivant avec force détails mon action qui consiste à enregistrer le fait que je sois en train de parler dans mon dictaphone décrivant avec force détails le fait que je sois en train de dicter dans mon appareil de prise de notes audiophonique, etc... ${ }^{112}$

L'auteur se demande aussi quel est l'intérêt de cet archivage ${ }^{113}$, qui nécessite un travail si laborieux qui prend le pas sur la vie, mais la réponse semble se profiler dans la forme de l'outil qui en quelque sorte crée le besoin en transformant notre appréhension du réel.

[...] l'homme s'invente de nouveaux outils pour répondre à des besoins récents, incidemment nous sommes façonnés en retour par nos outils qui altèrent nos gestes ou nos façons de raisonner, déformation qui créent, c'est sans fin, de nouveaux $<i>$ besoins $</ i>$ pour lesquels de nouveaux outils sont à inventer qui à leur tour altèreront notre appréhension du réel. ${ }^{114}$

Nous revenons, somme toute, à notre question initiale, à savoir si c'est l'éclatement des genres et les progrès technologiques qui rendent possible la représentation de soi par différents médiums ; ou bien à l'inverse si c'est la conscience d'avoir une identité soumise au changement constant qui demande l'élaboration d'outils permettant une représentation dynamique du moi. Internet, en tant qu'espace virtuel semble être illimité, ce qui permet une pratique continue de l'auto-archivage.

Cette mémoire archivée du quotidien réalisée par Philippe de Jonckheere, qui contient parfois des moments très intimes, des détails sur sa vie familiale, est un lieu dynamique, qui demande à être revisité, reconstruit. C'est aussi probablement un lieu de mémoire pour ses enfants, puisqu'il leur adresse de temps en temps la parole dans son blog. C'est un lieu dynamique en devenir qui s'apparente dans sa forme au carré du

\footnotetext{
${ }^{112} \mathrm{http}: / /$ www.desordre.net/bloc/pourquoi.html.

${ }^{113} \mathrm{http}: / / \mathrm{www} . d e s o r d r e . n e t / b l o c / 2004 \_06 \_20 \_a r c h i v e . h t m \# 108815479765208108$.

114 http://www.desordre.net/bloc/2004_06_20_archive.htm\#108815479765208108 Comme dans cette citation, l'auteur intègre de temps en temps les codes html aux différentes pages du site pour dévoiler sa construction. Voir notamment une des pages d'accueil, qui est une image d'écran du désordre telle qu'on le voit dans le logiciel de création de site web Dreamweaver : http://www.desordre.net/accueil.htm.
} 
tangram, qui contient en devenir une multitude de formes : le site contient d'ailleurs un jeu de tangram qui fait partie de son roman Chinois $^{115}$.

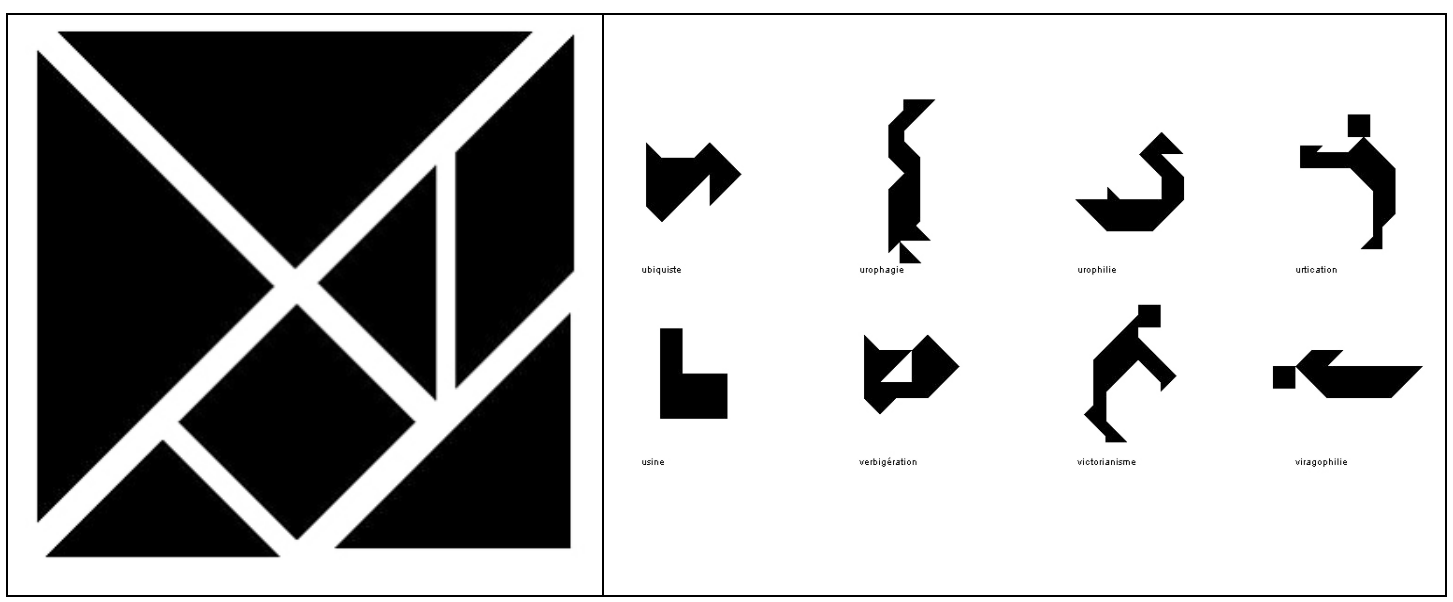

On trouve également un autoportrait de l'auteur, « une manière d'autoportrait à la fois involontaire et très fidèle », qui est aussi un autoportrait en devenir. Il s'agit d'un jeu de Memory, de format carré, composé à partir des 50 autres jeux de Memory confectionnés par l'auteur et qui, une fois achevé, s'ouvre sur une autre page web intitulée « autoportrait au carré ».

Les jeux de Memory, outre leur vocation à stimuler la mémoire du lecteur, constituent comme des «biographèmes » de Philippe de Jonckheere. Les jeux, de plus en plus sophistiqués, comme celui réalisé à partir d'une peinture de Jackson Pollock ou à partir de différentes gammes de gris, font appel à une capacité de mémoriser des détails très fins, basée toujours sur la comparaison de deux éléments. Le but premier de l'ajout de ce jeu sur son site est de retrouver et partager un souvenir, un plaisir d'enfance lié à un lot de cartes de Memory; mais sur les 50 jeux élaborés, plusieurs touchent à sa vie ou à celle de sa famille. Ainsi en va-t-il du Memory réalisé à partir de ses archives familiales (ci-dessous à gauche), qui devient une singulière façon de raconter une histoire de filiation ${ }^{116}$. Le Memory fait à partir des autoportraits ${ }^{117}$ - pratique constante dans son blog La vie (ci-dessous à droite) - celui fait à partir de photos de nu de sa femme ${ }^{118}$ ou celui fait à partir des photos vacances montrant ses enfants ${ }^{119}$, prolongent alors de manière ludique cette filiation. La juxtaposition des icônes/cartes de

\footnotetext{
115 Voir le roman: http://www.desordre.net/textes/romans/chinois/index.htm et le jeu de Tangram : http://www.desordre.net/textes/romans/chinois/tangram/game.html?initialForm=carr\%E9.

${ }_{116} \mathrm{http}: / / \mathrm{www}$. desordre.net/memory/Memoryoscar.html.

${ }_{117} \mathrm{http} / / /$ www.desordre.net/memory/Memoryautos.html.

$118 \mathrm{http}: / /$ www.desordre.net/memory/Memoryanne.html.

${ }_{119}$ http://www.desordre.net/memory/Memoryvacances.html.
} 
Memory sur le mode aléatoire ne permet aucune «lecture» linéaire, elle inscrit l'identité dans la pluralité.

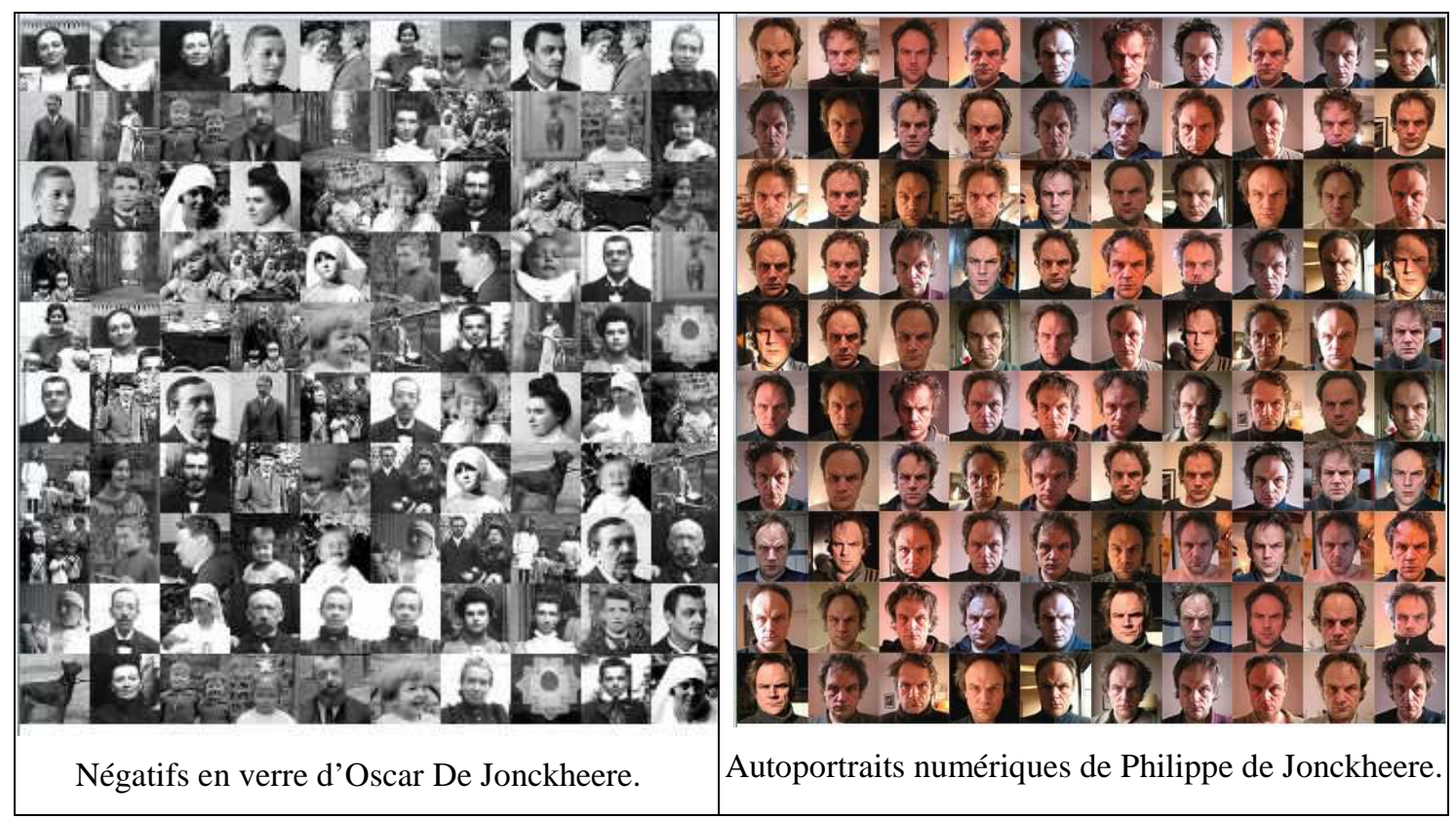

Chaque jeu de Memory est composé de 50 paires de cartes; l'ultime et cinquante et unième jeu ${ }^{120}$ est alors programmé de manière aléatoire à partir des 50 autres jeux de 100 cartes chacun, ce qui laisse au hasard un nombre de réalisations possibles qui dépasse l'imagination et les « limites de l'univers connu »:

[...] un milliard de milliards de milliards de fois supérieur au nombre d'atomes que l'on pourrait faire tenir dans la totalité de l'univers observable, c'est à dire dans les grandes largeurs — pour ainsi parler — une sphère de 30 milliards d'années-lumière de diamètre. ${ }^{121}$

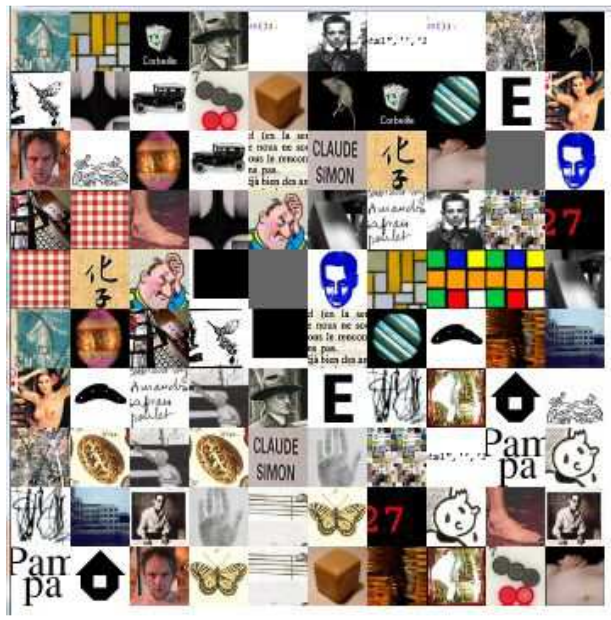

Une fois que le lecteur termine cette $51^{\text {ème }}$ partie (ci-contre), s'ouvre, comme nous l'avons déjà dit, l'autoportrait au carré (voir ci-dessous ${ }^{122}$ ), qui est un collage d'images exposées sur le site, ainsi que la mise en abyme de ce collage.

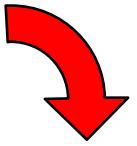

\footnotetext{
${ }^{120}$ http://www.desordre.net/memory/MemoryRandom.html.

${ }_{121} \mathrm{http}: / /$ www.desordre.net/memory/page002.htm.

122 http://www.desordre.net/photographie/numerique/autoportrait_carre/index.htm.
} 


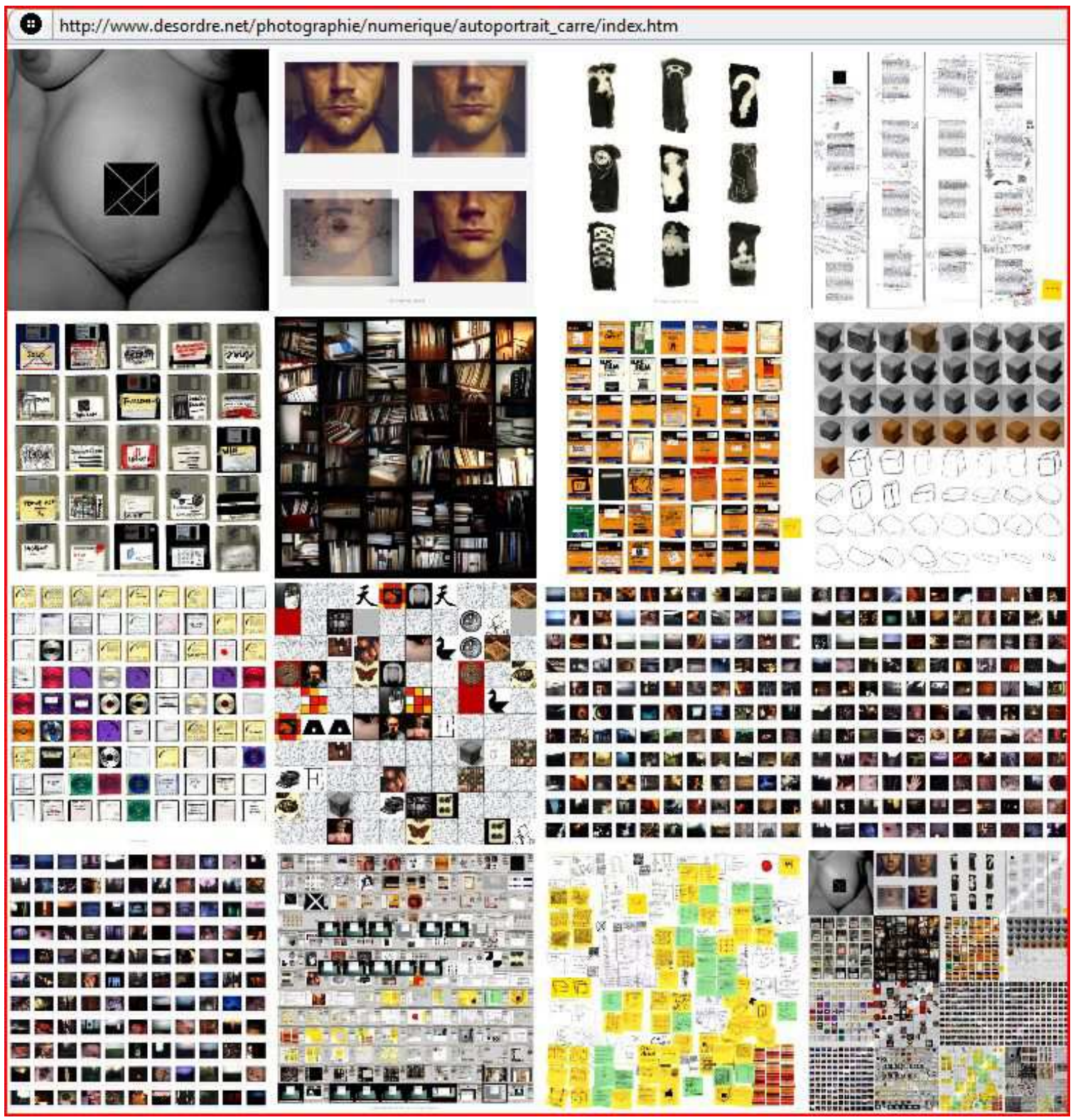

L'image est composée de plusieurs séries carrées qui pointent vers d'autres pages du site. Elle inclut une photo de sa femme enceinte marquée par la forme d'un tangram ; d'une série d'autoportraits au polaroïd intitulée «J'ai beaucoup changé » réalisé lors d'une séance de rasage; d'une série de rayogrammes qui renvoie au récit photo-textuel Les êtres chimériques; une partie du texte (en devenir) avec les corrections et annotations de son roman Chinois; les disquettes de sauvegarde 3,5 du site ; une série de photo de sa bibliothèque; les pochettes de ses photographies; une série de photo intitulée Soap opera sur la disparition progressive d'un savon; des CDs de musique ; l'ultime jeu de Memory; trois séries du journal photographique intitulé Pola Journal ; des clichés d'écrans sur le travail en cours dans le programme Photoshop; et enfin, des esquisses et des notes sur post-it. 
Contribuent à ce dispositif en devenir le dévoilement «des coulisses de la fabrication et des transformations ${ }^{123}$ », et la présentation de «la fabrication des images se fabriquant ». L'œuvre qui contient son propre devenir est prise dans un emboîtement sans fin, mise en abyme qui fait écho à l'épigraphe du site empruntée à Pierre Dac : «Et tout s'enchevêtra dans un désordre impeccable ».

À part la forme carrée qui symbolise l'œuvre en devenir, la juxtaposition, la sérialité et le hasard sont employés dans le principe de montage, jouant sur les sens qu'un désordre peut engendrer. De Jonckheere écrit à propos du parcours de lecture de son œuvre proposé par un ami :

Toutes ces images et ces textes qui se succèdent sans crier « Gare! » et qui cependant font presque systématiquement sens, demeure le plus étonnant à mes yeux dans cette affaire, à croire que si d'aventure on faisait aléatoirement se côtoyer deux images aux voisinages impensables, un pont finirait toujours par se construire, une pensée, effrayante, presque, pour ce quelle tient de possibles, et dont j'ai toujours eu l'intuition, mais jamais une aussi flagrante démonstration ... ${ }^{124}$

C'est le principe sur lequel se base ses récits photo-textuels (Champignons ${ }^{125}$, ou Trajets $^{126}$, par exemple) sur le sens qui jaillit de l'entre-deux. Une autre série, intitulée «Entre-Temps ${ }^{127} »$, repose sur cette même logique : une paire d'image, représentant une même chose prise à des moments différents créant un effet d'écart que souligne le texte.

Dans un des «Entre-temps », une anecdote ${ }^{128}$ nous raconte comment, un jour, le narrateur s'est rendu compte qu'habitant seul, il ne sait pas à quoi ressemble son appartement de l'extérieur quand la lumière est allumée à l'intérieur ; il l'observe alors et le photographie, puis, en rentrant, réalise que même s'il l'a vu maintes fois, il ne se rappelle pas à quoi ressemble de l'extérieur son appartement quand il n'y a personne et que la lumière est éteinte, donc il ressort pour le regarder et en faire une seconde photo. C'est de cette manière que la photographie tire les choses vers le dehors, vers l'existence, même si l'image est ensuite perdue, comme ce sera le cas de cette paire de photographies. Dans les autres paires, le texte vient s'intercaler entre les deux clichés, restituant, par le biais du temps que demande la lecture, l'écart temporel qui se forme entre les deux images.

\footnotetext{
${ }^{123}$ Voir notamment le plan du site, qui fut pendant longtemps la page d'accueil : http://www.desordre.net/plan.htm.

${ }^{124}$ http://www.desordre.net/labyrinthe/versions/versions_du_desordre_entier.html.

${ }^{125} \mathrm{http} / / / \mathrm{www} . d e s o r d r e . n e t / p h o t o g r a p h i e /$ rayogrammes/champignons/index.htm.

${ }^{126} \mathrm{http} / / / \mathrm{www} . d e s o r d r e . n e t / p h o t o g r a p h i e / n u m e r i q u e /$ trajets/voyages.htm.

${ }^{127} \mathrm{http} / / / \mathrm{www}$. desordre.net/textes/nouvelles/entretemps/index.htm.

${ }_{128}$ http://www.desordre.net/textes/nouvelles/entretemps/index.htm.
} 
Tout comme le journal intime, la pratique photographique se conçoit sur le mode du futur antérieur; anticipant le passage de l'instant, elle relativise le présent, son sens et sa valeur de vérité qui seront peut-être démentis demain, mais qui permettent aussi de devenir un souvenir, un ancrage auquel peut s'additionner un sens à chaque fois que la photo est revisitée, un sens mûri par l'écart du temps.

Dans les autobiographies, la vérité absolue du récit se trouve remise en question au profit d'une forme où le texte perd sa supériorité de moyen de transmission et l'on recourt à l'entre-deux d'un dispositif hybride ${ }^{129}$. Ou bien, à l'inverse, en choisissant de revendiquer le statut de fiction (ou autofiction), on obtient une valeur de vérité au second degré, qui ne cesse pour autant d'alimenter l'imagination du lecteur, d'avoir un impact sur lui. Se dessine alors une identité plurielle, débridée, non linéaire, juxtaposée, imagée et imaginaire, inconsciente et implicite. En tant que concept et en tant que pratique, la photographie participe à ce changement.

129 On pourrait même avancer que l'hétérogénéité ne concerne pas uniquement la représentation de l'identité par différents médias : ce n'est pas seulement l'identité qui devient fragmentaire, mais la vision du corps. Le corps hybride, moitié homme moitié machine, les cyborgs fréquemment représentés dans la science-fiction (livres, dessins, BDs, films), selon certains scientifiques, constituent déjà une réalité (une personne ayant un stimulateur cardiaque ou une hanche artificielle peut déjà correspondre à cette définition). 


\section{III.5. Photographie et fiction - la pluralité et la dissolution des frontières}

Si les récits autobiographiques et photobiographiques soulèvent la question de la part nécessairement fictive de l'identité - problématique qui dépasse celle de l'ancrage indiciel de la photo -, l'influence des récits en image appartenant à la culture populaire semble démontrer que l'usage de la photo dans des œuvres de fiction précédait le courant photobiographique, qui renouait alors, dans les années 1980, avec un discours réaliste déjà dépassé. L'évolution du roman-photo ou celle des éditions illustrées suivent un processus similaire, allant d'un rapport littéral entre le texte et l'image à des constructions hybrides reposant sur l'entre-deux.

Le premier livre illustré où la photographie joue un rôle dans la narration, Bruges-la-morte de Georges Rodenbach $^{2}$, est également une œuvre de fiction. Il relate l'histoire de Hugues Viane, qui n'arrive pas à surmonter la perte de sa femme jusqu'au jour où il rencontre une actrice qui ressemble à son épouse décédée. Dans son avertissement, l'auteur souligne que les clichés qui montrent la ville de Bruges, avec ses « quais, rues désertes, vieilles demeures, canaux ${ }^{3} »$, loin d'être un simple décor où se déroule l'action, deviennent le reflet psychologique

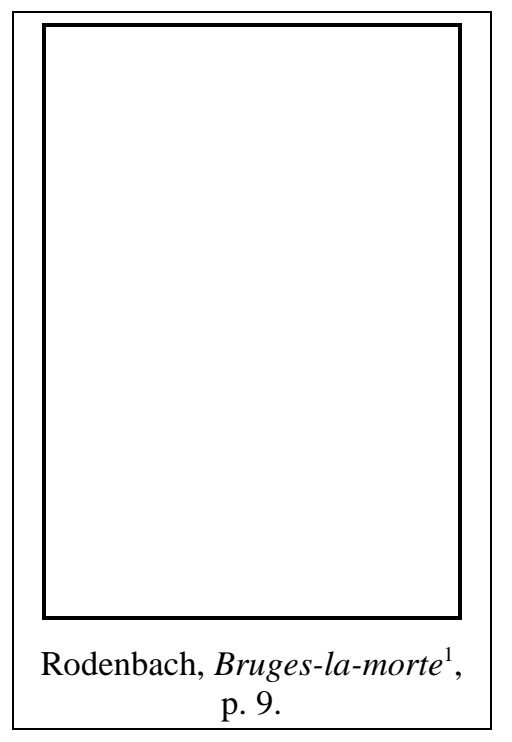
du héros, et préfigurent le dénouement dramatique du roman. L’insertion de clichés dans le livre veut faire partager aux lecteurs «la présence et l'influence de la Ville » pour qu'ils «sentent à leur tour l'ombre des hautes tours allongée sur le texte ${ }^{4} »$. Les tours sont réellement représentées sur les clichés avec des ombres tranchantes, mais les

\footnotetext{
${ }^{1}$ Voir l'image sur : http://sebald.files.wordpress.com/2007/08/bruges-canal.jpg (consulté le : 23/07/2009). ${ }^{2}$ RODENBACH, Georges, Bruges-la-morte, Paris, Flammarion, 1892. Le roman a été publié d'abord en feuilleton dans le Figaro en 1892, puis en livre chez Flammarion. Il a été réédité plusieurs fois, et il est actuellement disponible en texte intégral sans les images sur le site : http://users.skynet.be/fa007429/brutxt.htm (consulté le : 23/07/2009).

Il est également accessible avec des images de très mauvaise qualité sur google books : http://books.google.com/books?id=4FfsDI5QFUUC\&lpg=PA1\&dq=bruges $\% 201 \mathrm{l} \% 20 \mathrm{morte} \& \mathrm{hl}=\mathrm{fr} \& \mathrm{pg}=$ PA1\#v=onepage\&q=\&f=false (consulté le : 23/07/2009).

${ }^{3}$ « Avertissement de l'auteur», Ibid., p. 4-5.

${ }^{4}$ Ibid.
} 
reflets dans les canaux illustrent aussi l'idée d'une photographie comme interface où se reflètent le dehors et le dedans, la ville et l'âme du personnage ${ }^{5}$.

À leur tour, au début du $\mathrm{XX}^{\mathrm{e}}$ siècle, les collages et les photomontages de Dada et des surréalistes combinent photographies, dessins et textes, en recomposant le réel et en dépassant l'ancrage indiciel de la photographie. Breton lui-même pratiquait le collage ${ }^{6}$, mais suivant l'esthétique surréaliste, cette technique semblait révéler l'inconscient par le hasard objectif de la juxtaposition. On trouve toutefois des réalisations de cette époque dans ce qui est présenté explicitement comme une fiction. Magali Nachtergael cite $^{7}$, entre autres, la collaboration du photographe surréaliste Man Ray avec Max Morise et Marcel Duhamel qui donne lieu au roman-photo Les tribulations de Monsieur Wzzz... mettant en scène un personnage en fil de fer.

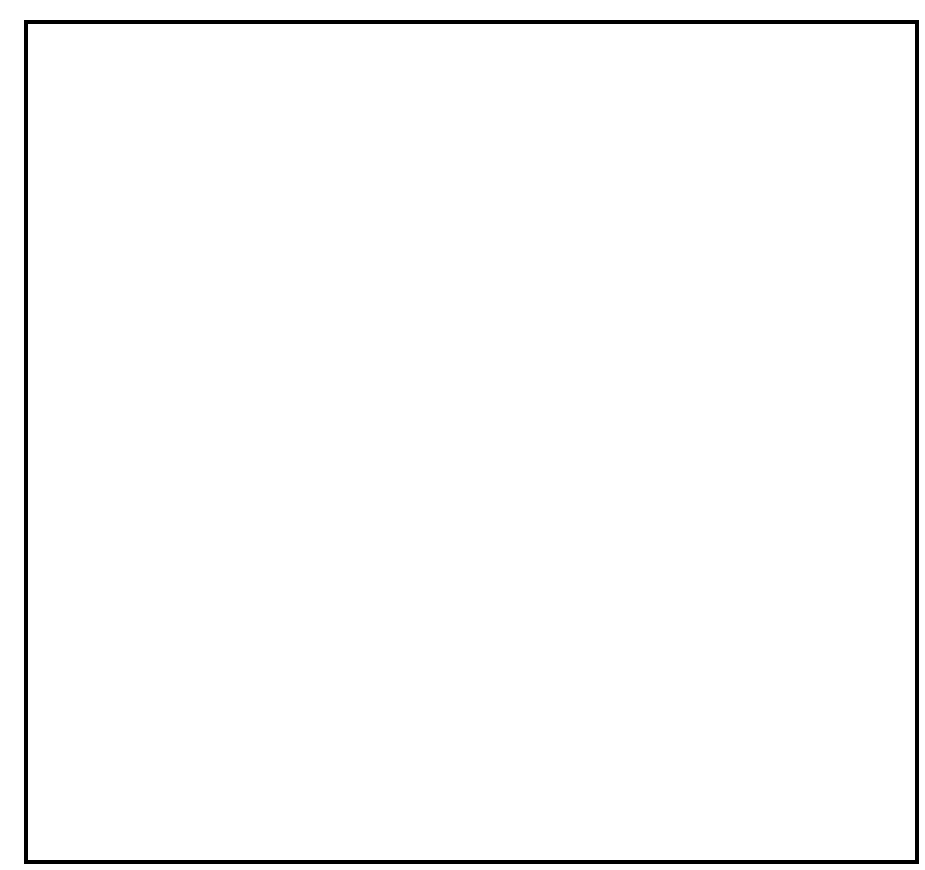

Max Morise, Marcel Duhamel, Man Ray, Les tribulations de Monsieur Wzzz..., 1928.

Le roman-photo est un des modèles de la culture populaire qui influencera les récitsphotos $^{8}$ (ou nouveaux romans-photos) qui apparaîtront dans les années 1970 (Duane Michals, Hervé Guibert). Le genre trouve son origine dans le ciné-roman, qui reprend en format carnet les principales images d'un film pour le rendre commercialisable. Le

\footnotetext{
${ }^{5}$ Voir sur le rôle de la photographie dans Bruges-la-morte les analyses de Jérôme Thélot, (Les inventions littéraires de la photographie, Paris, PUF, 2003) ; Daniel Grojnowski (Photographie et langage, Paris, José Corti, 2002) ; ou Magali Nachtergael, Ibid., p. 26-39.

${ }^{6}$ Ibid., p. 183.

${ }^{7}$ Ibid., p. 162.

${ }^{8}$ Ibid., p. 178-183.
} 
genre ne se transformera qu'après la Seconde Guerre Mondiale en feuilleton destiné majoritairement à un public féminin traitant d'histoires fictives souvent banales et stéréotypées, aux intrigues ressemblant aux «telenovelas ». Selon Benoît Peeters, l'origine strictement commerciale explique le peu de créations photo-littéraires inspirées par ce genre ${ }^{9}$. Dans ses propres romans-photos réalisés avec Marie-Françoise Plissart, Peeters explore les possibilités ouvertes par le mélange texte-image. Après la publication de Fugues ${ }^{10}$, une histoire de complot et de mésentente présentée selon le point de vue des trois personnages principaux, il constate que l'écriture ne fonctionne que comme un rajout, «il y a une rupture surtout quand c'est tracé à la main comme chez Duane Michals ${ }^{11} »$.

Dans Droit de regard ${ }^{12}$, il cherche alors à créer un récit en images sans aucun texte, un récit qui ressemble beaucoup aux séquences de Michals, avec ses jeux de miroir et son histoire en boucle qui se termine par la même image sur laquelle il s'ouvrait. La répartition des photographies sur l'espace de la page rapproche ses romans-photos davantage des bandes dessinées, car la taille et la disposition des cases sont également porteuses de sens. Ses autres récits-photos, Pragues ${ }^{13}$, ou Le mauvais $\propto e i l^{14}$, mettent également en place des dispositifs photo-littéraires uniques, jouant sur l'entre-deux de l'image et du texte, sur des effets de discordance, sur la typographie et sur la mise en page du texte (encadré par exemple comme une image-case autonome dans Le mauvais oeil dans l'exemple ci-contre).

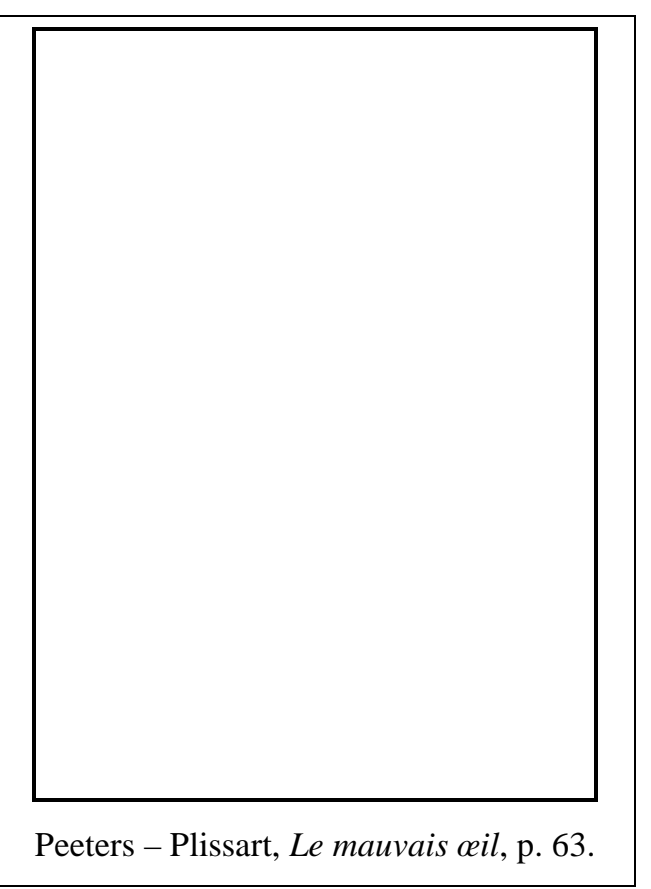

\footnotetext{
${ }^{9}$ PEETERS, Benoît Écrire l'image, Paris, Les impressions nouvelles, 2009.

${ }^{10}$ PEETERS, Benoît ; PLISSART, Marie-Françoise Fugues, Paris, Minuit, 1983.

${ }^{11}$ PEETERS, Benoît, Écrire l'image, Op. cit., p. 124.

${ }^{12}$ PEETERS, Benoît ; PLISSART, Marie-Françoise Plissart, Droit de regards, Paris, Minuit, 1985 (suivi d'une lecture de Jacques Derrida).

${ }^{13}$ PEETERS, Benoît ; PLISSART, Marie-Françoise, Prague, Paris, Autrement, 1985.

${ }^{14}$ PEETERS, Benoît; PLISSART, Marie-Françoise, Le mauvais ail, Paris, Minuit, 1986. Voir sur ce livre l'analyse de Laureline Meizel (d'où provient l'image insérée), La métalepse révélée au prisme du Mauvais oeil, un roman-photo de Benoît Peeters et Marie-Françoise Plissart. Image [\&] Narrative journal électronique, vol. X, issue 2, 2009. Disponible sur Internet (consulté le : 28/08/2009) : http://www.imageandnarrative.be/1_auteur_et_son_imaginaire/meizel.htm.
} 
Les romans-photos de Benoît Peeters, tout comme ses bandes dessinés de la série Les cités obscures, posent la question qui s'impose face à toute photographie: faut-il chercher la réalité derrière l'apparence ou l'apparence en elle-même constitue-telle une réalité ?

La photographe Marie-Françoise Plissart a également collaboré avec d'autres écrivains, pour des projets de genres différents : bande dessinée avec François Schuiten et Benoît Peeters (L'enfant penché; L'écho des cités; Voyage en utopie); livres destinés à la jeunesse avec Luc Dellisse (L'ours en cage ; La nuit d'en face); ou récit avec Filip de Boeck (Kinshasa. Récits de la ville invisible) ou avec Sandrine Willems (Élégie à Michel-Ange). Dans ce dernier on trouve une association singulière entre le texte et la photo: en plus des photos en double page, on trouve des clichés intégrés à l'initiale de début de chapitre, ce qui fait écho à la lettre ou initiale ornée dans les enluminures du Moyen-Âge (ci-dessous à gauche ${ }^{15}$ ).

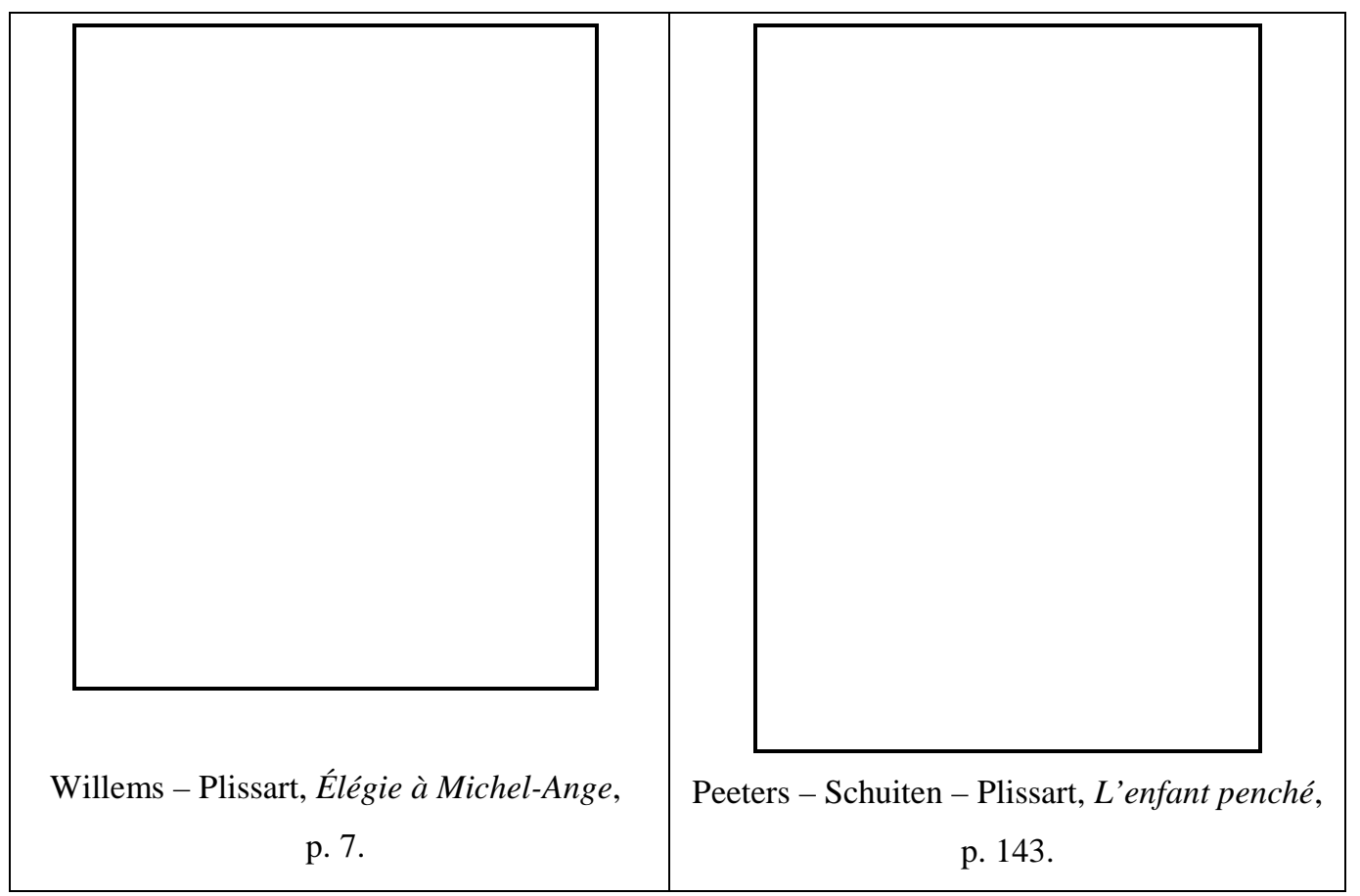

Dans les BDs mentionnées de Peeters/Schuiten/Plissart, la photographie est souvent combinée avec le dessin, faisant le pont entre les mondes parallèles qui sont mis en scène par l'un et l'autre médium. Dans L'écho des cités et Voyage en utopie, la photo

15 WILLEMS, Sandrine; PLISSART, Marie-Françoise, Élégie à Michel-Ange, Bruxelles, Les Impressions Nouvelles, 2005. Voir un extrait sur le site de l'éditeur :

http://www.lesimpressionsnouvelles.com/extraits/Michelangeextrait.pdf (consulté le : 28/08/2009). 
apparait comme un document qui problématise non plus la réalité, mais l'irréalité de ce monde imaginaire des Cités obscures.

Une bande dessinée récemment publiée, intitulée Le Photographe ${ }^{16}$, combine dans un récit autobiographique la photographie avec des images dessinées et du texte. Les trois tomes relatent l'histoire d'un photographe de presse, Didier Lefèvre, qui part en Afghanistan pour faire un reportage sur le travail de Médecins sans Frontières pendant la guerre contre l'Union Soviétique. Il ramène 4 mille clichés dont six seront publiés dans Libération ${ }^{17}$ le 27 décembre 1986. Treize ans plus tard, à l'incitation de son ami dessinateur Emmanuel Guibert, il en fera un livre en forme de BD.

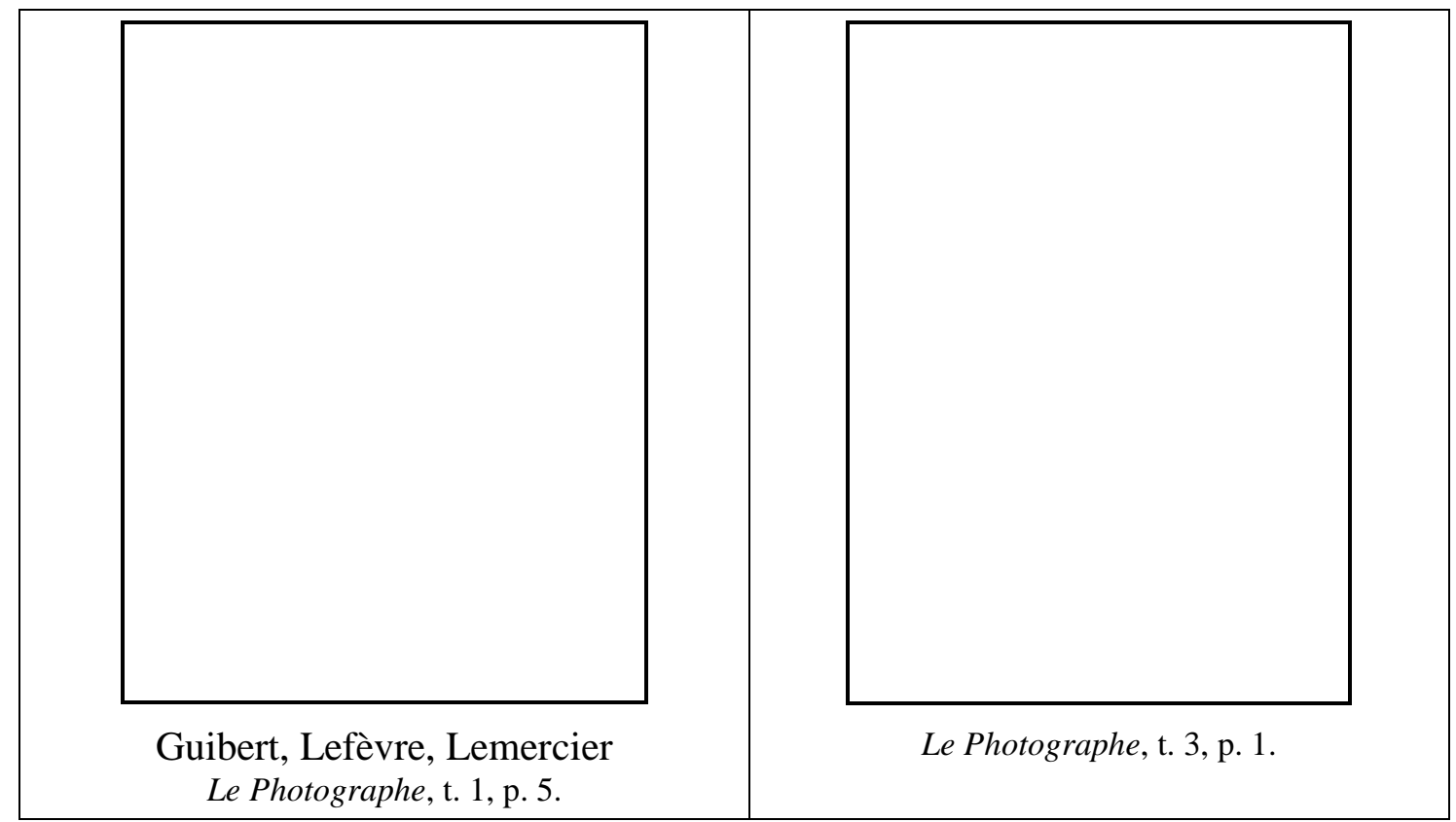

Il s'agit donc d'un récit rétrospectif où les planches contacts servent de base à la construction de l'histoire. Elles témoignent de l'écoulement du temps entre les prises de vues, mais parfois on y trouve la trace des photos retenues par le photographe, encadrées en rouge. Tandis que les photos révèlent toujours le point de vue du photographe, les dessins transcrivent le point de vue extérieur d'un narrateur omniscient (voir ci-dessous). Les bulles de texte ne s'ajoutent qu'aux dessins, s'ils ne forment pas une case séparée, mais de temps en temps plusieurs pages se succèdent sans texte

${ }^{16}$ GUIBERT, LEFEVRE, LEMERCIER, Le Photographe, Paris, Dupuis, tome 1-3, 2003-2006 Voir quelques extraits sur le site de l'éditeur : http://lephotographe.dupuis.com/didierlefevre.html (consulté le : 31/08/2009).

${ }^{17}$ Disponible sur le site de l'éditeur : http://lephotographe.dupuis.com/didierlefevre.html (consulté le : 31/08/2009). 
seulement avec des photos muettes, faisant parcourir au lecteur le paysage et le chemin rythmé par les rencontres occasionnelles de ceux qui viennent de face ou de ceux qui le dépassent.

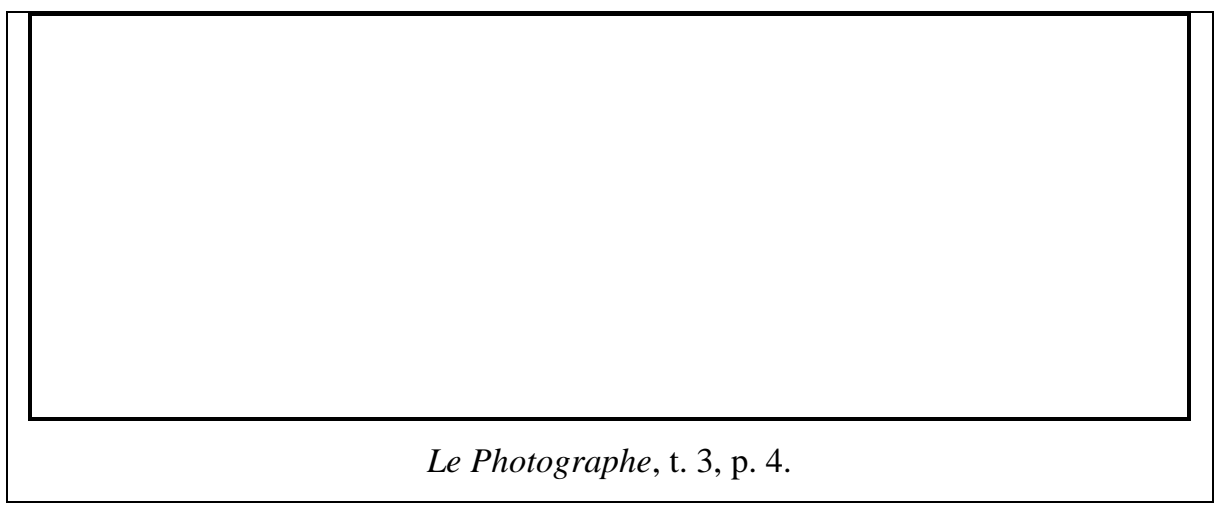

Les clichés accélèrent ou ralentissent l'histoire, proportionnellement à la taille qu'ils ont dans le livre. Ainsi au point culminant du troisième tome, les clichés occupent la page entière. Il s'agit de l'épisode où le narrateur franchit tout seul le col d'une montagne tandis que son cheval s'écroule, épuisé ; il croit alors réaliser ses derniers clichés avant de mourir. Ses images montrant le paysage enneigé, aride et sublime, et le cheval couché au premier plan, ralentissent l'histoire, en même temps qu'elles attestent par leur taille de la charge émotionnelle qu'elles véhiculent.

Ce dispositif hétérogène entraîne non seulement la dissolution des frontières entre les différents médiums, mais aussi le rapprochement entre la littérature «noble » et la littérature populaire. Le principe du livre constitue en lui-même un défi : comment transformer le genre de la bande dessinée, utilisé traditionnellement pour de la fiction, en un témoignage authentique de l'expérience vécue ? On pourrait classer ce livre dans la quatrième catégorie d'Heidi Peeters, où il n'importe plus que le récit soit une autofiction, et où, pour le lecteur, le photographe dessiné n'a pas moins de réalité que les photographies. On adhère à l'histoire et on suit les émotions dans lesquelles les photos nous emportent.

Parmi les genres « en marge » de la littérature, les œuvres destinées à la jeunesse semblent suivre la même évolution que l'illustration en général, allant d'une relation littérale d'illustration unissant l'image au texte à des dispositifs plus complexes. Ainsi 
en 1955 , le livre pour compter de Robert Doisneau ${ }^{18}, 1,2,3,4,5$, (ci-dessous à gauche) met en scène une vision idyllique de la campagne avec à chaque page des petits animaux (chatons, cannetons, etc.) à compter, tandis qu'en 2000 Tout un monde $e^{19}$, le livre de Katy Couprie et Antonin Louchard, construit un récit visuel sans texte avec parfois des photos abstraites déformées, présentant des raccords qui restent énigmatiques, restituant «tout un monde » dans le désordre de sa pluralité fragmentaire. Dans les livres destinés aux enfants, on retrouve ainsi toutes les techniques utilisées pour illustrer les œuvres littéraires. Par exemple, le Livre en image $\left(\right.$ Bilderbuch $\left.^{20}\right)$ de Hannah Höch contient des photomontages qui jouent entre la figuration et l'abstraction. Mais les livres de Tana Hoban, comme Les couleurs et des choses ${ }^{21}$ et Que vois-tu ?22 sont des livres-dispositifs impliquant la participation du lecteur. Dans Que vois-tu?, certaines pages interstices sont trouées, ce sont des pages fenêtres qui ne laissent entrevoir qu'une partie de la photographie se trouvant derrière. Il faut donc deviner avant de regarder de quoi il s'agit en tournant la page (dans l'exemple ci-dessous on voit le détail d'un tournesol). La découverte intensifie alors le plaisir de la lecture.

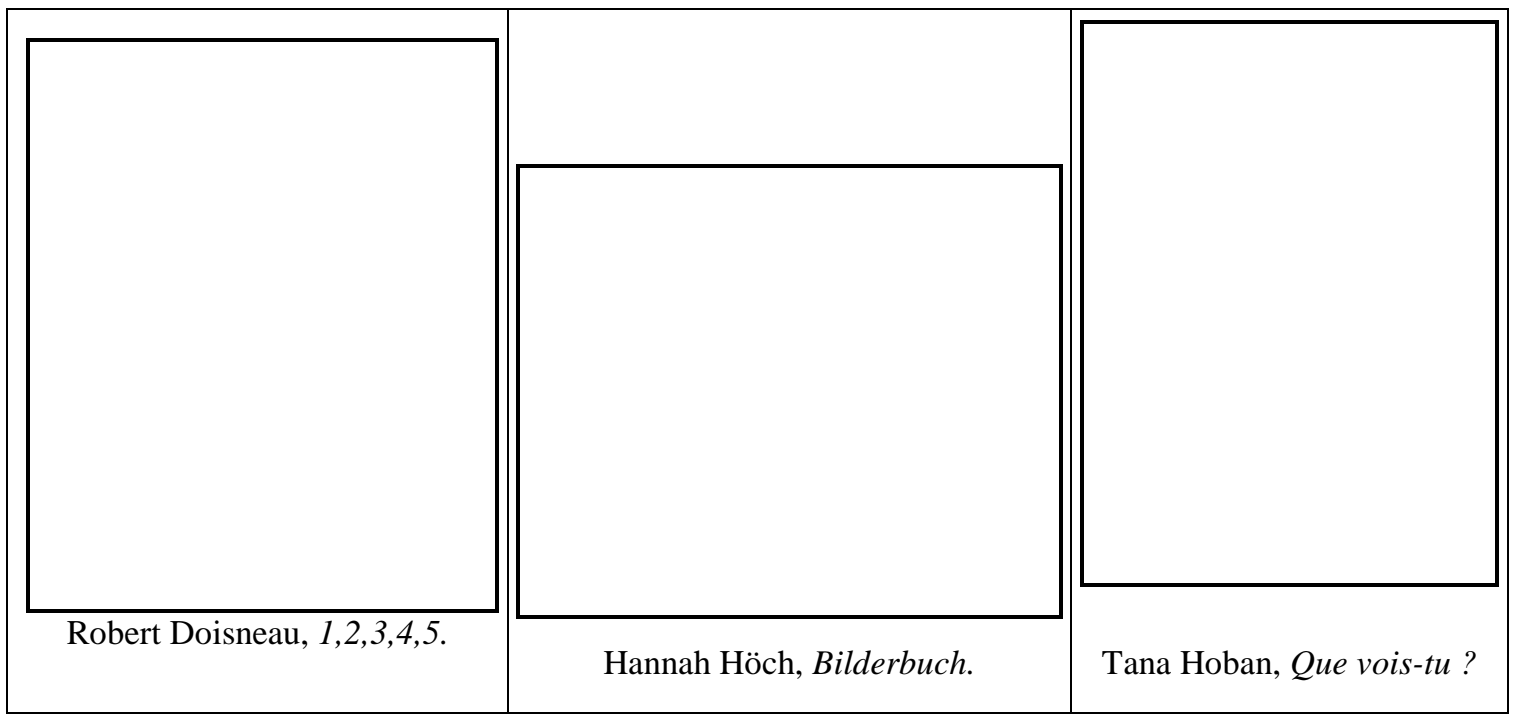

${ }^{18}$ DOISNEAU, Robert, 1,2,3,4,5, Lausanne, édition Clairefontaine, 1955. Voir l'image de la couverture : http://www.abaa.org/bibliozoom/image_viewer.php?imgURL=http://i.biblio.com/b/376x/231157376-0x.jpg.

${ }^{19}$ COUPRIE, Katy ; LOUCHARD, Antonin, Tout un monde, Paris, éd. Thierry Magnier, 2000.

${ }^{20}$ HÖCH, Hannah, Bilderbuch, Berlin, The Green Box, 2008 (réédition à partir du livre de 1945.) Voir un résumé en anglais sur le site de l'éditeur : http://www.thegreenbox.net/buecher_e/hoech_e.htm (consulté le : 31/08/2009).

${ }^{21}$ HOBAN, Tana, Les couleurs et des choses, Paris, L'école des loisirs, 1994. Voir une description des livres de Tana Hoban sur le site de Kaléidoscope, son éditeur français : http://www.editionskaleidoscope.com/AUTEURS-ET-LES-ILLUSTRATEURS/Hommages/tana-hoban.htm\#biblio.

${ }^{22}$ HOBAN, Tana, Que vois-tu ?, Paris, Kaléidoscope, 2003. Voir quelques extraits sur un blog: http://moncarnetamalices.over-blog.com/categorie-10180920.html (consulté le : 31/08/2009). 
Il faut noter toutefois, que l'apparition de nouveaux livres-dispositifs ne fait pas disparaître les illustrations littérales qui suivent le texte à la lettre.

L'élargissement de l'utilisation de la photographique dans les livres-dispositifs (présents dans tous les genres littéraires) est lié, comme le montre Magali Nachtergael, aux changements éditoriau ${ }^{23}$ : la réduction des coûts d'impression des images de bonne qualité et l'apparition d'alternatives dans les réseaux de diffusion permettent l'édition de livres à faible tirage. Ce phénomène est accéléré de nos jours par Internet et les livres virtuels (comme « cameo » ou « googlebooks »), mais à cela s'ajoutent certains services de photographie sur Internet qui proposent également l'impression en tirage limité de livres de photo : le client peut facilement éditer lui-même son livre grâce à un logiciel téléchargeable et il peut ainsi avec un peu d'investissement faire un livre de ses dernières photos de voyages par exemple. Cela permet (en théorie) à n'importe qui de publier un livre.

Avant cette évolution technique, dans les années 1980, certains éditeurs se firent les promoteurs de livres photo-littéraires. Ainsi, dans la collection «Les écrits sur l'image » dirigée par Alain Bergala, voient le jour La Correspondance new-yorkaise de Raymond Depardon, Suite Vénitienne de Sophie Calle, La disparition des lucioles de Denis Roche, ou le Manifeste photobiographique de Gilles Mora et de Claude Nori. Non seulement Bergala donne une visibilité à de jeunes photographes peu connus à l'époque (comme Sophie Calle), mais, selon Nachtergael, la collection veut aussi manifestement rompre avec la tradition française de la «belle image ». C'est à la même époque qu'aux éditions de Minuit paraissent les romans-photos de Benoît Peeters et Marie-Françoise Plissart, après la parution chez le même éditeur d'un premier romanphoto : Chausses-trappe de Lachman et Levine ${ }^{24}$.

Les publications illustrées de photographies prolifèrent ainsi dans des éditions qui allient un souci esthétique à une institutionnalisation du récit photographique comme forme littéraire à part entière : la quête de cette légitimité est très claire au sein des éditions de Minuit. En effet, Jérôme Lindon, d'après des propos de Benoît Peeters, «pensait créer le "Nouveau roman-photo" comme il avait créé le Nouveau Roman ${ }^{25} »$.

${ }^{23}$ NACHTERGAEL, Magali, Op. cit., p. 394-399.

24 LACHMAN, Edward; LEVINE, Elieba, Chausse-trappe, (Préface d'Alain Robbe-Grillet) Paris, Minuit, 1981.

${ }^{25}$ NACHTERGAEL, Magali, Op. cit., p. 398. Nachtergael cite notamment le mémoire de maîtrise de Laureline Meizel, qui a étudié plus amplement la genèse éditoriale des romans-photos publiés aux éditions de Minuit : MEIZEL, Laureline, Entre «scénarisation du visuel » et « visualisation du scénario 
C'est à l'instigation des éditeurs que se font des expérimentations liant texte et photographie. Ainsi les Carnets de voyage édités par Le Point du Jour combinent dans chaque livret une série de photos et le texte d'un écrivain, inspiré par les clichés. Comme le note Evelyne Rogniat ${ }^{26}$, le caractère expérimental des carnets donne lieu à des dispositifs phototextuels très divers.

Ce qui rend difficile la possibilité d'inventorier les productions photo-littéraires parues dans les trente dernières années, c'est que les maisons d'édition ne font pas non plus une distinction nette entre les différents genres, comme le note Nachtergael $^{27}$; ainsi on trouve quelques livres édités par des maisons d'édition non spécialisées comme Leo Scheer ou Gallimard. Mais le tirage restreint des éditeurs spécialisés, comme la maison d'édition Le Temps qu'il fait ${ }^{28}$ ou les éditions Fata Morgana ${ }^{29}$, rend également difficile la tâche d'inventaire, car ces livres sont difficilement accessibles. Avec l'avènement du numérique, on trouve également des éditeurs qui ne sont présents que sur le $\mathrm{Web}^{30}$ et dont les livres ne sont que peu diffusés dans les librairies, ou encore des œuvres présentées uniquement sur Internet, comme celles de plusieurs des invités du site « Désordre ${ }^{31} »$.

Partant des différents usages de la photographie qui se trouvent liés à la question de l'identité et à l'autobiographie nous sommes donc arrivés, au fil de ce long chapitre sur l'autobiographie photo-littéraire, à démontrer à plusieurs reprises que l'identité est pensée de nos jours par un modèle dynamique et complexe à l'image du « dispositif »

", le paradigme de l'équilibriste dans les récits photographiques de Benoît Peeters et Marie-Françoise Plissart, mémoire de Master 1, Paris I-Panthéon Sorbonne, inédit.

${ }^{26}$ ROGNIAT, Evelyne, «Chambres d'écho : propos sur la collection Carnet de voyage », in Littérature et photographie, Op. cit., p. 327-339.

${ }^{27}$ NACHTERGAEL, Magali, Op. cit., p. 395 et 431.

${ }^{28}$ Il s'agit de l'éditeur qui a publié les « textes et photographies » de Jean-Loup Trassard, Lorand Gaspar ou encore ceux de Gérard Macé, mais sur le site de l'éditeur (http://www.letempsquilfait.com/) on ne trouve pas non plus de rubrique spécialement dédiée aux œuvres photo-littéraires.

${ }^{29}$ Voir la liste des ouvrages photo-littéraires chez Fatamorgana tirés chacun seulement à 30 exemplaires : http://pagesperso-orange.fr/fatamorgana/collections/collec_hgm1.html (consulté le : 13/08/2009).

${ }^{30}$ Par exemple l'éditeur «Le Grand Os », spécialisé dans l'édition de livres d'artiste et de livres mêlant la poésie et la photographie. Voir : http://www.legrandos.com/htm_france/catalogue.htm\# (consulté le : 13/08/2009). Ou www.publie.net qui entre autres publie des œuvres photo-littéraires: (consulté le : 13/08/2009) http://www.publie.net/tnc/spip.php?mot9.

${ }^{31} \mathrm{http}: / /$ www.desordre.net/accessoires/graphismes/invites.htm (consulté le : 13/08/2009). Ou voir encore le site de Villabar qui propose des romans-photos en ligne : http://www.art-villabar.org/ (consulté le : 13/08/2009). 
comme notion philosophique. Ainsi l'ipséité décrit par Paul Ricœur intègre justement par la narrativité le temps et le devenir. On peut également démontrer un parallèle entre l'évolution de la théorie de la photographie et celle de l'autobiographie. Le caractère indiciel de la photographie (sa qualité de preuve et d'attestation) va de paire avec le pacte autobiographique qui suppose un rapport référentiel entre l'auteur et le narrateur. Pour ce qui est de l'autofiction (référentielle et fictionnelle à la fois), elle semble s'accorder avec la photographie contemporaine qui se donne à la fois comme document et fiction. L'idem serait alors lié à l'indicialité et à l'autobiographie tandis que l'autofiction serait un mélange d'idem et d'ipse. Le caractère «fictionnel » de l'autofiction paraît alors complexe. Comme on l'a vu, cette notion semble désigner plusieurs choses à la fois : des éléments imaginés sans valeur de vérité ; des éléments qui ont une valeur de vérité mais sont travesties et symboliques ou des éléments qui s'ancrent dans l'inconscient et l'imaginaire. Ce flou dans la définition favorise la confusion entre la réalité et le simulacre. Du point de vue pragmatique, dans l'effet produit par l'œuvre, la distinction entre la réalité et le simulacre n'est plus pertinente. C'est ainsi que dans le dernier sous-chapitre on a été amené à étudier quelques œuvres de fiction photo-littéraires qui ne revendiquent pas de pacte de véracité et utilisent tout de même l'image photographique dans diverses formes et diverses fonctions. C'est dans l'esprit de l'utilisation multiple de la photographie que nous avons évoqué les genres «en marge » de la littérature et que nous avons tracé les contours d'un état de l'évolution éditoriale contemporaine.

En effet, si on se place du côté de son utilisation, la pluralité caractérise à tous les niveaux les œuvres photo-littéraires : pluralité des genres, pluralité dans l'utilisation entre fiction et document, pluralité du type de dispositif employé et pluralité de leur diffusion. Les différents usages de la photographie que nous avons esquissés, son usage populaire, son usage dans les médias de masse, ses différents usages artistiques, participent également à cette pluralité - tout comme l'identité elle-même, sous le regard de la photographie, est pensée au pluriel. 
Pal, Gyöngyi. Le dispositif photo-littéraire en France dans la seconde moitie du XXe siècle Analyse de l'oeuvre de François-Marie Banier, Jean-Loup Trassard, Lorand Gaspar et Denis Roche - 2010 
II Partie : Zoom sur l'œuvre photo-littéraire de quelques écrivains photographes 


\section{Zoom sur l'œuvre photo-littéraire de quelques écrivains photographes}

Dans la partie précédente nous avons montré que l'utilisation de la photographie dans les œuvres photo-littéraires peut être très diverse et que la question de sa valeur de vérité n'a pas toujours d'importance. Cette partie analyse dans la même optique l'œuvre de quelques écrivains photographes pour explorer la multiplicité des usages à l'intérieur de l'œuvre d'une même personne.

François-Marie Banier, Jean-Loup Trassard, Lorand Gaspar et Denis Roche, malgré les différences d'âge, ont tous les quatre commencé à publier leur premier livre ou recueil de poésie dans les années 1960. Toutefois leurs pratiques littéraire et photographique sont dissemblables.

François-Marie Banier (1947) est le plus jeune parmi les quatre, pourtant au lieu d'être lié à des mouvements artistiques de sa génération, son œuvre s'inspire, entre autres, des écrivains et peintres de la première moitié $\mathrm{du} \mathrm{XX}^{\mathrm{e}}$ siècle : Louis Aragon, Samuel Beckett, Nathalie Sarraute, Salvador Dalí. Sa photographie se rapproche également de celle d'Henri Cartier-Bresson et il travaille lui-même à des reportages photographiques. Dans ses portraits, ses scènes de rue, il porte témoignage à l'enfance, à la vieillesse, aux marginaux et aux gens de la haute société. La sensibilité et la passion transparaissent dans son œuvre photo-littéraire, ainsi qu'une énergie par laquelle il cherche à transgresser les règles et à créer son propre style inclassable.

Jean-Loup Trassard (1933) s'intéresse à une branche de la photographie - tout à l'opposé du photojournalisme - à la photographie d'objet ou de paysage de sa terre natale. Au début de sa carrière littéraire, il faisait partie d'un groupe formé autour de Georges Lambrichs et des revues que ce dernier dirige : Les Cahiers du Chemin, puis la NRF. Les Cahiers du Chemin, à l'encontre de Tel Quel, refusait la critique littéraire et donnait la possibilité à des jeunes écrivains, qui cherchaient leurs propres voies, de publier leurs ouvrages. Trassard noue une amitié avec Jean Clay, journaliste et historien de l'art, et dans le cercle de Lambrichs avec Michel Chaillou, Michel Deguy et Gérard Macé. En 1980, il rencontre Georges Monti, éditeur de «Le Temps qu'il fait», où Trassard publie par la suite ses œuvres hybrides mêlant à chaque fois de différentes manières le texte et les photographies. 
C'est le même éditeur qui publie les œuvres hybrides de Lorand Gaspar (1925). Son parcours est pourtant bien différent. Il est médecin chirurgien et c'est en marge de cette activité, mais intimement lié à elle, que Gaspar réalise ses poèmes et ses photographies. De 1954 à 1970 il travaille à l'hôpital français de Jérusalem, puis il pratique au C.H.U. Charles-Nicole à Tunis de 1970 à 1995. Malgré la distance qui le sépare de la France, il est lié à beaucoup de poètes et artistes de sa génération, ce dont témoignent ses nombreuses collaborations (entre autres avec Étienne Hajdú, T’ang, Vieira da Silva, Arpad Szenes, Zao Wou-Ki). Une profonde amitié se dévoile également de sa correspondance avec Georges Perros ${ }^{1}$. La poésie de Gaspar naît pourtant de sa rencontre avec les déserts du Proche-Orient. Ses clichés pris lors de ses voyages forment alors une unité profonde avec sa poésie.

Denis Roche (1937) fait confondre lui aussi ses deux pratiques - photographique et poétique - en réalimentant ses expériences d'un domaine à l'autre et en explorant tour à tour les mêmes thématiques par les deux médiums (l'autoportrait, l'érotisme, la mort, le temps). Son approche, par rapport à celui de Gaspar, est plus conceptuelle et théorique. Il faisait d'ailleurs parti du comité de rédaction de la revue de littérature d'avant-garde Tel Quel formée autour de Philippe Sollers, une revue qui s'attaquait aux conventions littéraires de l'époque. Denis Roche a également créé et dirigé la collection «Fiction et Cie », au Seuil, jusqu'en 2005. Et, comme nous l'avons déjà évoqué, il fut membre fondateur en 1980, des Cahiers de la photographie avec Gilles Mora, Bernard Plossu et Claude Nori. Son œuvre est donc étroitement lié au courant photobiographique.

Nous allons donc étudier comment ces quatre auteurs questionnent et déconstruisent à leur tour la valeur de vérité de la photographie et éventuellement celle de l'autobiographie, comment ils utilisent les textes comme image ou le montage des livres pour créer des récits hybrides. En juxtaposant l'analyse de leurs œuvres photolittéraires nous chercherons des points communs qui caractériseraient cette double pratique qui est devenue visible et acceptée à la fin du XXe siècle sans pour autant qu'elle forme une école ou un mouvement revendiqué.

\footnotetext{
${ }^{1}$ GASPAR, Lorand ; PERROS, Georges, Correspondance 1966-1978, éd. établie et annotée par Thierry Gillyboeuf, Rennes, la Part commune, 2001.
} 


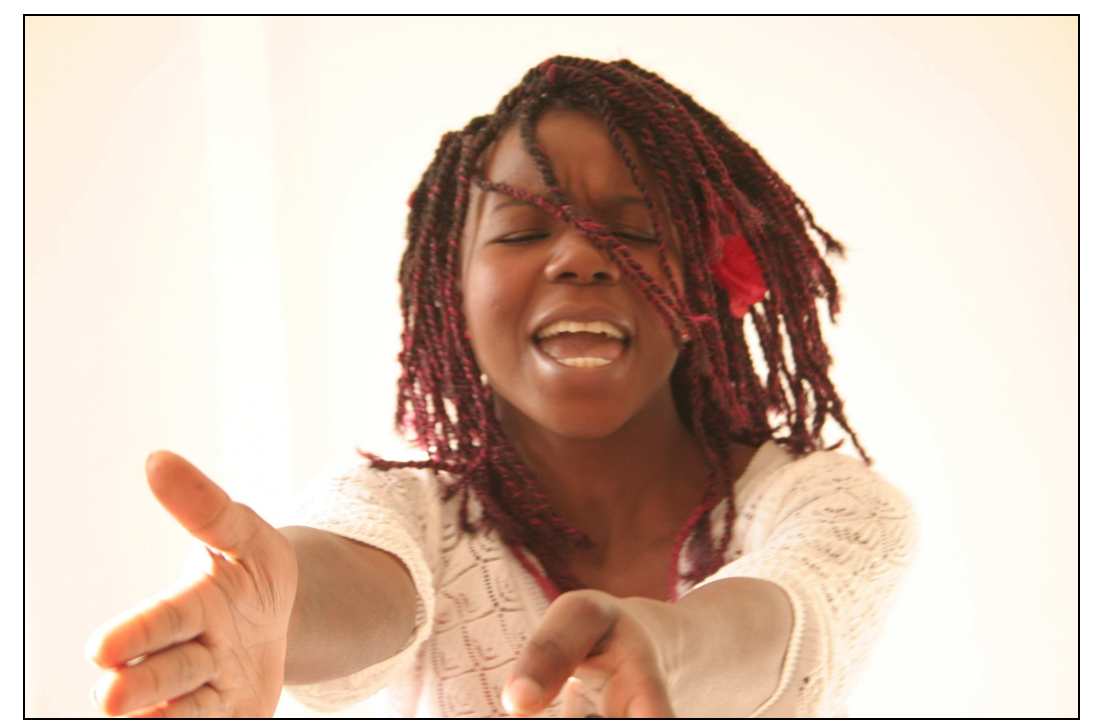

Pál Gy. : $\quad$ La passion de la vie 


\section{François-Marie Banier - la passion de la vie}

\section{Contenu du chapitre :}

V. François-Marie Banier - la passion de la vie

V.1. La famille universelle - le portraitiste de son temps

V.1.a. Les portraits d'écrivain - la photo intertextuelle 162

V.1.b. Portraits de peintre

V.2. Visages, passions

V.3. Photographie et théâtre

V.4. Iconotextes ou pratiques transversales

V.4.a. Les photographies écrites

V.4.b. Les photographies peintes.

V.5. Paratexte et parapicturalité.

V.6. La construction des livres et le récit visuel 205

V.6.a. Illustrations

V.7. La photographie dans les romans

V.8. Les jumeaux chez Banier.

V.9. François-Marie Banier - Conclusion

\section{Liste des abréviations}

Les résidences secondaires RS

Le passé composé $\quad P C$

La tête la première $\quad T P$

Balthazar, fils de famille $\quad B$

Les femmes du métro Pompe $\quad$ FM

Sur un air de fête $\quad$ SF 
L'œuvre de François-Marie Banier est particulière, car il combine plusieurs pratiques artistiques : la photographie, la peinture et l'écriture. Loin de tout courant esthétique contemporain il crée ainsi son propre style. François-Marie Banier est né à Paris en 1947. Selon Patrick Roegiers ${ }^{1}$ il pratique la photographie depuis l'âge de seize ans et publie son premier roman en 1969, à l'âge de vingt-deux ans. Toutefois, il ne commence à mêler les pratiques artistiques que tardivement dans les années 1990. L'œuvre de Banier se compose aujourd'hui de sept romans, de trois pièces de thêâtre, de huit livres photographiques et de quinze catalogues d'expositions personnelles. Des expositions lui ont été consacrées dans le monde entier au Japon, au Brésil, aux EtatsUnis, en Turquie, et dans plusieurs pays d'Europe. Il collabore régulièrement à des magazines en tant que reporter photographe, notamment aux Cahiers du cinéma et The New Yorker.

\footnotetext{
${ }^{1}$ ROEGIERS, Patrick, Un classique de la modernité, catalogue d'exposition François-Marie Banier, Tokyo Metropolitan Museum of Photography, Asahi Shimbun, 2000. (L'article est reproduite sur le site personnel de l'auteur : http://www.fmbanier.com/patrick roegiers 2 (consulté le : 15/05/2009).
} 


\section{V.1. La famille universelle - le portraitiste de son temps}

François-Marie Banier débute sa carrière littéraire avec son roman Les résidences secondaires $^{1}$ qui le fait très tôt remarquer par la critique pour son habileté à décrire les passions qui animent les milieux mondains, la vie oisive des grandes vacances dans la microsociété d'Héricy, résidence secondaire des parisiens. Ce premier roman contient déjà en germes les thèmes et le style qui caractériseront les clichés de Banier. L'histoire se présente comme une suite de portraits des habitants d'Héricy. On découvre les liens familiaux et amoureux qui unissent certains personnages, leurs manies, leurs passetemps, et ce n'est qu'en cours de route que nous apprenons que ces personnages gravitent autour de Thierry Dorival, héros du roman. Thierry est présenté comme un jeune homme, guidé par «le désir, le perpétuel désir ${ }^{2}$ » mais qui a aussi une part cachée, enfouie en lui, qu'il ne montre pas aux autres : «il n'était pas lui-même : il jouait une comédie, une comédie à personnages multiples ${ }^{3} »$. Dans la description de ses traits, ce sont également les passions qui dominent :

La beauté de Thierry Dorival était incontestable. Grand, les cheveux blonds, la tête haute, on lisait dans son regard une grande fierté d'avoir vingt ans. Il s'aimait à la folie, il aimait sa sensualité, ses lèvres, son ombre, sa voix, ses effets, la solitude, les autres, l'espagnol, le zoo de Vincennes, les impressionnistes, le cinéma, la musique. ${ }^{4}$

Son amitié avec André Mortimer, son amour pour Christine Le Murier, sa relation secrète avec Marguerite Solto, l'indifférence de ses parents présentent les difficultés de l'adolescence, l'âge où l'on n'est plus enfant mais pas encore adulte. Le roman se termine sur le projet de Thierry, sa décision de ne plus revenir à Héricy, lieu des passions de l'enfance, pour se lancer définitivement dans la vie. Ce projet est décrit sur le mode négatif, qui annonce déjà l'importance de la photographie dans les futurs textes de Banier :

Il n'irait plus cueillir le muguet en famille dans cet endroit que seule sa famille se vantait de connaître. Il n'ouvrirait plus les portes du garage où étaient entassés depuis des années sa voiture à pédales, son tricycle, sa bicyclette, ses jouets d'enfant. Il ne descendrait plus à la cave tirer le vin que les Dorival recevaient d'Aubussargues - c'était comme par hasard, là, et nulle part ailleurs,

${ }^{1}$ BANIER, François-Marie, Les résidences secondaires ou La vie distraite, Gallimard, Paris, "Folio" $\mathrm{n}^{\circ} 2444,1993$.

${ }^{2}$ Ibid., p. 23.

${ }^{3}$ Ibid.

${ }^{4}$ Ibid. 
qu'il y avait du bon vin. Il renonçait à son enfance, à son histoire, à tout ce qu'il aimait. Il abandonnerait Héricy. ${ }^{5}$

La description en négatif systématique dans le genre romanesque apparaît à la fin du $19^{\mathrm{e}}$ siècle, comme le suggère Philippe Ortel ${ }^{6}$, sous l'influence du procédé photographique. Ortel cite notamment comme exemple Une belle journée de Henry Céard. Si l'utilisation de la narration en négatif n'est qu'en partie liée à la photo, chez Banier il importe que les phrases négatives soient utilisées au futur. C'est une anticipation de la rupture avec l'enfance de Thierry, et ce mode au futur antérieur évoque la conception photographique de Banier: «Photographier parce que ce ne sera plus jamais comme $\mathrm{ça}^{7}{ }^{7}$. Comme Raymond Depardon ou Hervé Guibert, Banier ne voit pas dans l'acte la mélancolie d'un passé à jamais révolu et irrévocable, mais par l'anticipation de la perte une possibilité qui s'offre dans le présent d'agir pour en conserver au moins une trace.

Dès ce premier roman, Les résidences secondaires, nous trouvons en ébauche les thèmes et le style qui caractériseront les clichés de Banier, qu'il exposera assez tardivement. Sa première exposition, - une rétrospective au musée Georges Pompidou $^{8}$ - n'aura lieu qu'en 1991, quand l'artiste avait 44 ans. Banier révèle que c'est sous l'incitation d'Yves Saint Laurent qu'il organise cette première exposition :

C'est à Yves Saint Laurent, mon frère des années 1970, que je montre mes premières photographies de solitaires. Lui-même vit de façon retirée, pris par son métier et son désir de laisser une œuvre. [...] Yves, à qui j'apporte mes premières photographies, s'éprend de ces êtres à l'air délaissé mais qui avant tout sont pages de poésie. [...] Yves vibre comme si c'était lui que j'avais pris en flagrant délit de peine à vivre. Avec ferveur, il m'encourage, presque chaque jour, dans ma quête de vérités en marche, autant de points de départ à des monologues sans fin. ${ }^{9}$

Cette première exposition réunit essentiellement les photos de passants de rue et les portraits de célébrités. Ses portraits - plusieurs critiques insistent là-dessus - constituent une nouvelle famille, une famille intellectuelle, une famille de pensée prenant la place d'une famille de chair qu'il ne cesse de critiquer dans tous ses romans. « François-Marie

\footnotetext{
${ }^{5}$ Ibid., p. 132.

${ }^{6}$ ORTEL, Philippe, La Littérature à l'ère de la photographie, Nîmes, Jacqueline Chambon, 2002, p. 222227.

${ }^{7}$ BANIER, François-Marie, «La vie de la photo » paru dans plusieurs catalogue d'exposition mais le texte est disponible également sur le site de l'auteur: http://www.fmbanier.com/la_vie de la_photo (consulté le : 15/05/2009). Par la suite : «La vie de la photo » (les numéros de pages renvoient à l'album Rétrospective 2003, voir la note 9).

${ }^{8}$ Il s'agit de l'exposition rétrospective au Centre Georges Pompidou à Paris en 1991, dont a été tiré le catalogue intitulé Photographies (Paris, Gallimard / Denoël, 1991).

${ }^{9}$ «Yves Saint Laurent », François-Marie Banier, (catalogue de l'exposition, Paris, Maison européenne de la photographie, 26 mars-15 juin 2003), Paris, Gallimard, 2003, p. 324. Il s'agit du livre de la deuxième grande rétrospective qui a été consacrée à Banier, et pour le distinguer facilement des autres livres à titre similaire nous utiliserons désormais l'abréviation Rétrospective de 2003.
} 
Banier s'érige ainsi peu à peu une famille cosmopolite à sa mesure et son image ${ }^{10}{ }$ écrit Patrick Roegiers ; de même, Szegő György à propos de l'exposition de Banier à Budapest : «Il fonde une grande famille par ses photographies ${ }^{11}{ }$. C'est d'ailleurs ce que Banier laisse entendre quand il répond dans un entretien : «La plupart de mes modèles sont des artistes dont je partage la vie, amis dont j'aime et j'admire l'univers, l'art et la manière ${ }^{12} »$.

Curieusement, on trouve très peu de photographes (à l'exception d'Henri Cartier-Bresson ${ }^{13}$ ) dans le panthéon de Banier, mais plutôt des écrivains, des plasticiens, des architectes, des musiciens, des gens du théâtre, du monde du cinéma et de la mode, ainsi que des chefs d'État, des célébrités surtout françaises et anglophones. Ces portraits de gens connus sont publiés et exposés au milieu de gens de la rue, des ouvriers, des clochards, des handicapés, des vieillards et des gens habillés de manière extravagante. Ce mélange tisse une image du monde contemporain, projet qui n'est pas loin du travail photographique d'August Sander, qui tentait d'établir une certaine typologie du genre humain en photographiant ses contemporains ${ }^{14}$. Cependant chez Banier le personnage photographié n'est pas pris dans le décor de son lieu de travail, ce n'est pas l'identification à une classe sociale qui compte comme chez Sander, Banier est plutôt attiré par les pôles extrêmes, l'enfance et la vieillesse, les marginaux et les gens de la haute société, traités pourtant de la même manière, photographiés au moment de l'abandon, au moment où « grâce d'inattention, ils se révèlent ${ }^{15}$ ». Il s'agit pour lui de :

Photographier ce raccourci précieux: un sourire, l'air nonchalant ou décidé, ce geste, cette mimique qui sont l'axiome, la devise dont tout être est, plus ou moins malgré lui, le pantin. ${ }^{16}$

Banier se place par sa méthode dans la lignée des tendances contemporaines du portrait photographique. À propos de l'exposition intitulée Portraits/Visages, organisée par la

${ }^{10}$ ROEGIERS, Patrick, «Le roman photographique de François-Marie Banier », Rétrospective de 2003, p. 8. L'article est disponible sur le site de l'auteur : http://www.fmbanier.com/patrick_roegiers_1.

${ }^{11}$ SZEGÖ, György, «Szelíd paparazzo, vad festő » (Paparazzo tempéré, peintre effréné), Fotómüvészet (L'art photographique) 2001, $\mathrm{n}^{\circ} 1 / 2$.

${ }^{12}$ SANTANA, Raúl, «Un entretien avec François-Marie Banier », in BANIER, François-Marie, Fotos y pinturas (Photos et peintures), catalogue d'exposition, Buenos Aires, Centre Culturel Recoleta, 17 avril 21 mai 2000, publié à Paris, Gallimard, 2000, p. 34. Pour se référer à cet album nous utiliserons par la suite : Photos et peintures. Pour l'entretien voir : http://www.fmbanier.com/raul_santana (consulté le : $15 / 05 / 2009)$.

${ }^{13}$ Ce cliché est mentionné par Patrick Roegiers, mais il n'est pas publié dans les livres de Banier. Rétrospective de 2003, p. 7.

${ }^{14}$ Sur l'œuvre d'August Sander voir encore la page 33.

${ }^{15}$ BANIER François-Marie, « La vie de la photo », p. 330.

${ }^{16}$ Ibid., p. 331. 
Bibliothèque nationale de France, exposition qui retrace l'évolution du portrait de 1853 jusqu'à 2003, Thierry Grillet note qu'il s'agit désormais de :

[...] ne plus "tirer" le portrait, mais tourner autour, s'inscrire dans la périphérie, dans une sorte de marginalité. [...] Le visage cesse d'être le concept unificateur du portrait. Tous les jeux sur le dédoublement, la démultiplication des reflets, contribuent à ruiner ainsi la centralité du visage. ${ }^{17}$

Dans la série intitulée Le Regard des morts d'Alain Fleischer ${ }^{18}$, cet effacement doit être compris au sens littéral. Fleischer expose des portraits dans des bacs, des photos semblables à celles qu'on trouve sur les tombes des cimetières, et au cours de l'exposition même, les images disparaissent lentement du papier, soulignant ainsi leur précarité, le caractère éphémère du pouvoir de mémoire de la photographie. Même si, chez Banier, le visage ne s'efface pas, il y a rarement contact entre le photographié et le photographe, ce dernier essaye de se faire oublier lors de la prise de vue ; pas de pose, le sujet semble plutôt s'effacer dans le style du photographe. Son style s'apparente d'ailleurs à celui d'Henri Cartier-Bresson, qui dans ses portraits recherchait le « silence intérieur $\gg$ des personnes photographiées ${ }^{19}$.

\section{V.1.a. Les portraits d'écrivain - la photo intertextuelle}

Certains clichés de Banier, en plus d'être des portraits réussis, constituent un renvoi symbolique à l'œuvre des personnes représentées sur la photo. L'œuvre littéraire ou picturale de la personne représentée entre alors dans un dialogue intertextuel ou interpictural ${ }^{20}$ avec l'œuvre photo-littéraire de Banier. Ainsi fonctionnent notamment certains clichés d'écrivains. Photos souvenirs, mais aussi photos qui rendent hommage à l'œuvre de la personne représentée, tels les clichés de Louis Aragon, de Françoise

\footnotetext{
${ }^{17}$ GILLET, Thierry, «... et voici que la peau de son visage rayonnait... » in : AUBENAS, Sylvie (dir.); BIROLEAU, Anne (dir.), Portraits/Visages 1853-2003, Bibliothèque nationale de France/Gallimard, 2003, p. 13.

${ }^{18}$ Exposition au centre national de la photographie, Paris, avril-juillet 1995, cité par TISSERON, Serge, La mystère de la chambre claire. Photographie et inconscient, Paris, Les Belles Lettres, 1996, p. 70. Tisseron interprète cette série comme un projet photographique qui vise à nous faire accepter le deuil.

${ }^{19}$ Voir le livre publié à l'occasion de l'exposition Le Silence intérieur d'une victime consentante à la Fondation Henri Cartier Bresson, Paris, du 18 janvier au 9 avril 2006. Portraits par Henri CartierBresson, Paris, Thames \& Hudson, 2006.

${ }^{20}$ Nous employons ici les termes de Liliane Louvel, qui établit les rapports que peut entretenir un texte et une image en se basant sur la typologie de Gérard Genette. LOUVEL, Lilian, L' eil du texte, Presses Universitaire de Toulouse-Le Mirail, 1998, p. 142-143. Si Liliane Louvel définit ce terme d'interpicturalité comme un texte qui fait allusion à une image, nous élargissons ce terme en comprenant le rapport inverse : l'image qui fait allusion à un texte.
} 
Sagan, de Samuel Beckett, de Nathalie Sarraute, de Truman Capote, de Joyce Carol Oates, d'Emil Cioran, de Roland Barthes, de Claude Lévi-Strauss, de Salman Rushdie, de Tennessee Williams, de Bull Ogier, de Liv Ullmann, d'Ernesto Sabato ou encore de Michel Tournier. Sur les clichés de Louis Aragon et de Françoise Sagan, cette référence est même explicitée : en transformant ces clichés en photographie écrite ou peinte ${ }^{21}$, Banier inclue le titre de certains livres des auteurs portraiturés.

On trouve ainsi sur l'image d'Aragon ${ }^{22}$ les titres : Le paysan de Paris ; le Traité de style; Le fou d'Elsa; La peinture au défi. À côté de cette énumération, le texte de Banier raconte les circonstances de la prise de vue: l'habitude du poète de lire interminablement ses manuscrits pour ses invités.

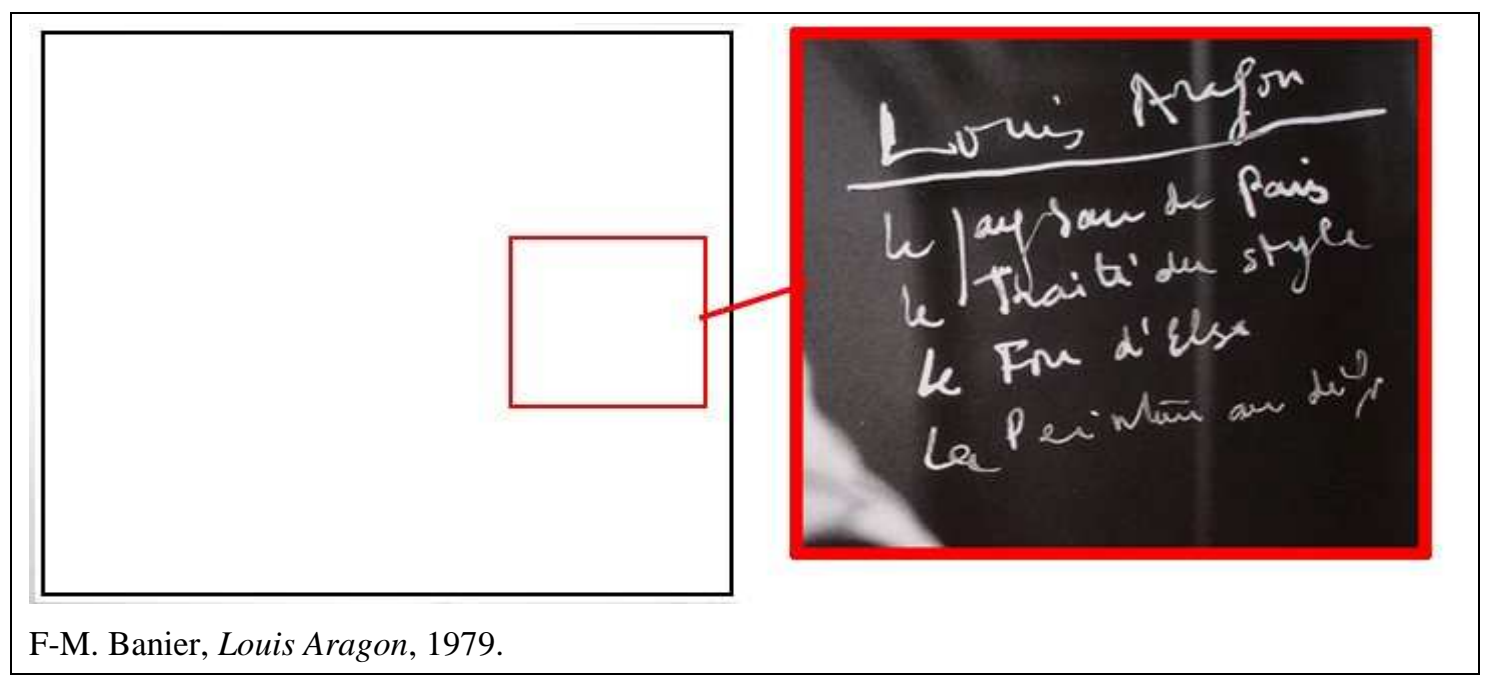

Les œuvres énumérées (est-ce un choix des lectures préférées de Banier ?) développent un regard nouveau sur la littérature, et introduisent plusieurs notions fondamentales dans l'ensemble des œuvres d'Aragon: les problématiques de la théorie de la connaissance et le merveilleux quotidien. Dans Le Paysan de Paris ${ }^{23}$ la longue rêverie sur le Passage de l'Opéra (lieu de rencontre des surréalistes qui était voué à disparaître pour laisser place au Boulevard Haussmann) incluent affiches publicitaires, images et mots qui attirent l'attention et éveillent la fantaisie du promeneur. Le hasard et les

${ }^{21}$ Voir sur ces méthodes le chapitre Iconotextes ou pratiques transversales à la page 186.

${ }^{22}$ Pour une question de place nous indiquons les titres complets des clichés dans les notes de bas de page. Louis Aragon, Paris, juin 1979. Pour l'écriture : ca. 1990, encre sur photographie, 50x60 Rétrospective de 2003, les photos s'insèrent hors pagination.

23 ARAGON, Louis, Le Paysan de Paris, Paris, Gallimard, 1926. Composé de 1924 à 1925, des prépublications avaient eu lieu dans La Revue Européenne. Voir sur la genèse du livre la présentation de Frank Meyer sur le site de l'Équipe de Recherche Interdisciplinaire sur Elsa Triolet et Louis Aragon : http://www.robertalessi.net/vigier/ERITA/spip.php?article87 (consulté le : 16/05/2009). 
rencontres inattendues sont l'occasion d'une révélation métaphysique du monde, et c'est ce que recherchent de façon privilégiée les surréalistes dans l'exploration du merveilleux quotidien. Ceci rappelle également la démarche des reporters photographes de cette époque (des années 1920-1930) parcourant la ville pour rapporter des clichés surprenants. François-Marie Banier adoptera à son tour cette méthode sillonnant Paris sur son scooter à la chasse aux images.

La particularité du livre Le Paysan de Paris se trouve dans l'hétérogénéité de sa structure où alternent collages textuels et graphiques, amalgame classé par Aragon sous le genre d'œuvre poétique. Ce dispositif éclaté s'apparente à la technique du collage pratiquée par les surréalistes ${ }^{24}$. D'ailleurs La peinture au déf $i^{25}$, un des autres titres que Banier indique sur sa photographie écrite, fait référence à une préface d'Aragon à une exposition de collages dans laquelle il retrace l'histoire du collage, citant le mouvement Dada et le cubisme, et où il analyse en profondeur les ouvrages surréalistes de Max Ernst, Salvador Dalí et Joan Miró.

François-Marie Banier ne fait pas de collages ${ }^{26}$, mais nous pouvons déceler dans son œuvre l'influence de ces mouvements avant-gardistes, surtout dans ses peintures et photographies peintes et dans sa manière désinvolte d'utiliser les couleurs, mêlant des mots aux taches et figures peintes, jusqu'à faire disparaître entièrement la photographie. La véhémence qui caractérise la peinture de Banier fait écho à la violence du Traité $d u$ style d'Aragon, qui se livre «à un jeu de massacre où rien de notre époque n'est épargné ou respecté : l'art, la politique, la morale, la civilisation occidentale ${ }^{27} \gg$. Dans cet essai polémique et provocateur qui manie l'insolence et l'humour, Aragon s'oppose également à la critique littéraire, qu'il accuse d'être aux mains de «prêtres démoralisés

\footnotetext{
${ }^{24}$ Comme le remarque Magali Nachtergael, cette composition narrative éclatée correspond à une quête d'identité qui rapproche la promenade du Paysan aux errances de Breton dans Paris et à son livre Nadja, qui est également composé de texte, dessins et photographies. NACHTERGAEL Magali, Esthétique des mythologies individuelles, thèse de doctorat, soutenu à l'Université Paris 7 sous la direction d'Eric Marty en 2008 , p. 121.

${ }^{25}$ Il s'agit de la préface au catalogue d'une exposition de collages à la Galérie Goemans (49, rue de la Seine, à Paris, mars 1930) qui sera repris dans: ARAGON, Louis, Les collages, Paris Hermann, 1980, p. 37-77.

${ }^{26}$ Le dessin intitulé «Nicoll Flemming » (11 mai 1995, 57 x $\left.77 \mathrm{~cm}\right)$ pourrait faire exception, car on trouve une image collée à la place d'un écran de télévision. Voir l'image sur le site de l'auteur: http://www.fmbanier.com/dessins_010_1 (consulté le : 10/10/2009).

${ }^{27}$ RISTAT Jean in : ARAGON, Louis, Traité du style, Paris, Gallimard, col. "L'imaginaire", 1928, texte du quatrième de couverture.
} 
d'un culte agonisant ${ }^{28} »$. Nous retrouvons là un autre trait commun avec Banier, qui a lui-même une attitude hostile envers la critique littéraire. La littérature, à l'opposé des institutions qui l'entourent, acquiert en revanche chez lui une fonction révolutionnaire et libératrice.

La littérature est de fait associée à une revendication de la liberté dans la photographie peinte de Françoise Sagan, où l'on trouve l'inscription « lit liberté » dans le coin gauche en haut de l'image.

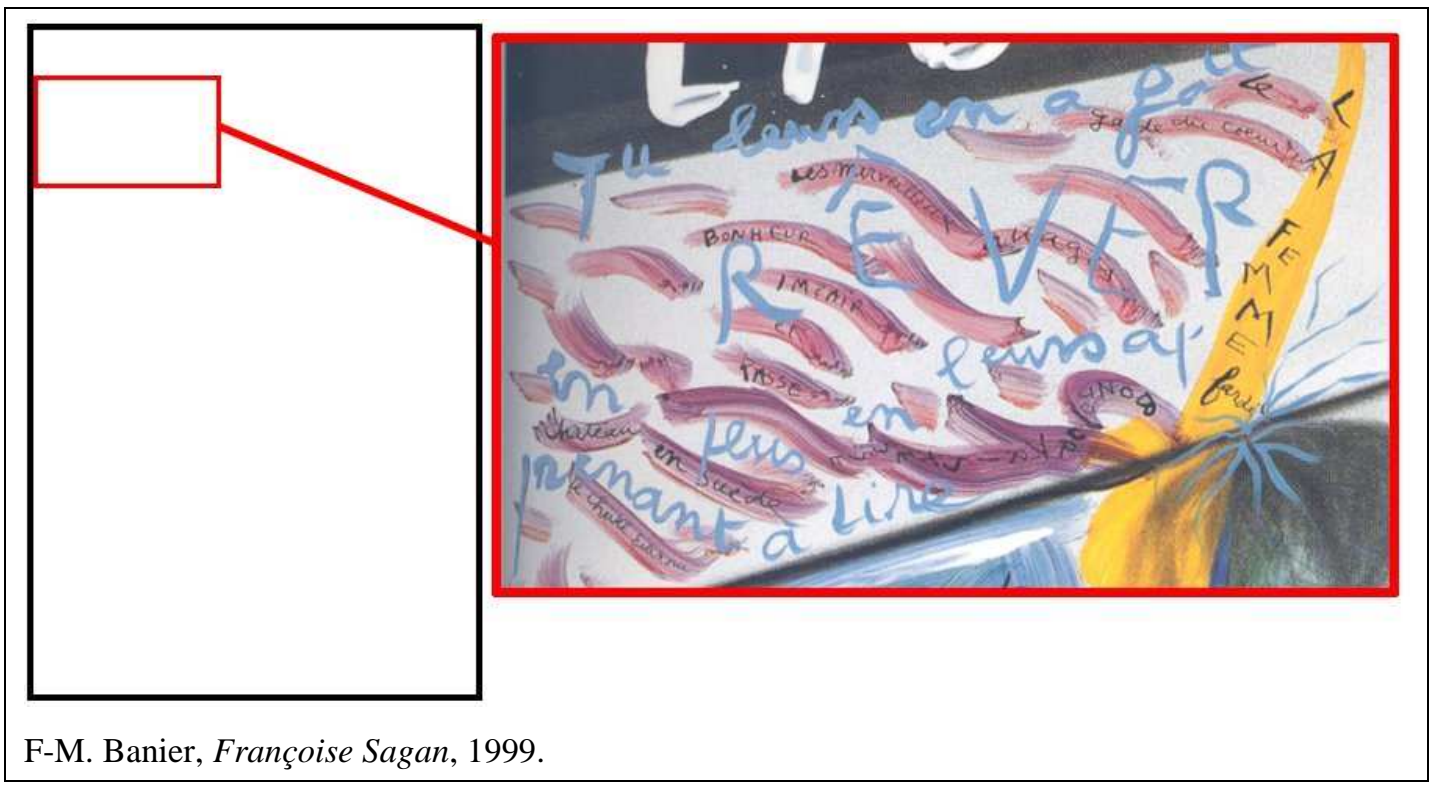

Sur l'image de Françoise Sagan ${ }^{29}$ (Rétrospective de 2003), Banier note également des titres de livres de l'auteure : Bonjour tristesse, La femme fardée, Le garde du cour, Les merveilleux nuages, Bonheur impair et passe, Château en suède, Le cheval évanoui. Il s'agit de quatre romans et trois pièces de théâtre. Nous pouvons de nouveau nous demander s'il s'agit d'un choix des lectures préférées, mais cette photographie peinte est aussi très intime et s'adresse à l'auteure par la phrase en bleu inscrite sur les titres : « tu leurs en a fait rêver en plus en leurs apprenant à lire » (voir ci-dessus dans l'extrait). Non seulement une amitié lie les deux auteurs, mais plusieurs de leurs livres traitent en effet des thèmes communs. Dans Bonjour Tristesse ${ }^{30}$, le premier roman que publie Sagan à l'âge de 18 ans, le personnage principal, Cécile est une jeune fille adolescente âgée de 17 ans qui découvre la vie, l'amour, comme le jeune héros des Résidences

${ }^{28}$ ARAGON, Louis, Traité du style, Op. cit., p. 42.

${ }^{29}$ Françoise Sagan, 1999, encre sur photographie, 160x110cm.

${ }^{30}$ SAGAN, Françoise, « Bonjour tristesse », Euvres, Paris, Robert Laffont, 1993, p. 3-65. 
secondaires $^{31}$ (le premier roman de Banier qu'il publie également très jeune). Les deux romans mettent en scène la vie oisive des vacanciers, prenant pour cadre une villa au bord de la Méditerranée avec peu de personnages chez Sagan, et Héricy, une résidence secondaire proche de Paris, où évolue toute une microsociété chez Banier. Le motif des vacances au bord de la mer rappelle d'ailleurs le roman Sur un air de fête ${ }^{32}$ de Banier, où le personnage principal, Guillaume Delastre, reporter photographe, passe un certain temps dans la villa du peintre Mendoza. L'amour accapareur de Guillaume pour Marie dans le même roman, fait alors penser au roman Les merveilleux nuages ${ }^{33}$ de Françoise Sagan.

On retrouve le même jeu de transcription d'éléments biographiques dans leurs romans. Les héroïnes de Sagan sous-tendent toujours une parenté avec l'auteur, tout comme l'identification de l'auteur et du narrateur est très présente dans l'œuvre de Banier. On retrouve l'auteur dans la figure de Balthazar, le fils mal aimé, ou bien dans Guillaume, le photographe ${ }^{34}$. Banier fait allusion, sur la photographie peinte de Sagan, à ce jeu consistant à semer l'équivoque entre la vie de ses personnages et sa propre vie :

Combien de fois nous lui avons demandé d'écrire sur elle... Comme si nous ne savions pas que sa politesse extrême n'était pas d'abord de la pudeur. À ne pas confondre avec prudence. Écrire le livre de Françoise... Sa malice, son courage, disons plutôt son intrépidité, son goût du jeu, du jeu qui fait que si on veut on n'a plus qu'à se pencher par le je qui la faisait tant rire chez les autres qui la plupart du temps la barbent. ${ }^{35}$

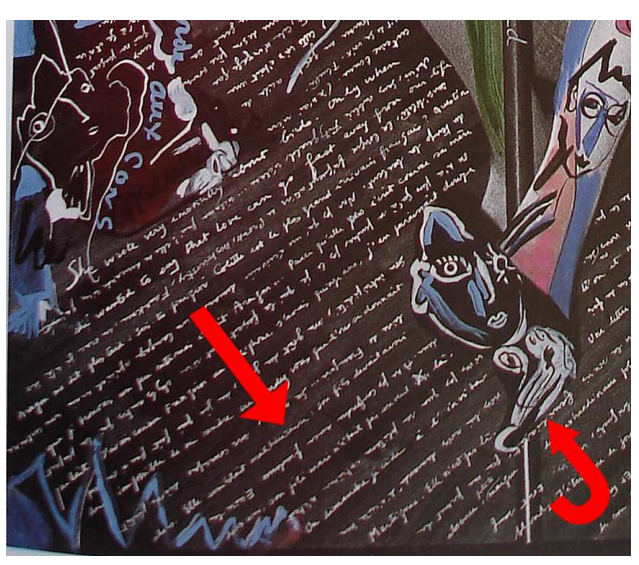

F-M. Banier, Françoise Sagan, « extrait ».

Banier écrit ces lignes dans un sens puis arrivé au bout de l'espace libre, il reprend dans le sens inverse. Ce jeu visuel fait penser à la méthode d'écriture de Marcel Proust qui dans ses carnets écrivait d'abord au recto puis reprenait le même cahier en sens inverse

\footnotetext{
${ }^{31}$ BANIER, François-Marie, Les résidences secondaires, Paris, Gallimard, "Folio" n²444, 1993.

${ }^{32}$ BANIER, François-Marie, Sur un air de fête, Paris, Gallimard, "Folio" n³283, 1999.

${ }^{33}$ SAGAN, Françoise, Les merveilleux nuages, in Euvres, Op. cit., p. 323-391.

${ }^{34}$ Voir le chapitre « La photographie dans les romans » p. 218.

35 Françoise Sagan, 1999, encre sur photographie, 160x110 cm, in Rétrospective de 2003, hors pagination.
} 
sur les pages du verso pour ajouter des notes et des corrections aux pages déjà écrites ${ }^{36}$. Proust ajoutait aussi des feuillets, des «paperoles », collés dans le cahier, témoignant d'un travail minutieux corrigé et réécrit à l'infini. Si nous rapprochons la méthode d'écriture de Proust à ce jeu visuel que pratique Banier sur la photographie peinte de Sagan, c'est que ce jeu peut également faire référence au fait que l'auteure a emprunté son nom d'écrivain à la Recherche de Temps Perdu.

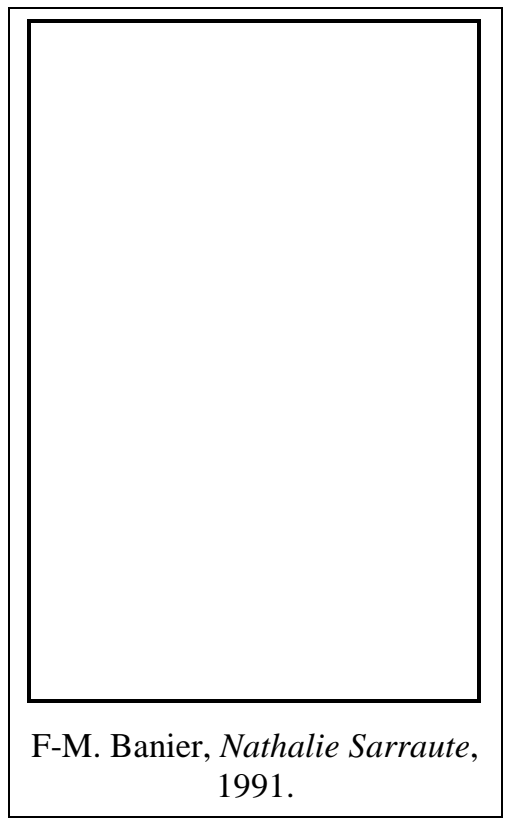

Une autre auteure dont l'œuvre dialogue avec celui de Banier est Nathalie Sarraute. Brice Matthieussent ${ }^{37}$ dans son analyse de la peinture de Banier recourt constamment à la comparaison avec les textes de Nathalie Sarraute, sans associer pour autant cette remarque au fait que les portraits de l'auteure ${ }^{38}$ permettent justement ce rapprochement, et que ces portraits de Sarraute fonctionnent alors comme des icônes intertextuelles. Matthieussent cite Nathalie Sarraute pour caractériser les textes qui surgissent sur les peintures et les photographies peintes de Banier. Capter les «sensations à l'état naissant », selon Matthieussent, constitue une méthode qui renvoie au livre Tropismes de Sarraute ainsi qu'à un passage du roman intitulé Martereau :

[ ...] des sortes de signes très rapides contenant tout cela, le résumant - telle une brève formule qui couronne une longue construction algébrique, qui exprime une série de combinaison chimiques compliquées - des signes si brefs et qui glissent en lui, en moi si vite que je ne pourrais jamais parvenir à bien les comprendre, à les saisir, je ne peux que retrouver par bribes et traduire gauchement par des mots ce que ces signes représentent, des impressions fugitives, des pensées, des sentiments souvent oubliés qui se sont amassés au court des années et qui maintenant assemblés comme une nombreuse et puissante armée derrière ses étendards, se regroupent, s'ébranlent vont déferler... ${ }^{39}$

\footnotetext{
${ }^{36}$ Voir : TADIE, Jean-Yves (dir), Marcel Proust, l'écriture et les arts, Paris, Gallimard/Bibliothèque nationale de France/Réunion des musées nationaux, 1999 (catalogue de l'exposition qui a eu lieu à la Bibliothèque nationale de France, du 9 novembre 1999 au 6 février 2000).

${ }^{37}$ MATTHIEUSSENT, Brice, «Une peinture sans début ni fin », in Photos et peintures, p. 105-118.

${ }^{38}$ Nathalie Sarraute, Oxford, juin 1991 (Rétrospective de 2003 ; Photos et peintures p. 73 ; Past present p. 110, (pour ce dernier : BANIER, François-Marie, Past-Present New-York, William Morrow, 1996). Voir sur le site personnel de l'auteur : http://www.fmbanier.com/photos_portraits_001_3 (consulté le : 15/04/2009).

${ }^{39}$ MATTHIEUSSENT, Brice, Op. cit., p. 117 citant l'ouvrage de Nathalie Sarraute, Martereau, Paris, Gallimard, 1972.
} 
Nous pouvons également nous demander si le point commun entre l'œuvre de Banier et celle de Nathalie Sarraute ne serait pas leur approche particulière de la réalité. Il existe selon Nathalie Sarraute deux sortes de réalité :

Il y a la réalité que tout le monde voit autour de soi, que chacun pourrait percevoir s'il se trouvait en face d'elle, une réalité connue, ou qu'il serait aisément possible de connaître, une réalité qui a été prospectée, étudiée depuis longtemps, exprimée dans des formes elles-mêmes connues, reproduites mille fois et mille fois imitées.

Ce n'est pas cette réalité-là qui est celle à laquelle s'attache le romancier. Elle n'est pour lui qu'une apparence, qu'un trompe-l'œil.

La réalité pour le romancier, c'est l'inconnu, l'invisible. ${ }^{40}$

Ancré dans la réalité visible, la photographie tend pourtant fixer l'autre réalité, l'invisible. De même, un parallèle s'établie entre le procédé de Sarraute qui utilise un «présent démesurément agrandi » ${ }^{41}$ décrit dans la préface de L'Ere du Soupçon et le procédé photographique qui gèle un instant, le découpe de la trame du temps pour l'agrandir, pour montrer justement la part invisible de la réalité, pour donner une autre signification à la réalité préexistante.

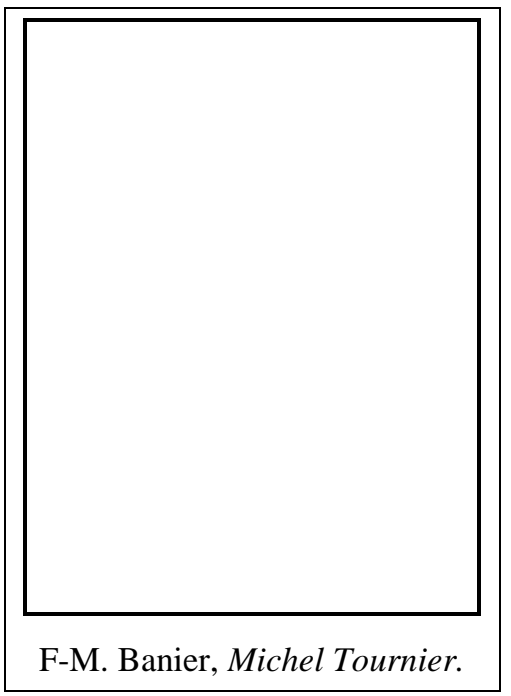

La photo de Michel Tournier et par conséquent son œuvre littéraire constitue un renvoi intertextuel d'une autre nature se mêlant au récit visuel du livre dans lequel se trouve le cliché. Ce dernier figure uniquement dans le livre Perdre la tête $e^{42}$, or ce livre est surtout axé sur les photos de gens de la rue, commençant et terminant sur une série de visage en gros plan affichant une expression qui peut sembler grotesque. Comment ne pas penser à la thématique de la scatologie et des ordures, sujets si chers à Tournier qui sous-tendent ses romans: Le Roi des Aulnes $^{43}$ et Les météores ${ }^{44}$. La photo a d'ailleurs été prise en 2004 comme la majorité des photos des gens de la rue (2004-2005), donc au cours de l'élaboration du projet. La photo de Tournier s'intègre particulièrement bien dans le contexte du livre Perdre la tête, mais d'autres thématiques rapprochent également les deux écrivains, notamment le

\footnotetext{
${ }^{40}$ SARRAUTE, Nathalie, Roman et réalité, in CEuvres complètes, Paris, Gallimard, 1996, p. 1644.

${ }^{41}$ SARRAUTE, Nathalie, L'ère du soupçon, Paris, Gallimard, 1956, p. 9.

${ }^{42}$ BANIER, François-Marie, Perdre la tête, Martin d'Orgeval (éd.), cat. Rome, Académie de France à Rome, Villa Medici; Nice, Théâtre de la Photographie et de l'image, Gallimard/Steidl, 2005-2006, p. 165.

${ }^{43}$ TOURNIER, Michel, Le Roi des Aulnes, Paris, Gallimard, collection Folio n ${ }^{\circ} 656,1970$.

${ }^{44}$ TOURNIER, Michel, Les météores, Paris, Gallimard, collection Folio n905, 1975.
} 
thème des jumeaux. Les personnages principaux du roman Les Météores sont des jumeaux, et le livre parle de la gémellité et de la quête de l'autre. L'imaginaire du livre Les Météores vient hanter les photographies de jumeaux de Banier ${ }^{45}$.

La gémellité est d'ailleurs un des deux thèmes que Tournier retient à son tour dans sa préface au catalogue de Banier intitulé On the $E d g e^{46}$. L'autre thème dont il écrit est celui du Brésil ${ }^{47}$, dont les clichés rejoignent l'imaginaire tournieresque célébrant la nudité et la beauté des corps, ces «nudités somptueuses » qui évoquent selon Tournier le paradis terrestre, une «terre de chair et de soleil, visages lumineux éclairés par l'amour de la vie, corps souples et sensuels qui appellent le $\operatorname{contact}^{48} »$. Chez Tournier, la célébration de la chair est mêlée dans ses livres à des mythes religieux (au thème de la transfiguration de la chair, ou encore à Adam et l'enfant androgyne). Le fragment de La vie de la photo dans lequel Banier utilise un registre religieux pour décrire la photographie peut être alors, à son tour, interprété comme une référence à l'œuvre de Tournier - remarquons d'ailleurs que sur le cliché de Tournier (Perdre la tête, p.165) à l'arrière plan flou nous devinons les contours d'une église, une fenêtre en ogive. Ainsi Banier note sur le visage dans La vie de la photo:

La force de ce qu'on appelle une tête. Représenté un milliard de fois, et forcément toujours à la manière de l'artiste, le Christ, malgré toutes ces «approximations », ces «transfigurations », aura toujours ce même regard bon, ce nez puissant, les mêmes cheveux qui encadrent des lèvres légèrement charnues puis effilées. Même peint autrement, menton rond, ou, par dérision, les cheveux en brosse ou cachés par une perruque, un détail, quelque chose, vous rappelle que c'est Lui, et, d'un coup, malgré les vandales, le «véritable Visage », le même que nous lui attribuons au fil des siècles, réapparaît. ${ }^{49}$

Le « véritable Visage » du Christ, celui qui est révélé par le voile de Véronique (l’image vraie $=$ «veron icon $»)$ forme en effet la base du récit de Tournier intitulé Les suaires de Véronique $^{50}$. Dans ce dernier, Véronique est photographe professionnelle et fait des expériences de photographie directe sur un modèle masculin appellé Hector. La

\footnotetext{
${ }^{45}$ Voir encore sur ce sujet le sous-chapitre : «Les jumeaux chez Banier » p. 221.

${ }^{46}$ Michel Tournier, « François-Marie Banier et la création photographique », On the Edge, Museum House Lange, Krefeld, 2004 (disponible également sur Internet sur le site personnel de l'auteur: http://www.fmbanier.com/michel tournier consulté le : 13/05/2009).

${ }^{47}$ Voir les clichés de Banier dans : BANIER, François-Marie, Brésil, Paris, Gallimard, 2001.

${ }^{48} \mathrm{Ibid}$. Il développe les mêmes sujets dans ses préfaces aux albums du photographe Gian Paolo Barbieri présentant des autochtones nus, jeunes, musclés et naturels. BARBIERI, Gian Paolo, Madagascar, Paris, édition Assouline, 1995, préface de Michel Tournier «La substance grise de Madagascar»; et BARBIERI, Gian Paolo, Tahiti Tatoos, Cologne, éd. Taschen, 1998, préface de Michel Tournier «Quand la peau parle ».

${ }^{49}$ BANIER, François-Marie, « La vie de la photo », p. 331.

${ }^{50}$ TOURNIER, Michel, «Les suaires de Véronique », Le Coq de bruyère, Paris, Gallimard, 1978, p. 139159.
} 
mythologie grecque, les références à la Bible se mêlent aux les croyances populaires sur la photographie dans cette histoire qui aboutit à la mise à mort et à l'effacement du modèle pour laisser place à l'effigie imprimée sur les toiles de lin du photographe.

La caractéristique principale des mythologies se trouve dans leur constante reformulation ou «mise à jour», conformément à leurs origines quand elles se transmettaient par la parole, et subissaient les changements que chaque conteur y ajoutait. Les jumeaux, le voile de Véronique sont deux mythologies récupérées par la photographie, devenues peut-être déjà des lieux communs, que les deux auteurs, François-Marie Banier et Michel Tournier exploitent respectivement.

Il est impossible de retracer tous les liens qui unissent les œuvres des écrivains portraiturés aux œuvres de Banier pour leur nombre considérable ; mais nous supposons que le photographe attache une plus grande importance à ceux dont le cliché est repris dans plusieurs de ses livres. C'est le cas des personnes mentionnées jusqu'ici (sauf pour Michel Tournier qui s'intègre avant tout dans le contexte particulier du livre Perdre la tête).

François-Marie Banier ne publie aucun texte critique sur la littérature. Par contre sur la photographie, on trouve plusieurs entretiens et un essai fragmentaire, La vie de la photo, texte déjà mentionné, qu'il republie dans plusieurs de ses albums ${ }^{51}$. Ces photographies d'écrivains fonctionnent alors comme un palimpseste iconique, qui remplace le discours critique ou simplement comme un hommage, un renvoi laconique et énigmatique qu'offrent les photos.

\section{V.1.b. $\quad$ Portraits de peintre}

Dans l'album Rétrospective de 2003 nous trouvons plusieurs portraits d'artistes : Arata Isozaki (architecte japonais), Ettore Sottsass (architecte et designer italien), Anish Kapoor (plasticien contemporain, principalement sculpteur, britannique d'origine indienne), Salvador Dali (peintre surréaliste), Andy Warhol (artiste du Pop Art), Louise Bourgeois (sculpteur), ou encore, dans l'univers de la mode: Yves Saint-Laurent

\footnotetext{
${ }^{51}$ On retrouve le texte dans Rétrospective de 1991, dans Rétrospective de 2003, dans Vivre, dans Private Heroes, ainsi que sur son site Internet. Voir les références complètes dans la bibliographie la section: Photographies de François-Marie Banier.
} 
(couturier), Madame Grès (couturière), Diana Vreeland (journaliste et éditrice du monde de la mode).

Puisque Banier pratique lui-même la peinture, on peut chercher des liens qui uniraient son œuvre, avant tout, à l'œuvre des peintres photographiés : il s'agit de Salvador Dalí, Andy Warhol et Alex Katz, dont le portrait figure dans Perdre la tête. Salvador Dalí est représenté sur plusieurs photos publiées. Celle de Rétrospective 2003 (ci-contre ${ }^{52}$ ) le montre assis sur un coin de chaise avec un air interrogateur dirigé vers une troisième personne qui se situe hors champ. Banier révèle qu'à l'âge de 16 ans, il est allé montrer ses propres peintures à Dalí, et qu'il a même pris des cours chez lui :

Je jetais des taches d'encre sur des feuilles de papier Canson. Pollock avait fait ça beaucoup plus tôt, ce que j'ignorais. En revanche ce que je savais, et que je ressentais, c'étaient les vibrations de ces dessins, la vie qu'ils recelaient. C'est avec ces dessins que je suis allé trouver la première fois Salvador Dalí pour en parler.

Dalí n'a pas vu Pollock dans ces taches. Mais il a vu moi. Avec qui il pourrait très bien s'amuser, ce que nous avons fait pendant quinze longues années. J'ai posé pour lui, j'ai suivi ses cours de dessin qui ne m'apportaient rien, en revanche j'ai beaucoup appris de sa curieuse façon de voir l'autre, de l'écouter [...] Son regard sur l'art, sa culture, ses goûts si bizarres ont renforcé mon esprit de liberté. ${ }^{53}$

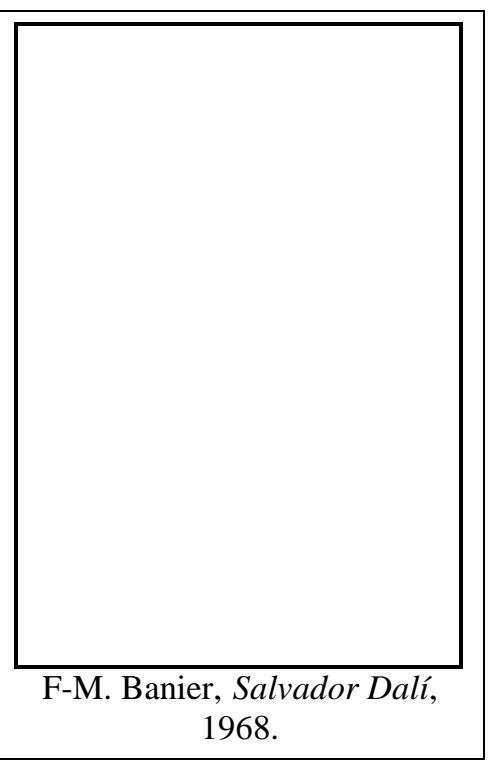

Dans les peintures et photographies peintes de Banier la liberté de l'esprit se traduit dans le geste créateur. Patrick Rogers décrit sa peinture comme :

Éruptive et pulsionnelle, située entre Keith Haring, Sigmar Polke et Cy Twombly, cette peinture d'éclaboussures et de giclures, séduit par ses teintes vives et pimpantes qui clament d'elles-mêmes ce que l'acte de peindre a de jouissif et de libérateur. ${ }^{54}$

Au delà de la liberté qu'elle revendique, sa peinture s'apparente au surréalisme par les thèmes, puisque souvent hormis les formes abstraites et les jets de couleurs pollockien, sa peinture figurative et narrative se caractérise par la mise en scène de souvenirs, rêves ou désirs. Parmi les peintres surréalistes, la peinture de Banier s'apparenterait alors à l'œuvre de Joan Miró, dont les toiles s'élaborent par accumulation de signes, des signes

52 Salvador Dalí, Paris, mai 1968, Rétrospective 2003.

${ }^{53}$ SANTANA, Raúl, «Entretien avec François-Marie Banier », Op. cit., Photos et peinture, p. 35.

${ }^{54}$ ROEGIERS, Patrick, Un classique de la modernité, Op. cit. (L'article est reproduit sur le site personnel de l'auteur : http://www.fmbanier.com/patrick_roegiers_2 (consulté le : 15/05/2009). 
qui constituent son monde, un monde stellaire chez Miró, «qui est cryptographie et sismographie du cosmos, des corps, de leur danse ${ }^{55} »$. Chez Banier comme chez Miró, peuvent figurer des mots sur la toile, et les signes viennent chez tous les deux s'inscrire sur une surface homogène, un arrière-plan qui rappelle le vide d'une feuille d'écriture. Jean-Pierre Mourey déclare que Miró «invente un alphabet et une plastique qui transforme la toile en planche à lire à déchiffrer ${ }^{56} »$; cette citation est également applicable à Banier.

Dans le livre Rétrospective de 2003, la photo de Salvador Dalí est suivie de celle d'Andy Warhol ${ }^{57}$ (cidessus à droite). Le portrait frontal de Warhol le montre avec un appareil photo en train d'adresser la parole au photographe, donc nous trouvons de nouveau le regard porté vers le hors champ comme sur la photo de Dalí. La photo a été prise probablement avant, ou après que Warhol ait pris lui aussi une photo. Andy Warhol portraituré avec un appareil photo dans la main, peut faire allusion au fait que Warhol était le premier à utiliser la photographie et l'aspect mécanique de la

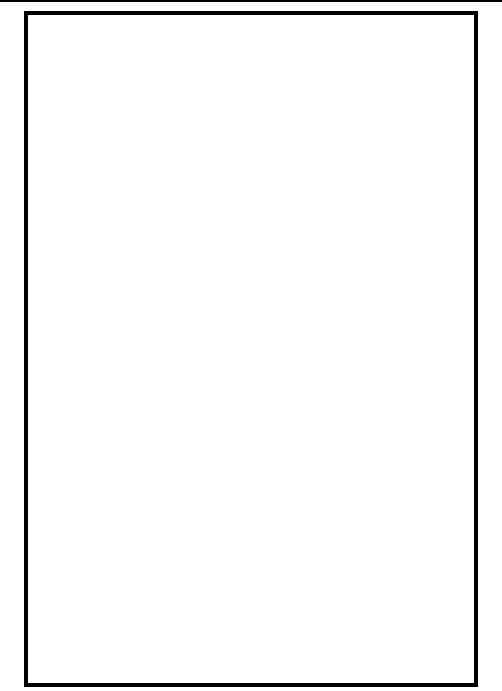
F-M. Banier, Andy Warhol, 1981. reproductibilité à des fins artistiques, même si la photo reste un matériau de base chez lui, qu'il sérigraphie sur des toiles.

Dans la préface que Banier rédige pour un catalogue d'exposition d'Andy Warhol, Banier mentionne la tendance du maître du Pop Art à tout documenter en photographiant, filmant ou enregistrant sur un magnétophone pour archiver, entasser et classer le temps. Banier écrit :

L'œuvre d'art n'est plus seulement description, serment, message, tour de force, vision, mais reflet immédiat de tout, de rien, de n'importe qui, de n'importe quoi, reproductible à l'infini. N'est-ce pas ça aussi la civilisation : ce désir de reproduction, ces miroirs éclatés d'un quotidien qui nous entraîne dans une danse effrénée, convulsive, jusqu'à ce qu'on passe le relais ? $^{58}$

\footnotetext{
55 MOUREY, Jean-Pierre, «Le ballet des signes dans l'œuvre de Joan Miró des années 1920-1930», Peinture et écriture 3. Frontières éclatées, sous la dir. de Montserrat Prudon, Paris, La Différence, 2000, p. 33.

${ }^{56}$ Ibid., p. 22.

${ }^{57}$ Andy Warhol, Paris, décembre 1981, Rétrospective 2003.

${ }^{58}$ BANIER François-Marie, « That little laugh Andy had » Préface du catalogue d'exposition Red Books, Pace MacGill Gallery, New York, Steidl, Göttingen, 2004. Le texte est disponible sur le site de l'auteur :
} 
Son œuvre s'apparente alors à celle de Banier, par le désir de reproduction.

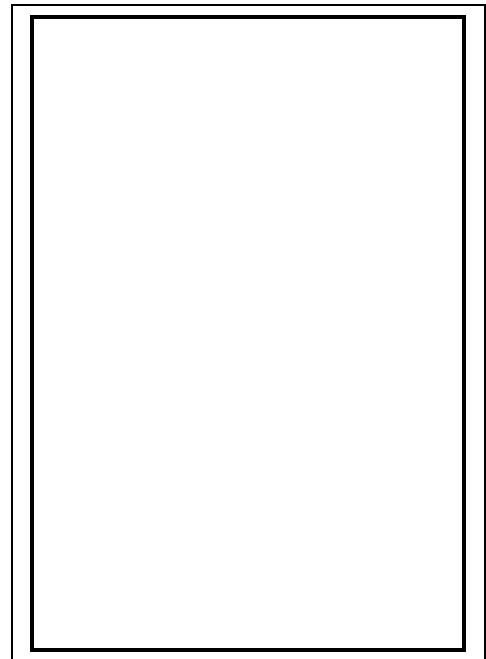

Pour finir, Alex Katz ${ }^{59}$ est un peintre américain dont on associe également l'œuvre au mouvement du Pop Art. La majorité de ses toiles sont des portraits, ce qui le rapproche du Banier portraitiste, cependant le fait que le portrait de Katz soit intégré dans le livre Perdre la tête, justifie un autre rapprochement. Il semble que ce soit avant tout l'expression du visage de Katz se laissant entraîner par un fou rire qui explique l'insertion de son portrait dans le livre, comme c'était le cas du portrait de Michel Tournier.

F-M. Banier, Alex Katz, 2003.

http://www.fmbanier.com/tx_010_that_little_laugh_andy_had_0 ; ainsi que quelques polaroïds pris par Andy Warhol sur Banier :

http://www.fmbanier.com/book_warhol_red_books_cat_pace_macgill_gallery_new_york_2004 (consulté le : 26/10/2009).

${ }^{59}$ Alex Katz, Paris, mai 2003, Perdre la tête, p. 91. 


\section{V.2. Visages, passions}

Comme dans le cliché de Michel Tournier ou d'Alex Katz, un bon nombre d'images présentent des expressions de visage dans Perdre la tête. Ce livre photographique débute sur des gros plans du visage de l'acteur Daniel Emilfork ${ }^{1}$.

F-M. Banier, Daniel Emilfork, 2004.

Il se termine aussi sur des gros plans de visages dans la rue ${ }^{2}$ (p. 185-217) - si nous considérons l'ensemble du reportage sur le bicentenaire de la mort de Louis XIV comme une annexe puisqu'il succède aux textes de la fin de l'ouvrage.

F-M. Banier, Anonyme Place Victor et Hélène Basch, 2005.

\footnotetext{
${ }^{1}$ Daniel Emilfork, Paris octobre 2004, Perdre la tête, p. 3-8, les photos insérées (p. 6-8) proviennent du site suivant : www.tpi-nice.org/expo/banier/index_banier.htm (consulté le : 06/12/2007).

${ }^{2}$ Les photos insérées s'intitulent: Place Victor et Hélène Basch, Paris novembre 2005 et figurent dans Perdre la tête, p. 196-201. Une série semblable est accessible sur le site d'artnet: (consulté le : 15/05/2009) http://www.artnet.com/artwork/425085601/412/place-pigalle-paris-mai-2005.html.
} 
Les gros plans montrent des visages traversés par différentes émotions : dégoût, rire, indifférence, tristesse, étonnement, ressentiment, agressivité.

Gilles Deleuze, en s'appuyant sur le Traité des passions de Descartes et la théorie des affects de Bergson, associe l'expression des passions aux gros plans dans le cinéma : «L'image affection, c'est le gros plan, et le gros plan, c'est le visage ${ }^{3} »$. Il explique ce rapprochement par le fait que le visage exprime les passions, il « recueille ou exprime à l'air libre toutes sortes de petits mouvements locaux que le reste du corps tient d'ordinaire enfouis ${ }^{4} \gg$. Le gros plan permet la lecture de ce qui est caché parce que le visage y perd son rôle social et son rôle d'individualisation. Le mot visage est employé en tant que métaphore d'une surface où se concentrent et réfléchissent les expressions, les passions, les affects, une image-affection : "il n'y a pas de gros plan de visage, le visage est en lui-même gros plan, le gros plan est par lui-même visage, et tous deux sont l'affect, l'image-affection ${ }^{5}$ ». Ainsi fonctionnent comme «visage » non seulement les visages, mais aussi les objets montrés en gros plan. Banier parle lui aussi des objets comme reflet de moments intenses, faisant ici référence aux images souvenirs que nous gardons des évènements :

Dans les moments les plus importants de notre existence - rupture, mariage, un sourire qu'on ne retrouve plus si vite sur des lèvres aimées -, quand la terre s'effondre ou que l'on renaît soudain, ce n'est pas un mot qui nous frappe d'abord, nous arrête, mais une image, souvent ridicule ou dérisoire, en tout cas étrange et presque toujours fixe : le pied de table d'un bureau, le chapeau cloche d'une inconnue, une courroie de sac à main qui traîne dans une allée.

Je n'aurai dû photographier que des objets, et ce sont des visages qui sont venus. ${ }^{6}$

Banier compare les souvenirs prégnants aux images fixes ce qui l'éloigne des propos de Deleuze qui parle d'image-mouvement sur laquelle nous allons nous arrêter un instant pour mieux voir comment le travail de Banier se positionne au sein de cette théorie. Cette notion assez complexe devient la métaphore chez Deleuze du mécanisme de la perception.

S'appuyant sur la théorie de Bergson - dans Matière et Mémoire ainsi que L'évolution créatrice - Deleuze distingue trois types d'image-mouvement : l'imageperfection, l'image-action et l'image-affection. L'identification de l'image avec le mouvement sert à surmonter l'opposition qui «consistait à mettre les images dans la

\footnotetext{
${ }^{3}$ DELEUZE, Gilles, L'image-mouvement, Paris, Minuit, 1983, p. 125.

${ }^{4}$ Ibid., p. 126.

${ }^{5}$ Ibid.

${ }^{6}$ BANIER François-Marie, « La vie de la photo », p. 336.
} 
conscience, et les mouvements dans l'espace ${ }^{7} \gg$. Réconciliation entre matière et lumière, entre image et mouvement, le mouvement est alors perçu comme :

une forme sensible (Gestalt) qui organise le champ perceptif en fonction d'une conscience intentionnelle en situation. [...] Il y a là une rupture avec toute la tradition philosophique, qui mettait plutôt la lumière du côté de l'esprit, et faisait de la conscience un faisceau lumineux qui tirait les choses de leur obscurité native. La phénoménologie participait encore pleinement de cette tradition antique ; simplement, au lieu de faire de la lumière une lumière d'intérieur, elle l'ouvrait vers l'extérieur, un peu comme si l'intentionnalité de la conscience était le rayon d'une lampe électrique («toute conscience est conscience de quelque chose»). Pour Bergson c'est le contraire. Ce sont les choses qui sont lumineuses par elles-mêmes, sans rien qui les éclaire : toute conscience est quelque chose, elle se confond avec la chose c'est-à-dire avec l'image de la lumière. ${ }^{8}$

L'image-perception sera alors l'image, le mouvement, cadrés par ce que nous percevons de la chose, en soi lumière et matière, ce que nous percevons en fonction de ce qui nous intéresse, selon nos besoins 9 . L'image-action est, à son tour, la réaction retardée que l'image perception provoque, «l'incurvation de l'univers », qui nécessite un intervalle pour s'effectuer : c'est « à la fois l'action virtuelle des choses sur nous et notre action possible sur les chose ${ }^{10} »$. Et finalement, l'image-affection que Deleuze définit d'après Bergson comme ce qui agit dans l'intervalle entre l'image-perception et l'image-action.

Il y a forcément une part de mouvements extérieurs que nous «absorbons », que nous réfractons, et qui ne se transforme ni en objets de perception ni en actes du sujet ; [...] Tel est le dernier avatar de l'image-mouvement : l'image-affection. ${ }^{11}$

Donc l'image-affection est la réaction, le micromouvement, le plus souvent involontaire, qui s'affiche sur le visage, surface de signification enfouie. Cette imageaffection peut à son tour être divisée en deux sous catégories, selon Deleuze, qui aboutit à cette distinction en analysant les gros plans de Griffith et d'Eisenstein. Elle se base sur l'intensité de l'affect. Deleuze rappelle que Descartes plaçait au degré zéro des passions l'admiration, tandis que Le Brun classe le désir, parmi les passions neutres, en tout cas ce sont deux passions qui suscitent un micro-mouvement du visage peu visible. Dès que ce sentiment s'intensifie et comprend des valeurs négatives, il devient de la haine, et agrémenté de valeurs positives, il devient de l'amour. Mais le degré zéro, l'admiration ou le désir, est si peu visible que Deleuze, en se basant sur les gros plans de Griffith, insiste sur le fait que dans ce cas, le visage se fond dans son contour, il devient une «surface de visagéification» (Deleuze signale qu'il emprunte ces termes à Wölfflin,

\footnotetext{
${ }^{7}$ DELEUZE, Op. cit., p. 83.

${ }^{8}$ Ibid., p. 84. et 89-90.

${ }^{9}$ Ibid., p. 93.

${ }^{10}$ Ibid., p. 95.

${ }^{11}$ Ibid., p. 96.
} 
Principes fondamentaux de l'histoire de l'art, Gallimard, p. 43-44). Tandis que quand il s'agit d'une passion intense, le contour s'estompe et certains traits, des «traits de visagéité $^{12} \gg$ prennent de l'importance.

Si nous insistons sur cette distinction que fait Deleuze entre «surface de visagéification » et «visagéité », c'est parce que Banier, sans les systématiser ni s'y référer, aboutit à des types visuels très similaires. Dans La vie de la photo il note :

Ce qui compte avant tout, la densité. Densité de la tristesse, par exemple. On aurait pu choisir émerveillement. Dans ces mots, densité compte autant que sentiment. Quand il s'agit de pierres précieuses, on parle de leur eau. Revenons à la photo: comme les belles pierres, certaines photographies tremblent. Roland Barthes aurait parlé de miroitement. ${ }^{13}$

L'intensité ou la densité de l'émotion transparaît sur l'image. On peut d'ailleurs distinguer, parmi les gros plans de visages de Banier, les deux types que Deleuze distingue. Les gros plans qui figurent dans Perdre la tête (ci-dessous à droite ${ }^{14}$ ) appartiendraient aux représentations de passions intensives où le contour s'estompe pour mettre en valeur les «traits de visagéité », tandis que certains gros plans, ou plans américains, montrent plongés des visages dans une réflexion, repliés sur eux-mêmes, des visages sans expression, une «surface de visagéification ». Ainsi fonctionne par exemple le cliché de Samuel Beckett ${ }^{15}$ (ci-dessous à gauche).

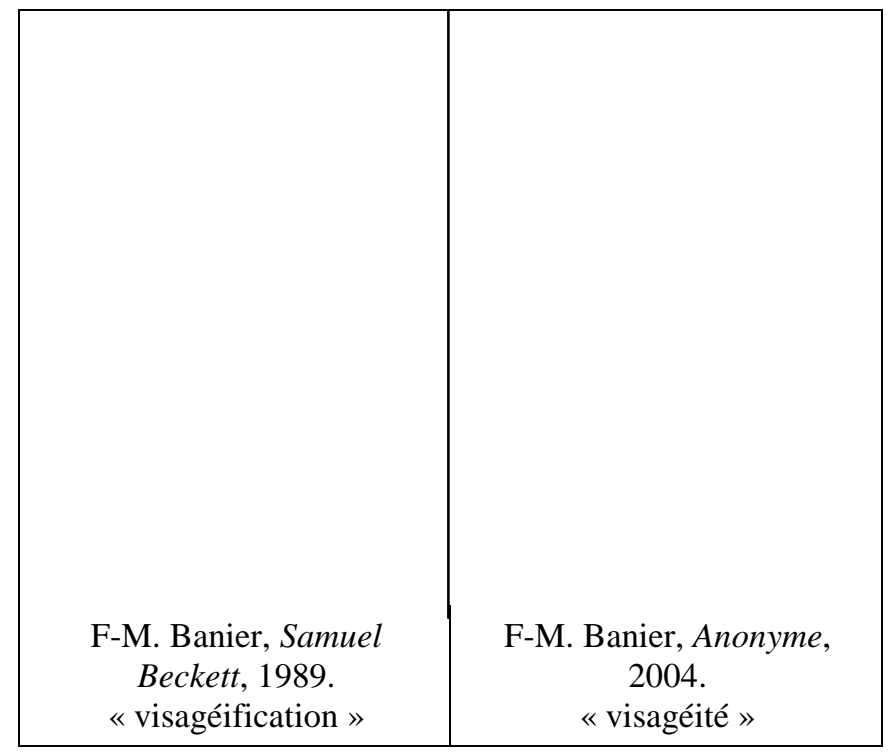

12 Ibid., p. 126.

${ }^{13}$ BANIER François-Marie, « La vie de la photo », p. 334. Nous soulignons.

${ }^{14}$ Anonyme, Paris, avril 2004, Perdre la tête, p. 213.

15 Samuel Beckett, Paris, septembre 1989. Disponible sur le site de l'auteur (consulté : le 10/10/2009) : http://www.fmbanier.com/beckett $004 \quad 3$. 
La représentation des passions remonte à une tradition ancienne dans les arts plastiques. $\mathrm{Au} \mathrm{XVII}^{\mathrm{e}}$ siècle, Charles Le Brun présente à l'Académie Royale de Peinture et Sculpture une conférence sur les passions qu'il illustre par des dessins des expressions principales de l'âme reflétée sur le visage ${ }^{16}$. Cet inventaire a servi comme modèle pendant longtemps à la représentation des passions dans la peinture. C'est avant tout le travail de Le Brun que souhaite prolonger et préciser le Dr Duchenne de Boulogne ${ }^{17}$ quand, au $\mathrm{XIX}^{\mathrm{e}}$ siècle, il entreprend de fixer par la photographie les expressions du visage provoquées artificiellement sur les nerfs avec des électrodes. En même temps, il s'agit d'une étude scientifique d'électrophysiologie, qui se veut la plus objective possible, sans retouche des épreuves. Cependant, comme le remarque André Rouillé, l'ouvrage se situe à mi-chemin entre un ouvrage scientifique et un ouvrage d'esthétique, comme le suggère déjà le sous-titre, Analyse électrophysiologique de l'expression des passions : «L'anatomie et la physiologie sont évoquées en même temps que Rembrandt et Ribera, et l'ouvrage se divise en une partie scientifique et une partie esthétique ${ }^{18} \gg$.

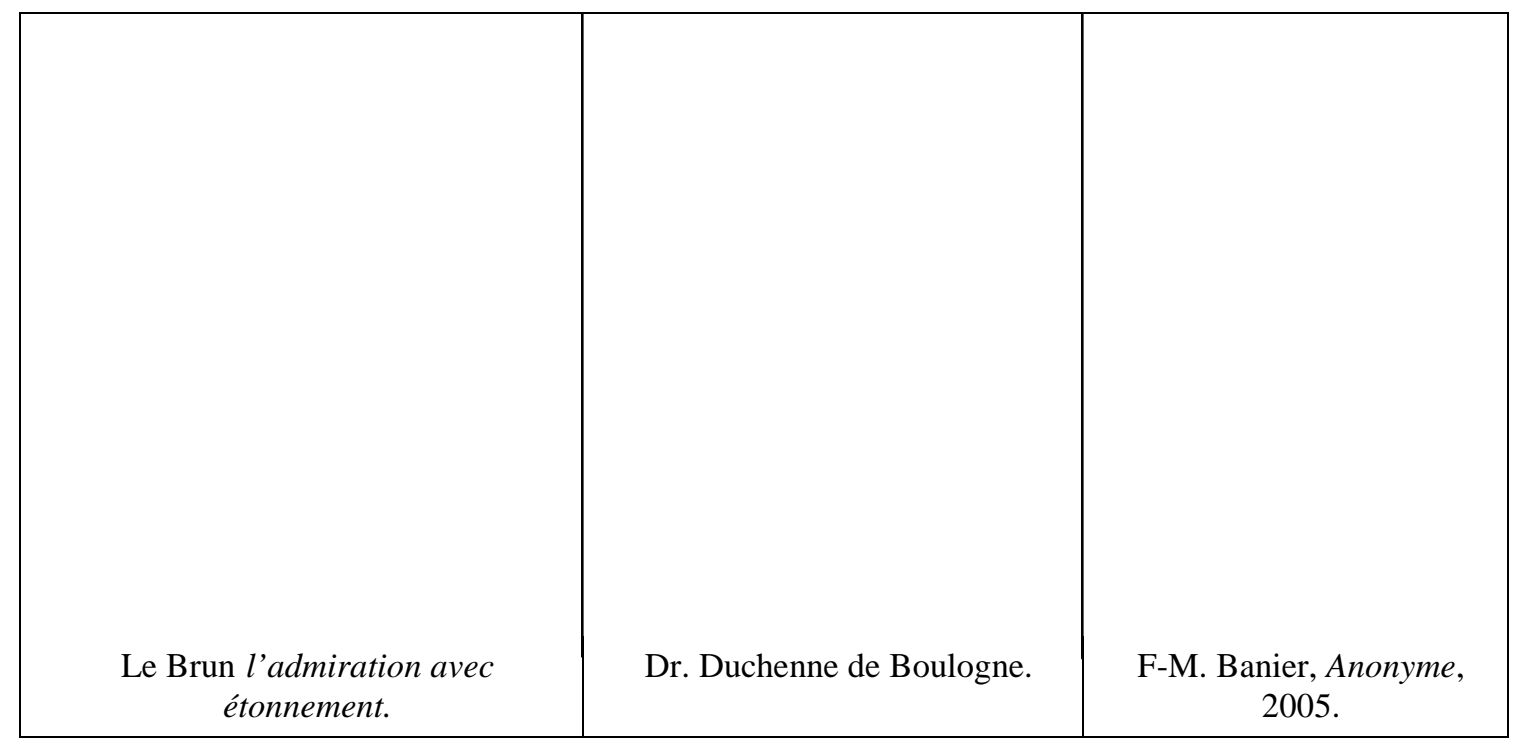

Par pur intérêt de confrontation visuelle nous plaçons ici l'image de Le Brun ${ }^{19}$ sur l'admiration avec étonnement, à côté des images du Dr. Duchenne de Boulogne ${ }^{20}$ et de

${ }^{16}$ LEBRUN, Charles, Expression des Passions de l'Âme (edit 1727), Paris/Lille, Aux Amateurs de Livres/Bibliothèque Interuniversitaire de Lille, 1990.

${ }^{17}$ SCHWARTZ, Emmanuel, «L'expression des passions : Duchenne de Boulogne, héritier de la doctrine Académique », in MATHON Catherine (dir.), Duchenne de Boulogne, Paris, Ecole Nationale Supérieure des Beaux-arts, 1999, p. 87.

${ }^{18}$ ROUILLÉ, André, La photographie, Paris, Gallimard, 2005, p. 137.

${ }^{19}$ LEBRUN, Charles, Op cit., planche 4.

${ }^{20}$ MATHON Catherine (dir.), Duchenne de Boulogne, Op cit., p. 203. 
Banier $^{21}$. Même s'il y a concordance, il faut lire les clichés de Banier non comme une démonstration (ce qui est le cas chez les deux autres auteurs), mais comme la trace d'une sensibilité poétique envers les sentiments des autres, la part enfouie de l'être, d'une ouverture vers l'autre dont témoigne la photo.

Le livre photographique de Banier, Perdre la tête, peut être lu alors comme un recueil de sentiments, de passions, de folies. Le titre renforce cette lecture en jouant sur la double signification de l'expression «perdre la tête » : au sens figuré s'affoler, perdre son sang-froid mais elle doit être prise aussi au sens propre, comme le montre la photo de frontispice et les photos de vieilles personnes tellement courbées que, vues de dos, leur tête disparaît sur l'image ${ }^{22}$; celle où le simple geste de soulever son chapeau mange la tête ${ }^{23}$; et par un jeu de superposition, la tête du travailleur peut être remplacée par une énorme disque en béton ${ }^{24}$.

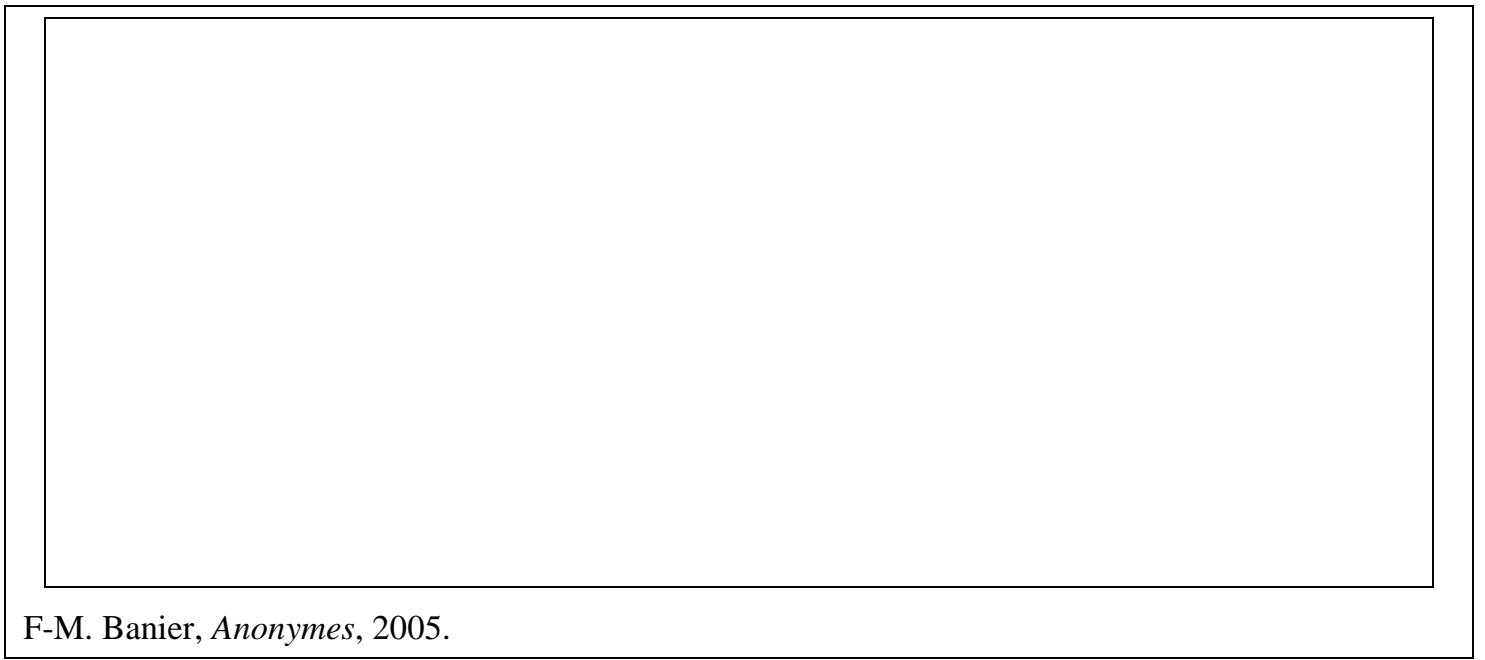

Dans un entretien, à la question «pourquoi avoir choisi ce titre », Banier répond :

Parce qu'on oublie tout de soi, et du monde, face à l'autre qui vous absorbe et que vous allez rendre par une image de cet instant unique : la rencontre avec un monde total. ${ }^{25}$

La prise de vue et ses conséquences sont donc également associées au délire et à l'irrationnel.

${ }^{21}$ Anonyme, Montmartre, Paris mai 2005, Perdre la tête, p. 194.

${ }^{22}$ Anonyme, Boulevard Raspail, Paris, janvier 2005, Perdre la tête, p. 11.

http://relationsmedia.photographie.com/?evtid=109784 (consulté le : 16/05/2009).

${ }^{23}$ Anonyme, Pont Royal, Paris, mai 2005, Perdre la tête, p. 149.

http://relationsmedia.photographie.com/?evtid=109784 (consulté le : 16/05/2009).

${ }^{24}$ Anonyme, Jardin des Tuileries, Paris, juin 2005, Perdre la tête, p. 21.

http://www.fmbanier.com/anonymes_021_1 (consulté le : 16/05/2009).

${ }^{25}$ BANIER, François-Marie, «Entretien réalisé par Martin d'Orgeval », Perdre la tête, Op. cit., p. 226. L'entretien est disponible sur le site de l'auteur : http://www.fmbanier.com/martin_d_orgeval_3 (consulté le : 16/05/2009). 
Les passions, la description des passions jouent également un rôle fondamental dans les romans de Banier. Le héros de plusieurs de ses livres (Les résidences secondaires, Balthazar fils de famille ${ }^{26}$, Les femmes du métro Pompe ${ }^{27}$ ) est un jeune adolescent ou un enfant, qui découvre les passions de l'amour, de l'amitié, ou de la haine envers ses parents. L'adolescence, n'est-ce pas l'âge des sentiments intensifiés, des sentiments extrêmes ?

L'album photographique intitulé Brésil célèbre ainsi l'énergie juvénile, les beaux corps musclés, la beauté de l'enfance, et décrit le pays comme une sorte de paradis :

Je ne venais pas au Brésil pour prendre des photographies mais pour en montrer. [...] Or - comme la conjonction va à ce pays d'un soleil si proche qu'on le touche du doigt comme on chatouillerait le menton d'un dieu bronzé - j'y ai rencontré la beauté à l'état pur : Comme on découpe du carton avec des ciseaux qui ne sauraient pas très bien où ils vont, guidés seulement par les caprices et les ondulations de la matière, l'objectif s'est laissé emporter par la transe. ${ }^{28}$

L'interprétation de l'œuvre de Banier par le biais de la théorie des passions permet de mieux comprendre la relation qu'entretiennent ses pièces de théâtre avec ses photographies.

Trouver le dessin, la complexité, l'ampleur, le chiffre de ce visage unique que chacun garde de sa vie, comme ces réflexes, ces mots de gourmand, d'avare, de sarcastique, d'indifférent, de dispendieux qui les résument et qui font dire aux autres quand on les leur raconte: " Je le reconnais bien là ». ${ }^{29}$

Il s'agit d'une quête de l'autre sur le théâtre de la vie : «Diamants les regards de ces femmes et de ces hommes qui vont et viennent sur leurs braises. Chants infinis ces corps qui dessinent en dansant leurs théâtres profonds ${ }^{30} »$.

\footnotetext{
${ }^{26}$ BANIER, François-Marie, Balthazar, fils de famille, Paris, Gallimard, "Folio" nº 1828 , 1987. Par la suite nous utiliserons l'abréviation : $B$.

${ }^{27}$ BANIER, François-Marie, Les femmes du métro Pompe, Paris, Gallimard, 2006/ Folio nº676, 2008. Par la suite nous utiliserons l'abréviation : $F M$.

${ }^{28}$ BANIER, François-Marie, Brésil, Op. cit. Le texte est disponible sur le site personnel de l'auteur: http://www.fmbanier.com/je_ne_venais_pas_au_bresil_pour_0 (consulté le : 13/05/2009).

${ }^{29}$ BANIER, François-Marie, «La vie de la photo », p. 331.

${ }^{30}$ BANIER, François-Marie, Brésil, Op. cit.
} 


\section{V.3. Photographie et théâtre}

La photographie au $\mathrm{XIX}^{\mathrm{e}}$ siècle, en rapprochant ce qui est lointain, exotique, en faisant circuler les photos de célébrité, notamment déjà par l'invention des cartes de visite de Disdéri, et plus tard par l'invention de l'offset et la montée de l'influence de la presse et de la presse illustrée, ont contribué à changer les lieux du monde en une scène de théâtre. Philippe Ortel analyse l'influence de la photographie dans l'univers scénique des pièces de théâtre au début du $\mathrm{XIX}^{\mathrm{e}}$ siècle : il repère notamment une influence dans la croissance de l'importance du décor, et un parallèle entre la scène de création et le procédé de la chambre noire qui caractérise les pièces de Victor Hugo ${ }^{1}$. La scène du théâtre devient elle-même un espace semblable à la chambre noire, où ce qui est représenté ne reflète plus un lien métaphorique mais un lien métonymique avec le monde ${ }^{2}$.

$\mathrm{Au} \mathrm{XX}^{\mathrm{e}}$ siècle des rapports plus complexes se tissent entre la photographie et le théâtre - il resterait d'ailleurs à étudier dans quelle mesure la photographie influence le changement progressif vis-à-vis de la représentation théâtrale. La fragmentation de l'action, la mise en question du langage et l'abandon du texte au profit d'éléments perceptibles visuellement (le mime, la danse), le rôle grandissant des metteurs en scène qui, enfin reconnus comme créateurs donnent vie à la pièce, tous ces changements montrent une transformation générale dans la prise en compte du visuel. Cependant le caractère transparent de la photo, le fait que nous soyons tellement habitués à voir partout des photographies, font que son rôle reste imperceptible - nous ne nous attardons pas sur son utilisation pour remplacer les décors, ou dans les affiches par exemple . $^{3}$

Chez François-Marie Banier, nous trouvons des clichés à tous les niveaux de la représentation théâtrale : des clichés d'auteurs de pièces de théâtre (Samuel Beckett), de

\footnotetext{
${ }^{1}$ ORTEL, Philippe, Op. cit., p. 47-53.

${ }^{2}$ Ibid., p.52.

${ }^{3}$ En parallèle à cette influence inconsciente, une étude resterait à faire aussi sur les auteurs et metteurs en scène qui favorisent la photographie ou pratique eux-même la photographie, cette étude pourrait démontrer dans quelle mesure une pièce théâtrale peut devenir «photographique ». Une étude de ce genre complèterait l'analyse de Chantal-Meyer Plantureux sur la photographie de théâtre (La photographie de Théâtre ou la mémoire de l'éphémère, Paris, Paris Audiovisuel, 1992) qui montre l'évolution à partir du portrait d'artiste, qui sert comme publicité ou comme document, vers l'emploi délibéré de la photo, les photographes qui revendiquent leurs photos d'acteurs ou de scènes comme création.
} 
metteurs en scène (Jean-Louis Barrault et Madeleine Renaud), des clichés d'acteurs sur scène (Patrice Chéreau), dans leur loge avant la représentation (Pascal Greggory, Isabelle Adjani) ou en dehors du théâtre (Pierre Clementi). Ces photos s'intègrent dans l'approche esthétique des portraits de Banier, montrant ces personnalités célèbres dans un moment intense, absorbées dans leur travail, ne faisant qu'un avec leur rôle ou dans un instant d'abandon.

Si les portraits de Banier s'accommodent de la théorie des passions, qui à son tour s'intègre dans la tradition des tragédies classiques, on pourrait s'attendre à ce que les pièces de Banier mettent en scène les passions de l'amour, le chagrin, ou la haine, or il n'en est que partiellement ainsi, car les pièces de Banier sont plus proches du théâtre de l'absurde de Beckett, où en fin de compte il ne se passe rien. Dans la pièce intitulée Nous ne connaissons pas la même personne ${ }^{4}$, un homme et une femme sont connectés par hasard sur une même ligne téléphonique, par la faute de la centrale. D’abord ils raccrochent puis, après plusieurs essais infructueux, commencent à parler. À parler, plutôt qu'à se parler. Chacun voulait en effet appeler son amoureux, et au fil des conversations qui se succèdent le doute s'infiltre, à cause d'une coïncidence des noms : leurs compagnons respectifs auraient fui ensembles? L'homme propose à plusieurs reprises un rendez-vous, mais la femme lui raccroche tout de suite au nez. Il n'y a pas de véritable dialogue entre eux, plutôt deux monologues, chacun racontant son histoire d'amour, profitant de l'anonymat de l'autre. La pièce est dédiée à Madelaine Castaing, décoratrice qui figure sur plusieurs photos de Banier. En général dans les pièces de Banier, nous trouvons peu d'indications sur le décor ou de didascalies qui montreraient une volonté de gérer la part visuelle et la mise en scène. Néanmoins, dans Nous ne connaissons pas la même personne, l'indication du début de la pièce rappelle la posture du photographe et fait référence au hasard et aux couleurs pour décrire la ville :

La ville a quelque chose d'incohérent, de couleur locale, et d'absent. C'était une grande ville. Blanche, entre la montagne et l'eau, elle s'étend un peu n'importe comment. Comme les dès jetés du cornet. La mer, le vent ne sont pas plus à décrire que le temps. Le décor viendra tout seul puisque c'est à Tanger que se situe l'action. Pardon, l'inaction. ${ }^{5}$

La description de la ville est superflue, comme la description d'une photo, car le référent saute aux yeux.

\footnotetext{
${ }^{4}$ BANIER, François-Marie, Nous ne connaissons pas la même personne, Paris, Grasset, 1978.

${ }^{5}$ Ibid. p. 9.
} 
Dans la pièce intitulée $J e$ ne t'ai jamais aimé $e^{6}$ nous retrouvons la forme du monologue. Un fils allant à son mariage reçoit contre son gré sa mère dans son appartement témoin, qui n'est pas encore achevé. Ils parlent mais paraissent ne pas s'entendre. La mère ne pense qu'à sa parure : c'est une mère narcissique, qui étouffe à tel point ses enfants qu'il est suggéré que la sœur du protagoniste se serait suicidée à cause d'elle. À travers leurs répliques, une relation familiale difficile se dessine, la relation du fils avec son père, docteur, qui buvait en cachette - on ne connaitra pas les circonstances de sa mort - ainsi que les tentatives de la mère voulant empêcher le mariage de son fils. Reproches sur reproches se succèdent - un univers qui fait penser au roman Balthazar, fils de famille et présuppose une part autobiographique, une parenté avec la vie de l'auteur.

Dans un entretien Banier évoque même la scène du film Amarcord de Fellini, en disant :

Dans le chaos épique des scènes de chaque déjeuner et de chaque dîner de mon enfance, scènes de colère dignes du repas de famille d'Amarcord de Fellini, il y avait de brefs moments de rêve, de vérité qui, au milieu de ces cris, auraient dus être sauvés. ${ }^{7}$

Nous pouvons d'ailleurs nous demander si c'est pour ce rapport particulier que figure une photographie de Fellini parmi les photos de Banier, une photo qui montre Fellini penché sur le viseur, absorbé dans la création.

Si nous insistons sur la forme du dialogue incompris ou du monologue, c'est parce qu'elle est souvent employée dans les pièces contemporaines pour traduire une «double impossibilité du héros [de] se saisir lui-même et [de] communiquer avec ses semblables $^{8} »$. Dans la pratique photographique de Banier ainsi que dans son approche théorique, nous retrouvons souvent la référence à la forme du monologue. Dans un entretien, il répond de la manière suivante quand on lui demande s'il établit un dialogue avec les gens photographiés :

Je cherche plutôt des monologues. Comme le médecin qui pose son stéthoscope sur votre cœur, je fixe mon objectif sur ce qui est le plus «parlant», qui ne passe pas toujours par les mots. Pour dire le charme, transcrire la vérité de l'être. ${ }^{9}$

Il fait le rapprochement d'ailleurs entre le fonctionnement de la photographie et les systèmes de communication par ligne téléphonique :

\footnotetext{
${ }^{6}$ BANIER, François-Marie, Je ne t’ai jamais aimé, Paris, Gallimard, 2000.

${ }^{7}$ SANTANA, Raúl, «Entretien avec François-Marie Banier», Op. cit., Photos et peintures, p. 37-38.

${ }^{8}$ HUBERT, Marie-Claude, Le théâtre, Paris, Armand Colin, 2008, p. 169.

${ }^{9}$ BANIER, François-Marie, « Entretien réalisé par Martin d'Orgeval », Perdre la tête, Op. cit., p. 225.
} 
Posséder une photographie, l'enrichir de nos expériences chaque jour. Ce rapport ressemble étrangement à celui que nous avons au téléphone, ou par lettre, avec ces gens que nous ne voyons pas et qui nous font participer à leur vie de loin : bébé est tombé par la fenêtre du premier, femme fatigue, elle fait la tête, empêché de tirer à l'arc, dépense trop en fringues, à Noël tout s'est arrangé. Ces photos sont cet au-delà inscrit, ce fleuve arrêté une seconde où se précipitent les mille et un faits presque éprouvés dont nous sommes le pauvre et le puissant écran à distance. ${ }^{10}$

La forme du monologue, en ce qui concerne la photographie, ne témoigne pas d'une impossibilité de communiquer avec autrui, il s'agit plutôt d'une distance nécessaire pour mieux voir et mieux comprendre, un écart qui devient garant d'objectivité et d'impartialité.

La photographie pour Banier a ce don de faire naître ou renaître les choses ou les sensations à distance suscitant l'imagination du regardeur. Dans ses pièces nous retrouvons à plusieurs reprises des scènes où c'est à l'imagination du lecteur/spectateur de constituer, créer l'objet ou le personnage. Dans Je ne t'ai jamais aimé le fils montre l'appartement inachevé à sa mère, il le décrit, comme s'il était déjà prêt, allant de chambre en chambre, commentant l'atmosphère qui règne. Leur relation se construit ainsi sur les birbes elliptiques de leur conversation (p. 49) :

\section{LA MÈRE}

Enfin, partout dans le monde, il y a des salles à manger...

\section{LE FILS}

Et des gens qui s'aiment.

\section{LA MÈRE}

La nôtre... une merveille avec ses assiettes peintes au mur. Là, les unes à côté des autres... des auréoles de saints !

\section{LE FILS}

Si tu y tenais tant que ça, pourquoi t'être acharnée à nous les jeter à la figure, les unes après les autres ? Il ne doit pas t'en rester beaucoup.

\section{LA MÈRE}

Ce que j'ai cassé, je l'ai cassé. Et tu l'avais méritée, cette soupière sur la tête !

\section{LE FILS}

Mais je les ai payés, ces disques !

\section{LA MÈRE}

Voleur... et menteur ! Avoir déclaré à la police : «Né de mère inconnue »! C'est surtout ça qui m'a fâchée.

\section{LE FILS}

Faire venir ce flic à la maison...

LA MÈRE

${ }^{10}$ BANIER, François-Marie, « La vie de la photo », p. 341. 
Et comment tu éduques les gens, toi ?

\section{LE FILS}

Oui, oui, je sais... il faut frapper les esprits.

Le vide fait surgir les ombres du passé, la mère voit leur propre appartement, et l'endroit fait renaître des souvenirs qui se transforment aussitôt en reproches.

Dans Hôtel du Lac ${ }^{11}$, la première pièce de Banier, c'est un des protagonistes que tente de recréer, d'inventer et d'imaginer chaque soir la microsociété de l'Hôtel pour se divertir et tuer le temps. Les habitants de l'Hôtel jouent le rôle (par un effet de théâtre dans le théâtre) des proches, parents et amis pour reconstituer la vie, la personnalité du protagoniste. L'univers du personnage principal, un jeune homme qui a fui ses parents, ressemble aux personnages incompris de ses autres pièces et romans. L'imagination de ceux qui jouent le rôle des proches et l'imagination du lecteur construisent le personnage comme les photographies peintes de Banier où l'imagination vient remplir et compléter par un flot de signes la photographie.

${ }^{11}$ BANIER, François-Marie, Hôtel du Lac, Gallimard, Paris, 1975. Voir une photo de la représentation de la pièce en 1977 par Albert-André L'Heureux au Théâtre Royal du Parc :

http://www.rueduconservatoire.fr/galerie.php?rep=galerie eleves\&tb=annuaire \&contenu $\mathrm{id}=763 \&$ positio $\underline{\mathrm{n}=17}$ (consulté le : 15/05/2009). 


\section{V.4. Iconotextes ou pratiques transversales}

Les œuvres plastiques de François-Marie Banier, où il combine la photographie et l'écriture ou la peinture, peuvent être considérées comme des iconotextes ${ }^{1}$. Rappelons que ce terme désigne, selon Alain Montandon, une œuvre où le texte et l'image s'imbriquent et forment une totalité insécable mais en gardant les valeurs spécifiques à chaque médium. Les photographies écrites et peintes de Banier se distinguent par leur structure, mais dans les deux cas, la photographie est utilisée comme une surface, un écran sur lequel sont posés des signes qui font partiellement disparaître la surface de la photo et modifient ainsi sa signification. La photo devient un écran similaire à la page blanche, similaire à l'arrière-plan des toiles peintes de Banier, qui sont soit laissées tout en blanc, soit couvertes par une première couche de couleur homogène sur laquelle viennent s'inscrire les taches ou les traits dans un second temps.

\section{V.4.a. Les photographies écrites}

Banier commence à écrire et peindre sur ses photos en 1997. Il nous révèle qu'à l'origine, c'est pour reprendre une photo ennuyante qu'il commence à écrire dessus. La raison sous-jacente : une recherche formelle pour renforcer la dichotomie du noir et du blanc en écrivant avec l'encre noire sur les taches blanches et avec l'encre blanche sur les taches noires, pour mettre en évidence la structure des lignes à l'intérieur de la photo, «parce que certaines masses de blanc ou de noir [...] ont leur vie, comme

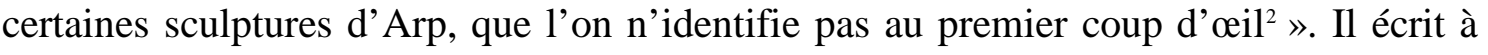
propos de la photographie intitulée Trois piquets dans la neige à Saint-Pétersbourg ${ }^{3}$ :

\footnotetext{
${ }^{1}$ MONTANDON, Alain, « Présentation », in Iconotextes, Paris, Ophrys, 1990.

${ }^{2}$ SANTANA, Raúl, «Entretien avec François-Marie Banier », Op. cit., Photos et peintures, p. 36.

3 Trois piquets dans la neige à Saint-Pétersbourg, Saint-Pétersbourg, 1991, encre sur photographie, 30x40cm, Rétrospective de 2003. http://www.fmbanier.com/files/active/1/2383 large.jpg (consulté le : 16/05/2009).
} 


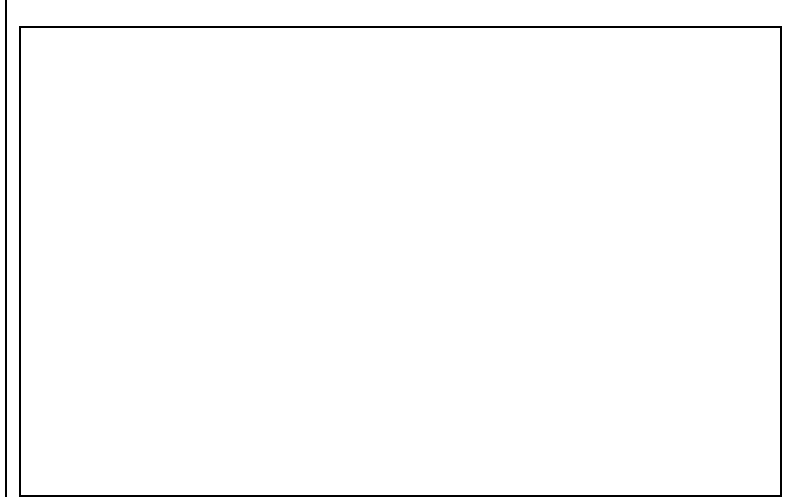

F-M. Banier, Trois piquets dans la neige à SaintPétersbourg, 1991.
[...] je trouve le sujet de cette photographie ennuyeux. Rien ne ressemble plus à une scène de neige qu'une autre scène de neige. Tout à coup, pour faire bouger la photographie, je place entre les piquets quelques lignes à propos de ma vie à l'époque. Alors que je croyais que c'est la confidence qui avait l'intérêt, en fait ce sont les lignes écrites qui découpent la neige qui vont me montrer comment l'intervention du trait peut faire basculer la photographie dans un autre monde. $^{4}$

Les lignes de l'écriture à l'encre noire déplacent ainsi la lecture des formes verticales des arbres et des piquets vers une lecture horizontale, et intensifie l'image par le jeu des lignes qui se croisent.

Le photographe Dieter Appelt considère que l'écriture de Banier sur les photos constitue comme une transformation de la forme visuelle en forme de pensée, ou encore en storyboard.

[...] la manière dont est traité le sujet de la photographie pourrait, si je peux avancer cette hypothèse radicale, transformer les œuvres en storyboards : nous assistons, au moyen de cette langue très spécifique de notations poétiques et littéraires, à un échange entre deux médias. Selon ce principe, ces formes doivent être comprises comme des instructions. Les différents états de ce processus, dans le champ d'action de cette photographie, pourraient être interprétées comme des didascalies pour une adaptation cinématographique. Les structures apparaissent telles des traces de mémoire là où l'écriture erre en quête d'un vague espoir, d'un objectif lointain. ${ }^{5}$

La singularité des photographies écrites se trouve dans l'espace structuré où se met en place un jeu de lignes et un texte. Nous pouvons distinguer d'ailleurs plusieurs types en fonction de la relation plus ou moins étroite que le texte tisse avec la photographie. Il y a les photos ancrage où le texte raconte les circonstances des prises de vue, ou encore le souvenir qu'évoque ce qui est visible sur la photo ; mais il y a aussi les textes qui sont des fictions en rapport avec l'image ou sans rapport explicite avec elle. Ainsi le texte peut être une fiction écrite à partir de la photo (La femme au perroquet), ou au contraire une fiction sans rapport apparent avec l'image (Le tricycle, 3 août 2002, encre sur photographie).

\footnotetext{
${ }^{4}$ SANTANA, Raúl, «Entretien avec François-Marie Banier », Op. cit,. p. 38.

${ }^{5}$ APPELT, Dieter, «Principe, fonction, forme et réalité subjective dans les photographies de FrançoisMarie Banier » préface au catalogue de l'exposition qui a eu lieu au Gagosian Gallery, Beverly Hills, Villa Oppenheim, Berlin, 2007. Le texte est également disponible sur le site personnel de l'auteur: http://www.fmbanier.com/node/1990 (consulté le : 16/05/2009).
} 


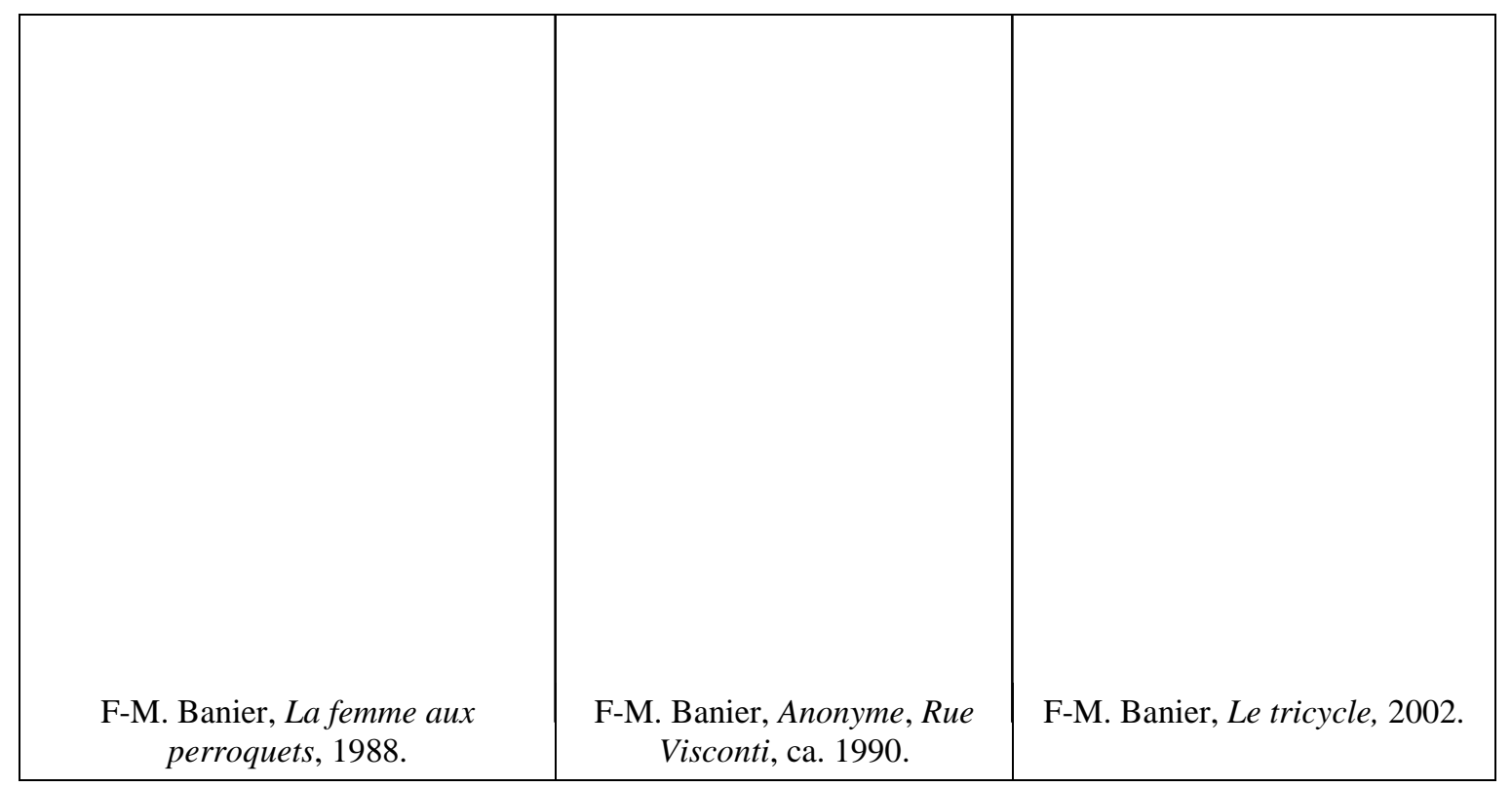

La femme au perroquet (ci-dessus à gauche) par exemple est une histoire inventée à partir du costume de la femme, «la folie du costume de la dame rien que çâ... ${ }^{6}$ [sic] », à laquelle s'ajoutent sur le bord des remarques adressées à un destinataire anonyme : «Vous détestez les photographies prises dans les cirques... ${ }^{7}$.

Le texte du cliché Le tricycle ${ }^{8}$, (ci-dessus à droite) ne montre par contre aucun rapport explicite avec l'image. Il retrace le monologue intérieur du narrateur préparant un attentat contre Otto Abetz et le général F. La relation du texte avec l'image reste alors énigmatique. Sur la photo de la Rue Visconti ${ }^{9}$ (ci-dessus au milieu), le texte raconte les circonstances de la prise de vue, et l'écriture attire l'attention sur un élément de la photo, sur les pieds gonflés de la personne qu'on ne remarque pas forcément au premier coup d'œil. Le texte dans ce cas modifie la lecture de l'image en renforçant la concentration et l'empathie du regardeur.

Sur d'autres photographies écrites, le texte est plus intime, la photo, comme un catalyseur, fait remonter des souvenirs, des souvenirs d'enfance, que Banier note sur

${ }^{6}$ La femme aux perroquets, Paris, décembre 1988, encre sur photographie, 1991, 40x30 cm, Photos et peintures, p. 37.

${ }^{7}$ Ibid.

${ }^{8}$ Le tricycle, 3 août 2002, encre sur photographie, 60x50 cm, Rétrospective de 2003. La photographie est également visible sur le site personnel de l'auteur : http://www.fmbanier.com/node/2399 (consulté le : 16/05/2009).

${ }^{9}$ Anonyme, Rue Visconti, ca. 1990, encre sur photographie, 60x50 cm, Rétrospective de 2003. La photographie est également visible sur le site personnel de l'auteur : http://www.fmbanier.com/node/2398 (consulté le : 16/05/2009). 
l'image, comme sur celle intitulée Saint-Moritz ${ }^{10}$ : «C'était à Fort Romen. Pas cette fois. Je parle de quand ils sont partis, mes parents, faire du ski [...] $\gg^{11}$. La particularité de la photographie à remémorer, évoquer des souvenirs est très présente dans tous les textes de Banier. La photographie est glorifiée pour être une trace et une preuve qui retient les moments importants: "Photo, il n'y a rien à dire que merci pour cette preuve $^{12} \gg$.

Toutefois le texte oscille entre une fonction purement formelle et sa signification parfois énigmatique. Sa fonction comme pure forme est accentuée par le fait que Banier travaille sur des formats immenses (parfois plus d'un mètre) qui, dans les reproductions sur les livres ou sur le site Internet personnel de l'auteur, deviennent illisibles. Ces signes sont alors avant tout donnés à voir, formant des fils de petites perles qui structurent l'image, comme dans l'image ci-dessous ${ }^{13}$.

F-M. Banier, sans titre.

Il est difficile de faire la distinction entre les photographies écrites et peintes de Banier, justement parce que l'écriture est utilisée comme une image, elle côtoie les dessins et fusionne avec eux. Parfois la critique ne fait pas de distinction non plus comme c'est le cas par exemple dans l'album Photos et peintures où les deux figurent ensemble dans le chapitre Photopeinture. On perçoit quand même une prédilection pour l'emploi de l'encre blanche ou noire dans les photographies écrites, mais les couleurs sont également utilisées pour peindre des mots.

\footnotetext{
${ }^{10}$ Saint-Moritz, 1989, encre sur photographie, 40x30 cm, ca. 1990, in Rétrospective de 2003.

${ }^{11}$ Ibid.

${ }^{12}$ BANIER, François-Marie, «La vie de la photo », Rétrospective de 2003, p. 341.

${ }^{13}$ L'image est publiée sur le site Internet de l'auteur sans légende. Voir : http://www.fmbanier.com/node/2393 (consulté le : 16/05/2009).
} 
Ce qui est par contre commun entre les deux, c'est que Banier utilise de préférence des photographies en noir et blanc comme surface de base. Il a pourtant aussi quelques clichés en couleur, mais ses photos en couleurs sont, par rapport aux photographies peintes, d'un ton plus doux, d'un ton pastel, pas si vives que les couleurs qui semblent sortir directement du tube. Le portfolio «Le Pérou de François-Marie Banier $^{14} \gg$ constitue la seule exception d'écriture sur des photographies en couleur, mais il est probable que le choix de la couleur soit imposé par le magazine.

\section{V.4.b. Les photographies peintes}

Les photographies peintes peuvent avoir la même fonction que les photographies écrites mais, désordonnées, elles témoignent de la rapidité de leur création, et entretiennent ainsi un rapport plus étroit avec les photos prises sur le vif. Les fragments de souvenirs désordonnés transforment l'image en une sorte de journal intime, ou une forme de correspondance. Rappelons la photographie peinte de Françoise Sagan où Banier adresse directement la parole à l'auteure : «relisant ta lettre je m'aperçois que l'orthographe et toi ça fait 2 c'est toi que j'aime ne prend qu'1 m. » (en vert ci-dessous) ; ou encore le message visuel qui s'intègre dans l'espace de l'image : «Je ne pouvais pas partir sans te laisser un mot sur l'oreiller» (ci-dessous en rouge). La frontière entre fiction et réalité est constamment brouillée.

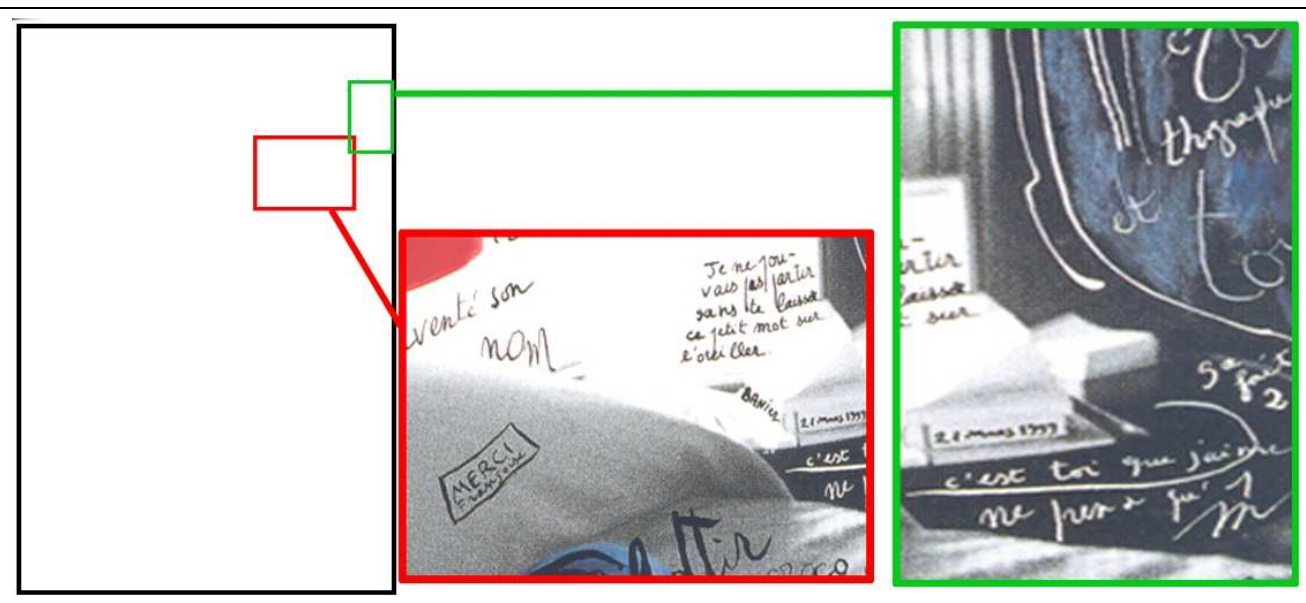

F-M. Banier, Françoise Sagan, 1999.

\footnotetext{
${ }^{14}$ BANIER, François-Marie, « Portfolio du voyage au Pérou », Officiel voyage, oct-nov. 2008. Disponible sur le site de l'auteur : http://www.fmbanier.com/content/presse/pdf/PDF-PresseFrance/PDFL_Officiel_Voyage/L_Officiel_Voyage_oct_nov08.pdf (consulté le : 25/10/2009).
} 
Brice Matthieussent dresse un inventaire des types de textes qui figurent sur les photographies peintes de Banier :

[...] mots isolés (« soulagement », « surface », « figure ») des fragments de fiction plus ou moins longs («Ils disent n'importe quoi », « et si elle me hait, qu’y puis-je ? »), des confidences («je n'oublie rien »), des maximes ou des devises («Le quotidien est discutable », «Fuyez l'horreur du regret»), des extraits de sa correspondance («Mon cher Yves,...»), des bribes de journaux intimes («I saw her with Fidel Castro and Kate Moss»), des anecdotes tragi-comiques, de brefs dialogues («Reste ma crevette please »), des légendes («arbres», «zones de chagrin», «main abandonnée », «fermoir de larme »), des vers isolés ( oiseaux cette nuit avaient les yeux bleus »), des notes télégraphiques, des suites de mots rappelant l'écriture automatique des surréalistes ( «dormez tranquille / fumée sans feu »), etc. tout cela réalisé avec une extrême liberté formelle, un foisonnement qui témoigne d'une grande rapidité d'exécution $[\ldots] .{ }^{15}$

En fin de compte Matthieussent compare les interventions scripturales de Banier à celle d'un enfant turbulent, qui met tout en œuvre pour transgresser les règles ${ }^{16}$.

Le sens de l'écriture reste tellement obscur sur certaines images que Banier note avec lucidité et une touche d'ironie sur la photo de Lucinda Childs ${ }^{17}$ : «On est allé chercher le livre de Champollion» (ci-dessous en bleu), «il y a sûrement certaines autres sources de joie que d'être une forme anonyme » (ci-dessous en rouge).

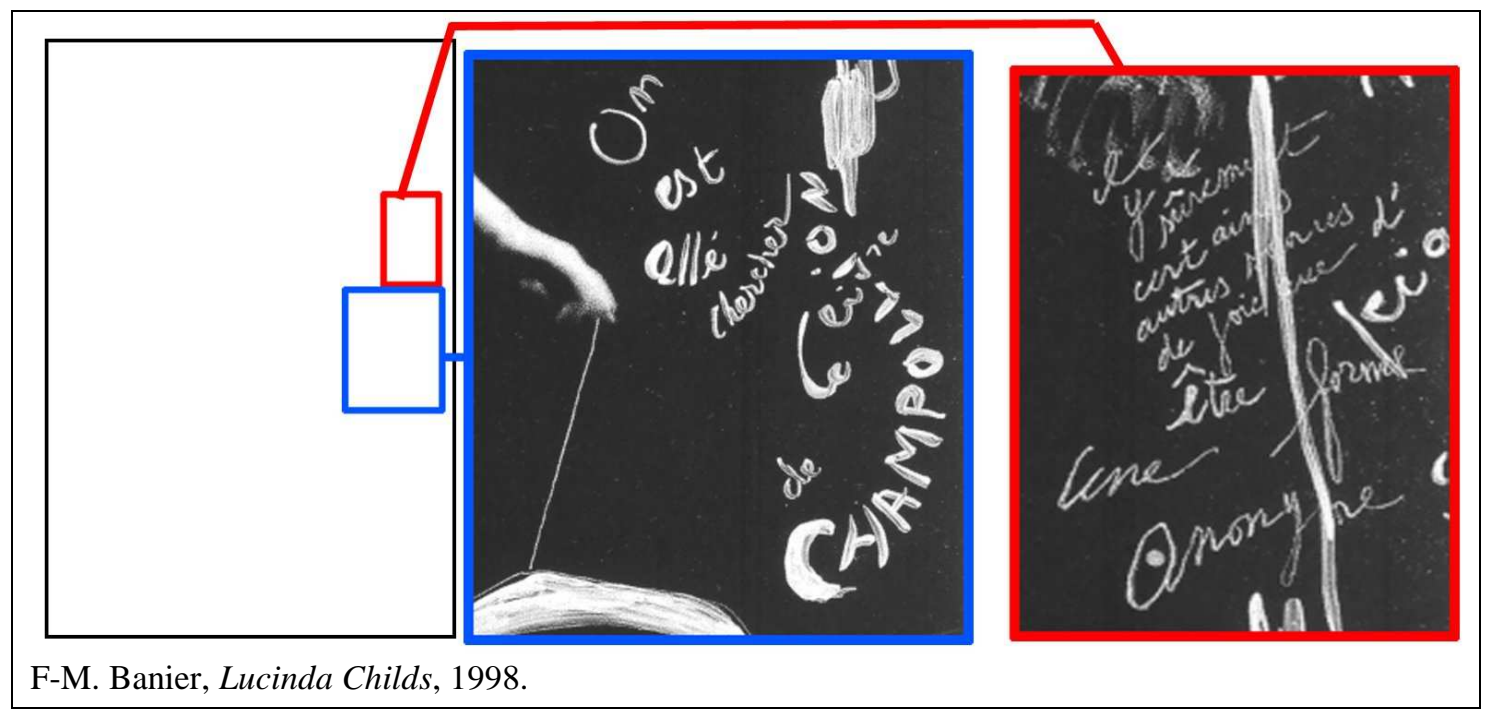

L'écriture se transforme en caractère visuel à plusieurs degrés. Comme sur les calligraphies, les mots se métamorphosent en formes qui participent à la création du rythme de l'image, le texte peut ainsi subir des déformations, la linéarité ou la taille des lettres sont bouleversées. Nous trouvons également des mots composés de lettres à

${ }^{15}$ MATTHIEUSSENT, Brice, « Une peinture sans début ni fin », Photos et peinture, p. 109.

${ }^{16}$ Ibid., p. 110.

${ }^{17}$ Lucinda Childs, 2 juillet 1998, encre sur photographie, 110x160 cm, Rétrospective de 2003. L'image est publiée sur le site personnel de l'auteur: http://www.fmbanier.com/node/2359 (consulté le : 16/05/2005). 
l'envers : sur Lucinda Childs «Reste ma cervelle please » (ci-dessous à gauche); mais aussi des lettres qui se transforment en image : le « $\mathrm{a} »$ du mot «anonyme » sur Lucinda Childs devient un œil (ci-dessus en rouge); le «a » de «ma tête » (ci-dessous) devient une tête sur Autoportrait ${ }^{18}$. Le jeu se joue aussi à l'envers, des formes se convertissent en lettres, ainsi la forme ronde du bouchon du lavabo remplace la lettre «o » de « reconnaître » et du mot «pour» sur le cliché Un lavabo chez les Noailles à Fontainebleau $^{19}$ (ci-dessous); la silhouette des jeunes gens forme des lettres dans Letters of people ${ }^{20}$; ou une tache involontaire de peinture orange peut être réutilisé pour la lettre « $\mathrm{o} »$ de « from »dans Cabourg ${ }^{21}$.

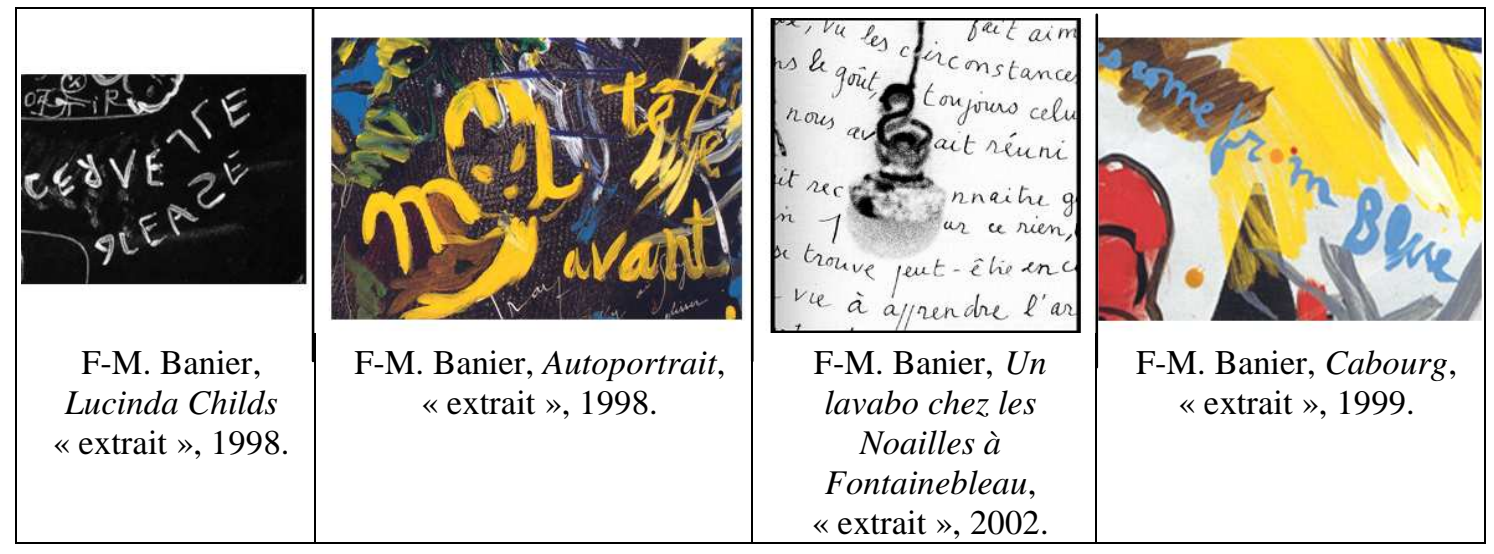

En ce qui concerne les dessins ou les figures sur les photos et les toiles peintes, dans la majorité des cas, ils établissent une relation avec le texte. Le texte explique l'image dessinée, donne un sens que l'image n'arrive pas à exprimer, comme sur la photo Héricy, la maison de mes parents ${ }^{22}$ : «a hat of my mother we suffer her hats » désigne une forme qui ressemble à la tête d'un oiseau enragé ; ou le texte «the hand of my father » où le mot « father » est écrit sur la main dessinée.

\footnotetext{
${ }^{18}$ Autoportrait, 13 avril 1998, encre et huile sur photographie, 160x110 cm, Rétrospective de 2003.

${ }^{19}$ Un lavabo chez les Noailles à Fontainebleau, Août 2002, encre sur photographie, 50x60 cm, Rétrospective de 2003. Reproduit sur le site personnel de l'auteur : http://www.fmbanier.com/node/2400 (consulté le : 17/05/2009).

${ }^{20}$ Letters of people, encre sur photographie, 11,8 x 15,7 inch, 2002, C international photo magazine, portfolio sur les photographies écrites de François-Marie Banier, 2008, p. 121. Voir sur le site de l'auteur http://www.fmbanier.com/content/presse/pdf/PDF-PresseEurope/PDF-C-international/C-internationalphoto-magazine-2008.pdf (consulté le : 17/05/2009).

${ }^{21}$ Cabourg, 3-4 mars 1999, encre sur photographie, 110x160 cm, Rétrospective de 2003.

${ }^{22}$ Héricy, la maison de mes parents, 13 août 2002, encre sur photographie, $60 \times 50 \mathrm{~cm}$, Rétrospective de 2003.
} 


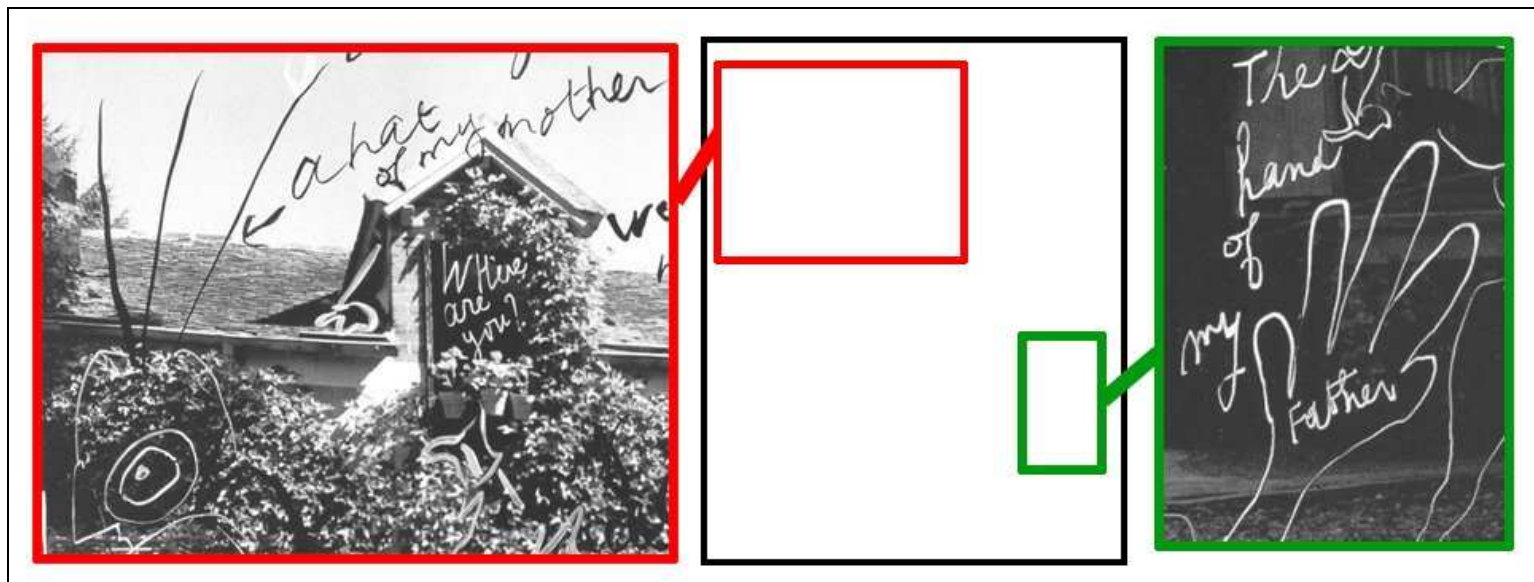

F-M. Banier, Héricy, la maison de mes parents, 2002.

En dehors de ces dessins narratifs, sur beaucoup de photographies peintes apparaissent des figures, des têtes, des bonshommes, qui font penser aux dessins d'enfant ou encore à des masques africains et à l'application qu'en a fait Picasso dans ses tableaux. Cependant le masque peut également faire référence au masque que porte chacun, à la pose devant l'appareil, que le photographe doit faire oublier pour «voir à travers $»^{23}$. Sur Autoportrait (ci-dessous à gauche), Banier porte une cagoule qui le masque entièrement et ne laisse visible que ses yeux. Le masque symbolise alors la part invisible; le photographe qui doit rester invisible pour ne pas altérer la scène et s'effacer pour faire voir de manière la plus objective possible. Mais dans un second temps, le dessin ajouté masque la photo en révélant ce qui est enfoui et se dérobe au regard. Le texte retranscrit la subjectivité de la scène comme le suggère le texte ajouté sur Autoportrait : «songe à tout ce qui est passé dans ta tête avant de venir ici ». On peut interpréter cette bribe de phrase au mode impératif, qui s'adresse à un tiers ou au futur soi-même, comme une invitation pour le lecteur-regardeur à ne plus regarder le portrait comme un simple reflet de la réalité. Une autre photographie peinte intitulée $C^{\prime}$ 'est mon masque ${ }^{24}$ (ci-dessous à droite) dialogue avec Autoportrait où le dessin prend littéralement la forme du masque et transforme l'image en autoportrait.

${ }^{23}$ BANIER, François-Marie, « La vie de la photo », p. 331.

${ }^{24}$ C'est mon masque, 1999, photographie peinte, 160x110 cm, Photos et peintures, p. 156. 


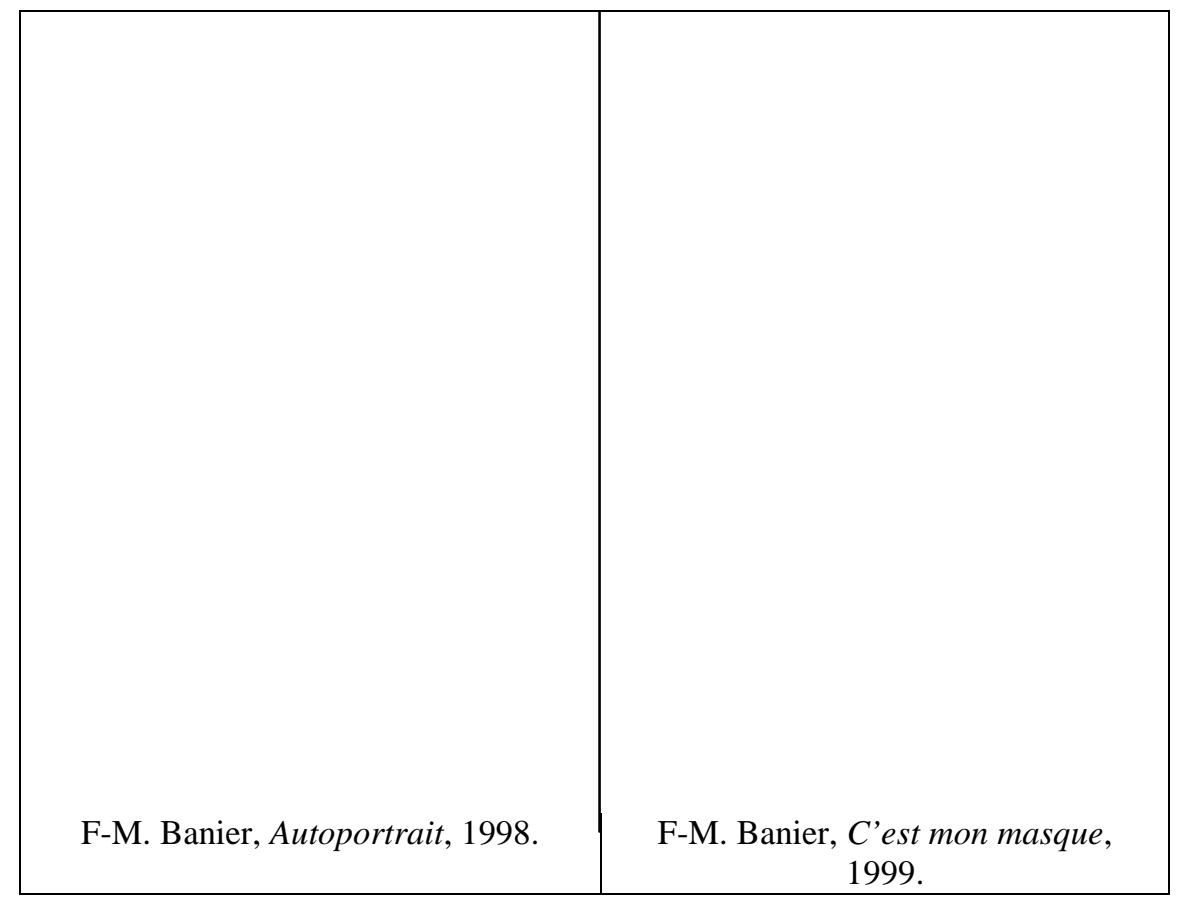

Une autre figure récurrente dans les œuvres de Banier est le motif de l'œil. La photographie peinte intitulée I am only an eye $e^{25}$ clôt le livre de la rétrospective de 2003 (si nous acceptons que la photo qui figure après les textes serve de cadre); son emplacement suggèrerait alors une importance accordée à l'œil. La photo qui sert d'arrière fond à l'image montre une scène chez un barbier. Dans le bout de miroir cassé se dessine le reflet du barbier et de son client; le barbier se prépare à recouvrir de mousse la barbe du client, mais tous les deux sont montrés dans le repli de leurs pensées.

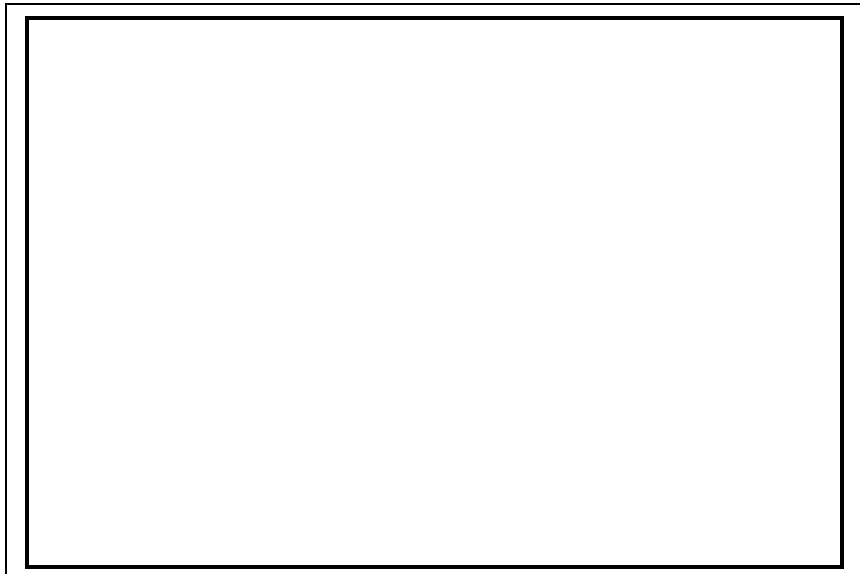

F-M. Banier, I am only an eye, 2001.
Sur la surface peinte quatre figures dessinées s'ajoutent sur le mur, utilisant les formes sur la photo, par exemple les trous du crépi pour la forme des yeux de la tête à gauche. Le dessin complète la partie invisible des personnages reflétés dans le miroir (le bras du barbier, la tête du client). Sur le côté droit, un

\footnotetext{
${ }^{25}$ I am only an eye, 8 mars 2001, encre sur photographie, $30 \times 40 \mathrm{~cm}$, Rétrospective de 2003. L'image est publiée sur le site personnel de l'auteur : http://www.fmbanier.com/node/2345 (consulté le : 16/05/2005).
} 
œil énorme, ayant comme poussé d'un pot de fleur, vient illustrer l'inscription «I am only an eye ». Cet œil unique, qui évoque celui de l'appareil photo, est un témoin qui n'intervient pas dans la scène mais il en est l'âme, la part invisible et cachée, que le dessin peut suggérer.

Sur d'autres images, comme Villandry $I .{ }^{26}$ (ci-dessous à gauche), l'œil devient le symbole du sexe féminin. Nous retrouvons le même motif en dessin que sur la photo de Nicole Kidman ${ }^{27}$ (ci-dessous) où c'est l'œil sur la photo qui est complété par une figure féminine. Sur le cliché de Nicole Kidman tous les dessins ajoutés tournent d'ailleurs autour de la sexualité, des personnages qui s'embrassent, ou d'autres qui bandent, se masturbent ou éjaculent. Fantaisie personnelle guidée par l'expression du visage de l'actrice sur l'image ou critique de la photo qui véhicule dans la société des symboles sexuels, des pin-up girls?

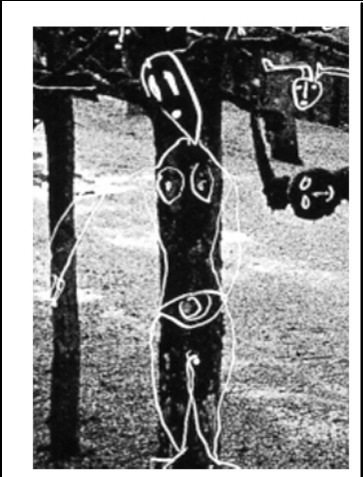

F-M. Banier,

Villandry I. « extrait » 1998.

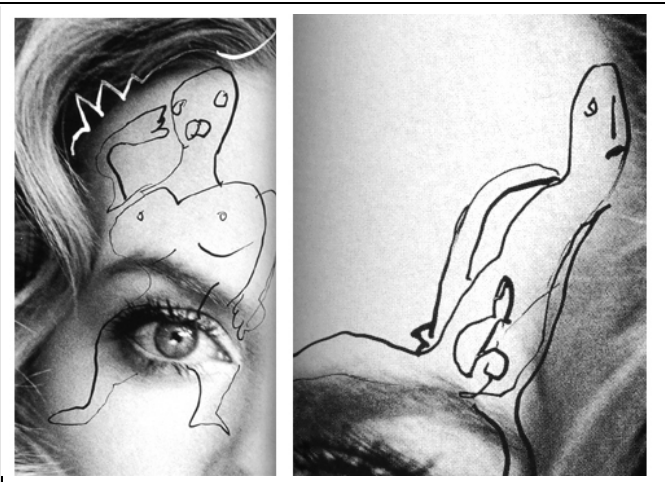

F-M. Banier, Nicole Kidman « extrait », 2002.

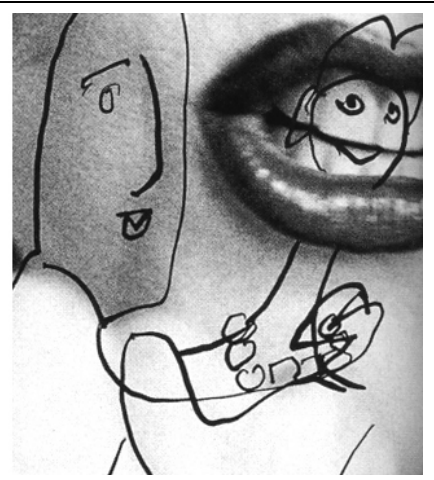

Martin d'Orgeval remarque que souvent ce sont les yeux ou le visage qui sont les seules surfaces épargnées des flots de signes et de peintures ${ }^{28}$. La photographie peut totalement ou partiellement disparaître sous cet entassement de signes. Les inscriptions, les lignes, les taches qui se superposent peuvent rendre impossible la lecture des textes. Ce qui est écrit se dissout dans les formes et les couleurs qui transforment définitivement l'écriture en signes purement visuels. D'ailleurs dans certains cas, l'ajout n'est pas narratif, mais simplement un flot rythmé, une explosion de couleur. Dans certaines photographies

${ }^{26}$ Villandry I., 1998, photographie peinte, $120 \times 85 \mathrm{~cm}$ collection particulière, Photos et peintures, p. 115.

${ }^{27}$ Nicole Kidman, 28 juillet 2002, encre sur photographie, 50x60 cm, Rétrospective de 2003.

${ }^{28}$ D'ORGEVAL, Martin, «L'autre éternel », Rétrospective de 2003, p. 15. L'article est publié sur le site personnel de l'auteur : http://www.fmbanier.com/martin_d_orgeval 4 (consulté le : 16/05/2005). 
peintes comme celles de musiciens : Ray Charles, Johnny Hallyday ou Mick Jagger ${ }^{29}$, le rythme des traits évoque le rythme de la musique, il devient le reflet d'une sorte de transe que l'auteur transcrit en signes abstraits.

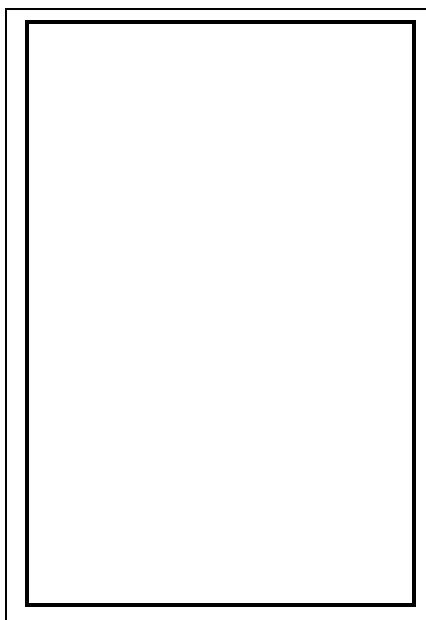

F-M. Banier, sans titre.

Banier utilise deux types de peinture, la peinture à l'encre et l'acrylique, qui ont des caractéristiques différentes. L'encre ou l'aquarelle sont des peintures qu'il faut superposer couche par couche ce qui grâce à leur transparence crée une nouvelle couleur. Ces surfaces sont remaniées par lavage, coulage d'encre, gros traits de pinceau, pour aboutir à une surface qui laisse transparaître la photo de base (comme dans l'exemple ci-contre $\left.^{30}\right)$. L'acrylique est par contre une peinture couvrante, où la photographie ne transparaît qu'aux endroits qui ont été épargné (voir l'exemple de C'est mon masque à la page 194 ; ou Fauteuil à la page 201).

Quand la photographie est investie de signes, dessins et écritures, il s'opère un changement dans le mode de lecture. Alain Montandon ${ }^{31}$ note à propos des iconotextes, que se produit un glissement ou un transfert entre les deux modes, la lecture de l'image et celle du texte, l'un agissant sur l'autre et installant un va-et-vient entre les deux où la béance qui se créent dans l'entre-deux devient significative.

Dans l'œuvre de Banier, nous retrouvons ce basculement de mode de lecture. Les textes et les fragments sur les photos participent à la lecture visuelle de l'image et, comme nous l'avons déjà évoqué, la publication des photographies écrites et peintes au format réduit des albums renforce le caractère formel de l'écriture. En dehors de cela, le point de vue unique qu'offre la perspective choisie sur une photo se trouve également ébranlé car les textes et les dessins peuvent surgir dans toutes les directions. Pour pouvoir les lire il faut tourner l'album. La signification primaire de la photo se métamorphose par le texte. Un changement s'opère également vis-à-vis de l'image reproductible qui devient une œuvre unique (régime de la peinture), même si Banier fait parfois plusieurs variantes peintes à partir de la même photo.

\footnotetext{
${ }^{29}$ Voir les images dans Rétrospective de 2003, ou celle sur Mick Jagger sur le site personnel de Banier : http://www.fmbanier.com/node/2346 (consulté le : 06/07/2009).

${ }^{30}$ L'image est publiée sur le site Internet de l'auteur sans légende. http://www.fmbanier.com/node/2353 (consulté le : 16/05/2009).

${ }^{31}$ MONTANDON, Alain, Op. cit., p. 6.
} 
Dans les photographies écrites et peintes, le lisible et le visible se mêlent pour déplacer le sens. Il en résulte un iconotexte qui est le reflet de l'inconscient de l'auteur, reflet du processus de la mémoire : des souvenirs, des mots et des figures surgissent de manière involontaire et réinvestissent la photo par le désordre dans lequel les pensées se présentent. Un fragment du texte La vie de la photo éclaire ce procédé : «Photographes tous ceux pour qui le souvenir est à penser, à étudier, à revivre ${ }^{32}$. » La photographie et la peinture sur les photographies deviennent alors une quête de soi, une quête du souvenir, des instants vécus. Une quête où la dimension visuelle acquiert une place primordiale car Banier insiste sur le fait que la mémoire visuelle est plus fragile que celle des pensées :

J'ai toujours souffert de cette infirmité visuelle : je ne vois plus ce que je viens de voir. C'est aussi pour réparer ce deuil constant que j'ai pris un appareil photo, comme l'aveugle se sert d'un bâton. ${ }^{33}$

La mémoire visuelle paraît alors semblable aux images mentales que suscite la lecture des textes. Les images mentales selon Wolfgang Iser $^{34}$ sont toujours floues, sans contours nets. Elles ne se réfèrent pas à des objets ou un monde réel, et ne ressemblent pas à la perception naturelle, elles sont avant tout porteuses de signification. Le lecteur construit l'image au cours de la lecture et l'image se modifie en rétroaction lorsque de nouveaux éléments apparaissent dans le récit. C'est dans cette mesure que la photographie devient indispensable :

Les mots, quels qu'ils soient, ne donnent pas cette autre dimension, ou en donnent trop. Reste en nous une idée, et, si attentifs si forts que nous soyons, manque toujours cet aspect qui l'emporte : leur présence. ${ }^{35}$

Les souvenirs visuels baignent dans le flou, comme les photos s'effacent partiellement sous les couches de mots, de pensées, de passions transcrites en taches de couleur, de rythme.

Cependant il faut noter que ce procédé découle d'une pratique, une obstination, qui a également un côté ludique. Sur le cliché du Moulin Rouge Banier écrit : «c'est ça la vie, on en badigeonne un bout en bleu et tout à coup on se lasse » et en bas de

\footnotetext{
32 BANIER, François-Marie, « La vie de la photo, p. 334.

${ }^{33}$ Marie Laure de Noailles, Rétrospective de 2003, p. 325. Le texte est reproduit sur le site personnel de l'auteur : http://www.fmbanier.com/marie_laure_de_noailles (consulté le : 16/05/2009).

${ }^{34}$ ISER, Wolfgang, L'acte de lecture, théorie de l'effet esthétique, Bruxelles, Pierre Madraga, (traduit de l'allemand par Sznycer Evelyne) 1976, p.250-252.

${ }^{35}$ BANIER, François-Marie, « La vie de la photo », p. 338.
} 
l'image : «Je me suis demandé si là-haut je ne devrais pas y ranger des livres ${ }^{36}$. » Côté enfantin, comme le suggère Matthieussent, vision pure, mais aussi une expérience proche de la transe où l'auteur peint à toute allure et avec les deux mains.

${ }^{36}$ Moulin-Rouge, Octobre, 1997, encre sur photographie, 110x160 cm, Rétrospective de 2003. 


\section{V.5. Paratexte et parapicturalité}

Selon Alain Montandon, «les pratiques usant de la lettre à des fins picturales et de la peinture à des fins d'écriture constituent la frontière interne de l'iconotexte ${ }^{1} \gg$. Il cite, entre autres, la pratique des mots dans la peinture et renvoie au livre de Michel Butor, qui dans Les mots dans la peinture ${ }^{2}$ étudie en premier les fonctions du titre, de la signature et des dédicaces (des mots en quelques sortes en marge de la peinture) avant d'analyser les mots proprement dits qui figurent dans la peinture. Nous pouvons mettre en doute le fait que la relation que le titre établit avec l'image puisse se classer parmi les iconotextes, cependant Butor démontre que dans certains cas les deux forment réellement une totalité indissociable. Selon lui, la fonction primaire des titres est leur rôle d'identification. Le titre aide à classer les œuvres et à s'y référer en leur absence ; d'ailleurs le titre n'est pas nécessairement donné par l'artiste.

Cependant il note qu'il existe plusieurs types de titres: «Il y a des titres éclatants, des titres qui sont des poèmes, qui se proclament ou se distillent, comme ceux des surréalistes, il y a aussi des titres de discrétion, ceux qui cherchent à se faire oublier $^{3}$. » Les artistes qui insistent sur l'autosuffisance de l'image cherchent à donner ainsi des titres neutres, souvent un numéro ou un code de référence, comme la photographe américaine Cindy Sherman. Le titre peut néanmoins renvoyer au sujet du tableau, éclairer ou ajouter un nouveau sens, qui n'est pas forcément visible sur l'image. Certains titres sont même indissociables de l'image. «Le titre est là pour combler une lacune. Il ne sert pas seulement à nous indiquer le sujet, ce qui est représenté par le reste de l'image, mais il contribue avec tout ce reste à représenter ce sujet ${ }^{4}$. » C'est notamment le cas des portraits où le nom propre sert à identifier la personne représentée : «[...] on pourrait même dire que ce visage dont il [le peintre] nous détaille les yeux, les lèvres, même les cheveux parfois un à un, apparaît à l'intérieur d'un nom ${ }^{5} \gg$.

\footnotetext{
${ }^{1}$ MONTANDON, Alain, « iconotexte » Dictionnaire International des Termes Littéraires : http://www.ditl.info/arttest/art2202.php (consulté le 08/12/07).

${ }^{2}$ BUTOR, Michel, Les mots dans la peinture, Genève, Paris, Albert Skira, Flammarion, 1967.

${ }^{3}$ Ibid., p. 18.

${ }^{4}$ Ibid., p. 29.

${ }^{5}$ Ibid., p. 31
} 
Le titrage des photographies diffère quelque peu de ceux des peintures. Comme la photographie renvoie toujours à un endroit concret et au moment où la photo a été prise, les photographies sont souvent désignées par un lieu et une date, ou par un texte qui explicite ce qu'il faut voir dans la photo. Dans ce cas, il reste confus s'il s'agit d'un titre ou d'une légende. Puisque c'est la pratique la plus courante, la pratique des photographes amateurs, collant leurs photos dans les albums de famille, indiquent la date, le lieu et encore les personnes représentées: le tendance veut qu'on ne pas marquer de titre pour désigner la valeur artistique de la photo, pour marquer l'autosuffisance de l'image ou encore pour signaler que l'image ne présente pas simplement le reflet de l'objet représenté mais qu'elle est une transposition artistique, qui montre autre chose.

Dans l'utilisation des titres chez François-Marie Banier, nous pouvons distinguer deux pratiques. Les photos portent souvent le lieu, la date au mois près, et le nom de la personne représentée s'il ne s'agit pas des gens de la rue. L'identification devient nécessaire pour augmenter la valeur documentaire, pour l'efficacité de la photo comme souvenir. En revanche, les titres des peintures et des photographies peintes reprennent souvent un élément graphique, des mots inscrits sur l'image (comme I am only an eye déjà analysée (voir p. 37). Les photographies peintes dont il existe plusieurs variantes sont numérotées en chiffres romains. Les dessins, par contre, sont souvent intitulés d'après la date, mais au jour près. Les titres des photographies chez Banier déplacent rarement le sens de l'image, d'ailleurs ils ne figurent pas toujours à côté de l'image, mais à la fin du livre comme dans Past present ou dans Perdre la tête. Les titres des photographies peintes tendent même à restituer l'image photographique qui s'est perdue dans le flot des couleurs (Tournesol I. ${ }^{6}$, ou Fauteuil ${ }^{7}$ ci-dessous à gauche et au milieu). Nous trouvons cependant quelques exceptions où elles reçoivent leur pleine signification grâce au titre, comme celle intitulée $N e$ lui faites pas de mâle $I I^{8}$ (cidessous à droite). Le titre qui joue sur l'homophonie du mot «mal » et «mâle », et l'identification du petit garçon et de l'auteur par l'intermédiaire des mots écrits sur l'image, renvoie aux enfants incompris et maltraités de ses romans.

\footnotetext{
${ }^{6}$ Tournesol I. 1999, photographie peinte, $160 \times 110 \mathrm{~cm}$, Photos et peintures, p. 124.

${ }^{7}$ Fauteuil, 1999, photographie peinte, $160 \times 110 \mathrm{~cm}$, Photos et peintures, p. 159.

${ }^{8}$ Ne lui faites pas de mâle II, 1998, photographie peinte, 160x110 cm, Photos et peintures, p. 141.
} 


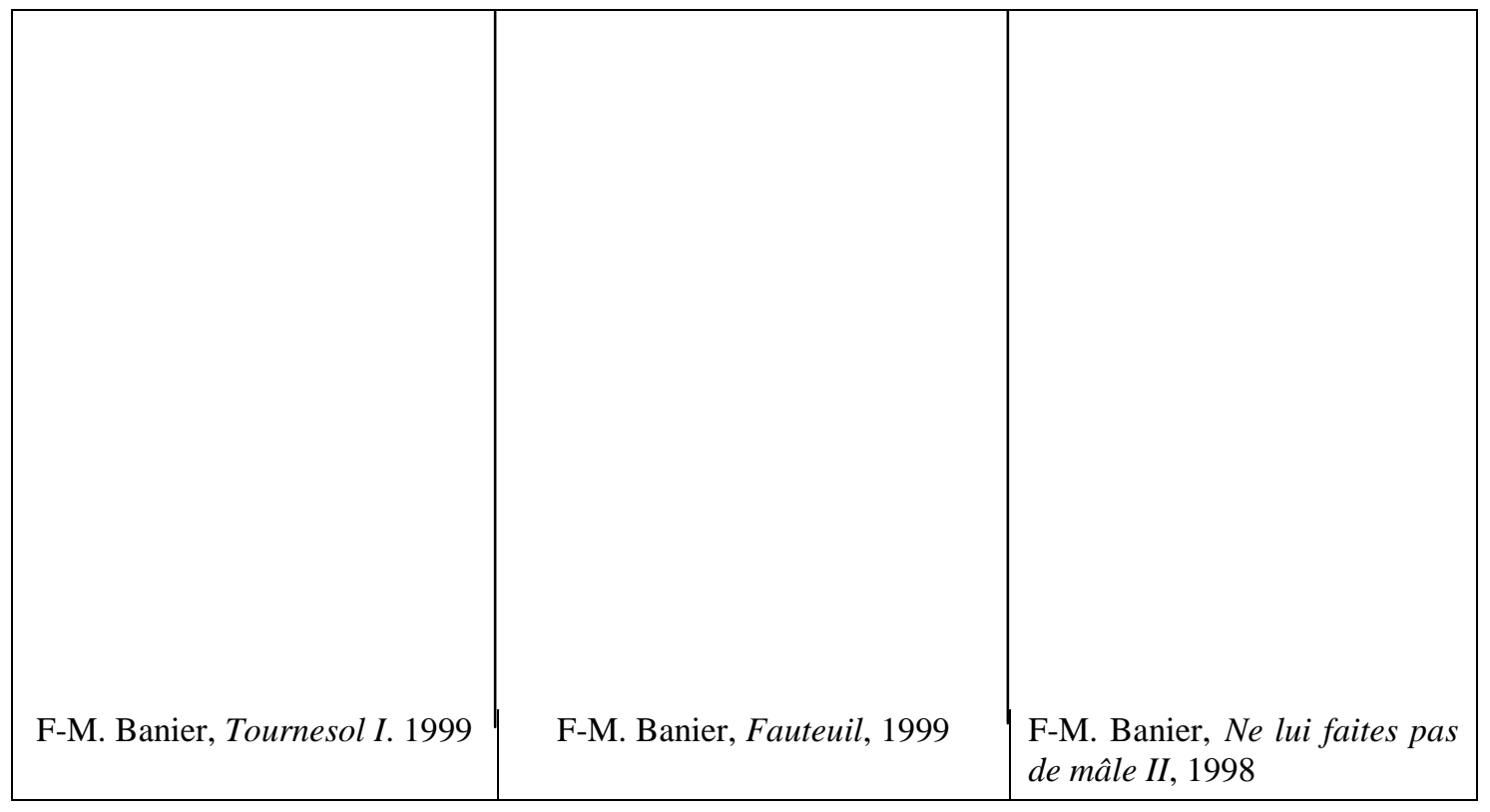

En ce qui concerne les mots figurant sur le tableau, Michel Butor les compare aux notes qu'inscrit le compositeur sur la partition pour que le pianiste puisse faire entendre telle ou telle œuvre9 ${ }^{9}$ Les écritures dans les scènes photographiées (les inscriptions sur les murs, les pancartes, les enseignes, les affiches publicitaires) peuvent à leur tour déplacer le sens de l'image. Dans les œuvres de Banier même si nous trouvons peu d'inscriptions à l'intérieur des photographies, les quelques cas révèlent une construction consciente du rapport entre le texte et l'image.

Les inscriptions deviennent révélatrice sur deux photos dans la série sur les ateliers de Chanel et son directeur artistique Karl Lagerfeld publiée dans le magazine The New Yorker $^{10}$. Sur la photo dont la légende indique Atelier Massaro, rue de la Paix, Paris, on voit une chaussure à talon haut perdue parmi des outils : scotch, règle, stylo et bouts de papiers. Malgré son abandon, la chaussure garde son élégance et évoque la grâce et la beauté de la personne qui doit la porter; l'inscription « Chanel» visible sur un des papiers tombés à terre ainsi qu'une date incomplète derrière laquelle on devine

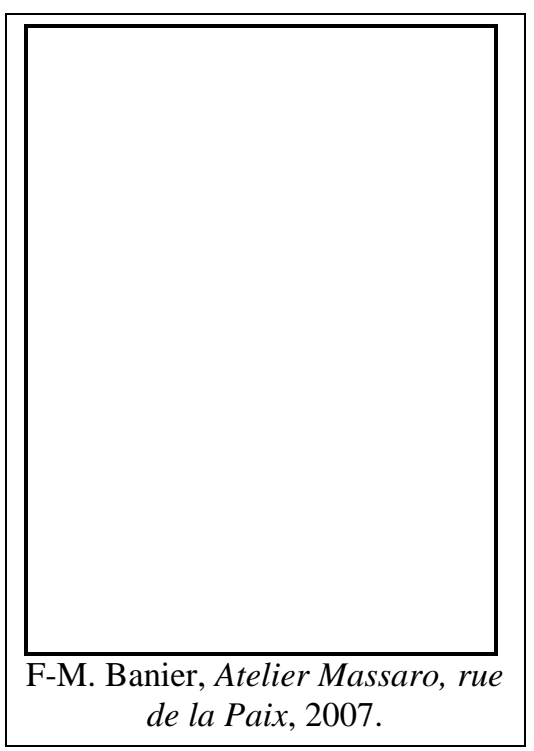

\footnotetext{
${ }^{9}$ BUTOR, Michel, Op. Cit., p. 149.

10 «Embellishing Chanel», The New Yorker, 19/03/07. L'image est reproduite sur le site personnel de l'auteur : http://www.newyorker.com/online/2007/03/19/slideshow_070319_Chanel (consulté le : 24/12/2007).
} 
«2007» retranscrivent le contexte. Ce désordre, l'élégance de la chaussure, et l'inscription, racontent les coulisses et l'histoire de la création de ce produit qui n'est d'habitude visible que dans l'ordre parfait et contrôlé de sa mise en scène (dans les défilés de mode, ou sur les images publicitaires).

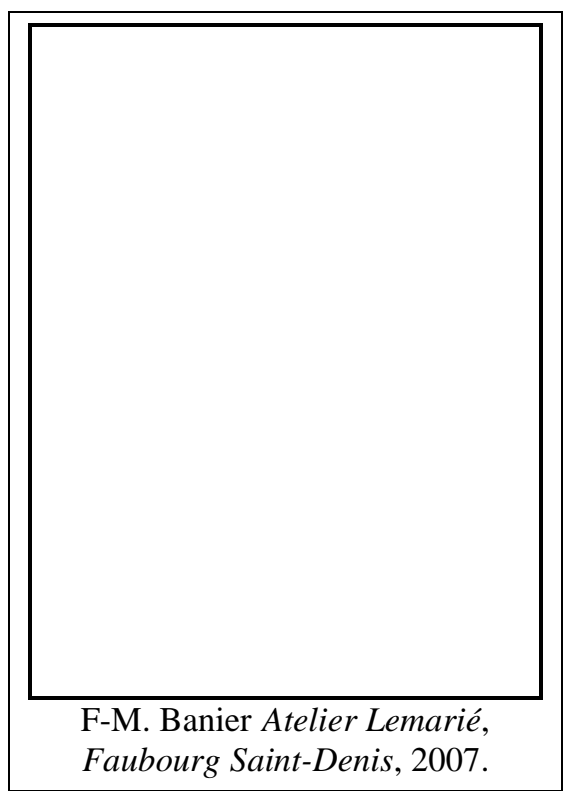

Une autre photo de la série, légendée Atelier Lemarié, Faubourg Saint-Denis, Paris, montre une étagère avec plusieurs boîtes de carton usées et enfouies dans le secret et la pénombre; seule leur usure témoigne d'une longue fréquentation. Les inscriptions révèlent leur contenu : il s'agit de boîtes où sont stockés les accessoires de décoration des vêtements. Les inscriptions : oiseaux, ailes, papillons, fantaisies plumeaux font penser à une autre photo de Banier, $L a$ femme au perroquet ${ }^{11}$ (voir p. 30) qu'il transforme en photographie écrite et dont le texte relate une histoire inventée à partir de la coiffe de la dame aux plumes d'oiseaux. Sur l'image ci-contre, les inscriptions sur les boîtes qui font référence aux couleurs : «jaune / vert », «blanc», «marine », «coloris passés (pour chapeaux)», convoquent notre fantaisie dans cet univers noir et blanc aux tons obscurs. Les couleurs vives que nous imaginons se cacher dans les boîtes rappellent les couleurs des photographies peintes de Banier.

Les inscriptions, si on les examine minutieusement, sont plus subtiles qu'on ne pourrait le croire. Sur une photo $^{12}$ de l'album Brésil (voir cicontre), l'inscription «center» coïncide avec le centre vers où convergent les lignes de force de la photo. La construction de l'image, les lignes que forment les pieds, la lumière

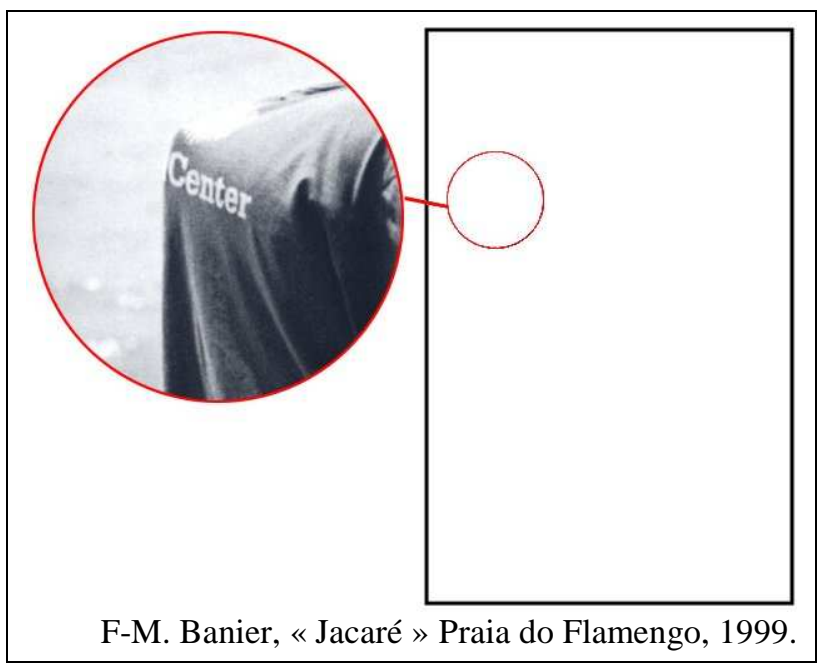

${ }^{11}$ La femme aux perroquets, Paris, décembre 1988, encre sur photographie, 1991, 40x30 cm, Photos et peintures p. 37.

12 «Jacaré », Praia do Flamengo, Rio de Janeiro, septembre 1999, in Banier Brésil, Paris, Gallimard, 2001, p. 115. 
sur les vêtements, la corde qui relie les bagages, la vague à l'arrière-plan, pointent tous dans la direction de l'inscription «center » qui est également le centre d'intérêt de l'image, ce qui donne sa signification entière au caractère bossu du promeneur (ou marchand ?) sur la plage.

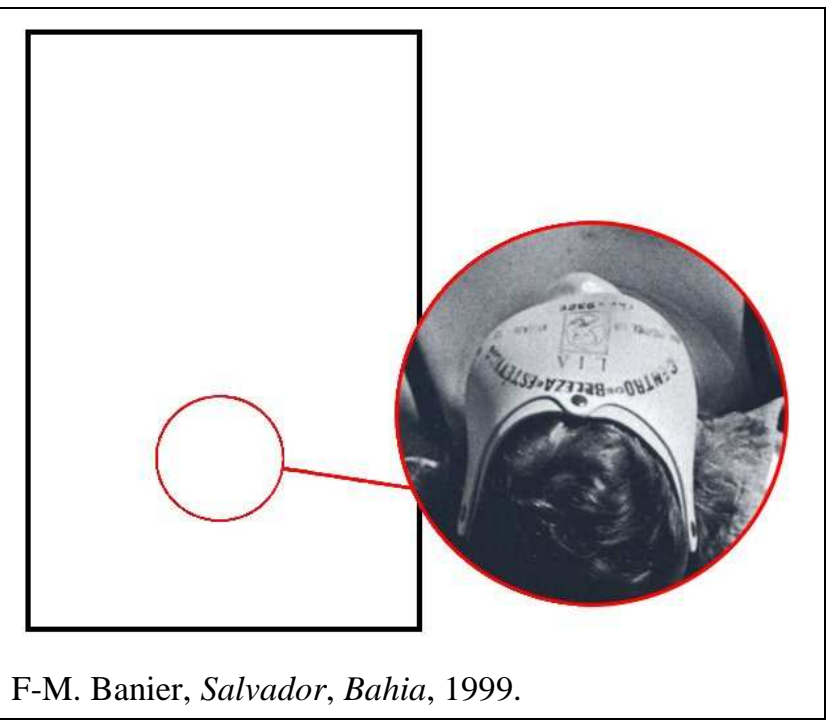

Sur la photo à la page suivante ${ }^{13}$ nous retrouvons l'inscription «centre » (également dans l'axe central de l'image) sur la casquette d'une femme corpulente prenant un bain de soleil. Il s'agit cette fois-ci d'une publicité pour un salon de beauté «Centro de beleza e estética » transformant ainsi l'image de la femme sans visage et aux pieds coupés par la vue plongeante, en une Venus de Willendorf moderne que l'on voit à l'envers. L'inscription déplace considérablement le sens de l'image.

Sur la photo de Louis Aragon ${ }^{14}$ (déjà mentionné dans le chapitre «Les portraits d'écrivain - la photo intertextuelle »), le texte visible sur l'image est le verso d'un manuscrit que l'auteur est en train de lire (ci-dessous).

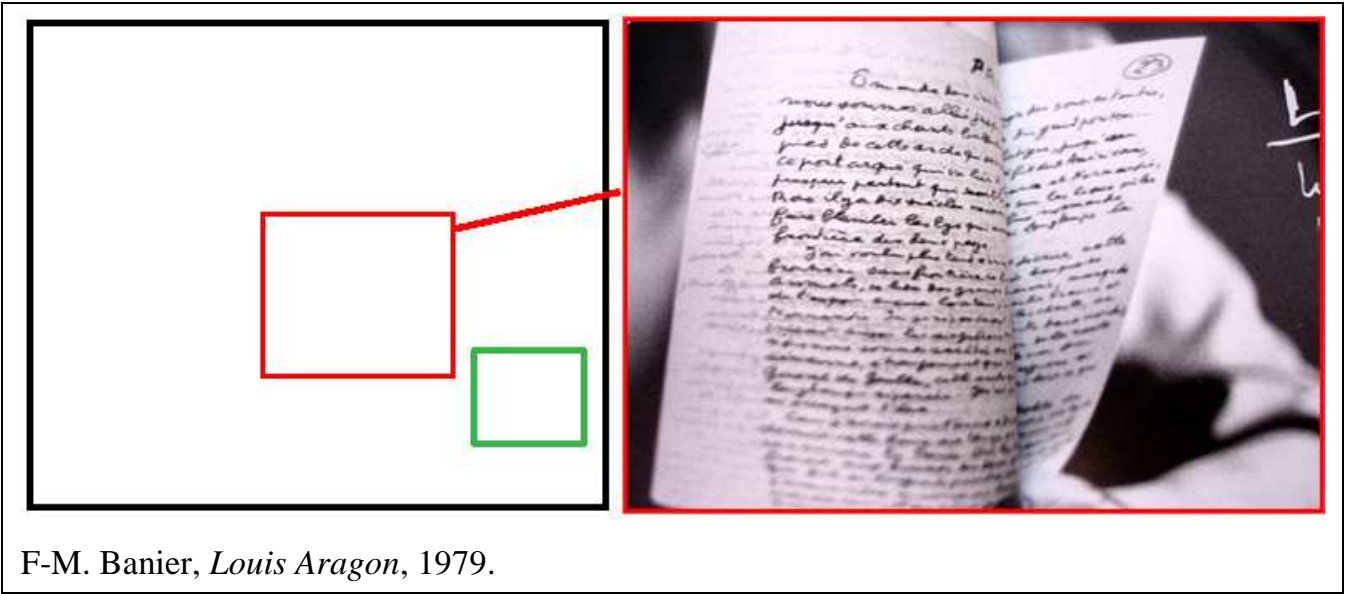

La profondeur de champ est réglée de manière à ce qu'on puisse lire nettement le texte que tient Aragon au détriment du contour flou de l'auteur. D'ailleurs le texte que rajoute

${ }^{13}$ Salvador, Bahia, juin 1999, Banier Brésil, p. 116.

${ }^{14}$ Louis Aragon, Paris, juin 1979. Pour l'écriture : ca. 1990, encre sur photographie, 50x60, Rétrospective de 2003. 
Banier pour transformer la photo en photographie écrite épargne les parties où le texte est lisible : il rajoute son propre texte sur les papiers qui traînent sur le bureau, sur des manuscrits écrits où le texte d'Aragon est trop flou pour être lisible, ou sur des feuilles vides tout simplement. Les textes des deux auteurs, le texte original sur la photo et le texte ajouté ultérieurement, se confondent. Banier écrit en bas de l'image (ci-dessus en vert) :

Ces coqs à l'âne. Vous avez vu les tours que je viens de jouer à Louis Aragon? Je lui ai laissé quelques pages en blanc. Cette nuit il vous les lira. Il était capable de tout.

Les inscriptions à l'intérieur des photos peuvent ainsi avoir plusieurs fonctions : références à l'objet représenté, rappels d'une partie invisible sur l'image, elles peuvent créer une opposition avec l'image, mais elles peuvent également la structurer.

Nous avons jusqu'ici analysé plusieurs interactions entre textes et images : texte sur l'image, en marge de l'image ou à l'intérieur de l'image ; il importe cependant d'élargir encore le champ, et de considérer les photos d'un même ouvrage dans leur ensemble, le parcours qui crée le récit visuel - traces également de choix esthétiques vis-à-vis de l'assemblage ou du montage du livre. 


\section{V.6. La construction des livres et le récit visuel}

Comme par coïncidence, les deux photos sur lesquelles figure l'inscription «centre » que nous venons d'analyser, s'enchaînent dans l'album Brésil, témoignant d'une construction subtile du support. Les livres de François-Marie Banier qui contiennent des photos, des photographies écrites ou peintes sont le plus souvent publiés à la suite à d'expositions. Pourtant ils ne sont pas de simples catalogues mais s'apparentent à des livres photographiques. L'organisation d'une exposition et la publication du catalogue, comme le souligne Martin d'Orgeval, requiert un travail précis de montage, qui se fait avec la participation de l'auteur, mais qui n'est pas exclusivement dirigé par lui.

Dans le livre Perdre la tête, un texte de Martin d'Orgeval, Notes sur le travail, explique les étapes du montage d'une exposition. Plusieurs phases de sélection se succèdent : sur la planche contact, sur les clichés retenus et agrandis, sur les tirages sélectionnés. Ces derniers sont laissés en repos et sélectionnés de nouveau, après quelque temps, pour retenir ce qui est réellement durable: «Ceci est la meilleure épreuve qu'on peut leur faire passer : nous avons entre-temps eu d'autres points de vue, nous changeons d'humeur [...]. L'éclairage change et nous voyons mieux¹. » Puis l'étape finale consiste à reconstruire un récit à partir des clichés qui sont tous des entités autonomes :

Trouver un début, une fin, créer un fil continu, un rythme, procéder à des ruptures et des rapprochements, insérer des séquences. Au cours de ce processus viennent les idées fortes : le titre, l'image de couverture, les partis pris esthétiques et narratifs. À la fin de ce travail de précision, notre désir est d'aboutir à un livre qui se lit à la fois comme un roman et comme un témoignage d'expériences et de trajectoires vécues, transmises à travers un filtre qu'on pourra nommer art, photographie, document - peu importe. ${ }^{2}$

Le sens de l'image est alors non seulement déformé par la part de liberté laissée au lecteur-regardeur dans l'interprétation des images, mais aussi par le choix fait par l'éditeur, ainsi que les contraintes matérielles qui jouent sur l'effet visuel de l'exposition ou du livre (technique d'impression, choix du papier, format, ressources financières, etc.). François-Marie Banier met pourtant en doute ce récit créé par le montage quand il précise sur une note manuscrite à la fin de Perdre la tête : «Il a été tiré 10 exemplaires

\footnotetext{
${ }^{1}$ D’ORGEVAL, Martin, Notes sur le travail, Perdre la tête, Op. cit., p. 231. Voir le texte sur le site personnel de Banier : http://www.fmbanier.com/martin_d_orgeval_6 (consulté le : 12/10/2009).

${ }^{2}$ Ibid.
} 
dits d'artiste, seulement parce qu'ils ont été coupés à la va-vite et composés au hasard, comme souvent l'ordre de la pensée et le désordre de la vision. Signés, chacun, et numérotés $s^{3} . »$

Le livre construit nécessairement une autre signification que l'exposition même s'il reprend les mêmes images, car l'espace de l'exposition nécessite un autre type de lecture, il n'a pas la linéarité imposée du livre. Dans ce dernier, entre autres, les photos présentées sur la double page peuvent entrer en dialogue direct l'une avec l'autre. Le montage des catalogues d'exposition révèle alors des partis pris esthétiques fondamentaux pour comprendre l'ensemble de l'œuvre. Ainsi l'ordre des clichés ne suit jamais l'ordre chronologique, ni pour l'ensemble de l'ouvrage, ni dans les séries sur une même personne: dans Private Heroes ${ }^{4}$, le chapitre intitulé «Temps » contient des portraits qui fonctionnent en majorité par paires, mais pas nécessairement.

La liste des photos du chapitre est la suivante :

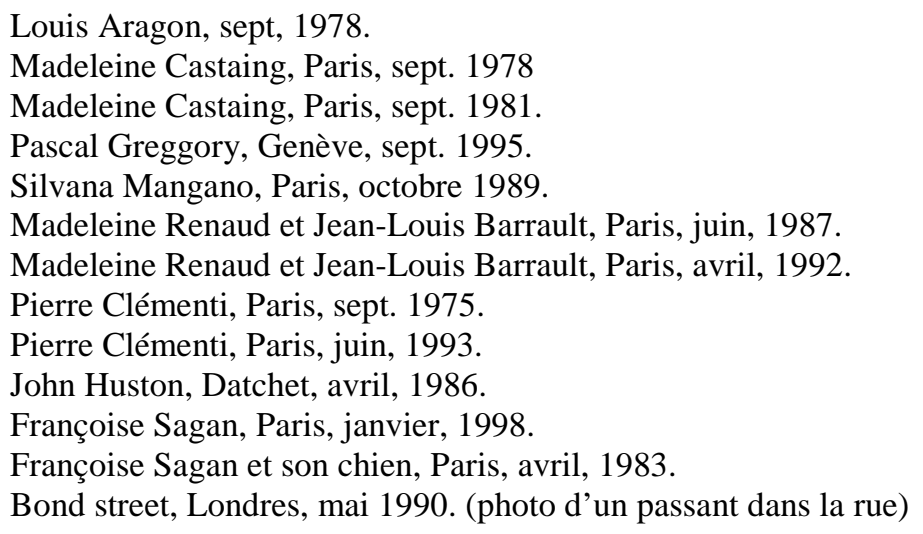

Quel temps désigne ce chapitre? S'agit-il avant tout d'un temps subjectif pour le photographe, un temps précieux passé avec les personnes représentées, qui évoque de bons souvenirs se présentant à la pensée dans le désordre ? Le choix de l'ordre des clichés reste un mystère qui n'est pas révélé, au lecteur de constituer sa réponse, ou de se laisser entraîner par la beauté des clichés ou des souvenirs que lui évoquent ses lectures, les pièces de théâtre ou film réalisés par les écrivains, réalisateurs et acteurs sur la photo ou simplement ce que les dates lui évoquent.

La composition des catalogues de Banier est dans tous les cas unique. Nous trouvons une grande variété dans la présentation visuelle du livre par le choix de

\footnotetext{
${ }^{3}$ Ibid., page éditoriale.

${ }^{4}$ Private Heroes, cat. Stuttgart, Württembergischer Kunstverein, Cantz, 1998.
} 
différents formats : grand format (Rétrospective de 2003, Past-Present), format moyen (Brésil, Photos et peintures) et petits formats (Vivre, Perdre la tête) ; par les diverses mises en page : photos qui occupent toute la page ou une page double (Rétrospective de 2003, Past-Present) ou avec une marge blanche et un cadre noir (Perdre la tête). L'ensemble de ces éléments visuels crée une esthétique, une atmosphère propre au livre. La structure des livres se caractérise également par une grande diversité. Les photos peuvent être regroupées sous des chapitres par thèmes (cf. Private Heroes qui se compose de la manière suivante: Femmes, Passants, Yves Saint-Laurent, Enfants, Temps, Vladimir Horowitz, Héros Privés, Photographie peinte, Peinture) ou par types d'image (cf. Photos et peintures, qui se divise en parties : photographies, photopeintures et peintures). L'on trouve encore des catalogues dans lesquels les mêmes thèmes sont regroupés mais non séparés en chapitres (Past-Present: gens de la rue, gens de dos, jumeaux, la danse, le cirque, toreros, animaux, photos alternant avec des portraits de célébrités). Les clichés représentant une même personne peuvent être regroupés (Rétrospective de 2003) ou à l'inverse dissociés (Perdre la tête) créant un effet d'écho entre les différentes parties du livre.

F-M. Banier, Perdre la tête, p. 54-60.

Un élément visuel peut permettre l'enchaînement des images, ainsi dans Perdre la tête (ci-dessus), la roue sous toutes ses formes apparaît dans une suite: une femme corpulente sur une mobylette (p. 54) est suivie d'une femme en chaise roulante au pneu crevé (p. 55), puis une foule en roller avec un monsieur en chaise roulant vu de dos (p. 56-57), un couple s'embrassant en roller (p. 59), un monsieur avec un outil de mesure (la roue de l'outil faisant écho à la roue d'une moto, p. 60), une femme assise dans une Rolls Royce (le visage de la femme est caché par une vitre, forme ronde qui est la mise en abyme de la forme des phares) etc. Autre type d'enchaînement peut reposer sur le geste, comme dans la Rétrospective de 2003 : la photo de la chanteuse 
française Barbara ${ }^{5}$ levant les bras, s'abandonnant au public à la fin d'un concert, est suivie de l'image d'un jeune homme musclé levant des bras pleins d'énergie sur la plage de Salvador ${ }^{6}$ (Bahia) au Brésil. L'enchaînement des images compose un récit, où les photos se succèdent, non pas tellement par leur signification, que par des jeux d'écho visuel, laissant ainsi le choix au regardeur d'interpréter la séquence d'images.

F-M. Banier, Barbara, 1998.

F-M. Banier, Anonyme, Salvador, 1999.

Des clichés d'une même personne se retrouvent ainsi insérés d'un livre à l'autre dans d'autres contextes. Par exemple les photos de Salvador Dalí et d'Andy Warhol, que nous avons déjà évoqués dans le chapitre «Portraits de peintres » (p. 14-171), se succèdent dans l'album Rétrospective de 2003, tandis que dans le catalogue Photos et peintures elles sont séparées. Le lien visuel dans le premier cas était le regard du modèle tourné vers le hors champ tandis que dans le deuxième cas il s'agit d'un nouveau contexte visuel. Ce ne sont pas exactement les mêmes clichés qui sont repris dans les deux livres: le décor et le point de vue de la caméra ne changent pas, seulement le geste. Des clichés voisins sur la planche contact sont donc utilisés pour l'un et pour l'autre livre. Dans Photos et peintures, la photo de Dalí assis dans un fauteuil est suivie par la photo de la Reine Élisabeth II également assise dans un fauteuil buvant du thér. Les deux clichés sont des vues latérales. La mise en page impose une confrontation des deux images, comme si Dalí était assis en face de la reine et bavardait avec elle. Pourtant, vingt-quatre ans séparent les deux prises de vue. Les deux

\footnotetext{
${ }^{5}$ Barbara, Paris, novembre 1998, Rétrospective de 2003.

${ }^{6}$ Salvador, Bahia, Juin 1999, Rétrospective de 2003.

${ }^{7}$ Salvador Dalí, Hôtel Meurice, Paris, mai 1968, Photos et peintures, p. 74.

${ }^{8}$ La Reine Élisabeth II, Paris, juin 1992, Photos et peintures, p. 75.
} 
photographies de la double page suivante ${ }^{9}$ montrent également des gens assis (vue latérale ou de trois-quarts), pris lors du tournage du film Le temps retrouvé de Marcel Proust réalisé par Raùl Ruiz (coproduction, Gemini Films, Les Films du Lendemain, France 2 Cinéma, 1999).

F-M. Banier, Photos et peintures, p. 74-76.

La photo d'Andy Warhol ${ }^{10}$ dans Photos et peintures est confrontée en double page à celle d'Yves Saint-Laurent ${ }^{11}$ (ci-dessous). Les deux protagonistes sont isolés d'un arrière-fond où transparaît le contour d'autres personnes, ils sont plongés dans une méditation intérieure : l'abandon du regard est renforcé par le geste involontaire de la main. Yves Saint Laurent est en train de jouer avec sa bague tandis qu'Andy Warhol replace ses lunettes sur son nez. Le rapprochement des deux clichés en fait deux génies solitaires.

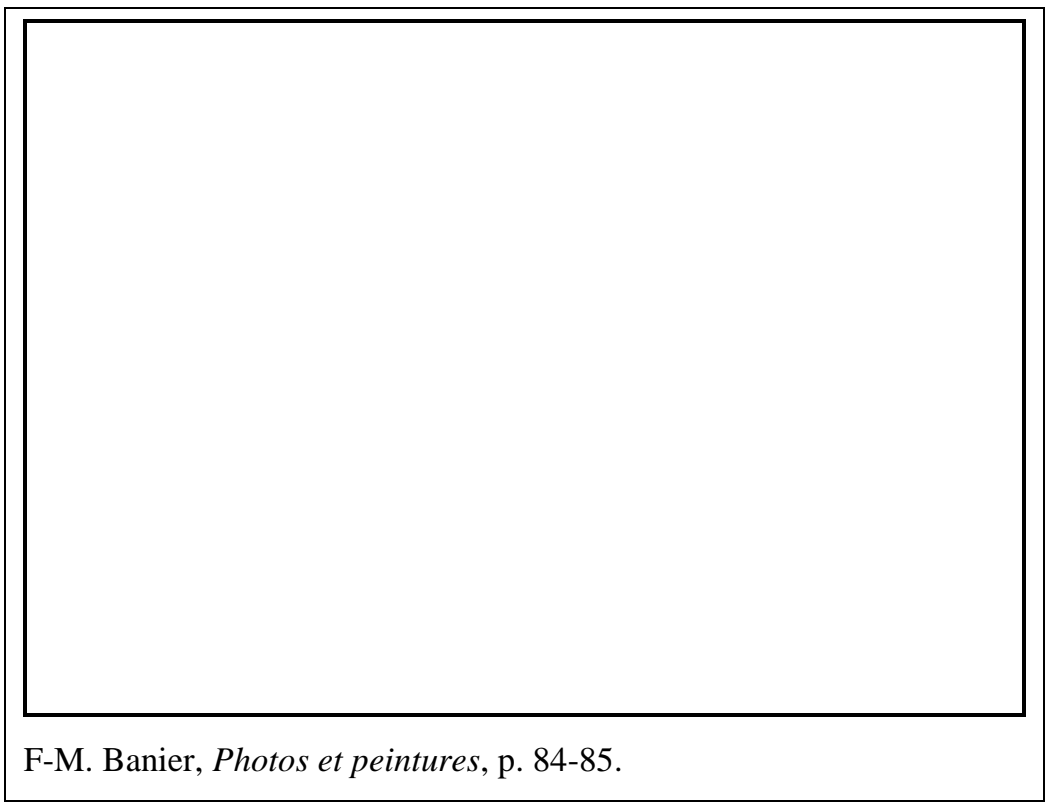

\footnotetext{
${ }^{9}$ Le temps retrouvé, Cabourg, février 1999, Photos et peintures, p. 76 et Marcello Mazzarella, Cabourg, février 1999, Photos et peintures, p. 77.

${ }^{10}$ Andy Warhol, Paris, décembre 1981, Photos et peintures, p. 85.

${ }^{11}$ Yves Saint-Laurent, Paris, décembre 1982, Photos et peintures, p. 84.
} 
Cependant, il faut noter que la lecture visuelle des suites de clichés n'est qu'inconsciente. Les récits visuels que composent les livres de photos de Banier laissent la liberté au lecteur de s'arrêter ou non sur une suite d'image et de se laisser choquer ou émerveiller par la similitude des gestes, du cadre, du point de vue, de l'arrière plan, etc. La lecture des images, d'un album d'images diffère de celui d'un livre écrit. L'album n'impose pas une lecture de gauche à droite et souvent il est juste feuilleté sans une «lecture » minutieuse. Le récit que le lecteur compose à partir des images sera un chemin, un parcours particulier, qui peut être renouvelé à chaque prise en main du livre. Le récit visuel, même s'il diffère du récit écrit puisque la cohérence est assurée par l'élément visuel et non par la cohérence du sujet, peut avoir recours à techniques narratives.

Dans plusieurs albums de Banier nous trouvons ainsi des éléments qui encadrent le «récit» visuel du livre. Dans Perdre la tête, par exemple, la série de gros plans de Daniel Emilfork précède la page du titre faisant écho aux gros plans pris dans la rue qui précèdent les textes (Contre le mur, Entretien de François-Marie Banier avec Martin d'Orgeval, Notes sur le travail) à la fin du livre. La dernière photo de cette série de gros plans de passants est reprise d'ailleurs en quatrième de couverture, tandis que la photo sur la couverture d'une dame «sans tête » dans la rue dialogue visuellement avec le cliché d'un passant «sans tête» qui suit les textes (Légendes, Biographie, Bibliographie, Notes de l'édition) à la fin du livre. Les photos se font écho d'un bout à l'autre du livre créant un le cadre de l'histoire racontée visuellement.

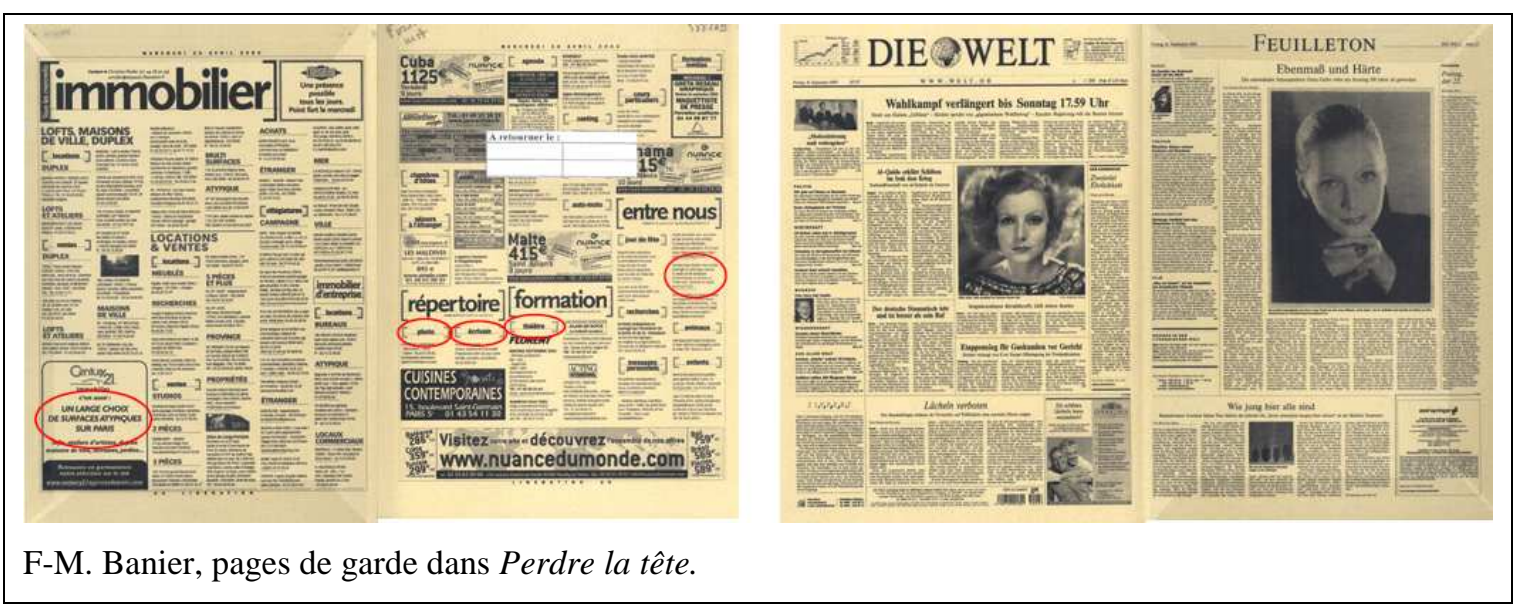

Les pages de garde forment également un cadre. Il s'agit de pages de presse, qui semblent replacer la signification de l'ensemble du livre dans un contexte de reportage photographique. Au début du livre, à la page de garde, figurent deux pages de 
Libération du mercredi 30 avril 2003 (ci-dessus à gauche), deux pages de petites annonces recto et verso d'une même page mais publiées dans l'ordre inverse (la page 26 est suivie de la page 25). Certaines inscriptions sorties de leur contexte primaire peuvent renvoyer au livre de Banier, ainsi «surfaces atypique sur Paris» (voir les parties encerclées en rouge), ou les rubriques situés l'une à côté de l'autre - «photo », « écrivain », «théâtre » - qui renvoient à la pratique photo-littéraire de Banier. Cependant l'une des petites annonces le concerne plus spécifiquement :

Samedi expo Banier nous avons échangé un très large sourire. Tu avais un fin parapluie de demoiselle. Je portais un T-shirt noir. J'aimerais te revoir. 06.07.63.75.57.

S'agit-il d'une rencontre fortuite peut-être à jamais perdue ? Un moment éclairé par la présence de l'autre ? La petite annonce révèle l'atmosphère du livre : les clichés sont le fruit d'une rencontre, d'un émerveillement, que le photographe garde en prenant la photo.

Les pages de garde à la fin du livre sont également tirées de la presse : il s'agit de deux pages du quotidien allemand Die Welt du 16 Septembre 2005 (ci-dessus à droite). Cette fois-ci, pas de petites annonces mais la une consacré à Greta Garbo avec sa photo et un renvoi à la page 27 du même journal - reproduit à côté dans le livre de Banier. Dans l'article, paru à l'occasion du centenaire de la date de naissance de Greta Garbo, le journaliste, Hanns-Georg Rodek, évoque à partir des photos de l'actrice le pouvoir de la mémoire collective, la mémoire visuelle. Le fait que le nom de Greta Garbo soit toujours connu serait, selon le journaliste, en rapport avec l'image contrôlée de l'actrice. L'image contrôlée ne la révèle cependant jamais comme elle était naturellement, toujours un visage de scène, dans des photos prises d'ailleurs souvent pendant la pose du tournage et pour la publicité de ses films. L'article est-il inséré dans le livre de Banier en raison de l'admiration qu'il voue à l'actrice ? Ou s'agit-il de la revendication du droit du photographe ${ }^{12}$ à faire des portraits qui montrent l'autre face de l'être, enfouie et cachée ? Ce ne sont que des interprétations possibles, mais dans tous les cas, la publication de ces pages de presse au début et à la fin du livre, sur un papier beige foncé identique renforce l'effet de cadre de l'ensemble du livre, et rappelle les procédés narratifs.

\footnotetext{
${ }^{12}$ Notons justement à propos de ce livre, que deux procès ont été entamés contre Banier pour atteinte au droit de l'image, procès inédits où la liberté de l'expression artistique a été favorisée contre le droit à l'image, puisque la publication n'a pas eu de conséquences graves. «Le photographe François-Marie Banier gagne un procès inédit sur le droit à l'image », Le Monde, 27 juin 2007, p. 24.
} 
D’ailleurs plusieurs romans de Banier utilisent le récit encadré. Le livre Les Résidences secondaires ${ }^{13}$, par exemple, commence par la présentation de Monsieur Pélissier faisant ses courses à Héricy, par le regard et les remarques des habitants du village sur les Parisiens qui ne viennent que pour passer les vacances. Le portrait de plusieurs personnages est dressé avant celui de Thierry Dorival, le héros principal du roman. Un zoom se fait sur le sujet, tandis qu'à la fin du livre nous retrouvons le mouvement inverse. Le roman se termine par l'évocation de Monsieur Pélissier, par une phrase presque identique à celle au début du livre. La phrase finale : «Pour Pélissier, Héricy n'a pas changé. Comme toujours il vient le samedi matin passer le dimanche à Héricy. Lui, il s'y sent bien. » $(R S, 146)$ fait écho à celle du début : « Pélissier, à Héricy, se sentait bien. » $(R S, 12)$.

L'analyse des albums photographiques montre que chaque album a sa propre organisation, est construit selon un concept différent, selon des contraintes distinctes ce qui fait que les mêmes images remployées d'un livre à l'autre s'inscrivent dans de nouveaux contextes, dans de nouveaux récits visuels et leur sens peut se modifier. Des éléments de l'image, sa structure ou le geste des personnes photographiées participent à l'élaboration du récit visuel à la construction aussi minutieuse que celle des romans de l'auteur.

\section{V.6.a. Illustrations}

L'écriture et la photographie s'imbriquent sur le même support dans les photographies écrites et peintes de François-Marie Banier, elles ne se trouvent pas juxtaposées et c'est ce qui forme sa singularité parmi les œuvres photo-littéraires. Cependant si l'on examine le livre comme objet dans sa totalité, en prenant en compte «l'énonciation éditoriale ${ }^{14} »$, nous pouvons interpréter comme illustration les dessins ou les photos sur la couverture utilisés pour les rééditions de ses romans en livre de poche, et dans ce cas l'image est le texte se trouvent séparés. Nous avons évoqué, que plusieurs dessins de

\footnotetext{
${ }^{13}$ BANIER, François-Marie, Les résidences secondaires, Paris, Gallimard, "Folio" n²444, 1993.

${ }^{14}$ Nous empruntons ce terme à Emmanuel Souchier «L'image du texte, pour une théorie de l'énonciation éditoriale », Les Cahiers de médiologie, 6 (1998), p. 137-145. Disponible sur Internet en fichier Pdf: (consulté le : 10/09/2009). http://www.mediologie.org/collection/06_mediologues/souchier.pdf.
} 
François-Marie Banier sont des dessins narratifs, dont le texte inclus dans le dessin, éclaire la signification de ce dernier (Voir l'exemple I am only an eye, p. 36.). Sur la couverture de l'édition Folio des romans de Banier les illustrations nouent un lien plus ou moins étroit avec la narration. Le type d'image employé varie selon les ouvrages, nous trouvons un dessin à l'encre (Le passé composé), des peintures à l'aquarelle (Les résidences secondaires; La tête la première), une peinture à l'huile (Sur un air de fête,), et des photographies de tiers (Balthazar, Les femmes du métro pompe).

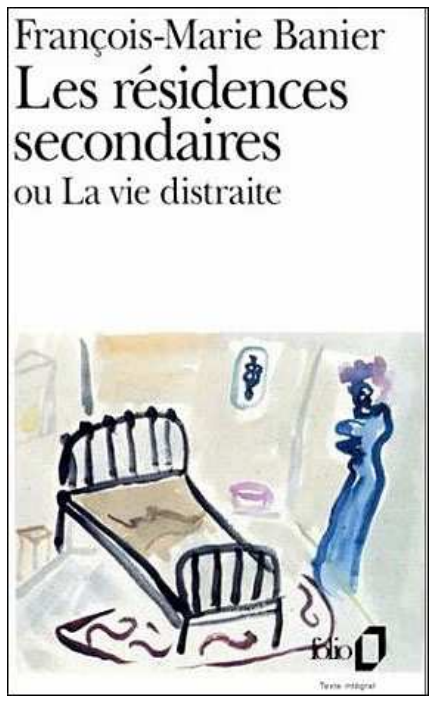

Le dessin sur Les résidences secondaires ou La vie distraite $^{15}$, le premier roman de François-Marie Banier, que nous avons déjà mentionné, présente un intérieur avec un lit et un personnage féminin sur la droite. La peinture ne représente ni la microsociété d'Héricy, ni le personnage principal Thierry Dorival. Les quelques guirlandes sur le dessin qui représentent probablement un tapis, les objets à l'arrière-plan, le tableau ou le miroir qui reflète la figure en bleu, la chaise, le tabouret et la fenêtre suggèrent qu'il s'agit de la chambre de Mme Marguerite Solto riche «propriétaire terrien » qui habita dans un château avec son mari et qui restera seule et libre suite au décès de son mari. Le dessin montre cette figure bleue dans sa solitude, elle n'a presque pas de visage mais des seins démesurément agrandis. Le grand lit sur la scène dessinée figurerait alors, la séduction et la conquête de Thierry par Mme Solto qui est décrit de la manière suivante :

Sans aucune préméditation, mais sans regret non plus, Thierry devint soudain l'amant de Madame Solto. Il en fut le premier surpris. Elle, point. Elle l'avait désiré depuis longtemps, attiré, puis conquis. C'était bien joué, au moment opportun. Il l'admirait ; elle l'avait violé. $(R S, 66$.

Cette première relation de Thierry fonctionne comme un tournant dans l'action, car il provoquera son éloignement d'André Mortimer, et laissera finalement un vide autour de Thierry après que Mme Solto succombera dans un accident de voiture et après que le château des Solto sera vendu à la municipalité à la fin du roman. Le sentiment de vide et de la solitude de Thierry préfigure déjà dans le dessin.

${ }^{15}$ La couverture du livre est reproduite sur le site personnel de l'auteur (consulté le : 16/05/2009) : http://www.fmbanier.com/rt_residences_secondaires001 
C'est également l'allusion à l'intrigue et l'évocation de la relation entre les

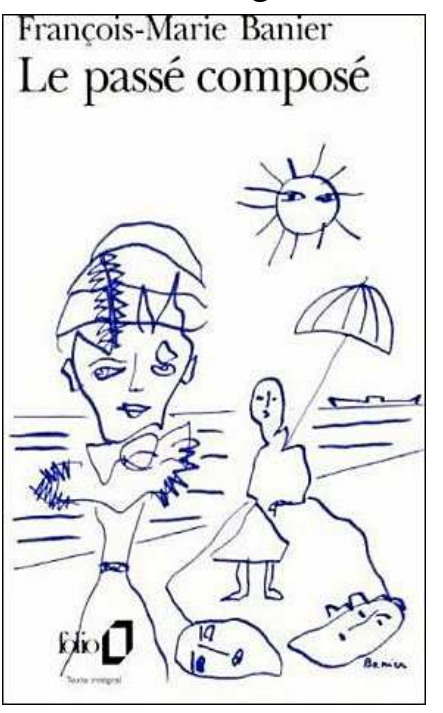
personnages que met en scène l'illustration en couverture du roman Le passé composé $e^{16}$.

Le dessin montre (voir ci-dessous) une plage avec deux personnages. La figure avec un parasol à l'arrière-plan est plus facilement reconnaissable, la jupe-triangle indique qu'il s'agit d'une fille : Cécile, le protagoniste principal du roman. L'histoire raconte la relation incestueuse entre Cécile et son frère Olivier, suite à laquelle ce dernier se suicide en se noyant. Cécile ne trouvera de sortie pour surmonter le choc que grâce à François qui ressemble à son frère. Ce dernier, au début se prête au jeu du remplaçant, mais après leur mariage s'éloigne d'elle petit à petit. Il ne reste à Cécile que de sombrer dans la folie. Sur le dessin, elle tient deux masques liés à des ficelles, qui peuvent symboliser à la fois le fait qu'elle perd son identité à la fin du roman, ainsi que le fait qu'elle confond son mari, François, avec son frère, Olivier. La rencontre de Cécile et François est particulière, car les noms évoqués renvoient aux noms de personnage dans Les résidences secondaires : «Un dimanche après-midi, à Héricy, près de Fontainebleau, chez Marie-Thérèse Le Murier, Cécile fit la connaissance de François de Chevigny » $\left(P C, 58\right.$, nous soulignons les noms repris $\left.{ }^{17}\right)$.

Sur l'image en couverture, au premier plan, la tête du personnage est beaucoup plus élaborée, il peut s'agir d'Olivier ou de François puisque les deux se ressemblent, mais la scène de plage fait penser plutôt au frère de Cécile qui s'est noyé. Les traits nerveux qui remplacent ses mains, pourraient indiquer sa noyade, tandis que la forme similaire sur sa tête en turban pourrait être une algue, comme le texte indique : «On retrouva vers la fin du mois d'août, sur un banc de sable, au milieu d'algues et de goémons, le corps bleu d'Olivier Lasserre. » $(P C, 54)$ Coïncidence intéressante que le dessin entier est fait à l'encre bleue. Le visage montre un air de défi plutôt qu'une expression désespérée. Le soleil est personnifié, il a des yeux comme sur les dessins

\footnotetext{
${ }^{16}$ BANIER, François-Marie, Le passé composé, (Grasset, Paris 1971) Gallimard, Paris, Folio n²564, 1994. Par la suite nous utiliserons l'abréviation : $P C$. La couverture du livre est reproduite sur le site personnel de l'auteur : http://www.fmbanier.com/passecompose001 (consulté le : 16/05/2009).

${ }^{17}$ Le modèle des œuvres d'Honoré de Balzac, La Comédie humaine, ou de Émile Zola, La série des Rougon-Macquart, est présent, mais ce n'est qu'un emprunt de nom chez Banier, les personnages ne sont pas identiques.
} 
d'enfance, mais on peut l'interpréter comme la figure du photographe, car il est le voyeur qui contemple la scène sans intervenir (sans pouvoir ajouter un mot puisqu'il n'a pas de bouche). D'ailleurs il n'y a pas de connections entre les deux figurent non plus. Cécile regarde dans la direction de son frère, qui a un regard dirigé vers le hors cadre. Dans l'arrière-plan on voit la mer avec les quelques lignes bleues et un navire qui flotte tranquillement au loin. Le dessin condense l'univers du roman dans cet instantané (le cadrage, la disposition des personnage, la perspective suggérée par la diminution de la taille de ce qui est plus loin, rappelle les vues photographiques), qui transmet l'état psychologique des personnages grâce au regard.

Dans les images en couverture de La tête la première ${ }^{18}$ et Sur un air de fête ${ }^{19}$, c'est également les personnages du roman qui sont représentés. Ils figurent un triangle amoureux autour du peintre Daniel Dongris ${ }^{20}$ dans le premier, et dans le deuxième le couple du célèbre peintre Juan Mendoza autour du photographe Guillaume Delastre. Dans le premier, c'est le mal de vivre et la difficulté de l'être qui est décrit, la quête d'identité à travers les histoires passionnelles du personnage principal. Dans Sur un air de fête par contre, c'est la fête, la désinvolture et la relation passionnelle, avec rupture et réconciliation que raconte le roman et que reprend l'inscription «dance was life » sur l'image. On pourrait deviner un appareil photo dans la tache noir (que nous avons encerclé en rouge ci-dessous à droite) du personnage bleu au milieu. Ainsi que sur l'image de La tête la première, dans l'axe central on peut voir un pinceau dans le trait noir avec ses poils rouge cinabre, ainsi qu'une palette dans la forme ronde, si ce n'est pas le corps du personnage et son pied. C'est intéressant, les lignes saccadées qui sortent de la tête du personnage à gauche, des signes qui ressemblent aux signaux morse, qui pourraient figurer la rêverie de Daniel Dongris, ses monologues intérieurs.

${ }^{18}$ BANIER, François-Marie, La tête la première, Grasset, Paris, 1972 / Gallimard, Paris, Folio ${ }^{\circ} 2715$, 1995. Par la suite nous utiliserons l'abréviation: TP. L'image est reproduite sur le site personnel de l'auteur: http://www.fmbanier.com/rt la tete la premiere (consulté le : 17/05/2007).

${ }^{19}$ BANIER, François-Marie, Sur un air de fête, Gallimard, Paris, 1990, Folio n 3283, 1999. L'image est reproduite sur le site personnel de l'auteur (consulté le : 17/05/2007) :

http://www.fmbanier.com/sur_un_air_de_fete_editions_gallimard_version_folio_1999

${ }^{20}$ Les noms des personnages dans les romans de Banier sont souvent des noms parlants, comme celui de Daniel Dongris, qui reprend phonétiquement d'Hongrie, et qui fait allusion aux origines hongroises de Banier, mais on pourrait encore mentionner le nom «Tudieu » que prennent des personnages secondaires dans plusieurs des romans (Le passé composé, p. 23 ; Balthazar, p. 226). Plusieurs personnages principaux ont d'ailleurs des noms de famille qui font référence à des peintres célèbres, comme Balthazar Klimpt dans Balthazar, fils de famille, ou Marcel Duchamp dans Johnny Dasolo. 
Sur l'image le personnage de droite tient un ballon sur lequel est écrit le nom de Banier, qui peut être soit un ballon, ou une bulle de texte et alors l'autre bulle pointue mais vide qui s'élance vers les signaux morses pourrait figurer la conversation échouée entre Daniel et Théa. Ils se parlent tout au long du livre, mais sans s'entendre. Les dialogues elliptiques donne une impression de présence et d'immédiateté, si caractéristique du style de Banier. Son écriture est un flot de phrases brèves, des paragraphes brefs qui se rapproche du langage parlé. Le style de son écriture rappelle l'immédiateté de la photographie, le rythme passionnel de ses peintures, le jet sans préméditation de ses dessins, qui pourtant traduisent et illustrent si bien ses romans.
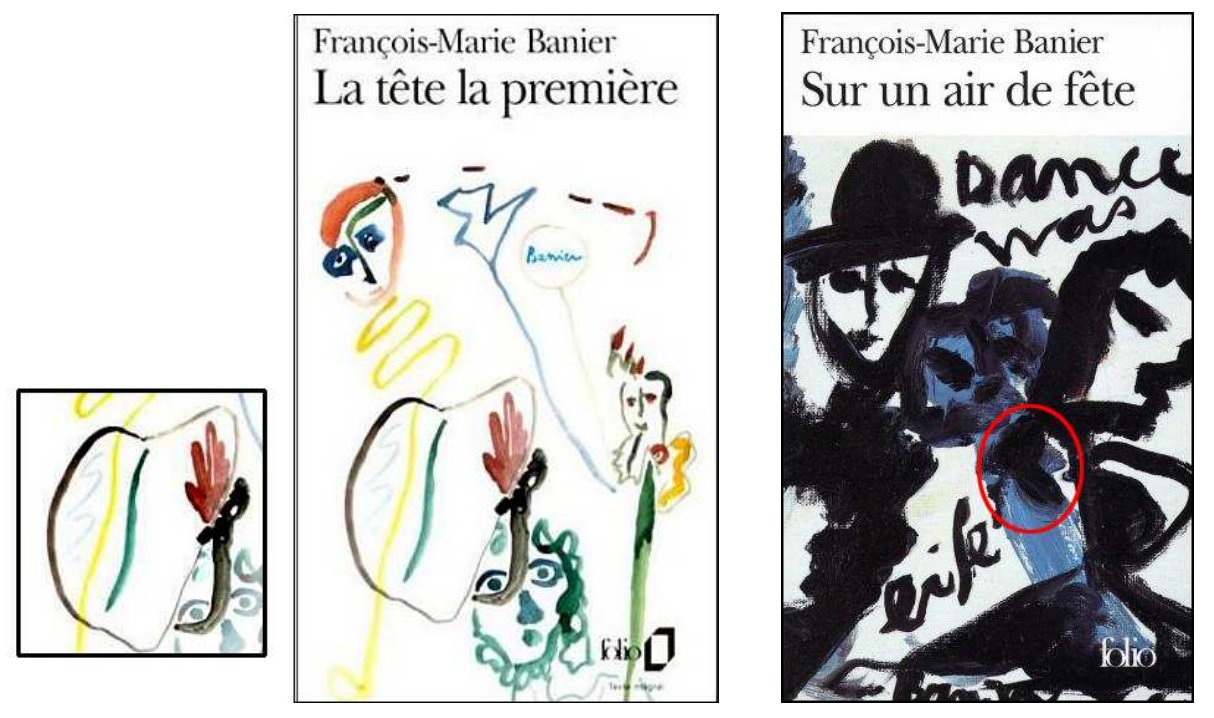

Cependant, le rapport entre le style immédiat du dessin et celui de l'écriture disparaît dans les romans de Banier illustrés en couverture par des photographies de tiers. Le roman Les femmes du métro Pompe ${ }^{21}$ est ainsi illustré d'une photo (sans mention de l'auteur) représentant Silvana Mangano - l'actrice que Banier photographie bien des années après ce cliché - et son fils. Dans le roman nous assistons à un théâtre des sentiments à travers l'histoire du jeune Sacha, fils d'agent de change à Paris, qui essaye par tous les moyens de séduire Pepita, une des femmes du métro Pompe. Encore une fois, nous retrouvons les passions comme sur les photos de Banier : «Les photographies ne sont pas des images. Elles sont théâtre, happenings, réflexions, douleurs, déchirures,

\footnotetext{
${ }^{21}$ BANIER, François-Marie, Les femmes du métro Pompe, Paris, Gallimard, 2006. L’image de la couverture est reproduite sur le site personnel de l'auteur : http://www.fmbanier.com/femmes_metro004 (consulté le : 17/10/2009).
} 
François-Marie Banier
Les femmes
du métro Pompe

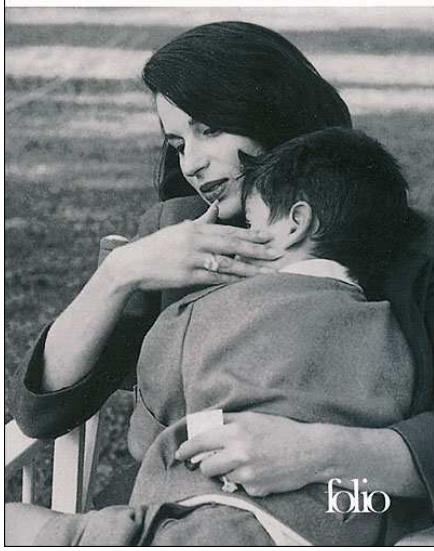

manques, mangues, mondes, claquement de doigts, elles ne sont $\operatorname{pas}^{22}$. » Le temps principal de la narration, le présent, permet, avec l'abondance des dialogues, des exclamations, des phrases elliptiques, de transcrire la pulsion de l'énonciation, de transformer le texte en une danse impulsive, une symphonie dédiée à l'amour jusqu'à la scène finale qui tourne en désarroi. Guidé par son amour, Sacha organise l'enterrement de la grand-mère de Pepita chez eux, profitant d'une absence des parents. L'enterrement se transforme tour à tour en «orgie» puis en pillage de l'appartement. Pour terminer, après la faillite de la famille causée par Sacha, on apprend qu'il s'agissait de souvenirs évoqués - l'imparfait de rupture $^{23}$ transforme le présent de la narration en un passé clos et lointain suggéré :

J'étais vraiment un petit garçon: je croyais qu'on allait déménager, partir sur la route, vivre comme les femmes du métro Pompe, arriver dans les villes le matin sans savoir où dormir le soir. [...] Je croyais que maman me reprendrait dans ses bras, au moins une fois ${ }^{24}$.

C'est à cette phrase finale que renvoie la photographie sur la couverture, au rêve de l'enfant pour un geste de tendresse.

Les illustrations en couverture dialoguent avec la narration des livres, mais si elles évoquent l'histoire, elles ne sont pas une transposition littérale d'une scène décrite, elles donnent plutôt une synthèse de l'atmosphère du roman. Le regardeur doit alors s'investir dans l'image et le texte pour retrouver le lien entre les deux.

\footnotetext{
${ }^{22}$ BANIER, François-Marie, « La vie de la photo », p. 332.

${ }^{23}$ HERSCHBERG-PIERROT, Anne, La stylistique de la prose, Paris, Belin, 1993, p. 88.

${ }^{24}$ BANIER, François-Marie, Les femmes du métro Pompe, Op. cit., p. 208.
} 


\section{V.7. La photographie dans les romans}

Des liens se tissent non seulement entre les romans et l'illustration en couverture, mais entre les romans et les photos publiées séparément dans des albums. Les romans de Banier se nourrissent d'éléments autobiographiques et il n'est donc pas surprenant de trouver plusieurs thèmes communs ou des éléments se faisant écho avec ses photos.

Par exemples dans Balthazar, fils de famille, le personnage principal pratique la peinture qu'il vend dans les rues avec succès. Il les nomme gribouillages, où le hasard est convoqué pour retranscrire l'essence des personnes portraiturées. Il décrit toutefois avec ironie le goût du public pour l'art abstrait :

Les seuls dessins qui plaisent en ce moment sont faits de quelques taches que j'enjolive d'un trait plus ou moins éloquent qui ne veut rien dire. Je glisse subrepticement du rose, du mauve, des petits points noirs entourés d'un cercle dentelé - ce peut être des amibes, des protozoaires, un têtard, le Mont Saint-Michel -, je brouille le tout et le tour est joué. $(B, 239)$

Dans Jonny Dasolo, c'est Jonny, une sorte de double du personnage principal, Marcel Duchamp, qui est un bon dessinateur et qui fait des sketchs en classe sur les professeurs et les élèves. On imagine alors ces sketchs et gribouillis semblables aux dessins de Banier.

De petits fragments presque imperceptibles dans les romans évoquent également des personnes photographiées et présentées dans ses albums. Par exemple, dans Le passé composé, François au tout début de sa relation avec Cécile «lui propos[e] de lui faire connaître Madeleine Castaing ${ }^{1}$ pour voir des tableaux de Soutine » $(P C, 64)$, et lors de leur premier rencontre, il arrive avec un disque de Barbara ${ }^{2}$.

Balthazar, lui, reçoit pour son anniversaire une photo de l'actrice, qu'il aime tellement, la photo de Silvana Mangano ${ }^{3}$ « dans un cadre en cuir, très joli » $(B, 101)$.

Parmi les photos de Banier prises lors du bicentenaire de la mort de Louis XVI, celle qui s'intitule rue de la Pompe fait tout de suite penser au roman Les femmes $d u$ Métro Pompe et à la scène finale des funérailles symboliques de la grand-mère de Pepita. Cette scène décrit le défilé d'une foule déchaînée dans l'appartement des parents

\footnotetext{
${ }^{1}$ Banier fait plusieurs photos de la décoratrice célèbre. Voir l'exemple sur le site personnel de l'auteur : http://www.fmbanier.com/photos_portraits_002_5 (consulté le : 17/05/2009).

${ }^{2}$ Voir la photo de la chanteuse faite par Banier à la page 208.

${ }^{3}$ Voir sur le site personnel de l'auteur : http://www.fmbanier.com/mangano_004 (consulté le : 17/05/2009).
} 
de Sacha, une foule incontrôlable. L'émotion est à son comble : «On hurle, on jure, on s'évanouit à qui mieux mieux. On pose son pied sur le corps d'une qui fait la morte et devant ce trophée, un pied sur la bête, on réclame un flash » $(F M, 184)$. La foule sur les photos n'est pas à ce point effrénée, mais les passions transparaissent sur les visages et le samu vient même récupérer quelqu'un qui s'est évanoui.

Les dédicaces s'adresse également à des personnes dont on retrouve les photos dans les albums (Balthazar à Pascal Greggory ${ }^{4}$; Nous ne connaissons pas la même personne à Madeleine Castaing).

Ces échos qui se font entre les livres et les photos constituent un subtil tissage autobiographique.

Plusieurs romans de Banier mettent en scène des personnages photographes ou décrivent des pratiques photographiques ; Banier en profite pour dresser en partie un autoportrait en décrivant l'identité du photographe. Dans La tête la première, Jeanne, l'amie du personnage principal Daniel Dongrie, est photographe de presse. Son activité n'est pas trop détaillée, mais c'est elle qui offre à Daniel une série de photos de Théa trouvée dans un studio (c'est la fille dont est épris Daniel). Cela fournit l'occasion de décrire la planche contact attisant le désir de Daniel :

Au-dessus d'une table en bois blanc j'ai épinglé au mur quelques photographies de Théa. Jeanne n'a rien dit. Au contraire elle trouve que cela meuble. Trente-cinq photos de Théa. Une planche de contacts. La première : une vue d'ensemble, avec un chapeau, les jambes écartées, des bas noirs. La seconde : elle relève ses jupes. La troisième : Théa se retourne. Ce n'est pas une jolie photo. La quatrième: Théa, coupée à la taille, les seins à l'air, elle vous offre un bouquet de violettes. Cinquième photo: uniquement les seins. Six... sept... huit... neuf... dixième photo : deux morceaux de visage : un œil ouvert, l'autre fermé, et la bouche de plus en plus près. [...] Je regarde Théa, elle me regarde mais elle ne le sait pas... Pendant presque un mois j'ai pensé à Théa. (TP, 128)

La description dévoile un corps morcelé, dominé, car il est «épinglé » au mur. La photo peut être investie par le fantasme érotique, mais comme le désir n'est pas partagé, elle est également la raison fondamentale du malaise du protagoniste qui n'arrive pas à créer une complicité aussi profonde dans ses liens avec des femmes (Jeanne ou Théa) qu'avec Charles, son meilleurs ami.

Sur un air de fête est le seul roman où la photographie tient un rôle central par le biais du protagoniste Guillaume Delastre, reporter photographe. Certains de ses propos

\footnotetext{
${ }^{4}$ Voir l'exemple sur le site personnel de l'auteur : http://www.fmbanier.com/photos_portraits $007 \quad 5$ (consulté le : 17/05/2009).
} 
sur la photographie rappelle ceux de Banier, mais il incarne également le stéréotype du reporter photographe semblable au protagoniste de Michelangelo d'Antonioni (Blow $U p, 1966)$, travaillant pour la mode, séduisant les filles à l'aide de l'appareil, pratiquant des « photos de voyeur » qu'il vend pour combler son déficit à des «journaux friands de mariage, de sang, d'indiscrétion » $(S F, 20)$.

C'est au court des dialogues entre Guillaume, son ami peintre Joan Mendoza et sa femme Gi, que se dévoilent les diverses facettes de sa photographie. On retrouve les mêmes propos que dans La vie de la photo : l'amour de la vie et le désir de la prolonger à tout prix :

- C'est pour moi une mémoire. J'ai toujours eu le sentiment de l'éphémère, de perdre ce que j'ai, ce que je vois. Je veux retenir, tout retenir.

Ce n'est pas tout à fait ce qu'il voulait dire, il cherchait ses mots. Gi insinua qu'il ne jouait pas le jeu. Qu'il était un voleur.

- Peut-être que je cherche à me persuader que je vis vraiment, que ceux que je rencontre existent pour de bon. $(S F, 118-119)$

La forme du dialogue permet de ne pas affirmer, mais de suggérer des interprétations possibles, ou encore d'exprimer des idées opposées.

Dans la plupart des romans, l'évocation des photos et des photographes, mais aussi des peintres et des peintures, s'inscrit seulement à l'arrière-plan, dans le décor, elle apparaît tout naturellement et reste presque invisible. C'est un détail insignifiant qui échappe, sauf si on concentre notre attention sur ce détail. Dans Le passé composé, par exemple, François propose lors de sa première rencontre avec Cécile de la prendre en photo. Dans Nous ne connaissons pas la même personne, se trouve mentionné un photographe visionnaire :

[...] le petit bonhomme, il avait inventé un procédé : il vous photographiait et vous montrait comment vous seriez dans vingt ans, dans quarante ans... Les gens s'y précipitaient. Quand la photo sortait blanche, il disait : "Vous c'est dans l'année », et on mourait dans l'année. ${ }^{5}$

Dans Balthazar, la mère inventant des bizarreries (et par conséquents jamais disponible pour son fils) dépose un brevet pour avoir inventé « la photo parlante » $(B, 257)$.

Ces photos et photographes dans les romans restent tout aussi enfouis que les éléments autobiographiques, ils sont tissés dans le corps du texte et travestis en fiction.

\footnotetext{
${ }^{5}$ BANIER, François-Marie, Nous ne connaissons pas la même personne, p. 25.
} 


\section{V.8. Les jumeaux chez Banier}

Plusieurs thèmes réapparaissent dans les photographies et les romans, mais nous nous attarderons sur le thème des jumeaux car il est essentiel dans la compréhension de l'ensemble de l'œuvre de Banier. Le thème des jumeaux en littérature ainsi qu'en photographie est lié étroitement au thème du double, du sosie, du couple, de la relation à soi, de l'autoportrait, de l'ombre, du miroir et de l'aliénation.

Le fantasme de la gémellité préoccupe tout le monde, comme le remarque Serge Tisseron, parce que ce fantasme «est au cœur de la relation que tout être humain entretient avec lui-même et avec ses semblables ${ }^{1} »$. Il ajoute que deux fantasmes se développent par rapport à la gémellité, elle symbolise soit le couple idéal, une entente profonde et harmonieuse, une unité parfaite, une gémellité assumée, soit le reflet identique est vécu comme inquiétant, bouleversant et mettant en péril l'individualité, la personnalité de chacun. Dans ce cas, l'autre identique devient un rival et les jumeaux vont chercher à s'éloigner l'un de l'autre.

L'identité des jumeaux se joue sur deux plans : un comportement semblable les caractérise, même gestes, même goûts - et, ce qui est encore plus troublant et que révèle la photographie : une apparence physique identique, jusqu'à être confondus même par leurs propres parents. Cette problématique en cache une autre beaucoup plus large, qui ne concerne pas uniquement les jumeaux : comment coïncider à son propre image ? Selon Tisseron la photographie joue un rôle primordial dans cette question : «Avec elle [la photographie], nous ne sommes plus réductibles à aucune image qui nous représente parce que nous n'avons plus une image, mais plusieurs $»^{2}$. C'est également l'image qui peut sauver le couple de jumeaux, la prise en compte d'un regard extérieur qui fait qu' «ils cessent de se regarder l'un l'autre pour commencer à s'intéresser à... l'image

\footnotetext{
${ }^{1}$ TISSERON, Serge, «Désir de jumeau, angoisse du double », in L'ère du double, sous la dir. de Patrick Roegiers, Paris, Marval, 1998. p. 87. Ce livre est un acte de colloque qui a accompagné en 1996 une exposition consacrée à la gémellité (Double vie, double vue, catalogue de l'exposition, Paris, Actes Sud, Fondation Henri-Cartier Bresson, 1996). Cette exposition a eu lieu dans le cadre du Mois de la photo à Paris dont le catalogue reprend également des clichés de jumeaux (Mois de la photo à Paris, Paris, Maison Européenne de la photographie/Paris Audiovisuel, 1996).

${ }^{2}$ TISSERON, Serge, Op. cit., p. 95.
} 
du couple ${ }^{3} »$. Assumant leur gémellité, les jumeaux jouent sur cette image en cherchant la similitude, par des vêtements identiques, par exemple.

Les œuvres littéraires qui traitent la gémellité ${ }^{4}$ décrivent l'univers étrange de cette confrontation. Jean Arrouye cite entre autres les romans de Michel Tournier (Les météores, Gallimard, 1975), de Bruce Chatwin (Les jumeaux de Black Hill, Grasset, 1993) et de Ken Follet, (The Third Twin, Macmillan, 1996). Dans ces romans au centre desquels se trouve une quête d'identité, l'enjeu de la narration est de savoir si un dénouement heureux, une gémellité assumée peut être possible.

Les photographies de jumeaux de François-Marie Banier semblent refléter une gémellité assumée : ils portent des vêtements identiques, ils se promènent ensemble, dans les bras l'un de l'autre. Leur complicité, une entente profonde se lit sur l'image. Ce ne sont pas des portraits posés, frontaux comme la plupart des photographies traitant ce thème (Diane Arbus, Dominique Delpoux, Laura Samson Rous ${ }^{5}$ ) mais des images prises à la sauvette dans les rues, des clichés qui s'intègrent dans une sous-catégorie par rapport aux images prises par Banier des passants dans les rues. Ce sont des jumeaux qu'il cherche à trouver et retrouver dans les rues, et qu'il suit pour les photographier, pour imaginer ensuite leur vie, leur histoire par les mots qu'il ajoute aux photos.

Ouvrir des mondes secrets, ce n'est pas autre chose que signifie ma poursuite des jumelles. Quand je les voyais l'une cramponnée à l'autre, je ne pensais qu'à raconter ce duo qui me fascinait. Devant l'objectif, elles partaient, cherchaient à éviter mon regard sur elles. Les jumeaux de la rue Rivoli, même réflexe. A croire que les paires fuient les miroirs, leur double dont la concurrence les trouble. ${ }^{6}$

Nous ne voyons ni pose, ni dialogue entre le photographe et ses modèles, si ce n'est la surprise d'être photographié, un regard étonné, et méfiant même.

\footnotetext{
${ }^{3}$ Ibid. p. 94.

4. Voir l'analyse de Jean Arrouye qui énumère un grand nombre d'ouvrage littéraire sur ce thème : «Les jumeaux dissemblables ", in L'ère $d u$ double, Op. cit., p. 41-53. Sur le double en général dans la littérature, ainsi que sur l'ombre, le miroir et l'autoportrait: JOURDE, Pierre, TORTONESE, Paolo, Visages du double, Paris, Nathan, 1996.

${ }^{5}$ Mois de la photo à Paris, Op. cit., p. 96-97. Voir également l'article de ROEGIERS, Patrick, «L'épopée du double ou la poétique des jumeaux en photographie », in : L'ère du double, Op. cit., p. 65-73.

${ }^{6}$ BANIER, François-Marie, « La vie de la photo », p. 335-336.
} 


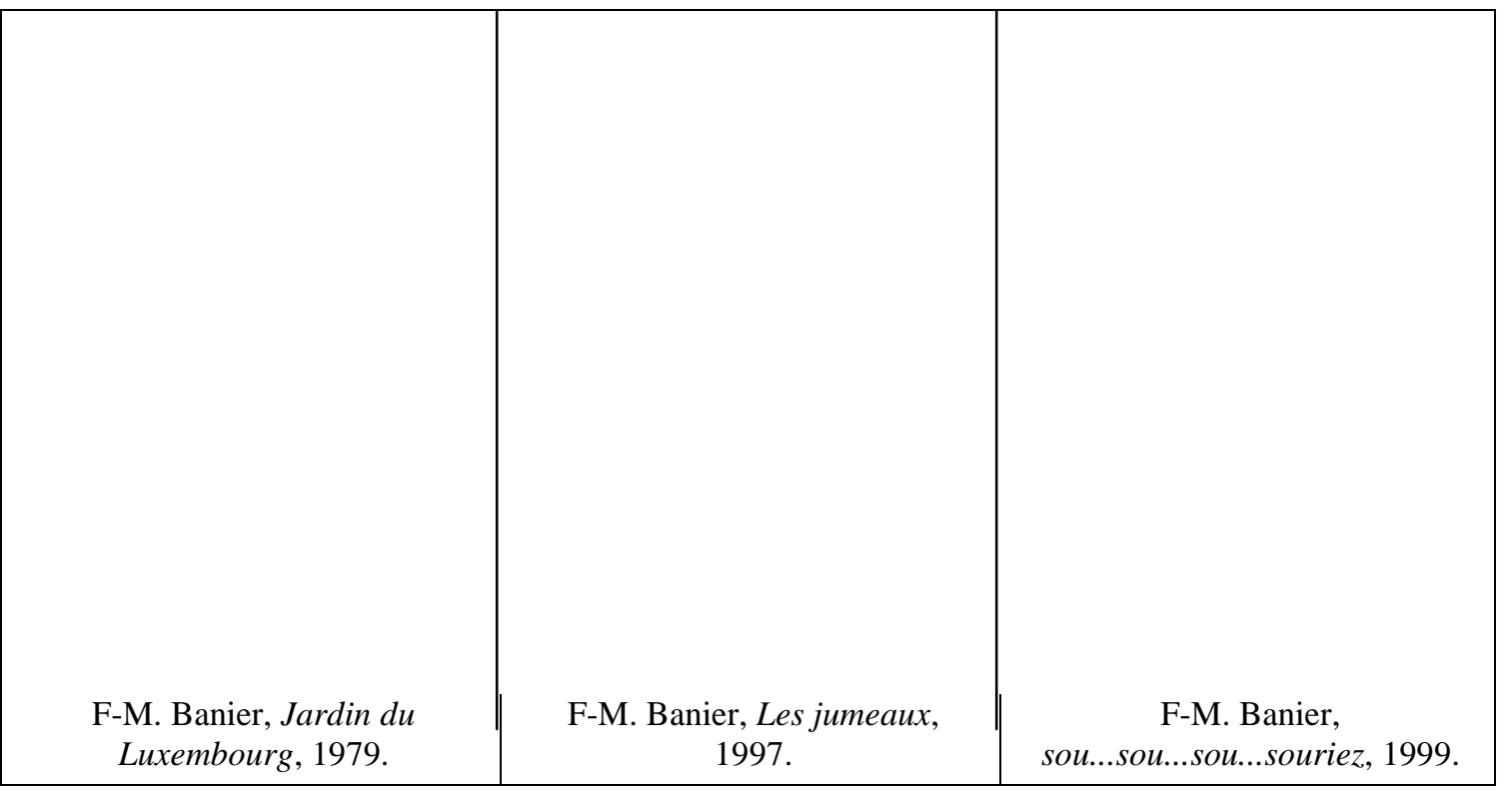

Pourtant, une douceur, une relation quasi amoureuse apparaît derrière les mots ajoutés à l'image (ci-dessus à gauche $\left.{ }^{7}\right)$ :

Je leur ai imaginé tous les prénoms. Toutes les naissances, tous les passés, et surtout je ne vous ai plus imaginé sans moi. Où êtes vous? Où êtes vous passées Elles m'ont semé. Quel quartier hantez-vous? Je vous en supplie faites-moi signe. Faisons amis. ${ }^{8}$

Parmi les personnages des romans de Banier nous trouvons un couple de jumelles dans Balthazar, fils de famille. Elles ne sont que des personnages secondaires, des jumelles dont Balthazar fait la connaissance à l'école de danse de M. Bruno, où il vient s'inscrire pour faire de la danse et où on le confond, le prenant pour un professeur de danse qui vient pour l'annonce. Les jumelles Coryse et Marysa sont identiques, et Balthazar les mélange souvent ce qui crée des malentendus sur lesquels jouent les deux sœurs jumelles.

Coryse m'aime. Marysa ne m'aime pas. L'ennui, c'est qu'on ne peut pas les reconnaitre. Brunes, les cheveux courts, elles sont décidées à monter un numéro de cabaret avec moi. [...] Quant elles arrivent séparément au cours de danse, je ne sais pas à laquelle je parle : je crois que c'est Coryse, et c'est peut-être Marysa. Laquelle m'a demandé : «Où étais-tu cette nuit? » J'ai pensé qu'elle voulait savoir si sa sœur était avec moi. Pour m'en tirer, j'ai répondu : «J'ai oublié. » Vexée, elle m'a tourné le dos. $(B, 229$.

7 Les références des photos de gauche à droite: Jardin du Luxembourg, Paris, 1979, encre sur photographie, 40x30 cm, 1991, Photos et peintures, p. 27 ; (http://www.fmbanier.com/node/2397); Les jumeaux, 1997, encre sur photographie, $160 \times 110 \mathrm{~cm}$, collection particulière Photos et peintures, p. 29 ; sou...sou...sou...souriez, 1999, photographie peinte, $160 \times 110 \mathrm{~cm}$, Photos et peintures, p. 111.

${ }^{8}$ Jardin du Luxembourg, Paris, 1979, encre sur photographie, $40 \times 30 \mathrm{~cm}, 1991$, Photos et peintures, Op. cit., p. 27. (http://www.fmbanier.com/node/2397). 
Nous les voyons uniquement par l'œil de Balthazar, car ce n'est pas la problématique de la gémellité qui est au centre du roman; beaucoup plus, elles symbolisent un univers étrange qui revêt même une touche d'exotisme, car elles ont le projet de fuir ensemble avec Balthazar pour monter un spectacle dans des cirques, ce que le héros refuse finalement. Le couple des jumelles reste un univers clos, impénétrable, qui fait que la gémellité reste une dimension de rêve, mais elle n'offre pas une alternative aux autres couples dans l'ensemble de l'œuvre de Banier.

De nombreux couples dans les romans sont malheureux. Les protagonistes rêvent de

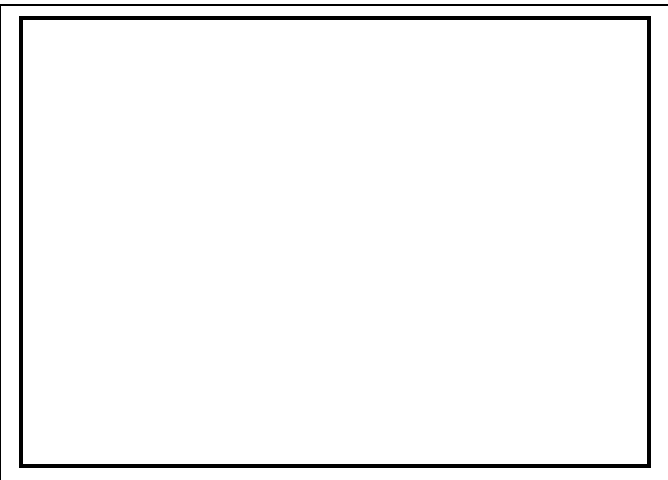

F-M. Banier, Vladimir Horowitz et Wanda Toscanini Horowitz, 1985.

s'appartenir à jamais, de vouloir retrouver les mêmes sentiments chez l'autre, d'être en quelque sorte un double complémentaire comme les jumeaux, mais en général, ils sont contrariés et incompris dans leur amour jaloux qui exige l'amour absolu de l'autre, l'exclusivité, un amour à la folie. Ainsi dans Sur un air de fête, le photographe, Guillaume Delastre, suit Marie en cachette, se brouille constamment pour ne pas retrouver la même affection chez elle. Leur relation est dédoublée par la relation non moins exaltée du peintre Mendoza et Gi, personnages fictifs qui évoquent le couple ami de Banier sur lequel il publie plusieurs photographies : Vladimir Horowitz et Wanda Toscanini ${ }^{9}$ (ci-contre). Banier décrit leur relation dans : «Vladimir Horowitz », les dîners et le caractère sensible du pianiste, le «Frankenstein en smoking » capable de miracle, « les mains en l'air, dans le vide, sans rien en dessous que le parquet, dans ce geste magique de la musique qu'il aurait pu faire surgir même sans instrument ${ }^{10} »$. Mais les photographies de couples sont très fréquentes chez Banier comme le remarque d' ailleurs Patrick Roegiers ${ }^{11}$.

On trouvent aussi des amitiés qui se forment comme des doubles: André Mortimer/ Thierry Dorival (Les résidences secondaires) ; Daniel Dongris/ Charles (La tête la première); Johnny Dasolo/ Marcel Duchamp (Johnny Dasolo). Le couple le plus

\footnotetext{
${ }^{9}$ Vladimir Horowitz and Wanda Toscanini Horowitz, Paris, May 1985, Past present, p. 110-111.

${ }^{10}$ «Vladimir Horowitz », Rétrospective de 2003, Op. cit, p. 322-323.

${ }^{11}$ ROGIERS, Patrick, «Le roman photographique de François-Marie Banier », Rétrospective de 2003, Op. cit, p. 10 .
} 
malheureux est celui de Cécile et Olivier dans Passé composé. Si Olivier se suicide, ce n'est pas à cause du regard des autres, du repentir qui l'envahit à cause de sa relation incestueuse avec sa sœur, mais parce qu'il ne peut pas admettre que Cécile veuille sortir retrouver d'autres gens, après ces jours où ils s'étaient enfermés dans la maison, à vivre des moments éclatants, un amour excessif, une parfaite dissolution dans l'autre. Olivier voulant l'exclusivité ne peut que choisir le suicide. Cécile, pour qui Olivier était une sorte de double, la seule personne dont le goût, la personnalité s'accorde si bien avec la sienne, va sombrer dans la folie, après s'être rendue compte que François, qu'elle épouse pour sa similitude avec son frère et qu'elle prend pour un sosie d'Olivier, ne veut plus jouer le jeu.

Le thème de la gémellité peut s'étendre à toute sorte de double. Parmi les portraits de Banier, nous trouvons ainsi des clichés représentant une seule personne qui est dédoublée par un jeu de miroirs dans la photo de Marie Laure de Noailles ${ }^{12}$, et celle de Pascal Greggory ${ }^{13}$.

F-M. Banier, Marie Laure de Noailles, 1968.

F-M. Banier, Pascal Greggory, 1995.

Selon l'inscription sur le cliché de Greggory, l'acteur incarnerait celui qui a le don de se dédoubler, de devenir l'autre :

Three dimensions of Pascal Greggory

An actor in front his mirror before his performance : who am I? Who am I going to be? They have the choice. This power. Pascal Greggory twenty years ago created my first play. ${ }^{14}$

Mais en poussant encore plus loin l'interprétation du double, on peut également considérer le procédé de la photographie comme une fabrication de doubles, comme le

\footnotetext{
${ }^{12}$ Marie Laure de Noailles at home, Paris, juin 1968, Past present, p. 38-39.

${ }^{13}$ Pascal Greggory, Geneva, septembre 1995, Past present, p. 242-243.

${ }^{14}$ Ibid. «Trois dimensions de Pascal Greggory. Un acteur devant son miroir avant la scène : qui suis-je ? qui est-ce que je vais devenir? Ils ont ce choix. Ce pouvoir. Pascal Greggory a interprété ma première pièce il y a vingt ans. » (Nous traduisons).
} 
dédoublement de la réalité, même si le discours de Banier sur la photo n'aborde pas le sujet. Comme Patrick Roegiers le remarque à propos de l'exposition sur les jumeaux :

Conçue tel un moulage, une empreinte, une trace, un duplicata, exempt parfois de copyright, par le truchement de la lumière et de son impression sur la surface sensible, elle figure en soi une gémellation originelle et l'épreuve (ou le tirage) est en principe identique à l'image initiale, à savoir la matrice que constitue le négatif. Mais si l'on compare une épreuve à une autre, ces deux exemplaires pourtant si proches d'aspect sont en même temps différents, non interchangeables et aussi peu semblables que des jumeaux monozygotes ayant des différences physiques et morphologiques évidentes, malgré un patrimoine génétique identique. ${ }^{15}$

Chez Banier l'amour est alors le motif pour dédoubler la réalité, l'instant, le même amour que chez la plupart des personnages romanesques qui sont à la recherche de leur double.

${ }^{15}$ ROEGIERS, Patrick, « Avant-propos », in L'ère du double, Op. cit., p. 8. 


\section{V.9. François-Marie Banier-Conclusion}

Quand il parle de la photographie, François-Marie Banier recourt constamment à la métaphore de l'écriture et vice-versa. Photographier devient une pratique pour transcrire le roman que chaque être porte en soi, et écrire sur les photos participe à la transformation romanesque de la photo. Banier compare le geste d'écrire sur la photo, qui va jusqu'à faire disparaître l'image, à la relation qu'entretiennent les personnages romanesques avec leur modèle :

« [...] la photographie a quand même été mon point de départ. Elle disparaît comme le portrait de Charles Haas, héros de la vie sociale, s'efface derrière celui de Swann, héros du livre, le roman, prenant largement le pas sur la vie du narrateur. ${ }^{1}$

De même l'auteur transpose des éléments autobiographiques dans ses romans pour mieux s'effacer. De même, dans la photographie reprise d'un livre à l'autre la part autobiographique laisse la place à la construction du récit visuel.

Dans la quête de l'autre, dans l'amour de la vie, dans la fulgurance des signes amassés tantôt par la photo, tantôt par la peinture, tantôt par l'écriture, il y a cette envie de retenir et de conserver les choses. Si l'écriture envahit la photo et l'efface partiellement, la photo à son tour, influence le style de l'écriture. Le texte de réflexion, La vie de la photo, devient fragmentaire, idées brèves, notes courtes et circoncises se succèdent, séparées visuellement par un blanc comme des icônes placées l'une après l'autre. Mais dans les romans, on trouve souvent des dialogues elliptiques, des phrases et paragraphes brefs qui se rapprochent du langage parlé et confèrent au texte une présence et immédiateté qui ont pour modèle la photographie. La photographie devient le vecteur de toute l'œuvre Banier, elle en est le point de départ et le point d'arrivée.

\footnotetext{
${ }^{1}$ SANTANA, Raúl, «Entretien avec François-Marie Banier », Op. cit., Photos et peinture, p. 39.
} 

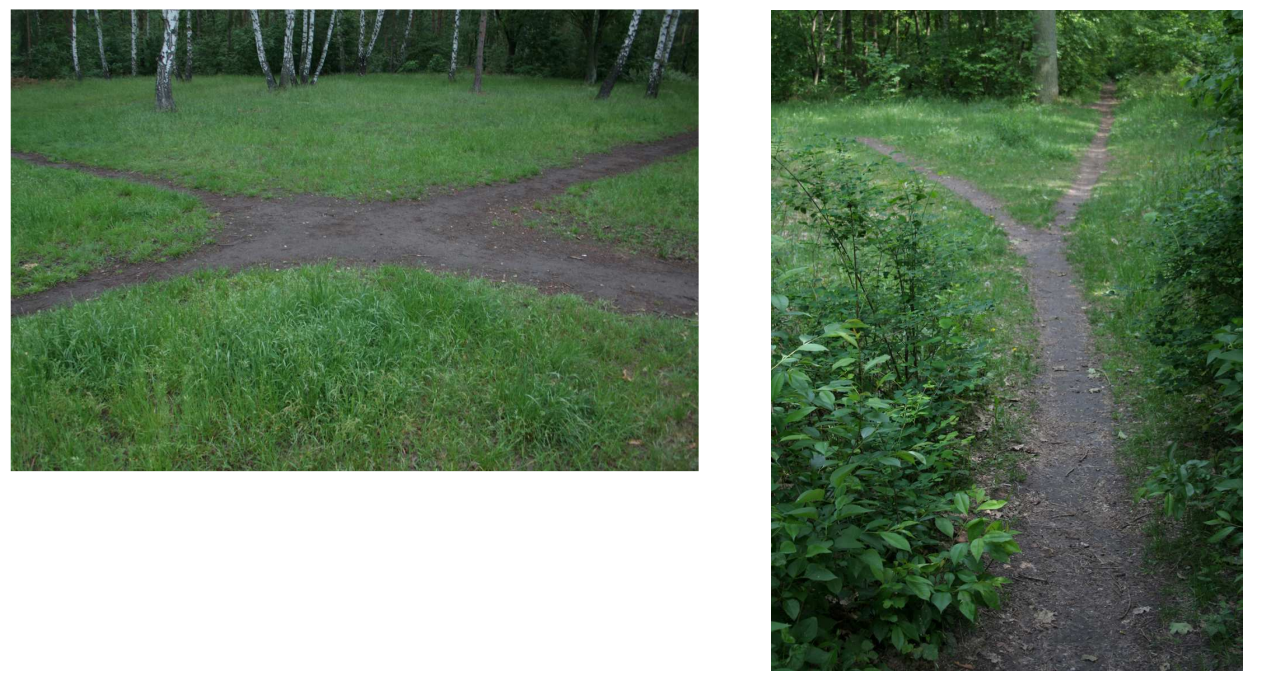

Pál Gy. : $\quad$ Les chemins xy, les chemins de l'enfance

en hommage à la mère de Jean-Loup Trassard et à ma mère mathématicienne 


\section{Jean-Loup Trassard - le jeu des illusions}

\section{Contenu du chapitre :}

VI. Jean-Loup Trassard - le jeu des illusions 229

VI.1. L'espace habité par les souvenirs 232

VI.1.a. Tardifs instantanés - les multiples facettes du modèle photographique

VI.1.b. Dormance - la photographique comme schème ............................... 237

VI.1.c. Au-delà des genres........................................................................ 241

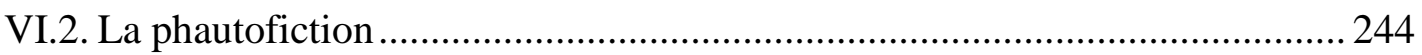

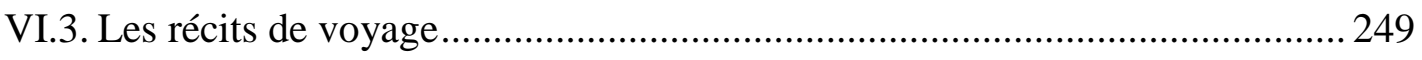

VI.4. L'énigme photographique ou l'espace intime de l'entre-deux ..................... 260

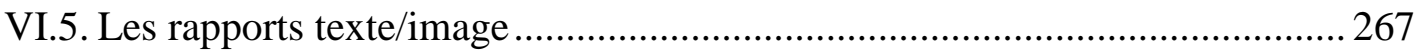

VI.5.a. Inventaire des outils à main dans une ferme - la poétique de

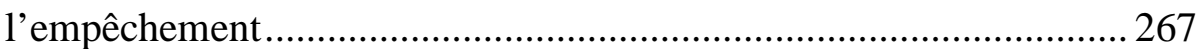

VI.5.b. Archéologie des feux - une trace de lumière.................................... 269

VI.5.c. Territoire - la surface plane fragmentée ............................................ 270

VI.5.d. Ouailles - le récit en image........................................................... 273

VI.5.e. Tumulus - le crépuscule des civilisations....................................... 276

VI.5.f. Nuisibles - le labyrinthe de la pensée............................................. 277

VI.5.g. La Composition du jardin - la sonate visuelle................................... 280

VI.5.h. Sanzaki - la ronde des saisons ......................................................... 283

VI.5.i. Les livres illustrés par des dessins .................................................. 285

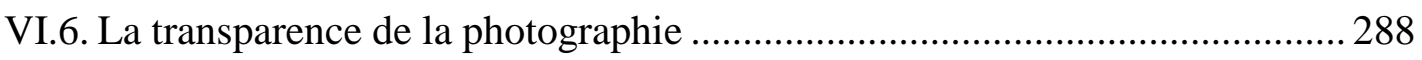

VI.7. Jean-Loup Trassard - Conclusion................................................................ 291

\section{Liste des abréviations utilisées :}

$\begin{array}{ll}\text { Campagnes de Russie } & C R . \\ \text { Dormance } & D . \\ \text { Images de la terre russe } & I T R . \\ \text { La composition du jardin } & C J . \\ \text { Le voyageur à l'échelle } & V E . \\ \text { Les derniers paysans } & D P . \\ \text { Objets de grande utilité } & O G U . \\ \text { Sanzaki } & S \\ \text { Tardifs instantanés } & T I .\end{array}$


Contrairement à François-Marie Banier, Jean-Loup Trassard fait nettement la distinction entre sa pratique photographique et littéraire : le seul point de rencontre, selon lui, serait l'identité du thème'. En effet, la majeure partie de l'œuvre littéraire et photographique de Trassard est centrée sur son lieu natal, la Mayenne, le bocage, ou plus précisément l'entourage de sa maison. Une enfance campagnarde influence toute son œuvre d'écrivain et de photographe. Selon la biographie publiée sur le site de la maison d'édition «Le temps qu'il fait », son principal éditeur, il apprend, très tôt la photographie grâce à son père, photographe amateur lui-même :

Mon père m'a d'abord offert une boîte Kodak. Je crois même que j'en ai eu deux successives. Puis assez vite il a trouvé, en occasion, un Vestpocket à soufflet, me disant que ce modèle lui avait laissé un très bon souvenir. Je ne connaissais alors que trois sujets : le fils du cultivateur voisin, compagnon quotidien durant bien des années, puis mon chien, une bâtarde noire à pattes blanches, puis mon vélo bien astiqué, la pédale élégamment appuyée sur la marche du perron... ${ }^{2}$

Une évolution se fait sentir à l'intérieur de l'œuvre de Trassard, allant de récits brefs, prenant souvent place dans un univers fantastique à la poétique très marquée où les personnages sont en quête d'une fusion avec le règne végétal (L'amitié des abeilles, L'érosion intérieure, L'ancolie, etc.) vers des textes de plus longue haleine où la part autobiographique de la genèse est de plus en plus accentuées (Tardifs instantanés, L'espace antérieur, Dormance, La Déménagerie). Il est aussi l'auteur de plusieurs livres où il juxtapose des textes et des photographies, qu'il qualifie d' « ethnopoétique ». Trassard explique ce mot inventé de la manière suivante : "Il y a à la fois un souci ethnographique ou technique de vérité et en même temps les choses sont abordées sous l'angle poétique ${ }^{3} \gg$. Outre ces œuvres hybrides, les photographies de Jean-Loup Trassard font également l'objet d'expositions dans des bibliothèques, galeries ou musées ${ }^{4}$. Dans ce cas le texte ne joue généralement pas de rôle, et les expositions restent

\footnotetext{
${ }^{1}$ Ainsi dans l'entretien avec Arlette Bouloumié, il précise : «je ne fais pas trop le lien entre l'écriture et la photographie. Je ne pense pas qu'il y ait une réelle influence de l'une sur l'autre. » (L'écriture du bocage : sur les chemins de Jean-Loup Trassard, textes réunis et entretien par Arlette Bouloumié, Angers, Presses de l'Université d'Angers, 2000, p. 598.) Voir aussi le questionnaire ci-joint à la page 294. Nous tenons ici à remercier Jean-Loup Trassard pour l'amabilité avec laquelle il a répondu à nos questions.

${ }^{2}$ http://www.letempsquilfait.com/Pages/Auteurs/Trassard/trassard.html (consulté le : 13/07/2006) Notons ce trait commun des photographes qui affirment la genèse de leur identité de photographe en se remémorant les premiers appareils et leurs premières photos prises qu'ils montrent rarement par ailleurs.

3 «Entretien avec Arlette Bouloumié », in L'écriture du bocage : sur les chemins de Jean-Loup Trassard, textes réunis et entretien par Arlette Bouloumié, Angers, Presses de l'Université d'Angers, 2000, p. 600.

${ }^{4}$ Le site du fonds de Jean-Loup Trassard de l'Université d'Angers contient une liste des expositions de Trassard ainsi que quelques photos inédites, comme celles de l'exposition du 21 octobre 2005 au 19 novembre 2005 organisée à l'Université d'Angers.

http://bu.univ-angers.fr/expos/rubriques/elements/affiche element.php?ref_element=84\&ref_notice $=434$ (consulté le : 23/05/2008).
} 
sans publication. Mais malgré ce qu'affirmait Trassard, la photographie est imbriqué chez lui dans l'écriture à plusieurs niveaux et sous différents aspects. 


\section{VI.1. L'espace habité par les souvenirs}

Le bocage mayennais décrit et photographié avec obstination par Jean-Loup Trassard, tient lieu pour lui de «maison », au sens bachelardien'. Il s'agit de son lieu natal, et du lieu où il a vécu toute sa vie, un espace habité et peuplé de souvenirs qu'il transforme en espace poétique, continuant, comme quand il était enfant, à l'investir par son imaginaire.

Les écrits autobiographiques de Trassard explorent ce lieu pour le prolonger. La photographie acquiert une importance essentielle dans ce projet. Non pas, comme on pourrait l'attendre, en tant que document servant de base à l'écriture, mais comme modèle ou «schème », pour reprendre l'expression de Jean-Bernard Vray².

\section{VI.1.a. Tardifs instantanés - les multiples facettes du modèle photographique}

Le livre Tardifs instantanés de Trassard institue déjà par son titre un rapport avec la photographie. La quatrième de couverture précise :

Portraits d'instants, portraits de lieux, d'objets familiers, la serre, la pompe, un escalier, images démobilisées de l'exode, de l'Occupation, de la Libération, scènes villageoises comme celle des nègres montrés dans une baraque foraine ou celle de l'arrivée de la Vierge de Boulogne, rencontres furtives à Paris, dans la rue, le métro, une église... ces brèves proses ont en commun avec des photographies d'être nettes quant à leur objet et cernées d'oubli, de silence, pour ce qui n'est pas à l'intérieur du cadre, l'instant d'avant et l'instant d'après. Elles jouent donc avec le discontinu de la conscience et du souvenir, mais un rapprochement ici leur permet - puzzle où les angles blessants s'ajointent aux moments de douceur - de former légende pour le narrateur, les paysages assemblés esquissent peut-être un visage où se reconnaîtra le photographe: son autoportrait lacunaire. ${ }^{3}$

Les brèves proses, récits d'une longueur de deux à trois pages, qui constituent le livre sont comparées aux clichés, bien qu'elles ne se présentent pas comme des images figées, avec cet arrêt dans le temps et le mouvement qui caractérise les instantanés. C'est bien plutôt la photographie en tant que dispositif qui permet la comparaison.

\footnotetext{
${ }^{1}$ BACHELARD, Gaston, La poétique de l'espace, Paris, PUF, (1957) 1998.

${ }^{2}$ VRAY, Jean-Bernard, «Jean-Loup Trassard : la dormance et la trace », in Traces photographiques, traces autobiographiques, (sous la dir. de Danièle Méaux et Jean-Bernard Vray), Saint-Étienne, Publications de l'Université de Saint-Étienne, 2004, p. 262.

3 TRASSARD, Jean-Loup, Tardifs instantanés, Paris, Gallimard, 1987. Par la suite nous utiliserons l'abréviation : TI. (Nous soulignons.)
} 
Trassard précise que les souvenirs racontés sont «nets quant à leur objet », et nous trouvons en effet un goût pour les petits détails insignifiants ${ }^{4}$ dans la description de l'arrière-plan de la scène. Ainsi par exemple le récit qui raconte comment, enfant, il regardait défiler les avions des alliés dans la cour :

Précisément je puis montrer, sur le sable de la cour - gros sable, peu d'herbe qui pousse - l'endroit où $\mathrm{j}$ 'avais les pieds ce jour là. Devant les fenêtres de la salle à manger, mais beaucoup plus près du massif qui occupe le milieu de la cour. À l'époque, je crois qu'il y avait dedans des ponceaux, pas tous rouges, certains doubles à pétales blancs et roses. Tache de couleur, irrégulière par ses manques, juste à distance des volets blancs et du portail, lattes de bois aussi en blanc. [...] $(T I, 106)$

L'auteur ajoute que les récits sont «cernées d'oubli, de silence, pour ce qui n'est pas à l'intérieur du cadre, l'instant d'avant et l'instant d'après ». Mais les souvenirs évoqués ne se réduisent pas à un instant, à l'intérieur du récit il y a bien un déroulement de temps, du mouvement dans l'espace, le regard qui se déplace de l'intérieur vers l'extérieur (on pourrait même appliquer les notions cinématographiques de fondu enchaîné et de travelling ${ }^{5}$ ). L'ensemble du récit de quelques pages est bien plutôt une tranche de temps, coupée et prélevée. Notons encore que sur la quatrième de couverture l'auteur parle de «narrateur» et de «légende», au double sens du terme, l'un se référant aux mythes, et l'autre aux textes qui accompagnent une image. L'emploi de cette expression fait penser au travail de thèse de Magali Nachtergael, qui soutient qu'un lien se tisse entre la montée des mythologies individuelles et la fonction de la photographie dans notre société ${ }^{6}$. Trassard associe d'ailleurs le narrateur à un photographe qui, par les récits, tire son autoportrait.

Mais attardons-nous sur l'analyse du livre chapitre par chapitre car la critique a tendance à reprendre les propos de l'auteur concernant le rapprochement avec la photographie sans en montrer les différentes facettes. Le livre se compose de cinq chapitres, intitulés : Quoi ?, Exode, Naguère, Ici et là j', Petits portraits, des chapitres distincts en style et en contenu.

\footnotetext{
${ }^{4}$ Le détail superflu était perçu au $\mathrm{XIX}^{\mathrm{e}}$ comme une des caractéristiques de la photo qui assurent son objectivité réaliste parce que rien ne lui échappe. La photo était en cela opposée à la peinture qui «sacrifie» les détails pour une compréhension plus claire, ce sacrifice étant le gage de la valeur artistique.

5 «J'aurais aimé faire des films, mais j'aime aussi beaucoup l'immobilité de la photographie. » avoue Trassard dans l'entretien avec Arlette Bouloumié, in L'écriture du bocage, Op. cit., p. 598.

${ }^{6}$ NACHTERGAEL, Magali, Esthétiques des mythologies individuelles, thèse sous la direction d'Eric Marty soutenue à l'Université Paris 7 en 2008. Voir le chapitre : "L'autobiographie photo-littéraire », p. 64.
} 
Le titre Quoi ? pourrait se référer à l'énigme qu'on ressent face à n'importe quelle photo sans légende. Le rythme y est accéléré, le style devient saccadé et télégraphique, par l'emploi de la parataxe, de la juxtaposition sans liaison entre les propositions, de l'énumération sans article ou préposition, voire de l'omission de verbes par endroit. Le lecteur est obligé de s'arrêter et de revenir en arrière dans sa lecture pour recomposer les bribes.

Une fille à côté, devant les jambes toile bleu d'un garçon, ils attendent conducteur absent, je tourne devant le véhicule essayant de démasquer le visage enfin perçoit mon regard s'étonne : pas elle ! oh agréable soulagement! continue comme qui traverse, poste, reviens, prenant exprès le même trottoir, encore là : de biais, grenat, pneu arrière monté sur la pierre, passant d'un coup d'œil vers l'intérieur, cheveux châtains bouclés pareils mais ce visage il est vulgaire. Je me retourne encore pour voir où j'ai dû achopper l'angle, à cause de cette position fausse, une main alors cachant les yeux sur la bouche a coupé mon souffle. Je remonte, elle n'est pas rentrée. (TI, 19)

Pascal Rannou en analysant deux recueils de nouvelles, Paroles de laine ${ }^{7}$ et l'Ancolie ${ }^{8}$, relève déjà une tendance à l'utilisation des phrases nominales et de l'ellipse qui confère au message une « aura d'étrangeté » :

De fait, le message semble souvent lacunaire, comme si toute liberté était laissée au lecteur de meubler selon son imagination des évocations fuyantes et ambiguës. [...] Irrité, perturbé, le lecteur est aussi fasciné, car si le sens se dérobe il est à repeupler, et c'est la tâche exaltante que lui propose l'écrivain. ${ }^{9}$

Ce style est poussé à l'extrême dans Quoi ? par rapport aux autres écrits de Trassard ce qui l'apparente au style des Dépôts de savoir \& de technique de Denis Roche ${ }^{10}$, même si le principe n'est pas le même ; mais l'effet énigmatique, le rythme accéléré et machinal sont semblables.

Les récits du chapitre Quoi? se déroulent dans un espace urbain : un narrateur adulte parle de ses impressions éphémères, de rencontres furtives (une femme qu'il croise dans l'immeuble, une autre femme rencontrée dans une église, des ouvriers dans la rue). Ces impressions, moments d'intensité, mobilisent le hasard qu'on lie également à la photographie, à une certaine pratique photographique de l'instantané à la CartierBresson.

Les chapitres Exode et Naguère sont moins lacunaires quant à leur style et leur construction. Exode réunit des souvenirs d'enfance de la période de l'occupation, alors

\footnotetext{
${ }^{7}$ TRASSARD, Jean-Loup, Paroles de laine, Paris, Gallimard, 1989.

${ }^{8}$ TRASSARD, Jean-Loup, L'ancolie, Paris, Gallimard, 1975.

${ }^{9}$ RANNOU, Pascal, «Un mayennais au souffle cosmique : Jean-Loup Tassard », in Voix d'ouest en Europe, souffles d'Europe en Ouest, Actes du colloque International d'Angers 21-24 mai 1992, textes réunis par Georges Cesbron, Angers, Presses Universitaire d'Angers, 1993, p. 562.

${ }^{10}$ ROCHE, Denis, Dépôts de savoir \& de technique, Paris, Seuil, col. "Fiction \& Cie ", 1980.
} 
que sa famille a quitté la maison par peur de l'invasion allemande. Les récits respectent la chronologie des évènements même s'il ne s'agit pas de narration continue. Quant aux chapitres suivants, Naguère ne suit plus cette chronologie, les souvenirs liés à la guerre viennent en vrac, et de même Ici et là j' relate encore d'autres souvenirs d'enfance sans aucun souci de la chronologie. Le dernier, Petits portraits, construit encore sur un autre modèle, contient des portraits de lieux ou d'objets qui portent en creux la trace d'une vie, d'une chaleur humaine qui les habite et qui les anime.

Les trois premiers récits de Petits portraits sont dédiés à Francis Ponge. Nous trouvons en effet chez Trassard une préoccupation semblable à celle de Ponge, celle de vouloir rendre compte des objets de la manière la plus précise et la plus rigoureuse possible (par l'évocation de l'étymologie du mot, les caractéristiques précises allant jusqu'à donner la taille en centimètre, etc.). Il ne s'agit pas pourtant chez Trassard de porter son attention sur des objets simples ou banals, mais sur les choses qui ont un lien avec la vie de l'auteur (outils particuliers de la ferme, de la vie agricole, de son enfance). Trassard précise ainsi lors d'un entretien avec Jean-Baptiste Para :

Ce qui différencie mon travail des intentions de Ponge, c'est notamment que chez lui l'objet semble situé hors d'espace et de temps. Par là même, il permet très souvent le concept : c'est le galet, pas un galet. Chez moi, chaque objet est vu avec son usure. Je l'ai sous les yeux, voire dans la main lorsque j'écris. ${ }^{11}$

L’importance accordée à l' ancrage spatiotemporel tient-elle à l'influence souterraine de la photographie ? Certains de ses portraits d'objets et de lieux évoquent d'ailleurs des prises de vue, l'objet est contemplé à travers l'appareil : «À l'heure où j'aurais pu dîner. Le soleil se couchait. Découvert presque par l'objectif de mon appareil, cet endroit. Portion d'endroit. J'avais vu dans la serre des éclairages faibles » (TI, 133. Nous soulignons). Le boîtier devient un outil pour explorer et habiter l'entourage familier. La vue photographique permet de mettre à plat, d'étirer, de faire d'un paysage, une image abstraite :

C'est plutôt d'en bas que je vois. Pour photographier la prairie. Longue, ou manière de petite vallée, douce. Pas plus fermée que infinie : tourne au fond de l'image. [...] J'en tire des portraits, nus dans leur armure d'écorce, sur prairie rase. Ou l'été leurs feuillages, harmonieux étagés. En arrière, des pommiers font le rappel graphique. [...] et dans le viseur, à droite la clôture arrête l'œil. (TI, 136)

Ou encore :

${ }^{11}$ PARA, Jean-Baptiste, « La langue et la terre : rencontre avec Jean-Loup Trassard », Europe, $n^{\circ} 787-$ 88, 1994, p. 193. 
Les fenêtres disjointes sont bloquées. J'en cadre l'arrondi du haut dans le rectangle : mise au point sur les vitres roussies de fumée avec toiles d'araignées noires, en arrière le bois peint des persiennes, un rai de soleil infiltré reliant l'un à l'autre les plans. $(T I, 139)$

Le texte se spatialise en utilisant des adverbes de lieu: le haut, le bas, à l'arrière ; pourtant la description ne s'effectue pas d'un point de vue fixe, le regard tourne, retourne, de l'espace clos du cabinet des servantes on sort dans la cour, (notons le mouvement intérieur - extérieur), et l'on repère ce même mouvement fluide dans le temps, avec des sauts en arrière ou en avant. Pour décrire un chariot l'auteur raconte comment il l'utilisait à l'âge de dix ans, puis « vingt-six ans plus tard » comment il a fait fabriquer un nouveau chariot à l'identique du premier par peur de le voir se dégrader, et comment «quinze années encore, aujourd'hui » il utilise encore le premier : l'objet devient un compagnon de vie qui en garde la "trace". « Je ferai de ma vie le saut par-dessus l'autre » $(T I, 153)$, écrit-il évoquant le saut temporel lié à l'objet. Dans la description de fenêtres, le saut temporel est lié à une image, le reflet dans une chaudière, qui permet le renversement des valeurs, et celui du cours du temps :

[...] la chaudière pour les lessives contient un reste d'eau noire, luisante ${ }^{12}$. Miroir et, soudain renversement de l'horizontal en vertical, je vois gisant là, car le diamètre est identique la vitre absente de la lucarne. Sur cette face poches rides cheveux blanchis, mais comment faire jouer le verrou, tourner le cadre à l'intérieur de ce dormant de fonte, pour qu'à la petite fenêtre ronde basse parente d'un œil-de-bœuf qui depuis le grenier veille les jardins - paraisse fraîche image inquiète de mon enfance ? Inquiète ou grave ? solitaire se hissant mains rebord sablonneux avaitelle... dehors n'est pas du tout le même quand on regarde, c'est le jeu, depuis un intérieur... avaitelle aperçu ma vieillesse également solitaire ? $(T I, 140)$

Les deux âges, celui de l'enfance et de la vieillesse donnent l'impression de se rejoindre sur la surface plane et miroitante. Cette dernière rappelle déjà le vocabulaire photographique, mais le dispositif, comme posture explorant le monde (et ce même sans appareil), semble aider à remonter le temps en révélant justement les traces laissées sur les objets :

À sa surface nulle [du hangar], le bois porte trace, je l'ai dit, d'aventures dont les durées furent bien différentes : veines, sciages, peintures, sur quoi inscrits des éclatements autour des nœuds [...] De près ces marques offrent à l'objectif des paysages verts ou bleus, plages blanches où la pluie efface la peinture. (TI, 160. Nous soulignons.)

La notion de trace qu'on retrouve fréquemment dans le vocabulaire de Trassard, évoque les théories de la photographie contemporaines, et particulièrement celui de François

12 Nous soulignons. L'insistance sur les couleurs noir et blanc qui évoquent les photographies monochromes revient plus tard dans le texte : «Le plâtre des murs, où il s'écaille, montre le blanc d'un ancien pays cerné par des mers noires ou grises selon les couches. Je suis de cette époque là, petite raie sur le côté, vêtu de blanc l'été durable, bien avant que [...] semaines semaines années le blanchissage vienne à tout obscurcir. » $(T I, 141)$ Nous soulignons. 
Soulage. Comme nous l'avons déjà mentionné, Soulage désigne la photographie en tant que trace essentiellement énigmatique qui avant tout interroge le sens et ouvre sur l'imaginaire en ce qu' « elle convoque le récepteur à interpréter, à interroger, à critiquer, bref à créer et à penser, mais de façon inachevable ${ }^{13} »$. Ses propos font écho à ceux de Francis Ponge qui qualifie le poème d'interminable ${ }^{14}$.

Chez Trassard, la description des objets devient de fait un projet interminable : «Je devrais ajouter mille détails. À serrer de près les objets, j'ai appris qu'on ne finit pas de les décrire. [...] il faudrait donner des mesures, préciser chacune des formes, dire...» $(T I, 151)$. Mais ce qui est fantasmé n'est pas tellement la description même, mais plutôt le rêve de faire voir par le texte, simplement comme par une photo, de mettre en face de l'objet réel. Trassard écrit à propos d'une plante : «il y a (ne croyez pas que ceci soit une description, j'évoque, j'essaye le plus simple) il y a une plante $[\ldots] \gg(T I, 134)$. L'écriture doit toucher, évoquer, approcher, en sachant qu'elle ne peut jamais atteindre l'objet.

\section{VI.1.b. Dormance - la photographique comme schème}

Dans Dormance ${ }^{15}$, le roman autobiographique, ou roman néolithique de Trassard, nous retrouvons la fusion entre la photographie et l'écriture. Jean-Bernard Vray démontre que la trace ${ }^{16}$ dans ce livre, c'est aussi le schème photographique qui sous-tend l'œuvre. L'intrigue se situe à l'époque préhistorique et raconte comment un jeune homme, Gaur, part de son village en quête d'un nouvel endroit pour s'installer - endroit qui sera justement celui où vit le narrateur et qui coïncide géographiquement avec celui de l'auteur. Gaur revient ensuite dans son hameau pour repartir avec sa femme Muh, sa sœur Souaou et son compagnon Pek. Les deux tiers du livre narrent ainsi leur installation, la fabrication et l'invention des objets, la construction des habitats, leurs

${ }^{13}$ SOULAGE, François, «La trace ombilicale » in Traces photographiques, traces autobiographiques, Op. cit., p. 23. Voir le chapitre «Le paradoxe de l'empreinte » à la page 48.

${ }^{14}$ Sur Francis Ponge voir: COLLOT, Michel, Francis Ponge entre mots et choses, Seyssel, Champ Vallon, 1991. Notons d'ailleurs qu'un des livres de Denis Roche fait également référence à cette formule de Ponge : MORA, Gilles, La photographie est interminable, entretien avec Denis Roche, Paris, Seuil, 2007.

15 TRASSARD, Jean-Loup, Dormance, Paris, Gallimard, 2000. Par la suite nous utiliserons l'abréviation : $D$.

${ }^{16}$ VRAY, Jean-Bernard, « Jean-Loup Trassard : la dormance et la trace », Op. cit., p. 263. 
préoccupations quotidiennes, la chasse, la culture de plantes, l'apprivoisement des aurochs, le temps qui passe, la naissance des enfants des deux couples (Ouen et Lul). Le livre se termine par la mort de Muh et le retour de Gaur dans son village natal pour ramener sa mère dans le hameau.

Trassard s'inspire dans le choix du thème de Dormance, des cours d'ethnologie et de préhistoire de Leroi-Gourhan qu'il a suivis ${ }^{17}$. Leroi-Gourhan dans L'Homme et la matière souligne l'importance de la matière, des outils, et des techniques qui les façonnent :

Parmi les disciplines ethnologiques, la technologie constitue une branche singulièrement importante, car c'est la seule qui montre une totale continuité dans le temps, la seule qui permette de saisir les premiers actes proprement humains et de les suivre de millénaires en millénaires jusqu'à leur aboutissement au seuil des temps actuels. ${ }^{18}$

Les outils portent les traces de leur fabrication et de leur probable utilisation. C'est à partie de ces vestiges qu'on peut reconstituer la vie de l'homme à l'époque de la préhistoire. Le peu de connaissance que nous avons de cette période crée un parallèle entre ces traces lacunaires inscrites dans la matière et l'instabilité du signifiant des photographies. Le récit de la vie de Gaur dans Dormance est également plein de trous, et d'incertitudes, ce que reflètent le style fragmentaire du texte, les sauts dans le temps, ainsi que graphiquement les paragraphes nettement distingués par les blancs. L'écriture devient alors semblable aux fouilles archéologiques, au déchiffrement des empreintes, il s'agit de «fouiller le temps comme une terre» pour en sortir «des images plus ou moins larges » $(D, 71)$.

Écrire devient le geste d'écarter des branchage pour voir, c'est en rêverie, en questions, en recherche, en idées ou images qui surgissent, pousser une phrase au milieu des embûches, des ratures, qui se fraye un chemin, tel un chien à la chasse, et révèle par fragments, détail précis ou perspective plus large mais floue, une existence dont la mise au jour, plus exactement les parts tirées de l'ombre, m'apprendront peut-être le lien par lequel j'y suis attaché. $(D, 81$. Nous soulignons)

Trassard associe le travail imaginaire de l'écrivain consistant à inventer une histoire, une fiction, au processus de reconstitution des souvenirs, ainsi qu'à l'activité psychique des rêves. Dans tous les trois, l'image est primordiale. L'histoire de Gaur se présente au narrateur sous forme d'images, images floues, lacunaires dont le caractère discontinu va permettre le rapprochement avec les photographies. «Des souvenirs trouvés dans ma

\footnotetext{
${ }^{17}$ «Entretien avec Arlette Bouloumié », Op. cit., p. 573.

${ }^{18}$ GOURHAN, Leroi, L'homme et la matière, Paris, Albin Michel, 1943 et 1971, p. 9.
} 
mémoire comme des photographies dans une boîte ${ }^{19}$ » précise Trassard à propos du livre Tardifs instantanés, où l'on retrouve également le procédé employé pour l'écriture de Dormance.

C'est sous forme d'images que certains instants se recomposent dans ma pensée, je devrais plutôt dire entre mes mains, puis se dissolvent les images - n'en reste que ce qui est écrit - mais l'attente comme la durée des faits à quoi elles donnent accès sont difficiles à estimer. $(D, 222)$

Les souvenirs sont comme une boîte de photographies, mais par un effet de renversement, les clichés, porteurs de traces, marques du temps, comme la madeleine de Proust, suscitent des souvenirs involontaires que l'écriture « enregistre ».

Selon Jean-Bernard Vray: «La trace autobiographique dans Dormance est constamment associée à la trace photographique ${ }^{20} »$. Les traces autobiographiques parsèment le récit sous forme de sauts du temps de la préhistoire au temps du narrateur, à son enfance, et au présent de la narration, à l'acte d'écriture. Mais une seconde trace apparaît, plus métaphorique, celle de la coïncidence de l'intrigue avec des évènements de la vie de l'auteur. Ainsi la mort de la figure féminine, la femme de Gaur, fait allusion à la mort de la mère de Trassard. À la fin du récit, le fait que Gaur ramène sa mère dans son hameau peut se lire comme une possibilité de sauver, de faire revivre, ou du moins raviver la figure maternelle par l'écriture. Jean-Bernard Vray parle ainsi de l'identification et la fusion de la mère et de la campagne, du paysage qui devient maternel et intime, à propos de la scène de la promenade jusqu'au «châtaignier creux » :

Il s'agissait d'une énorme ragole, un arbre court, autrefois émondé, dont le bois avait éclaté, s'était ouvert, vidé du ventre, on pouvait y entrer à deux, mère et enfant. Les grosses et basses branches avaient été, par le temps, elles aussi vidées de leur cœur, puis elles étaient tombées, il en restait deux belles lucarnes cernées d'un manchon de bois raviné, très dur. Ma mère disait que si nous observions là, au crépuscule, nous allions peut-être voir quelque chose. Elle pensait aux fées dont les rondes sur l'herbe sont ensuite dessinées par les cercles de champignons rosés. $(D, 17)$

Cette image est de nouveau évoquée à la fin du roman, le fils regardant la mère « aperçue en silence, par la lucarne du châtaigner » $(D, 321)$. Cette identification entre du paysage et de l'intime - au sens de «maternel »- mais aussi au sens d' «intérieur » car propice à la rêverie et au développement de l'imaginaire, cette fusion apparente l'écriture avec la photographie. La majorité des photographies de Trassard sont des

19 «Entretien avec Blandine Benoît et Philippe Arbaizar» dans la Campagne de Jean-Loup Trassard. Écrits et photographies, BPI, Centre Georges Pompidou, 1992, cité par Jean-Bernard Vray («Jean-Loup Trassard : la dormance et la trace », p. 262).

${ }^{20}$ VRAY, Jean-Bernard, Op. cit., p. 267. 
photos de paysage, qui par renversement et par l'écriture deviennent des paysages intimes. Jean-Bernard Vray note qu'il y a :

[...] la même traque par l'écriture et la photographie, le même arpentage d'un lieu unique, du «corps du paysage », dans la fiction par personnages interposés, dans le récit autobiographique par ce « regard les yeux fermés » qui «lève » des images, et aussi dans la prise de possession photographique. ${ }^{21}$

Le titre Dormance, évoquant l'image de la graine enfoncée dans la terre par Muh en attente de la germination, symbolisent le long travail de l'écriture ${ }^{22}$, un procédé qui est volontairement et textuellement associé à la photographie :

De quelle plante ces graines qui après des années de dormance, ont bien voulu boire à même le sol, gonfler d'abord puis éclater pour qu'à la fente de leur écorce s'élance un germe, une feuille, une tige ? Il est difficile de le savoir tant que je n'ai pas fouillé la terre dans la prairie de Grise Haie, entouré d'étonnement par les mufles humides, tant que je n'ai pas posé sur ma paume avec le souple pince qui sert quand je manipule les vieux négatifs de photos un grain, même un seul grain carbonisé, qui puisse être observé au microscope et désigné scientifiquement, c'est-à-dire en latin de botaniste, par exemple triticum dicoccum pour l'amidonnier, une variété primitive de blé. ${ }^{23}(D$, 226-227.)

La confusion qu' offre la position du mot dans la phrase entre le grain de céréale et le grain de l'image photographique rappelle la double pratique artistique, poétique et photographique, et leur assimilation ${ }^{24}$.

L'étude de Joseph Fahey, antérieure à la publication de Dormance, associait déjà «une expérience du monde profonde et originale, en enracinant l'écriture dans l'expérience muette de l'objet et du visible ${ }^{25}$ » et l'expérience du grain photographique, expérience de l'agrandissement où «l'on passe de l'image visible à la matière photographique elle-même ${ }^{26} »$, où la texture des cristaux argentiques de l'émulsion devient visible.

Le topos de la graine revient dans plusieurs des livres de Trassard, comme dans Archéologie des feux. La graine symbolise l'expérience du monde, mais aussi le mécanisme du souvenir. Selon la citation de Dormance ci-dessus, les souvenirs attendent la germination, ou la révélation par l'écriture ou la photographie, qu'il faut

\footnotetext{
${ }^{21}$ VRAY, Jean-Bernard, Op. cit., p. 268.

${ }^{22}$ Lors d'un entretien, il précise que l'élaboration du texte lui a pris seize ans, onze ans de travail préparatoire, de prise de note et cinq ans d'écriture. «Entretien avec Arlette Bouloumié », p. 601.

${ }^{23}$ Nous soulignons l'expression latine : «triticum dicoccum », qui est mise en italique dans le livre.

${ }^{24}$ La métaphore permet de comprendre le titre de son livre pour enfant illustré par Florence Euvremer : TRASSARD, Jean-Loup, Les Graines d'homme, Paris, Flammarion, 1971.

${ }^{25}$ FAHEY, Joseph, «Le grain de l'expérience : le rôle de l'image photographique dans les œuvres de Jean-Loup Trassard », in L'écriture du bocage, p. 498.

${ }^{26}$ Ibid.
} 
fouiller, toucher, observer et désigner. Décrire ou photographier devient alors une exercice pour se remémorer :

[...] ce n'est pas pour me forger une mémoire mais pour m'en débarrasser que j'ai fait ce livre. Comme je les aime beaucoup, mes souvenirs, je ne les ai pas jetés, ni même sélectionnés, j’ai gardé absolument tout ce qui m'est revenu en mémoire, mais en faire un livre m'a débarrassée d'eux. ${ }^{27}$

Mais le texte ne donne après coup que «l'imparfaite illusion d'une présence retrouvée » $(D, 119)$, il contient donc cette marque, affiche la part d'illusion, la part de fiction ${ }^{28}$ dans l'écriture de soi. Nous trouvons ainsi fréquemment des points d'interrogation, des suppositions. Si le pouvoir de la langue est insuffisant, car inachevable, la photographie ne comble pas non plus cette béance entre l'objet et sa représentation. La part autobiographique est aussi mise en doute ; ainsi trouvons-nous dans les deux fragments déjà cités des adverbes de modalité exprimant le doute :

[...] les paysages assemblés esquissent peut-être un visage où se reconnaîtra le photographe : son autoportrait lacunaire (TI, quatrième de couverture)

Écrire devient le geste d'écarter des branchage pour voir, [...] les parts tirées de l'ombre m'apprendront peut-être le lien par lequel j'y suis attaché. $(D, 81$. Nous soulignons.)

Nous pouvons alors nous demander quelle est l'influence de la photographie dans le devenir lacunaire, décomposé, fragmenté du récit d'une vie. Si c'est en partie sous la pression de la photographie que surgit cette remise en question du pouvoir de la langue, de la possibilité de décrire les objets. À l'inverse, c'est le pouvoir des images qui est en cause, et en fin de compte la possibilité de se construire une image et de s'y (re)connaître. Dans un mouvement intime/extime, le «je » sera alors de plus en plus marqué dans les textes de Trassard.

\section{VI.1.c. Au-delà des genres}

Dans les publications récentes de Trassard s'affiche un «je » narrateur qui se confond avec la figure de l'auteur, mais pas dans l'objectif avoué d'écrire une autobiographie.

27 «Entretien avec Arlette Bouloumié », p. 586-587.

${ }^{28}$ Notons toutefois, que Trassard refuse l'appellation « autofiction » pour ses romans, peut-être par refus d'être catalogué, ou à cause de la confusion qui règne autour de la définition du genre. Voir ses réponses à notre questionnaire à la page 294. 
Comme nous l'avons noté, Trassard caractérise d' «ethnopoétiques ${ }^{29}$ » les ouvrages publiés aux éditions Le Temps qu'il fait, dans lesquels il juxtapose des photographies aux récits. Il s'agit de faire correspondre l'approche poétique avec «un souci ethnographique ou technique de vérité ${ }^{30} »$. Chaque livre photo-textuel paraît explorer un nouveau lien entre le récit et l'image, que nous analyserons en détail dans le chapitre intitulé « Les rapports photo-texte».

Toujours dans ce mouvement mêlant l'intime et l'extime, ses livres les plus récents combinent une étude rigoureuse presque scientifique (par l'analyse étymologique, le recours aux termes spécialisés, aux termes du patois, par les méthodes de recherche : enregistrements, entretiens, recherche dans les archives, dans des lettres, dans les textes anciens), et l'évocation de souvenirs d'enfance. Ces ouvrages se situent alors à la frontière avec plusieurs genres.

Déménagerie ${ }^{31}$ combine ainsi l'histoire du déménagement d'un voisin et ami de son père avec la description des objets et animaux de la ferme emmenés avec eux. Plusieurs voix se font entendre: celle des lettres, des interviews mentionnées, cohabitent avec la vision de l'enfant et du narrateur adulte. Sur la quatrième de couverture, l'auteur qualifie cette œuvre de «bavardage, comme autour de la table lorsque le jour est bas, les histoires de ceux qu'on a connus s'appellent l'une et l'autre entre les tasses ». Le caractère discontinu est lié alors non plus seulement aux souvenirs qui apparaissent en images, mais à l'alternance des paroles qui entrent en communication.

Le titre de Conversation avec le taupier ${ }^{32}$ marque également ce déplacement vers le modèle oral. Il s'agit d'un récit qui a pour base plusieurs dialogues enregistrés avec des taupiers de la commune du narrateur (auteur), enregistrements de personnes décédées depuis, traces d'un métier aujourd'hui disparu. Le texte retranscrit la manière de parler des taupiers, les mots et les expressions en patois qui sont parfois éclairés par le narrateur ou bien par une note explicative située en dehors du texte sur la marge. Ce patois, dont le sens reste par endroits obscur pour le lecteur, apporte une couleur locale et une musique particulière au texte fragmenté. C'est avant tout un langage associé à un

\footnotetext{
${ }^{29}$ «Entretien avec Arlette Bouloumié », p. 572.

${ }^{30}$ Ibid., p. 600.

${ }^{31}$ TRASSARD, Jean-Loup, La Déménagerie, Paris, Gallimard, 2004.

${ }^{32}$ TRASSARD, Jean-Loup, Conversation avec le taupier, Cognac, Le Temps qu'il fait, 2007.
} 
lieu géographique concret, à un paysage, à ce même espace intime auquel sont liés les récits autobiographiques.

Le parcours de ces livres de Trassard (Tardifs instantanés, Dormance, Déménagerie ou Conversation avec le taupier) démontre que la photographie sous-tend explicitement ou implicitement ses écrits autobiographiques. À l'image du récit formé par les albums photos, l'espace poétique habité par les souvenirs devient fragmentaire et discontinu. 


\section{VI.2. La phautofiction}

Même si, en creux, toutes les œuvres de Jean-Loup Trassard sont reliées à sa terre natale et la photographie sous-tend ses œuvres autobiographiques, on ne trouve jamais de photos de famille dans ses livres. Les seules photos qui ont pour but d'évoquer des souvenirs, sont des reconstitutions. Mais à contrairement à Sophie Calle ou Christian Boltanski, dans la série Juste absente de Trassard, les photos jouent avec l'illusion de faire revivre la mère, c'est le fantasme qui domine et non la perte. Les photos représentent des scènes reconstituées selon ses souvenirs, qui montrent les activités créatrices de sa mère (peinture, esquisse, écriture ou modelage), des scènes où la disposition des objets (ordre-désordre) donne l'impression que sa mère vient juste de sortir du cadre pour aller chercher quelque chose. L'absence est fondamentale car le rêve et le fantasme exigent que l'objet ne soit pas présent. Rappelons que Roland Barthes ne montre pas non plus la photo de sa mère/enfant grâce à laquelle il aurait trouvé le noème de la photographie ${ }^{1}$. Présence et absence constituent la dialectique de l'image du deuil et selon Serge Tisseron, la photographie par rapport au deuil sollicite son spectateur selon trois modes :

Elle peut s'imposer comme la preuve de la vie du disparu [...], comme le témoignage d'un passé révolu, ou enfin comme la représentation transfigurée et inaltérable que nous voulons en garder et que son existence réelle ne menace plus. ${ }^{2}$

La représentation de la figure maternelle est transfigurée chez Trassard également. Sa mère, décédée quand il n'avait que douze ans, devient le symbole de la création. Elle en est le vecteur et la source : «Je pourrais même dire que tout lui est dédié ${ }^{3}$ ». Trassard dit hériter de sa mère la sensibilité artistique : «toutes [les activités artistiques représentées sur l'image] manifestent une pensée poétique à laquelle, initié par ma mère, je me suis tôt associé ${ }^{4} \gg$.

\footnotetext{
${ }^{1}$ Ibid., p. 160.

${ }^{2}$ TISSERON, Serge, Le mystère de la chambre claire. Photographie et inconscient, Paris, Les Belles Lettres, 1996, p. 75.

${ }^{3}$ «Entretien avec Arlette Bouloumié », Op. cit., p. 518.

${ }^{4}$ TRASSARD, Jean-Loup, «Piège à temps », in Traces photographiques, traces autobiographiques, p. 50 .
} 

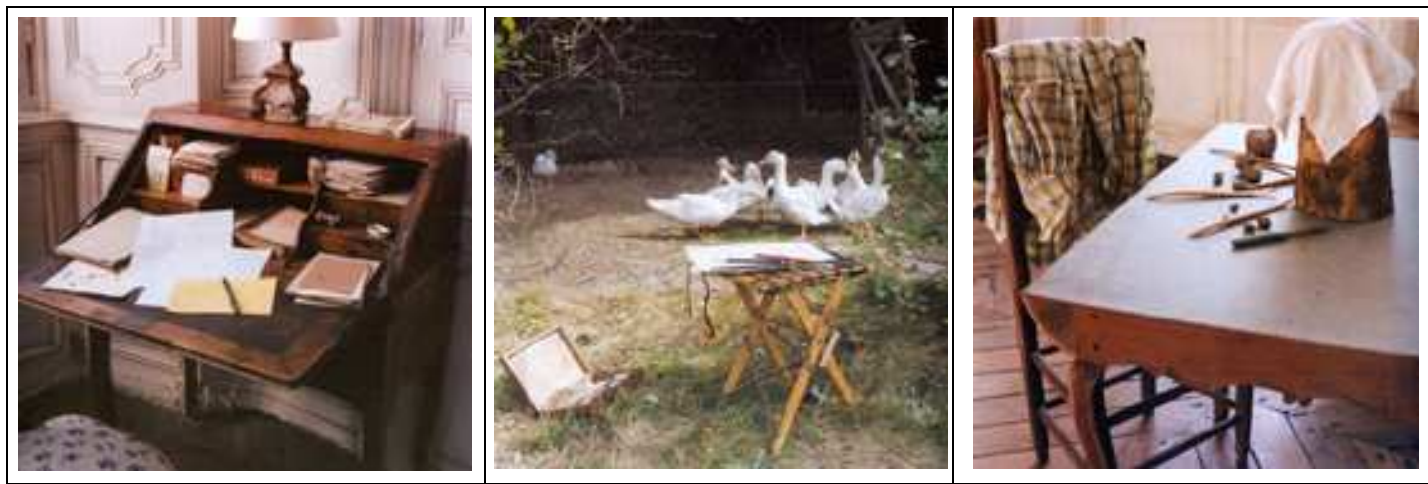

J-L. Trassard, Juste absente planches III, II et IV.

[...] j'ai eu l'idée de créer des scènes qui, non seulement évoquent le temps où ma mère vivait, mais fixent sur chacune d'elle une minute particulière, semblable à une minute de la vie de ma mère, comme si je la recueillais dans le miroir, lequel était là, est toujours là, a reflété, voire conservé d'une façon que nous ne percevons pas encore, les personnes, les objets, que j'ai vus avec mes yeux d'enfants. ${ }^{5}$

Les scènes composées sont particulières, car les objets montrés appartiennent à la mère de Trassard. «Les objets sont authentiquement ceux de ma mère. S'il n'est pas informé, le spectateur ne peut lire l'image ${ }^{6} \gg-$ écrit-il. Donc la photographie s'appuie avant tout sur le texte explicatif qui l'accompagne.

A propos de photographies qui ont besoin que j'explique au spectateur ce qu'il regarde, je reconnais que je ferais peut-être mieux de ne pas les montrer, aucune de ces images ne livrant ellemême dans son pré-carré, sa vraie signification. ${ }^{7}$

Ce constat renforce l'importance du texte joint à l'image et remet en cause le pouvoir de l'image. Ou plutôt, la signification se déplacerait vers l'intimité, car les clichés veulent révéler l'invisible, les images ne sont que des insinuations et ce qui est montré reste partiellement caché. Ainsi dans les images de Juste absente les créations (dessins, écritures) ne se distinguent pas nettement ou sont volontairement cachées (modelage). Les produits artistiques ne sont jamais au centre de la composition, jamais vraiment perceptibles, on discerne des taches, preuve qu'il y a quelque chose d'écrite, de dessinée sur la feuille, mais on ne voit pas quoi. Les couleurs douces d'un ton pastel où les bruns et les bleus dominent renforcent l'effet de nostalgie. Les objets et les lieux donnent l'illusion de la présence de la mère, pour le «plaisir à figurer une illusion temporelle ${ }^{8}$ », mais comme le souligne l'auteur il ne s'agit que d'une illusion éphémère : «la petite

\footnotetext{
${ }^{5}$ Ibid., p. 47. (Les images ci-dessus correspondent aux planches III, II et IV qui s'insèrent hors pagination à la fin du livre.)

${ }^{6}$ Ibid.

${ }^{7}$ Ibid., p. 48.

${ }^{8}$ Ibid., p. 49.
} 


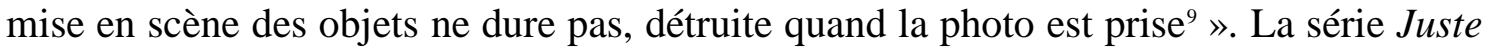
absente est ainsi un hommage à sa mère, non seulement par l'évocation ou invocation, mais aussi par le prolongement de l'acte créateur : «à cause de cette complicité avec ma mère dans la découverte de la campagne, j'ai toujours pensé qu'en écriture je prenais le fil arraché à leurs mains [il fait aussi allusion à son grand-père], qui me sont chères ${ }^{10} »$. Ces scènes qui deviennent photobiographiques ou plutôt phautofictionnelles, composent des vues qu'il aurait pu prendre en tant qu'enfant.

La série de photos de Jean-Loup Trassard intitulée Les derniers paysans, joue également sur l'illusion de la mise en scène pour faire revivre des instants révolus comme dans Juste absente. Il s'agit d'une série de photos de scènes recomposées de la vie des fermes à l'aide de jouets en plomb que l'auteur a gardés depuis son enfance. Chaque photo est accompagnée d'un court texte expliquant la scène. On imagine combien l'auteur a dû s'amuser à les reconstituer, jeu ludique, au cours duquel il peut revivre l'excitation de l'enfant, mais jeu qui a pour enjeu de garder la mémoire d'un certain mode de vie agricole «traditionnel » qui a disparu depuis son enfance. Dans la préface il écrit :

Le moindre objet annonce une durée, ses avant et après, le précaire des tâches inachevées se fait presque éternel, les muettes petites bouches viennent de se taire. C'est ce temps que je prélève, des soixantièmes de seconde de bonheur agricole. Et les instantanés transforment l'immobilité en geste. $^{11}$

Ce n'est pas seulement l'habile composition de l'image qui crée l'illusion de l'instantané et donne l'apparence du geste qui précède ou suit le moment figé, mais aussi le texte qui donne corps et vie à la scène :

\footnotetext{
${ }^{9}$ Ibid., p. 48.

${ }^{10}$ Ibid., p. 50.

${ }^{11}$ TRASSARD, Jean-Loup, Les derniers paysans (Textes et photographies), Cognac, Le Temps qu'il fait, 2000, p. 8. Par la suite nous utiliserons l'abréviation : DP.
} 
«pe... tit, petit, petit, petit... sur un ton que les volailles connaissent, la fermière fait se rassembler à l'endroit le plus sec de la cour où elle jette le grain toutes sortes d'ailes qui descendent des toits, s'ouvrent pour aider la course. Tandis que les becs frappent le sol, elle compte ses poules. » $(D P, 24$. $)$

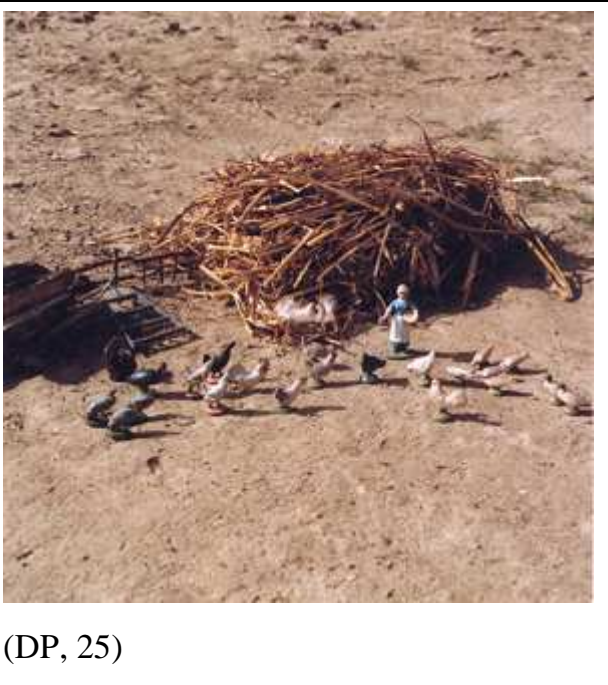

Les scènes ne sont pas seulement des souvenirs d'enfance, mais aussi des méditations sur les moments privilégiés de la vie à la ferme. S'agit-il vraiment d'instants de bonheur agricole comme l'annonce la préface ? La scène de la vache malade qu'on doit battre avec un bâton pour la faire rentrer à l'étable, ou le cochon qu'on s'apprête à tuer, ne sont pas des scènes pour lesquelles se serait enthousiasmé un enfant : on y distingue plutôt le bonheur de l'adulte à retrouver ses jouets d'enfance pour redonner vie et remémorer (la volonté pédagogique sous-tend la création) l'univers de la ferme.

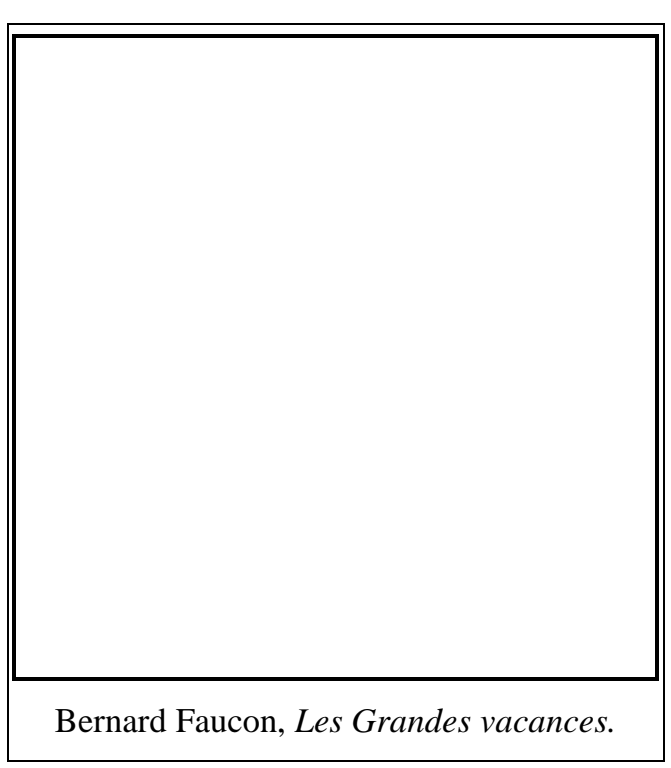

Arlette Bouloumié compare ce livre à celui de Bernard Faucon, Les Grandes vacances, qui fait lui aussi revivre des moments de son enfance, en composant des scènes avec des mannequins d'enfants de dix ans, avec un souci de précision car il recourt à des mannequin des années 60 , époque où l'auteur avait lui-même 10 ans. Faucon, pour semer le trouble dans ses compositions, introduit de temps en temps de vrais enfants dans la scène (comme dans le cliché ci-contre intitulé Jeux de plage $\left.{ }^{12}\right)$, pour afficher le leurre de ces instantanés. Selon Arlette Bouloumié, Jean-Loup Trassard et Bernard Faucon « $[\ldots]$ loin de tout réalisme mimétique, $[\ldots]$ mettent leur art au service

${ }^{12}$ Bernard Faucon, Les Grandes vacances, http://www.bernardfaucon.net/photos/index.htm (consulté le: 04/06/08). 
de l'imaginaire au point de déstabiliser le spectateur entraîné dans une sorte de rêve éveillé ou de perception visionnaire ${ }^{13} »$.

Chez Trassard, les figurines sont posées sur un socle vert, l'arrière plan fausse l'échelle; la touffe d'herbe colossale, l'énorme trace dans la boue, ou encore les pommes gigantesques chargées sur le chariot, servent également à créer l'illusion tout en soulignant la supercherie.

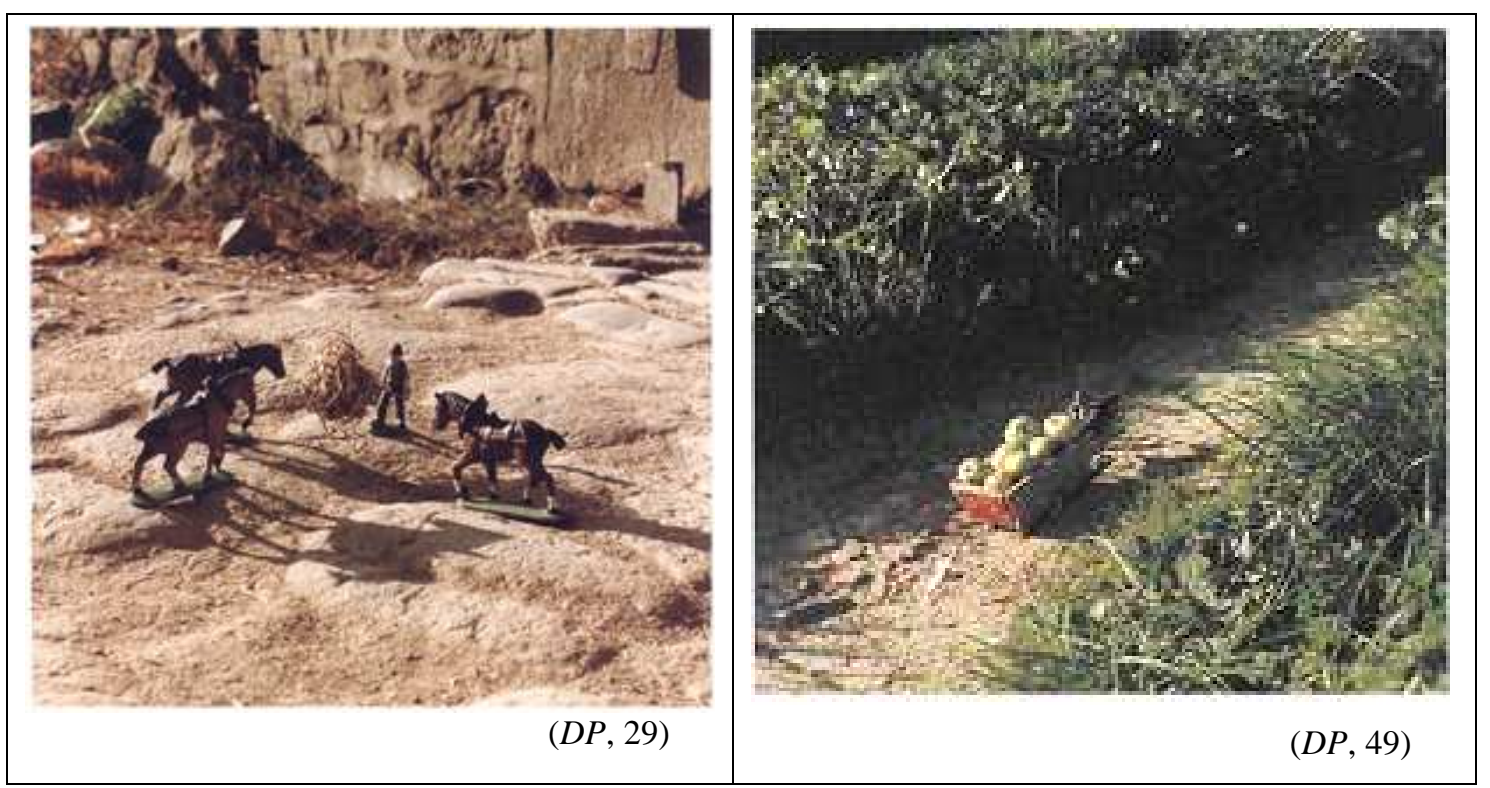

Ce qui importe est de ne pas être dupe, quand la photo veut déjà nous faire croire à une transparence et une objectivité vis-à-vis de la réalité, créer l'illusion en affirmant qu'il s'agit d'une illusion.

${ }^{13}$ BOULOUMIÉ, Arlette, «Photographie et Jeux d'illusion : Jean-Loup Trassard, Lucien Clergue et Bernard Faucon», in L'art français et francophone depuis 1980, sous la dir. de Michel Bishop et Christopher Elson, Amsterdam/New York, Rodopi, 2005, p. 31. 


\section{VI.3. Les récits de voyage}

Les récits de voyage se démarquent des récits autobiographiques car ils explorent un lieu inconnu et lointain. Philippe Antoine, comparant les récits de voyages en Russie d'Olivier Rolin ${ }^{1}$ et de Jean-Loup Trassard ${ }^{2}$, montre que le dispositif photographique est au cœur de la démarche des deux écrivains. Trassard prend réellement des photos lors de son voyage, tandis qu'Olivier Rolin refuse les clichés qu'il considère superficiels et les rejette pour ne pas tomber dans l'écueil des touristes qui prennent des photos sans regarder. Pourtant leur démarche est semblable, ils collectent des impressions pour les transcrire par le texte, sensations qui sont «le résultat d'interactions entre le moi et le monde [...] la trace que le monde laisse chez qui le contemple, et que le texte développe $^{3} \gg$. Le récit de voyage oscille entre l'intime et l'extime, et en cela est comparable, selon Philippe Antoine, à la photobiographie telle que Gilles Mora et Claude Nori la définissent dans le Manifeste photobiographique ${ }^{4}$. Autre trait commun chez les deux écrivains, ils font allusion à leurs lectures autour du pays visité . Cette référence à la mémoire culturelle constitue un autre élément biographique, les souvenirs de lectures fonctionnant comme repère pour le lecteur également, et entretenant le mouvement intime/extime, la comparaison entre le pays imaginé, rêvé par les lectures et la réalité. Selon Philippe Antoine « un des devoirs du voyageur consiste à recenser les objets du monde qui confirment les dires de la bibliothèque ${ }^{6} »$.

Chez Trassard, à part les souvenirs de lectures, nous retrouvons des références à des photographies autant qu'à des films :

Par groupe de dix environ, vieux et jeunes mélangés, les verrats sont vautrés dans diverses positions, nous regardent de leurs petits yeux puisque nous les regardons... l'ambiance me fait penser à celle parfois vue en photographie des cellules pour «droit commun » surpeuplées. $(C R$, 110)

\footnotetext{
${ }^{1}$ ROLIN, Olivier, En Russie, Paris, Seuil, Points, (1987) 1997.

2 TRASSARD, Jean-Loup, Campagnes de Russie, Paris, Gallimard, (1989), 1992. Par la suite nous utiliserons l'abréviation : $C R$.

3 ANTOINE, Philippe, «Voyages photobiographiques», in Traces photographiques, traces autobiographiques, p. 253.

${ }^{4}$ Voir le chapitre «Le modèle photobiographique » à la page 83.

5 Trassard cite Tourgueniev, Formosov, Gogol, Tchekhov, et Gorki, mais refuse en même temps la rencontre avec des écrivains contemporains que veulent lui organiser ceux qui l'accueillent.

${ }^{6}$ ANTOINE, Philippe, Op. cit., p. 255.
} 
Par le très large escalier qui monte au niveau de l'eau jusqu'à la route, puis par l'escalier encore plus monumental qui, en face, monte de la route à la ville (impossible de ne pas penser à celui d'Odessa, filmé par Eisenstein dans le Cuirassé Potemkine) [...]. $(C R, 168)$

Les deux livres de Trassard sur la Russie éclairent le lien qui se tisse entre le cliché et le texte, car Campagnes de Russie (1989) prend la forme d'un récit de voyage classique,

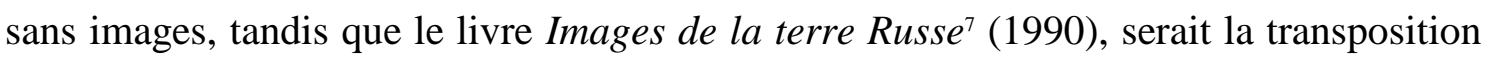
poétique de cette expérience accompagnée de photos. Mais Campagnes de Russie, le livre sans photos, relate aussi les circonstances de certaines prises de vue, dont les images sont reconnaissables dans l'autre livre. Le texte rappelle ainsi l'étonnement ou le mécontentement des gens ne comprenant pas pourquoi il photographie la campagne ou des vieux bâtiments, car ces prises de vues diffèrent des photos touristiques :

[...] j'ai l'impression de pénétrer dans un film d'autrefois, en noir et blanc - je regarde, on ne me remarque pas -, et le temps ici, ou l'air qu'on respire, semblent encore liés à l'éternité. Une femme surgit, nous parle aimablement, une autre arrive dans un chariot à pneus avec cheval rouquin, une troisième s'avance à sa barrière... Sergueï renseigne, je suis français, lui moscovite... « Ici c'est un vieux village, si vous le photographiez, à l'étranger on dira que chez nous ce n'est pas bien ! » $(C R, 73)$

Tandis que je prends quelques photographies, une femmes passe, me lance sans s'arrêter un discours, au ton et au visage maussades je vois bien qu'elle n'est pas contente que je photographie quelque chose d'ancien. $(C R, 244)$

Pourtant dans ce pays dans lequel il semble remonter le temps, les photos prennent un intérêt ethnologique. Avec cette référence aux constructions anciennes, ce livre de voyage annonce déjà l'écriture de Dormance, son livre néolithique. Il écrit à propos de petits hangars :

[...] ce mode de construction est précisément celui que les archéologues, d'après les restes retrouvés dans les tourbières, attribuent en France aux populations néolithiques dont le savoir venait de l'Est (des régions danubiennes, ou même caucasiennes). (CR, 202)

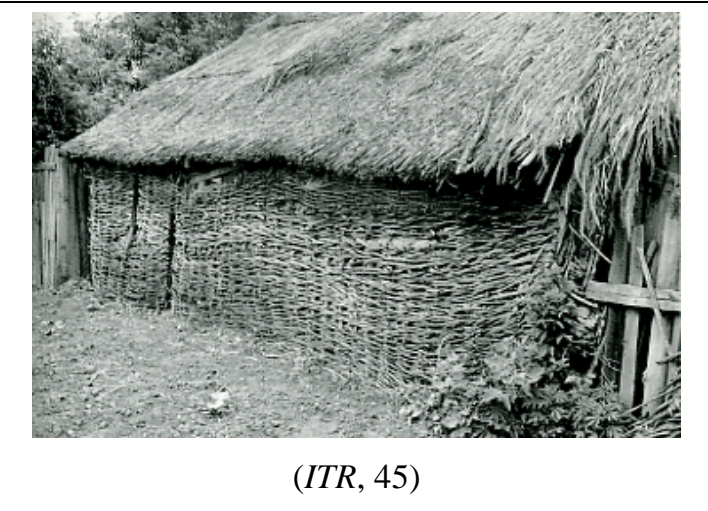

Dans l'autre livre, Images de la terre russe, nous devinons quelle est l'image (ci-dessus à droite) dont parle le texte.

\footnotetext{
${ }^{7}$ TRASSARD, Jean-Loup, Images de la terre russe (Textes et photographies), Cognac, Le Temps qu'il
} fait, 1990. Par la suite nous utiliserons l'abréviation : ITR. 
Le récit de voyage se transformant en images (comme l'indique le titre du livre), il subit en premier lieu une fragmentation. Le caractère continu, la chronologie respectée des évènements laissent place à une image par page associée à un texte court qui sert de légende. Mais le texte ne raconte pas forcément la situation de la prise de vue, il semble être plutôt une rêverie à partir de la photo.

Si l'on compare un paragraphe de Campagnes de Russie qui décrit une prise de vue avec le cliché qui est publié dans le second livre, le procédé de transposition se dévoile:

Une jeune fille est venue s'asseoir juste derrière nous, très jolie. Parce qu'elle m'a regardé plusieurs fois sans trop de gêne avec des yeux exceptionnels, je lui demande - sourire, mimique si je peux la photographier. Elle dit que oui. Sergueï engage notre conversation. Elle s'appelle Elena. Grands yeux très clairs, gris-vert, un petit peu maquillés, dans un visage d'une belle finesse, cheveux bouclés, robe dans les mauves (tissu avec un fil brillant), veste de laine sur les épaules d'un mauve éteint mêlé de beige, améthyste à ses boucles d'oreilles ainsi qu'à sa bague. $(C R, 166)$

Le texte s'arrête sur la description détaillée : les matières, les couleurs..., tandis que la description devient inutile lorsque la photo est présente ${ }^{8}$. La légende à côté de l'image se détache de la prise de vue car elle raconte également ce que chronologiquement l'auteur a su d'elle, plus tard, lors d'une seconde rencontre. La légende mentionne l'avenir dont elle rêve, qui par un tour de passe-passe, fait rêver le lecteur sachant que ce futur s'est depuis transformé en passé. C'est le même élan, que Barthes décrit à propos d'une photographie d'André Kertész, déjà cité à propos d'Hervé Guibert : Ernest, Paris, 1931 montrant de face un écolier ; «Il est possible qu'Ernest vive encore aujourd'hui : mais où ? comment ? Quel roman'? !»

\begin{tabular}{|l|l|}
\hline & $\begin{array}{l}\text { Passagère de la Volga, Elena, dix-neuf ans, grands yeux } \\
\text { gris-vert, est venue s'asseoir sur le banc à côté, un peu } \\
\text { curieuse ou du moins amusée. L'objectif se tournant vers } \\
\text { elle, poliment interrogatif, elle a répondu en sourires } \\
\text { modestes et paroles franches. Maîtresse d'un jardin } \\
\text { d'enfants, Elena rêve de fidélité, du mari qui vaudra son } \\
\text { père. Elle n'est pas descendue à l'autre rive, un homme } \\
\text { l'attendait sur une île. Le bateau l'a donc emmenée, } \\
\text { remontant songeuse la Volga. }\end{array}$ \\
\hline
\end{tabular}

\footnotetext{
${ }^{8}$ On sous-entend le refus d'une tautologie, même si la photo en noire et blanc paraît appauvri par rapport à la description qui évoque les couleurs. Décrire n'a pas seulement la fonction de rendre visible, mais de mettre l'accent sur certains aspects du visible, ou de la sensation.

${ }^{9}$ BARTHES, Roland, La chambre claire, Op. cit., p. 132.
} 
La photo montre Elena rêveuse, comme si l'objectif l'avait suivi sur le bateau après que Trassard et son guide sont descendus sur l'autre rive. L'ensemble du livre ne respecte pas non plus la chronologie du voyage comme l'annonce le texte :

[...] plusieurs photos choisies pour ce qu'elles représentent assez le climat rencontré en Russie. Sans les ordonner selon la trajectoire vacillante du voyage, telle que l'inscrit un dessin rajouté au crayon sur la carte du pays. (ITR, 9. Nous soulignons.)

Ainsi les images prises lors d'une fête, une fête décrite à la fin du livre Campagnes de Russie, se trouvent au milieu du livre Images de la terre russe, où d'ailleurs les deux images montrées ne se succèdent pas non plus, l'une se trouvant à la page 34 , l'autre à la page 40 (voir ci-dessous).

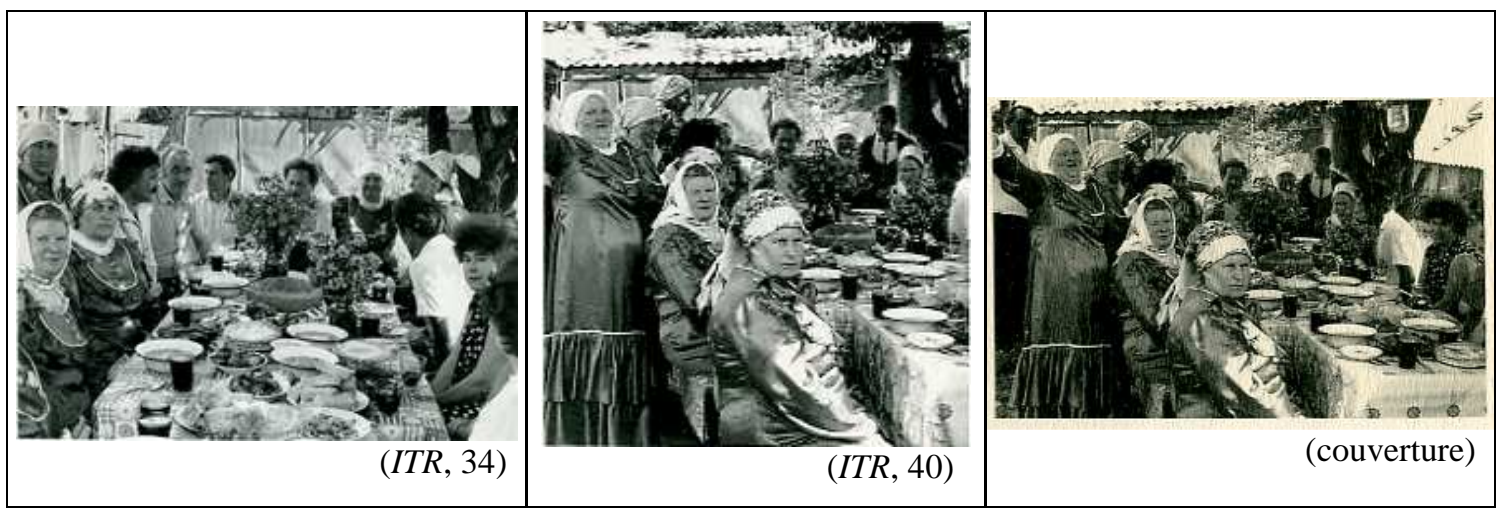

Le cadrage et le format changent, d'une vue frontale prise au 24x36 nous passons à une vue diagonale en carré qui évoque le format 6x6, mais qui est peut-être la même photo que celle publiée en couverture, seulement recadrée (ci-dessus à droite).

Le texte parle d'une «trajectoire vacillante du voyage », comme si ce nouvel itinéraire qui se dessine dans le livre intégrait le discontinu et le désordre des souvenirs. Ce voyage au second degré marque aussi les hésitations du photographe, le ratage du réel, les échecs dans la retranscription de ce que l'œil a vu :

[...] le flou de la précipitation se mêle aux erreurs d'éclairage, au change incompréhensible du sujet (comme si visant l'oiseau je n'avais eu que la branche vide) ou le bougé d'alors ne permet plus aujourd'hui, sinon à grande peine, un départ mental vers là-bas, quand l'œil fouille une sorte de brouillard, glisse sur des formes qu'un ratage, presque rien, suffit définitivement à rendre banales. $(I T R, 9)$

Le projet du voyage est étroitement lié au regard, un regard porté sur les choses, sur le pays : «Brefs comme volés ou longuement émus, quelques regards sur les êtres et les choses parmi, on s'en doute d'innombrable regards puisque je suis allé pour voir» $(I T R, 9)$. Les vues se mêlent aux souvenirs, aussi le texte ne raconte-t-il pas seulement des images, mais également des souvenirs tactiles, olfactifs, etc. L’image fonctionne comme embrayeur de souvenirs, mais aussi comme preuve. 
Trassard souligne la valeur de preuve des clichés, il parle de «fixation sur papier [...] d'un instant unique au cours de la rencontre », pour « témoigner au moins de notre souriant échange ce jour particulier », mais il met en même temps en doute cette valeur de preuve en ajoutant qu' «il faut [en] être persuadé » comme s'il avait à se persuader lui-même, à se convaincre de la réalité de ses propres souvenirs.

Si les souvenirs subissent une transposition poétique (la sonorité interne, le rythme rapprochent les légendes des poèmes en prose), il est possible que ce soit dû au travail du temps. Images de la terre russe paraît un an après Campagnes de la Russie, les souvenirs ont eu l'opportunité de se condenser, de subir le travail, l'érosion, l'usure du temps, pour acquérir une dimension onirique :

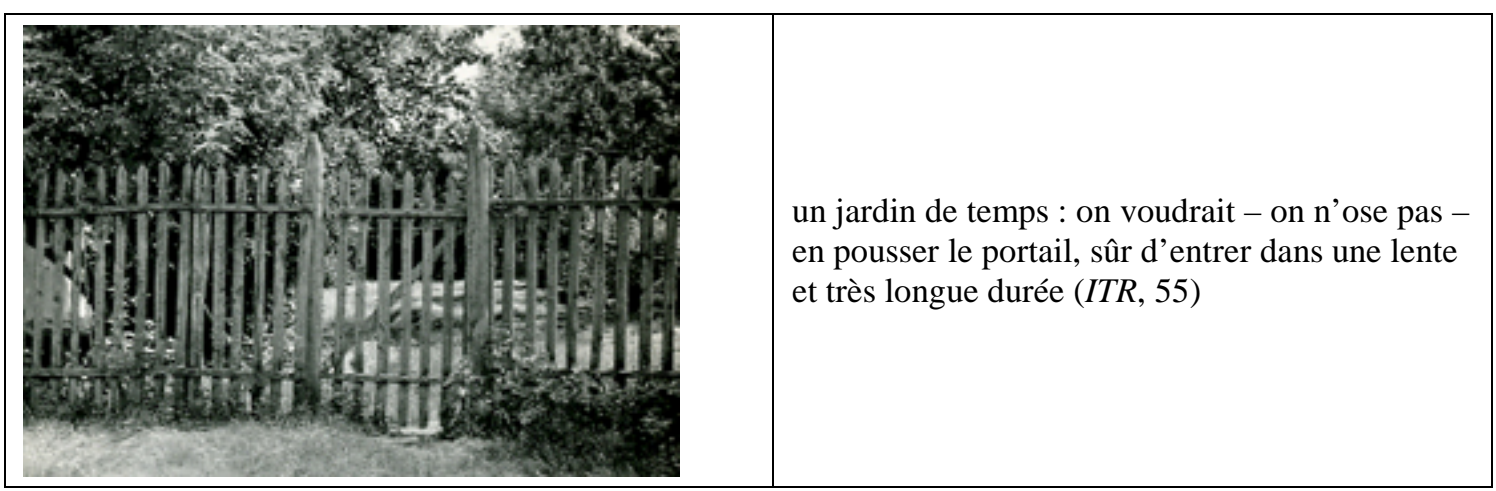

Les nombreuses photos de chemins qui se faufilent et se perdent à l'horizon renvoient aux images publiées dans d'autres livres de Trassard, aux routes et chemins de son pays natal, la Mayenne (voir notamment l'image du livre Objets de grande utilité insérée à la page 265), ce qui crée un écho visuel entre les livres, entre les souvenirs.

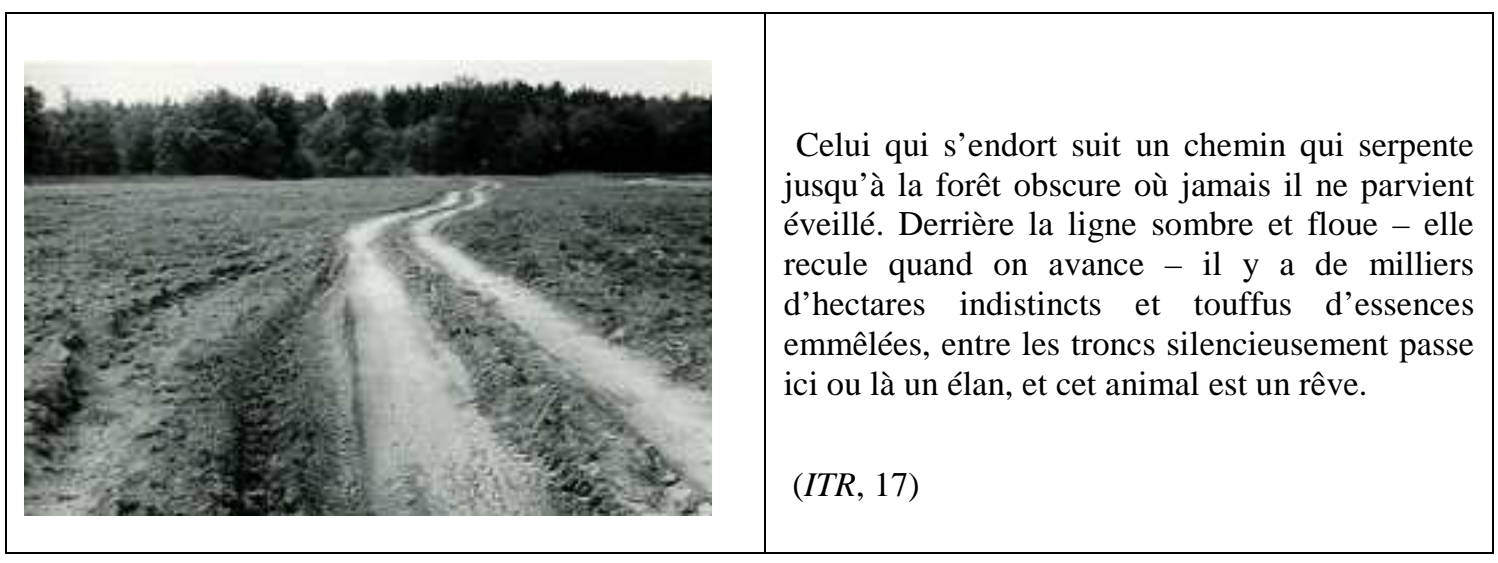

Embrayeurs de souvenirs, départs pour le rêve, les photos de voyage semblent toutefois apporter une nouvelle dimension: les paysages lointains se mettent à communiquer visuellement avec les paysages natals, confèrent un nouveau sens à ces derniers, l'exotique renvoie au familier. C'est ce nouveau regard dont parle l'auteur dans 
Campagnes de Russie, jetant un coup d'œil par la fenêtre du train ${ }^{10}$ : «Voyager, c'est aussi observer la forme des échelles » $(C R, 24)$.

Cette petite remarque évoque déjà le titre de son livre «Le voyageur à l'échelle ${ }^{11} », q^{\prime}$ 'il publia quatorze ans plus tard. Le mot échelle y est à prendre au double sens du terme au puisqu'il nous y livre des textes et des clichés énigmatiques d'un voyageur inventé qui se serait beaucoup déplacé grâce à des échelles (ci-dessous).

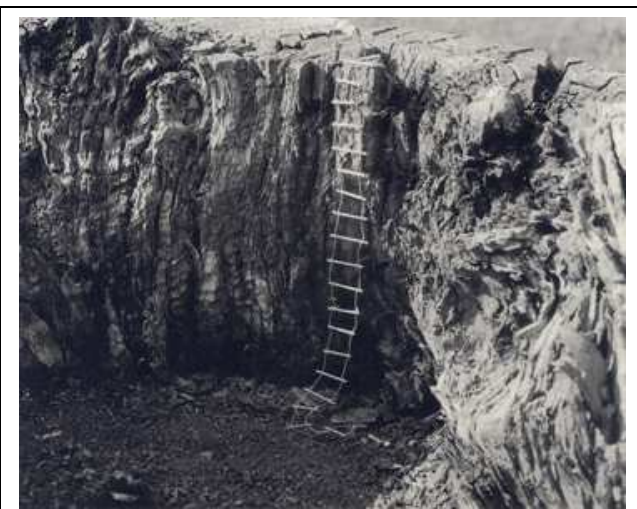

$(V E, 49)$ Les mêmes clichés ont fait l'objet de plusieurs expositions $^{12}$ avant la publication, et ont subi une transformation allant vers la mise en fiction dans l'espace du livre. Jean-Paul Guichard décrit (avant la publication du livre) l'exposition intitulée: «Carnet d'un voyageur, croquis photographiques » et cite le seul bref texte qui accompagnait les photos en reproduisant et respectant la taille de la police utilisée pour le

carton de présentation de l'exposition en Mayenne :

\author{
Ruines et cavernes, fleuves traversés sur \\ d'incertaines passerelles, cratères et déserts, \\ embarcations taillées au couteau et perdues, \\ maigres villages accablés par les pierres... \\ Ces croquis photographiques ont été pris à genoux, \\ au pied levé contre la pente d'un éblouis, \\ l'œil couché au ras de l'insolite, tandis que \\ jacassaient violemment les voix d'oiseaux \\ plus du tout ordinaires mais \\ immenses, parfois presque compréhensibles. ${ }^{13}$
}

\footnotetext{
${ }^{10}$ Notons la ressemblance de la vue par la fenêtre du train et du dispositif photographique, le cadre et l'écran à travers lequel le paysage se révèle. Philippe Ortel parle aussi de cette ressemblance entre le train et la photographie, inventés à la même époque, tout deux considérés comme le symbole de la modernité.

${ }^{11}$ TRASSARD, Jean-Loup, Le voyageur à l'échelle, (Textes et photographies), Cognac, Le Temps qu'il fait, 2006. Par la suite nous utiliserons l'abréviation: VE.

${ }^{12}$ Jean-Paul Guichard cite notamment l'exposition à la Galerie Jacques Barbier à Paris en 1997, à la Bibliothèque de Mayenne en 1999, et à la Bibliothèque de l'Université d'Angers également en 1999. GUICHARD, Jean-Paul, «La photographie est un jeu d'enfant », in L'écriture du bocage, Op. cit., p. 498-519.

${ }^{13}$ Ibid. p. 506.
} 
La graphie du texte suit le changement d'échelle qui s'opère quand on s'accroupit pour photographier, «l'œil couché au ras de l'insolite ». La présentation dévoile le procédé tandis que les pistes s'embrouillent dès que les clichés sont publiés dans le livre.

Voyageur à l'échelle se compose d'un texte d'introduction signé par Noémie Bayère et Anton Iakrel, puis suivent les reproductions associées à un texte bref en face de chaque photo. Le texte de présentation attribue les photos et les textes à Hippolyte Deume, voyageur défunt, dont la vie et l'œuvre semblent énigmatiques. Seules les photos révèlent qu'il s'agit d'un jeu, de photos fictives, reconstructions de prises de vue qu'aurait pu faire un voyageur du XIX ${ }^{\mathrm{e}}$ siècle (les clichés en noir et blanc accentuent cet effet d'ancienneté), des photos qui, comme dans Les derniers paysans, transforment le monde lilliputien arrangé en démesurément grand. Le texte de présentation sème aussi le doute, parlant de «l'hypothèse selon laquelle H. Deume, en parallèle à de bien réels déplacements, aurait travaillé sur le voyage mental» $(V E, 19$.) ou encore de « la danse du réel avec l'imaginaire, et ses figures » $(V E, 21$.$) . La description de la maison du$ défunt, sa correspondance et ses manuscrits retrouvés font référence indirectement à Trassard, qui se met en scène à travers le personnage de fiction.

La correspondance révèle, en effet, qu'il échangeait beaucoup avec des ethnologues, hommes ou femmes, comme avec des peintres et photographes de paysages, artistes qui se plaisent, chacun de sa façon, à représenter l'espace. $(V E, 17)$

Le nom «Hippolyte Deume », comme tous les noms dans les récits de Trassard, est un nom parlant. «Deume » évoque la demeure, le verbe demeurer, et la durée, tandis qu'Hippolyte pourrait faire allusion au premier autoportrait fictif, la photo en noyé d'Hippolyte Bayard (voir à la page 86). Trassard utilise fréquemment des noms en $\mathrm{H}$ comme il le révèle dans un entretien : «c'est en fait le halètement que cela représente. [...] Ça donne une fragilité que j'aime bien au personnage ${ }^{14} »$, mais $l e ~ « h »$ fait également référence au nom de son village Saint-Hilaire-du-Maine. Comme dans le cas du récit de voyage en Russie, les lieux évoqués dans Voyageur à l'échelle fusionnent avec le paysage natal du photographe :

Ces écrits, dont la langue se faufile de la science à la littérature, ont pour caractère d'être à la fois précis - on y touche le rigoureux des cailloux, le velouté des feuilles, la tiédeur de la boue - et remarquablement discrets quant aux latitudes et aux méridiens, Hippolyte Deume paraissant considérer la localisation comme étendue, alors que nous ignorons toujours sur quel continent nous sommes. [...] Mais tandis qu' Hippolyte Deume affirme sa présence dans un paysage très concret

${ }^{14}$ «Entretien avec Arlette Bouloumié » p. 585. 
[...] il ne manque pas - de revenir mentalement à son jardin de Plaissé, la connaissance profonde qu'il en a, par tous les sens convoqués, lui permettant alors, au moins pour quelques minutes, d'être là-bas en même temps qu'ici. (VE, 18-19)

Cependant, le doute s'instaure : ne s'agit-il pas réellement de photos prises sur le lieu natal de Trassard? En effet, l'introduction parle de «textes brefs en vue d'une grande construction poétique et géographique sans cesse remise à plus tard » $(V E, 22)$. On y reconnaît le projet « ethnopoétique » de Trassard.

Le dispositif phototextuel joue avec les illusions : travestissement de l'auteur dans le personnage, confusion entre «l'ailleurs et l'ici », et l'illusion optique qu'évoque le titre. Le texte adossé aux photographies qui sont attribuées à Hippolyte Deume parle également des illusions que donnent les dimensions : «les habitations dénonçaient une population de petite taille (ou alors avec Ghir nous étions devenus géants). » (VE, 40)

Pourquoi les hautes dimensions attirent-elles, ne sommes-nous pas à la mesure de notre planète, pas habitués sur elle? Il semblait improbable que nos courtes enjambées pussent conduire au but. À travers la chaleur où l'espace ondulait j'essayais toujours de nous imaginer là où nous n'étions pas encore. $(V E, 28)$

Cependant les photos peuvent aussi être prise comme des clichés d'un ethnologue, reconstituant les habitats de tribus lointaines: cabane, hangar, niche à chien, embarcation sur la rivière.

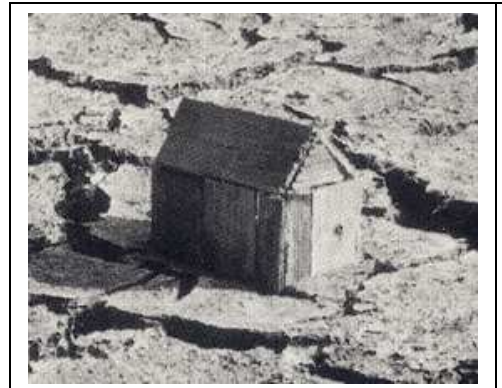

$(V E, 33$, extrait)
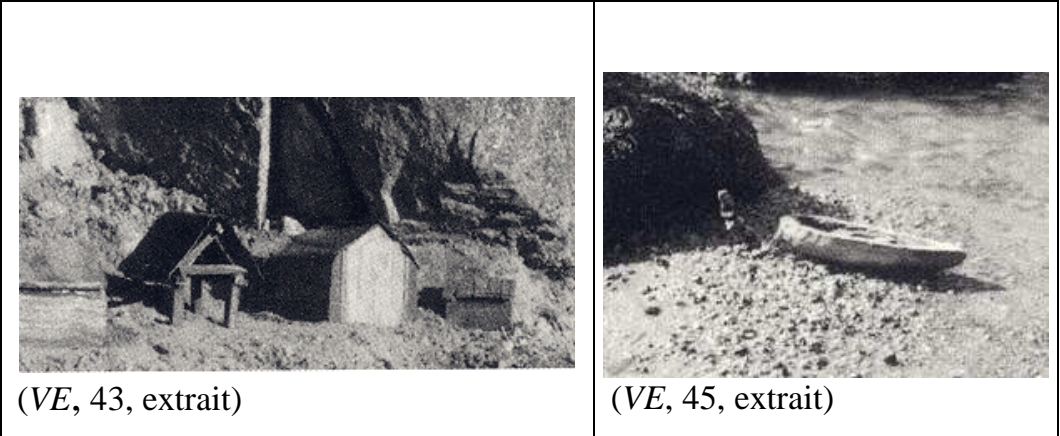

Les noms courts dans Voyageur à l'échelle : « Oaca » (p. 30), « Ghir » (p. 40), «Feth», (p. 50), rappellent les noms des protagonistes néolithiques de Dormance : «Ouen», « Gaur », «Pek ». La photo de Voyageur à l'échelle prise à travers les racines et l'arbre en creux rappelle l'arbre dans lequel se hisse Gaur dans Dormance et celui qu'évoque Trassard au début du roman en souvenir d'un moment et d'un secret partagé avec sa mère, souvenir qui déclenche l'écriture de Dormance :

Il s'agissait d'une énorme ragole, un arbre court, autrefois émondé, dont le bois avait éclaté, s'était ouvert, vidé du ventre, on pouvait y entrer à deux, mère et enfant. Les grosses et basses branches avaient été, par le temps, elles aussi vidées de leur cœur, puis elles étaient tombées, il en restait deux belles lucarnes cernées d'un manchon de bois raviné, très dur. Ma mère disait que si nous observions là, au crépuscule, nous allions peut-être voir quelque chose. Elle pensait aux fées dont les rondes sur l'herbe sont ensuite dessinées par les cercles de champignons rosés. $(D, 17)$ 


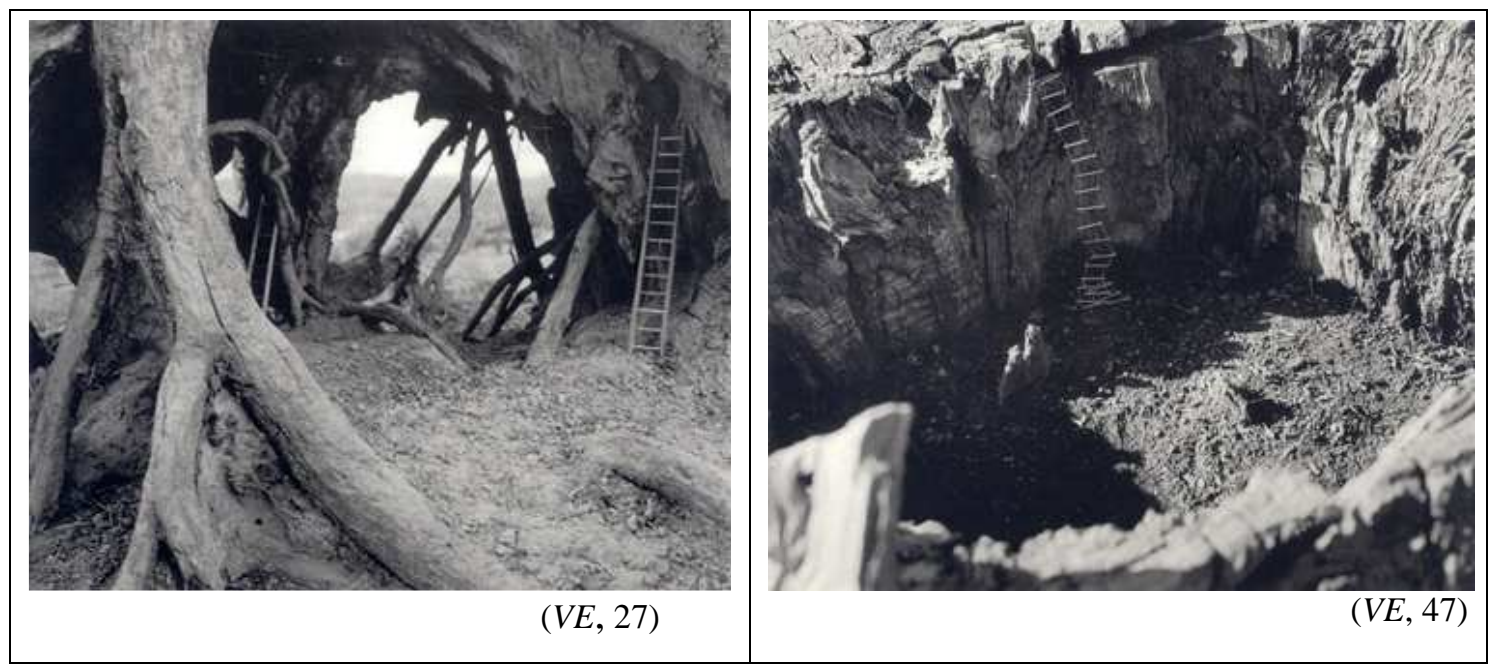

La suite de photos peut également se lire comme un voyage initiatique, évoquant comme souvent dans les récits trassardiens, la fusion avec les éléments. La montée puis, plus tard, la descente dans l'arbre en creux, l'image de la grotte, la traversée de l'eau, la montée vers le ciel suggérée par la dernière image et son texte (ci-dessous à droite et la citation en dessous) constituent donc les différentes étapes de cette initiation. Notons que la disposition des échelles sur l'image provoque également une sensation d'élévation plutôt que de descente.

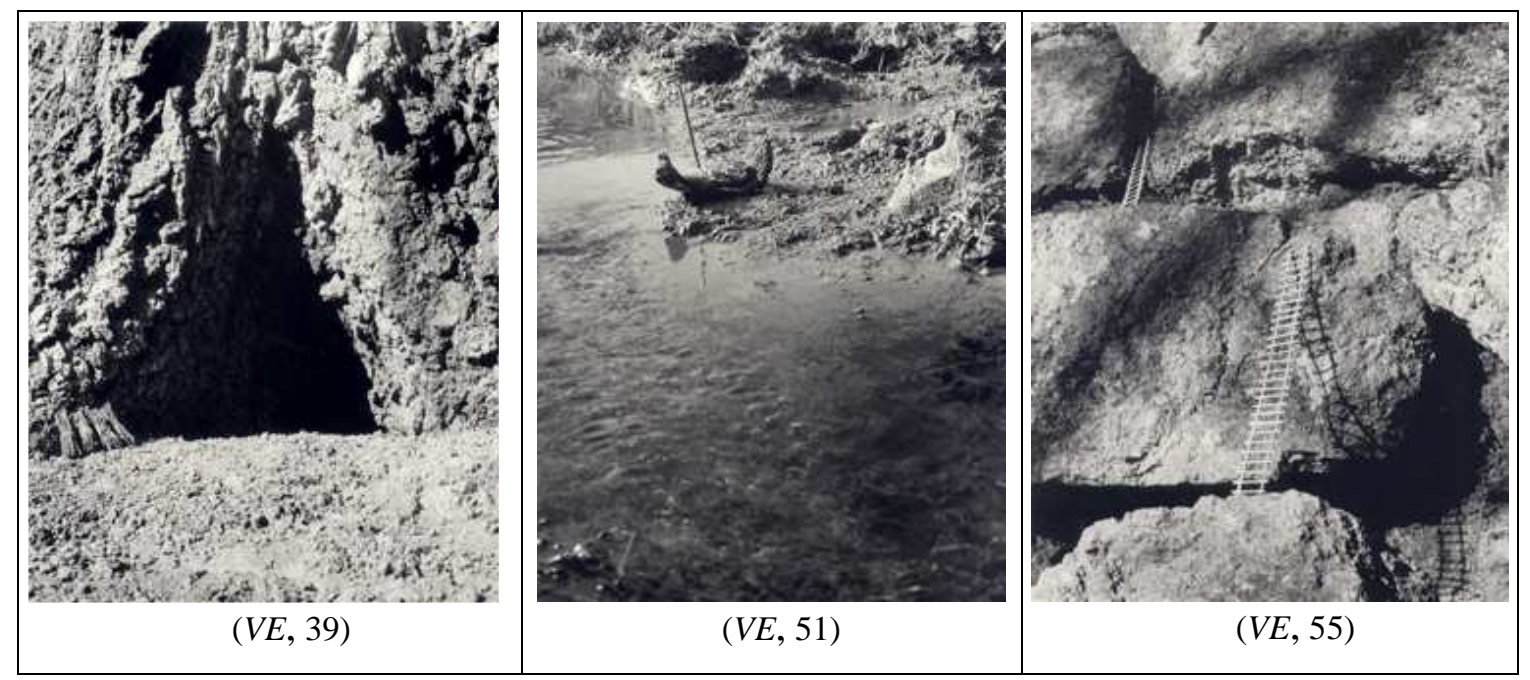

Échelles portés sur le dos, échelles nouées sur place, barreau tenu après barreau lâché pour hisser ou retenir mon poids. Et pourtant mises bout à bout, tremblantes, elles entreraient à peine dans le ciel $(V E, 54)$

Comme dans la série Juste absente, les quelques éléments (cabane taillée dans le mur, tas de bois posé à l'entrée de la grotte, tas de bois en désordre), font sentir la présence humaine, comme si les gens étaient seulement sortis du cadre un instant. 


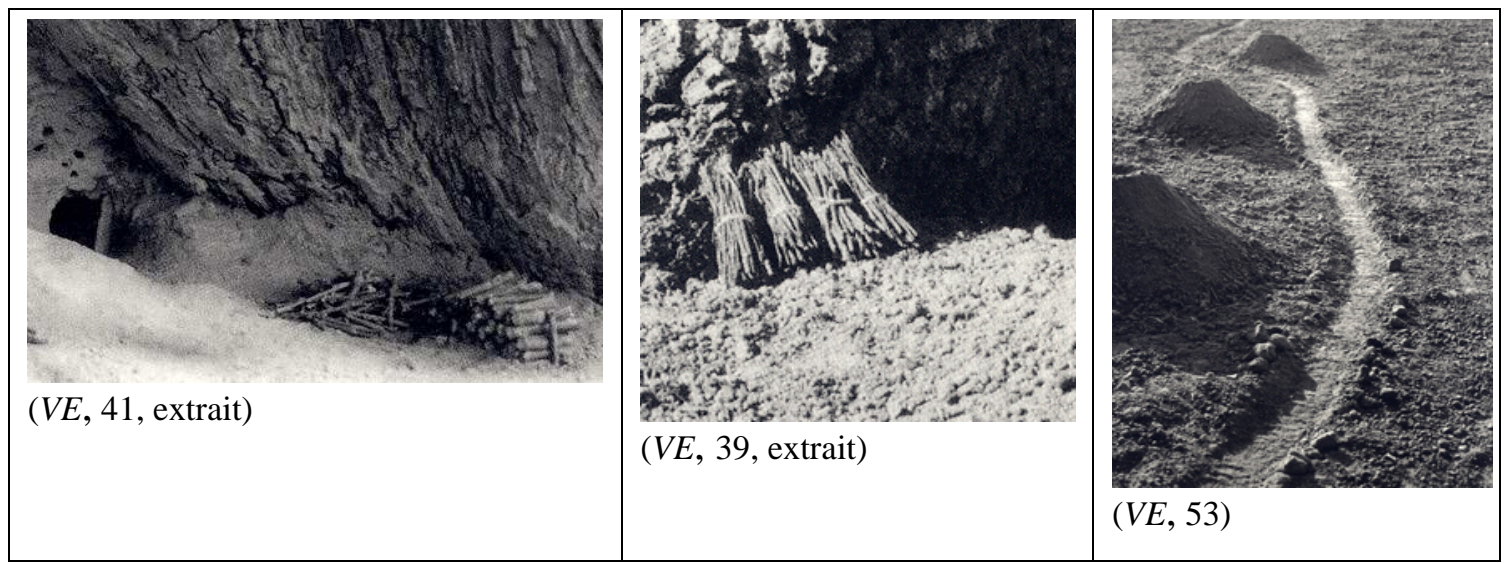

L'image qui montre trois cônes de terre (des taupinières selon d'Arlette Bouloumié ${ }^{15}$ ) à côté desquels se faufile une route, fait penser aux géoglyphes énigmatiques de la civilisation Nazca, ou encore à des créations de land art.

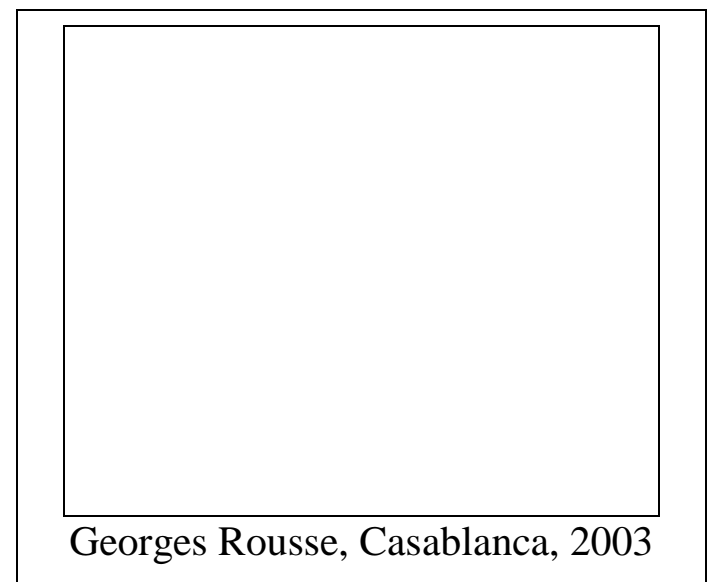

Il faut noter justement, que dans la pratique du land art, mouvement né à la fin des années 1960, nous retrouvons également ce rôle grandissant de la photographie. Au début, elle ne servait qu'à garder une trace des œuvres soumises à la destruction de l'érosion naturelle, tandis que de nos jours certaines installations, comme dans l'œuvre de Georges Rousse ${ }^{16}$ (voir l'exemple ci-contre), sont directement fabriquées en vue de la photo, utilisant l'illusion que crée la platitude de l'image. Les lieux, des espaces intérieurs dans le cas de Rousse, sont voués à la destruction, et l'œuvre développe donc une poétique de l'éphémère.

Trassard joue lui aussi sur l'illusion de la perspective, et le lieu choisi, l'entourage de sa maison, se métamorphose en lieu de rêve, lieu du voyage mental, voyage dans le temps (au XIX ${ }^{\mathrm{e}}$ siècle dans Voyageur à l'échelle ou retour à la préhistoire dans Dormance).

15 BOULOUMIÉ, Arlette, «Photographie et Jeux d'illusion : Jean-Loup Trassard, Lucien Clergue et Bernard Faucon », L'art français et francophone depuis 1980, Op. cit., p. 38. Interprété ainsi, l'image renvoie aux écrits de Trassard sur les taupes et à sa fascination pour ses créatures terriennes en voie de disparition. Voir «Le lait des taupes », L'amitié des abeilles, Cognac, Le Temps qu'il fait, 1985, p. 5159, et Conversation avec le taupier, Cognac, Le Temps qu'il fait, 2007.

${ }^{16}$ Voir le site officiel de l'architecte : http://www.georgesrousse.com/. L'image provient toutefois d'un blog : http://www.stanislasurbietorbi.com/actualites/reportages/rousse/rousse.html (consulté le : 14/09/2009). 
L'écriture devient, à son tour, un voyage intime et imaginaire comme le suggère Trassard à travers l'anecdote de ses premières lectures :

La première page était bleue. Je mangeais ma soupe avec des pâtes et ces pâtes avaient formes de lettres. [...] Je vois - c'est l'effet du temps écoulé, le regard intérieur d'aujourd'hui approche par le dos, jusqu'à presque se fondre en lui, le petit corps assis d'autrefois, drapé dans sa petite robe de chambre - je vois ma position devant l'assiette, celle-ci placée un peu à gauche. Mangeant très lentement, j'essayais de former des mots, n'y arrivait pas [...] Je venais de commencer à apprendre à lire avec ma mère, dans ce premier livre (« la lecture sans larmes ») les personnages s'appelaient toto lili rené, ils avaient de grosses têtes rondes avec une frange, je les trouvais antipathiques. Comme je n'étais pas très appliqué, me fâchais de ne rien y comprendre et voulais toujours fuir au jardin - ma mère s'en plaignit à mon père - quand je prenais plus sagement ma leçon, elle me délivrait un bon point. [...] J'ignorais de façon absolue qu'ils me seraient inusables billets passeport monnaie vers des paysages, des rencontres ou des aventures, qu'ils changeraient ma vie durant contre ce long voyage dans la langue, caravane de mots, train des phrases. ${ }^{17}$

Il s'agit d'un voyage imaginaire, où l'exploration du territoire intime se confond avec l'exploration de la langue.

${ }^{17}$ TRASSARD, Jean-Loup, L'espace antérieur, Paris, Gallimard, 1993, p. 11-12. 


\section{VI.4. L'énigme photographique ou l'espace intime de l'entre-deux}

Comme chez nombre de photographes ${ }^{1}$, la distinction entre espace et intime, extériorité et intériorité s'estompe chez Trassard. Jean Onimus se demande alors s'il n'est pas contradictoire de parler d'espace à propos de l'intime. Il rappelle que dans la tradition philosophique, la spatialité est le caractère inhérent de la nature qui la distingue de l'esprit ${ }^{2}$. Pourtant ce sont bien des «expressions spatiales qu'utilise instinctivement la conscience pour s'appréhender elle-même ${ }^{3}$ », des expressions qui se basent sur «une expérience vécue et qui ne saurait être vécue autrement ${ }^{4} \gg$. Chez Bachelard également, l'espace devient intime dès qu'il est investi et habités. La question est également pertinente dans le cas de la photographie, car dans sa fonction la plus courante (photos de nos proches gardées dans le porte-monnaie), elle témoigne du rapport intime de son usage.

L'intime concerne également les œuvres hybrides de Jean-Loup Trassard composées de textes et de photographies. Comme le note Joseph Fahey, «le lien n'est jamais explicite [entre le texte et les clichés] : les textes ne renvoient pas aux photographies qu'ils accompagnent et les photographies n'illustrent pas le contenu du texte ${ }^{6} \gg$. Jean-Loup Trassard nous éclaire à ce sujet, décrivant ses œuvres comme :

[...] de petits livres où l'écriture et la photographie ne viennent pas s'expliquer l'une et l'autre, mais se rencontrent dans un espace intime pour dire chacune à sa façon un lieu, une campagne. [...] Sans qu'une pratique déteigne sur l'autre, elles sont plutôt considérées quand l'une et l'autre peuvent entrer en jeu comme deux paumes serrées pour puiser l'eau. Ainsi essaieront-elles de retenir, chacune avec ses moyens mais ajointées, une généreuse part des sensations que les paysages, les objets, peut-être même les personnages, feront sourdre, jusqu'à la nécessité d'en rendre compte. ${ }^{7}$

\footnotetext{
1 Voir notamment le chapitre «Noir limite» ou «La dissolution du clivage entre intériorité et extériorité » à la page 101 et 106.

${ }^{2}$ ONIMUS, Jean, «Phénoménologie de l' «Espace » poétique », Espace et poésie, sous la dir. de Michel Collot et Jean-Claude Mathieu, Paris, Presses de l'École Normale Supérieure, 1987, p. 69.

${ }^{3}$ Ibid. Onimus donne les expressions suivantes en exemple : rentrer en soi ou en sortir, descendre dans ses profondeurs, se fixer un horizon.

${ }^{4}$ Ibid.

${ }^{5}$ BACHELARD, Gaston, La poétique de l'espace, Op. cit.

${ }^{6}$ FAHEY, Joseph, «Le grain de l'expérience : le rôle de l'image photographique dans les œuvres de Jean-Loup Trassard », in L'écriture du bocage : sur les chemins de Jean-Loup Trassard, Op. cit., p. 485. Il faut ajouter cependant que deux de ses livres, Images de la terre russe et Ouailles, font exception à cette règle.

${ }^{7}$ TRASSARD, Jean-Loup, «Sous les nuages d'argents », Jean-Loup Trassard, Prospectus hors série des éditions Le temps qu'il fait, octobre 1994, cité par Jean-Bernard Vray, «Jean-Loup Trassard: la
} 
Il se crée donc un lien «intime » entre le texte et la photographie, « intime » aussi dans le sens de caché et non-visible.

Le livre intitulé Objets de grande utilité contient ainsi des textes et des photographies apparemment sans lien explicite. Le texte recense des objets, tandis que les photos montrent des paysages. Il s'agit d'objets ordinaires, d'ustensiles communs utilisés jadis dans les fermes. La description est minutieuse, va jusqu'à donner la taille en centimètre, le fonctionnement et les souvenirs qu'ils suscitent chez l'auteur. Dépeindre les objets tient également du défi :

Des objets si simples qu'on croit à première vue n'avoir rien à en dire, sinon justement cette simplicité étonnante. A force de toucher pourtant, et sur les traces infimes de sa vie ancienne, une relation se fait jour entre la nudité même de l'objet et les souvenirs ou sensation qu'il éveille.

Sans doute ne parle-t-il pas tout seul: s'il est muet d'abord, le jeu consiste à regarder suffisamment cet objet pour faire peu à peu se déployer l'atmosphère qui le nimbe en secret audelà de ses mensurations. ${ }^{8}$

On pourrait se demander, s'il suffit de «regarder suffisamment l'objet», pourquoi la photo de l'objet est absente. Méfiance face à la photographie ? L'illusion parfaite que donne l'image cacherait-elle son essence? L'image dont le référent est toujours concret rendrait-elle impossible l'énoncé de généralités sur l'objet ? Le caractère problématique de la description s'allie à l'impossibilité de la représentation. En citant Linay du Pairier, un auteur du XVII ${ }^{\mathrm{e}}$ siècle $^{9}$, Trassard rappelle que le problème de la représentation n'est point nouveau, la photographie n'a fait que resurgir le débat dans la deuxième moitié du $\mathrm{XX}^{\mathrm{e}}$ siècle par la remise en cause de son objectivité et de sa référentialité.

La description, comme nous l'avons déjà dit à propos de Dormance, aboutit en fin de compte à l'impossibilité de la description :

(si j'écris un nom, je m'aperçois que celui-ci ne couvre pas l'objet : [...] Il faudrait donc décrire. Les mots visitent, pénètrent, miment le plat, le rond, se roulent à la surface, tentent d'animer, soupèsent et, tournant autour, s'accumulent, s'attachent entre eux, derrière leur danse finalement c'est sans doute heureux - laissent encore filer l'objet que je croyais croquer.) (OGU, 81-82)

De même la photographie résiste à la représentation du réel :

Ce que j'en attends [de la photographie] ... pour aller vite, d'abord le plaisir de travailler sur l'espace, de réduire tout un paysage à un petit rectangle, et de disposer les masses et les lumières à

dormance et la trace », in Trace photographiques, traces autobiographiques, Op. cit., p. 262. Nous soulignons.

${ }^{8}$ TRASSARD, Jean-Loup, Objets de grande utilité, Paris, Le temps qu'il fait, 1995, p. 9. Par la suite nous utiliserons l'abréviation : $O G U$. Nous soulignons.

${ }^{9}$ « «Si je refuse encore l'appui d'aucun dessin, il semble que les mots employés à décrire ne fassent qu'intriguer pour une confusion et l'objet soudain dispersent les morceaux », écrivait Linay du Pairier en $1676 \ldots », O G U$, p. 24. 
l'intérieur de ce rectangle. Ensuite un moyen supplémentaire pour essayer de saisir et de représenter le réel qui résiste tellement (c'est heureux !). ${ }^{10}$

La raison d'être de la description des objets transforme néanmoins le texte. Le texte intègre à son tour toutes les fonctions de la description ${ }^{11}$ et revêt un caractère d'inventaire, révèle le caractère du narrateur, acquiert un statut d'étude ethnographique et archéologique, ainsi qu'il évoque les souvenirs de l'auteur éveillés par les objets.

Certes, il est question de la description et des problèmes que soulève cette description, mais il s'opère un « déplacement » de l'objet vers « un certain espace » :

L'objet, que ses limites abruptes séparent d'un autre objet, isolé ou du moins isolable, déplacé même, non seulement continue d'appeler à lui d'autres objet mais, je me rends compte à le dépeindre, continue de porter, et transmettre, l'idée d'un certain espace qui l'entourait. (OGU, 33. Nous soulignons.)

Les objets isolés et déplacés de leur entourage d'origine, comme dans un musée d'ethnographie, sont présentés par trois dans chaque chapitre. Le lieu qu'évoque l'ensemble des outils est cette ferme de jadis, dont l'atmosphère rappelle l'enfance de l'auteur, cette vie campagnarde disparue qui a fait place aux nouveaux modes d'agriculture $^{12}$. Les triplets ne s'organisent pas pour autant autour des lieux, mais autour des sens. Celui du premier chapitre, par exemple, rappelle les sens du toucher (le peigne du cheval), du goût (le pichet à cidre) et de l'ouïe (le soufflet). Nos cinq sens sont engagés ainsi dans la compréhension du texte.

Les quinze photographies, qui ajoutent une dimension visuelle à l'écriture, représentent des paysages énigmatiques, ne montrant pas des fermes, les lieux qu'évoquent les objets, mais des chemins et des prés dans la campagne. Le récit intitulé «Un miroir des ornières ${ }^{13}$ », publié dans le recueil L'ancolie, peut néanmoins constituer une réponse à cette énigme. Le récit décrit des chemins dans la campagne faisant écho aux photos dans Objets de grande utilité. Le narrateur explique :

Je suis en effet partisan d'une description détaillée des chemins, centimètre par centimètre pour ainsi dire : largeur, état du sol, tournants et pente, le niveau par rapport aux champs (ou degré

\footnotetext{
${ }^{10}$ «Entretien avec Arlette Bouloumié », Op. cit., p. 598.

${ }^{11}$ «Quand donc un objet vient-il à susciter le récit de ses fonctions et apparences ? Précisions techniques et flatteuses dans un catalogue, peinture qui est censée révéler le caractère du possesseur dans un roman traditionnel, mesures et comparaisons dans l'étude d'un ethnographe ou d'un archéologue, évocation chargée de sentiments dans le déploiement (peut-être dialogué) du souvenir... » $(O G U, 67-68)$

${ }^{12}$ Nous retrouvons la même nostalgie pour la campagne chez Jean-Loup Trassard et chez Raymond Depardon dans La ferme du Garet, que nous avons déjà évoqué.

${ }^{13}$ TRASSARD, Jean-Loup, «Un miroir des ornières », L'ancolie, Paris, Gallimard, 1975, p. 81-108.
} 
d'enfouissement), l'aspect des deux talus, leur hauteur, de quoi ils sont plantés. Et surtout: comment à chaque endroit du chemin, on se sent. ${ }^{14}$

Le mot «miroir» dans le titre du récit annonce déjà l'importance du dispositif photographique. Or, la photographie contribue à part entière à la genèse de ce texte, puisque le narrateur mentionne le projet réalisé pour la mairie d'un recensement des chemins avant leur rénovation, par une étude photographique et par « un cadastre dessiné par les mots ${ }^{15} »$.

L'autre origine du texte que le narrateur indique est un rêve :

[...] tout a commencé une nuit. J'étais loin de la région, j'ai rêvé d'un itinéraire. [...] il s'agissait d'une étude sérieuse, dans un livre, qui cherchait donc avec les documents utiles à reconstituer un itinéraire hésitant, le tissage brut d'une existence. ${ }^{16}$

Dans la genèse s'entremêlent aussi le sérieux et le rêve comme au niveau du texte cohabitent souvenirs d'enfance, rêves, et citations du dictionnaire.

La description constitue progressivement un inventaire typologique des chemins (renvoyant aux photos publiées dans l'autre livre) : les chemins partant du village vers les fermes; les chemins ne menant nulle part; les chemins en creux ; les chemins pentues; les chemins larges le long des près ; les chemins feuillus ou cernés de haies, les chemins pris à pied ou en charrette.

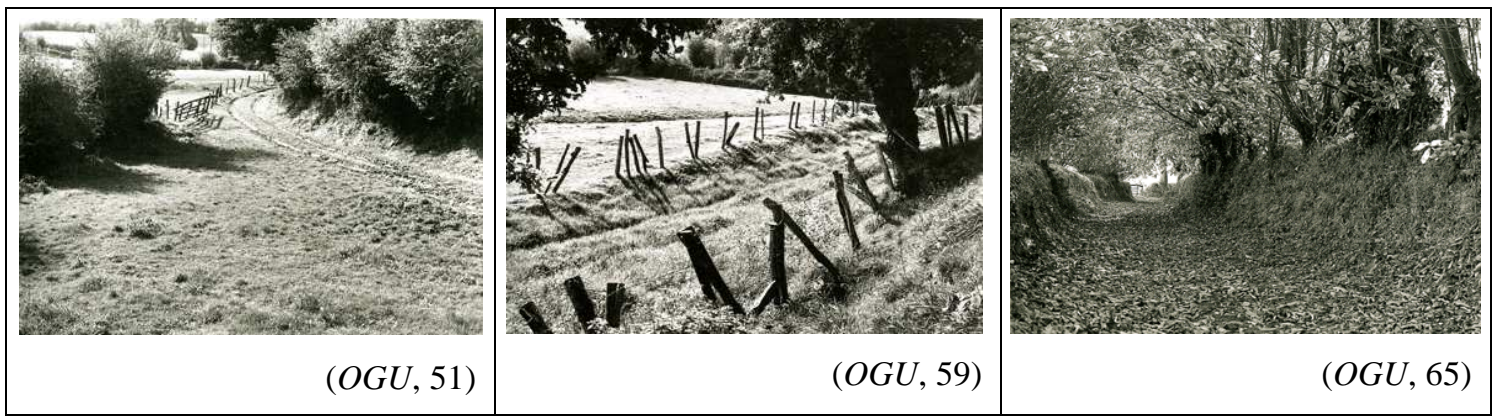

Le style de la description des chemins change constamment, tantôt subjectif, tantôt objectif. Le texte présente tantôt l'univers macroscopique, tantôt il se rapproche du microscopique, comme si le narrateur variait le grand angulaire et le téléobjectif. Toutefois, ce mouvement intérieur dans le texte ne reflète aucun tourment, le style de son écriture est limpide. Jean Arrouye souligne d'ailleurs une corrélation entre le texte

\footnotetext{
${ }^{14}$ Ibid., p. 94-95.

${ }^{15}$ Ibid., p. 86. Le projet mentionné a probablement donné lieu à la publication du livre : TRASSARD, Jean-Loup, La Mayenne des chemins creux : 70 circuits de petite randonnée pédestre, Association départementale de la randonnée pédestre de la Mayenne.- A.D.R.P.M., 1985, titre cité sur le site de la communauté d'Ernée : http://www.cc-lernee.fr/biblio.php (consulté le : 21/07/2008).

${ }^{16}$ TRASSARD, Jean-Loup, «Un miroir des ornières », Op. cit., p. 87.
} 
et l'image dans le mouvement vertical de flux et reflux, qui entraîne le regard toujours en dehors du cadre ${ }^{17}$.

Les itinéraires se nourrissent de la mémoire, des souvenirs d'enfance ; ainsi, les lieux décrits se transforment en espaces intimes, dans le même temps que la description commémore les espaces disparus, car « les chemins sont aussi les voies de l'oubli ».

J'ai photographié des chemins. J'ai la preuve de leur passé profond, même s'ils ont été transformés parfois en petites routes avec du barbelé des deux côtés. ${ }^{18}$

Les photos deviennent intimes par l'ancrage nécessairement autobiographique du médium, et inversement la photo projette ce caractère sur le récit, le sentiment de présence, la certitude du «ça a été ${ }^{19}$ ». Le texte, en revanche, déplace le contenu de l'image, et peuple le paysage neutre et objectif de souvenirs d'enfance et de révélations de l'auteur sur son moi. L'espace intime, dans lequel se rencontrent photographies et écriture, a donc cette double caractéristique de puiser dans la mémoire pour restituer la mémoire.

En fin de compte, dans Objets de grande utilité, les photos de paysage s'associent aux objets par leur tendance à l'effacement, leur disparition due au temps qui passe.

Les outils et la matière portent en eux-mêmes la marque et la trace de l'homme, comme le creux du sabot évoque la présence du pied $^{20}$, comme les outils décrits dans Objets de grande utilité reflètent en creux l'activité humaine :

Nombre d'objets usuels par quoi l'homme s'entoure (pierres dans la chevelure d'une comète) portent évidemment la marque, la mesure, de son corps. Ainsi parler de tels objets n'est pas, comme on a pu le croire, choisir l'inanimé, mais parfois chercher la silhouette qu'ils dessinent en creux de l'homme ou de la femme occupés à les faire mouvoir. $(O G U, 87)$

De même, la représentation des lieux révèle la présence imperceptible de l'humain, «l'intimité d'un homme avec l'espace dans les limites d'une zone graphiquement reproduite. Chemins, sentiers, prairies [...]. Un homme mais invisible dans le territoire de son rêve ${ }^{21} »$.

\footnotetext{
${ }^{17}$ ARROUYE, Jean, «Voir venir. Fonctionnement symbolique de la photographie dans Inventaire des outils à main dans une ferme », in L'écriture du bocage, Op. cit., p. 467-483.

${ }^{18}$ TRASSARD, Jean-Loup, «Un miroir des ornières », Op. cit., p. 86-87.

${ }^{19}$ BARTHES, Roland, La Chambre claire, Paris, Cahiers du cinéma/Gallimard/Seuil, 1980, p. 176.

${ }^{20}$ TRASSARD, Jean-Loup, « D'un fût gélif », L'ancolie, Op. cit., p. 133-155.

${ }^{21}$ TRASSARD, Jean-Loup, «Un miroir des ornières », Op. cit., p. 87.
} 


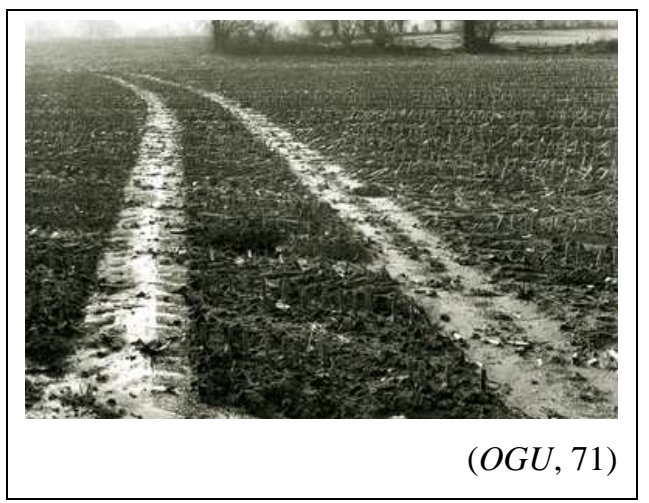

Comme sur le cliché, sur les chemins boueux s'imprime réellement et non pas seulement symboliquement la trace de l'homme. En fin de compte l'écriture devient elle-même trace, elle devient trace, une marque intime, un chemin à prendre qui mène ailleurs, car la «fonction secrète du chemin, [est] à savoir : faire passer

l'esprit d'un monde vers un autre ${ }^{22} »$, et le style des textes trassardiens reflète ce mouvement :

C'est toujours le style de Trassard, cette phrase semée d'insistantes aspérités destinées à la ralentir, de minuscules décisions à prendre concernant la syntaxe et le sens; ce cours limpide mais non facile, qui fait que le lecteur ne puisse jamais s'abandonner à l'inconscience du fil de l'eau, à penser à autre chose, à quitter de son regard par lui-même imaginé le fond de cailloux sur lequel il s'avance : toujours voir où on met le pied et, au besoin, changer l'appui et le moment et le rythme. Et, par instants, revenir sur ses pas, se remémorer le chemin parcouru, le réviser... ${ }^{23}$

Le mouvement de la lecture, le mouvement du regard sont imposés par des caractéristiques négatives: l'absence, l'invisible, le creux et évoquent le procédé photographique, autant que le discours poétique contemporain sur le blanc, le vide, le non-lieu ${ }^{24}$.

L'espace ne se réduit pas au visible mais comporte une part irréductible d'invisible. [...] la donation de l'espace dans la perception n'est jamais pleine ni entière, elle en appelle à l'ouverture d'un autre espace : celui de la parole, qui est aussi espace de l'Autre. [...] c'est un non-lieu qui donne lieu à l'écriture. ${ }^{25}$

Toutefois, si l'espace tient lieu de mémoire et creuse dans les souvenirs à partir d'un vide, ce n'est pas en premier lieu par un mode de lecture lié à la vue, mais par le caractère affectif de l'espace. Jean Onimus, reprenant les catégories proposées par Cassirer (Struktur-Raum, l'espace organiquement vécu et affectif, et Funktions-Raum, l'espace collectif des activités fonctionnelles), souligne la proximité qui relie l'espace affectif et l'espace poétique ${ }^{26}$. Ce dernier, nourri par l'imaginaire et la fantaisie de l'écrivain, devient un espace de substitution, qui nous permet «d'élargir, de transcender

${ }^{22}$ Ibid., p. 104.

${ }^{23}$ CAMPION, Pierre, Composition à la française, compte rendu du livre «La Composition du jardin » (Texte et photographies de Jean-Loup Trassard, aux éditions Le Temps qu'il fait, 2003) http://pierre.campion2.free.fr/trassard2.htm\#FN2 (consulté le : 07/05/2007).

${ }^{24}$ BLANCHOT, Maurice, L'espace littéraire, Paris, Gallimard, 1992.

${ }^{25}$ COLLOT, Michel, MATHIEU, Jean-Claude, «Présentation», Espace et poésie, Paris, Presse de L'ENS, 1987, p. 8.

${ }^{26}$ ONIMUS, Jean, « Phénoménologie de l' "Espace" poétique », Op. cit., p. 74-75. 
notre propre spatialité27 $»$ tout en l'apaisant (rappelons la métaphore de l'eau que les deux paumes serrées - la photographie et l'écriture - viennent puiser).

La photographie, comme nous l'avons évoqué dans le chapitre «Le sens sensible de la photographie » semble également fonctionner sur le mode affectif, plus que le texte, la vision des choses nous touche. Chez Trassard les chemins parcourus, l'espace vide de la photographie évoqué par le texte, la feuille blanche traversée par l'écriture, appellent l'intime comme un espace affectif, l'espace de la création. Ainsi l'espace intime, l'entre-deux qui unit les photographies et l'écriture, devient le lieu intime de la création.

${ }^{27}$ Ibid., p. 75. 


\section{VI.5. Les rapports texte/image}

La nature de ce rapport intime change de livre en livre. Chaque livre constitue une nouvelle approche, un nouveau rapport entre le texte et l'image, mais selon un lien implicite qui reste énigmatique essayant d'éviter que le texte et l'image ne soient pléonastiques. Dans l'entretien avec Arlette Bouloumié l'auteur confie : « [...] j'essaye de ne pas écrire un texte tout à fait comme le précédent ${ }^{1} »$ et encore «j'ai fait un parallèle, non pléonastique, sauf dans un des six livres, entre les photos et les textes et avec des formules chaque fois un peu différentes ${ }^{2} »$. Nous nous attarderons donc à l'analyse détaillée des différents rapports entre le texte et l'image dans les œuvres hybrides mêlant photographies et écritures. En apparence, ces livres photo-littéraires se ressemblent ${ }^{3}$, ils sont du même format (imposé probablement par l'éditeur) avec une photo sur la couverture (sauf dans le cas de Tumulus), qui peut être la reprise d'une photo du livre ou un cliché inédit. Dans plusieurs livres nous trouvons une photo en petit format sur la page de titre et celle de l'achevé d'imprimer. Le nombre des photos publiées est identique dans plusieurs livres. La majorité des livres comprennent des photos en noir et blanc (sauf Les derniers paysans) et les photos sont présentées sur des pages isolées du texte (sauf dans Images de la terre russe).

\section{VI.5.a. Inventaire des outils à main dans une ferme - la poétique de l'empêchement}

Dans Inventaire des outils à main dans une ferme ${ }^{4}$, la photographie fonctionne de manière symbolique comme le souligne Jean Arrouye. Sur plusieurs photos, le regard est gêné dans son parcours par le flou de l'arrière plan, le brouillard ou une barrière, ce qui constitue selon Arrouye : «une poétique de l'empêchement de la connaissance de cette vie campagnarde qui est célébrée par le texte ${ }^{5} \gg$. Le texte rend hommage aux outils

\footnotetext{
${ }^{1}$ «Entretien avec Arlette Bouloumié », p. 592.

2 «Entretien avec Arlette Bouloumié », p. 600. Il faut noter toutefois que dans ses réponses à notre questionnaire il contredit ses propos.

${ }^{3}$ Voir le tableau comparatif dans l'annexe $\mathrm{n}^{\circ} 1$ à la page 292.

4 TRASSARD, Jean-Loup, Inventaire des outils à main dans une ferme (Textes et photographies), Cognac, Le Temps qu'il fait, 1995.

5 ARROUYE, Jean, «Voir venir. Fonctionnement symbolique de la photographie dans Inventaire des outils à main dans une ferme », in L'écriture du bocage, p. 474.
} 
à main qui ont été remplacés par les machines, ces outils à main qui avaient travaillé et façonné les espaces représentés sur les photos. Le thème du livre rappelle celui d'Objets de grande utilité, publié aussi en 1995, mais les images ont une autre fonction et un autre format (à part la photo sur la couverture, toutes sont de format portrait). Jean Arrouye souligne la ressemblance des paysages vides en noir et blanc avec des tombeaux et accentue l'importance de l'image montrant deux personnes travaillant avec un tracteur, seule photo du livre où des personnes soient visibles.

Un homme conduit le tracteur, qui fauche du foin; une
femme le suit, du côté de la coupe, maniant un outil, broc ou
bataigne, détourné de sa fonction car utilisé apparemment
pour dégager la lame de fauche mécanique de l'herbe qui
'accumule sur elle. C'est la première étape de la disparition
des instruments à main. Dès qu'une botteleuse sera adjointe
au tracteur, ce dernier outil maintenu ne sera plus nécessaire.
Puis viendra le temps d' « une vie agricole qui est d'usure -
arrachements, terre éventrée, arbres secoués - et non
d'attente ${ }^{6}$.

Arrouye souligne le suspense que crée le décalage temporel entre les photos et le temps des outils à main, un temps révolu commémoré par le texte. Un mouvement de flux et reflux caractérise, selon lui, la lecture de l'ensemble texte-photographie, où l'empêchement du regard dans l'espace représenté reconduit «imaginairement le spectateur à la lisière de lieux où il n'y a plus rien à apprendre du bon usage des outils à main d'une ferme ${ }^{7} »$.

La photo de couverture (ci-contre) possède une fonction spéciale, selon l'interprétation de Jean Arrouye : cette photo «affirme alors que les autres insinuent ${ }^{8} \gg$. Elle affirme, notamment avec le tonneau de cidre transformé en niche à chien, le changement de fonction que subissent les outils tombés en désuétude.

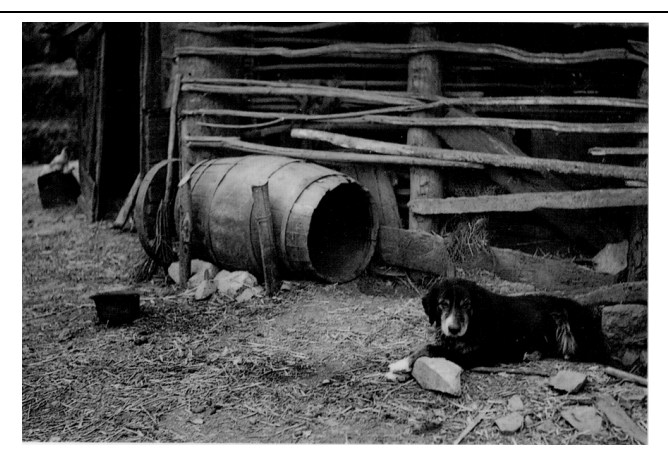

Inventaire, photo de couverture.

${ }^{6}$ Ibid., p. 479-480. Nous reprenons la description de Jean Arrouye à la page 41 (extrait ci-dessus) du livre de Trassard, car elle montre bien comment un savoir préliminaire est nécessaire pour interpréter l'image, notamment pour voir une femme dans la figure à peine visible à côté du tracteur, (mais il se peut aussi que la mauvaise qualité de la reproduction empêche de la déchiffrer correctement).

${ }^{7}$ Ibid., p. 483.

${ }^{8}$ Ibid., p. 467. 
La fonction générale de l'image dans ce livre est donc d'insinuer le sens du texte non pas de manière littérale mais par l'effet optique, par l'empêchement du regard.

\section{VI.5.b. Archéologie des feux - une trace de lumière}

Dans Archéologie des feux $x^{9}$, le texte est présenté en bloc, il n'y a pas de paragraphes qui couperaient visuellement son unité, mais c'est la photo qui marque la séparation et devient ainsi un élément de composition qui structure le texte en le divisant en unités ou chapitres. L'image est un arrêt, elle remplace le vide, le blanc de la démarcation du chapitre, tout en dérangeant la lecture linéaire du texte. L'importance de cet élément visuel dans la structure du texte est renforcée par l'absence de pagination, l'image devient donc également un élément de repère. Les différents «chapitres » se construisent autour des topoï trassardiens : le chemin, le sabot, la pierre, les animaux domestiques, les graines, etc... tandis que les photos représentent différents bâtiments de la ferme abandonnée : grange à foins, grange pour le bois, grenier pour les graines, cages d'animaux. Ce n'est qu'à la fin du récit que la thématique du feu apparaît dans le texte, mais on s'approche progressivement du thème par l'évocation des chemins, de la fumée, des signes et des traces de feu, pour ensuite souligner l'importance du feu dans l'organisation de la vie paysanne.

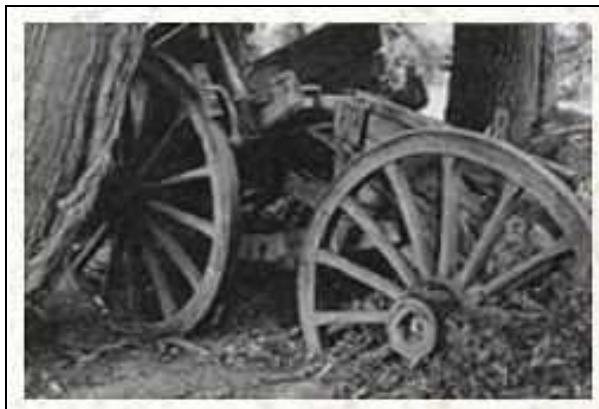

Archéologie des feux, photo de couverture.
Les photos ne montrent pas non plus de feu, mais l'évoquent sous forme de matières inflammables bois, foin, ou objets qui en portent la trace : bidon à lait avec une chaînettes pour l'accrocher sur le feu, bouts de fer rouillé ${ }^{10}$, ainsi que des chariots ou charrettes qui ont probablement servi à déplacer le bois découpé (comme celle qui se trouve sur la couverture du livre).

\footnotetext{
9 TRASSARD, Jean-Loup, Archéologie des feux (Textes et photographies), Cognac, Le Temps qu'il fait, 1993.

${ }^{10}$ « Pourtant, avant de partir, les agriculteurs ont fait un dernier feu et celui-là peut être fouillé. [...] Bois, chiffons, cordes, cuirs, ont brûlé, reste au-dessus de la cendre et des charbons un entrelacement de ferraille rouillée que le feu a marquée en noir, même de reflets bleutés. » Archéologie des feux, sans pagination.
} 
Le feu n'est pas montré, mais sur plusieurs images, un brin de lumière traverse en diagonale le cadre, pour en quelque sorte «allumer la scène » d'une lumière vive accentuée par l'intensité du contraste entre le noir et le blanc. Selon Joseph Fahey, le parallèle entre le feu et la photographie ${ }^{11}$ est à chercher ailleurs : les flammes s'inscrivent sur le bois de l'armoire qu'évoque Trassard, elles laissent leur empreinte dans la matière, comme la lumière sur la pellicule ou le papier photographique.

Toutefois, celui qui a su au moment opportun acquérir une armoire [...] regarde sur le poli du bois, douceur obtenue par l'essuyage durant des dizaines et des dizaines d'années, comme un reflet, une lueur, qu'on avive au chiffon laineux, des anciennes flambées, celles qui projetaient sur les murs de grandes ombres, épaules et têtes. ${ }^{12}$

Selon Joseph Fahey, «l'important n'est pas ce qui est immédiatement visible - ici l'armoire - mais l'image qui y est enfouie et que seul un certain type de regard peut rendre sensible ${ }^{13} »$, ce regard, pourrions- nous ajouter, qu'est le regard de l'enfant.

La thématique du feu s'inscrit en creux dans le texte et les photos. Selon Joseph Fahey, c'est le silence respectif du texte et des photos qui donne lieu à une certaine expérience du monde qui fait prendre en compte la matérialité, le contact physique des choses :

Écrire revient à tenter de retrouver ce contact physique, d'éprouver le monde sur ce mode qui habituellement résiste à l'écriture. C'est finalement en conjonction avec la photographie que le texte réussit à établir ce contact. La photographie impose à l'écriture son silence, c'est à travers ce silence que les mots peuvent caresser les choses. ${ }^{14}$

\section{VI.5.c. $\quad$ Territoire - la surface plane fragmentée}

Les photos de Territoire sont regroupées par deux, à part la première ; elles représentent des paysages traversés par des clôtures, haies, saut-de-loup, fossés, qui dans un mouvement horizontal ou vertical tranchent la composition de l'image. Elles deviennent le symbole d'un territoire en décomposition, asséché, craquelé, sans vie. Le contraste de

\footnotetext{
${ }^{11}$ FAHEY, Joseph, «Le grain de l'expérience : le rôle de l'image photographique dans les œuvres de Jean-Loup Trassard », in L'écriture du bocage, p. 494.

12 TRASSARD, Jean-Loup, Archéologie des feux, sans pagination. Il s'agit ici d'une armoire de Trassard que son père a vendue, la remémoration de l'armoire avec ces traces du feu et l'ombre des personnes devient alors la remémoration du foyer, l'ombre de la mère. La lecture autobiographique de ce fragment permet de comprendre la «douceur» du polissage, et d'assimiler le regard sur les ombres au regard curieux, ébloui de l'enfant qui s'étonne, et découvre le jeu des ombres.

${ }^{13}$ FAHEY, Joseph, Op. cit., p. 495.

${ }^{14}$ FAHEY, Joseph, Op. cit., p. 496.
} 
la lumière crue rend encore plus aigu ce déchirement. Par ces compositions le paysage est mise à plat, il acquiert un niveau d'abstraction, se transforme en lignes, ce qui l'apparente à une carte géographique ou une page d'écriture.

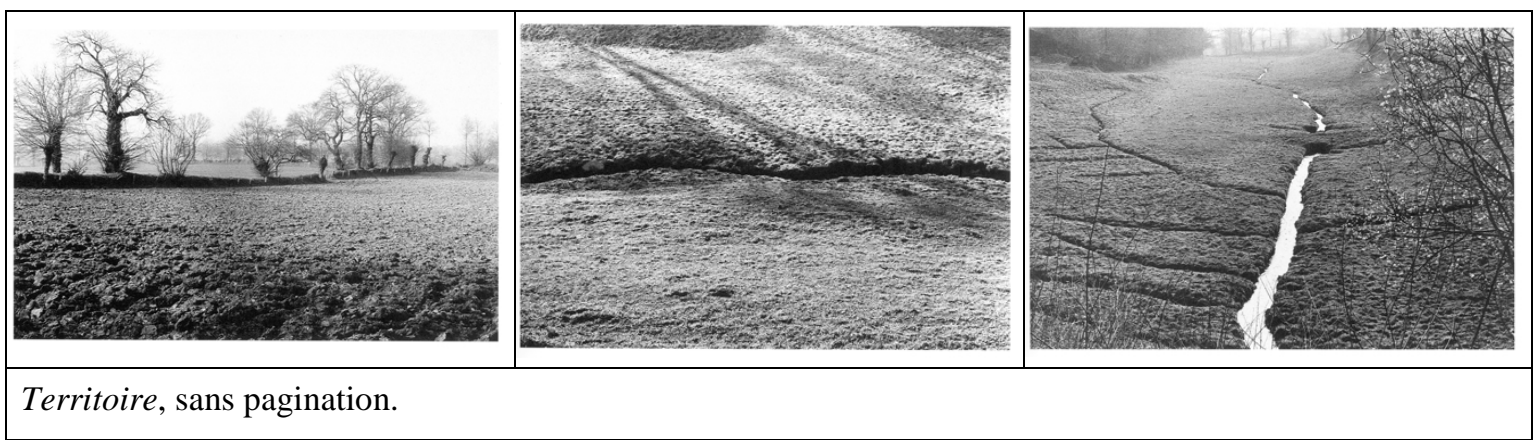

Les photos de Territoire font penser à la description d'une prise de vue d'un autre livre, Dormance, son roman néolithique d'inspiration autobiographique que nous avons déjà mentionné :

Devant cette vallée plus tard j'ai pris habitude de guetter par brume ou par neige ou l'été quand sont poussiéreux les sentiers que tracent les bestiaux qui ce déplacent et la poussière sent alors l'herbe sèche, la bouse: je n'ai jamais photographié là qu'un vide, mais entouré de lignes, de formes, clôtures ou arbres, sillon du ruisseau dans le fond. J'ai attendu, je suis revenu, j'ai cherché l'angle pour une meilleure visée. Par le regard j'ai appliqué mon corps sur la déclivité, au plus doux l'ai couché en longueur sur le creux, mais chaque pente conduit à la courbure et, du fond où le ruisseau suit son entaille sûre, l'œil incessamment s'émerveille des pentes, les remonte : [...]. $(D, 31$, Nous soulignons).

Dans Territoire, le texte semble de nouveau entretenir aucun lien apparent avec les clichés apposés, si ce n'est le style qui est commun. Si les photographies paraissent aplatir le paysage, qui devient de pures formes composées de lignes accentués, le texte donne la même impression en décrivant des lieux ou des objets immobiles, comme des natures mortes - un nœud de chanvre dans la broussaille, des piquets ou triques posés, une étable, un gnomon, etc. La description présente une image stylisée, comme si le paysage était une surface plane ou un dessin :

Formes et dimensions varient mais le plus souvent les étables sont logées dans un bâtiment, une partie de bâtiment, qui s'ouvre par une porte assez large et deux lucarnes, symétriques de chaque côté de la porte. Les lucarnes sont en demi cercle, petite voussure soulignée à l'extérieur de briques sur chant qui dessinent comme des cils au-dessus d'un d'œil. D'ailleurs, la position des lucarnes de part et d'autre de l'entrée, qui est évidemment plus basse, sorte de bouche, donne à cette façade d'étable un aspect stylisé de visage. ${ }^{15}$

Cette métaphore rassemblant différents éléments qui forment un visage apparaît déjà dans Tardifs instantanés comme le dispositif des écrits autobiographiques :

${ }^{15}$ TRASSARD, Jean-Loup, Territoire (Textes et photographies), Cognac, Le Temps qu'il fait, 1989. Sans pagination. Nous soulignons. 
«[...] les paysages assemblés esquissent peut-être un visage où se reconnaîtra le photographe : son autoportrait lacunaire » (TI, quatrième de couverture)

La description d'objets dans Territoire, notamment celle des quatre piquets adossés au mur, suscite l'imagination des gens qui les ont placé à cet endroit, et par le biais du texte, les photos montrant des paysages vides, des clôtures et des piquets, sont peuplées de traces de la présence absente de l'homme:

Ensuite les quatre hommes entrèrent à la maison tapant de leurs chaussures la terre et les crottes contre les marches, puis derrière la porte accrochèrent leur ciré s'ils tendaient une clôture, leur fourrure s'ils chassaient à l'épieu : ces quatre têtes de bois gris accotées contre la rouille ne disent pas en quel siècle s'est brièvement fait entendre le bruits des heurts. (Territoire, sans pagination.)

L'abstraction découle non seulement de l'anticipation à la prise de vue de l'image comme surface plane mais aussi du zoom avant, jusqu'au point où l'ensemble s'estompe et seuls les détails restent visibles sur la surface :

La peinture, brun presque orangé, s'est craquelée, le bois qu'elle couvre a vieilli sans bouger, sans autre fatigue qu'être battu par les pluies mouillé séché mouillé, années au long... (Territoire, sans pagination.)

La suite de photos qui montre la même clôture puise différents angles et distances, suit le même mouvement :

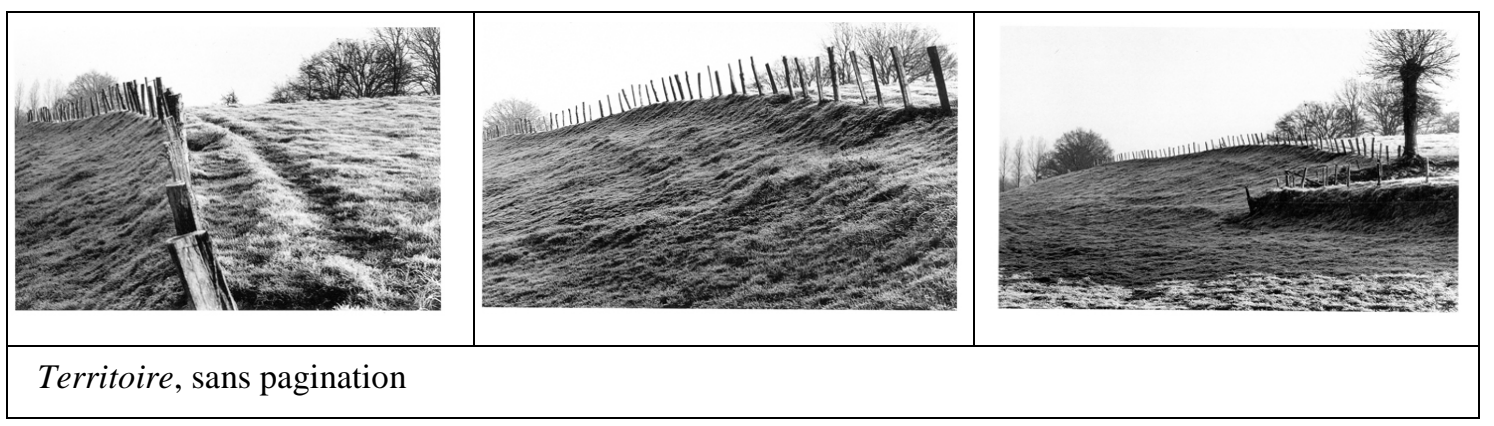

La particularité de la mise en page de Territoire, tient au fait qu'à chaque fois deux clichés se suivent sans texte intercalé. Il ne s'agit par pour autant de clichés mis par paire, comme ils ne sont pas mis l'un en face de l'autre. Mais ils permettent un arrêt plus long dans le texte, comme si ce dernier devenait fragmenté, tranché et décomposé à l'image du territoire. 


\section{VI.5.d. $\quad$ Ouailles - le récit en image}

Dans le livre Ouailles $^{16}$, les photos traitent du même sujet que le texte: la vie des bergers dans le Queyras (Hautes Alpes), la description d'un métier en voie de disparition, comme plusieurs métiers de la campagne que Trassard remémore dans ses autres textes (le sabotier, le taupier, etc...). Le sujet de la photographie et du texte est le même, mais le texte ne sert pas de légende ; il propose plutôt un autre parcours parallèle sur le même sujet. Le récit, même s'il n'a pas de visée autobiographique, marque son enracinement dans la vie de l'auteur. Le début raconte comment le narrateur-auteur vient retrouver un berger dans le Queyras, lieu où il retourne pendant plusieurs années sur une période de dix ans avec le projet d'écrire un livre. Il fait remonter sa prédilection pour ce thème à ses lectures d'enfance, à l'un de ses premiers livres « dans lequel une pâquerette qui avait nourri un agneau en lui offrant deux de ses feuilles entreprend de le retrouver »(Ouailles, 8), ainsi qu'à ses lectures d'adolescence :

[...] ce n'est que durant l'adolescence que je retrouvai les moutons: par des livres sur la transhumance qui soudain (soleil, poussière, plantes odorantes, mots accentués) fut avec le désert

l'un des ailleurs que j'opposai aux pluies de notre campagne. (Ouailles , 7)

Un pays de rêve, donc, inconnu, à découvrir, à explorer, où le narrateur revient régulièrement en été pour interroger plusieurs bergers, faire des recherches, suivre les troupeaux. La fonction de la photographie est différente dans ce projet, comme il ne s'agit pas ici d'un lieu «habité », mais d'un lieu «exploré ». Dans une première approche, nous pouvons constater que les photos fournissent le cadre du récit, un repère visuel, mais la suite d'images peut également se lire comme un récit indépendant du texte. Ce récit visuel nous fait parcourir le paysage des Hautes Alpes, suivre la transhumance des moutons, pour s'arrêter sur le portrait du berger avec son chien, le berger contemplant au loin les moutons qui sont hors cadre (ci-dessous). La dernière photo montre le berger de dos s'éloignant avec ses chiens. Une fin qu'on pourrait interpréter comme le symbole de la disparition du métier.

${ }^{16}$ TRASSARD, Jean-Loup, Ouailles (Textes et photographies), Cognac, Le Temps qu'il fait, 1991. Il faut remarquer cependant que le titre peut se lire de manière ironique, car au-delà de son premier sens d' «animal », le «brebis », « ouailles» est utilisé pour désigner les chrétiens que le curé («le bon berger ») doit garder. 


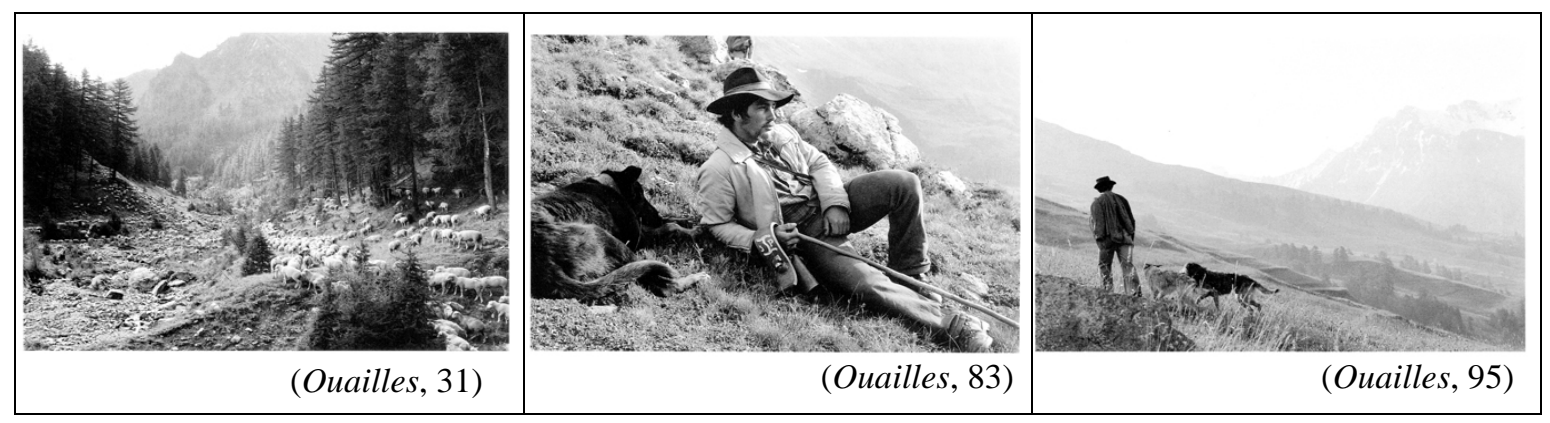

Les photos ne suivent pas l'ordre chronologique du texte et les thèmes évoqués, mais nous trouvons tout de même des correspondances entre le texte et les photos. Des correspondances qui ne sont pas forcément mises en évidence par la mise en page, le décalage provoquant un mouvement dans la lecture : on avance ou on revient alors en arrière pour revisiter l'image, mouvement qui renforce la prise en compte de la spatialité du livre.

La photo sert également comme base à la métaphore que développe le texte :

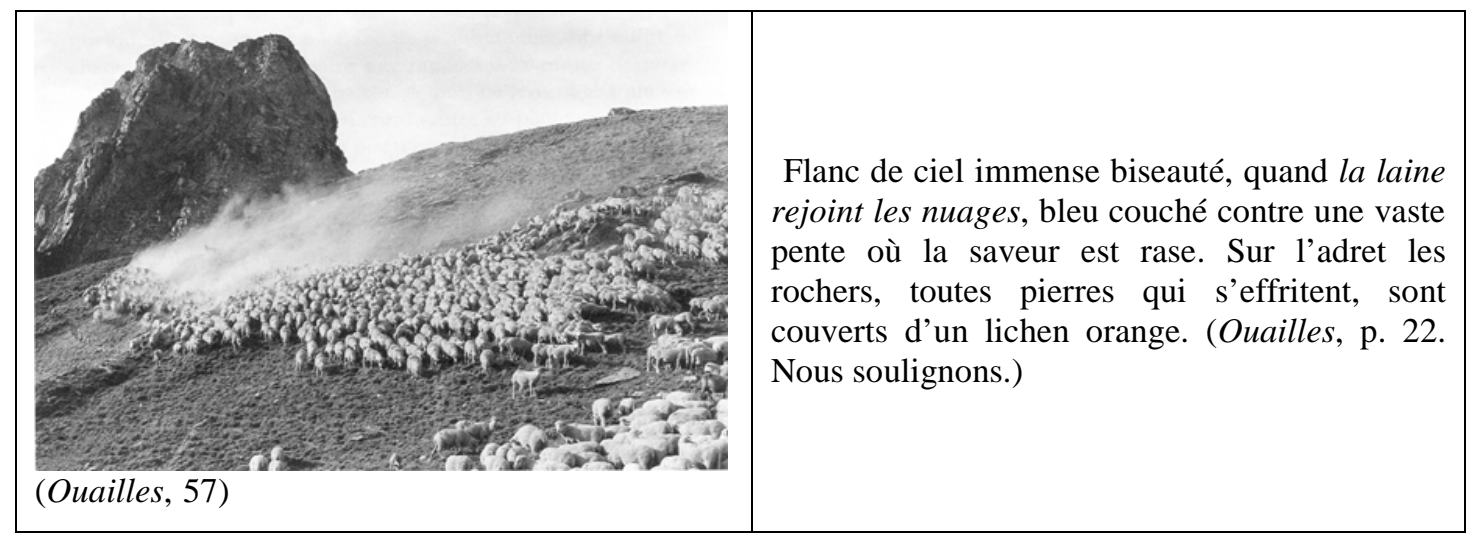

Ou encore :

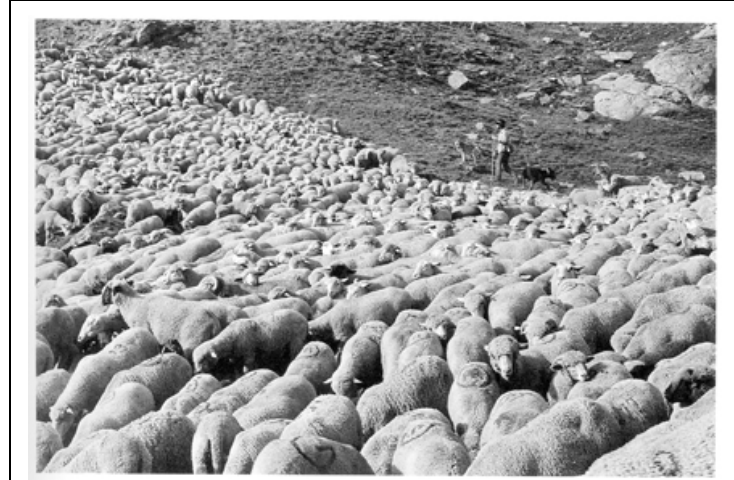

(Ouailles, 49)
Nous sommes, dans un flot de laine, entourés par les sonnailles qui chantent toutes à la fois selon marche, course, trottinements, l'oreille vibre... « la sonnaille rectangulaire est appelée platelle... celle-là c'est la canabre ou le cambis en provençal...», halètement du chien, souffles de vent, piétinement vers un reste de neige, chacune distincte dans leur concert le berger au milieu du troupeau mouvant me désigne toutes les sonnailles. Il dit: «je suis un passionné de cloches... »

(Ouailles, 47-48. Nous soulignons.)

La photo fonctionne également comme élément graphique qui structure le texte. La fin de la section marquée par la date «1980-81», est suivie de trois photos sans texte, et marque ainsi une pause de plus longue haleine dans le texte. Sur ces photos nous 
retrouvons une recherche graphique comme sur les photos de Territoire, avec des traits en diagonales qui se croisent.

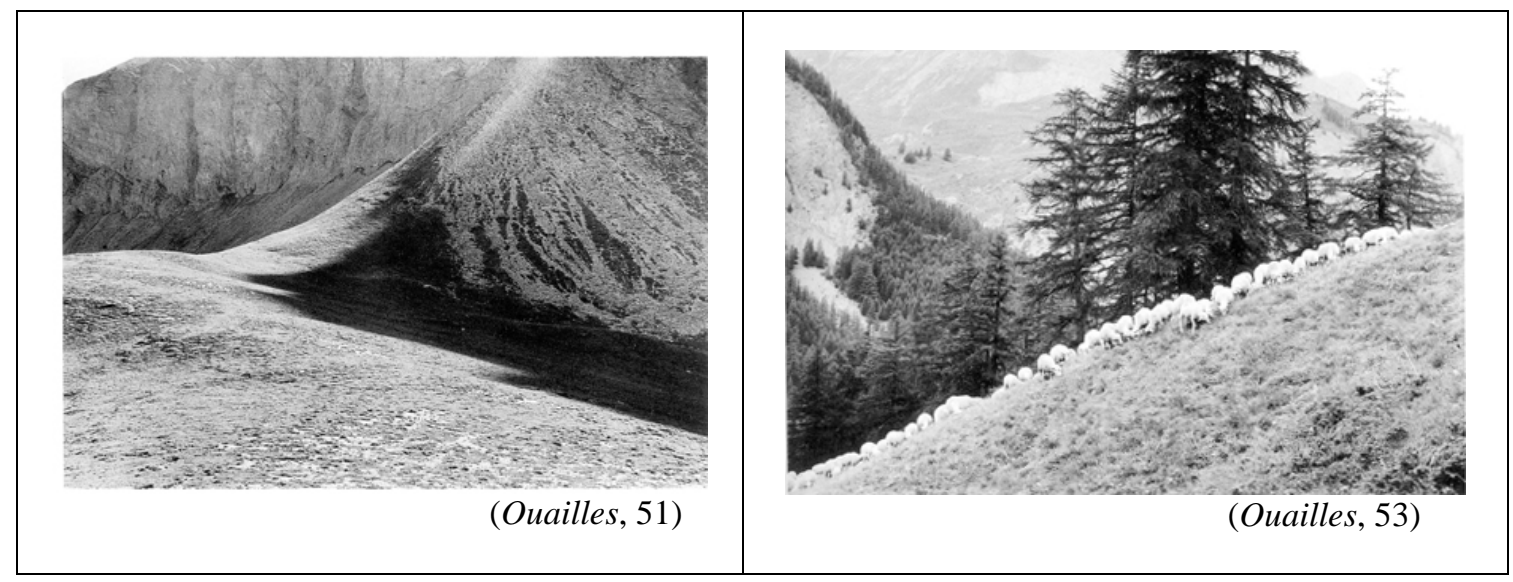

Non seulement il y a une correspondance graphique entre les photos de Ouailles et les photos de Territoire, mais le texte fait référence, par le biais du cours d'eau et la lumière reflétée sur l'eau, à des photos publiées dans d'autres livres :

Au bord, l'eau saute, petite cascade où se prend la lumière. Une eau très froide mais que la chaleur du corps à l'effort trouve fraîche. Jambes écartées, je la prends dans les deux mains - aux endroits accueillants du torrent, où l'on a envie de rester jouer - et me la jette sur les bras, les épaules, puis à la figure frottant puis sur le torse nu, devant, derrière, avec un rire pour l'eau dans le soleil, car la sensation est si vive à l'instant qu'on oublie tout, sauf un désir peut-être de faire partager cette eau glacée, cette lumière. Nous continuons à grimper la montagne par ses torrents escaliers agrémentés d'eau, spectacle, bruit, j'y relève et manipule un temps quelques pierres, un grand bâton aux fibres tournées, sèches, dures, tous ses nœuds érodés par la chute, le tranchant des cailloux, un bâton d'homme préhistorique.

(Ouailles, 81-82. Nous soulignons.)

La figure du berger symbolise en fin de compte un savoir-faire, une connaissance hors du commun. Il a une ouie exceptionnelle, sait distinguer les différents tintements des sonnailles, mais il a aussi la capacité de différencier visuellement chaque animal, dans un troupeau de plusieurs centaines de têtes. Il a «l'œil aux bêtes », selon l'expression du texte, c'est-à-dire qu'il est «capable de repérer chacune des brebis dans la masse moutonnante.»(Ouailles, 93). Le métier de berger s'apparente alors à celui du photographe qui doit avoir l'œil pour capter les images. 


\section{VI.5.e. $\quad$ Tumulus - le crépuscule des civilisations}

Le livre Tumulus ${ }^{17}$ est un livre à deux voix, où les photos ne sont pas de l'auteur, mais d'un autre photographe : Jean-Philippe Reverdot. Les photos ne sont pas pour autant des illustrations du texte mais, comme dans les autres livres de Trassard où il publie ses propres photos, l'image garde une certaine autonomie par rapport au texte.

Le titre Tumulus, amas de pierre élevé au-dessus d'une tombe, donne déjà le ton du livre. C'est de l'enterrement d'une civilisation rurale proche de la terre et des éléments naturels, de cette civilisation rurale dans ses diverses apparitions adaptées à des lieux géographiques et des conditions climatiques différentes qu'il va être question. Ainsi sont évoqués par chapitre des chasseurs de rennes de la taïga, la chasse à l'ours sur une île, le transport de sel à dos de chameaux, des esquimaux, la forêt tropicale, la steppe avec ses chasseurs à cheval, la chasse à dos d'éléphants. Le lieu géographique n'est pas précisé, tout comme l'époque reste floue, mais c'est le décor, les mots spécialisés qui fournissent la couleur locale, et permettent de deviner de quel lieu il s'agit : ainsi l'évocation des chameaux nous conduit dans le désert, les igloos chez les esquimaux. Chaque chapitre offre ainsi une brève image floue d'une civilisation mais se clôt également sur sa disparition et le vide qui subsiste :

Cependant la tourmente de neige effaçait les maisons en neige, éteignait la rougeâtre lueur aux fenêtres vitrées d'un boyau, bouchait au sommet le nez par où la fumée devait sortir, et silencieusement sous la neige, igloo après igloo, après baleines et après phoques, ils disparurent, comme l'huile lentement, sous la neige, ainsi que toujours ils l'avaient conté l'ours blanc se changeait en bouillard. (Tumulus, 22-23)

Les chapitres n'ont pas de titres mais ce sont les photos qui marquent la séparation entre les entités thématiques. Les photos, par leur univers sombre (les tons clairs sont presque absents), créent un effet de deuil mais aussi de surréel, comme s'il y avait une distance infranchissable. Ce sont des clichés de différents éléments naturels posés sur un tissu gris, sur un fond homogène qui évoque la stérilité d'une vitrine d'exposition. Les éléments isolés et déplacés de leur milieu d'origine deviennent inquiétants - l'univers minéral fait accroître cette angoisse. Ainsi trouvons-nous la photo d'une motte de terre ; de deux tiges d'une plante épineuse mises dans de l'eau ; d'un oiseau empaillé les pattes en l'air, dans la raideur et la position de sa dernière chute ; d'une pierre de cristal ; d'un

17 TRASSARD, Jean-Loup, Tumulus, avec les photographie de Jean-Philippe Reverdot, Cognac, Le Temps qu'il fait, 1996. 
poisson mort dans du formol ; de feuilles de ronce ; d'une tête humaine dans du formol ; de branches en vrac dans un bocal; et d'un bocal vide contenant seulement quelques gouttes d'eau visibles sur le verre. Certains liens se tissent entre le texte et l'image, mais des liens qui ne sont pas évidents : le cliché du cristal précède le chapitre sur les nomades qui transportaient le sel à travers le désert sur des chameaux, les ronces sont suivies par le texte sur la forêt tropicale, le poisson illustre le passage sur les esquimaux. Mais dans le plus souvent le lien reste énigmatique: s'agit-il de vestiges de la civilisation humaine?

La série fait penser aux photos du photographe hongrois Barta Zsolt Peter qui, dans une série intitulée «codeX», photographie des objets scientifiques (plantes, animaux, parties de corps humains) de la manière la plus objective possible, provoquant cependant de vives émotions chez le spectateur ${ }^{18}$.

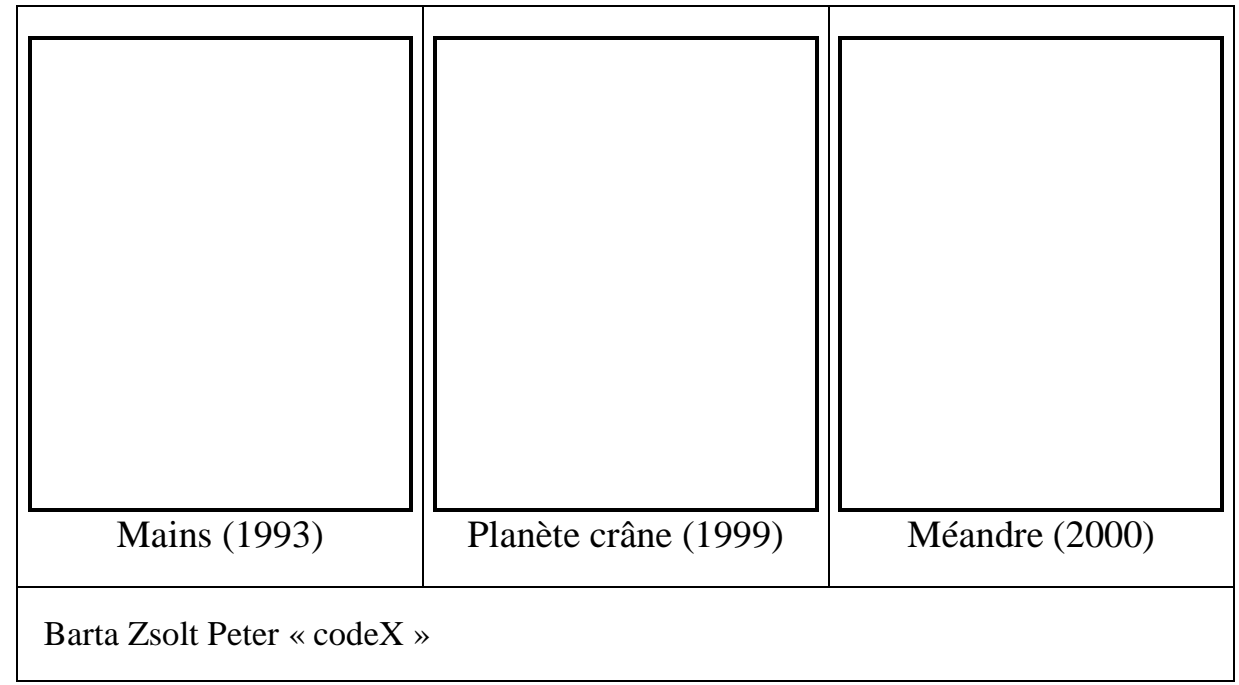

VI.5.f. $\quad$ Nuisibles - le labyrinthe de la pensée

Le texte de Nuisibles n'est pas fragmentaire, mais constitue un récit continu: le narrateur raconte le déroulement de la capture d'animaux nuisibles. La chasse se fait sous terre à l'aide de chiens et d'une sonde, d'un tube enfoncé. De quels animaux s'agit-

${ }^{18}$ BARTA, Zsolt Péter, codeX, Budapest, Datanet Távközlési Kft., 1999.

Les photos proviennent du site : http://www.digibodies.org/barta.html (consulté le : 21/07/2008). 
il, le texte ne le dit pas, mais Pierre Campion y voit des blaireaux ${ }^{19}$. Selon Campion, la chasse, à laquelle participent des hommes issus de différentes classes sociales, évoque toute la société agraire hiérarchisée :

Dans cette brève expédition se réalise tout un mode de la vie ancienne (dont les photos de leur côté décrivent le milieu) : une terre mouillée d'eaux, une société agraire hiérarchisée, plusieurs langues superposées, une haine violente à l'égard des espèces concurrentes, et le goût invétéré de la chasse comme une guerre. ${ }^{20}$

La particularité de la description est d'essayer d'imaginer les sentiments des animaux pourchassés, de montrer leur point de vue :

À l'intérieur ils ont compris, sans voir les hommes armés sur la pente du taillis, rien que par l'ouïe et mieux encore par l'odorat ou plus précisément par intuition peut-être venue d'une crainte qui se perd dans la nuit de leur sang, que les autres ont envie de les tuer. Simplement ils ne savent pas pourquoi, les manger sans doute, non, ils ignorent qu'il s'agit d'éliminer ceux qui vivent sous terre. $^{21}$

Deux univers s'opposent, celui des humains, à l'extérieur, au-dessus la terre, qui sans le voir cherchent à imaginer ce qui se passe sous terre, et le monde enfoui des animaux nuisibles, au-dessous, qui à leur tour, selon le texte, tentent de comprendre ce qui se passe à l'extérieur afin de trouver une issue pour fuir.

Le garde avec sa sonde tâche de suivre le chien sous la terre, comme le texte tente de cerner les pensées, les émotions, les sentiments des habitants assiégés : «Constant voit par l'oreille, et nous, les six debout, comme recueillis, trois appuyés à leur outil, on essaie de voir ce que l'écouteur raconte» (Nuisibles, 33. Nous soulignons).

Les spécificités de cette chasse aveugle fait penser au fonctionnement du texte littéraire qui fait voir, suscite des vues imageantes, des images mentales sans montrer, et qui puise dans une mémoire (collective ?) qui n'est pas celle du lecteur :

Entendent-ils un chuchotement, le froissement de tissu que font les gestes ! Pas sûr. Plutôt le nez qui renseigne, encore est-il nécessaire de fouiller une mémoire qui n'est même pas la leur. (Nuisibles, 10. Nous soulignons.)

Tout au long du récit, on éprouve une sorte de compassion pour ces animaux qui peuplent le même paysage, les mêmes espaces intimes qui sont évoqués dans d'autres

19 CAMPION, Pierre, Des blaireaux et des hommes, compte rendu du livre Nuisibles (Textes et photographies de Jean-Loup Trassard, Cognac, Le Temps qu'il fait, 2005). http://pierre.campion2.free.fr/trassard_nuisibles.htm (consulté le : 07/07/2008).

${ }^{20}$ Ibid.

${ }^{21}$ TRASSARD, Jean-Loup, Nuisibles (Textes et photographies), Cognac, Le Temps qu'il fait, 2005, p. 30. Nous soulignons. 
livres de Trassard : «Pour explorer les champs, ils ont leurs sentiers, ou le creux des ornières » (Nuisibles, 13).

La cohérence et la linéarité du récit se trouvent pourtant brisées par l'insertion des photos qui ne font pas référence au récit, et ne forment pas non plus de récit visuel cohérent comme dans Ouailles. L'interprétation de ces images semble de nouveau problématique. S'agit-il seulement, comme le suggère Pierre Campion, du décor de la vie campagnarde? Plusieurs photos montrent un espace clos qui conduit à une issue : lit souterrain d'un cours d'eau, chemins en creux entourés d'arbres, qui font penser au terrier des animaux nuisibles.

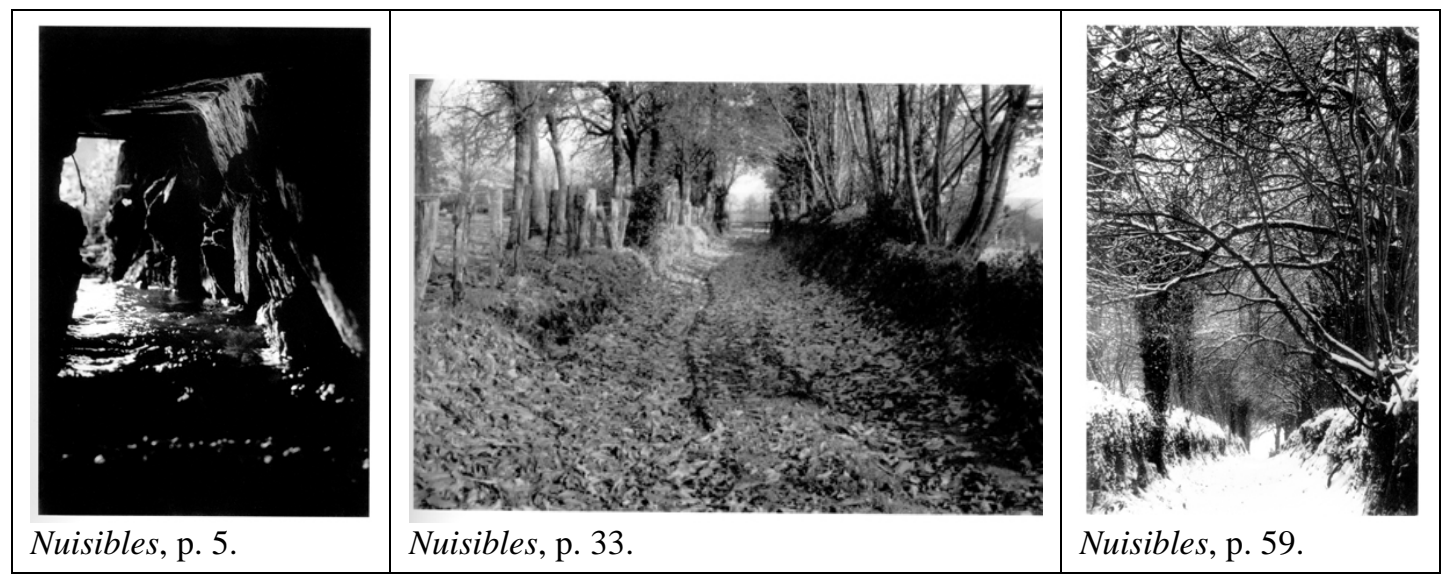

D'autres photos montrent, à l'inverse, des barrières qui empêchent le passage. Sur deux autres clichés, des véhicules abandonnés, un chariot et un tracteur, envahis par les herbes et le lierre, oubliés sur un coin de la route, attestent du temps qui passe, tout comme les clichés de bâtiments délaissés. Nous trouvons également à deux reprises la photo d'un arbre creux, lieu propice au développement du rêve et de l'imaginaire dans Dormance, mais qui peut également héberger un animal, ou une sortie du terrier. Ces images (creux, passage, arrêt, retour, débouché ou cul-de-sac, avec des outils et des bâtiments abandonnés) symbolisent-elles les galeries enfouies et souterraines, les couloirs de la pensée et des souvenirs ?

La photo en petit format de la page du titre (ci-dessous au milieu), qui représente une cage de face, fait ainsi référence au texte de la fin du livre qui mentionne ce qu'il advient des bêtes attrapées : quand le trou est creusé, on tire sur les bêtes, ou bien on les prend par une pince, on les assomme, ou les garde comme jeu pour les chiens plus tard. L'image du début préfigure la fin du texte, tandis que la fin rappelle début, la photo en petit format de l'achevé d'imprimer représentant le lit d'un ruisseau qui traverse le champ (ci-dessous à droite) et faisant écho au cliché de la couverture (un cour d'eau 
asséché, ci-dessous à gauche). Ce décalage provoque un effet de boucle et renforce l'idée d'une construction labyrinthique.

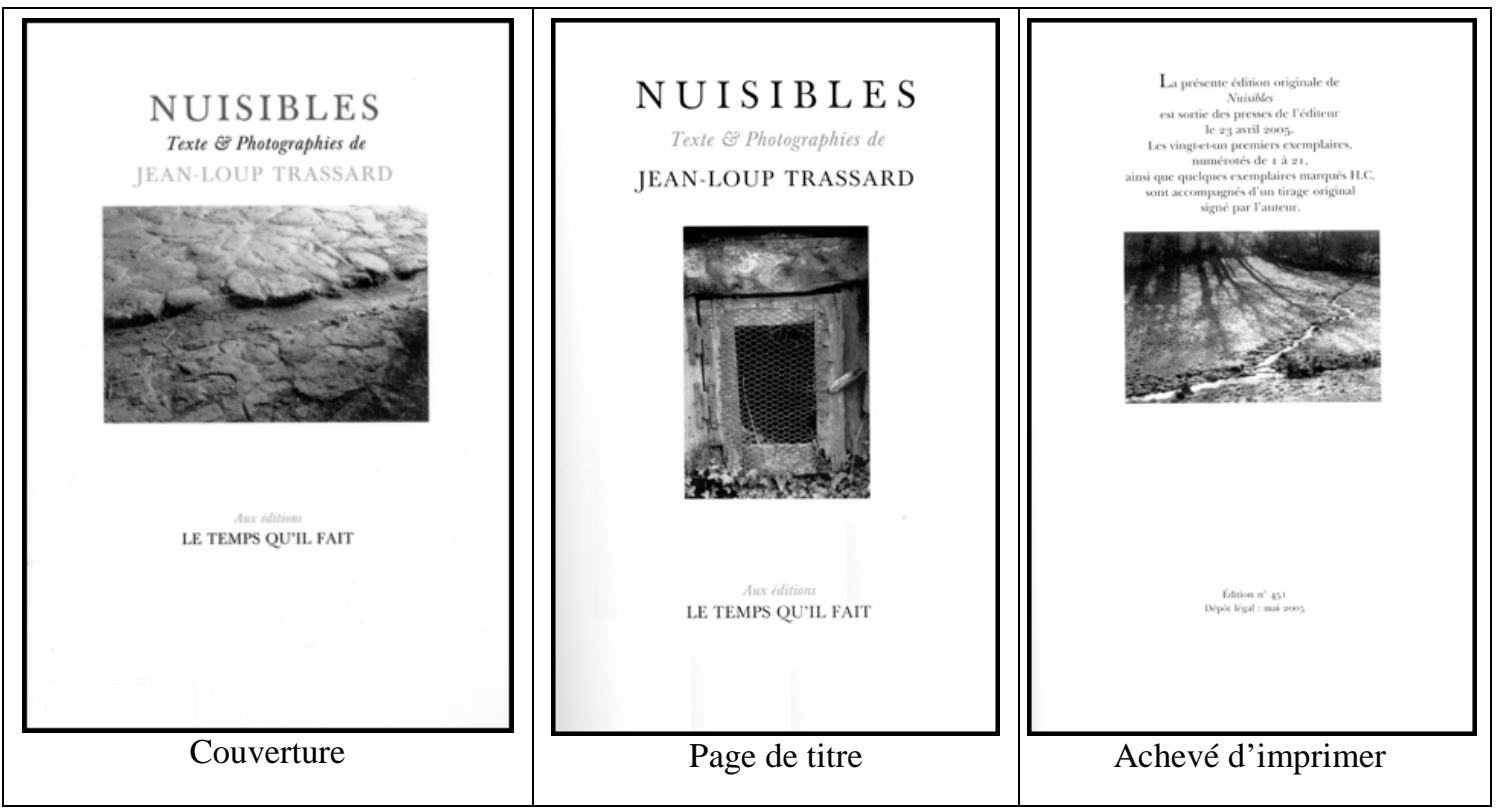

Le récit de la capture se termine par l'évocation de la photo non réalisée : «La photo ne sera pas pour ce soir. Le jour tellement bas, la brume est arrivée de bonne heure » (Nuisibles, 58). Doit-on y voir une volonté de laisser l'imaginaire du lecteur peupler par ses propres images le labyrinthe des pensées provoquées par le texte ? La photo qui clôt le récit (à droite sur la page précédente) : un chemin sous la neige immaculée, véhicule une sensation d'apaisement et d'éternité, mais aussi de mélancolie et de mort.

VI.5.g. La Composition du jardin - la sonate visuelle

La Composition du jardin ${ }^{22}$ repose sur la dialectique du dehors (le jardin) que décrit le texte et du dedans (le château) que montrent les photos, comme Nuisibles faisait jouer la narration à l'extérieur et à l'intérieur du terroir. Dans La Composition du jardin, le narrateur, un jardinier, raconte le projet d'aménagement d'un jardin, un tertre que le comte Bichain de Montigny vient d'acquérir entre la Bretagne et la Normandie, au sud d'Ernée. Pierre Campion, d'après le nom de l'architecte du château mentionné, Jean Baptiste Ceineray (personnage historique), situe la narration à la deuxième moitié du

\footnotetext{
${ }^{22}$ TRASSARD, Jean-Loup, La Composition du jardin (Textes et photographies), Cognac, Le Temps qu'il fait, 2003. Par la suite nous utiliserons l'abréviation : CJ.
} 
$\mathrm{XVIII}^{\mathrm{e}}$ siècle $^{23}$. Le jardinier raconte le projet d'aménagement au futur, puis au milieu du livre, passe à un récit au passé : «Aussi, à partir de cet instant, raconterai-je au passé ce que je mis en œuvre et réalisai, plutôt qu'au futur, comme je viens de le faire, ce que j'avais pour idée » $(C J, 26)$. Selon Campion, on assiste constamment au déplacement de la description, et c'est par ce détour que le sens des photos du château se révèle :

D'abord, décrire c'est comprendre.

À la vue, ce château propose une énigme, que l'écrivain résoudra en déplaçant plusieurs fois son énoncé. Du château on passe à son jardin, du jardin à la pensée qui l'informe encore, de cette pensée à celui qui la forma et dans le temps où il la forma, et cette pensée elle-même on l'atteindra par le texte supposé que l'auteur du jardin en écrivit. C'est une espèce d'archéologie, conduite dans la conviction que la compréhension de ce qui est ne saurait passer par la description et l'explication directes. ${ }^{24}$

Dans ce jeu de déplacement, la vue occupe une place importante, le plan et les illusions que crée l'espace deviennent un modèle pour l'écriture. La description des plans énumère les mesures en centimètres pour montrer l'harmonie des proportions et révéler les choix volontaires de la composition. «C'est dans ce rôle caché des plans, ou des mesures, que j'ai toujours puisé le plus de contentement » $(C J, 34)$ - avoue le jardinier. Il détaille la recherche d'un effet de grandeur produit par les trompe-l'œil que crée la disposition du jardin sur la pente du terrain.

[...] ; au-delà de quoi il y a encore un massif de chaque côté mais ceux-là sont moins longs, ce n'est pas important, l'œil ne les mesure pas, alors que la longueur des premiers agrandit nettement le jardin par l'impression tout de suite offerte au regard qui descend les marches ; $[\ldots](C J, 45)$.

Nous retrouvons la préoccupation de Trassard de «taquiner le sens de l'espace chez le spectateur ${ }^{25} »$ par ses photos (essentiellement ceux du Voyageur à l'échelle).

Même si le texte parle de trompe-l'œil, les photos insérées dans le livre n'exploitent pas les effets de la perspective. Il s'agit de vues d'intérieur, des coins de la maison. Sur certains clichés, le jardin apparaît néanmoins, mais seulement à travers les vitres ou les reflets de miroirs.

${ }^{23}$ CAMPION, Pierre, Composition à la française, compte rendu du livre La Composition du jardin (Texte et photographies de Jean-Loup Trassard, aux éditions Le Temps qu'il fait, 2003) http://pierre.campion2.free.fr/trassard2.htm (consulté le : 22/07/2008)

${ }^{24}$ Ibid.

25 «Entretien avec Arlette Bouloumié », Op. cit., p. 597. 
Jean Arrouye, en analysant un cliché pris de l'extérieur, du jardin, mais montrant l'intérieur du bâtiment (ci-contre), explique comment l'image, faisant allusions à des œuvres de peintres flamands, fonctionne comme « invitation à outrepasser les données du visible ${ }^{26} »$.

Son sujet ultime est la traversée des apparences, et l'instauration d'un espace de rêverie heureuse. Dans cette photographie imaginative la perception du réel s'enrichit du souvenir de ses représentations antérieures pour en proposer une image transfigurée. $^{27}$

L'insertion des clichés dans le livre, de photos qui sont nécessairement postérieures au temps de la narration, met en

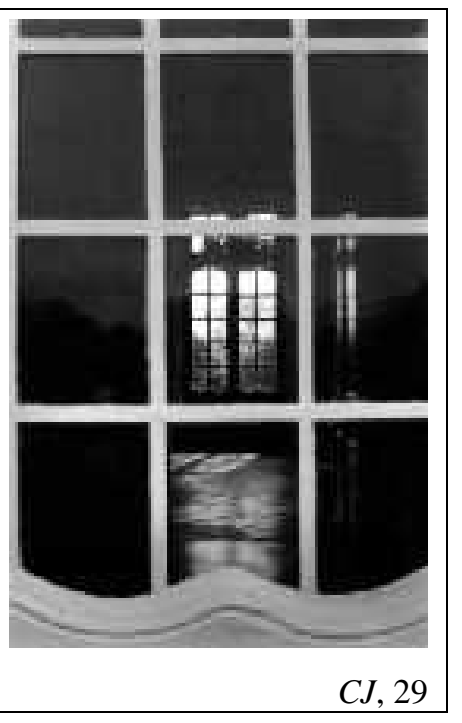
doute la valeur de vérité du texte. Ce que le lecteur non averti ne perçoit pas, c'est qu'il s'agit de la description du propre jardin de l'auteur ${ }^{28}$, et des vues de sa propre maison, où Trassard cherche à retracer les particularités, les secrets enfouis de l'espace intime qui figure dans la majorité de ses autres livres.

Le jeu intérieur/extérieur marqué visuellement par le texte et la photo apparaît non seulement dans les livres hybrides photo-littéraire, mais aussi dans plusieurs récits présentant une alternance typographique, comme dans «Les dehors et les dedans d'une forêt »(Ancolie), ou «Hors des lies»(Paroles de laines). Dans «Les dehors et les dedans d'une forêt » les pages recto sont imprimées en caractères droits tandis que le verso est en italique. Dans «Hors des lies » se succèdent deux sortes de paragraphe, un grand et un petit.

Les paragraphes s'enchaînent topographiquement; quand la ligne s'arrête, je ne mets pas de ponctuation et le paragraphe suivant, différent dans son objet, commence exactement en face, sans majuscule, de façon à créer visuellement une possibilité plus rapide pour le lecteur de passer de l'un à l'autre. C'est la volonté à la fois de partager les sujets et de les rapprocher. C'est l'essai très modeste de jouer une sonate [...] Il y a donc alternance de deux voix ou deux voies comme on veut l'écrire. ${ }^{29}$

La photographie et le texte dans La Composition du jardin fonctionnent également sur ce schéma, une sonate visuelle où le rythme ternaire est assuré par les déplacements temporels successifs du récit.

\footnotetext{
26 ARROUYE, Jean, Intérieur de manoir, http://mucri-photographie.univ-paris1.fr/article.php?id=20 (consulté le : 21/07/2008).

${ }^{27}$ Ibid.

${ }^{28}$ Voir le questionnaire adressé à l'auteur à la page 294.

29 «Entretien avec Arlette Bouloumié », Op. cit., p. 590.
} 


\section{VI.5.h. Sanzaki - la ronde des saisons}

Dans $S a n z a k i^{30}$, la relation entre le texte et les photographies tourne cette fois-ci autour du temps. Le récit narre les aventures de Léandre, un fermier qui s'est spécialisé dans la contrebande d'alcool de cidre distillé dans les fermes et qui est poursuivi par la police. Le titre, qui par la graphie, évoque, selon Pierre Campion, l'atmosphère des mangas japonais $^{31}$, est en réalité un jeu de mot sur le nom «sans acquit » que donne la police au protagoniste tant qu'ils ne savent pas l'identifier. Le livre s'organise en très courts chapitres de deux à quatre pages maximum, des séquences dont les titres courts et simples mentionnant des lieux ou des objets font penser au livre Objets de grande utilité. Nous retrouvons même les topos trassardiens dans les titres : «Ferme», «Chemin », «Grenier», «Étable», intercalé au milieu d'autres qui évoque la narration: Voiture, Alambic, Bistrot, Garage, Herse, Vélo, Volante, Gendarmerie, Machine à écrire, Fumier, Journal, Herse, Tôle, Draps.

L'histoire fait alterner le récit du fraudeur et celui de la police. Fidèle au topos trassardien, la police poursuivent les traces du premier. Selon le site de l'éditeur «Le Temps qu'il fait », il s'agit d'un «synopsis décrivant les scènes principales d'un projet de film conçu comme policier rural ${ }^{32} »$, ce qui rejoindrait l'aveu de Trassard dans l'entretien avec Arlette Bouloumié d'avoir toujours voulu faire des films ${ }^{33}$. Le dispositif filmique est surtout présent dans les changements de point de vue à l'intérieur du récit. Ces changements indiqués par le narrateur s'apparentent à des indications scénographiques, mais en même temps prennent place dans le corps du texte.

Outre le point de vue qui change de chapitre en chapitre, le récit est souvent elliptique, nous trouvons par exemple une brusque coupure dans la scène de poursuite de la voiture trafiquée de Léandre. Le récit décrit d'abord les sentiments et les pensées de Léandre qui se sait poursuivi, puis le narrateur précise : « Nous ne sommes plus avec Léandre mais dans la voiture des poursuivants » $(S, 49)$. On retrouve la même stratégie dans la scène finale quand les gendarmes viennent le chercher à la ferme ; ils l'attendent

\footnotetext{
30 TRASSARD, Jean-Loup, Sanzaki (Textes et photographies), Cognac, Le Temps qu'il fait, 2008. Par la suite nous utiliserons l'abréviation : $S$.

${ }^{31}$ CAMPION, Pierre, Délicates images, compte rendu du livre Sanzaki (Textes et photographies de JeanLoup Trassard, Cognac, Le Temps qu'il fait, 2008) : http://pierre.campion2.free.fr/trassard_sanzaki.htm (consulté le : 2009/04/05).

${ }^{32} \mathrm{http}: / /$ www.letempsquilfait.com/Pages/Parutions/novembre/Sanzaki.html (consulté le : 2009/04/05).

33 «Entretien avec Arlette Bouloumié », Op. cit., p. 598.
} 
caché tandis qu'il approche du côté de la prairie, mais le narrateur omniprésent intervient :

Par un habile retournement de perspective (facile quand il s'agit de faire revivre au moyen de l'écriture et nécessaire à vrai dire, parce qu'il est rare qu'une histoire n'ait pas deux faces), nous voilà aux côtés de Léandre. $(S, 78)$

D'autres procédés peuvent être encore considérés comme filmique, tels les plans fixes à la fin de chaque chapitre, ou le travelling par lequel débute le livre :

Dans la campagne cloisonnée par des haies, leurs branchages d'automne, nous traversons doucement une prairie. Il faudra franchir un ruisseau - on l'entend couler fort - ensuite longer une haie, enjamber comme en volant une grosse barrière en bois et, vers la droite, suivre un chemin d'abord en creux qui monte. $(S, 7)$

Mais il ne faut pas en croire que nous sommes dans un simple scénario. Ce côté filmique est là entre autres pour attiser la sensibilité du lecteur. Ce dernier est constamment interpellé par le narrateur dont les préoccupations rejoignent celui de Trassard dans ses autres livres. Il questionne avant tout la réalité et la possibilité d'en rendre compte par la description ou par les images, comme le note d'ailleurs Pierre Campion dans son compte rendu ${ }^{34}$. Le narrateur insiste sur les difficultés à retranscrire la scène :

Une odeur est sans doute le plus difficile à transmettre. Le bruit s'écrit, un chien aboie, tout lecteur l'entend à peu près, on peut aussi l'enregistrer, faire écouter. Sur les couleurs aussi nous sommes accordés, ou presque. Mais une odeur, forte ou subtile, passe au travers des mots qui n'en ramène guère. Quant à l'image, il ne faut pas espérer qu'elle capte quoi que ce soit de propre à faire sentir. Pourtant, ce qui alerte quand on entre dans la cour de ferme ce jour là c'est l'odeur, d'une façon irrépressible elle dénonce l'activité. Pas un bon jour pour visiter, les fermiers préfèrent être tranquilles pendant que ça se passe. Mettons que nous avons obtenu leur autorisation, il est donc permis d'observer, de décrire. Mais pas l'odeur ! $(S, 21)$

Les sept photographies qui accompagnent et rythment le récit tout au long du texte ne révèlent rien de l'intrigue. Elles montrent des pommiers, sans feuilles, dans la brume, ou au contraire tout fleuris, ou avec les pommes déjà tombées par terre, ou récoltées dans une bâche en plastique, puis entassé dans un coin de la ferme. Seule la dernière photo, qui figure en taille réduite sur la page de l'achevé d'imprimé, contient la présence humaine, les mains d'une personne ramassant les pommes dans un panier. La mise en série des images évoque le cycle des saisons, elle raconte le lent mûrissement des pommes jusqu'à la récolte, et précède précisément le récit évoqué par le texte: la

34 CAMPION, Pierre, Délicates images, Op. cit. : http://pierre.campion2.free.fr/trassard_sanzaki.htm (consulté le : 2009/04/05). 
distillation du cidre, les préparatifs du commerce clandestin, la nuit de la transaction, la poursuite des gendarmes, la fuite de Léandre.

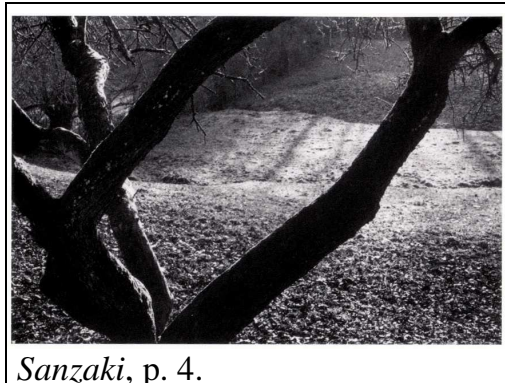

Sanzaki, p. 4.

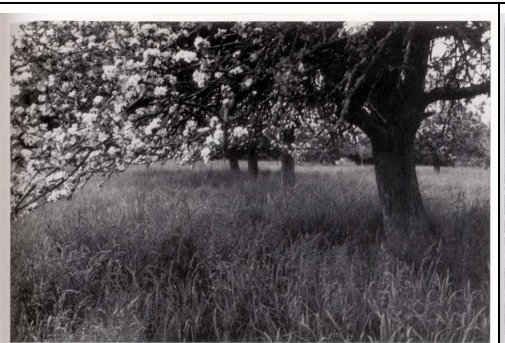

Sanzaki, p. 23.

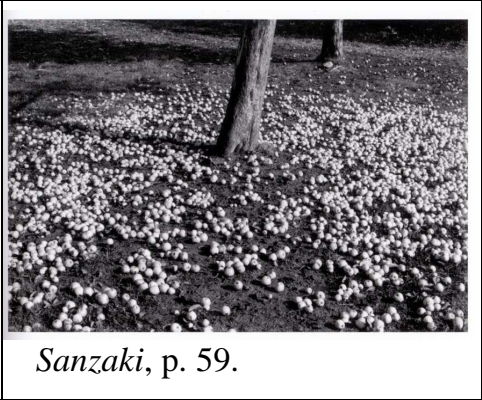

Seul le premier cliché du livre (ci-dessus à gauche) coïncide avec le temps de la narration qui se passe en automne, ce que les feuilles tombées par terre suggèrent. On pourrait l'identifier comme le point de vue de Léandre, qui à la fin de l'histoire par un jour brumeux s'approche à travers les champs, puis aperçoit les draps, signe de danger convenu avec sa femme, et se retire à travers les bois. C'est également le seul cliché qui est imprimé au verso, comme s'il faisait partie de la narration, tandis que les autres se trouvent au recto, précédé parfois d'une page vierge au verso, pour accentuer la rupture entre les chapitres. Le récit que forme les images précède celui du texte (elles en sont le prétexte), cependant le fait d'avoir inséré les images éparpillées dans le corps du texte bouleverse cette chronologie. Les photos par leur ton noir et blanc s'accordent bien avec les années 1960, temps de la narration, et pourtant elles doivent être récentes, faites pour le livre. Passé et présent se rejoignent de toutes parts renforçant ce temps cyclique qui domine l'histoire racontée par les images.

\section{VI.5.i. $\quad$ Les livres illustrés par des dessins}

Bien que moins connu pour ses livres illustrés, Jean-Loup Trassard est également l'auteur d'un livre pour adultes, Ligature ${ }^{35}$, illustré par les estampes de Daniel Nadaud, ainsi que de huit livres destinés au jeune public écrits en collaboration avec différents dessinateurs.

C'est aussi pour mes enfants, quand ils étaient petits, que j'ai voulu inventer quelques histoires, puis les écrire. Après j'ai pu les faire éditer, en regrettant de ne pas savoir dessiner pour les illustrer, car dans les plus anciens de mes livres, les dessins que j'ai si souvent regardé avec minutie parlaient autant, sinon plus, que le texte, et leur climat me reste présent encore

\footnotetext{
${ }^{35}$ TRASSARD, Jean-Loup, Ligature, (illustré par Daniel Nadaud) Plancoët, Hôtel continental, 1990.
} 
aujourd'hui. Je crois vraiment que ce sont ces livres-là, depuis les premiers, qui m'ont lancé vers la littérature. ${ }^{36}$

L'intérêt de ces livres pour enfants est qu'ils traitent les mêmes sujets que ceux des livres «ethnopoétiques »: l'homme préhistorique dans Les Graines d'homme ${ }^{37}$; le cours du ruisseau et sa fonction dans Histoires fraîches ${ }^{38}$; la fonction des fermes, les problèmes agricoles, le paysage (le cadastre, les chemins, les prairies, les champs, les haies) dans Une classe de nature ${ }^{39}$; et le temps (les glaciers, les monuments historiques) dans Une classe de neige ${ }^{40}$. La volonté pédagogique de transmettre un savoir lié à la nature transparaît dans ces deux derniers qui racontent les aventures d'une classe parisienne qui va à la campagne au printemps et en hiver. Dans Une classe de nature nous retrouvons une structure polyphonique, donnant la parole à plusieurs voix et marquée typographiquement par l'écriture en italique : un narrateur omniscient dont l'identité reste cachée laisse la parole dans chaque chapitre à un enfant qui raconte ses souvenirs à ses parents sous forme de lettre.

Le rôle que peut remplir l'illustration dépend largement du dessinateur, cependant celui-ci est le plus souvent imposé par l'éditeur. Le mode énigmatique sur lequel fonctionnent la plupart des rapports texte-image chez Trassard n'est pas du tout utilisé dans ses livres illustrés. D'ailleurs, Trassard n'a repris qu'un seul dessinateur, Bernard Jeunet, pour collaborer à un deuxième livre ${ }^{41}$. Les images de Bernard Jeunet illustrent très fidèlement le texte, dont la fonction pédagogique peut alors passer également par l'image. Nous trouvons ainsi les dessins des oiseaux ou des plantes évoqués par le texte dans Une classe de nature. Les dessins au crayon créent un visuel fin avec des tons fondus et des contours doux, une idylle de la campagne propice à la rêverie.

Selon un passage d'Espace antérieur déjà cité, l'image, dans les livres pour enfants, acquiert un rôle affectif. Le dessin doit venir à l'appui du texte, pour faire aimer le texte, ce que Trassard reproche dans ses souvenirs à sa première lecture :

\footnotetext{
${ }^{36}$ «Entretien avec Arlette Bouloumié », Op. cit., p. 575. Nous soulignons.

${ }^{37}$ TRASSARD, Jean-Loup, Les Graines d'homme, (illustré par Florence Euvremer) Paris, Flammarion, 1971.

${ }^{38}$ TRASSARD, Jean-Loup, Histoires fraîches, (illustré par Patrice Roy), Paris, l'École des loisirs, 1981.

${ }^{39}$ TRASSARD, Jean-Loup, Une Classe de nature ou Comment repiquer les petits citadins en pleine terre, (illustré par Bernard Jeunet), Paris, l'École des loisirs, 1984.

${ }^{40}$ TRASSARD, Jean-Loup, Une Classe de neige, (illustré par Lise Cœur) Paris, l'École des loisirs, 1982.

${ }^{41}$ Il s'agit de Classe de nature déjà cité et de Bleue bergère (Paris, l’École des loisirs, 1985).
} 
Je venais de commencer à apprendre à lire avec ma mère, dans ce premier livre (« la lecture sans larmes ») les personnages s'appelaient toto lili rené, ils avaient de grosses têtes rondes avec une frange, je les trouvais antipathiques. Comme je n'étais pas très appliqué, me fâchais de ne rien y comprendre et $[\mathrm{je}]$ voulais toujours fuir au jardin $[\ldots]^{42}$

Les livres pour enfants de Trassard sont plus proches de ses phautofictions, Les derniers paysans ou Voyageur à l'échelle, car les images suivent le texte plus à la lettre que dans ses livres « ethnopoétiques ».

À la fin de ce parcours des livres hybrides photo-littéraires se dégage une multitude de rapports possibles entre textes et photographies, articulant de diverses manières le visible et l'invisible, le dehors et le dedans, le temps et l'espace. Le choix de la pellicule noir et blanc donne une touche ancienne à la photo et crée un décalage temporel entre le temps suggéré par les images et celui évoqué par les récits. Le ton monochrome renforce également l'ambiance de deuil qui pèse sur le déclin des fermes, tandis que l'utilisation de la photographie en couleur dans Les derniers paysans et la série Juste absente revêt un côté rêveur, de gaîté et de joie par le retour à l'univers de l'enfance.

La disposition en apparence similaire des photos varie en fonction des livres selon une construction subtile qui comprend en soi la reprise ou non de la photo en couverture, l'insertion d'images en petit format sur la page du titre et l'achevé d'imprimer, l'utilisation de l'image dans la structuration du récit pour créer des pauses, des arrêts de différentes longueurs. Les photos fonctionnent alors comme des éléments graphiques abstraits qui déplacent le sens du texte pour créer une esthétique de l'entredeux. Mais les photos peuvent également former un récit indépendant du texte.

Pourtant le choix des photos à publier est fait par l'éditeur, ainsi que la mise en page et la disposition des images. L'auteur fait une proposition et l'éditeur fait son choix «dans un accord très agréable ${ }^{43}$ ». Mais l'importance de l'éditeur dans l'aspect final du livre peut bouleverser notre analyse. Les correspondances entre le texte et l'image sont-elles vraiment dues à l'intention de l'auteur ou les parallèles tissés entre texte et photos sont-ils le fruit d'une lecture personnelle?

\footnotetext{
${ }^{42}$ TRASSARD, Jean-Loup, L'espace antérieur, Op. cit., p. 11.
}

${ }^{43}$ «Entretien avec Arlette Bouloumié », Op. cit., p. 600. 


\section{VI.6. La transparence de la photographie}

La résurgence des thèmes dans les divers livres de Trassard (récits, romans, livres hybrides photo-littéraires, livres pour enfants) montre que son écriture est essentiellement topique. La plupart des topoï trassardiens (le chemin, l'outil, la trace, le creux) sont également liés indirectement à la photographie, ainsi que certains thèmes que nous n'avons pas encore mentionnés : celui du loup et du cadran solaire.

La trace et le loup, comme le note Jean-Pierre Richard, explorent la littéralité du nom de l'auteur :

Et ce n'est sûrement point hasard si la hantise du loup (Harloup) et la passion des traces répètent au secret de la matière la littéralité du nom de l'écrivain : Jean-Loup Trassard. ${ }^{1}$

L'imaginaire de la chasse lié à la photographie est repérable dans le langage familier. Quand on parle de «charger» l'appareil, de «viser» et «prendre » la photo, on identifie la photographie à la chasse. L'analogie est tellement profonde que de nos jours - écrit Susan Sontag - le safari au fusil est remplacé par le safari photo: «Le photographe charge maintenant de vrais fauves, harcelés et trop rares pour qu'on les tue $^{2} »$. Cependant même si l'intérêt de l'auteur pour le loup et les traces pourrait nous permettre d'assimiler chez lui la photographie à la chasse, la nature des photographies de Trassard le différencie d'un type de photographie qui est d'habitude lié à ce champ. Si on reprend les deux catégories que distingue Michel Tournier - la photo a posteriori ou le «pris sur le vif » qu'il identifie à la chasse, et la photo a priori, «calme, où tout à été prévu, étudié, calculé ${ }^{3} \gg-$ les photos de Trassard entreraient dans ce dernier groupe. Le loup et les traces, plutôt que pour la chasse, s'apparentent aux photographies pour le dialectique du visible/invisible qu'ils portent en soi. Le loup est un animal dont on ne perçoit que les traces, mais qui est très rarement visible : «le loup n'est pas fait pour être vu, c'est la certitude de sa présence qui compte $»(C R, 233)$. Des références au loup reviennent dans plusieurs de ces livres, ainsi dans Ouailles, Campagnes de Russie et Dormance, mais nous ne trouvons aucune photo de loup ou de trace de loup.

\footnotetext{
${ }^{1}$ RICHARD, Jean-Pierre, L'état des choses. Études sur huit écrivains d'aujourd'hui, Paris, Gallimard, NRF, col. "Essais", 1990, p. 162.

${ }^{2}$ SONTAG, Susan, Sur la photographie, édition du Seuil, 1973, présente éd. 1983, p. 29.

${ }^{3}$ TOURNIER, Michel, Le Tabor et le Sinä̈, Paris, Belfond, 1988, p. 85.
} 
Le cadran solaire s'apparente également à la photographie car c'est à l'aide de la lumière qu'il affiche le temps. Dans Une classe de neige, on croise une dame passionnée de cadrans solaires, qui les photographie, les répare, les remplace pour les sauvegarder ${ }^{4}$. Dans Territoire, nous retrouvons la description d'un gnomon que forment les objets laissés sur le mur : une barrique posée sur un clou et un fil de fer barbelé. Le soleil y inscrit l'ombre et le temps :

L'intérieur du cercle requiert les yeux où, tenu d'instant en instant contre le mur, son mortier craquelé, le temps semble fugitivement écrire : l'astre lui-même, en sa distance, ne peut plus passer indifférent devant cet assemblage. (Territoire, sans pagination)

La plupart des topoï (le chemin, l'outil, la trace, le creux) sont explorés non seulement par le texte, mais deviennent le sujet des photos. Il se tisse ainsi un lien intertextuel et interpictural complexe entre les livres.

Nous trouvons tout naturellement des photographes dans plusieurs des récits de Trassard, sans qu'un rôle particulier leur soit attribué. Dans Une classe de nature, on rencontre par exemple un ancien coiffeur-photographe :

Un petit homme, cheveux blancs et joues roses, raconte: coiffeur et photographe pendant longtemps, depuis sa retraite il se passionne pour les photographies qui montrent son village, ou ceux des environs, à l'époque où il était jeune. (Classe de nature, 17)

Le photographe raconte ensuite aux enfants quels sont les métiers qui ont disparu (le bourrelier, le sabotier, le charron, le menuisier) et comment le village a vieilli depuis son enfance. Le discours fait penser à celui de l'auteur pour la ressemblance de ses intérêts.

Dans L'amitié des abeilles, la nouvelle qui donne le nom au recueil, un narrateur photographe raconte la déception de son ami Juvigné face au monde littéraire de la ville, puis sa retraite à la campagne où il essaie de se consoler auprès de l'amitié des abeilles. Cependant un jour les abeilles le piquent et, - suit un saut dans la narration que le narrateur justifie par son départ au Danemark pour faire des photos - il trouve en revenant son ami Juvigné marié : «Il ne risquait plus guère de grandes désillusions ${ }^{5}$ ». Nous retrouvons dans cette nouvelle le jeu sur les identités. L'auteur se travestit à un certain degré dans les deux personnages : le narrateur et Juvigné.

\footnotetext{
${ }^{4}$ TRASSARD, Jean-Loup, Une classe de neige, Op. cit., p. 60.

5 TRASSARD, Jean-Loup, «L'amitié des abeilles », L'amitié des abeilles, Paris, Gallimard, 1961 et Cognac, Le Temps qu'il fait, 1985, p. 19.
} 
Ces photographes mentionnés ne pratiquent pas la photo «prise sur le vif », et un certain mépris se lit dans «Le piège à lumière » pour la photographie superficielle :

Les copains traitent les filles comme du matériel, gaspillage de fidélité. J'aimerai la femme qui me sera intermédiaire dans mon effort d'adaptation à l'existence. Eux se bâtissent une gloire quotidienne avec les filles qu'ils connaissent et saluent, avec celles qui montent en voiture et celles qui viennent voir leurs photographies. ${ }^{6}$

Le titre de la nouvelle fait également référence à la photographie, mais hormis le passage cité, il ne s'agit pas de prises de vue, mais de l'amour et de l'attente de Maud à Paris. Par l'analogie avec l'amour, la photographie est elle-même définie comme le fruit d'une attente qui apporte une lumière dans l' « effort d'adaptation à l'existence ».

$\mathrm{Si}$, dans certains récits, les personnages sont des photographes, nous croisons tout naturellement des photographies comme décors sur les murs. Ainsi dans Campagnes de Russie dans le bureau d'Andreï on voit « une grande photographie encadré d'un énorme sanglier mort» et «une quantité de photos en format de carte postale» $(\mathrm{CR}, 237)$. Dans «Cheveux d'herbe», on en retrouve dans la maison, le lieu natale où veut se fondre le narrateur après que le «hasard [l'a] m'a cueilli mort entre deux $\operatorname{pas}^{7} »$ :

Devenu éternellement présent, je découvre ma maison présente, prise déjà dans son silence. Le temps pour elle s'est arrêté avec le réveil de bois dans la lingerie. Les photographies ont été décrochées, quelqu'un a balayé, puis a tiré la porte ; personne n'est revenu. ${ }^{8}$

Mentionner des photographies, tout comme décrire des prises de vue dans ses livres autobiographiques devient tout aussi naturel que l'exploration des topos par les deux médiums. Nous retrouvons là ce dont parle Philippe Ortel, la transparence de la photographie, pratique devenue naturelle et commune, si habituelle qu'on ne la perçoit même plus.

\footnotetext{
${ }^{6}$ TRASSARD, Jean-Loup, « Le piège à lumière », L'amitié des abeilles, p. 83-84. Nous soulignons.

${ }^{7}$ TRASSARD, Jean-Loup, «Cheveux d'herbe », L'amitié des abeilles, p. 31.

${ }^{8}$ Ibid. p. 35.
} 


\section{VI.7. Jean-Loup Trassard - Conclusion}

Nous retrouvons la photographie à plusieurs niveaux dans l'œuvre de Jean-Loup Trassard. Elle sert de modèle pour le récit autobiographique par l'analogie des souvenirs qui resurgissent nets et flous, cernés par le désordre et l'oubli comme les images d'une boite de photographies retrouvée. Le style de l'écriture se fragmente et l'incertitude s'infiltre dans le texte. S'opère une prise de conscience de l'impossibilité à atteindre la réalité, et la description, quant à elle, est également mise en doute. Il ne s'agit pas pour

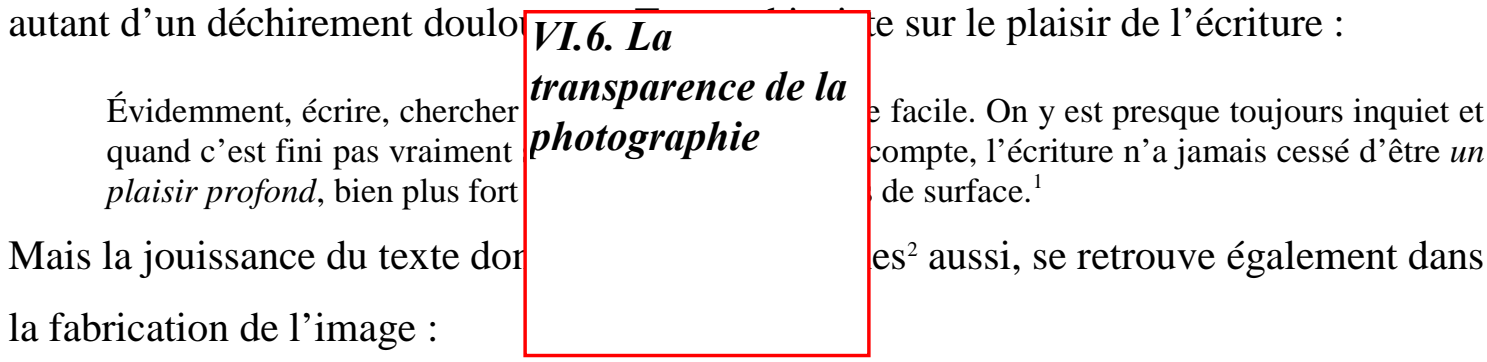

J'aurais aimé faire des films, mais j'aime aussi beaucoup l'immobilité de la photographie. Ce que j'en [de la photographie] attends... pour aller vite, d'abord le plaisir de travailler sur l'espace, de réduire tout un paysage à un petit rectangle, et de disposer les masses et les lumières à l'intérieur de ce rectangle.

Si elle n'est pas la réalité, l'ombre de la caverne peut néanmoins être sauvée, et en maintenant le doute et l'écart, l'ombre devient une trace qui par le mouvement de la recherche, le constant déplacement, la reprise, la fouille apporte non plus une, mais des significations. Le visible conduit vers l'invisible et inversement, et un écart se creuse entre le texte et l'image. L'illusion visuelle que crée la photographie, l'illusion de l'espace (la déformation de la taille des choses) et celle du temps (le sentiment de présence des choses) sont parcourues de manière ludique dans des œuvres où la frontière entre autobiographie et fiction s'estompe. Dans les œuvres hybrides photolittéraires la photographie devient un élément inséparable du texte, du livre-objet, elle donne une spatialité au texte, une nouvelle dimension.

\footnotetext{
1 «Entretien avec Arlette Bouloumié », p. 602. Nous soulignons.

${ }^{2}$ BARTHES, Roland, Le Plaisir du texte, Paris, Seuil, 1973.

3 «Entretien avec Arlette Bouloumié », p. 598. Nous soulignons.
} 
ANNEXE $n^{\circ} 1$ : Comparaison des livres hybrides de Jean-Loup Trassard

\begin{tabular}{|c|c|c|c|c|c|c|}
\hline Titre & $\begin{array}{l}\text { Nombre de } \\
\text { photos }\end{array}$ & $\begin{array}{l}\text { Photo sur la } \\
\text { couverture }\end{array}$ & $\begin{array}{l}\text { Photo en marge du } \\
\text { récit }\end{array}$ & Pagination & $\begin{array}{l}\text { Particularités de la } \\
\text { mise en page }\end{array}$ & Sujet \\
\hline $\begin{array}{l}\text { Inventaire des outils à } \\
\text { mains dans une ferme }\end{array}$ & $\begin{array}{l}15 \text { photos }+1 \\
\text { sur la } \\
\text { couverture }\end{array}$ & une nouvelle photo & & 凶 & & La poétique de l'abandon \\
\hline Territoire & $\begin{array}{l}15 \text { photos }+1 \\
\text { sur la } \\
\text { couverture }\end{array}$ & $\begin{array}{l}\text { reprise en couverture } \\
\text { de la neuvième photo }\end{array}$ & & 凶 & $\begin{array}{l}\text { Les clichés sont } \\
\text { insérés par deux à } \\
\text { part la première }\end{array}$ & $\begin{array}{l}\text { Le territoire en } \\
\text { décomposition }\end{array}$ \\
\hline Images de la terre russe & $\begin{array}{l}40 \text { photos }+1 \\
\text { sur la } \\
\text { couverture }\end{array}$ & $\begin{array}{l}\text { reprise en couverture } \\
\text { de la photo à la page } \\
40 \text { dans un autre } \\
\text { format }\end{array}$ & & $\nabla$ & $\begin{array}{l}\text { Le texte et l'image } \\
\text { sont présentés l'un } \\
\text { au dessus de l'autre }\end{array}$ & $\begin{array}{l}\text { La campagne russe, sous } \\
\text { l'angle des topoï } \\
\text { trassardiens }\end{array}$ \\
\hline Archéologie des feux & $\begin{array}{l}14 \text { photos }+1 \\
\text { sur la } \\
\text { couverture }\end{array}$ & une nouvelle photo & $\begin{array}{l}2 \text { petites photos sur } \\
\text { la page de titre et } \\
\text { l'achevé d'imprimer }\end{array}$ & $凶$ & $\begin{array}{l}\text { La photo sépare les } \\
\text { chapitres }\end{array}$ & $\begin{array}{l}\text { L'inscription en creux du } \\
\text { thème du feu dans l'image } \\
\text { et le texte }\end{array}$ \\
\hline Ouailles & $\begin{array}{c}15 \text { photos }+1 \\
\text { sur la } \\
\text { couverture } \\
\end{array}$ & $\begin{array}{l}\text { reprise en couverture } \\
\text { de la neuvième photo }\end{array}$ & $\begin{array}{l}2 \text { petites photos sur } \\
\text { la page de titre et } \\
\text { l'achevé d'imprimer }\end{array}$ & $\begin{array}{l}\square \text { sauf les pages } \\
\text { avec les photos }\end{array}$ & & $\begin{array}{l}\text { Récits parallèles en image } \\
\text { et en texte sur les bergers }\end{array}$ \\
\hline Objets de grande utilité & $\begin{array}{l}15 \text { photos }+1 \\
\text { sur la } \\
\text { couverture }\end{array}$ & une nouvelle photo & & $\nabla$ & & $\begin{array}{l}\text { L'impossibilité de la } \\
\text { description, mise en face } \\
\text { des objets (texte) et des } \\
\text { chemins (photos) }\end{array}$ \\
\hline Tumulus & $\begin{array}{l}9 \text { photos de } \\
\text { Jean-Philippe } \\
\text { Reverdot }\end{array}$ & $\begin{array}{l}\text { Pas de photo sur la } \\
\text { couverture }\end{array}$ & & $\begin{array}{l}\square \text { sauf les pages } \\
\text { avec les photos }\end{array}$ & $\begin{array}{l}\text { La photo sépare les } \\
\text { chapitres }\end{array}$ & $\begin{array}{l}\text { Récits parallèles en image } \\
\text { et en texte sur la } \\
\text { disparition des civilisations } \\
\text { rurales }\end{array}$ \\
\hline
\end{tabular}




\begin{tabular}{|c|c|c|c|c|c|c|}
\hline Titre & $\begin{array}{l}\text { Nombre de } \\
\text { photos }\end{array}$ & $\begin{array}{l}\text { Photo sur la } \\
\text { couverture }\end{array}$ & $\begin{array}{l}\text { Photo en marge du } \\
\text { récit }\end{array}$ & Pagination & $\begin{array}{l}\text { Particularités de la } \\
\text { mise en page }\end{array}$ & Sujet \\
\hline Les derniers paysans & $\begin{array}{l}42 \text { photos }+1 \\
\text { sur la } \\
\text { couverture }\end{array}$ & une nouvelle photo & $\begin{array}{l}4 \text { petites photos sur } \\
\text { les pages de titre et } \\
\text { l'achevé d'imprimer }\end{array}$ & $\nabla$ & $\begin{array}{l}\text { A chaque photo } \\
\text { correspond un texte } \\
\text { court présenté sur la } \\
\text { page à côté }\end{array}$ & $\begin{array}{l}\text { Scènes de vie à la } \\
\text { campagne avec } \\
\text { figurines d'enfances }\end{array}$ \\
\hline $\begin{array}{l}\text { La Composition } d u \\
\text { jardin }\end{array}$ & $\begin{array}{l}15 \text { photos }+1 \\
\text { sur la } \\
\text { couverture }\end{array}$ & une nouvelle photo & $\begin{array}{l}2 \text { petites photos sur la } \\
\text { page de titre et } \\
\text { l'achevé d'imprimer }\end{array}$ & $\nabla$ & & $\begin{array}{l}\text { Le dialectique du dehors et } \\
\text { du dedans, les traces de la } \\
\text { composition du jardin }\end{array}$ \\
\hline Nuisibles & $\begin{array}{c}14 \text { photos }+1 \\
\text { sur la } \\
\text { couverture }\end{array}$ & une nouvelle photo & $\begin{array}{l}2 \text { petites photos sur la } \\
\text { page de titre et } \\
\text { l'achevé d'imprimer }\end{array}$ & $\nabla$ & & $\begin{array}{l}\text { Le dialectique du dehors et } \\
\text { du dedans, les galeries } \\
\text { souterrains des animaux }\end{array}$ \\
\hline Le voyageur à l'échelle & $\begin{array}{l}15 \text { photos }+1 \\
\text { sur la } \\
\text { couverture }\end{array}$ & $\begin{array}{l}\text { reprise en couverture de } \\
\text { la photo à la page } 29\end{array}$ & $\begin{array}{c}2 \text { petites photos sur la } \\
\text { page de titre et } \\
\text { l'achevé d'imprimer }\end{array}$ & $\nabla$ & $\begin{array}{l}\text { A chaque photo } \\
\text { correspond un texte } \\
\text { court présenté sur la } \\
\text { page à côté }\end{array}$ & $\begin{array}{l}\text { Installations de paysages en } \\
\text { miniature d'un voyageur } \\
\text { fictif }\end{array}$ \\
\hline Sanzaki & $\begin{array}{l}7 \text { photos }+1 \\
\text { sur la } \\
\text { couverture }\end{array}$ & $\begin{array}{l}\text { reprise en couverture de } \\
\text { la photo à la page } 65\end{array}$ & $\begin{array}{l}1 \text { photo en taille } \\
\text { réduite sur la page de } \\
\text { l'achevé d'imprimer }\end{array}$ & $\begin{array}{c}\square \text { sauf les } \\
\text { pages avec les } \\
\text { photos }\end{array}$ & $\begin{array}{l}\text { la suite des images } \\
\text { forme un récit, qui } \\
\text { précède le récit } \\
\text { décrit dans le livre } \\
\text { les photos à part la } \\
\text { première (p. 6) se } \\
\text { trouvent sur la page } \\
\text { du recto }\end{array}$ & $\begin{array}{l}\text { Le récit d'un trafiquant } \\
\text { d'alcool traqué par la police }\end{array}$ \\
\hline
\end{tabular}




\section{ANNEXE n $^{\circ}$ : Questionnaire adressé à Jean-Loup Trassard}

1. Dans la présentation sur le site de l'édition Le Temps qu'il fait, l'éditeur fait mention que vous aviez commencé à faire de la photographie en tant qu'enfant. Quand et comment vous est venu l'idée d'utiliser vos photographies dans vos œuvres ?

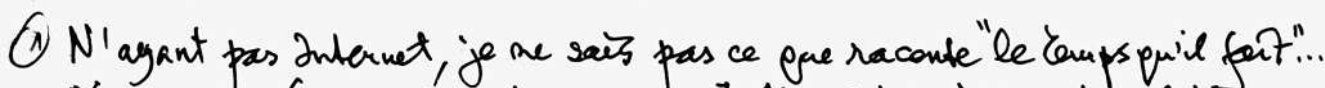
Yai connmente en faut, ari, avec une koite Kodak à faire des photos mars Seulement de mon copain er visin, de mon rélo er de mon petit chien. Quand Xai en 1taus mon pêre m'a pêté un Rolleiflex dout se servait ma mère, desrlà que jai commencé à me trurner vers le paysage, mais je ne

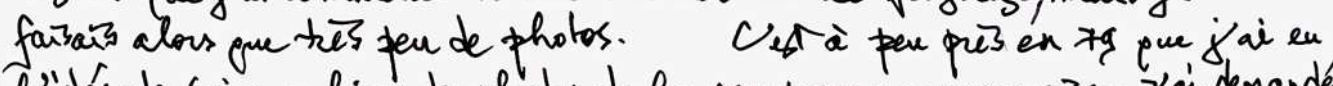
bidée de saire un lire de photos de la campagne mayennaise. yai demandé chez Gollimard si in pouvait Denvisager, on m'a det non. Puns eu 1980, Geonges Monti m'a poposê de publier guelenes photos en nuême teunps pue destextes, ce pui m' a êtonné mauss tont de suite intéresse.

2. Vous ne mentionnez jamais vos années d'adolescence dans vos œuvres. Aviez-vous écrit et fait des photos à cette époque ? Que représentent-t-elles ?

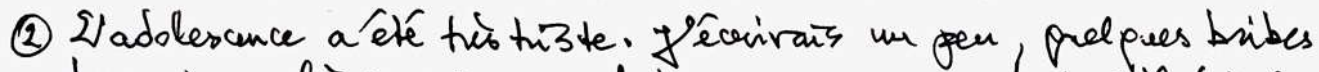
de ces pages là se retrouveront daus mes carnets de tarail (je les tape à Uordinateur mari ils me seront pecetêtre pas publiés). En photo, $\gamma$ aiconsenté ma 3e- photographie: une vie du fameux ruissean, beaucoup thotographié par la surte. Y ai fait aussi prelores photos des cheraux percherens du vorisin. Ex déjà des cheminu creur.

3. Dans l'entretien avec Arlette Bouloumié vous dites «je ne fais pas trop le lien entre l'écriture et la photographie. Je ne pense pas qu'il y ait une réelle influence de l'une sur l'autre. » Pourtant vos œuvres ne cessent de tisser des liens entre le texte qui fait surgir les souvenirs en vrac comme dans une boîte de photographie, ou les photographies réelles qui remémorent un passé révolu. Vous entendiez ce décalage entre l'écriture et la photographie en quel sens?

(3) Phologuphic er éconture sont deux moyeus gue jutilize parallilement pour essayer ve baisir et de dire le réel, yni se trouve ête, four le principal, cette miene caupague du breage mayennais... Donc cele rappoche les ghotos des eccuits dans ce pui of monté. Et puis, je

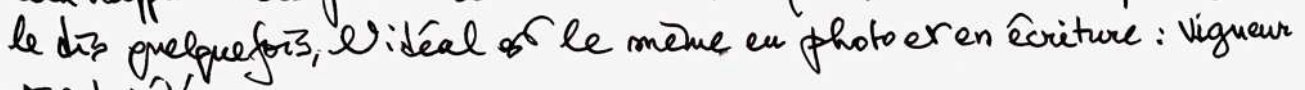
et sobriété.

4. Quel rôle faut-il accorder selon vous à la photographie dans la mémoire et les souvenirs? Vous servez-vous ou consultez-vous vos propres photos ou photos de vos proches pendant l'écriture, notamment pour faire remonter des souvenirs ?

(4) Enorme ce role, êridemment. Er sourent productice de plaitin en 
farrant revair les fersounes qui ne sont plus là, la photo saphice ement tout un chacun. Mairs je ne me sers acecunement de photos ancienves on réceutes pour êcrire. Sauf de mes pro pres photes russes paur leur faire des sonter de légendes dans "Images de la tere russe".

5. Vous dites également dans l'entretien avec Arlette Bouloumié que vous essayez de « ne pas écrire un texte tout à fait comme le précédent». Dans les œuvres qui mêlent "texte et photographies» recherchez-vous l'exploration de nouveaux rapports entre le texte et l'image ? Êtes-vous influencé par d'autres auteurs et/ou photographes qui mêlent dans leur travail l'écriture et l'image (ou la photo)?

(5) Sainerais twouver, bien sin, un nowveare raffert ente texte et fhoto a chappe petit live are TqF mais je m'y arrive pas. I faudrait peuser, saus doute, les deux eusamble er je ne le gas pas... Ancure influence, non, pour la meilleure des raisons: je ne regarde pas, on Guère, ce gre font les autres daus le rafprocheruents ente littérature es photo.

6. Voyez-vous, comme le fait Roland Barthes, la photographie comme un deuil ?

(6) Non, absolument pas. Cela dit, je n'ai pas lu le live de Barthes sur la photo.

7. Dans vos livres ce qui m'avait aussi beaucoup frappé, c'est les jeux temporels. Dans la Composition du jardin, le narrateur en cours de route change du présent au passé, et dans plusieurs livres (dans Dormance ou dans Archéologie des feux) le temps survole la préhistoire jusqu'à nos jours dans une même phrase. Dans Sanzaki, les photos forment un récit qui précède celui raconté par les mots. Les temps s'imbriquent, se condensent, dans plusieurs livres les photos et les récits forment des boucles, évoquent le temps cyclique. Que pensezvous du rapport entre la photographie et le temps?

(7) Ie faudrait un jett' essai pour rêpandre à cette dernicie pustion sous differents angles, je ne peux pas m 'y lancer $\mathrm{Ti}$, ge rais seulement vous dire pue deprus prefues annees avec "Ees derniers paysans", puirs arec "gusk absente" et plus récemment arec "Petits caillovex", ces deux dernières expositions n 'étant pas reprises en livres, je trataille consciemment sur le temps. Essayant notanment de saisir, au-dessus des -bjets de ma mière, le teups daubufois. Ou, un gen moins nettement, le temps de la petite en fance - la mienve ou celle de pui se reconnaî trait dans ces jonets - sur des getits objets darant gueve, assez nettement datés.

8. Que pensez-vous de la photographie digitale?

(B) Mafoi, sien! fen'en fars pas et are surs pas proche de cerex pui traveilleut en numérieje, donc à vrai dive pas reuseigné du tout! 
9. Le rapport entre les textes et les photographies sont dans la plupart de vos ouvrages implicites, "pour éviter le pléonasme» dites-vous, mais le rapport reste comme cela énigmatique et donne une tâche au lecteur de déchiffrer l'énigme, est-ce un effet recherché de laisser une plus grande créativité au lecteur ? Quelle place accorder au lecteur ?

(5) He ne $\mathrm{cror}^{3}$ pas gue ce sont ênigmati pue, irimagine gue le lecteur vort bien àla fors le décalage es la relation. X serait certairement sonhaitable de laisser plus de place au lecteur, mart, comment? Ie fanbr ait y réfléchin arant Dourdir un projet, je me laisse suirement trop aller àce qui vient assez naturelleweut comme alliance texte/photos. En ériture, purs gnien me dit grelprefors pue dis difficile à lire, je réponds ne je propese un jen de langue au lectreur, il faut on'll se fasse bon lecteur, accepte de participer! Er soit attentif de de petits détails sill vent profiter rraiment de ce puilui es propose. Nêanmoins, je n'ai pas envie en iun live, arec on sans photo, soit constitué consme un jen ou 'il faut trowver une piste or une solution, cela devient àce moment-là ue gadget, en tout cas à mon sens?

10. Voyez-vous un rapport suite aux pensées de Leroi-Gourhan sur l'outil, entre l'outil qu'est l'appareil photographique et l'homme moderne ou post-moderne ?

(10) X ya si longtemps pue jai lu la lires de Seroi-Gourhan pue jeme me souvieus plus asser précisément de ce onl il dit deur bontil. He me seuble tout de même gue cof notre intermé diaire pour transformer la matière. St a pareil photographigne of ghtót un cafteur, encore atil besin du film, du bain de sévélateur, du papier et du firateur... Sans cette chaîne mise en seume par la main et loeil du tireur mons ne verrions rien de ce que Dobjectif a ru. Alons er aftareil of un entie si bon vent, maes Vun genie tere particalier.

11. Dans La composition du jardin, en lisant le texte j'ai cru reconnaître la description de votre propre jardin, l'escalier qui y mène du salon, la légère pente du terrain qui donne l'illusion de grandeur venant d'en bas, s'agit-il de la description de votre propre jardin et les photos de votre maison? S'agit-il d'une sorte d'« autofiction » comme dans la plupart de vos œuvres?

(11) Il ragit bien du jardín, tel gu'à mon idée il a dû êtee pensé puis tack a la fin du $18 \mathrm{E}$. Erles photos sont des détailes de la maison. Fe slagisait de me montur mi la marison elle même, ni le jardin decut! "Awtofietion", mon, je me place simplement ala tonte fin du 1 sesiècle.

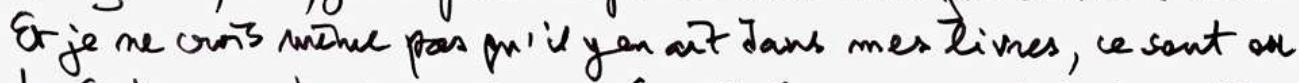
desfiztions ou des sourenirs carbement, En ce moment je traraille sur pulpue chose gui eutzlace donvenirs erinvention, à mon avisce n'et pas non plus de $D$ antofiztion. 
12. Plusieurs de vos livres posent l'énigme de la réalité qui nous entoure et l'incapacité de l'écriture ou de la photographie de révéler le Tout. Êtes-vous influencé dans vos propos par des modèles philosophiques?

(12) Mais non! Erop pen cultivé, on même instwit, pour avsir eutête un discours tenu gar guelgue phulosophe, "réréler le tout", je ne dirairs pas che car mon ambition es bien plus modexte sta majuscule a "tont" fait un peu religileur (ce dont je suis eloigree). Oef plus une envie de dire er de monter on'une anbition Dailleurs. Or pas beroin des philosophes pour s'aperceroir gne le reel nous passe entre les doigts gnand an essaie dele saisir par e's ant, vor à dire de representer. Finalement on se contente de suggéerer, mais cela permet aubsi de dire autre chose pue le rêd, en somme d'y ajouter.

13. Dans l'entretien avec Arlette Bouloumié vous mentionnez quelques écrivains dont l'œuvre vous a influencé, ajouteriez-vous encore d'autres écrivains découverts depuis? Quels sont les photographes et/ou les films de cinéastes qui vous ont influencé ?

(13) Ce ne sont pas da anteurs gni m'ont influencé mairs pre jaime parhizulierement. He semble en'on errinfluence par tout ce gr'on liz, sueme le maurars parce en'on y vit ce gilil ne faut pas faire. Comme thotographes ... un seul m'a donné une idée (pue je mbi pas surexploitée mars, un peu suivie prand meme) Jes Walker Evans, par une photo des petits dbjets bien propres dune marion tees pauke, cele mia servi dans les fermes.

14. Je me suis intéressée à ce phénomène contemporain qui veut que l'on se fabrique non seulement une identité, mais une image. En tant qu'écrivain aviez vous une emprise sur vos portraits publiés (au dos de certains ouvrages, sur le site de l'éditeur, etc.) ?

(14) Pas grand chose à dire, Je r'ai de photo portrait sur arecur liver. Pour leur site les editeurs fout ce puils reulent. If n'ai sien su n'ayant fas Dterwex. Par conke, mon fils est en twain de me faire un site et nous choizissons soigneusement prelepes pertiaits.

15. Lors que vous organisez une exposition de photos, comment cela se passe-t-il ? Jusqu'à quel point maitrisez-vous l'organisation de l'exposition ? Y a-t-il un parcourt proposé comme c'est le cas dans les livres, une sorte d'installation que vous soumettriez ? Y a-t-il des textes qui accompagnent les photos?

(15) Rien daus Dorganisation ne mi eft jamais thuposé, mais en géveral je laisse celui pui recort mon expasition la présenter à sa guise par j'll aut sa participation er la satisfaction pni paut en découler. De mênce, cans les lives avec photos, je laisse Gorges Monti choizir Uordre des photos.

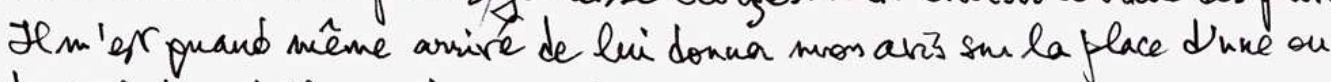
deux photos, et il en a temu compste. 
16. Fréquentez-vous des galeries spécialisées dans la photographie ? Consultez-vous des magazines spécialisés ? Avez-vous des préférences, des choix techniques vis-à-vis de la photographie : appareil, pellicule, papier photo ?

(16) Non, sauf guand 'jexperars al a golerie Barbier-Beltz à Paris, là je royais les expositions de tour les photographes de cette galeric, dont, s'occuprait phus ou moins Bernand Samarche- Kadel. Sa galerie of t fermé, je ve fé prente plus pre yean thilitpe Reverdot. Je ne his aucun maparine de photo. Quant àle techmique ... je surs archirvel! Apareils : id ai revendu Hasselblad pri ne me donnait ancune inage nette, sürement un Ibjectif défectueux. He fais da couleur avec un NiKKormat et le nove orblanc arrec un Sica acheté doccasion. Pellicules: plutsot Kodak. Papier: je n'ai jamais fait de tirages done je n'y counais rien!

17. Dans quelle circonstance est née l'idée de vos livres d'artistes en collaboration avec Odile Levigoureux (Lettre à la prêle et Lettre au lin)?

(17) Daxiel Serizareux, peintre, m'a êut apers arsir lu, nous nons Léjà. Sa feurme odile ar artiste aussi et, entre autes créatiens, elle M'a dit un jour "je fors des lines arec du papien trié des plantes". Yai demandé gi faisart le texte. Personne. Yai affirme des lines saus terte ne sont tes des lives"er iai proposé di érire à chague fors une lette à la plante. Si noke éditeur (le TqFque 'Y ai branché lén dessus) tient le coup, normalement mous devons encose en realiser twis, pour abir une série de six.

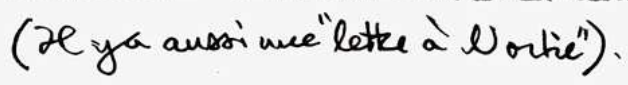


Pal, Gyöngyi. Le dispositif photo-littéraire en France dans la seconde moitie du XXe siècle Analyse de l'oeuvre de François-Marie Banier, Jean-Loup Trassard, Lorand Gaspar et Denis Roche - 2010 


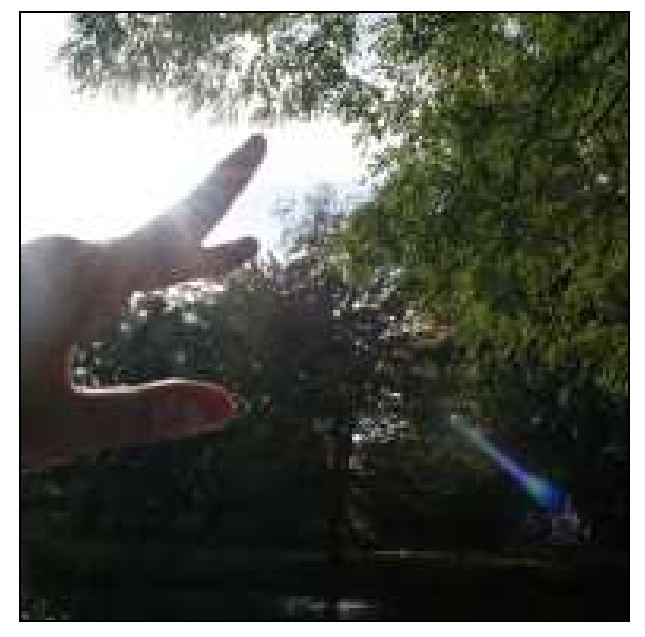

Pál Gy. : Tissage de lumière 


\section{Contenu du chapitre}

VII. Lorand Gaspar - poète de la lumière 301

VII.1. Le caractère autobiographique de son oeuvre 303

VII.2. Paysage de lumière 307

VII.3. Parallèles photographiques : pierre, archéologie, érosion, langage, silence 312

VII.4. Une approche spinoziste.

VII.5. Au-delà des apparences 321

VII.6. La représentation vivante 326

VII.7. Idéogrammes 330

VII.8. Les livres d'artiste et les lectures d'images 340

VII.9. La poétique du visuel 350

VII.10. Lorand Gaspar - Conclusion 356

ANNEXE $n^{\circ} 3$ : Exemples du cheminement des œuvres de Lorand Gaspar à travers les différentes publications 358

ANNEXE ${ }^{\circ} 4$ : Ouvrages de Lorand Gaspar rassemblant textes et images........ 359

\section{$\underline{\text { Liste des abréviations : }}$}

Approche de la parole

$A P$

Carnet de Patmos

$C P$

Carnets de Jérusalem

$C J$

Egée suivi de Judée

É-J

Feuilles d'observation

FO

Journaux de voyages

$J V$

Patmos et autres poèmes

$P$

Sol absolu et autres textes 
L'œuvre de Lorand Gaspar est à la fois proche de celle de Jean-Loup Trassard dans son aspiration, et éloignée pour ce qui est des thèmes. Son thème privilégié étant en effet le désert. Jean-Michel Maulpoix, dans son étude sur la poésie contemporaine, classe l'œuvre de Gaspar sous l'appellation « habiter le monde », qui conviendrait aussi pour Trassard, même si ce dernier ne compose pas de poème mais des récits en prose. Les poètes que Maulpoix rassemble sous cette expression (Yves Bonnefoy, André du Bouchet, Philippe Jaccottet, Jacques Dupin et Lorand Gaspar) cherchent à réconcilier la poésie avec le monde sensible, mais ils peuvent également «être rassemblés autour de leur quête commune du lieu et de la présence, ainsi que d'un rapport insistant à l'élémentaire ${ }^{1} »$.

Lorand Gaspar est poète, photographe, traducteur de poètes hongrois et grecs, rédacteur du journal tunisien Alif, mais il est avant tout médecin chirurgien. Ses vastes centres d'intérêt recouvrent l'archéologie, les neurosciences, la peinture, le collage, la calligraphie chinoise, la musique, l'ornithologie et sa curiosité universelle font de lui, selon Philippe Rebeyrol' ${ }^{2}$, un nouvel Érasme, qui ne sait pas tout mais désirerait tout savoir. Lorand Gaspar a publié deux livres hybrides aux éditions Le Temps qu'il fait où figurent ses propres textes et ses photographies : Carnet de Patmos (1991) et Carnets de Jérusalem (1997). Ses photos ont également fait l'objet d'une exposition à Marseille (Lorand Gaspar, Espaces; Catalogue de l'exposition à la BM de Marseille, décembre 1984 - janvier 1985) et d'une exposition au Musée Nicéphore Niepce (Lorand Gaspar, Châlons-sur-Saône, Musée Nicéphore Niepce, 1989). D’autres photos sont parues dans des actes de colloque et dans diverses revues ${ }^{3}$. Il a également publié un livre en collaboration avec James Sacré4, dont le texte poétique accompagne les photographies de Lorand Gaspar. Dans plusieurs des livres de Gaspar nous trouvons des images d'autres artistes qui accompagnent les poèmes ou les illustrent, ce qui dévoile les liens multiples qui rapprochent son œuvre des images.

1 MAULPOIX, Jean-Michel, La poésie française depuis 1950. Habiter le monde, (consulté le : 26/11/2008) http://www.maulpoix.net/Habiter1950.html.

2 REBEYROL, Philippe, «Lorand et Spinoza », in Lorand Gaspar, sous la dir. de Daniel Lançon, Cognac, Le Temps qu'il fait/Cahier seize, 2004, p. 209. Par la suite pour citer les actes de ce colloque nous utiliserons l'abréviation : Lorand Gaspar (2004).

${ }^{3}$ Une bibliographie très détaillée établie par Daniel Lançon se trouve à la fin des actes, Lorand Gaspar (2004), p. 356-412.

${ }^{4}$ SACRÉ, James, Mouvementé de Mots et de couleurs, Cognac, Le Temps qu'il fait, 2003. 


\section{VII.1. Le caractère autobiographique de son oeuvre}

À première vue, la photographie de Lorand Gaspar semble entretenir un lien étroit avec l'autobiographie. Les photos témoignent des lieux par où le poète est passé.

En 1982 Lorand Gaspar publie chez Gallimard un essai autobiographique (dans le recueil Sol absolu et autres textes) dans lequel il évoque les lieux importants de sa vie. Le premier endroit qui le marque est la Siculie ${ }^{1}$, lieu de sa naissance, de son enfance et son adolescence, qu'il mentionne souvent lors des entretiens ${ }^{2}$. Dans son œuvre poétique, Gaspar évoque plusieurs fois ses origines comme le rappelle Gisèle Vanhese : « À travers ses souvenirs, l'enfance apparaît surtout associée à une saison, l'hiver ${ }^{3}$ », d'où peut-être l'importance de la couleur blanche dans son œuvre. Ses souvenirs recréent un univers de paix et de douceur: «ces choses au-dehors qui tombent lentement, / le jasmin, la neige, l'enfance ${ }^{4} \gg$. La Transylvanie sera non seulement le lieu de la première rencontre avec la poésie (l'initiation du professeur de lycée «aux mystères de la poésie de Rimbaud» $S A$, 9), mais aussi celui des premières photographies :

Je ne me souviens plus quelle était ma motivation exacte à l'âge de douze ans (j'avais à la même époque commencé à écrire dans des carnets) quand j’avais exprimé le désir de faire des photographies. Je me rappelle simplement que j'avais des sensations visuelles très fortes par moments dans la nature qui formait l'essentiel de mon environnement quotidien : grand jardin à la maison, la montagne et les forêts. ${ }^{5}$

Ses premières photos et ses premiers poèmes ne sont pas publiés, et l'on retrouve là un trait commun entre Lorand Gaspar et Jean-Loup Trassard, celui de remonter dans leurs écrits autobiographiques leurs affinités avec la photographie et la littérature jusqu'à l'enfance.

\footnotetext{
${ }^{1}$ La Siculie (ou Székelyföld en Hongrois) se situe à l'Est de la Transylvanie, c'est une région habitée par les Sicules, un groupe ethnique parlant la langue hongroise. Voir à ce sujet : http://fr.wikipedia.org/wiki/Sicules_\%28Roumanie\%29 (consulté le : 18/09/2009).

2 «Entretien avec Daniel Lançon», in Lorand Gaspar (2004), p. 43-54 ; «Entretien sur la photographie avec Georges Monti », in Lorand Gaspar (2004) p. 159-162, "Petite biographie portative », in Transhumance et connaissance, (colloque organisé à Cerisy en 1994) textes réunis par Madeleine Renouard, Paris, Jean-Michel Place, 1995, p. 11-16.

3 VANHESE, Gisèle, «L'espace autobiographique dans l'œuvre de L. Gaspar » in Lorand Gaspar, Poétique et poésie, colloque international, 25-27 mai 1987, sous la dir. de Yves-Alain Favre, Pau, Université de Pau, 1989, p. 151-163.

${ }^{4}$ GASPAR, Lorand, Sol absolu et autres textes, Paris, Gallimard, 1982, p. 62. Par la suite nous utiliserons l'abréviation : $S A$.

5 «Entretien sur la photographie avec Georges Monti », in Lorand Gaspar (2004), p. 159.
} 
Les photos de Lorand Gaspar sont principalement des images prises lors de voyages : photos du désert de Judée, de Jérusalem, de Patmos en Grèce, des États-Unis (Holbrook), de l'Inde. Les titres même de certains recueils de poèmes - Égée/Judée, Patmos - renvoient à des lieux concrets et soulignent l'importance de l'expérience personnelle, la rencontre du poète avec un espace réel. Selon Gaspar, la Judée est le lieu d'«un passé prodigieux » qui contient «dans sa continuité, la réalité vivante d'un présent multiple et complexe » $(S A, 13)$, si bien que les lieux concrets deviennent les points d'ancrage des poèmes, et dans de nombreux poèmes nous retrouvons le nom des lieux (villes, montagnes, déserts) ${ }^{6}$. Maxime Del Fiol remarque que les lieux liés à la poésie gasparienne, les espaces désertiques et ceux proches de la mer (lieux habités ou totalement désertiques), dessinent une géographie triangulaire reliant les déserts du Proche-Orient en bordure de la Mer Rouge, les îles de Grèce et la Tunisie ${ }^{7}$. Si sa poésie s'ancre dans des lieux où il a vécu pendant un certain temps, les photographies rompent avec le pôle triangulaire offrant un panorama visuel plus vaste (incluant les photos prises lors de ses voyages en Inde et aux États Unis).

Le caractère autobiographique des photographies de Gaspar semble se renforcer dans Carnet de Patmos ${ }^{8}$ et Carnets de Jérusalem ${ }^{9}$, textes accompagnés de ses clichés. Le titre «Carnet» signale sa source autobiographique, néanmoins ce ne sont pas des ouvrages simplement autobiographiques, mais une œuvre à genre hybride où alternent récit de voyage et essais scientifiques (réflexion sur l'histoire de la Judée, sur l'archéologie, sur la philosophie). Le texte est également un mélange de registre de langue car on y trouve la poésie en prose, le langage scientifique tout comme le langage familier, par endroit alourdi de citations bibliques ou scientifiques ${ }^{10}$.

\footnotetext{
${ }^{6}$ Maxime del Fiol, dans les actes du colloque sur Lorand Gaspar organisé en Tunisie, attire l'attention dans la présentation à l'importance des lieux auxquels se réfère le poète (soulignant ainsi l'importance du fait que le colloque soit organisé à Tunis, proche de Sidi-bou-Saïd, du lieu où a habité pendant un certain temps l'auteur). Il rajoute qu' «il resterait à préciser le rapport exact qui s'établit, chez Lorand Gaspar, entre l'œuvre et la diversité des lieux parcourus [...] et des lieux habités ». DEL FIOL, Maxime, «Présentation », in Un poète près de la mer, (Textes réunis par Maxime Del Fiol et Moncef Khémiri), Tunis, Sud, 2004, p. 14.

${ }^{7}$ Ibid. p. $14-15$.

${ }^{8}$ GASPAR, Lorand, Carnet de Patmos (Textes et photographies), Cognac, Le Temps qu'il fait, 1991. Par la suite nous utiliserons l'abréviation : $C P$.

${ }^{9}$ GASPAR, Lorand, Carnets de Jérusalem (Textes et photographies), Cognac, Le Temps qu'il fait, 1997. Par la suite nous utiliserons l'abréviation : $C J$.

${ }^{10}$ Selon Kassab-Charfi, dont l'analyse s'appuie sur le recueil Judée, les différents registres utilisés apparentent le poème en prose à un scénario, qui « ouvre » le poème, fragilisant la parole en même temps que de l'inscrire dans un prolongement, une non-finitude qui crée par la figure du paradoxe un équilibre
} 
Cependant, ni les textes ni les photos de Gaspar ne visent à rendre des impressions momentanées ou à capter des souvenirs malgré leur connotation autobiographique. Il s'agit plutôt d'une quête de l'éternel. Lors d'un entretien sur la photographie avec Georges Monti, Gaspar avoue :

[...] curieusement, je n'ai jamais eu d'attirance pour les photos souvenir, qu'il s'agisse de paysages ou de personnes. Mon cerveau visuel aimait déjà faire des " cadrages " correspondant à des compositions d'ombres et de lumières, de formes et de mouvements. ${ }^{11}$

Véronique Montémont dans son analyse de la genèse des Carnets de Patmos soutient que les poèmes et les photographies sont de caractère autobiographique dans la mesure où ils veulent faire «partager une beauté dont l'expérience a bouleversé celui qui l'a faite $^{12} \gg$ :

[...] le discours autobiographique esquive à la fois la relation circonstanciée des actes accomplis et la visée purement introspective, pour se tourner vers une description dynamique de la manière dont le sujet percevant est touché, en bien ou en mal, par le monde sensible. Il en ressort l'expression, on ne peut plus intime, d'un amour immense pour les paysages traversés, d'une tendresse pour certains des êtres croisés, et c'est en cela que la photographie se coule dans le dessein autobiographique. ${ }^{13}$

Les photos de Gaspar sont des photographies de création, pour reprendre les catégories de Michel Tournier qui fait la distinction entre photographie de prédation et de création $^{14}$ ou d'André Rouillé, qui se référant à Paul Klee, décrit la photographie créatrice comme capable de montrer une vision de la réalité jusque-là inaperçue ${ }^{15}$. Gaspar soutient la même idée dans son texte publié lors de son exposition au musée Nicéphore Niepce :

dialectique. KASSAB-CHARFI, Samia, «À l'ombre d'une si calme catastrophe ou l'écriture du paradoxe dans Judée de Lorand Gaspar », in Un poète près de la mer, Op. cit., p. 105-122.

${ }^{11}$ «Entretien sur la photographie », Op. cit., p. 159.

${ }^{12}$ MONTEMONT, Véronique, «Lorand Gaspar : genèse des Carnets de Patmos », (mis en ligne le : 15 février 2007.) http://www.item.ens.fr/index.php?id=27103 (consulté le: 03/03/2008). Il s'agit d'un dossier appelé Carnets de Patmos qui contient plusieurs archives et dactylogrammes relatifs à différents ouvrages : Carnet de Patmos ; Égée/Judée ; Feuilles d'observation, manuscrits qui conservent «plusieurs strates d'écriture, qui se sont étagées sur une période de vingt à trente ans ».

${ }^{13}$ Ibid.

${ }^{14} \ll$ je te prends en photo donc je diminue ta substance, je te mange en quelque sorte. Or cette pente prédatrice de la photographie c'est celle de tout un chacun faisant de la photo de tourisme. [...] un photographe n'est grand que s'il a réussi à inverser ce courant maudit de la prédation pour aboutir au courant inverse à savoir celui de la création » TOURNIER, Michel, «Création et prédation », Les Cahiers de la photographie, édition du colloque sur la photographie organisé à Paris I - Panthéon Sorbonne, 1982 , p. 85.

${ }^{15}$ ROUILLÉ, André, La photographie, Paris, Gallimard, 2005, p. 542. 
Et ce que certains amoureux de la photographie essayent désespérément de saisir c'est leur «vision » éveillée par une rencontre, c'est une force d'exister en eux et dans les choses, dans les autres. ${ }^{16}$

D'ailleurs ses photographies publiées ou exposées dans des galeries sont rarement accompagnées de titres ou de légendes, ce qui expliciterait leur visée artistique. La « vision » qui naît au contact des choses que Lorand Gaspar veut transmettre par ses photographies ne peut se comprendre qu'au regard de l'œuvre poétique. James Sacré, auteur du livre Mouvementé de Mots et de couleurs dans lequel son texte poétique dialogue avec les clichés de Lorand Gaspar, affirme de même :

J'ai pensé que Lorand Gaspar

Photographiait ses propres livres dans ces couleurs de désert. ${ }^{17}$

Il s'ensuit que l'œuvre photographique de Lorand Gaspar est de nature autobiographique dans la mesure où la photographie parle toujours du photographe suivant la définition indicielle. Mais cet aspect autobiographique s'efface derrière sa visée universelle.

${ }^{16}$ GASPAR, Lorand, Exposition de Lorand Gaspar, Musée Nicéphore Niepce, Ville de Chalon-surSaône, 16 juin/10 septembre 1989 (sans pagination).

${ }^{17}$ SACRÉ, James, Mouvementé de Mots et de couleurs, Cognac, Le Temps qu'il fait, 2003, p. 60. 


\section{VII.2. Paysage de lumière}

La majorité des photos ${ }^{1}$ publiées de Gaspar nous montrent le désert qu'il connaît bien puisque à Jérusalem derrière son jardin commençait déjà le désert : «certains jours - écrit-il - j'obéis à mon besoin de bouger. Ayant traversé le wâdi Djose j'arrive avec les premiers rayons du soleil dans les collines nues, à l'Est, derrière le jardin » $(C J, 9)$. Lorand Gaspar a effectué plusieurs voyages dans le désert, dans le Hoggar notamment à la poursuite des peintures rupestres (décrites dans Journaux de voyages). Le désert semble être un lieu privilégié,

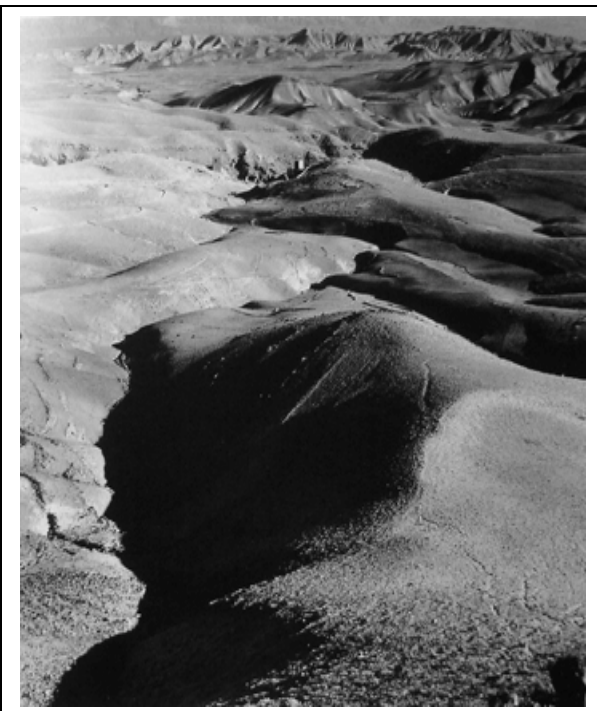

Carnets de Jérusalem non seulement pour la photographie, mais aussi pour la poésie. Il est avant tout une rencontre directe entre le poète et la nature, la lumière dans la nature.

Chez Gaspar la lumière doit être comprise à la fois comme une réalité physique et dans son sens figuré. Le dictionnaire Petit Robert donne les significations suivantes au mot lumière: «I. ; Agent physique capable d'impressionner l'œil, de rendre les choses visibles. II ; Ce qui éclaire, illumine l'esprit ${ }^{2} »$. Pour ce qui est de la réalité physique de la lumière, Gaspar est influencé par les écrits d'Einstein ; il avait en effet, dans son adolescence, étudié les découvertes scientifiques et les pensées du physicien³ Gaspar fait ainsi allusion dans un entretien sur la photographie à la physique de la lumière (révolutionnée par Einstein en 1905 dans «Production et transformation de la lumière considérée d'un point de vue heuristique $\left.{ }^{4} »\right)$ qui «ne fournit que des longueurs d'ondes variables et des photons ${ }^{5} \gg$.

\footnotetext{
${ }^{1}$ La date, le lieu ni le titre ne sont jamais marqués sur les photographies de Lorand Gaspar, de plus les photos s'insèrent hors pagination dans les livres. Nous signalons donc seulement le titre du livre d'où provient chaque photo.

${ }^{2}$ Le CD-ROM du Petit Robert version électronique 2.1, 2001.

${ }^{3}$ CAMELIN, Colette, « Approches de la lumière : Einstein et Gaspar », in Lorand Gaspar, (2004) p. 197 209.

${ }^{4}$ Ibid., p. 204.

${ }^{5}$ «Entretien sur la photographie », Op. cit., p. 162.
} 
La lumière incarne aussi ce qui est immanent au monde. La même lumière nous éclaire depuis la naissance du monde, une lumière qui est comme éternelle, source de la vie (« les plantes/ seuls êtres directement bran-/ché sur l'énergie solaire, .../ ... sans elles point de / vie animale - $\$ S A, 122$ ) et de manière métaphorique elle est la lumière qui éclaire nos pensées.

Or cette lumière à double essence est associée dans la poésie au «bonheur de l'instant où la lumière de l'aube comme un commencement absolu vient purifier le monde ${ }^{6} \gg$. L'aube est réellement et de manière métaphorique le passage de l'obscurité à la lumière, où les objets dont nous ne percevions qu'un contour flou prennent forme. Cette expérience du passage à la clarté revient constamment chez Gaspar :

Cinq heures du matin. Là où tout à l'heure il n'y avait encore que des flaques d'un gris vaseux entre les pins plus sombres au bout du jardin, une luisance vert et or, intense et corrosive, allumée, on dirait, dans les pierres et les rares buissons, augmente rapidement dans la pâte obscure. Passage entre matière et lumière. Lumière des corps et de la pensée. Présence simultanée, plus que passage, dans une réalité qui leur est commune. $(C J, 9)$

Ou encore :

Il faut se lever avant l'aube pour entendre, comme un bruit d'eau souterraine, la lumière remonter dans les fûts des colonnes. Sentir, à cette heure, le parfum du rien sur les pierres rongées, si incroyablement allégées par la respiration du vide. ${ }^{7}$

Gaspar, s'inspirant de la philosophie de Spinoza et de sa propre expérience de chirurgien, ne fait pas la différence entre l'esprit et le corps. La lumière du matin «lumière de corps et de pensée » est la source du poème comme la source de la photographie.

Chaque matin d'un bond

Le soleil prend pied dans mon visage.

Je m'empare de cette brûlure comme d'un gouvernail

Le matin devient l'heure de la création poétique, c'est l'heure de «préparer un café et s'adonner au vice impuni de la lecture ou de quelque griffonnage, protégé par une grande nappe de silence - et de fraîcheur en été » $(C J, 9)$. Il est intéressant de noter l'analogie avec la photographie qui préfère la lumière du matin et du soir, plus susceptible de rendre la forme des objets, offrant des ombres douces, tandis que la lumière de midi donne des ombres aiguës et tranchantes. La quête de la clarté entreprise

\footnotetext{
${ }^{6}$ ALLAIRE, Suzanne, « Poésie et lumière », in Lorand Gaspar, (2004), p. 246.

${ }^{7}$ GASPAR, Lorand, Feuilles d'observation, Paris, Gallimard, 1986, p. 85. Par la suite nous utiliserons l'abréviation : $F O$.
} 
dans la poésie se poursuit d'ailleurs dans l'expérience photographique : «Je crois qu'il y a une sorte de photographie qui cherche, qui voudrait apporter une lueur de compréhension dans nos obscurités - or, toute compréhension nous aide à vivre, est joie $^{8} \gg$. Le passage à la clarté est comparé dans le Carnet de Patmos au développement de la photo, à la phase «magique » quand on plonge le papier blanc dans un révélateur, un mélange de produits chimiques, et apparaissent lentement les formes en noir :

\begin{abstract}
J'attends l'aube. J'attends que le village «d'en haut », Khora, doucement se « développe » dans la fenêtre de ma chambre noire. Un noir positif, intense, pénétrant, omniprésent. Il ne s'agit pas d'un manque, d'une absence, non, le corps entier le palpe ; les organes, leurs fluides chimie, la pensée s'y meuvent comme dans une eau profonde - je sens leurs coups de nageoires -, effleurent en passant une lampe lointaine, un clignotement, des mondes. $(C P, 37)$
\end{abstract}

Cependant la lumière «n'est plus ce milieu immatériel, idéel et transparent où les choses viennent manifester l'éclat et l'évidence de leur essence immuable, mais un tissu d'une matérialité subtile, opacité poreuse d'une fluidité toute palpable ${ }^{9} »$, comme le montre Jean-Pol Madou, dans son analyse La chaire, mise en abîme de la lumière. Paradoxalement la lumière ne donne pas à voir, mais plutôt à toucher, à palper, elle est l'objet d'une quête. La poésie est ainsi définie comme une quête de la clarté :

Ce que cherche ma parole sans cesse interrompue, sans cesse insuffisante, inadéquate, hors d'haleine, n'est pas la pertinence d'une démonstration, d'une loi, mais la dénudation d'une lueur imprenable, transfixiante, d'une fluidité tour à tour bénéfique et ravageante. Une respiration .

Classer, isoler, fixer; ces exercices menés à leur somnolente utilité, nous voici mûrs pour l'insomnie de la genèse. ${ }^{10}$

Toutefois, selon Gaspar «Le poème n'est pas une réponse à une interrogation de l'homme ou du monde. Il ne fait que creuser, aggraver le questionnement » $(S A, 26)$. La quête d'un moment de lucidité et de joie doit être sans cesse répétée, reprise du rien, car «nos sens et notre pensée s'encombrent sans cesse de reflets, perdent cette fluidité vivace que nous appelons âme parfois » (Ibid.).

à chaque aube dans le granit du cœur

tu rapprends à bouger la lumière - $(S A, 79)$

Les oxymores fréquents dans la poésie de Gaspar (par exemple : «feu obscur », «nuit lumineuse », « face claire de la nuit ») représentent cette recherche à tâtonnements ${ }^{11}$, qui renoue avec le mythe du regard aveugle et de la cécité voyante ${ }^{12}$.

\footnotetext{
${ }^{8} \ll$ Entretien sur la photographie », p. 161.

9 MADOU, Jean-Pol, «La chair, mise en abîme de la lumière », in Transhumance et connaissance, (colloque organisé à Cerisy en 1994) textes réunis par Madeleine Renouard, Paris, Jean-Michel Place, 1995 , p. 54.

${ }^{10}$ GASPAR, Lorand, Approche de la parole, Paris, Gallimard, (1978) 2004, p. 24. Par la suite nous utiliserons l'abréviation : $A P$.
} 
La photographie doit faire face à la même impossibilité à capter le moment, car dès que l'on déclenche le sujet devient objet ${ }^{13}$, et il faut alors recommencer. Ce thème n'est pas développé chez Gaspar en rapport avec la photographie, mais il apparaît davantage chez Denis Roche, qui réclame «qu'on prenne de la photographie, qu'on en prenne tout le temps de manière répétitive, et que ce soit instantané ${ }^{14} »$.

Mais revenant à la lumière, celle du matin émerge surtout du paysage, du désert, de la mer et des murs blancs d'Égée comme sur la photo le paysage s'inscrit grâce à la lumière.

Ces lieux de connivence intime entre les hommes et une terre, un «paysage », entre l'action humaine et le mouvement des choses du monde [...] sont des foyers d'énergie et de clarté, à la manière des grandes compositions musicales qui nous « réordonnent », nous ressourcent, nous réconcilient corps et âme, nous réinsèrent dans la conscience d'une unité infiniment plus vaste. (CJ, 58-59).

Les thèmes photographiques de Gaspar se limitent d'ailleurs aux paysages. Même les gens photographiés se fondent dans le paysage, ils sont inséparables du monde, car une harmonie ancienne relie l'homme à la nature, un équilibre institué par la tradition.

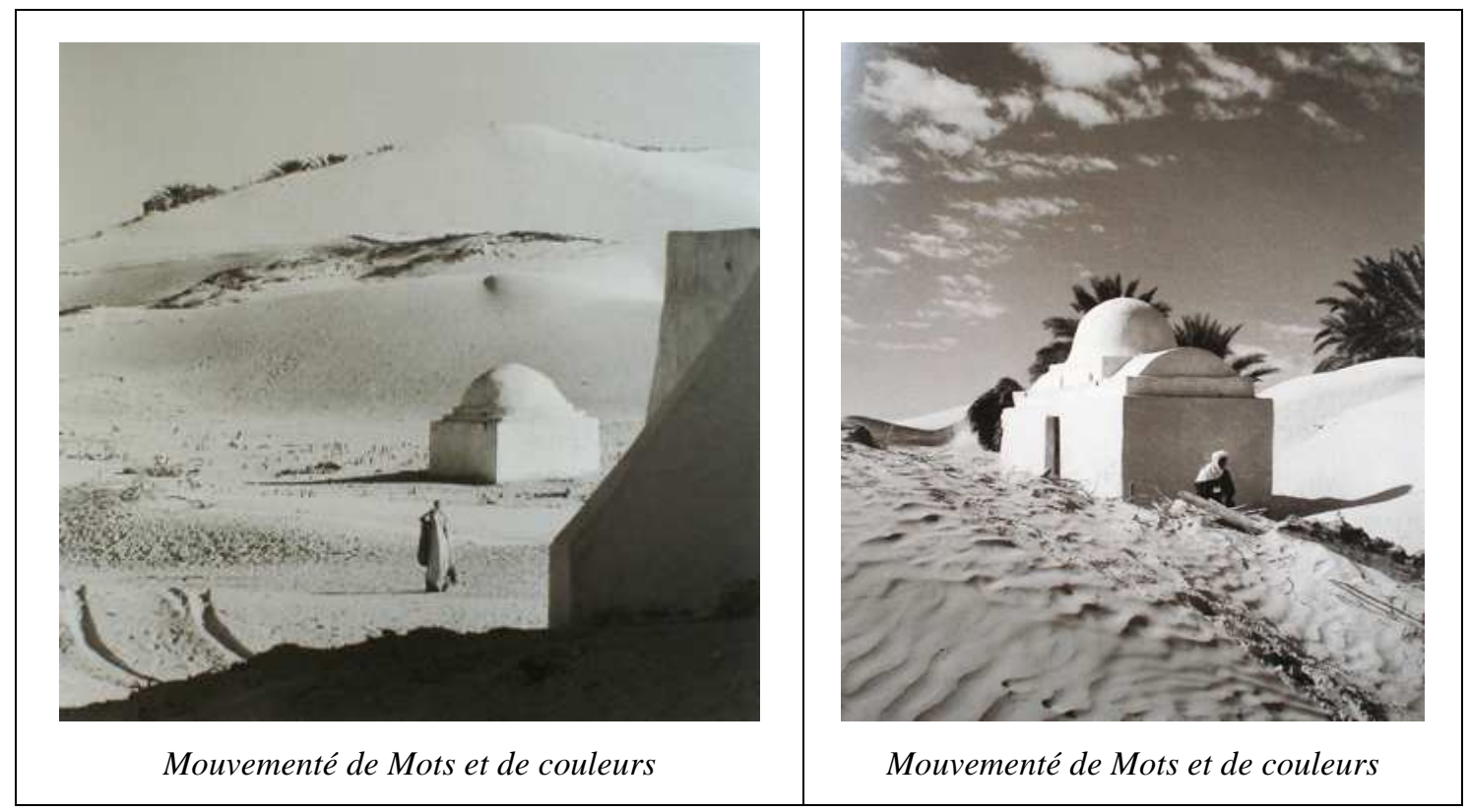

Selon Serge Canadas «tout désigne le paysage comme le lieu d'une articulation du regard, du corps, du monde et du langage. Le feu de l'esprit a percé les limites de ce que

\footnotetext{
${ }^{11}$ CANADAS, Serge, « Du paysage au poème », in Poétique et poésie, p. 419.

${ }^{12}$ VANHESE, «L'espace autobiographique dans l'œuvre de L. Gaspar », Op. cit., p. 157.

${ }^{13}$ BARTHES, Roland, La Chambre claire, Cahiers du cinéma, Paris, Gallimard, Le Seuil, 1980, p. 29.

${ }^{14}$ ROCHE, Denis, La disparition des lucioles, (réflexions sur l'acte photographique), Paris, Étoile, 1982, p. 72 .
} 
nous appelons espace, et de l'explosion résulte une énergie que l'âme recueille pour animer la création ${ }^{15} ~$. La photographie révèle cette rencontre du poète et de la lumière dans le paysage.

${ }^{15}$ CANADAS, « Du paysage au poème », Op. cit., p. 423. 


\section{VII.3. Parallèles photographiques : pierre, archéologie, érosion, langage, silence}

Parmi les photos de Gaspar se trouvent de nombreuses photos de pierres, des déserts de pierre ou des pierres blanches des murs de Patmos. Dans sa poésie, la pierre traduit le passage de la lumière dans la matière.

\section{NOUS FOUILLERONS LES PIERRES CLAIRES JUSQU'À L'EXTREME LIMITE DE L'OBSCUR}

La pierre renvoie aux fouilles archéologiques auxquelles Gaspar a assisté, mentionnées dans Carnets de Jérusalem. La pierre paraît elle aussi capter la lueur des temps anciens :

[...] pour nous limiter à ce qui a été bâti au cours d'une longue l'histoire, et dont il reste des traces concrètes, la pierre et la lumière communes mises à part, en effet, quelle incroyable diversité dans les éléments de cette composition! Se superposent, se côtoient, s’imbriquent partout des styles, des structures, témoignages de façons de vivre, de penser et de s'émouvoir d'époques différentes $(C J, 53)$.

Ou encore :

Silex

Comme une sombre et chaude origine dispersée désert de poème dans la lumière du soir mettant à nu dans l'œil la durée

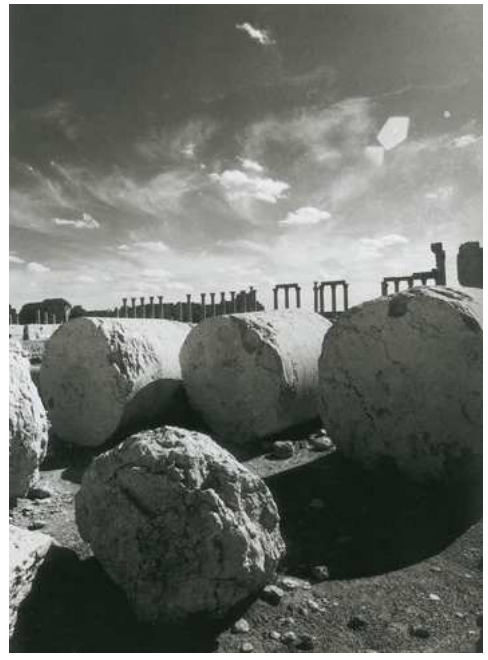

Lorand Gaspar, (2004)

Chez Gaspar la photographie, comme la pierre, véhiculent notre présence ou appartenance au monde et à la matière, en même temps qu'elles nous confrontent à l'écoulement du temps. Le poème évoque alors un souvenir d'enfance retrouvé :

Ces photos floues que le temps a bougées.

La lumière se cherche sur nos mains et soudain tout est plume neige neige $(S A, 67)$ 


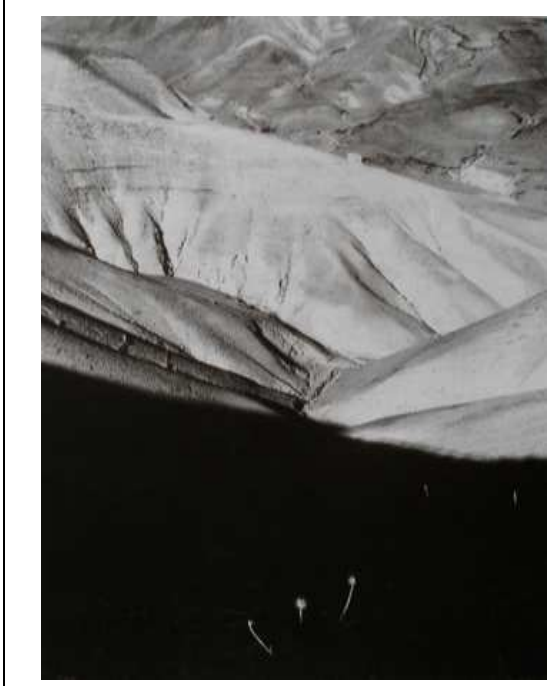

Lorand Gaspar, (1989)

La pierre, qui dans le désert semble être une matière dépourvue de toute vie organique, est paradoxalement porteuse de lumière. Les pierres travaillées par l'érosion deviennent sable et le sable « merveilleusement léger et polis / corps cristallins proches de la perfection » $(S A, 106)$ contient une microflore, un signe de vie, qui s'anime dès la première pluie. Ainsi se détache de la zone d'ombre grâce à un rayon de soleil la seule plante dans le paysage aride de la photo. Le règne minéral, comme le montre Jurí Pechar, associé au règne végétal peut devenir un lieu de résurrection de la vie ${ }^{1}$. L'érosion qui permet à la pierre de devenir sable et porteur de vie devient le symbole du travail poétique :

\title{
ÉROSION
}

\author{
travaux de même ardeur que \\ la cohérence de la matière \\ la langue aux rythmes innombrables \\ déployée effritée recomposée

Ou encore dans Approche de la parole :

Le texte poétique est le texte de la vie, travaillé par le rythme des éléments, construit, érodé par tout ce qui est ; fragmentaire, plein de lacunes, laissant apparaître dans les failles des signes plus anciens. Trame d'ardeur et de circulation : chacun peut $\mathrm{y}$ lire autre chose et aussi la même chose. $(A P, 29)$

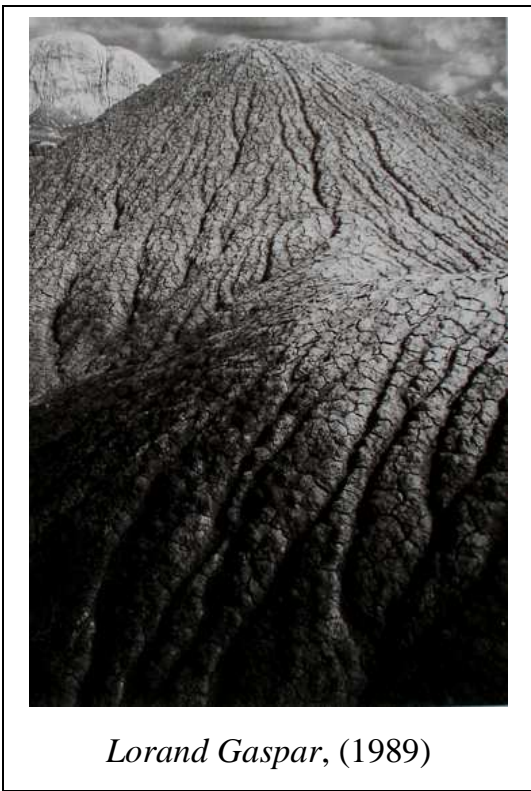

Le désert de sable malgré son vide apparent, est porteur de vie, et ce vide apparent, ce silence va devenir chez Gaspar figure de style, d'un côté le silence de l'ellipse («Travailler dans l'aigu, le serré/ cultiver l'ellipse » (SA, 124)) et de l'énumération; de l'autre côté le blanc qui délimite les vers, comme dans le poème intitulé « TERRE ET PEAU BRÛLEES » $(S A, 132)$ :

\footnotetext{
${ }^{1}$ PECHAR, Jĭrí, « Réflexions sur 1'articulation vie/désert », in Transhumance et connaissance, Op. cit., p. 22.
} 
espace d'un cri

entouré d'

espace

entouré de

rien

Le vide c'est aussi le «don de la lumière qui dénude, épure et laisse pressentir la force jaillissante du spirituel ${ }^{2} »$. C'est le blanc qui fait surgir la texture des idéogrammes dans Sol Absolu. Ainsi la lecture visuelle rapproche les poèmes des photographies de Gaspar. Certains idéogrammes imitent même des formes que l'on retrouve sur des photos, tel le poème « PENINSULE ARABIQUE $^{3} »(S A, 96)$ qui fait penser au jeu de lignes que dessine le sable ondulé sur une de ses photographies :

PÉNINSULE ARABIQUE

$$
\text { HEDJAZ }
$$

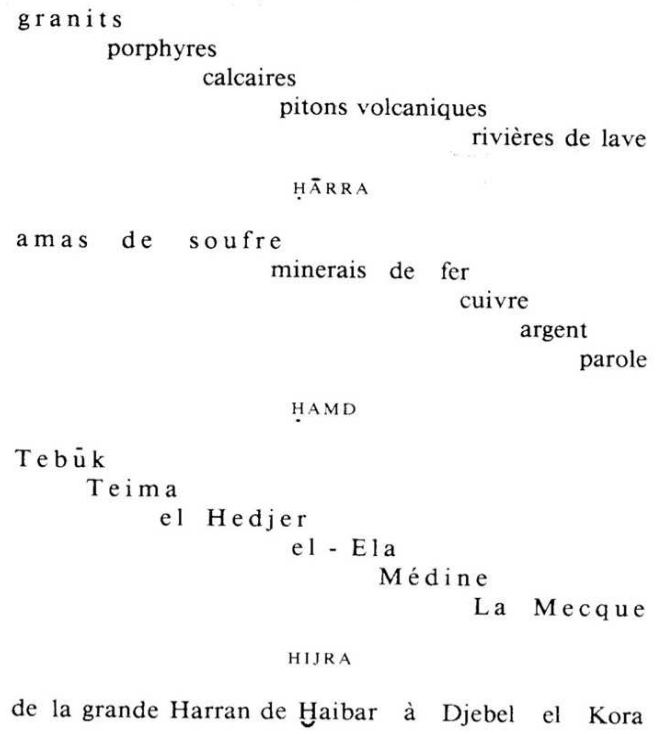

la familiarité du vide sous les noms disséminés

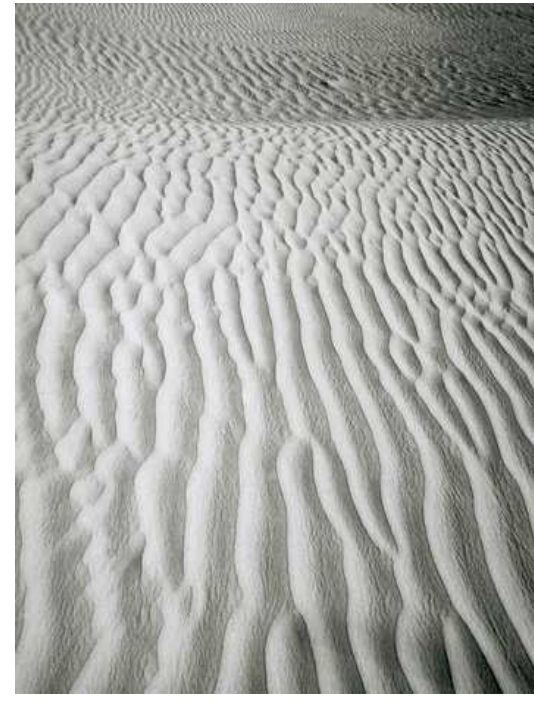

Lorand Gaspar, (2004)

\footnotetext{
${ }^{2}$ ALLAIRE, Suzanne, « Poésie et lumière », in Lorand Gaspar, (2004) p. 246.

${ }^{3}$ Pour reproduire exactement la disposition du poème, nous reproduisons une image scannée à partir du livre, de même que les photographies.
} 


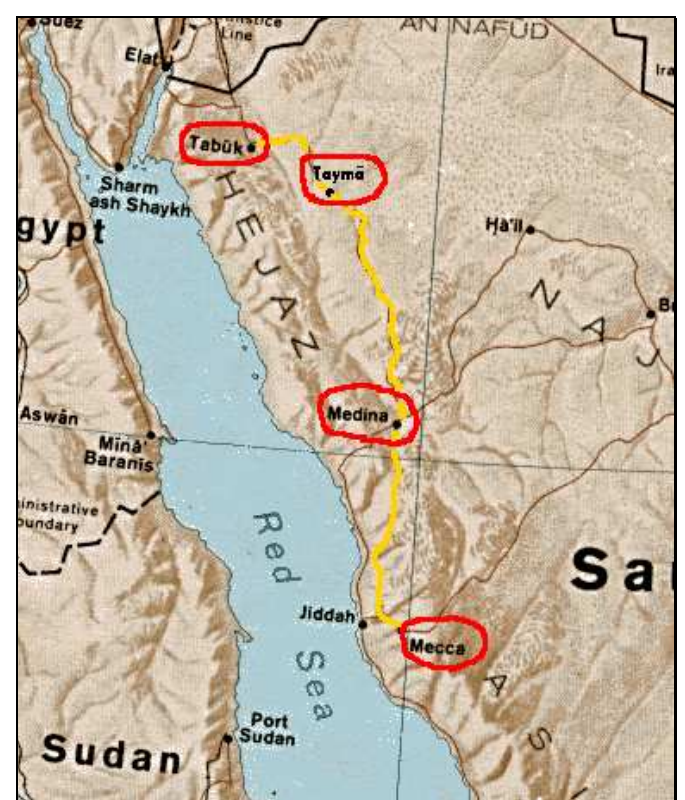

Mais les noms des villes du même poème dessinent également un itinéraire sur la carte ${ }^{4}$ de la péninsule arabique (il suffit de tourner la carte pour que les noms se présentent sur une ligne comme dans le poème), itinéraire qu'ont dû emprunter depuis des siècles les pèlerins allant à La Mecque et les caravaniers transportant leurs marchandises. Le poème traverse d'abord un paysage minéral en surface (granits, prophyres, etc.) pour plonger dans les richesses souterraines des mines (souffres, fer, cuivre, ...). Les noms «vides » en apparence

se peuplent ainsi de significations.

Le poème «SILEX » $(S A, 104)$ déjà cité, reprend, quand à lui, la forme en miroir d'une pierre photographiée :

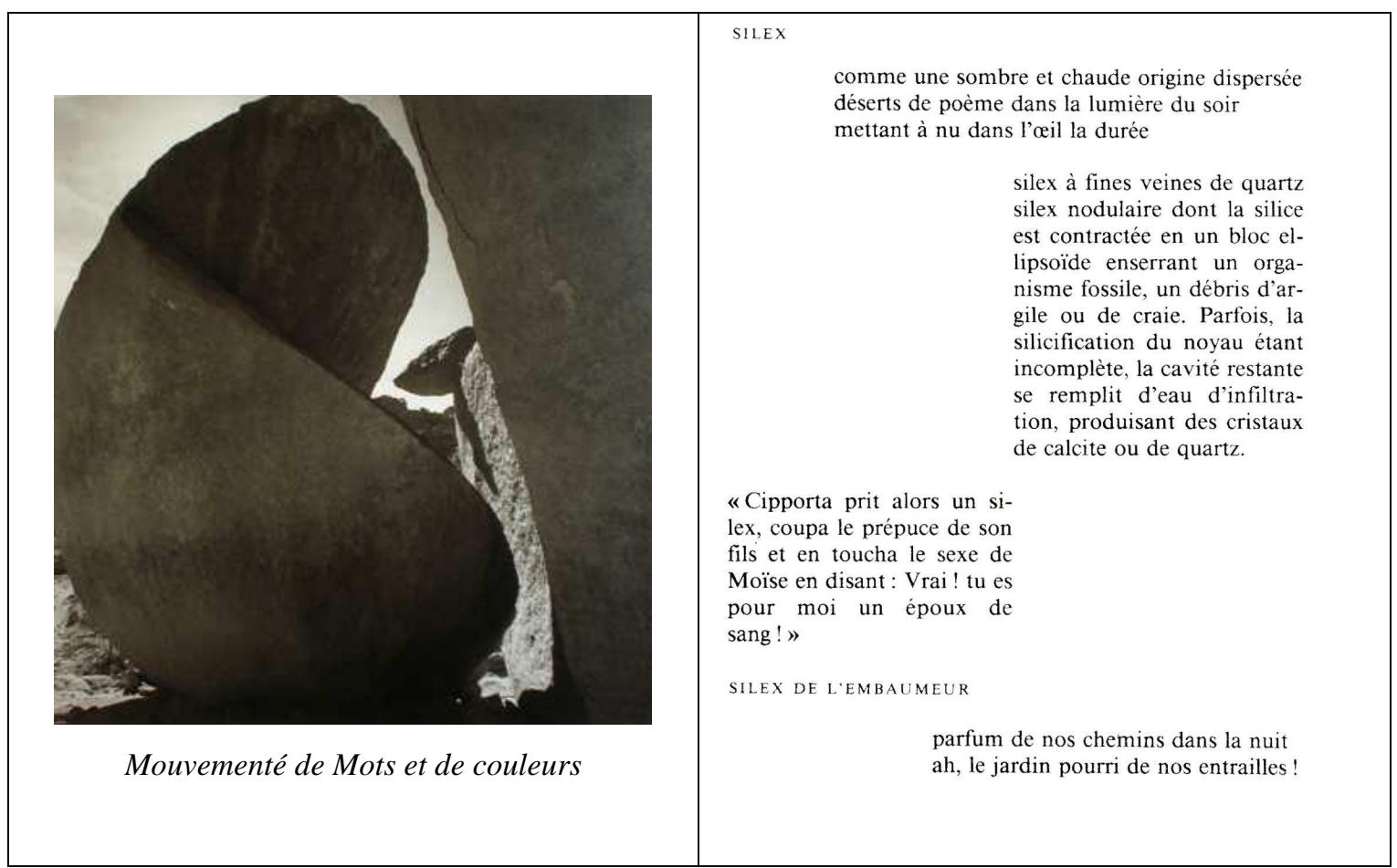

${ }^{4}$ Véronique Montémont signale également dans son analyse de la genèse des Carnets de Patmos, que le dossier comprend, en plus des différentes versions des chapitres des carnets, des cartes et des photocopies de documents que l'auteur a consulté, mais sans s'attarder sur la fonction de ces cartes géographiques. MONTEMONT, Véronique, «Lorand Gaspar : genèse des Carnets de Patmos », (mis en ligne le : 15 février 2007.) http://www.item.ens.fr/index.php?id=27103 (consulté le : 03/03/2008). 
Les blocs du poème limités par le blanc, comme les parties de la pierre taillées par l'érosion, témoignent de différents époques, mettent littéralement «à nu dans l'œil la durée »: d'un présent de l'énonciation, nous passons à l'énoncé scientifique «atemporel», puis à une citation de la Bible remontant ainsi aux origines, pour terminer par l'évocation de la mort.

Les photographies de Patmos cherchent elles aussi à accentuer le blanc, l'inscription de la lumière qui conduit les yeux à l'intérieur de la photo horizontalement de gauche à droite - constituant la ligne de force de la photo comme celle du poème.

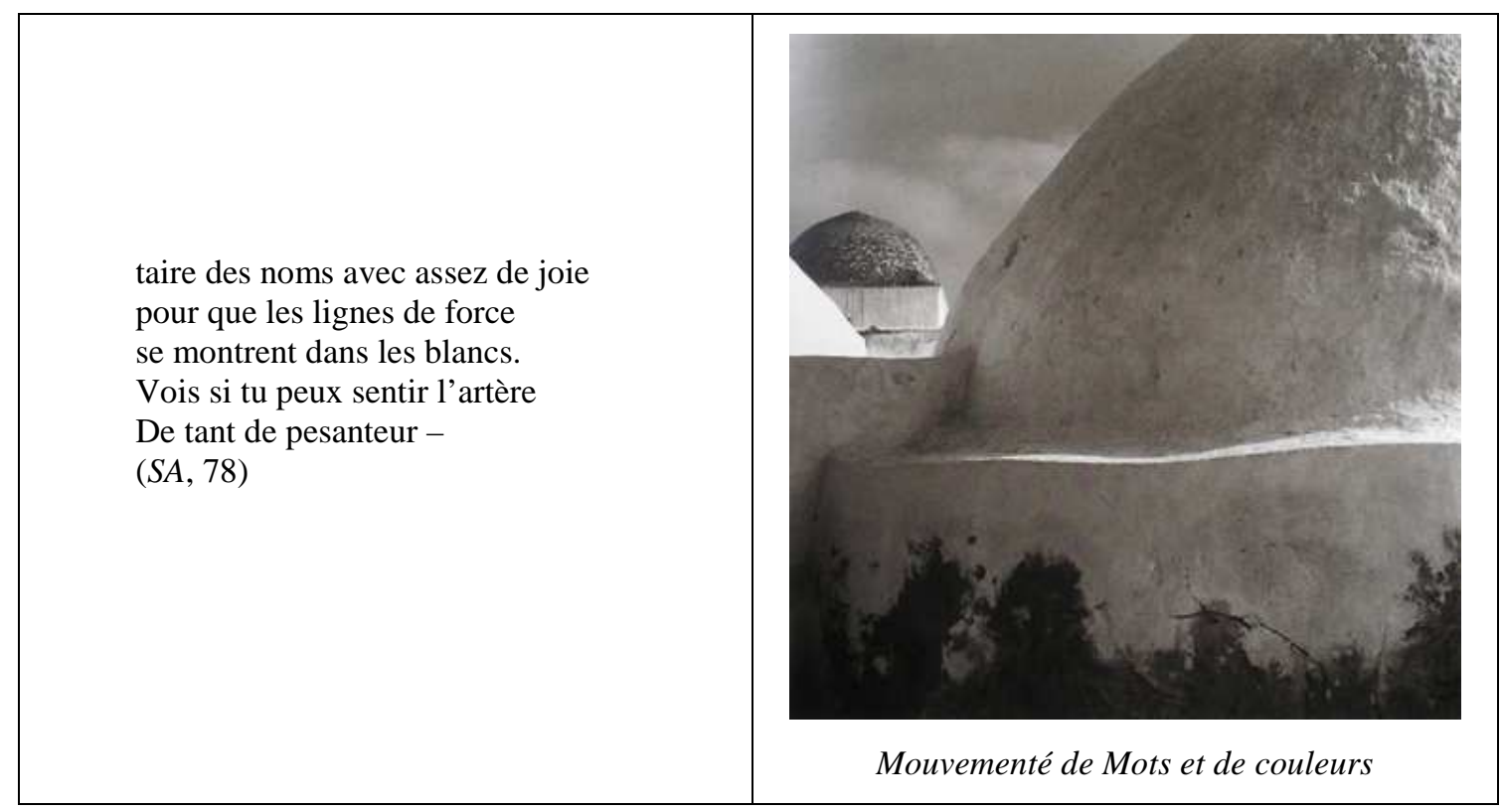

Selon Danièle Favriaud, l'emploi délibéré de la ponctuation noire et de la ponctuation blanche insère le corps, le rythme et l'infini du langage dans le texte poétiques. Cependant le blanc et le silence sont aussi « le non-dit poétique en puissance, comme la parole peut être un dit insuffisant ${ }^{6} \gg$.

Le noir et blanc acquièrent ainsi dans les photographies un sens symbolique, surtout dans les photos de Patmos, où le blanc et le noir se trouvent accentués par les filtres qui noircissent le ciel. Ce contraste renforcé métamorphose le bâtiment photographié (ci-dessous à droite) en pure forme, à la fois abstraite et concrète, l'apparentant à des signes calligraphiques sur la page.

\footnotetext{
5 FAVRIAUD, Michel, «La poétique de Lorand Gaspar»: entre ponctuation noire et ponctuation blanche, in Lorand Gaspar, (2004), p. 223-242.

${ }^{6}$ CONSTANDULAKI-CHANTZOU, Ioanna, «Silence et poésie », in Poétique et poésie, p. 246.
} 
Le noir et blanc deviennent le symbole du passage de la lumière dans les choses, symbole du silence et de la quête de clarté.

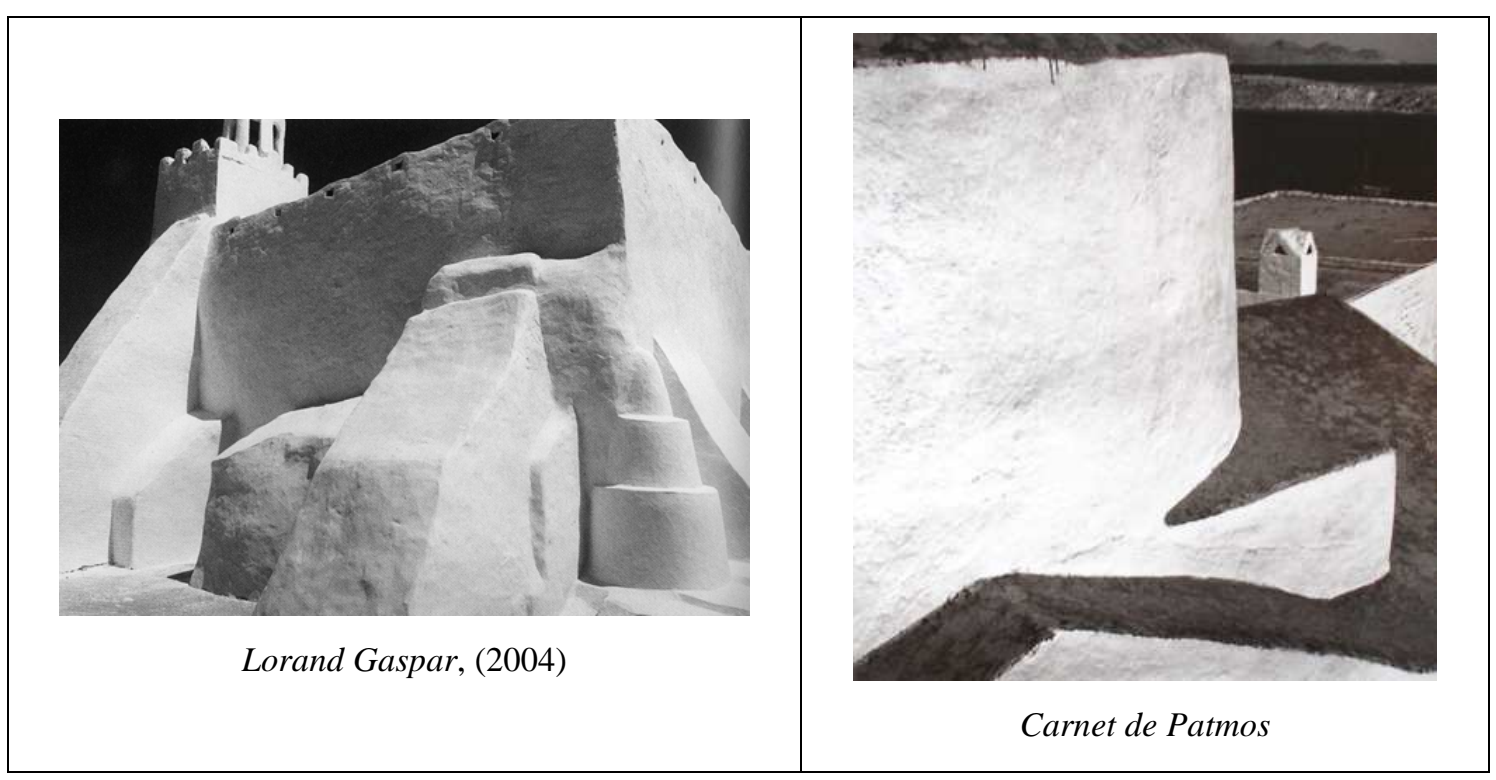

Les photographies de Lorand Gaspar semblent transmettre le silence profond du paysage et des êtres. On pourrait leur appliquer la formule antique de Sémonide à propos de la peinture : «La peinture est une poésie muette, tandis que la poésie est égale à une peinture parlante ${ }^{7} \gg$. Ce silence, renforcé par la volonté de ne pas donner de titres aux photographies, semble renouer comme les pierres avec le corps du monde.

Jour après jour, le mutisme patient de ces pierres, la pulsation silencieuse de ces images, comme une lumière d'étoiles lointaines, disparues, et si proches pourtant dans la perception d'un mouvement continu, dans tel trait, dans tel caillou, dans tel lézard ou insecte, dans tel lieu. Le vaet-vient constant du diaphragme de l'esprit entre l'infiniment ouvert et l'intimité du reclos, le sentiment d'une puissance infrangible, et le toucher des contours friables. Cette grande chose pulmonaire où les vents se dilatent et se resserrent. Pour rien.

Marcher contre ces angles, ces arêtes, dans la lumière tout à coup immobile. Marcher dans l'intensité toute interne de la terre. ${ }^{8}$

Les photographies sont des émanations du monde traversé par le corps du poète, comme la poésie. La photo veut saisir «ce monde qui nous apparaît fait de choses qui ne nous apparaissent point ». Elle veut montrer la «fêlure où dans un moment d'inattention le cristallin se glisse » ou encore «l'étonnant silence de l'incommencé ${ }^{9} »$.

\footnotetext{
${ }^{7}$ Cité par Ulrich WEISSTEIN dans son essai d'approche historique de la relation du texte à l'image : «Comparing Literature and Art », in Proceedings of the IXth Congress of International Comparative Literature Association, Innsbruck, 1979, p. 19.

${ }^{8}$ GASPAR, Lorand, Journaux de voyages, Paris, Le Calligraphe, 1985, p. 89. Par la suite nous utiliserons l'abréviation : $J V$.

${ }^{9}$ « Entretien sur la photographie », p. 161.
} 


\section{VII.4. Une approche spinoziste}

Lorand Gaspar s'affirme spinoziste, et les pensées de Spinoza traversent ses œuvres. Au cœur de son travail se situe comme dans l'Éthique l'idée d'une unité profonde du monde, où l'homme est en étroite correspondance analogique avec les choses, conception unitaire, «monisme semblant procéder d'un immanentisme inspiré de ce «deus sive natura » de l'Éthique ${ }^{1} »$ :

A chaque pas dans la nudité rigoureuse des courbes, à travers les variations infinies des rapports de la lumière, du regard, de tout le corps sensible et de la pensée, se dégage, se précise l'intuition d'une vérité, vécue, dans l'apprentissage que proposent à certains le désert, son mouvement et son immobilité, sa lumière et sa nuit. Intuition d'une continuité, la même dans le déploiement de la matière dite inerte ou vive et de la pensée. Un monde perçu dans son fond sans fond, débarrassé de toute superstructure, de tout ornement capable de distraire le regard et la réflexion. ${ }^{2}$

Ou encore :

Nous oublions que quoi que nous fassions, quoique nous pensions, sans en excepter nos haines ou nos destructions, nous restons des parties de la nature, des visages de son activité, des façons d'être de son énergie. $(F O, 24)$

Comme nous l'avons déjà mentionné, Gaspar s'inspirant de la philosophie de Spinoza et de sa propre expérience de chirurgien ne fait pas la différence entre le corps et l'esprit. Dans un article intitulé «Sciences, philosophie et arts », il souligne le fait Spinoza dès le XVII ${ }^{\mathrm{e}}$ siècle avait osé attribuer une puissance infinie à la Nature, dans la mesure où nous ne pouvons la concevoir qu'existante, c'est-à-dire sans cause extérieure et sans limitation d'aucune sorte :

[...] le nom toujours arbitraire, conventionnel que nous lui donnons (Nature, Cosmos ou Dieu) importe peu, du moment que nous la concevions comme immanente à cette existence sans bornes, inséparable de ce qu'elle produit depuis «toujours », «sans commencement ni fin $^{3}$ ».

Il importe de comprendre la place de l'image dans la pensée spinoziste pour comprendre la place réelle de la photographie dans l'œuvre de Lorand Gaspar. La conscience, selon Spinoza, est naturellement le lieu d'une illusion. Elle est de telle nature qu'elle recueille des effets, mais elle ignore les causes ${ }^{4}$.

\footnotetext{
${ }^{1}$ COMBE, Dominique, «Poétique et poésie », in Lorand Gaspar Transhumance et connaissance, p. 68. Nous recourons dans cette lecture comparative à des textes critiques plutôt qu'aux textes originaux de Spinoza, car ce sujet pourrait faire l'objet d'une thèse en soi.

${ }^{2}$ GASPAR Lorand, Approches d'un désert vivant, Villeneuve-lès-Avignon, encres de Claude Garanjoud, 1999, non paginé.

${ }^{3}$ GASPAR, Lorand, « Sciences, philosophie et arts » in Lorand Gaspar, (2004), p. 110.

${ }^{4}$ DELEUZE, Gilles, Spinoza Philosophie pratique, Paris, Minuit, 1981, p. 29.
} 
Nous sommes dans une telle situation que nous recueillons seulement «ce qui arrive » à notre corps, « ce qui arrive » à notre âme, c'est-à-dire l'effet d'un corps sur le nôtre, l'effet d'une idée sur la nôtre. Mais, ce qu'est notre corps sous son propre rapport, et notre âme sous son propre rapport, et les autres corps et les autres âmes ou idées sous leurs rapports respectifs, et les règles d'après lesquelles tous ces rapports se composent et se décomposent - tout cela, nous n'en savons rien dans l'ordre donné de notre connaissance et de notre conscience. ${ }^{5}$

En acceptant ce constat du caractère trompeur de la conscience, la question se pose de savoir comment éviter les illusions et former des idées adéquates des choses. Selon Deleuze, la réponse se trouve dans la forme même de L'Éthique, qui repose sur une affirmation spéculative ${ }^{6}$.

[...] l'idée de quelque chose qui convient avec nous, qui se compose avec nous, nous conduit à former l'idée adéquate de nous même. ${ }^{7}$

La rencontre est au cœur de sa réflexion, tout comme elle devient importante chez Gaspar - la bonne rencontre provoque de la joie et augmente la puissance d'agir, contrairement à la mauvaise rencontre, qui entraîne de la tristesse et diminue la puissance d'agir.

Sera dit bon (ou libre, ou raisonnable, ou fort) celui qui s'efforce, autant qu'il est en lui, d'organiser les rencontres, de s'unir à ce qui convient avec sa nature, de composer son rapport avec des rapport combinables, et, par là, d'augmenter sa puissance. Car la bonté est affaire de dynamisme, de puissance, et de composition de puissances. Sera dit mauvais, ou esclave, ou faible, ou insensé, celui qui vit au hasard des rencontres, se contente d'en subir les effets, quitte à gémir et à accuser chaque fois que l'effet subit se montre contraire et lui révèle sa propre impuissance. ${ }^{8}$

Spinoza utilise la métaphore du poison qui ne se compose pas avec le corps, mais le détruit, pour rendre explicite l'idée de la rencontre qui nous aveugle, figure à laquelle Lorand Gaspar fait également allusion.

Le soleil couché dans sa barque souterraine nos doigts aveugles cherchent les couleurs dans ta bouche des caillots de ténèbres dans ton ventre la douleur du venin savoir de ta vie si tu peux la comprendre -

Il est possible de tracer plusieurs parallèles entre les pensées de Baruch Spinoza et celles de Lorand Gaspar, mais ces pensées nous intéressent en ce qu'elles éclairent également le rôle de la photographie dans l'œuvre du poète.

La poésie et la photographie deviennent alors « un passage, une transhumance où la chair se fait esprit par la médiation du verbe qui est à la fois corps et pensée, et cela n'est possible que parce que les mêmes lois régissent les pensées et les choses, d'où l'importance de la référence à la pensée de Spinoza dont l'un des axes fondamentaux est l'affirmation d'un parallélisme entre le

\footnotetext{
${ }^{5}$ Ibid. p. 30.

${ }^{6}$ Ibid. p. 42.

${ }^{7}$ Ibid. p. 57.

${ }^{8}$ Ibid. p. 35.
} 
registre de l'espace et celui de la pensée, qui seul garantit l'authenticité et la réciprocité des liens entre le corps et l'esprit. ${ }^{9}$

${ }^{9}$ LEDOUX, Michel, «Lorand Gaspar, une rencontre », in Lorand Gaspar (2004), p. 34-35. 


\section{VII.5. Au-delà des apparences}

Une unité profonde rassemble la nature, le corps et l'esprit, mais qu'en est-il des images qu'élabore l'esprit? Lorenzo Vinciguerra dans son analyse traitant du rôle de l'image chez Spinoza, souligne que les images mentales sont comme des traces ou «impressions du corps ${ }^{1} »$.

L'image devient l'image de quelque chose, c'est-à-dire son idée signifie quelque chose, non en tant que pure impression ou sensation, car pour cela il aurait fallu au moins qu'elle ressemblât à son objet (ce que Spinoza exclut), mais grâce à l'enchaînement (concatenatio) avec d'autres images. $^{2}$

L’image, qu'elle soit mentale ou réelle, ne ressemble pas à l'objet perçu, elle constitue une trace de «lumière », une « rencontre » avec la chose, elle s'attache à une suite d'images et une suite d'expériences associées inconsciemment et inséparablement à elle.

La poésie gasparienne est très liée au regard, à la rencontre avec la lumière, à un émerveillement de voir, dans une unité soudain retrouvée au milieu du chaos des apparences. Selon Afifa Marzouki, la présence, l'appartenance au monde se révèle grâce aux yeux. Le regard est «le premier détecteur de la beauté immédiate et insoupçonnée qui nous entoure. [...] Regarder semble toujours susciter un état d'hébétude et de grâce qui, en ouvrant à l'intelligence du monde, ouvre à la création ${ }^{3}$ ».

Lorand Gaspar s'intéresse au fonctionnement de la vision, non seulement en tant que poète mais également du point de vue scientifique. Dans son entretient avec Georges Monti, il attire l'attention sur le fait que ce sont les «cônes » de notre rétine et les nombreuses aires visuelles du cerveau qui transforment la réalité physique telle que nous la percevons ${ }^{4}$. L'image qu'on voit est ainsi produite en deux temps. Dans une première phase, l'œil capte la lumière de manière semblable au procédé de la chambre noire 5 .

\footnotetext{
${ }^{1}$ VINCINGUERRA, Lorenzo, «Le sens de l'image », Magazine littéraire, $\mathrm{n}^{\circ}$ 370, novembre 1998, p. 45. ${ }^{2}$ Ibid., p. 46.

${ }^{3}$ MARZOUKI, Afifa, «Approche de la parole poétique de Lorand Gaspar », in Un poète près de la mer, p. 40.

${ }^{4}$ «Entretien sur la photographie », p. 162.

${ }^{5}$ Rappelons, que l'œil et la chambre noire, repose sur la loi physique de la lumière et que Gaspar avait étudié, selon Camelin Colette, les découvertes d'Einstein à ce propos. CAMELIN, Colette, « Approches de la lumière : Einstein et Gaspar », in Lorand Gaspar, (2004) p. 197-209.
} 
Sans cet organe subtil qu'est l'œil nous ne pouvons pas voir, car la première étape de la vision est liée à la capacité des cellules sensibles de notre rétine tapissant le fond de nos yeux, de capter des signaux électromagnétiques compris entre des limites précises, bien connues. $(A P, 302)$

Il remarque d'ailleurs que dans la science de la physique «les couleurs n'ont pas d'existence physique propre $^{6} »$, la lumière n'est qu'onde et photon. Du point de vue de la représentation «mimétique » du réel, le fait que les photos soient en noir et blanc ou en couleur serait insignifiant. Toutefois la prépondérance des photos en noir et blanc traduit un choix esthétique chez Lorand Gaspar.

Dans une deuxième phase, les aires visuelles du cerveau transforment les signaux captés par l'œil en image.

Après le travail déjà assez complexe des deux types de cellules de la rétine, ces informations sont transmises aux neurones corticaux des différentes aires visuelles de la face interne et externe du cortex occipital où elles sont soumises à un nouveau travail bien plus complexe. Ce que nos connaissances encore bien modeste face à la complexité prodigieuse de cet organe constitué de quelque cent milliards de cellules nerveuses organisées en ensembles richement interconnectés, nous apprennent d'essentiel, c'est que la vision est un processus actif. Nous sommes donc loin de la conception ancienne d'une vision mécanique qui photographierait (ou filmerait quand il s'agit de mouvement) ce qui occupe à chaque instant notre champ visuel changeant, suffisamment éclairé ; images qu'ensuite notre cerveau pragmatique, expérientiel viendrait analyser, interpréter, juger, mémoriser afin que nous soyons capables de reconnaître ce qui au sein de tout ce qui nous entoure nous est utile ou nocif, cause de plaisir ou de déplaisir [...] par rapport à des empreintes périnatales ou comparé aux divers modèles plus ou moins stable institués par les conditionnements de notre éducation et de nos apprentissages divers de la vie, capables aussi bien de nous ouvrir que de nous fermer. (AP, 302-303.)

Au-delà des fins biologiques d'une vision mécanique, Gaspar suppose que la vision peut être également créatrice, dans une certaine mesure :

Quoi qu'il en soit, notre cerveau fait un travail d'élaboration considérable à partir des informations spécifiques déjà nombreuses et subtiles qu'il est capable de relever, de distinguer. Il les structure, les compose, y fait un choix de certains attributs récurrents, relativement stables. Nous pourrions dire qu'il est à la recherche de l'essence, de la nature propre ${ }^{7}$, spécifique des choses vues et revues. La curiosité, la recherche et l'accueil de ce qui est nouveau n'est pas spécifique à la vision. Mais nous pouvons être plus ou moins ouverts dans tel ou tel domaine exploré par nos sens et pensée. (AP, 303. Nous soulignons.)

La vision serait alors naturellement conservatrice, chercher ait l'unité dans la diversité. Par cette distinction des deux étapes de la vision (œil-cerveau), on comprend la comparaison dans les poèmes de l'œil avec la chambre noire, qui dans un premier temps capte l'image sans interpréter, sans accéder à une signification, mais qui est de

\footnotetext{
${ }^{6}$ Ibid., p. 162.

${ }^{7}$ Cette faculté de la vision de rechercher l'essence, la nature propre des choses, est également à la base du langage. La communication n'est possible que grâce à notre capacité à regrouper sous des noms communs les choses désignées qui sont toujours uniques. Notons encore que le travail du cerveau, «structurant et composant » la vision, fait penser au travail du poète sur le langage.
} 
même matière et d'énergie que le monde vers lequel s'élance un mouvement dans la première pulsion qui anime le regard :

Oratoire dans la pierre lentement refroidie.

Dans le blanc de nos yeux la chambre noire

de toute sa chimie mordant les visages

si long fut le jour

de vents crayeux et d'ossements

la nuit tant de fois rompue

de gestes brefs qui se décolorent -

Ou encore :

les soleils du monde un paquet d'oursins dans la caverne encore fraîche de l'œil. ${ }^{8}$

Gaspar recourt donc à la physique de la lumière et à la neuroscience pour souligner la distance entre la réalité et la vision de l'objet. L'œil est semblable à la caverne de Platon, parce qu'il capte un monde qui « est très loin de ce qu'est cette "réalité" infiniment complexe ${ }^{9} »$; mais Gaspar ne fait pas pour autant allusion à un monde idéal, dont l'ombre ou le reflet perçu ne serait qu'une copie imparfaite.

La différence entre la réalité et la vision de l'objet se retrouve dans la distinction que le philosophe Henri Van Lier fait entre le réel et la réalité dans son livre sur la philosophie de la photographie :

La réalité désigne le réel en tant qu'il est déjà ressaisi et organisé dans des systèmes de signes, donc par des signaux intentionnels, conventionnels et systématiquement définis [...] Le réel, par contre, c'est ce qui échappe à la réalité ainsi comprise, tout ce qui est avant elle, après, en dessous, ce qui n'est pas encore apprivoisé dans nos relations techniques, scientifiques, sociales, ce que Sartre, par exemple, a appelé les quasi-relations de l'en-soi. ${ }^{10}$

Cependant chez Lorand Gaspar entre «l'ombre de la caverne » et le monde qui s'y reflète il se trouve bien une analogie grâce à l'unité profonde de la nature dans ses modulations infinies.

Ombres charnelles dans la forêt dépouillée des fûts, dans le trou humide de la caverne oculaire $\quad(E ́-J, 33)$

Une analogie non pas dans les apparences, mais dans la structure, le mouvement, dans la matière et la pensée.

${ }^{8}$ GASPAR, Lorand, Egée suivi de Judée, Paris, Gallimard, 1980, p. 14. Par la suite nous utiliserons l'abréviation : É-J.

9 «Entretien sur la photographie », p. 160.

${ }^{10}$ VAN LIER, Henri, Philosophie de la photographie, Paris - Bruxelles, Les Impressions Nouvelles, (1983) 2005, p. 42. 
C'est en vain que nous accusons de tromperie les apparences. Ce travail de nos yeux, de nos doigts, de nos cerveaux, de notre pensée qui produit l'univers des images et des idées, des plus simples aux plus chimériques, aux plus anti-images, est lié à des mouvements en nous qui existent réellement. Fragments et mélanges de fragments d'une vérité ou d'une réalité inaccessibles. $(F O, 24)$

L'accent est ainsi mis sur la relativité de nos sens, leur aptitude à confondre les apparences avec la réalité. «Le monde que construisent mes sens, mon cerveau et mon intelligence, est relatif à nos sens, à cette intelligence et aux connaissances limitées d'une époque historique ${ }^{11}$. » L'objectif de la photographie est alors de communiquer «les images captées par le cerveau et les techniques photographiques... que ce même cerveau a inventées », des images qui naissent de «la rencontre des "choses" et d'une lumière ${ }^{12} »$.

La deuxième phase de la vision relie les images entre elles dans un réseau d'images, de pensées et de sensations. Selon Michel Ledoux, les expériences les plus récentes en neuroscience semblent confirmer cette position. Il explique le fonctionnement du processus de la perception de la manière suivante :

[...] lorsque le nouveau-né ouvre pour la première fois ses yeux, il se trouve en face d'un ensemble de formes et de taches colorées sans signification pour lui. Aucun objet n'est isolé parce que non intégré dans un ensemble d'associations signifiantes. Mais peu à peu et par le jeu de ses expériences successives, tel objet va se trouver lié à d'autres cartes perceptives : cette chaise, par exemple, au geste de s'asseoir, de se reposer; la table aux aliments qui y seront déposés ou à la feuille de papier sur laquelle on va se mettre à écrire. Lorsque la table et la chaise seront de nouveau aperçues, les associations réentrantes les isoleront dans l'ensemble du champ visuel, elle deviendront des objets et s'enrichiront d'un certain nombre de significations qu'un mot plus tard rassemblera. ${ }^{13}$

Il s'ensuit que les images et les mots entretiennent dans la langue des liens beaucoup plus complexes qu'un simple rapport référentiel. L'unité mot-objet se transforme continuellement au fil de nos expériences et des réseaux de significations que nous créons, réseaux dont les éléments ne s'activent pas nécessairement et toujours de la même manière quand l'objet entre dans le champ de notre vision. Lorand Gaspar fait allusion à la relation que les mots et les images entretiennent avec la réalité :

Mots et images,

Idées de mots et d'images,

Se composent, s'articulent, se dénouent,

Molécules vivantes de la vie

Réseau mobile de cris, lueurs,

\footnotetext{
${ }^{11}$ «Entretien sur la photographie », p. 160.

${ }^{12}$ Ibid.

${ }^{13}$ LEDOUX, Michel, «La création, de Spinoza aux neurosciences », Europe, n 918 , octobre 2005, p. 127.
} 
De nœuds d'énergie

D'un flux continu

Que ne peuvent figurer les images

Que ne peut imaginer le cerveau

Ni même la vitesse des rayons

Croisés de milliards de neurones

Ou les lavis de vols d'hirondelles

Pourtant, quelque part

C'est la même chose -

$(A P, 196)$

La représentation poétique s'articulera alors autour de la recherche de cette unité, audelà des apparences, d'un rapport référentiel et d'un sens intelligible. 


\section{VII.6. La représentation vivante}

Maxime del Fiol s'interroge sur le fonctionnement des images dans l'œuvre de Gaspar. Selon lui :

L'œuvre d'art s'établit donc dans l'immanence philosophique d'une ontologie matérialiste du vivant comme le mouvement de la réalité du monde et comme l'œuvre de ce mouvement, et la création poétique [...] peut se rêver chez Lorand Gaspar comme un effacement de la médiation représentative, où le poème se donnerait à lire comme l'inscription immédiate et vivante du monde sur la page, comme la page vivante du monde, dans une transparence en mouvement entre le monde, le sujet et le langage : ainsi la poésie, «devenir nu du vivant ${ }^{1}$ », figurerait moins le monde qu'elle n'en serait la figure même. ${ }^{2}$

Cet effacement de la médiation représentative, selon l'analyse de Fiol, passe par le sens sensible plutôt que le sens intelligible. Au déploiement du sens sensible participent la musicalité du poème, le rythme, le devenir visuel du poème avec l'accentuation des blancs ou la disposition des vers dans les idéogrammes, mais également les images mentales que suscite le poème chez les lecteurs.

Fiol fait la distinction, à la suite de Paul Ricœur³, entre l'image, «moment non verbal d'un fait verbal, [...] la forme sensible prise par le sens dans une élaboration mentale figurative ${ }^{4} »$, et le concept, «le ressaisissement sémique du sens par luimême ${ }^{5}$ », ou en d'autres termes la distinction entre l'imagination et l'intelligible. Puis il établit la différence entre trois sous-catégories d'images mentales du point de vue du référent: l'image référentielle qui renvoie à un objet réel; l'image référentielle qui renvoie à un objet imaginaire « où la conscience reconnaît l'existence purement mentale de son objet ${ }^{6} »$, et la référence métaphorique ou littéraire qui «affirme que la position d'existence de son objet n'est ni entièrement réelle, ni entièrement imaginaire, mais qu'elle est inscrite dans le paradoxe d'un "est" et d'un "n'est pas" simultané7 ».

L'image référentielle, dans cette poésie qui parle du monde, qui représente le monde, et ne cesse de confronter le poème à l'expérience vécue, dérive majoritairement d'une représentation visuelle et se donne comme la transcription littérale - par une prédication littérale - de l'image perçue dans

\footnotetext{
${ }^{1}$ Cité par Maxime del Fiol de : GASPAR, Lorand, Sentes, Tunis, Société tunisienne des arts graphiques, 1979, p. 23.

${ }^{2}$ FIOL, Maxim Del, «Sens vivant de l'image », in Un poète près de la mer, (Textes réunis par Maxime Del Fiol et Moncef Khémiri), Tunis, Sud, 2004, p. 84.

${ }^{3}$ RICEEUR, Paul, La métaphore vive, Paris, Le Seuil, Point essais, 1975.

${ }^{4}$ FIOL, Maxim Del, «Sens vivant de l'image », Op. cit., p. 93.

${ }^{5}$ Ibid.

${ }^{6}$ Ibid. p. 95.

${ }^{7}$ Ibid. p. 96.
} 
l'expérience fondamentale du regard, qui surdétermine l'inscription sensible du sujet dans le monde. ${ }^{8}$

L'apparition des images mentales, suivant les réflexions de Fiol, préserve « la fluidité et la vérité référentielle du flux imaginal perceptif en réglant l'organisation des images du poème sur l'enchaînement des images perçues ${ }^{9} »$, l'enchaînement se fait par juxtaposition, superposition et contiguïté qui caractérisent l'exercice réel du regard et qui « entraîne[nt] irrémédiablement les images dans le mouvement du monde ${ }^{10}$ ».

Dans un deuxième temps, Maxime del Fiol examine l'image métaphorique dans laquelle le mouvement s'inscrit grâce au paradoxe d'un «sens littéral impossible et un sens métaphorique incertain, flottant, et qui porte en lui l'instabilité dynamique d'une orientation $^{11} »$.

La métaphore [fait] advenir le mouvement du monde au langage dans une tension de la signification qui lui permet de dire le mouvement en tant qu'il est porté au langage, mais en restant dans le vacillement ontologique d'un moment heuristique où «l'expérience de réalité » n'est pas encore « d'une certaine façon la vérité ». ${ }^{12}$

Le vacillement ontologique de l'image, en accord avec le sensible qui se déploie en dehors de l'imaginaire du poème (le rythme, la musicalité, la structure du poème) donne un sentiment d'ouverture et de mouvement vers le dehors, poussant à surmonter les apparences et à aller au-delà.

Fiol ne donne pas d'exemple dans son article, sauf la première strophe du premier poème de Patmos (mais sans l'analyser en détail) :

\author{
Dans la ruelle pavée de mer \\ trois vieilles vêtues de noir \\ éclairées du blanc d'un mur \\ accueillent la nuit
}

Dans cette strophe nous retrouvons essentiellement des images référentielles, chaque vers offrant une image transformée à son tour par l'image du vers suivant, jusqu'à devenir son négatif.

Il y a bien un mouvement «visuel » à l'intérieur du poème, un changement de ton dans les couleurs : de la ruelle paisible baignée par le bleu de la mer on passe au

\footnotetext{
${ }^{8}$ Ibid. p. 98.

${ }^{9}$ Ibid. p. 99.

${ }^{10}$ Ibid.

${ }^{11}$ Ibid. p. 100.

${ }^{12}$ Ibid. p. 102. (Fiol pour les parties en parenthèse cite P. Ricœur La métaphore vive, p. 310.)
} 
noir des vieilles femmes, sublimé ensuite dans le blanc du mur, lequel devient à son tour un blanc relatif, une lueur à peine perceptible, apaisée par le noir qui l'entoure.

Les strophes suivantes (que Fiol ne cite pas) transforment cependant ce déploiement d'images référentielles en images métaphoriques :

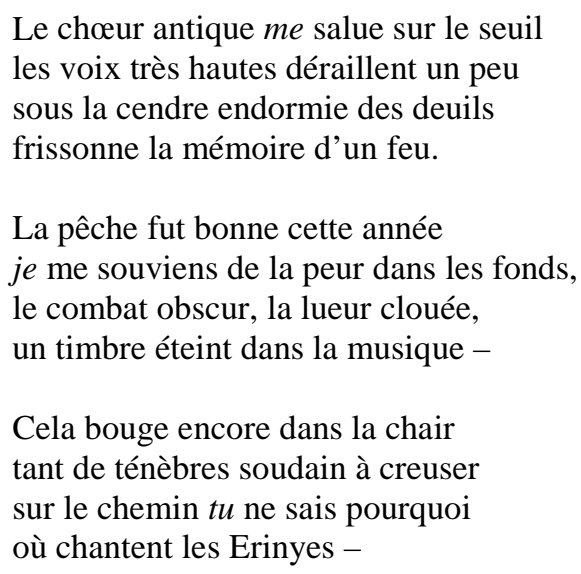

\section{$(P, 9$. Nous soulignons $)$}

Les vieilles en deuil se métamorphosent en membres d'un chœur antique, apparition qui associe soudain le temps de l'Antiquité au présent. Le temps semble être éternel dans le combat contre les ténèbres ou apparences à creuser, à élucider, c'est un sentiment, comme inscrit dans la chair, d'être touché, cloué, mais sans comprendre, une signification incertaine, une affirmation spéculative.

L'image qui se donne à voir dans la rue, sur le seuil d'une maison, est prolongée par l'imagination, on entre dans la mémoire des vieilles en deuil, leurs préoccupations de tous les jours - «la pêche fut bonne cette année »-, puis dans la chair des poissons « la peur dans les fonds, / le combat obscur »; mémoire et imagination qui sont à la fois celles du sujet double ${ }^{13}$, et celles des vieilles femmes, inséparablement liées à un lieu géographique, et aux réminiscences mythologiques (le chant des Erinyes) qu'éveille ce lieu particulier.

Ce déplacement extérieur - intérieur, visible - invisible, vision - imagination, se trouve explicité dans le poème suivant de Sol Absolu (pour ne citer qu'un exemple) par la répétition de deux vers qui donnent le cadre, sorte d'oxymore visuel :

\footnotetext{
${ }^{13}$ Le « je » de l'énonciation est souvent interpellé par un «tu » dans les poèmes de Gaspar.
} 
Le port est repeint de noir

il y a deux ou trois bateaux très blancs

où manque la nuit -

fenêtres où rêvent

des îles enfouies dans les yeux.

O tant de nuit mangée à blanc nous avions aussi un destin de fenêtre où quelqu'un a crié de joie le silence le port au soir deux ou trois bateaux très blancs où manque la nuit -

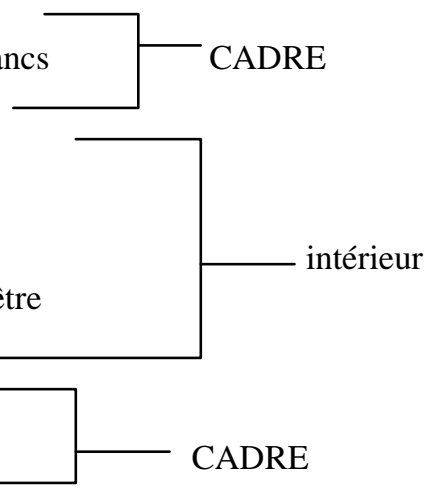

$(S A, 46)$

Il semble alors, contrairement aux propos de Maxime del Fiol, que le sens sensible et le sens intelligible ne devraient pas être nettement dissociés, tout comme l'image référentielle ne peut nettement se distinguer de l'image métaphorique; elles sont imbriquées l'une dans l'autre, dans le réseau de souvenirs qui les motive, et se présentent dans un mouvement de va-et-vient, où le lecteur se trouve à son tour impliqué. 


\section{VII.7. Idéogrammes}

Dans le chapitre Parallèles photographiques, nous avons déjà analysé quelques poèmes idéogrammatiques et la signification du «blanc» qui délimite et structure les vers, lumière immanente qui s'inscrit dans la photo et le poème, qui transporte le regard vers le sens sensible. Nous nous attarderons toutefois encore un peu sur les structures des poèmes idéogrammatiques publiés dans Sol Absolu, pour comprendre le sens visuel qu'offrent les poèmes, puis, à leur tour, les photographies. Lorand Gaspar est influencé par l'art chinois, ce que prouve sa collaboration avec plusieurs peintres chinois qui ont illustré ses poèmes (Zao Wou-Ki, T'ang), ou son article sur la conception de l'art en Chine ${ }^{1}$.

Rappelons que le terme idéogramme désigne des signes représentants un mot en eux-mêmes, des signes uniques et complets, mais en même temps abstraits, comme on en trouve dans l'écriture chinoise ou japonaise. Le rapport avec les choses représentées n'est pas arbitraire, mais graphiquement motivé. Ses mécanismes de juxtaposition font de chaque idéogramme composé une petite métaphore aux yeux du lecteur². Un des grands enjeux de la poésie occidentale du $\mathrm{XX}^{\mathrm{e}}$ siècle sera d'essayer de renouer avec les origines de l'écriture (entre autres sur le modèle de l'écriture chinoise ${ }^{3}$ ), d'être à la fois corps et esprit, une corporalité retranscrite par le geste. Du Coup de dés de Mallarmé à

\footnotetext{
${ }^{1}$ GASPAR, Lorand, «De la poétique de Saint-John Perse. De la conception de l'art en Chine ancienne. Rapport imaginés - », Bulletin de la société Paul Claudel, $\mathrm{N}^{\circ}$ 87, $3^{\mathrm{e}}$ trimestre, 1982, p. 5-16. Dans l'article il s'agit de montrer par une analyse, qui s'attarde sur le développement historique du taoïsme, la résonance profonde entre la conception chinoise de la nature et la poétique de Saint-John Perse, une influence non directement visible dans les poèmes mais dans leur visée, comme si le poète appartenait à la même « famille d'esprit », ce qui rapproche en fin de compte également Lorand Gaspar de l'art chinois. ${ }^{2}$ Nous reprenons ces propos sur l'idéogramme chinois, car c'est dans ce sens qu'il a influencé la poésie visuelle occidentale, mais les recherches de nos jours démontrent que l'écriture chinoise est davantage une écriture transcrivant des morphèmes et de fait n'est pas tout à fait dissociée de sa prononciation phonétique. Au cours de son histoire, elle a également évalué vers une écriture plus abstraite. L'adoption du terme logogramme reflète ce changement dans la théorie de l'écriture. Nous retrouvons néanmoins des tableaux de comparaison très parlants montrant comment certains caractères ont conservé l'idée qu'ils représentent visuellement (par exemple sur Wikipedia) : http://en.wikipedia.org/wiki/Chinese_character (consulté le : 24/10/2008).

${ }^{3}$ La description que propose Henri Michaux sur les idéogrammes chinois renoue avec ce mythe (MICHAUX, Henri, Idéogrammes en Chine, Fata Morgana, 1975), mais ses dessins à l'encre ou les logogrammes de Christian Dotremont sont autant d'exemple de l'influence de la calligraphie sur la poésie. DOTREMONT, Christian, Des logogrammes, Rennes, Ubacs, 1991. Voir également quelques images sur un blog : http://crab.wordpress.com/2008/07/02/free-writing/ (consulté le : 10/10/2009).
} 
la poésie concrète, on constate une montée de l'influence de la matérialité de l'œuvre poétique, essayant de contenir tout ce que le langage ne peut pas contenir ${ }^{4}$.

Les poèmes idéogrammatiques de Lorand Gaspar dans Sol absolu s'inscrivent ainsi dans la lignée de poètes recherchant les possibilités visuelles du langage pour s'exprimer. Cependant l'interprétation des poèmes de Lorand Gaspar pose problème, car le sens de leur disposition spatiale reste mystérieux. Comme le note Roger Little, dans la plupart des cas, plusieurs interprétations sont possibles 5 .

Les critiques ont interprété par

PIERRE

PIERRE

exemple le poème ci-contre de

encore une

manières très diverses : bucrane

PIERRE

pictographique à l'orée du désert,

sable

gamma radiographique du vide,

illimité

trépied de four ou de support

RIEN

sacrificiel... ${ }^{6}$

Cette signification visuelle mystérieuse rappelle que l'interprétation de la photographie elle aussi reste mystérieuse et silencieuse. La disposition du poème est-elle le signe de son insuffisance à figurer le monde ? ou plutôt le signe que sa signification passe par une quête et un apprentissage?

Selon Jean-Yves Debreuille la disposition des idéogrammes de Gaspar a pour fonction de faire suivre un cheminement :

On le constate, les mots eux-mêmes se déplacent dans la page, s'espacent, filent vers les marges, s'avancent en colonnes, se déclinent en gradins. Les caractères varient: capitales, italiques, alphabet arabe même. Tout est invitation au parcours et à la surprise, et en même temps témoigne d'une architecture rigoureuse mais mystérieuse. ${ }^{7}$

Pour Roger Little, les blancs qui délimitent les vers traduisent le souffle vital qui nous traverse, nous soulève et nous dépasse ${ }^{8}$. L'espacement du mot « respiration », dans le poème ci-dessous, comme un système de capillaires aspire le blanc de la page.

\footnotetext{
4 Sur l'évolution de la poésie concrète du $\mathrm{XX}^{\text {ème }}$ siècle voir le résumé de Didier Moulinier: http://www.la-poesie-elementaire.net/poetique/poetique_poesie-visuelle.htm (consulté le : 20/10/2008) ; ainsi que : MAUNET, Isabelle, La Poésie à la lettre et à la question : Du coup de dés aux poésies concrète et visuelle, thèse soutenue en 2000 à l'Université François Rabelais (Tours) sous la dir. de JeanClaude Lieber.

${ }^{5}$ LITLLE, Roger, « Représentation et imaginaire de l'espace », in Transhumance et connaissance, p. 123.

${ }^{6}$ Ibid.

${ }^{7}$ DEBREUILLE, Jean-Yves, Lorand Gaspar, Seghers, Paris, 2007, p. 40.

${ }^{8}$ LITTLE, Roger, «Respirations de Lorand Gaspar », in Poétique et poésie, p. 145.
} 


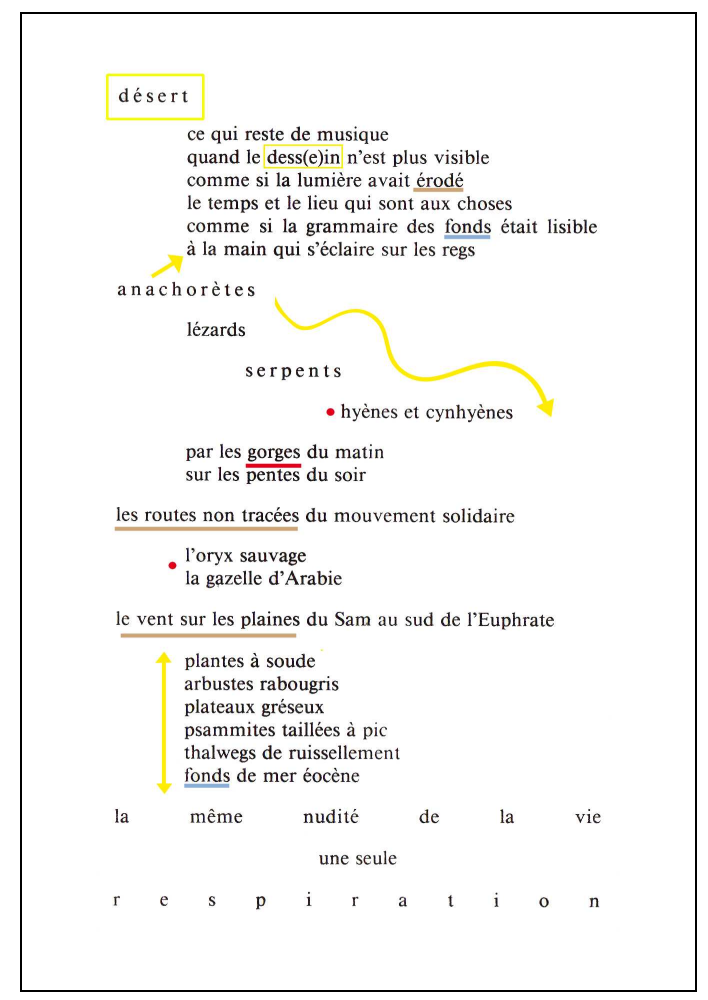

Analysant en premier lieu le poème ci-contre $(S A, 100)$, Roger Little met à jour une équivalence entre le rythme et la respiration à partir des pratiques chinoises du yoga.

[...] l'aération du vers libre et l'espacement variable [qui] prêtent à la page comme une respiration visible. Ce sont là aussi des ouvertures où l'imagination peut s'insinuer à la découverte de la vie interstitielle, permettant ainsi au lecteur de partager l'expérience de l'émerveillement dont il est à son tour capable. Le rythme du monde que perçoit le poète est ainsi transmis en direct non seulement par la séquence des mots mais encore par les rythmes du vide. ${ }^{9}$

Le blanc aère la page, donne le rythme, la musique du poème, en même temps qu'il est en parfait harmonie avec ce qu'il décrit : le désert.

La disposition l'un en dessous de l'autre dans une colonne place les éléments énumérés (animaux, plantes, minéraux) sur le même plan. Cette énumération ne se veut pas exhaustive, et les blancs sous-entendent qu'on pourrait continuer la liste. L'énumération confère donc un caractère infini au poème, le vide du désert et du poème se peuple ainsi par le dess(e)in retracé, l'idée du dessin parcouru et redécouvert par le lecteur. La disposition sur la page invite à un double mouvement de lecture, de haut en bas et de bas en haut imitant le rythme de la respiration. Ainsi le mot «anachorètes » conserve son double sens, en renvoyant au vers qui le précède (retour vers le haut : «à la main qui s'éclaire sur les regs », où surgit l'ermite replié dans la méditation et la prière solitaire dans le désert); et à ceux qui le suivent (mouvement vers le bas : «lézards, serpents, hyènes et cynhyènes », où surgit l'image du papillon de nuit répandu en Afrique du Nord - Clostera anachoreta ${ }^{10}$ ). Les mots sont placés dans un «mouvement solidaire » de ce qu'ils décrivent : les routes tracées par le vent sur les plaines, les thalwegs (route de la vallée) façonnés par les eaux, les courbes que laisse le passage d'un serpent - guirlandes qu'imite la disposition des mots -, le blanc qui forme « les routes non tracées » par lesquelles rejoignent hyènes et cynhyènes leur proies : l'oryx sauvage et la gazelle d'Arabie «par les gorges du matin / sur les pentes du soir ».

\footnotetext{
${ }^{9}$ Ibid.

${ }^{10}$ http://fr.wikipedia.org/wiki/Anachor\%C3\%A8te (papillon) (consulté le : 10/11/2009)
} 
Par cette lecture de haut en bas et de bas en haut, le mot « respiration » à la fin $\mathrm{du}$ poème devient non seulement un système de capillaires qui alimente «les poumons » du poème, l'invite à l'élévation, mais aussi les fonds et fondements du poème, une couche géologique ou strate qui préserve par fossilisation « la grammaire

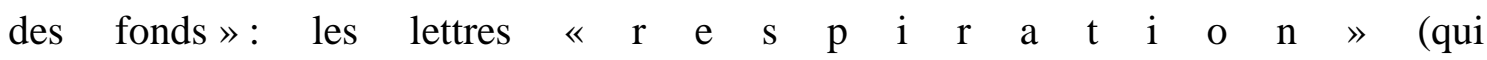
redeviennent lettres en soi par la séparation des blancs), comme les «fonds de mer éocènes » conservent les traces fossilisées de la faune et de la flore disparues de la surface de la terre depuis des millions d'années.
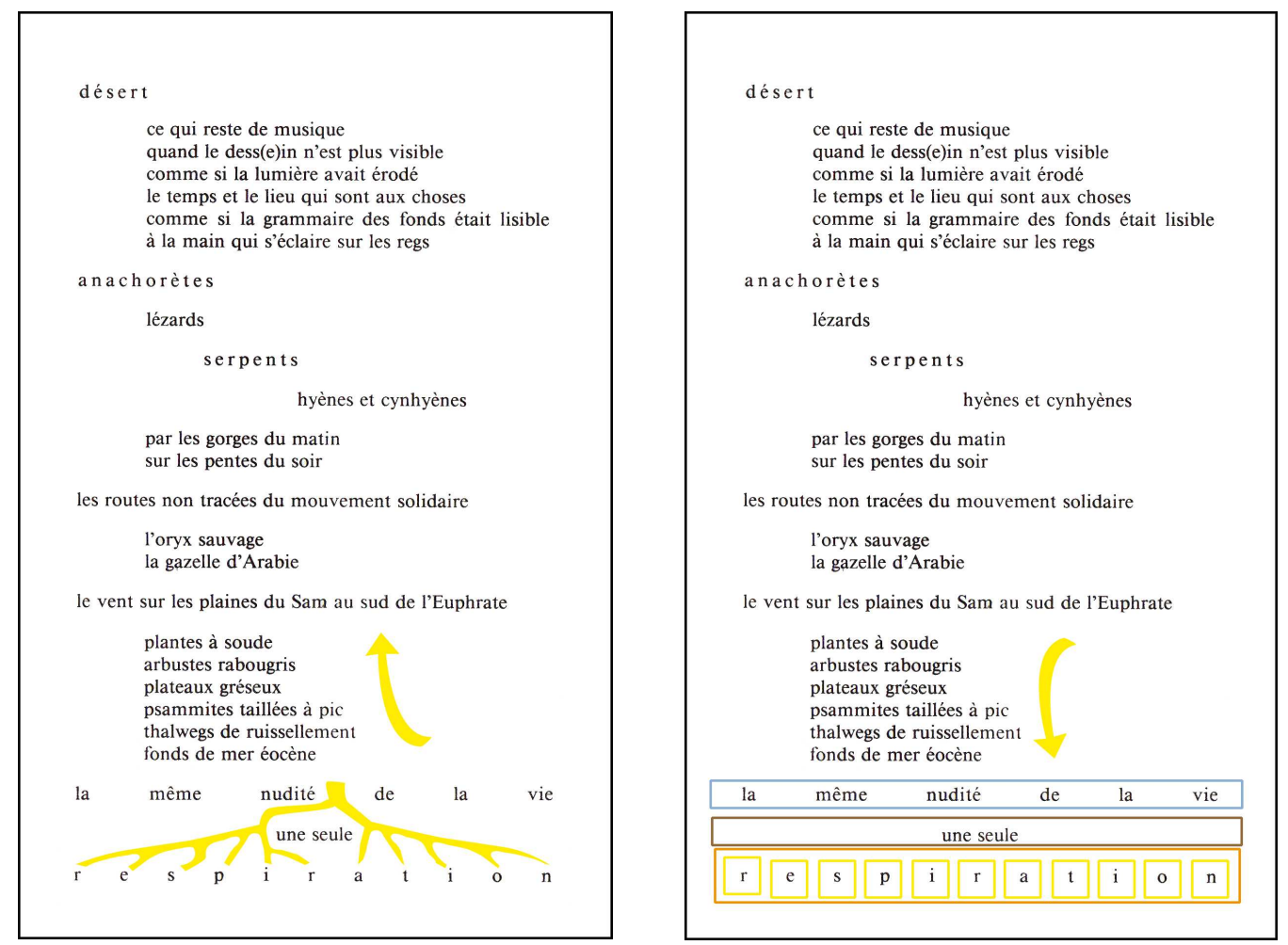

Cependant il ne s'agit que d'un des parcours possibles que nous avons voulu ici expliciter à l'aide de traits en couleurs ajoutés au poème, pour souligner son dynamisme interne comme il on le fait dans l'analyse d'un tableau.

En interprétant les poèmes idéogrammatiques selon les règles qui déterminent les idéogrammes chinois ${ }^{11}$, on pourrait également voir dans ces figures idéographiques comme une tension, une énergie et une dynamique, celle du mouvement et de la vie transposés dans les formes. Selon Jenny Chan, c'est à partir du corps, du mouvement du corps, de son orientation, de la verticalité qu'est pensée originairement la dynamique

\footnotetext{
${ }^{11}$ Lorand Gaspar a collaboré avec plusieurs peintres chinois, Zao Wou-Ki, 'Tang, et avec Henri Michaux, lui-même influencé par les idéogrammes chinoises, ce qui justifie cette analyse comparative.
} 
des idéogrammes chinois ${ }^{12}$. La direction et l'ordre des traits sont strictement déterminés et tiennent à l'usage du pinceau. Chaque signe est composé de traits élémentaires parmi lesquels on peut distinguer : le trait horizontal ; le trait vertical ; le point ; le crochet et les traits obliques (de haut en bas et de bas en haut) ${ }^{13}$. À l'origine, les idéogrammes et la peinture chinoise représentaient la cosmologie chinoise ; la disposition et l'orientation des traits est ainsi significative et désignent, en partant du bas :

- le grain de riz qui éclate, soit la matière, la terre, l'énergie qui provient du bas du corps, la racine du Principe Vital.

- l'élément intermédiaire est le Feng : le vent. Sans le souffle, il n'y a pas de vie.

- l'élément supérieur représente la vapeur, qui est l'image de la conscience, le Shen, fondement et force créatrice de la vie. ${ }^{14}$

Le papier du peintre ou du calligraphe symbolise également le Ciel et la Terre (le haut et le bas) et le blanc de la page, le vide devient l'élément qui les relie. Selon François Cheng, le vide «favorise l'interaction, entre Ciel et Terre, et par là, entre Espace et Temps ${ }^{15}$ », il est «le lieu par excellence où s'opèrent les transformations, où le Plein serait à même d'atteindre la vraie plénitude ${ }^{16} »$. L'analogie s'impose avec la photographie ci-dessous, publiée dans Mouvementé de Mots et de couleurs, et un poème de Sol Absolu qui pourrait illustrer la photo et les propos sur le vide dans la calligraphie chinoise, vide qui fait le lien entre le Ciel et la Terre, mais qui transporte le regard dans l'infini, au-delà de l'horizon visible.

Ciel compact inentamable.

La terre est prise dans les tables dures de sa loi qui renvoie le regard

infiniment derrière sa source

à l'ossature liquide de son chant.

$(S A, 107)$

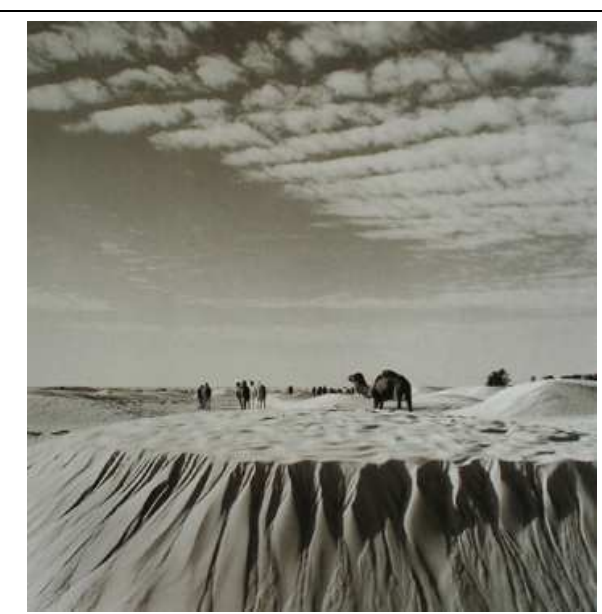

Mouvementé de Mots et de couleurs

\footnotetext{
${ }^{12}$ CHAN, Jenny, Entre corps et pensée : l'idéogramme comme théâtre de l'originaire, thèse soutenu à l'Université Lumière de Lyon en 2006 sous la direction de Alain Ferrant. http://demeter.univlyon2.fr/sdx/theses/lyon2/2006/chan_j (consulté le : 23/10/2008).

${ }^{13}$ ALLETON, Viviane, L'écriture chinoise, Paris, PUF, 1970, p. 26.

${ }^{14} \mathrm{http}$ ://fr.wikipedia.org/wiki/Idéogramme (consulté le : 24/10/2008).

${ }^{15}$ CHENG, François, Vide et plein, Le langage pictural chinois, Paris, Seuil, 1991, p. 67.

${ }^{16}$ Ibid. p. 45.
} 
Chez Lorand Gaspar, nous retrouvons la question de l'orientation qui anime l'écriture chinoise. Plusieurs idéogrammes s'organisent selon la dynamique du «trait» horizontal et vertical et le vide qui les entoure, comme on l'a vu dans le poème « respiration ». Dans d'autres poèmes, les strophes forment des colonnes qui font penser aux tableaux chronologiques (indiquant côte à côte par exemple les événements de l'histoire, de la littérature et de la philosophie) pour faire sortir par la disposition visuelle une équivalence, tout en maintenant la spécificité qui les différencie. Dans les poèmes de Gaspar, le fait que le texte continue sur la page suivante sur la même colonne (exemple ci-dessous à gauche) laisse supposer qu'à l'origine le poème était conçu pour figurer dans sa continuité et qu'il se prêterait mieux à l'édition en rouleau (comme les anciens parchemins chinois).

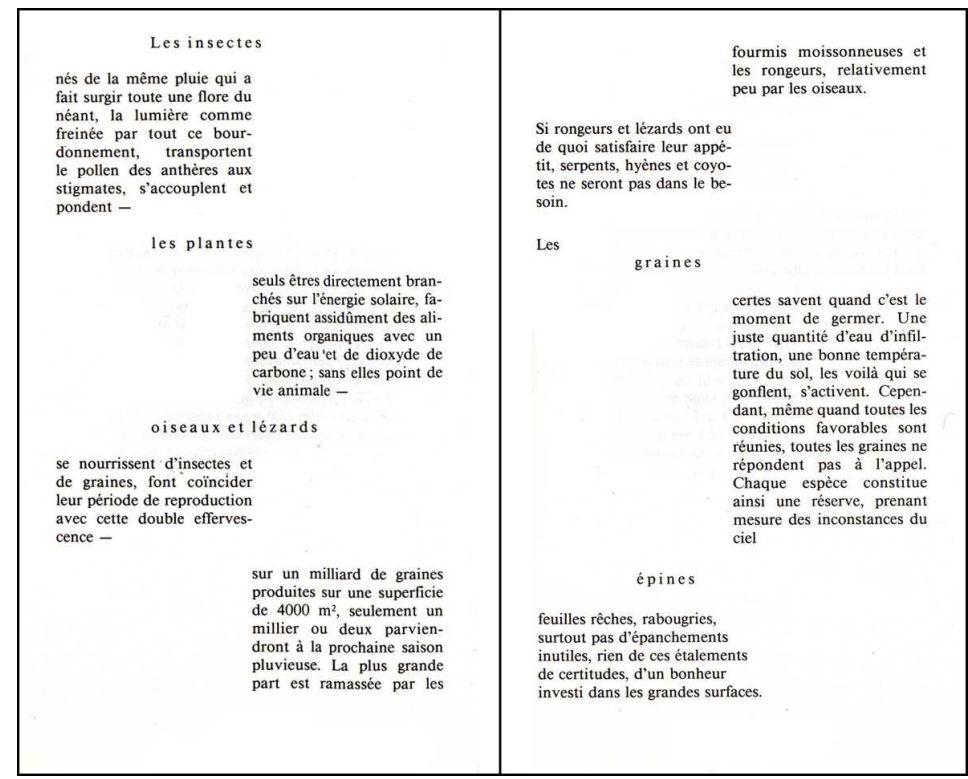

(SA, 122-123, disposition originale)

Jusqu'à la dernière strophe, sur les «épines », qui se détache de par son contenu et par son alignement à gauche et non justifiée, les strophes sur la colonne de gauche parlent des animaux et celles de droite des plantes. Chaque bloc reste ouvert puisque la dernière ligne n'est pas complète. Le tiret d'incise (-) appelé merveilleusement gondolatjel $=$ «signe de pensée $»$ en hongrois, ne marque pas l'insertion d'une parole rapportée ou une remarque entre parenthèse, mais il ouvre plutôt le poème à la réflexion, à la pensée.

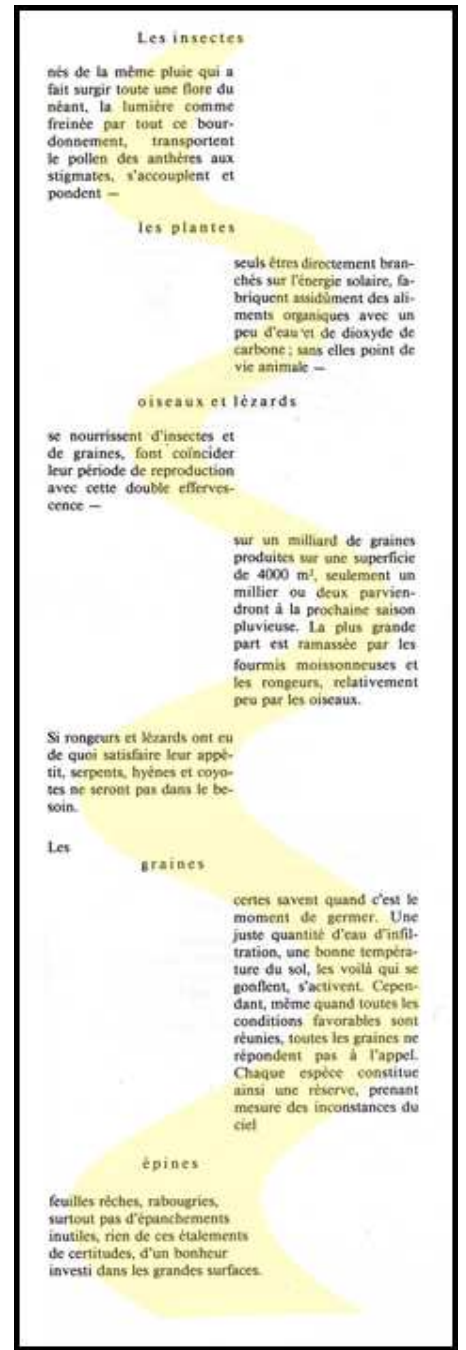

(disposition continue avec son dynamisme intérieur $S A, 122-123$ ) 
Le tiret d'incise entretient également en lien de parenté avec le trait de l'écriture chinoise, le trait du geste qui relie le corps et l'esprit. Les noms communs désignant des catégories («les insectes », «les plantes », « oiseaux et lézards », «les graines », «épines ») par leur disposition décalée servent de transfert entre les deux colonnes créant ainsi une forme ondulée qui rappelle de nouveau l'ondulation du sable.

Cette construction en colonnes réapparaît à plusieurs reprises au long du recueil pour faire la distinction entre différentes époques ( $S A, 150-151)$, ou souligner les différences du mot désert dans les langues de peuples qui ont peuplé successivement et/ou simultanément le même espace du Proche Orient (SA, 153-154, voir la page 154 ci-dessous à droite). Ce dernier exemple peut être mis en relation avec la page 114 où l'on trouve différentes écritures (ci-dessous à gauche) : deux mots en écriture cunéiforme (sumérien et akkadien ?) ; un en hébreux ; un en hiéroglyphes égyptiens ; un en arabe ; désignant peut-être chacun le mot désert et la surprenante richesse visuelle des écritures de peuples cohabitant dans le même espace.

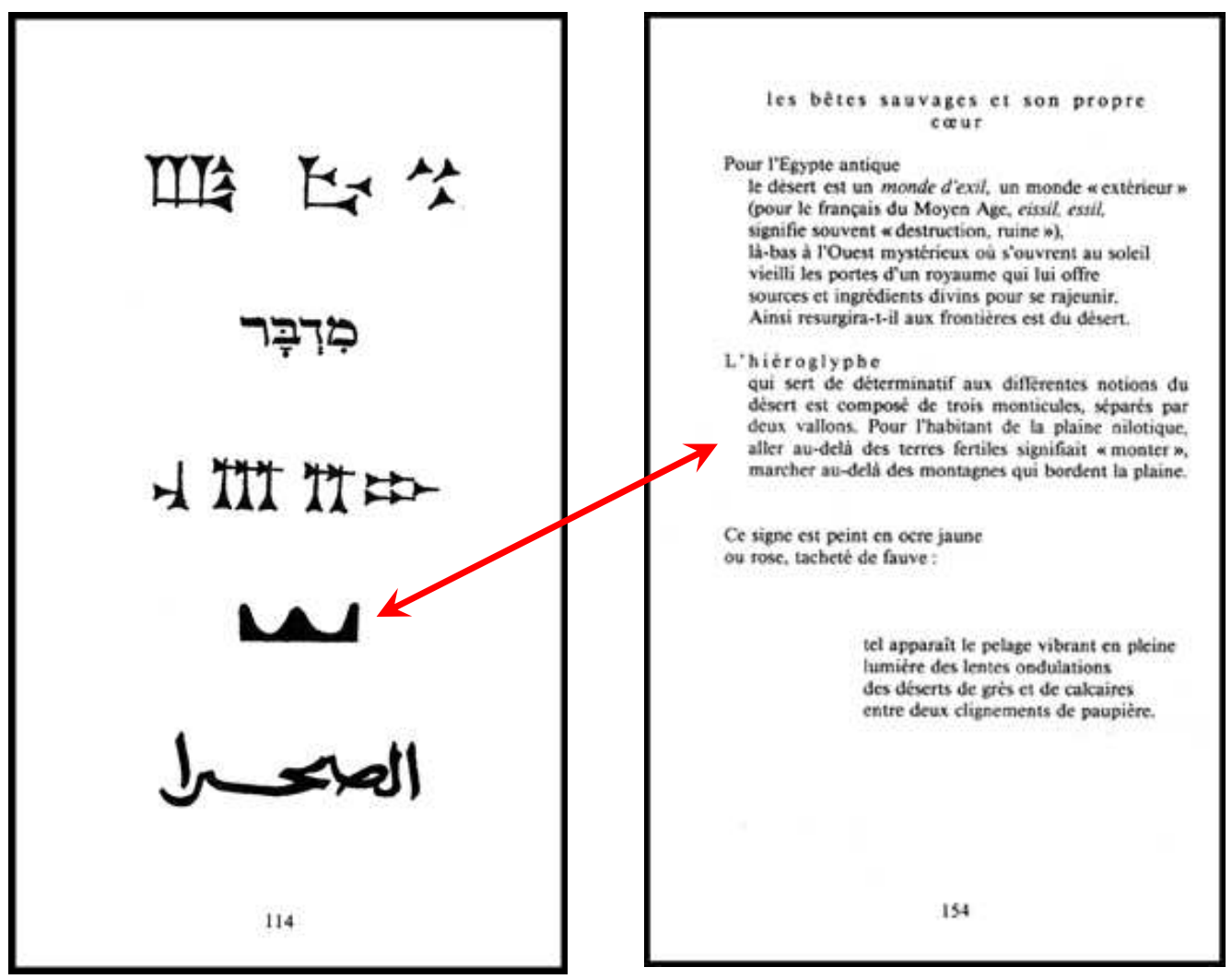

La structuration en colonne de ces poèmes fait également penser aux différentes strates des fouilles archéologiques qui se superposent, aux civilisations construites les unes sur les autres. Le blanc isole nettement les blocs de texte en même temps qu'il les relie en une même matière. 
D'autres procédés visuels sont ainsi fréquemment employés dans Sol Absolu: énumération en vertical (exemple ci-dessous en rouge) ou à l'horizontal en espacement les mots sur la même ligne (ci-dessous en vert), utilisation de la majuscule, mots étirés et recours à différentes tailles de police.

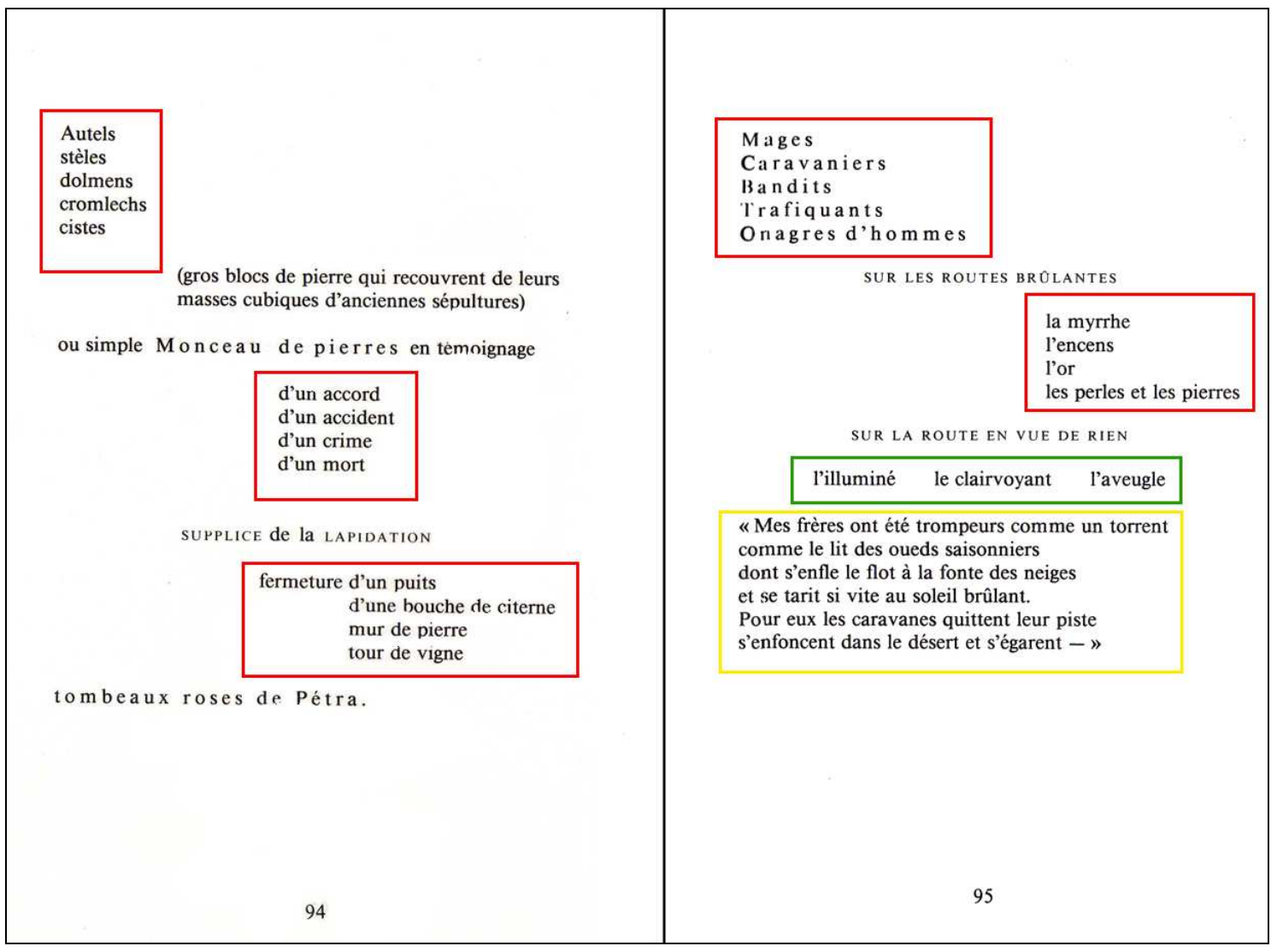

L'usage de l'énumération vertical d'éléments appartenant au même champ lexical instaure une égalité entre les éléments, mais entourée de blanc la liste reste ouverte, l'énumération pourrait se continuer jusqu'à l'infini. En tant que complément d'objet dans l'exemple ci-dessus elle marque l'hésitation entre les significations des monceaux de pierres. Leur sens reste incertaine et ouverte, comme le sens de la disposition spatiale. Et c'est bien là un effet voulu et recherché, car à travers l'investissement visuel de la page et par l'utilisation des blancs se dévoile la richesse du vide, du lieu et du temps (citations et fragments de différentes époques se trouvent rassemblés), autant de portes qui s'ouvrent à l'imagination, lui confèrent une impression d'infini, enrobée d'un voile de mystère, celle d'une construction invisible dont on perçoit l'unité dans la multiplicité de ses apparences.

Selon Roger Little la recherche du dépassement du vide «s'enracine nécessairement dans l'ici et le maintenant de la vraie vie, la seule - "toi n'ayant que ce 
temps et ce lieu" -, qui n'est donc pas ailleurs comme le voulait Rimbaud mais qui fonde inéluctablement toute exploration de l'ailleurs ${ }^{17} »$. Cet enracinement spatiotemporel nous ramène de nouveau à la photographie qui est à son tour un émerveillement dans un temps et lieu précis, une forme retrouvée dans le chaos des apparences.

Ce lieu est vide et plein, un lieu habité par les mots et par l'imagination qu'il engendre, un Sol qui est absolu, car lieu de genèse, du jardin édénique décrit dans la Bible, mais aussi lieu de genèse du texte de Gaspar.

PIERRE

encore une

PIERRE

sable

illimité

RIEN

$(S A, 93)$

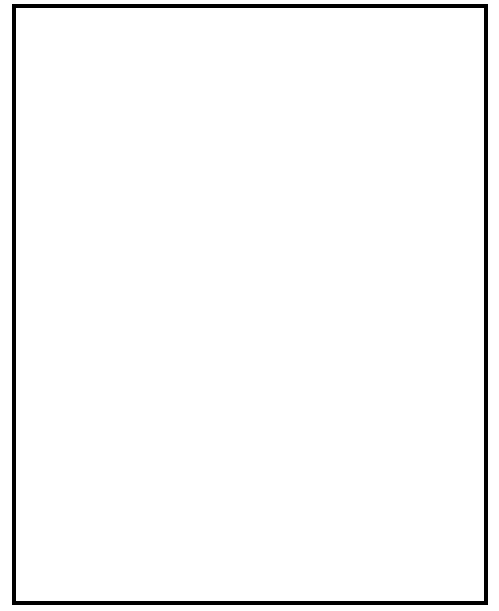

Zao Wou-Ki, Genèse, 1981

Aussi comparera-t-on ce poème cité en début de chapitre pour leurs formes similaires à une peinture à l'encre de Zao Wou-Ki (ci-dessus) qui fut publiée dans le livre de Lorand Gaspar: Genèse, (Fata Morgana, 1981), peinture qui fait partie d'une série ${ }^{18}$ (cidessous) illustrant dans le même livre la genèse, déploiement d'énergie qui, de haut en bas, progressivement investit les vastes plaines du rien.

${ }^{17}$ LITTLE, Roger, «Représentation et imaginaire de l'espace», in Transhumance et connaissance, p. 123.

${ }_{18}$ Les images proviennent du site de la galerie Michel Fillon (consulté le: 24/10/2008): http://www.michelfillion.com/detail.php?titre=zao-wou-ki-genese. 
Le recueil Sol Absolu peut alors se lire, par analogie avec l'écriture chinoise, comme une vaste étendue, qui témoigne par sa diversité étonnante de «la réalité vivante d'un présent multiple et complexe» $(S A, 13)$ et dont certains poèmes (qui sont aussi systématiquement repris par les critiques) sont des nœuds «d'énergie et de clarté » $(C J$, 59), comme sur les encres de Zao Wou-Ki, les traits forment un tourbillon, une explosion, un jaillissement à peine visible, entouré de vide, d'un blanc qui devient un « espace(s) d'accueil où chaque lecteur peut investir sa propre expérience ${ }^{19}{ }$.

${ }^{19}$ COLLOT, Michel, «La syntaxe nominale dans la poésie française », Ellipses, blancs, silences, actes du colloque du CICADA, 6-8 décembre 1990, textes réunis par Bertrand Rougé, Pau, Université de Pau, 1992, (p. 105-114) p. 114. 


\section{VII.8. Les livres d'artiste et les lectures d'images}

Lorand Gaspar a collaboré avec plusieurs peintres pour créer des livres objets où ses poèmes sont accompagnés d'illustrations. Comme le note Anne Flanagan, on peut délimiter deux phases dans sa production :

Gaspar a ainsi une production double, celle de sa poésie accessible au plus large public par la lecture d'éditions de poches, et celle de ces livres d'art, quasi secrète, vouée à un public très restreint pouvant acquérir les volumes tirés à un très petit nombre d'exemplaires. ${ }^{1}$

Cependant nous ajouterions encore une phase, car les poèmes sont souvent publiés en premier lieu dans des revues (accompagnés ou non par des illustrations), et suivent un cheminement particulier à travers chaque nouvelle forme d'édition ${ }^{2}$, trajectoire au cours de laquelle ils peuvent se modifier considérablement (abréviation, rajout, déformation, insertion d'image, ...).

Parmi les livres accompagnés d'images, Anne Flanagan distingue les livres d'art, où des illustrations viennent enrichir les poèmes, mais qui conservent la lecture linéaire qu'offre le livre ; et une autre catégorie qui serait le livre objet où l'on quitte la lecture classique linéaire et d'un ordre déterminé, par exemple grâce aux feuilles détachables (Approches d'un désert vivant, Villeneuve-Lez-Avignon, 1999, encres de Claude Caranjoud). Il est parfois difficile de trancher : à partir de quand on peut parler de livre objet ? Le livre d'art ou livre objet «illustré » invite toutefois à un autre type de lecture où non seulement les images participent à la construction d'une signification mais aussi la qualité et la texture de la page, ce qui renoue avec les propos de Gaspar sur la vue qui donne accès au toucher et à la quête à laquelle le lecteur est invité. L'exemple d'Amandiers est représentatif de la façon dont les poèmes mène leur propre vie et resurgissent dans différents contextes (voir l’annexe n³ à la page 358).

Une version abrégée d'Amandiers parait d'abord dans la Nouvelle Revue Française en 1974, puis en 1980 paraît le poème entier accompagné d'estampilles d'Étienne Hajdú, artiste d'origine transylvanienne connu surtout pour ses sculptures. Hajdú a commencé à développer le procédé des estampilles vers 1957, une technique de

\footnotetext{
${ }^{1}$ FLANAGAN, Anne, «Lorand Gaspar et ses livres d'art », in Poétique et poésie, p. 176.

${ }^{2}$ Voir quelques exemples dans l'annexe $\mathrm{n}^{\circ} 3$ ci-joint du cheminement du texte à travers les différentes éditions que nous avons reconstruit en nous basant sur la bibliographie établie par Daniel Lançon dans les actes du colloque sur Lorand Gaspar (Cognac, Le Temps qu'il fait, 2004, p. 356-412.).
} 
gravure qui utilise le relief créé par la pression sur le papier pour faire sortir le dessin

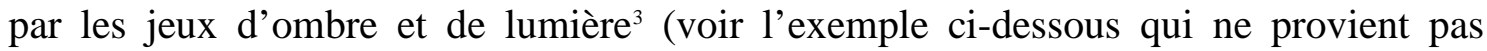
d'Amandiers, mais explicite la méthode utilisée).

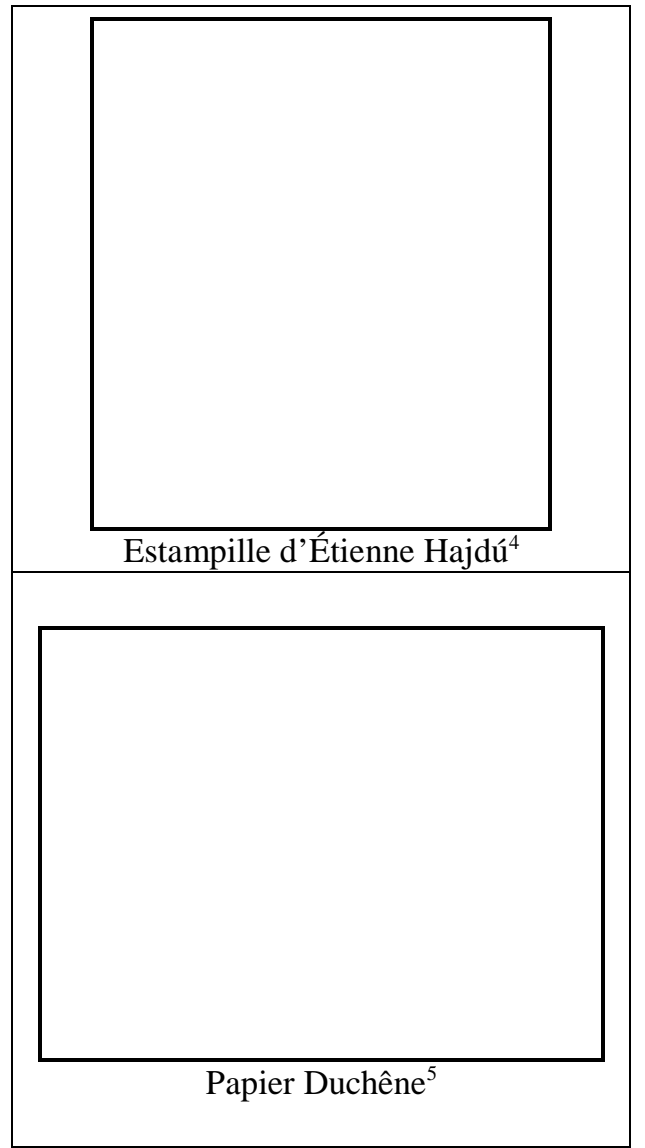

Les formes des estampilles, comme le remarque Anne Flanagan, vivent grâce à la lumière et ne sont jamais statiques; si l'on tourne la page, le point de vue change, ainsi que la forme du dessin. Le papier utilisé pour Amandiers (1980) est plus doux au toucher que l'estampille ci-contre (il ressemble plutôt à l'exemple en dessous) et conserve les marques, les petits morceaux, qui le composent. La douceur du papier et le procédé qui utilise les jeux d'ombre et de lumière entrent en dialogue avec les poèmes de Gaspar, encore plus que les formes représentées, qui symbolisent de manière abstraite les branches de l'amandier, ses fleurs, ses feuilles, ou l'arbre entier. La fragilité et la vulnérabilité de la fleur d'amandier trouvent un écho dans la délicatesse du papier. L'amandier, qui est un des premiers arbres à fleurir au printemps, évoque «ce bonheur [est] simple au bout du cheminement obscur ${ }^{6} \gg$. Le procédé de l'estampille, comme l'arbre en fleur devant la maison de Gaspar en Tunisie, offre aussitôt à la vue une évidence.

Comme cette cécité nous voit soudain dans notre sommeil!

Écoute comme il fond ce peu de blanc tombé au fond de l'œil ! (Amandiers, 1980)

Les formes en creux des estampilles surgissent soudain grâce à la lumière, mais l'expérience se poursuit car au revers de la page la forme réapparaît en relief. On observe un double jeu de creux et de relief, de lumière et d'ombres, d'impressions, des termes qui évoquent la photographie et les préoccupations du poète sur la lumière.

\footnotetext{
${ }^{3}$ FLANAGAN, Anne, «Lorand Gaspar et ses livres d'art », Ibid, p. 176.

4 Illustration sur le web pour la publicité d'un livre d'Étienne Hajdú Paris, MNAM, 1973, http://www.tobeart.com/Expo/Hajdu-MNAM73.htm (consulté le : 12/11/2008).

${ }^{5}$ http://www.moulindelarroque.com/pages/index.php (consulté le : 12/11/2008).

6 GASPAR, Lorand, Amandiers, (huit estampilles d'Étienne Hajdú) Fata Morgana, 1980 (sans pagination).
} 
Gaspar est conscient de cet effet des estampilles, comme il le note dans un texte pour le catalogue d'exposition d'Étienne Hajdú :

Ne pouvait-on pas demander à cette feuille de papier blanc de l'accueillir [la forme] aussi sensuellement, aussi innocemment transparente et brûlante qu'un pétale d'amandier, qu'un flocon de neige ? [...]

Ce que les corps composés par Hajdú nous apportent, c'est à la fois la graine et le ciment, le battement et le souffle. Ils nous aident à mieux percevoir le monde, un monde guéri de sa fragmentation, un réel qui se déroule d'un seul tenant, mû par la même respiration de la lumière. ${ }^{7}$

Dans Apprentissage ${ }^{8}$, sous le chapitre «Approches de l'étendue » qui réunit des textes sur plusieurs peintres, notamment sur Hajdú, Gaspar parle de corps capables d'étendre l'étendue, «l'étendue en tant que source d'elle-même sans fond, et déploiement sans limites » $(A P, 273)$. Grâce au toucher c'est l'espace qui s'étire:

Sentir naître sous ses doigts des volumes noués par les rencontres, foyers d'énergie, de rayonnement. Figures tranquilles ceintes dans leur puissance d'aller, de se déplier. Masse de vibration serrée, compacte, aiguisée pour un départ.

Intensité immobile dans le regard. Immobile et pourtant ressentie comme une pulsation.

Les doigts plongent, mus par le chant. Leurs mouvements dégagent des courbures et des pentes, éclairent des épaisseurs où affleure le silence. $(A P, 273)$

De la même manière, l'espace et la signification du poème Amandiers (1980) se déploient et s'étendent à travers la vue et le toucher qu'offrent les estampilles.

La republication des poèmes d'Amandiers en 1996 accompagnés des lavis de T’ang Haywen (voir l'annexe $n^{\circ} 3$ à la page 358) montre toutefois que les images n'ont pas un strict rôle d'illustration, elles viennent ajouter aux poèmes une énergie par une approche commune (c'est souvent d'ailleurs une amitié qui relie le poète et l'artiste).

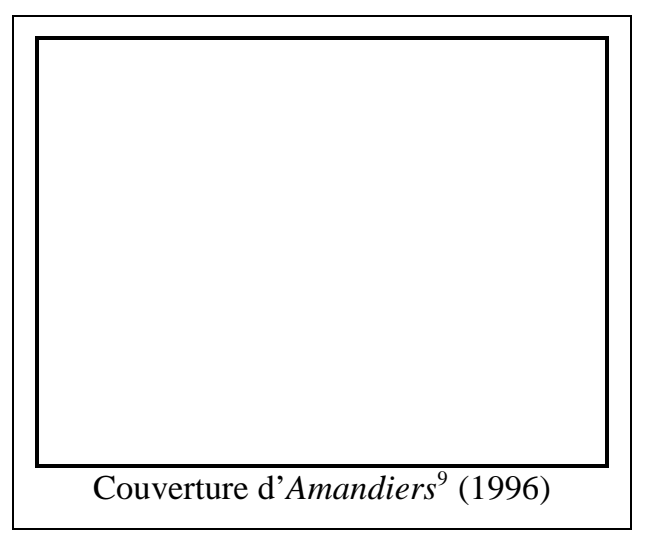
Les lavis de T'ang ne figurent pas les fleurs d'amandiers ou des formes qui évoqueraient la plante, mais le texte n'est plus tout à fait le même non plus car il s'agit d'une version augmentée par rapport à la première publication des parties Sidi Bou Saïd I, Raouad et Lianria. Les papiers Ingres Thalo et Conquéror n'ont plus la douceur et le grain du papier Duchêne, mais il ne s'agit pas

\footnotetext{
${ }^{7}$ GASPAR, Lorand, « Préface à Étienne Hajdú », Sculpture, lavis, estampilles, Tunis, Galerie Irtissem, 28 avril -15 mai, 1980. Cité par Anne Flanagan, Ibid, p. 182.

${ }^{8}$ GASPAR, Lorand, Apprentissage, Paris, Deyrolle, 1994. Repris dans Approche de la parole suivi de Apprentissage, Paris, Gallimard, 2004, p. 273. (L'ouvrage auquel nous nous référons.)

${ }^{9}$ La photo provient du site d'un atelier de reliure artisanale :

http://www.libellus.fr/galerie/gaspar_amandiers/index.html (consulté le : 14/11/2008).
} 
pour autant d'un papier ordinaire, et dès la prise en main le lecteur est conscient qu'il s'agit d'un livre très soigné (voir la couverture ci-dessus).

La technique du lavis s'accorde elle aussi avec les propos de Gaspar. Cette méthode de peinture utilise une seule couleur qui plus ou moins diluée avec de l'eau crée un effet de clair-obscur, le plus clair étant les parties où la page blanche transparaît. Cette technique de peinture provient de la Chine et tout comme la calligraphie, elle attache une importance au trait qui est le signe du souffle de la vie. Ainsi dans le texte de Gaspar sur T'ang publié dans Apprentissage $e^{10}$, le poète fait plusieurs fois référence $\mathrm{au}$ «souffle vivant » $(A P, 274-280)$ qui anime le mouvement des encres du peintre. Les propos de T'ang sur sa propre activité d'artiste sont très proches de ceux de Gaspar sur la poésie, car tous les deux parlent d'une énergie qui alimente leur travail, une énergie qui trouve sa source dans la nature. Selon 'Tang :

La peinture incarne l'énergie. Elle agit comme la force cosmique qui crée les étoiles et entraîne les saisons. Cette énergie rayonne et son rayonnement touche et émeut le spectateur. Nous n'avons pas affaire à une énergie brutale mais subtile, qui unit en même temps tension et détente. [...] Nous ne sommes que des cellules sensibles entrant dans le courant, nous captons l'énergie à sa source, cette saisie immédiate se matérialise par l'encre le papier et le pinceau. ${ }^{11}$

Les encres de T'ang dans le recueil déplacent finalement le centre d'attention auparavant sur l'amandier (l'arbre en fleur, symbole de la beauté et de l'harmonie soudain retrouvée) pour l'ouvrir à une signification plus large, plus abstraite, celle du rythme et de la musique du monde qui se reflètent dans le poème.

Energie, mouvement, vie, désir, pensée, langage, - des noms que nous donnons à des aspects différents de la même vivacité. $(F O, 63)$

Tandis que l'énergie commune qui alimente les deux œuvres est perçue par le poète et peut être perçue à son tour par le lecteur, Gaspar insiste sur la relativité de cette harmonie retrouvée :

Or, quelque chose en moi sait que l'ordre et l'harmonie convenable à ma « composition » ne sont qu'une construction ou, si l'on veut, une des figures parmi une infinité d'autres que peut revêtir la nature selon le point de vue où se place l'observateur; je "sais" que dans ces tumultes, ces désordres à mes yeux, il y a une cohérence, une musique dénuée de sons, comme avait dit Mi Fou. $(A P, 274)$

${ }^{10}$ GASPAR, Lorand, Approche de la parole suivi de Apprentissage, Paris, Gallimard, 2004, p. 274-280.

${ }^{11} \mathrm{http}: / /$ www.tanghaywen.org/index/Projet-Frame1.htm (consulté le : 14/11/2008). Entretien de J. P. Desroches avec T'ang Haywen (extrait du catalogue d'exposition de Quimper 28 janvier - 16 avril) reproduit sur le site personnel du peintre. 
L'image est une voie d'accès qui permet d' " entrer » dans l'univers du poème en même temps qu'elle offre une sortie sur le monde, elle invite le lecteur à poursuivre sa quête, en soulignant qu'il ne s'agit que d'une entrée possible.

Encre de T'ang avec une note manuscrite de Lorand Gaspar ${ }^{12}$

À la suite de ces deux livres d'art, le poème Amandiers (voir l'annexe n³ à la page 358) va resurgir dans d'autres publications destinées à un public chaque fois plus large (ouverture qui s'accompagne d'une perte de la valeur artisanale de l'objet en tant que livre d'art), en même temps que le poème au contact des autres poèmes qui l'entourent (Patmos, 2001 et 2004) s'inscrit dans un autre paysage, acquiert une autre étendue.

La collaboration de Lorand Gaspar avec d'autres artistes témoigne d'une richesse dans l'utilisation de l'image dans divers contextes et sur différents supports (magazine, livre d'art, livre objet, catalogue d'exposition, ouvrage critique - voir l'annexe $n^{\circ} 4$ à la page 359). En plus de ses propres textes publiés avec ses propres photos (dans des magazines, livres ou catalogues d'exposition), Lorand Gaspar collabore avec des artistes pour réaliser des livres d'art (Étienne Hajdú, Zao Wou-Ki, Árpád Szenes, Claude Caranjoud, Claude Ballaré), utilise des dessins (ceux d'Henri Michaux, ou une partition de Bach et des dessins scientifiques) pour structurer un de ses livres, Approche de la parole, mais prête également ses photos pour l'illustration (Yves Bonnefoy, Mátyás Varga, James Sacré). Dans de nombreuses revues il fait figurer un texte en prose, réflexions ou poème(s) accompagnés soit de ses propres photos soit d'œuvres d'autres peintres pour lesquels il ressent de l'affinité. Ses photos, des

\footnotetext{
${ }^{12}$ KLAPKA, Ronald, «Lorand Gaspar, la musique secrète de la vie commune », sur le site remue.net : http://remue.net/spip.php?article1061 (consulté le : 16/11/2008). La photo provient du catalogue de l'exposition Pierres de chant, réalisée par Tanguy Dohollau, pour le Festival Etonnants Voyageurs de Saint-Malo en 1992.
} 
fragments de ses manuscrits ou des poèmes inédits, tout comme des œuvres d'autres poètes-amis ou des images de peintres-amis viennent enrichir les ouvrages critiques consacrés à son œuvre, les transformant partiellement en livres-hommages. Gaspar est également l'auteur de plusieurs textes d'introduction pour des catalogues d'exposition d'artistes dont il apprécie l'œuvre. Les mêmes textes sans images réapparaissent parfois dans des revues ou dans des livres.

Compte tenu de ses diverses collaborations il est parfois difficile d'établir laquelle des deux œuvres a été source d'inspiration pour l'autre. Vouloir comprendre et transcrire l'œuvre picturale d'autres artistes semble être toutefois une étape importante dans le développement d'une sensibilité visuelle, l'apprentissage d'une lecture visuelle. Le chapitre «Approche de l'étendue » dans Apprentissage, que nous avons déjà évoqué, réunit des «lectures » d'œuvres des artistes suivants : Étienne Hajdú, T'ang, Vieira da Silva, Arpad Szenes, Zao Wou-Ki, Jean de Maisonseul, Alexandre Hollan, Roger Van Rogger. Ses «lectures » sont plutôt le récit d'une «rencontre » entre le poète et les œuvres décrites, rencontre au sens spinozien du terme de ce qui alimente le corps et augmente sa puissance d'agir, « rencontres qui nous ouvrent à une joie profonde » $(A P$, 151). Il s'agit d'une rencontre dynamique et active «comme s'il [le corps] reconnaissait quelque chose qui le concerne de près, une vérité sur l'autre, en même temps que sur lui-même et ses liens avec le monde » $(A P, 151)$. La préface du chapitre avertit le lecteur de la dimension personnelle de cette lecture des images :

Assurément, il ne peut s'agir pour moi dans ces notes sur le travail de quelques peintres et un sculpteur dont les œuvres me sont proches, de chercher à dégager un sens particulier, conscient ou inconscient, que chacun d'eux exprimerait dans son travail.

Je ne puis parler que de ce que je vois, ressens, à force de les regarder, toucher, de suivre intérieurement, comme il m'arrive de le faire pour la musique, leurs mouvements, peindre et sculpter à mon tour les idées et les images qui me viennent en leur compagnie, en les habitant avec ma propre vie. (AP, 271, italique par l'auteur)

En effet, au lieu de parler de tableaux concrets, le poète s'attarde sur les aspects de l'œuvre qui l'intéresse, et ses réflexions divaguent et se détachent parfois de l'œuvre décrite. Par exemple, le dernier chapitre dédié aux paysages de Roger Van Rogger parle avant tout du mécanisme de la vision, de la connivence entre l'espace du monde et celui de l'esprit, sans s'attarder sur la particularité des paysages abstraits du peintre.

Ce qui compte c'est le rapport dynamique que peuvent provoquer les images des autres, qui mobilise l'expérience de chacun, qui donne accès à un savoir intériorisé grâce à la participation active de son élaboration, et qui s'inscrit donc dans le processus d'apprentissage de la vie. C'est le même rapport dynamique qui est demandé dans la 
construction de la notion de la beauté dont parle Gaspar dans le premier chapitre d'Apprentissage qui porte le même titre :

[...] mon corps capable de détecter certains aspects du réel dont il construit des perceptions sensibles et des images, mais aussi les idées que mon esprit en forme, les relations qu'il établit entre les effets de cette rencontre dynamique et ceux, plus ou moins proches, inscrits dans notre mémoire, tout cela vibre ensemble en ce sentiment qui me pousse à parler de beauté. $(A P, 148)$

C'est le mouvement dynamique de la pensée qui relie la beauté et l'acte créateur et non le produit de l'acte - l'image, la peinture, la photographie - même si à son tour l'œuvre matérielle peut mobiliser des connexions nouvelles, étendre notre champ de vision et de pensée.

Le sentiment du beau qu'il m'est donné de ressentir parfois, et que j'essaie sans doute vainement de dégager, n'est pas séparable ni même distinct du «travail » du créateur ou de celui qui patiemment approfondit sa vision et sa conscience au contact des choses de l'art ou de la vie quotidiennement rencontrée, il est le travail même, cet apprentissage. $(A P, 157)$.

Si on examine les gravures, peintures, et sculptures des artistes auxquels Gaspar consacre son texte dans Apprentissage, on peut constater que le point commun qui les relie c'est leur attachement à l'art abstrait et à l'exploration de la dynamique de l'image (voir les exemples ci-dessous ${ }^{13}$, qui ne sont peut-être pas les plus typiques de chaque artiste, mais qui explicitent notre propos sur la recherche de l'abstraction). On y trouve peu de portraits, plutôt des paysages ou des images en lien avec des éléments naturels (la pierre - Jean de Maisonseul ; l'arbre - Alexandre Hollan ; l'eau - Koïchiro Kurita).

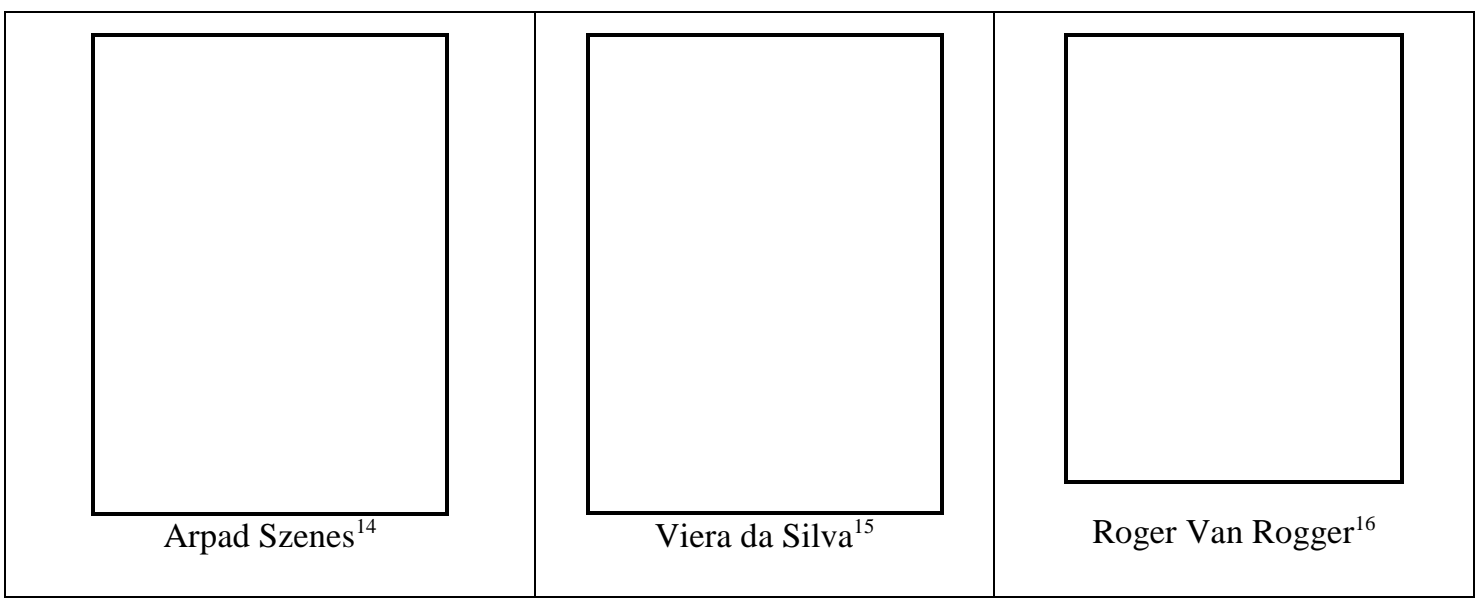

13 À ces exemples s'ajoutent les peintures de Jean de Maisonseul qui ne sont pas téléchargeables mais peuvent être consultées sur le site :

http://babelouedstory.com/voix_du_bled/expo_caom_peinture/expo_caom_peinture.html

et pour les sculptures d'Étienne Hajdú : http://www.louiscarre.fr/artistes/etienne-hajdu (consulté le 22/11/2008)

${ }_{14}$ Arpad Szenes, Sefar I, 1983 grattage, 17,5 x 23,5 cm. Reproduit sur le site de la Galerie Michelle Champetier. http://www.mchampetier.com/Etching-Arpad-Szenes-5074-work.html (consulté le : 22/11/2008). 


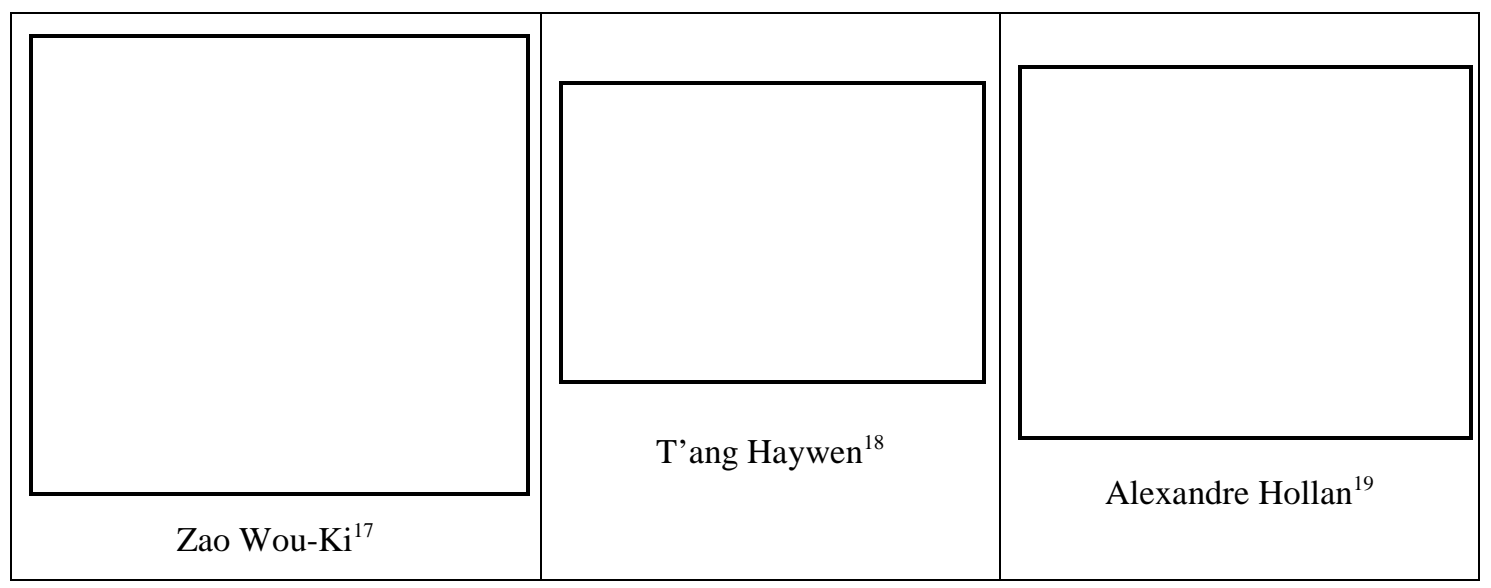

Parmi les photos de Gaspar, en revanche nous retrouvons très peu l'influence de l'art abstrait, sa photographie est d'avantage en rapport avec sa poésie. Pourtant, quand il accepte d'accompagner par son texte l'œuvre du photographe Koïchiro Kurita, son choix se porte bien sur un photographe dont l'œuvre dénote également un certain penchant pour l'abstraction. Ainsi dans le cliché ci-dessous, intitulé Summer grasses, (mais qui figure sans titre dans Le mouvement $d u$ monde ${ }^{20}$, ouvrage accompagné des poèmes de Gaspar), un champ de hautes herbes peut se transformer en traits (rappelant la technique de grattage) qui se répartissent dans un ordre dynamique.

${ }^{15}$ Viera da Silva, Un été de sel, 1989, aquatinte, 20,6 x 28,8 cm. Reproduit sur le site de la Galerie Michelle Champetier. http://www.mchampetier.com/Gravure-Maria-Helena-Vieira-Da-Silva-10551.html (consulté le : 22/11/2008).

${ }^{16}$ Roger Van Rogger, Sans titre, 1968, peinture à huile, exposition de Van Rogger « Abstraction et Mystique » du 4 octobre au 5 novembre 2000 présentée sur le site de « la Maison des Arts » à Châtillon : http://www.ville-chatillon.fr/mda/archive van_rogger.htm (consulté le : 22/11/2008).

17 Zao Wou-Ki, sans indication de titre ou de date sur le site de la Galerie Berthet-Aittouarès. http://www.galerie-ba.com/artistes/Zao\%20Wou\%20Ki/zao_wou_ki.htm (consulté le : 22/11/2008).

${ }_{18}$ T'ang Haywen, sans indication de titre ou de date sur le site personnel du peintre : http://www.tanghaywen.org/index/Projet-Frame1.htm (consulté le : 22/11/2008).

${ }^{19}$ Alexandre Hollan, sans indication de titre ou de date sur le site de la galerie Vieille du temple. http://www.associationdesgaleries.org/galerie.cgi/histo_galerie/71 (consulté le : 22/11/2008).

${ }^{20}$ KURITA, Koïchiro, Le mouvement du monde, textes et poèmes de Lorand Gaspar. Le livre ne contient pas d'indication sur l'édition; on sait seulement qu'il a été édité suite à l'exposition de Kurita « Hydrosphère » à la Galerie Camera Obscura en mai et juin 2001. 


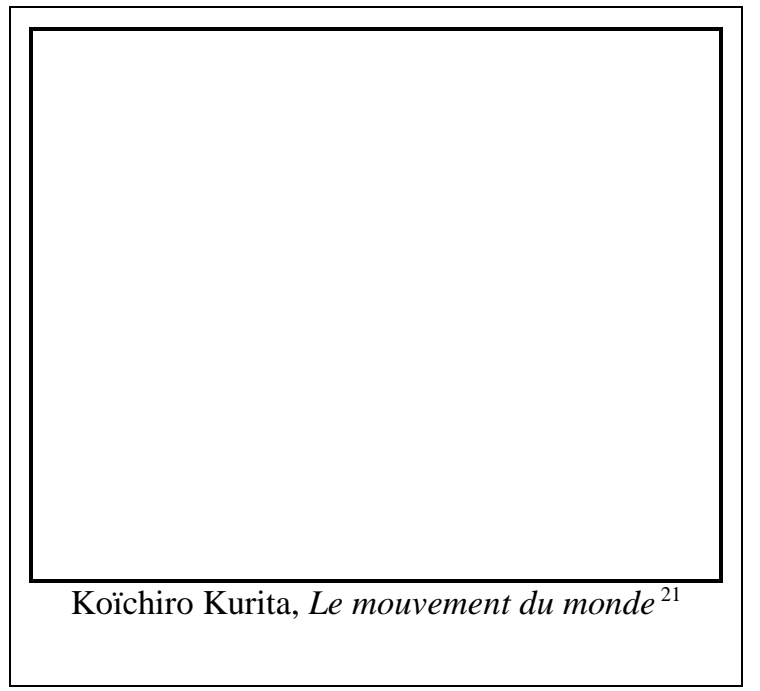

Le changement du titre de l'œuvre - le livre s'intitule Le mouvement du monde tandis que l'exposition s'appelait Hydrosphère - montre à quel point le texte de Gaspar influence la lecture des photographies. Le texte de Gaspar n'est pas une introduction, il s'étale sur tout le livre en alternance avec les photos. Ce sont en majorité de courts fragments (d'une ou deux lignes) qui font penser par leur densité et leur longueur à des haïkus. Le texte n'offre pas de clé d'interprétation aux images, mais plutôt une réflexion autour des images qui incitent chacun à chercher des clés de lecture en soi-même.

L'écriture, le dessin, les formes qu'isole dans la durée un arrêt sur l'image attendent un regard qui efface les contours, rend leur fluidité aux choses. ${ }^{22}$

L'expérience de chacun devient bien un élément indispensable dans la lecture des images, et Gaspar invite explicitement chaque lecteur à la fin de son texte sur Jean de Maisonseul à poursuivre son travail d'interprétation des images :

Je laisse à chacun de continuer sa méditation en se regardant dans ces fontaines que sont ses tableaux qui nous regardent. (AP, 291, Nous soulignons)

Les lectures d'images que propose Gaspar dans Apprentissage, sont comme des miroirs où il se reflète lui-même, un reflet qui se trouve amplifié par le fait de publier ces lectures sans images. En même temps les images sont eux aussi des reflets étirant de la sorte l'étendue-pensée du texte gasparien. La polysémie des images semble conférer une liberté au poème pour se déployer, une liberté de cheminement pour le lecteur-

\footnotetext{
${ }^{21}$ Koïchiro Kurita, Summer grasses, Lozere, France, 1996, platinum print, 20,3 x 25,4 cm, reproduit sur le site (consulté le : 10/11/2008) : http://www.artnet.fr/artwork/424696597/117186/koichiro-kurita-summer-grasses-lozere-france.html.

${ }^{22}$ KURITA, Koïchiro, Le mouvement du monde, Op cit., (sans pagination).
} 
regardeur. L'enthousiasme d'Henri Michaux à propos d'un ouvrage illustré par Zao Wou-Ki résume cette idée :

Lire un livre, en substance, est très ennuyeux car le chemin y est tout tracé par les lignes et les pages. Aucune liberté de cheminement. En revanche, dans un tableau, promenade ad libitum : «à gauche, aussi, à droite, en profondeur, à volonté. Pas de trajet, mille trajets ». Tout est là, certes, mais rien n'est encore connu dans le premier regard. «C'est ici qu'il faut vraiment commencer à LIRE. $\gg^{23}$

Si l'image permet donc d'ouvrir les modes de lecture possibles, la fréquente republication des textes de Lorand Gaspar sur des supports différents, accompagnés ou non par des images, crée également une sensation d'infini au sens de l'étendu qui s'étire.

${ }^{23}$ MICHAUX, Henri, Lecture de huit lithographies de Zao Wou-ki, in Euvres de Michaux, Paris, Gallimard, Bibliothèque de la Pléiade, vol. II, 2001. Cité sur le site de Jean-Michel Maulpoix: http://www.maulpoix.net/zao.html (consulté le : 24/10/2008). 


\section{VII.9. La poétique du visuel}

Le rapport entre les images et le texte n'est jamais explicite dans les livres illustrés de Gaspar, de même, dans ses œuvres cohabitent ses propres textes et ses propres photos, le lien n'est pas souligné par la mise en page, le texte ne fonctionne jamais comme une légende de l'image ou une transcription/description littérale. Pourtant des liens subtils se tissent entre des fragments de poèmes ou de textes et les images, dès qu'on sort de la contrainte de la juxtaposition sur le page même de l'unité de l'objet-livre. Le seul contre-exemple pourrait être le catalogue d'exposition Espace ${ }^{1}$, où sur presque toutes les pages photos et fragments de poème entretiennent un lien évident; mais l'on ne peut pas savoir s'il s'agit du choix délibéré ou d'une décision de Claude Pocheron, le responsable de l'exposition et du catalogue. À part ce livre de Gaspar, le rapport entre la photographie et le texte est à chercher au-delà de la page située en regard. Citons par exemple le rapprochement non-littéral entre la photographie ci-dessous et le texte qui figure quelques pages plus tôt dans Carnets de Jérusalem, où les toits pris en contreplongée renforcent l'idée de « couches superposées » de la ville :

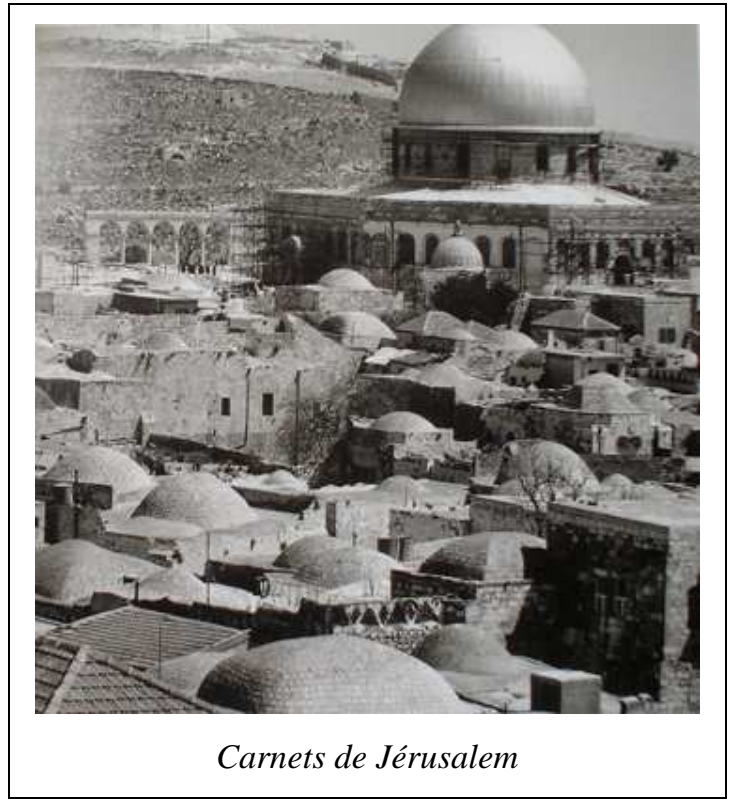

« Nulle part autant que dans cette ville je n'ai été conscient de toutes ces couches superposées d'événements, de scènes de la vie quotidienne où des gens comme nous déambulaient, souffraient, riaient et pleuraient $\gg(C J, 25)$.

${ }^{1}$ GASPAR, Lorand, Espaces. Catalogue de l'exposition à la BM de Marseille, décembre 1984-janvier 1985. 
Certaines photos semblent illustrer des textes parus dans d'autres livres, comme les photos de touaregs publiées dans l'acte du colloque de 2001 et le livre Mouvementé de mots et de couleurs qui trouvent qui font écho aux fragments de Journaux de Voyage :

Parmi les visages que garde encore ma mémoire il y a une majorité de vieillards. [...] dans ses yeux clairs une vibration tellement plus vieille que son regard sur le monde. $(J V, 54)$

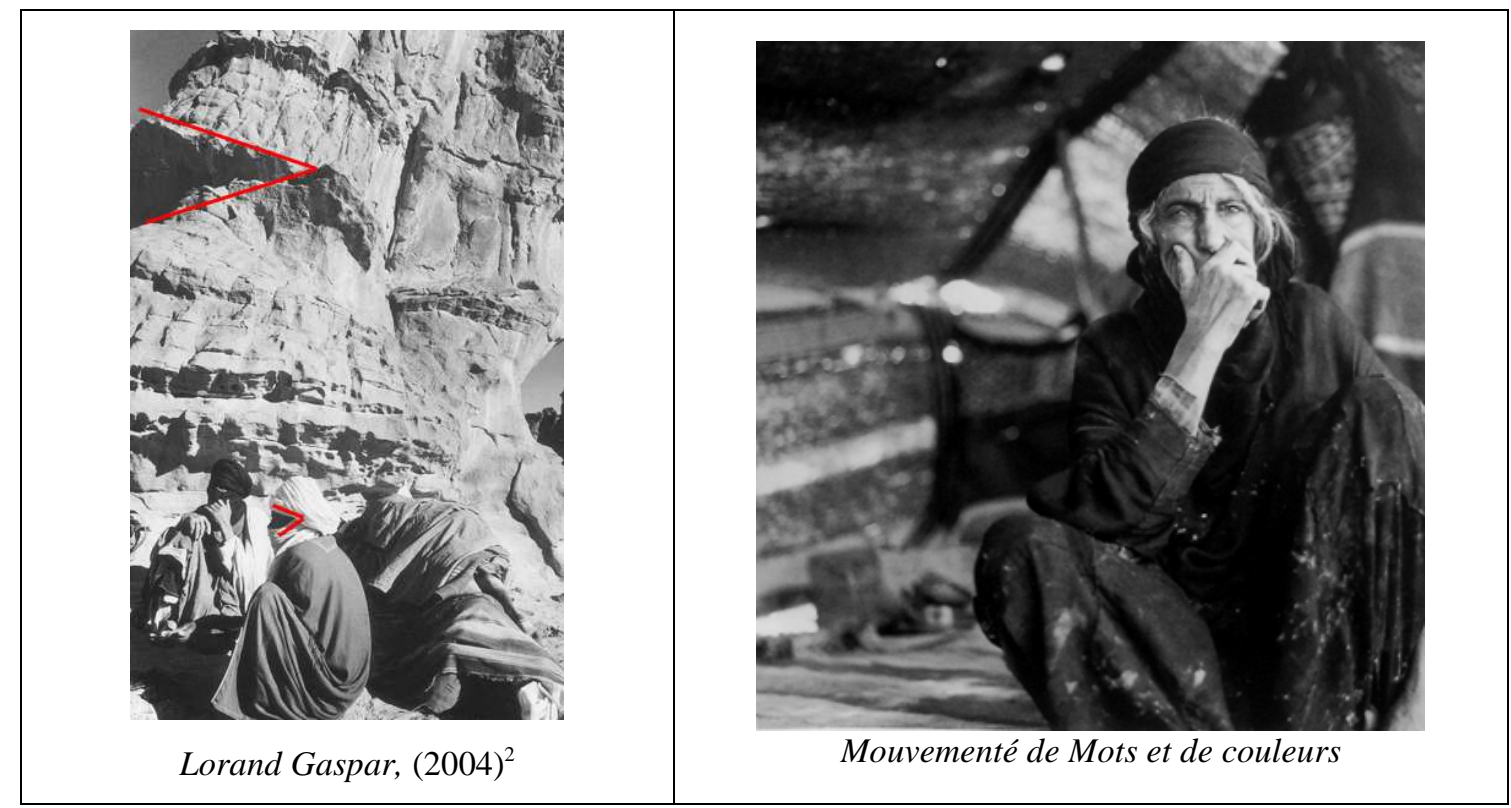

D'autres photos encore pourraient être considérées comme le symbole même de la poésie de Gaspar - telle cette femme tissant une étoffe aux motifs géométriques (cidessous).

Véronique Montémont, dans son analyse de la genèse des Cahiers de Patmos, compare en effet le processus d'écriture chez Lorand Gaspar à un travail d' artisanat ${ }^{3}$. Le poète retravaille plusieurs fois ses textes par «condensation et déplacement ${ }^{4}$ », en ajoutant peu, mais en supprimant beaucoup et en cherchant le mot exact, la formule plus imagée. «[...] ces micro-retouches contribuent de façon déterminante à la souplesse et

\footnotetext{
${ }^{2}$ Notons sur la photo l'ombre du rocher en forme de triangle qui reprend la forme du visage du touareg assis au premier plan, ce qui révèle une construction très fine de l'image et une approche poétique du visuel.

${ }^{3}$ MONTEMONT, Véronique, «Lorand Gaspar : genèse des Carnets de Patmos », (mis en ligne le : 15 février 2007.) http://www.item.ens.fr/index.php?id=27103 (consulté le : 03/03/2008).

${ }^{4}$ Ibid.
} 
à l'aération du texte et ont un impact sur l'équilibre général du style, extrêmement reconnaissable, de l'auteur ${ }^{5} »$.

Les jeux d'échos commencent déjà au sein même des clichés, dans les petits détails presque invisibles et dans les jeux de rythme à l'intérieur des photos. Sur la photo de la femme tissant (ci-dessous), le rythme de l'étoffe est renforcé par le rythme du mur de pierre laissant ainsi la réalité extérieure se refléter de manière abstraite dans le tissu artisanal. À peine perceptible sont le fil avec lequel elle tisse son étoffe et le geste de sa main. L'image est fixée dans l'instantané éternel et cette immobilité n'est transgressée que par ce petit mouvement de la main presque invisible, qui devient la métaphore de la création poétique.

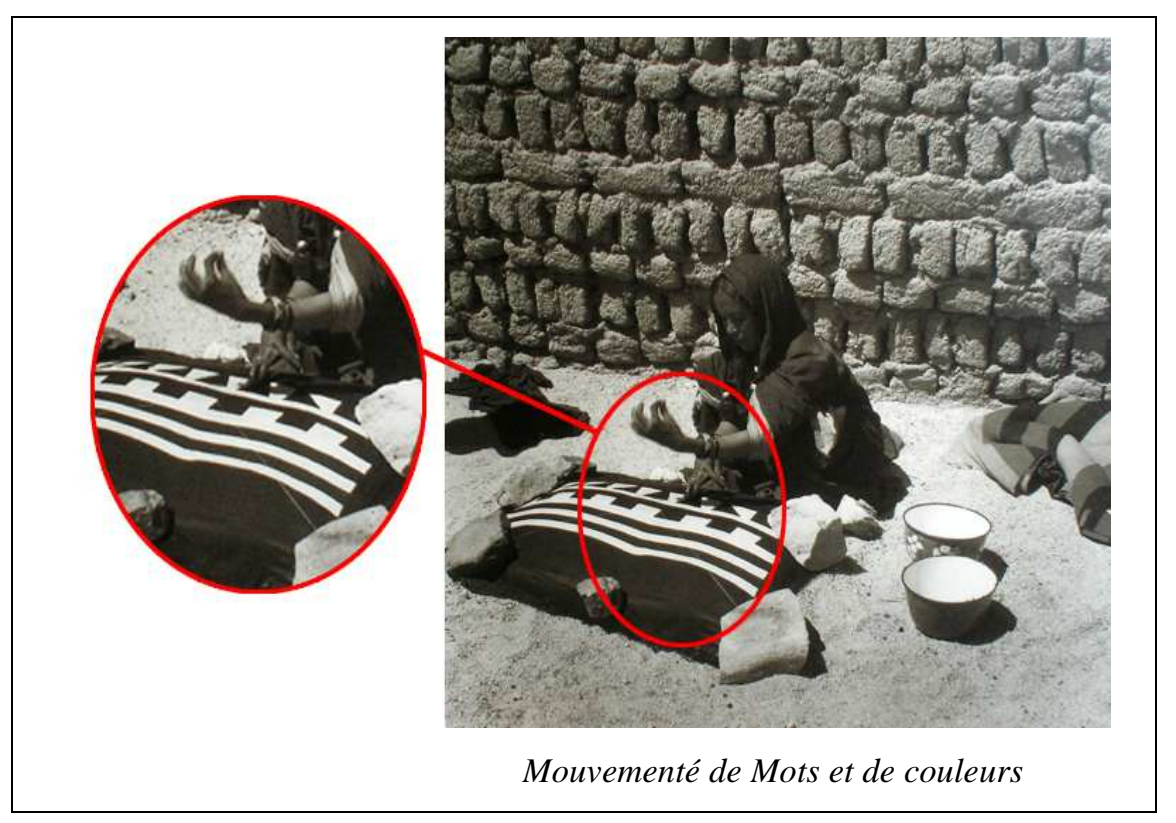

De nombreux liens se tissent également entre les photos et les textes, mais à l'intérieur du livre les photos gardent une certaine autonomie par rapport à l'écrit. Elles dont placées sur une page hors-texte et sans pagination (mais il faut à nouveau se demander s'il s'agit là du choix du poète ou de l'éditeur). Les photographies, dans Carnets de Jérusalem et Carnet de Patmos, contribuent bien à conférer une atmosphère au texte. Dans le premier, la gamme des gris équilibrée et les formes ondulées des montagnes adoucissent l'aridité du désert. Les vues sont toujours très larges, comme pour retranscrire la grandeur du désert, mais ne donnent jamais accès à une surface lisse et homogène qui provoquerait une sensation du vide. Caillou, courbure de montagne, 
buisson ou ciel ciselé contribuent à la richesse visuelle du contenu - tandis que les photos de Carnet de Patmos nous plongent dans un univers minéral où, contrairement aux photos de Carnets de Jérusalem, le noir et le blanc est accentué par des filtres. Le blanc des murs brille avec le même éclat au premier plan comme à l'arrière plan, créant un effet de juxtaposition, abolissant la perspective et aplatissant le cadre. Les photos donnent le ton du livre, en plus d'inscrire le texte dans un paysage réel.

L'utilisation des photos chez Lorand Gaspar est avant tout poétique. Pratiquer la

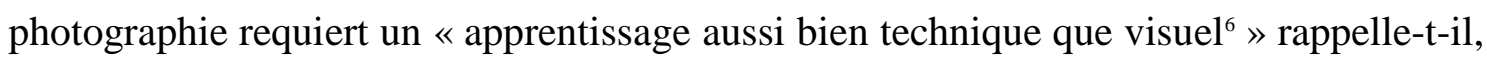
et dans ce visuel propre à Gaspar on retrouve des éléments qui font penser à des figures de styles poétiques. Aussi pourrait-on interpréter la photo ci-dessous comme une métaphore visuelle, où les buissons de la montagne deviennent chèvres :

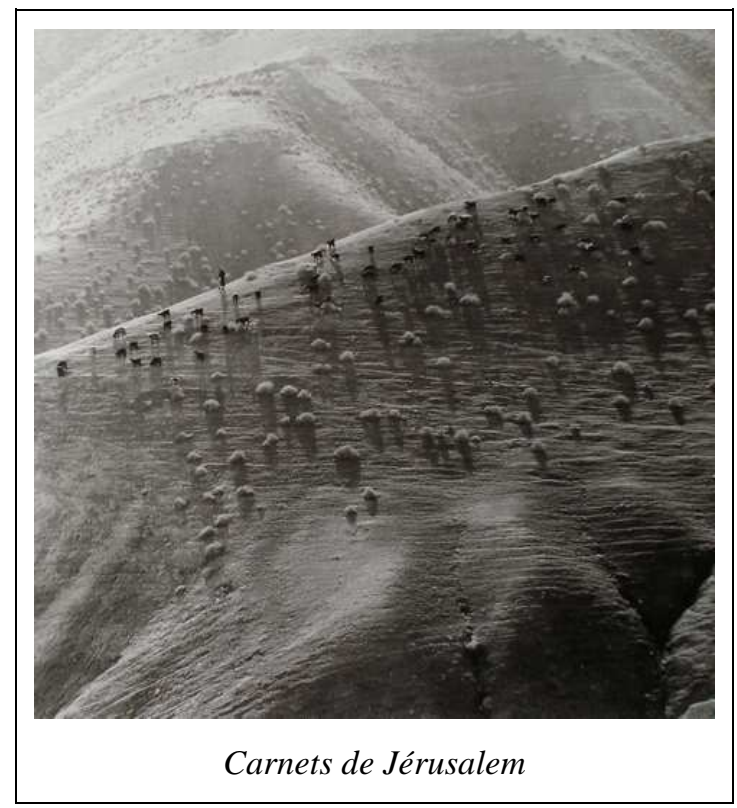

Encore faut-il pour percevoir les petits détails fins des photos de Gaspar, regarder la photo dans un format assez grand, et laisser le regard errer à l'intérieur de l'image.

Autre figure poétique : le jeu avec la perspective, qui pourraient être perçus comme un équivalent visuel de la figure de la syllepse, mais au lieu du non respect de l'accord grammatical au profit du sens, dans le cas, de l'image c'est le sens commun qui

\footnotetext{
${ }^{6} \ll$ Entretien sur la photographie », p. 160.
} 
est contredit à cause des règles de la perspective, ce qui fait que le vase devient plus grand que le chameau, et le jeune enfant plus grand que son aîné.

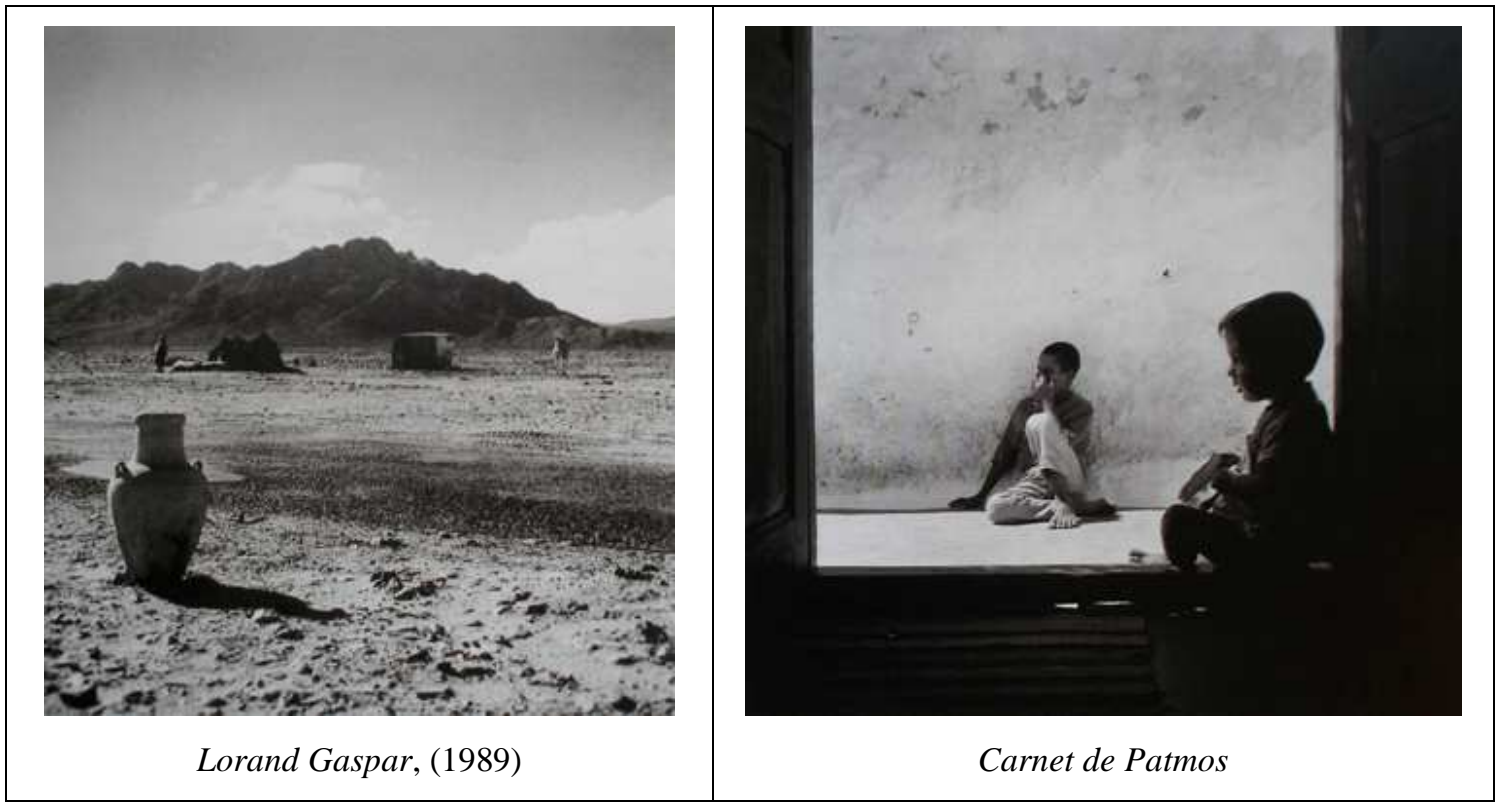

L'oxymore visuelle du ciel noirci grâce à un filtre appartient également aux techniques poétiques du visuel. La bipolarité noir et blanc se retrouve d'ailleurs dans les photographies en couleur avec la recherche de deux teintes ou deux couleurs opposées (souvent le rouge et le bleu ou le violet et l'orange).

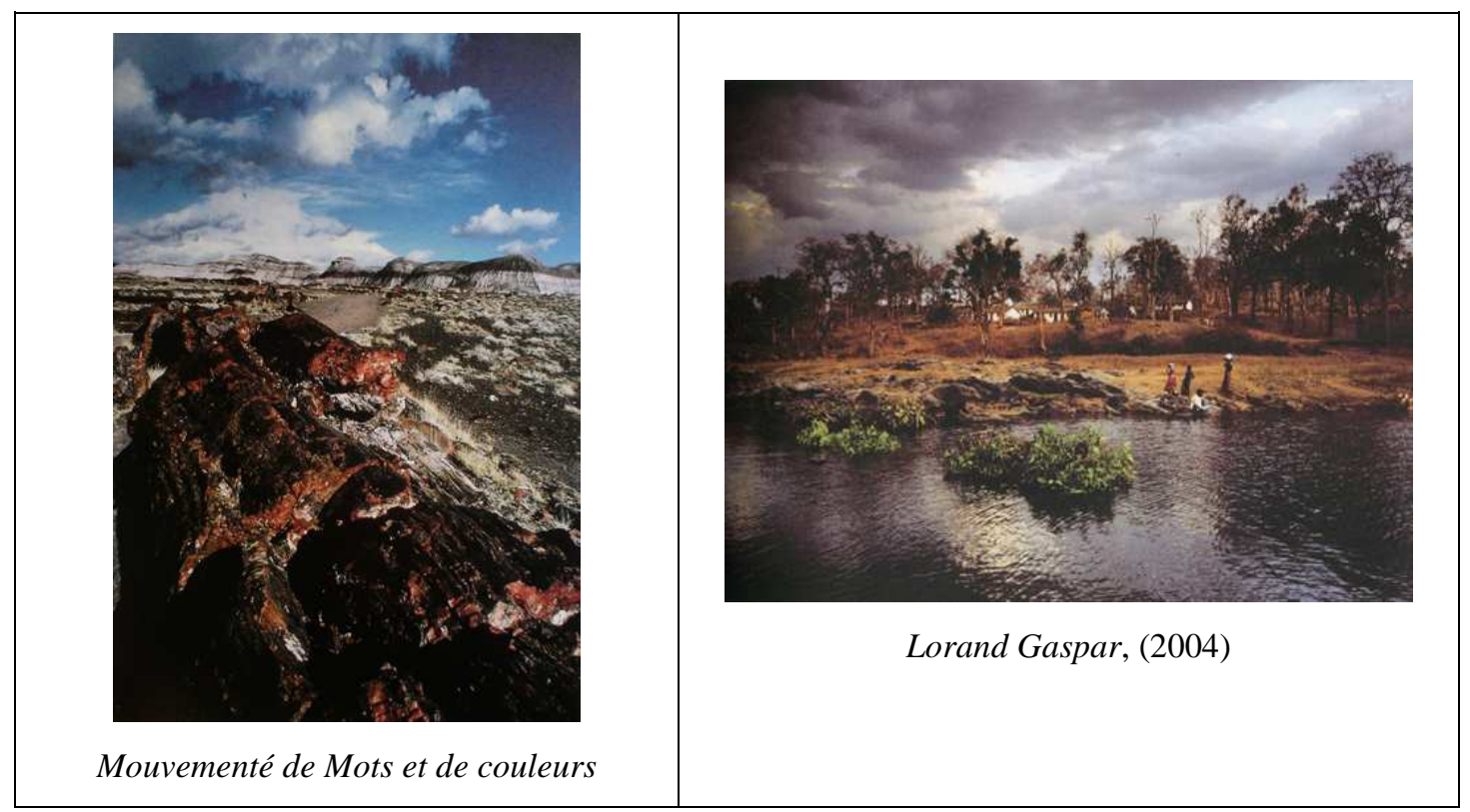

Grâce à cette approche poétique du visuel, les photos communiquent avant tout un sens sensible au texte. Lorand Gaspar évoque ainsi l'image qui «communique » une sensation avant même de signifier : la photo fixait «quelque chose qui me "parlait" 
visuellement et que je ne savais "expliquer"7 ». Comme l'observe Jean-Pol Madou à propos de la poésie de Gaspar: «quelque chose m'est donné avant même que ne se déploie l'horizon visuel. Ce quelque chose m'est donné dans une évidence que le déploiement de l'horizon videra de sa force ${ }^{8} \gg$.

${ }^{7}$ «Entretien sur la photographie », p. 159.

${ }^{8}$ MADOU, Op. Cit, p. 54. 


\section{VII.10. Lorand Gaspar - Conclusion}

Les analogies entre les textes et les photos de Lorand Gaspar sont multiples, tout comme les dispositifs dans lesquels nous les retrouvons. La photographie participe pleinement à une réconciliation de la poésie avec le monde sensible, non seulement par les images qui sont le reflet d'un lieu et véhiculent la sensation de présence de ce bout de réalité qui s'offre au photographe, mais aussi par le procédé qui nourrit la réflexion sur la compréhension du monde et du travail d'écriture.

La démarche du photographe est semblable au travail du poète sur le langage. Le photographe par son boîtier découpe, décompose la réalité en fragments. Il isole les objets et les êtres de leur entourage pour les fixer sur la pellicule. Le poète qui travaille sur le langage travaille de la même manière sur les mots : «Classer, isoler, fixer » $(S A, 26)$ les mots, pour leur conférer un sens nouveau. La recherche des éléments qui rythment le paysage dans les photos, les sentiers de pierres dans les montagnes ou simplement les zones d'ombre et de lumière rappellent tout autant le rythme des poèmes.

Selon Annie Dulong, il existe un lien profond entre le travail de création poétique et photographique ${ }^{1}$. Les processus se ressemblent, selon elle, au niveau de la sensation créatrice et du geste créateur, qu'elle décrit comme le fruit d'une attente qui mobilise : frustration, condensation, découpe temporelle, puis dépôt. Sa définition, sans y faire référence, correspond aux propos de Denis Roche (comme nous le verrons dans la partie suivante). Le geste créateur comme l'acte photographique ne peuvent se répéter, ils correspondent à «une expérience de présence au monde : en réponse à un trouble, un geste est accompli, mouvement de découpe qui propose, par le biais du regard, une lecture, une reconfiguration du monde ${ }^{2} »$. L'accent est ainsi mis sur la sensation et l'expérience - « [...] ce qui est posé sur le papier — image ou poème -

\footnotetext{
${ }^{1}$ DULONG, Annie, Le geste créateur, 2003, http://www.unites.uqam.ca/grep/AnnieDulong.pdf (consulté le : 08/08/2008). Toutefois, il nous semble que cette analogie entre le geste créateur et la photographie bien que tout à fait caractéristique dans le cas des poèmes de Lorand Gaspar est à restreindre à un certain type de photographie et de poésie. On ressent à présent un rapport étroit, mais il se limite historiquement à la photographie qui par le geste indiciel veut témoigner d'une présence au monde.

${ }^{2}$ Ibid.
} 
semble le dépôt, le reste d'une expérience ou d'une sensation ${ }^{3} »-$ qui souligne tout autant l'importance du corps, l'ancrage personnel, et autobiographique de celui qui a vécu l'expérience.

L'œuvre de Lorand Gaspar retranscrit l'expérience sensible de la rencontre avec la beauté, avec un moment sublime qui envahit le corps. Les poèmes et les photographies deviennent la célébration de la beauté, du silence et de l'absolu.

${ }^{3}$ Ibid. 
ANNEXE $n^{\circ} 3$ : Exemples du cheminement des auvres de Lorand Gaspar à travers les différentes publications

\begin{tabular}{|c|c|c|c|}
\hline Revue & livre objet & \multirow{4}{*}{$\begin{array}{l}\text { Patmos et autres } \\
\text { poèmes, Paris, } \\
\text { Gallimard, 2001, coll. } \\
\text { «blanche » } \\
\text { (20 exemplaires sur } \\
\text { vélin pour l'édition de } \\
\text { tête) }\end{array}$} & \multirow{4}{*}{$\begin{array}{l}\text { Patmos et autres } \\
\text { poèmes, Paris, } \\
\text { Gallimard, 2004, coll. } \\
\text { Poésie, } \mathrm{n}^{\circ} 390 \text { (édition } \\
\text { de poche) }\end{array}$} \\
\hline $\begin{array}{l}\text { «Amandiers »(extraits), } \\
\text { La Nouvelle Revue } \\
\text { Française, n²64, déc. } \\
1974, \text { p. } 50-55 .\end{array}$ & 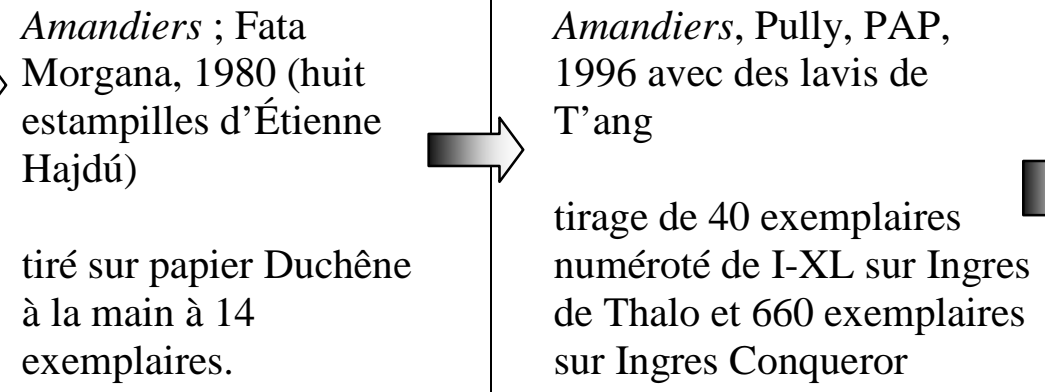 & & \\
\hline $\begin{array}{l}\text { «Genèse », La Nouvelle } \\
\text { Revue Française, n 342-343, } \\
\text { juillet août 1981, p. 39-43 } \\
\text { nouvelle version : } \\
\text { «Genèse », Seyssel, Le } \\
\text { Nouveau Recueil, n52, } \\
\text { sept. - nov. 1999, p. 5-9. }\end{array}$ & $\begin{array}{l}\text { Genèse avec trois eaux fortes de Zao Wou-Ki, Thierry } \\
\text { Bouchard, } 1981 .\end{array}$ & & \\
\hline $\begin{array}{l}\text { «Patmos », La Nouvelle } \\
\text { Revue Française, n438-439, } \\
\text { juillet-août, 1989, p. 48-53. } \\
\text { «Patmos II » Seyssel, } \\
\text { Recueil } \mathrm{n}^{\circ} 13,1989, \text { p. } 5-7 .\end{array}$ & $\begin{array}{l}\text { Patmos, Pully, PAP, 1989, avec un lavis de T'ang } \\
\text { tiré en } 500 \text { exemplaires sur Ingres de Thalo et } 13 \\
\text { exemplaires avec un lavis original de T'ang }\end{array}$ & & \\
\hline
\end{tabular}


ANNEXE $n^{\circ} 4$ : Ouvrages de Lorand Gaspar rassemblant textes et images

\begin{tabular}{|c|c|c|c|c|}
\hline texte & image & titre & support & relation entre texte-image \\
\hline \multirow{8}{*}{\multicolumn{2}{|c|}{$\begin{array}{l}\text { textes et photos de } \\
\text { Lorand Gaspar }\end{array}$}} & Porte-des-Singes, n $5,1977$. & magazine & 8 clichés avec poèmes \\
\hline & & $\begin{array}{l}\text { Lorand Gaspar, Espaces, Marseille, Sud, } \\
1983 .\end{array}$ & $\begin{array}{l}\text { catalogue } \\
\text { d'exposition }\end{array}$ & 15 clichés, poèmes inédits \\
\hline & & $\begin{array}{l}\text { Lorand Gaspar, Égée-Judée, Aporie, n9, } \\
1988 .\end{array}$ & magazine & 2 clichés avec poèmes \\
\hline & & $\begin{array}{l}\text { Lorand Gaspar. Musée Nicéphore Niepce, } \\
1989 .\end{array}$ & $\begin{array}{l}\text { catalogue } \\
\text { d'exposition }\end{array}$ & $\begin{array}{l}10 \text { clichés texte d'introduction } \\
\text { et entretien }\end{array}$ \\
\hline & & $\begin{array}{l}\text { Carnet de Patmos, Le Temps qu'il fait, } \\
1991 .\end{array}$ & livre & 12 clichés, parallèle à la prose \\
\hline & & $\begin{array}{l}\text { Arabie heureuse et autres journaux de } \\
\text { voyage, Deyrolle, } 1997 .\end{array}$ & livre & une photographie en couverture \\
\hline & & Carnets de Jérusalem, 1997. & livre & 16 clichés, parallèle à la prose \\
\hline & & Scherzo, ${ }^{\circ} 4,1998$. & magazine & 4 clichés avec poèmes \\
\hline \multirow{2}{*}{$\begin{array}{l}\text { texte de } \\
\text { Lorand } \\
\text { Gaspar }\end{array}$} & $\begin{array}{l}\text { photo de René } \\
\text { Rousset et } \\
\text { Claude Ballaré }\end{array}$ & $\begin{array}{l}\text { «Que fuyons-nous en voyageant? ? in : } \\
\text { Sable, Tunis, } 1972 .\end{array}$ & livre & $\begin{array}{l}\text { réflexions qui accompagnent } \\
\text { l'image }\end{array}$ \\
\hline & $\begin{array}{c}\text { photo de } \\
\text { Koïchiro Kurita }\end{array}$ & $\begin{array}{l}\text { Le mouvement du monde, livre faisant suite } \\
\text { à l'exposition « Hydrosphère » à la Galerie } \\
\text { Camera Obscura en mai et juin } 2001 \text {. }\end{array}$ & livre & $\begin{array}{l}\text { poèmes qui accompagnent } \\
\text { l'image }\end{array}$ \\
\hline
\end{tabular}




\begin{tabular}{|c|c|c|c|c|}
\hline \multirow{12}{*}{$\begin{array}{l}\text { texte de } \\
\text { Lorand Gaspar }\end{array}$} & \multirow{12}{*}{$\begin{array}{l}\text { images d'autres } \\
\text { artistes }\end{array}$} & $\begin{array}{l}\text { Approche de la parole, Gallimard, } 1978 . \\
\text { Frontispice d'Henri Michaux. }\end{array}$ & livre & l'image accompagne le texte \\
\hline & & $\begin{array}{l}\text { Sentes, Tunis, 1979. Frontispice de Claude } \\
\text { Ballaré. }\end{array}$ & livre & l'image accompagne le texte \\
\hline & & $\begin{array}{l}\text { Amandiers, Bagneux, 1980. Huit estampilles } \\
\text { d'Étienne Hajdú. }\end{array}$ & livre d'art & l'image illustre le texte \\
\hline & & $\begin{array}{l}\text { Genèse, Thierry Bouchard, 1981. Trois } \\
\text { eaux-fortes de Zao Wou-Ki. }\end{array}$ & livre d'art & l'image illustre le texte \\
\hline & & $\begin{array}{l}\text { Séfar, Fata Morgana, 1983, illustrations au } \\
\text { grattage d'Àrpád Szenes. }\end{array}$ & livre d'art & l'image accompagne le texte \\
\hline & & $\begin{array}{l}\text { Journaux de voyage, Le calligraphe, } 1985 . \\
\text { Encres de Zao Wou-Ki. }\end{array}$ & livre d'art & l'image accompagne le texte \\
\hline & & Patmos, PAP, 1989. lavis de 'Tang. & livre d'art & l'image accompagne le texte \\
\hline & & $\begin{array}{l}\text { La Maison près de la mer, Thierry } \\
\text { Bouchard, 1991. Quatre lavis de 'Tang. }\end{array}$ & livre d'art & l'image accompagne le texte \\
\hline & & $\begin{array}{l}\text { Pour accompagner Àrpàd Szenes, Marie, } \\
\text { 1993. Frontispice d'Ầrpàd Szenes. }\end{array}$ & livre d'art & le texte accompagne l'image \\
\hline & & $\begin{array}{l}\text { Apprentissage, Deyrolle, 1994, un lavis de } \\
\text { 'Tang en couverture. }\end{array}$ & livre & l'image accompagne le texte \\
\hline & & $\begin{array}{l}\text { Amandiers, Pully, PAP, 1996. Lavis de } \\
\text { 'Tang. }\end{array}$ & livre d'art & l'image accompagne le texte \\
\hline & & $\begin{array}{l}\text { Approche d'un désert vivant, Villeneuve- } \\
\text { Lez-Avignon, 1999, encres de Claude } \\
\text { Caranjoud }\end{array}$ & livre objet & l'image illustre le texte \\
\hline
\end{tabular}




\begin{tabular}{|c|c|c|c|c|}
\hline \multirow{5}{*}{$\begin{array}{l}\text { texte d'autres } \\
\text { auteurs }\end{array}$} & \multirow{5}{*}{ photo de LG } & $\begin{array}{l}\text { Yves Bonnefoy, L'arrière-pays, Paris, } \\
\text { Flammarion, } 1982 .\end{array}$ & livre & $\begin{array}{l}1 \text { cliché choisi pour illustrer le } \\
\text { texte }\end{array}$ \\
\hline & & Espaces de Lorand Gaspar, Sud, 1983. & ouvrage critique & 12 clichés \\
\hline & & $\begin{array}{l}\text { Gravure rupestre. Poème de Mátyás Varga } \\
\text { (traduit par L.G), } 1998 .\end{array}$ & livre & $\begin{array}{l}5 \text { clichés sans rapport aux } \\
\text { poèmes }\end{array}$ \\
\hline & & $\begin{array}{l}\text { Mouvementé de mots et de couleurs, Le } \\
\text { Temps qu'il fait, } 2003 .\end{array}$ & livre & $\begin{array}{l}25 \text { clichés, le texte de James } \\
\text { Sacré est écrit à partir des } \\
\text { photos }\end{array}$ \\
\hline & & $\begin{array}{l}\text { Cahier Lorand Gaspar, Le Temps qu'il fait } \\
2004 \text {. }\end{array}$ & ouvrage critique & 16 clichés \\
\hline
\end{tabular}

\section{Textes de Lorand Gaspar pour des catalogues d'exposition}

- Exposition Chirurgie graphique. Collage de Claude Ballaré. Maison de la culture Ibn Rachiq du 17 au 23 janvier 1972. Repris dans Chirurgie graphique (1975).

- Étienne Hajdú. Sculptures, lavis, estampilles. Galerie de l'information, Tunis, 28 avril- 15 mai 1980. Repris, très modifié et partiellement dans La Nouvelle Revue Française (1992) et dans Apprentissage (1994).

- Zao Wou-Ki. Exposition. Galerie de l'information, Tunis, 9-20 décembre 1980. Repris dans Zao Wou-Ki, Encres (1986) et en nouvelle version, dans Apprentissage (1994).

- Exposition Viera da Silva, Galerie de l'information, Tunis du 12 au 24 mai 1982. Repris en nouvelle version dans La Nouvelle Revue Française (1992).

- Exposition T'ang, 5-27 octobre 1989, (Lyon, Atelier Pierre Olivier, 1989), Repris partiellement dans Poésie 92, dans Lorand Gaspar. Pierres de chant (1992), et Apprentissage (1994).

- Exposition Olivier Giroud. Château de Ratilly. Centre d'art contemporain, du 22 juin au 30 sept. 1991. (Le Temps qu'il fait, 1991). 


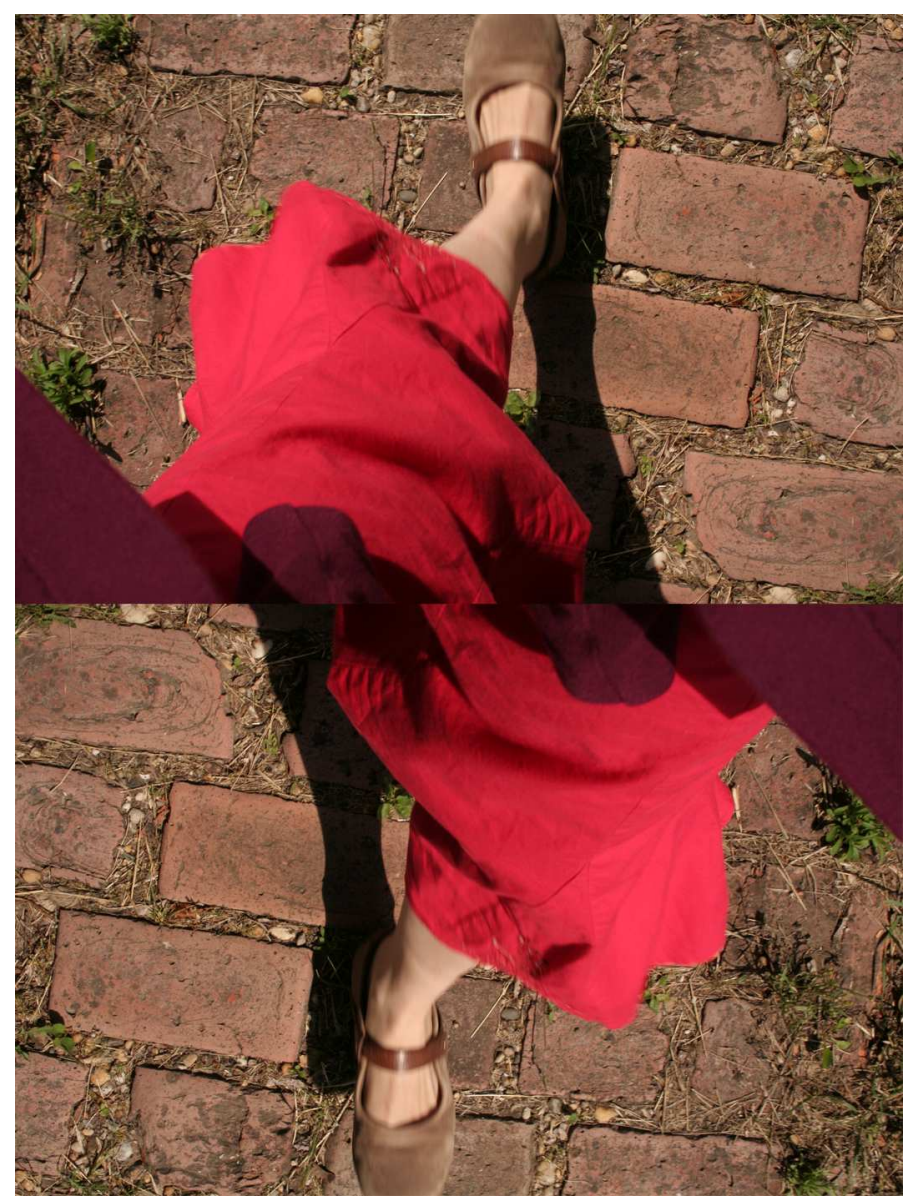

Pál Gy. : $\quad$ Le va-et-vient dans le cadre 


\section{Contenu du chapitre}

VIII. Denis Roche - les allers retours entre littérature et photographie 363

VIII.1. L'approche critique d'une œuvre en construction 365

VIII.2. Théorie littéraire / théorie photographique 374

VIII.3. La dimension autobiographique 383

VIII.3.a. Entrer dans le cadre. 386

VIII.4. Éros et le déclic sexuel de l'obturateur. 393

VIII.4.a. La poésie érotisée 393

VIII.4.b. Le fantasme de la photographie 396

VIII.4.c. La photographie comme chant d'amour 401

VIII.4.d. Analogies théorique et thématique 404

VIII.5. Le temps à l'épreuve 414

VIII.6. Poésie et photographie en mouvance 423

VIII.7. Denis Roche - Conclusion

ANNEXE n5 : L'évolution vers l'iconicité de recueil en recueil

ANNEXE $n^{\circ} 6$ : Structure temporelle du livre Les Preuves du Temps 438

\section{$\underline{\text { Liste des abréviations }}$}

Dépôts de savoir \& de technique

$D S T$

La disparition des lucioles

$D L$

La poésie est inadmissible

PI

Louve basse

$L B$

Notre Antéfixe

NA

Dans la maison du Sphinx

$M S$

Photolalies

PH

Ellipse et laps

EL

Le Boîtier de mélancolie

$B M$

Légendes de Denis Roche

$L D$ 
L'acte créateur qui ouvrait sur l'expérience du sensible chez Lorand Gaspar revêt un caractère mécanique dans l'œuvre de Denis Roche. À l'image de la photographie sa poésie prend figure ${ }^{1}$ dans la vitesse et dans la dynamique des combinaisons possibles. Denis Roche faisait partie du groupe «Tel Quel» entre 1962 et 1973, et c'est dans la revue qu'il publia ses premiers recueils : Récits complets (1963), Les idées centésimales de Miss Elanize (1964) Éros énergumène (1968). Selon l'Histoire de Tel Quel retracée par Philippe Forest ${ }^{2}$, il se tenait à l'écart des engagements politiques du groupe, néanmoins nous retrouvons la caractéristique telquelienne dans son cuvre dans l'importance qu'il accorde à la critique littéraire et à l'autocritique. Ainsi au centre de son œuvre se trouve la critique du langage (du langage poétique et du langage des images). Il partage également avec le groupe «Tel Quel» le ton avant-gardiste et révolutionnaire, une sorte de violence et véhémence qui caractérisent avant tout sa poésie. Sa pratique photographique (sa première exposition ${ }^{3}$ est présentée en 1978) ainsi que sa réflexion sur la photographie modifient progressivement son œuvre littéraire, au point qu'il s'éloigne de la poésie après la publication de son recueil intitulé Le mécrit (1972) pour se consacrer à des œuvres où le dispositif photographique est de plus en plus présent. La photographie intervient alors dans son œuvre comme modèle à l'écriture, mais elle apparaît conjointement au texte dans divers ouvrages hybrides, voir s'autonomise par rapport au texte dans les expositions et les catalogues d'exposition. Parmi les quatre écrivains photographes c'est de Denis Roche qui cherche systématiquement à faire confondre la photographie et la littérature.

\footnotetext{
${ }^{1}$ Jean-Michel Maulpoix, dans son étude sur la poésie contemporaine que nous avons déjà évoqué, classe l'œuvre de Denis Roche, parmi les poètes qui cherche à « Figurer » le monde en élaborant un nouveau langage. http://www.maulpoix.net/Figurer1960.html (consulté le : le 10/10/2009).

${ }^{2}$ FOREST, Philippe, Histoire de "Tel Quel", Paris, Seuil, 1995.

${ }^{3}$ Galérie L'œil 2000, 39 photographies, Châteauroux, France et Photographie actuelle en France, 1978, exposition collective itinérante organisée par la direction générale des relations culturelles, scientifiques et techniques du ministère des Affaires étrangères, Paris.
} 


\section{VIII.1. L'approche critique d'une ouvre en construction}

En parallèle avec l'évolution de l'œuvre de Denis Roche vers la photographie, on note un changement progressif dans la réception de l'œuvre et l'approche critique. Après avoir pratiqué une analyse purement formelle (Roubaud, 1978) la critique passe à une analyse du sens critique dissimulé entre les vers, y voyant une rupture poétique/postpoétique (Prigent, 1977), pour ensuite revenir grâce au concept de la photographie à l'étude à la fois de la forme et du sens, approche qui voit dans cette production «postpoétique » une refiguration «au-delà de la figuration»(Gleize, 1983). Comme le rappelle Luigi Magno dans sa thèse sur l'œuvre de Denis Roche, les premiers commentateurs de son œuvre poétique n'y ont vu que le projet de défigurer la convention de l'écriture, dont le produit deviendrait du coup illisible. L'investissement formel fait en fin de compte éclater les lois qui encodent la poésie².

Ainsi Jacques Roubaud reconnaissait dans les poèmes de la période allant jusqu'au recueil Le Mécrit une tentative formelle de remise en question du vers et la redéfinition du vers libre ${ }^{2}$. La critique du vers libre, selon Roubaud, ce n'est pas la destruction du vers libre, mais « une destruction de ce qui n'est pas libre dans le vers libre $^{3} \gg$. Il remarque les touches d'ironie par lesquelles tout ce qui délimitait le vers est déconstruit. On trouve notamment l'unité sémantique qui est rompue ; la majuscule en début de vers qui se déplace au milieu ou à la fin de la ligne ou qui est complètement abolie jusqu'à n'avoir que le blanc comme l'unique marque qui distingue «l'identité du vers »; le trait d'union qui est supprimé dans la coupure des mots en fin de vers.

La déconstruction du vers s'accompagne de l'utilisation progressive d'éléments visuels : recours au blanc; aux fautes de frappe ; aux signes de ponctuations utilisées en dehors des règles; aux signes typographiques : phrases soulignées, ou autres traits et lignes; les calligrammes, une évolution qui va jusqu'à insérer des dessins dans $L e$ Mécrit. La publication en un volume «complet» rend plus visible cette évolution

\footnotetext{
${ }^{1}$ MAGNO, Luigi, Dialectique(s) de l'écrit et de l'image chez Denis Roche, thèse soutenue sous la direction de Jean-Marie Gleize et Jacqueline Risset à Lyon en 2006, p. 60-63.

${ }^{2}$ ROUBAUD, Jacques, «Le mètre énergumène », La vieillesse d'Alexandre, Paris, Ramsay, (1978 pour la première édition) 1988, p. 163-177.

${ }^{3}$ Ibid., p. 176.
} 
progressive ${ }^{4}$. Ces signes interviennent comme des éléments gênants dans la lisibilité du texte, comme des composants énigmatiques perturbant la signification. La publication complète révèle l'exploration systématique que met en place le poète : dès qu'une technique de brouillage de sens fonctionne : dès qu'elle est épuisée dans une série de poème, elle est remplacée par une nouvelle technique dans la prochaine série, quitte à ce que la technique précédente réapparaisse plus tard, légèrement modifiée ${ }^{5}$.

Selon Christiant Prigent, les éléments perturbants la signification dans l'écriture rochienne visent à dévoiler le spectacle de l'écriture.

Se mettre en posture d'observer le «spectacle des altérations de la pensée naturelle » dans «l'élaboration des produits lyriques de la fiction» implique une distance du sujet qui écrit par rapport à cette production lyrique. [...] Pour n'être pas dupe de ce qu'on agit, il faut un mode de mise en évidence du fonctionnement textuel qui fasse en sorte que celui qui lit ne se trouve pas à son tour englué dans le spectacle donné. ${ }^{6}$

Parmi les procédés employés par Roche pour mettre à nu la contrefaçon de la poésie, Christian Prigent met l'accent sur l'excès de sens. La mise en évidence du fonctionnement poétique passe par un travail de «surenchère métaphorique », «une dépense du signifiant». Le poète n’écrit pas mais «mécrit», comme l'indique le titre de son dernier recueil de poèmes, (Le Mécrit) paru en 1972. Dans ce recueil, Denis Roche met fin à la poésie qu'il juge « inadmissible », il parle «contre les paroles » pour « défigurer la convention », pour déjouer «l'idéologie poétique » qu'attend le lecteur. Le poème est secondaire, il est même ridiculisé, parce qu'il ne dévoile que l'avidité du lecteur, sa faim de sens, son désir d'une « intelligence SYMBOLARDE $(P I, 433)$. Dans le livre intitulé Carnac, Denis Roche rassemble des fragments de textes relatifs à «l'usage» des pierres mégalithiques (brochures touristique, explications anthropologique, photographies, etc.) pour démontrer, selon Christian Prigent, «qu'il s'agit d'un système outrageusement codé, mais ne codant rien d'autre que l'énigme ${ }^{7}$ ».

Toutefois, selon Jean-Marie Gleize, il ne faut pas prendre le poète à ses propres mots, l'opération sémiotique, le «terrorisme critique », la défiguration du sens,

\footnotetext{
${ }^{4}$ Pour les références aux recueils de poèmes nous utiliserons également la publication intitulée « $œ u v r e s$ poétiques complètes » qui en 1995 regroupe toutes les publications jusqu'au recueil Le Mécrit sous le titre : La poésie est inadmissible, œuvres poétiques complètes, Paris, Seuil, 1995, p. 9. Par la suite nous utiliserons l'abréviation $P I$.

${ }^{5}$ Voir l'annexe n`5 à la page 434.

${ }^{6}$ PRIGENT, Christian, Denis Roche, Paris, Seghers, 1977, p. 24.

${ }^{7}$ PRIGENT, Op. Cit., p. 21. (Juste pour l'anecdote : le livre Carnac permet toutefois une lecture à la lettre et non ironique comme l'atteste le fait qu'il soit classé à la BNF dans la section « histoire », parmi les ouvrages traitant la préhistoire.)
} 
« risque[nt] en effet d'interdire l'accès au mouvement du texte, qui produit incessamment des effets de sens, des effets de structures, des "effets d'intrigue" [...]. Effets qui sont calculés au plus près, ménagés, pour diriger le plaisir du lecteur ${ }^{8} »^{\text {. Jean- }}$ Marie Gleize analyse ainsi non ce qui tend à détruire le sens, ce qui lui apporte un caractère discontinu, mais les procédés qui à l'inverse assurent une certaine cohérence au texte. Ainsi en va-t-il de la répétition sémantique ou narrative, la répétition littérale des lignes avec les micro-changements qui mettent en évidence le processus de composition de l'écriture. Dans les écrits «post-poétiques », avant tout dans Notre Antéfixe ${ }^{9}$ et Dépôts de savoir \& de technique ${ }^{10}$, l'effet de sens se construit autour de la position du sujet, de son lieu et de son lieu d'être qui réinscrit ainsi, selon Gleize, l'œuvre de Denis Roche dans le paysage problématique de la poésie depuis LamartineHugo $^{11}$. Ce qui obsède Denis Roche, c'est le pouvoir d'enregistrement, l'immédiateté, et le rapport paradoxal de la photographie avec la réalité, ce qui en fait un outil intéressant dans le projet d'autoportrait et d'autoprojection, de la mise en scène de soi-même, dans le travail autobiographique où le « je est un autre ».

Les Dépôts de savoir \& de technique empruntent leur méthode d'écriture à la photographie, comme le précise Denis Roche. Chaque ligne du texte est le prélèvement d'un texte déjà écrit, qui est déposé ligne après ligne pour provoquer un effet d'empilement. Le texte déjà écrit est cadré, découpé et prélevé pour ensuite être déposé pour former une empreinte. Le résultat final dans les dépôts-antéfixes ${ }^{12}$ est un portrait, car le matériau de base consiste en des textes de toute sorte trouvés chez les personnes « portraiturées » (des amis ou des proches) : des livres qu'ils sont en train de lire, des brochures de publicité ou fragments de journal intime. Notre Antéfixe, qui propose un portrait-autoportrait du couple peut se lire alors comme un :

\footnotetext{
${ }^{8}$ GLEIZE, Jean-Marie, Poésie et figuration, Paris, Seuil, 1983, p. 228.

${ }^{9}$ ROCHE, Denis, Notre antéfixe, Paris, Flammarion, 1978. Par la suite nous utiliserons l'abréviation : NA. Le livre contient deux textes : «L'entrée des machine» qui est l'avant propos explicatif, « Notre Antéfixe » et 40 photographies montrant le couple. Les deux textes seront ensuite repris dans Dépôts de savoir \& de technique, dépôts $\mathrm{n}^{\circ} 9$, mais non les photos. «L'entrée des machines » sera également repris dans La disparition des lucioles, p. 47-59.

${ }^{10}$ ROCHE, Denis, Dépôts de savoir \& de technique, Paris, Seuil, col. " Fiction \& Cie ", 1980. Par la suite nous utiliserons l'abréviation : DST.

${ }^{11}$ GLEIZE, Jean-Marie, Poésie et figuration, Op. cit., p. 263.

${ }^{12}$ Sur les 19 Dépôts on trouve 6 dépôts qui sont des portraits-antéfixes : $\mathrm{n}^{\circ} 8$ Antéfixe de Bernard Dufourd \& et Martine Vatin ; $n^{\circ} 9$ Notre Antéfixe, $n^{\circ} 11$ Antéfixe de Micheline Peyrot, $n^{\circ} 14$ Antéfixe de Bernard Noël et de Collette Deblé, ${ }^{\circ} 15$ Antéfixe de Françoise Peyrot, $n^{\circ} 18$ Antéfixe d'Hubert Damisch $\&$ de Teri Wehn-Damisch.
} 
[...] chant d'amour et de désir (de savoir et de technique) dont l'axe « narratif » principal est celui de la relation entre les deux corps et les deux prénoms du couple auteur-personnage du texte : voyages, lectures et amour (font) sont la vie et le roman du couple, et la matière même du texte. ${ }^{13}$

La «refiguration au-delà de la figuration » se joue dans l'effet de sens que produisent les bribes qui se font échos, tout comme dans le mouvement, la scansion à la fois phonétique et visuelle.

En 1978, Denis Roche publie son livre La disparition des lucioles (réflexions sur l'acte photographique) dans lequel il précise en avertissement liminaire «qu'il ne saurait y avoir de photographie de la littérature, il ne saurait y avoir de "littérature" de la photographie, car la "littérature" de la photographie, c'est la photographie ellemême ${ }^{14} »$. La critique ${ }^{15}$ suit désormais cette affirmation et considère l'œuvre dans son ensemble, comme une œuvre qui se construit et se nourrit en suivant les deux axes de l'écriture et de la photographie, dans un brouillage des frontières, dans l'entre-deux d'une œuvre hybride. Parmi les œuvres «post-poétique» de Denis Roche, nous pouvons toutefois distinguer plusieurs manières d'entrelacer la photographie et le texte, ce que résume le tableau ci-dessous.

\begin{tabular}{|c|c|c|c|c|}
\hline $\begin{array}{l}\text { texte au schème } \\
\text { photographique }\end{array}$ & $\begin{array}{l}\text { photos qui ont un } \\
\text { rôle narratif dans } \\
\text { le texte }\end{array}$ & $\begin{array}{l}\text { textes sur les } \\
\text { photos de tiers }\end{array}$ & œuvres hybrides & albums de photo \\
\hline $\begin{array}{l}\text { - Essais de } \\
\text { littérature }^{\text {arrêtée }^{16}} \\
\text { - Dans la maison } \\
\text { du Sphinx (1992) }\end{array}$ & $\begin{array}{l}\text { - Louve basse } \\
\text { (1972) } \\
\text { - Dépôts de } \\
\text { savoir \& de } \\
\text { technique } \\
\text { (1980) }\end{array}$ & $\begin{array}{l}\text { - préfaces pour des } \\
\text { photographes } \\
\text { Bernard Plossu, } \\
\text { Manuel Alvarez } \\
\text { Bravo, Jacques } \\
\text { Damez, Ralph } \\
\text { Gibson } \\
\text { - Écrits } \\
\text { momentanés } \\
\text { (1988) } \\
\text { - Le Boîtier de } \\
\text { mélancolie } \\
\text { (1999) }\end{array}$ & $\begin{array}{l}\text { - Légendes de Denis } \\
\text { Roche (1981) } \\
\text { - Conversations } \\
\text { avec le temps } \\
\text { (1985) } \\
\text { - La disparition des } \\
\text { lucioles (1982) } \\
\text { - Photolalies (1988) } \\
\text { - Ellipse et laps } \\
\text { (1991) }\end{array}$ & $\begin{array}{l}\text { - Photographies } \\
\text { 1965-1989, } \\
(1989) \\
\text { - Les preuves du } \\
\text { temps, (2001) }\end{array}$ \\
\hline
\end{tabular}

\footnotetext{
${ }^{13}$ GLEIZE, Jean-Marie, Poésie et figuration, Op. cit., p. 263.

${ }^{14}$ ROCHE, Denis, La disparition des lucioles (réflexions sur l'acte photographique), Paris, l'Étoile, 1982, p. 8. Par la suite nous utiliserons l'abréviation : $D L$.

${ }^{15}$ C'est cette perspective que l'on retrouve dans le numéro 23 des Cahiers de la photographie consacré à Denis Roche (1989), la thèse de Luigi Magno (Dialectique(s) de l'écrit et de l'image chez Denis Roche, Op. cit., 2006) ainsi que le colloque qui lui est consacré en 2007 (Denis Roche, L'un écrit, l'autre photographie, sous la direction de Luigi Magno, Lyon, ENS, 2007).

${ }^{16}$ Les Essais de littérature arrêtée se composent de bribes de journal intime dont certaines parties ont donné lieu à des publications en 1981, 1985, 1986, 1989, mais qui n'ont jusqu'à nos jours jamais été publiées en entier. Voir à ce propos l'analyse de Luigi Magno, (Dialectique(s), Op. cit., p. 217-224).
} 
Plusieurs modèles sont proposés par la critique pour tenir en compte de cette œuvre double et foisonnante, tels le modèle de l'essaim, du blob ou du va-et-vient.

Dans sa thèse, Luigi Magno $^{17}$ propose l'essaimage comme formule qui caractériserait l'entrelacement du texte et de l'image, expression qui traduit à la fois l'idée du déplacement du texte vers l'image et de l'image vers le texte, et l'idée du déplacement de l'ensemble texte/image. Magno analyse notamment le chapitre intitulé «Quatre textes » publié dans Le Mécrit le, où sur une double page figurent deux calligraphies chinoise, une image et des signes calligraphiques espacés en image (voir ci-dessous).

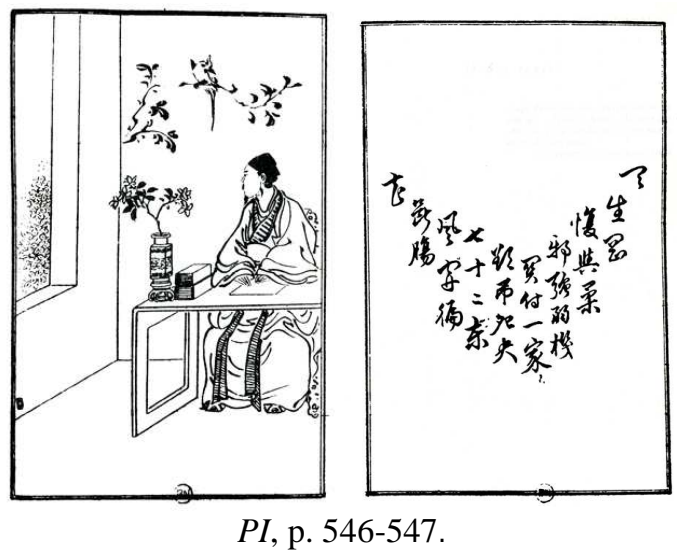

Denis Roche reviendra sur cette illustration dans son livre Louve basse, où il la décrit de la manière suivante : « À gauche, un mandarin quelconque, à sa table de travail, et qui regarde vers la fenêtre, tournant le dos au texte en grappe, en essaim, qui semble travailler la partie de droite de l'illustration ${ }^{18} \gg$. Le fait que le mandarin tourne le dos symbolise à la fois la posture que prend Denis Roche vis-à-vis de la poésie avec Le Mécrit («nous tournons le dos à ce bois » écrit-il plus loin sur la même page de Louve Basse, le bois faisant référence à son tour à la poésie entamée dans son premier recueil Forestière Amazonide), et la singularité de la photographie qui permet de voir à quoi on ressemble de dos, qui fait référence à sa pratique des portraits photographiques, (tout comme elle fait écho avec la série de photos publiée à la fin de Louve basse sur laquelle nous reviendrons).

Luigi Magno attire notre attention sur l'image de gauche où une feuille blanche est posée sur la table devant le mandarin. Le visage de ce dernier est non seulement

\footnotetext{
${ }^{17}$ MAGNO, Luigi (Dialectique(s), Op. cit., p. 94-99.

${ }^{18}$ ROCHE, Denis, Louve basse, Paris, Seuil, col. "Tel Quel", 1972, p. 160. Par la suite nous utiliserons l'abréviation : $L B$.
} 
tourné dans la direction opposée par rapport à l'essaim de texte, mais il est orienté vers la fenêtre, vers l'ouverture sur le mur. Son regard est ainsi projeté vers le monde. En passant par une relecture de La Table de Francis Ponge, Luigi Magno dévoile l'analogie de la fenêtre et de la feuille d'écriture, de la fenêtre-écriture qui nie le mur par le mouvement de haut vers le bas que l'écriture exige à l'inverse du mouvement allant du bas vers le haut de la construction d'un mur. L'image, selon Magno, est ainsi une mise en abîme de la page du poème sur la table et du poème figuré par la fenêtre, elle donne à voir «les mécanismes qui président à la composition matérielle, physique de l'écriture ${ }^{19} »$. La calligraphie peut se lire, comme le suggère Magno, comme un envol, un essaimage de signes sur la page, page qui par les marques du cadre représente également une fenêtre. En même temps, une certaine continuité se crée entre l'image de droite et celle de gauche : on peut lire l'essaim de mot comme une prolongation des méandres des feuilles sur l'image de gauche, une réalité non plus séparée, mais de même nature. L'essaim symbolise alors un envol, une nouvelle liberté conférée à la littérature tout comme à la photographie. Le terme réapparaît alors chez Roche dans le livre Dépôts de savoir \& de technique, comme le principe de cette nouvelle littérature :

Ce fut le bruit des gens et de leur vie, de leur histoire et de leur autorité qui m'atteignit en premier; Il me semblait avoir à la main un gigantesque fer à cheval aimanté, une harpe magnétique vibrant à même la peau de mon torse, être devenu moi-même tout entier cet essaim attirant fait de signes, de grappes maïssées de syllabes, se nourrissant d'autres essaims, d'autres vols compacts, d'autres arrivées incroyable de sons et de gestes divers. $(D S T, 12)$

Lors du colloque sur Denis Roche, Luigi Magno propose néanmoins un autre terme, celui de blob, pour décrire la relation des textes et des images. Il le définit en se penchant sur l'étude minutieuse des transformations qui s'opèrent entre la parution des articles de Denis Roche dans le magazine City, entre 1984-1987, et leur republication dans un ensemble intitulé Écrits momentanés ${ }^{20}$. Denis Roche proposait dans chaque numéro du magazine City une « lecture » personnelle à partir d'une photographie de son choix ; chaque fois d'un photographe différent. La republication sous forme de livre a entraîné plusieurs petites modifications, telles des différences textuelles, des photos non reprises ou recadrées. La mise en page, ainsi que le changement de régime dans la lecture par la juxtaposition et la mise en série dans le même espace continu du livre,

\footnotetext{
${ }^{19}$ MAGNO, Luigi, (Dialectique(s), Op. cit., p. 96.

20 ROCHE, Denis, Écrits momentanés, Chroniques Photo du Magazine, City, 1984-1987, Paris Audiovisuel, 1988.
} 
transforme considérablement l'œuvre initiale, selon Luigi Magno. Le titre Écrits momentanés revendique pour le texte la même précarité que le signifiant d'une photographie, proposant un écrit sur des clichés instantanés, dont le signifiant est instantané. Luigi Magno définit alors cette œuvre mixte comme un blob, terme emprunté à l'architecture qui caractérise une forme complexe qui frôle l'informe. L'œuvre constitue :

[...] une forme qui, au niveau du genre, n'est plus définissable ni délimitable et qui se donne proprement comme créature polymorphe: fiction, commentaire, passage critique, narration anecdotique, récit autobiographique, fiction critique, critique fictionnelle, prose, voire poésie. ${ }^{21}$

Cette définition peut s'étendre à l'œuvre entière de Denis Roche, qui apparaît alors comme une œuvre provisoire et inachevable, l'inscrivant également dans la filiation des œuvres de Francis Ponge.

Quant au terme de va-et-vient, il est suggéré par Denis Roche, mais il fournit une formule qui sera ensuite reprise par la critique. Le terme décrit avant tout la pratique photographique de Denis Roche qui consiste à se photographier au déclencheur à retardement, de se placer dans le cadre et d'échapper partiellement à la pose, au contrôle de sa propre image, technique découverte, semble-t-il, par hasard, ce qu'il décrit comme une anecdote dans l'introduction à l'exposition L'autoportrait photographique ${ }^{22}$.

L'autoportrait de San Onofrio avait dit ceci : J'ai considéré évidemment le cloître dans sa plus grande dimension puisqu'il était rectangulaire et j'ai dit à $F$. que nous allions nous asseoir à un bout, dans l'entrecolonnement central et que je disposerai mon appareil photo à l'autre bout, bien en face. [...] F. et l'appareil une fois installés, à chaque bout de l'enceinte [...] j'armai le déclencheur, déclenchai et me précipitai à toute jambes vers l'emplacement «vide et muet » que je m'étais destiné quelques secondes auparavant [...] J'entendis le déclic alors qu'à fond de course j'opérai le pivotement qui allait me permettre de me retrouver assis sereinement au côté de ma compagne. Comme une flèche entre les deux épaules, pas raté $d u$ tout. F riait à ne plus en finir. $(D L, 100)$

${ }^{21}$ MAGNO, Luigi, «Blobs momentanés », in L'un écrit, l'autre photographie, Op. cit., p. 275.

${ }^{22}$ Préface aux Autoportraits photographiques, Centre Georges Pompidou, Herscher, 1981, repris dans La disparition des lucioles sous le chapitre : «Brève rencontre » p. 97-110. 


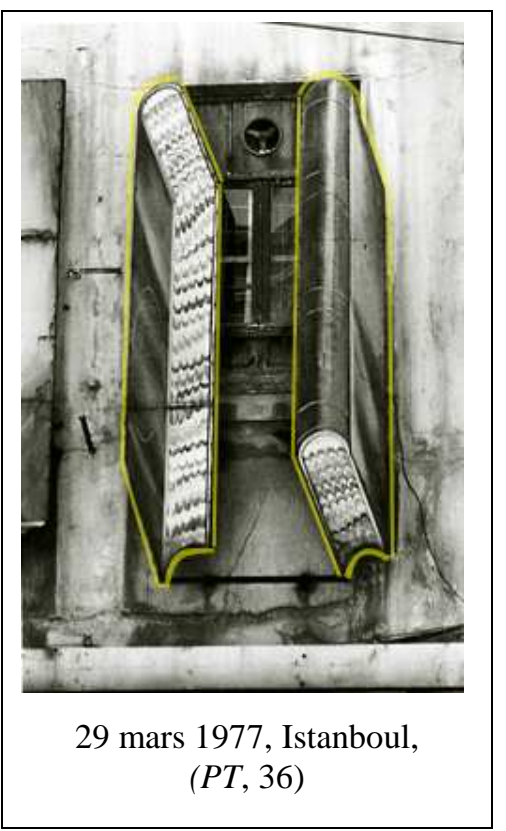

La disparition des lucioles semble tout à fait se construire sur ce modèle du va-et-vient entre l'écriture et la photographie. Le livre s'ouvre d'ailleurs avec la photo ci-contre qui crée une illusion de mouvement vertical opposé, de haut en bas et de bas en haut, une tension de va-et-vient, mais dessinant aussi la forme de deux livres, vu de face et vu de dos (ce que nous avons signalé en jaune), deux volet-livres qui cachent et cadrent partiellement la vue de la fenêtre. Dans le premier chapitre de La disparition des lucioles intitulé «Aller et retour dans la chambre blanche » $(D L, \mathrm{p} .11-23)$ nous retrouvons également des photographies prises au déclencheur à retardement (qui se doublent de la légende écrite en dessous), et le texte joue à rendre visible la mise en scène de l'écriture dans le va-et-vient qui s'installe entre la prise littérale du texte et les indices de son montage. Quand Denis Roche écrit :

M'entendant même parler, tentant d'établir le contact avec les phrases à écrire en proie à l'intermittent «jaspinage» de ma surface profonde, à la recherche de la moindre chose qui permette l'enchaînement des idées, l'amorce qui m'amènerait à écrire cette « Préface des confins » que voici. $(D L, 12)$

ou quand il écrit s'imaginer en train d'écrire, mais «vu de dos », il intègre son autoportrait vu d'un cadre extérieur dans le texte. Quand le texte se termine par la reprise de la première phrase à l'identique, qui enferme le texte dans une boucle répétitive, ou quand, juste avant la fin, il évoque un film de Wajda, qu'il est «en train de regarder », le doute s'installe vis-à-vis de l'enregistrement littérale instantanée et incontrôlée. Est-il en train de regarder le film ? Est-il en train d'écrire ? Quel est ce présent que le texte met en scène ? En empruntant son modèle à la photographie, le texte devient à la fois instantané, ancré dans le présent, paraissant échapper à la maîtrise, et à la fois construit et contrôlé.

À plusieurs reprises surgit ce terme de va-et-vient tout au long du livre $L a$ disparition des lucioles. Appliqué à la littérature, le modèle photographique semble pouvoir la renouveler et la pousser « au-delà du principe d'écriture ${ }^{23} »$.

\footnotetext{
${ }^{23}$ L'expression fait référence au titre d'un article publié dans Tel Quel, nº67, 1976, comme l'indique Denis Roche $(D L, 57)$.
} 
Il faudrait d'abord accepter l'idée que la photographie ne soit le décalque ou le substitut de rien, qu'elle soit son propre sujet et que ce sujet seul soit son étude, sa définition, sa visée.

Ensuite, à son contact, on se forgerait nécessairement un autre œil, un discours nouveau [...] Ainsi apparaîtrait une terminologie fraîche. Enfin fraîche. Sans précédent, sans jurisprudence.

Ainsi un aller et retour, un va-et-vient parlant et cliquetant, s'installerait entre la littérature (non l'écriture) et la photographie (non pas l'épreuve mais le fait instantané) dont l'allure et le bruit, le vent même, car ça irait vite et il faudrait bien que chacun suive, relancerait enfin la vieille balle plus loin. (DL, 53. Nous soulignons.)

Dans les livres «post-poétique » se crée ainsi un véritable aller-retour entre les textes et les photographies, un dialogue sur la photographie, où le dispositif se prête comme une technique (instantané, prise littérale, cadrage), un schème de l'écriture, et où l'image évoquée ou présente, juxtaposée au texte, engendre un entre-deux.

La lettre et l'image sont des lièvres levés en permanence, qui entretiennent ensemble des murmures d'en bas et des idées qui montent, avec, par moments, des saillies qui fusent diagonalement dans l'air, qu'elles vont et viennent sur place sans épuisement ni ralenti, se travestissant tour à tour au point de jouer à être chacune l'anamorphose de l'autre, préconisant le chahut de la présence, et peut-être rien d'autre. ${ }^{24}$

Le terme de va-et-vient réintègre alors le mouvement du regard, de l'œil qui balaye incessamment le champ qui s'offre devant lui.

Ce terme est suggéré par Denis Roche, mais il est également employé par la critique. Jean-Marie Gleize le réutilise dans la préface au colloque sur Denis Roche :

On présuppose une synonymie, au moins une équivalence, en tous cas une circulation, le va-etvient de l'une à l'autre pratique, et la communication de l'une par l'autre, la mise au point (par exemple) au-delà du principe de poésie (des principes formels définissant une spécificité poétique, la poéticité stricto sensu) de formes d'écritures autres, autrement, de dispositifs (ou systèmes réglés de contraintes) conçus au contact de la pratique photographique. ${ }^{25}$

Dans notre analyse, nous suivrons également cette voie, passant par l'analyse des points de convergence entre l'écriture et la photographie, mais en recherchant non seulement ce que la littérature devient en côtoyant ce dispositif, mais également, à l'inverse, ce que la photographie devient dans un contexte littéraire.

${ }^{24}$ ROCHE, Denis, Dans la maison du Sphinx. Essais sur la matière littéraire, Paris, Seuil, 1992, p. 11. Par la suite nous utiliserons l'abréviation : $M S$.

${ }^{25}$ GLEIZE, Jean-Marie, «Préface. J'écris donc je photographie », in L'un écrit, l'autre photographie, Op. cit., p. 18. 


\section{VIII.2. Théorie littéraire / théorie photographique}

En tant que poète telquelien, Denis Roche attache une grande importance à la critique littéraire, en s'expliquant dans ses préfaces et dans des entretiens. Dans son parcours, non seulement la littérature tend à se confondre avec la photographie, mais la critique littéraire se mêle aussi progressivement à sa théorie photographique.

Dès son premier recueil Forestière Amazonide, publié en 1962, Denis Roche pose le problème du langage poétique et du signifiant. Il écrit dans l'Avant-propos :

La poésie doit tout mettre en œuvre pour arriver à ses fins, aussi bien l'expérience intérieure du poète que la réalité environnante, aussi banale soit-elle. Elle rejoint en cela la peinture contemporaine. Du matériau poétique constitué d'événements fantastiques, de phénomènes quotidiens, d'objets décriés, ou de chaussures à clous, le poète tire une quantité de langage insensée. Ainsi par la grâce d'une re-création, se trouve définitivement fixé un langage absolu, incommunicable, un « no man's land » infranchissable, mais qui autorise peut-être un survol. ${ }^{1}$

Ce «langage absolu », ou « langage secret » ne dévoile cependant que l'importance de l'acte créateur. Denis Roche en citant Mircea Eliade rapproche le travail poétique à l'euphorie du chaman et à l'inspiration du prophète, puis il conclut :

L'audience est la même cherchant des réponses, des clés à ses frayeurs, ne posant pas les questions qu'elle ne saurait définir, mais trouvant sa satisfaction dans l'attention même qu'elle porte aux actes créateurs, c'est-à-dire « révélateur ». $(P I, 9)$.

Le mot « révélateur», selon Luigi Magno, annonce déjà la photographie, même si dans sa thèse il démontre à quel point l'œuvre poétique de Roche est redevable avant tout aux modèles de la peinture abstraite, notamment à celle de Paul Klee et de Vassily Kandinsky². C'’est à partir de la même référence que Stéphane Baquey compare l'œuvre de Denis Roche au primitivisme. La référence est donnée sur un ton ironique, mais «elle maintient une forme d'expérience qui est héritière de cette croyance ${ }^{3}$ », même si les contextes sociaux ne sont pas les mêmes. Le rapprochement avec la magie du chaman dévoile que ce n'est pas le produit ou la création littéraire qui compte mais l'acte créateur: "S'il n'y a plus lien de sujet ou de discours, il y a lien de création » $(P I, 53)$. L'influence accordée à l'acte créateur dans la littérature fait écho à

\footnotetext{
${ }^{1}$ Nous utiliserons pour les citations de recueils de poèmes, la publication intitulée « œuvres poétiques complètes » qui en 1995 regroupe toutes les publications jusqu'au recueil Le Mécrit sous le titre : La poésie est inadmissible, œuvres poétiques complètes, Paris, Seuil, 1995, p. 9. Par la suite nous utiliserons l'abréviation $P I$.

${ }^{2}$ MAGNO, Luigi, Dialectique(s), Op. cit., p 65.

${ }^{3}$ BAQUET, Stéphane, Le primitivisme de Denis Roche. Lyrique amazonide, Paris, éd. des archives contemporains, 2008, p. 16.
} 
l'importance dans l'œuvre rochienne de l'acte photographique, ce qu'indique également le sous-titre de son livre théorique ${ }^{4} \mathrm{La}$ disparition des lucioles. Réflexions sur l'acte photographique. L'important ce n'est pas l'image, mais l'acte et le geste qu'il présuppose. Le geste poétique ou photographique, selon Stéphane Baquey, donne accès à «l'expérience ritualisé de l'excès ». L'excès c'est tout ce qui échappe à la structuration du savoir, « un excédent qu'aucune positivité ne saurait réduire, excédent du désir, du temps, de la mort ${ }^{5} \gg$.

Si la littérature est jugée « inadmissible » parce qu'elle ne dévoile que la faim de sens du lecteur, la photographie est à son tour critiquée pour ne produire que des simulacres, des leurres. De ce point de vue, l'appareil photo et la machine à écrire sont identiques : «Les appareils photos, comme les machines à écrire, sont des machines à fabriquer des leurres et des ex-votos, c'est-à-dire la même chose. Ils sont à la fois proies et heures, sens et cibles » $(D L, 67)$. Selon Denis Roche, la photographie s'inscrit dans un au-delà de la représentation et l'aborder du point de vue de la mimésis n'offre qu'une étroite approche «surannée », qui a été développé en comparaison avec la peinture, pour justifier son statut artistique :

[...] le coup de la caverne de Platon ne tient pas devant une planche de contacts. Que pourrait-on encore faire de cette vieille idée que le monde n'est qu'une illusion quand, dans une soirée entre amis, ou devant sa belle-sœur nue, on déclenche à la fois le flash ${ }^{6}$ qu'on jette sur le monde et la sortie, comme crachée par l'appareil, de l'épreuve en couleur qu'on n'a plus qu'à coller dans un album?

La question n'est évidemment pas si simple. Une autre vieillerie fait surface : la représentation. Pas celle de Platon, mais l'autre : celle de Cézanne, qui n'est pas non plus très éloignée de celle de Gertrude Stein ou de Joyce qui ramenaient tout cela au mot d' «identité ». $(D L, 50)$

Cette référence à Cézanne renvoie à la question de la surface et de l'écran déjà évoquée, Cézanne étant à la fois le premier peintre à rompre dans ses tableaux avec l'unique point de vue qu'offre la perspective et le premier à introduire les différentes surfaces et

\footnotetext{
${ }^{4}$ Le livre est constitué d'un regroupement d'articles de Roche mêlant textes et images et qui ne reflètent pas simplement une visée théorique ; néanmoins certains extraits sont repris dans des ouvrages théoriques sur la photographie ce qui justifie qu'on le traite ainsi. Par exemple «L'entrée des machines » est traduite dans livre de Wolfgang KEMP, Hubertus con AMELUNXEN, Theorie der Fotographie I-IV. 1839-1995, München, Schirmer/Mosel, 2006, p. 386-397.

${ }^{5}$ BAQUET, Stéphane, Le primitivisme de Denis Roche, Op. cit...p. 10.

${ }^{6}$ Le mot « flash » renvoie à la notion de «flash signifière limite », employé dans Louve Basse, défini par l'auteur comme un «bloc associatif machinique » $(L B, 19)$ qui introduit une coupe visuelle sur la page, flash qui à la fois aveugle la personne photographiée, et l'éclaire sur la photo, flash qu'on utilise en plein jour pour donner de l'importance à certains objets ou personnes qu'on veut accentuer sur l'image. Mais il implique aussi implicitement le bruit «ssstchlak » du flash actionné, bruit violent et agressif qui s'ajoute aux bruits de fond du livre (par. ex. : klong, klong; vllouf p. 144, voui voui p. 179).
} 
volumes dans la peinture pour les mettre en évidence (surface élaborée par des formes géométrique de base : la sphère, le cône et le cylindre). Denis Roche s'y réfère aussi quand il parle de la langue comme surface, ou de la photographie qui sert «à faire au réel sa peau » :

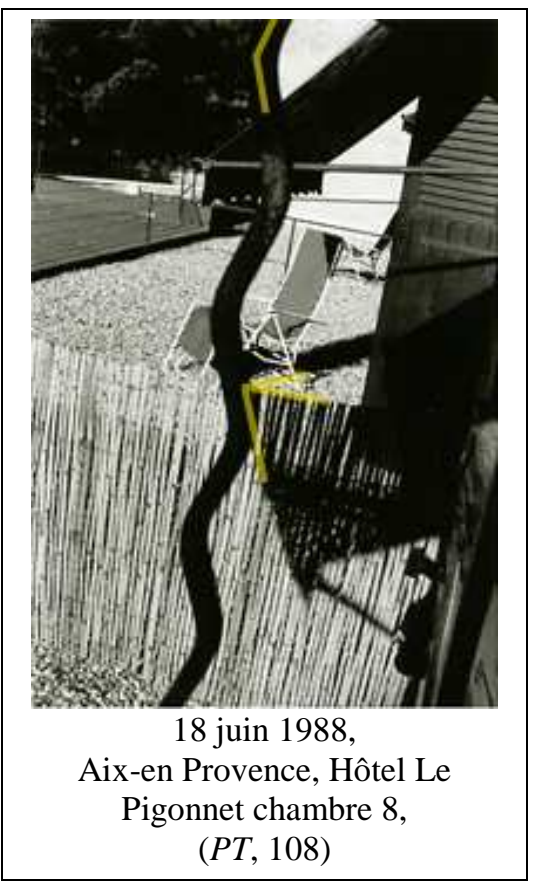

On le sait: il n'y a d'activité humaine, artistique ou non, encore moins littéraire, que de surface. [...] ainsi de l'horizon qui est comme l'électrocardiogramme du mourant, l'horizontal narguant le vertical; ainsi des toiles que peignent les peintres après s'être assurés qu'elles étaient bien tendues entre leurs cadres de bois; ainsi également des feuilles de papier, format international, sur lesquelles les écrivains s'acharnent toujours à déposer et à étaler leur encre ou à frapper du carbone ; ainsi de notre peau qui est le peu que nous connaissons de notre corps, même si un doigt ou une langue ou un sexe part ici ou là, en exploration dans un trou de la partenaire...

Ainsi, donc, de la glace qu'on suce, l'absorbant de surface en surface, jusqu'à ce que cette surface ne soit plus qu'un point et que, dans cette fraction de seconde où cela se produit, il n'y ait plus rien. $(D L, 48)$

Dans cette évidence, éprouvée vertigineusement - c'est-à-dire jusqu'au fou rire - se pourrait-il qu'on trouvât, par défaut d'intérieur, une explication du langage, ou bien celle de la nécessité de disposer d'une métaphysique, ou de son substitut, c'est-à-dire l'art ? (DL, 48-49)

Denis Roche exploite d'ailleurs dans ces photos l'ambiguïté des surfaces alignées ${ }^{7}$, avec des prises de vue qui donnent à la fois l'illusion de la trois dimension et mettent en évidence la platitude de l'image. Dans la photo ci-dessus par exemple, la barre ondulée qui vient trancher en deux l'image est cadrée de manière à ce que s'alignent l'ombre du parasol, la barre et l'ombre de la chaise dépliante (les points que nous avons marqué en jaune). Mais la barre efface aussi la distance entre le mur blanc et le fond avec des arbres, créant une ambiguité spatiale. Le blanc du mur paraît sauter au premier plan, on le sent même plus proche que le parasol. Les jeux de lignes, l'ombre de la chaise dépliante qui se poursuit dans l'ombre projetée sur le volet, qui forme une ligne parallèle à la plateforme en bois de l'arrière-plan, renforcent la surface plate comme image structurée.

Roche fait également un clin d'œil à Cézanne dans le dernier chapitre des Dépôts de savoir \& de technique intitulé « Je vous dois la vérité en littérature et je vous

\footnotetext{
${ }^{7}$ On trouve d'ailleurs chez Cézanne le même procédé. Voir sur Cézanne et les jeux de représentation des surfaces sur le site Figures ambiguë : http://figuresambigues.free.fr/SommairesJeux/jeuarts.html (consulté le : 03/03/2009).
} 
la dirai », titre qui fait référence à l'énoncé de Cézanne : «Je vous dois la vérité en peinture et je vous la dirai $^{8}$ ». Cette «vérité » que révèlerait la peinture de Cézanne passe par l'opération de transcription de la visibilité naturelle à un niveau de visibilité artistique, et par la prise en compte de la distance qui les sépare qui permet « de restaurer, par l'imaginaire, le rêve voire la pensée, la réalité primitive déformée sur la toile $^{9} \gg$. La peinture chez Cézanne donne avant tout à penser, et la formulation au futur de la phrase « Je vous dois la vérité en peinture et je vous la dirai » explicite qu'il s'agit d'une quête inachevée, voire inachevable, mais aussi que « la vérité ne serait universelle qu'à condition d'être subjective ${ }^{10} \gg$.

\section{Le livre Dépôts de savoir \& de technique,} comme nous l'avons déjà dit, accentue la platitude de la page, la surface sur laquelle sont déposées les lignes d'écritures déjà faites. Si Denis Roche mentionne ces dépôts comme des portraits, c'est qu'au-delà du principe initial (les textes prélevés sont recueillis chez la personne portraiturée), la disposition adoptée sur la page est également celle du «portrait » cadré à la verticale, et non à l'horizontal comme le paysage (même si les formats habituels des livres exigent à l'avance cette disposition verticale). Il traite

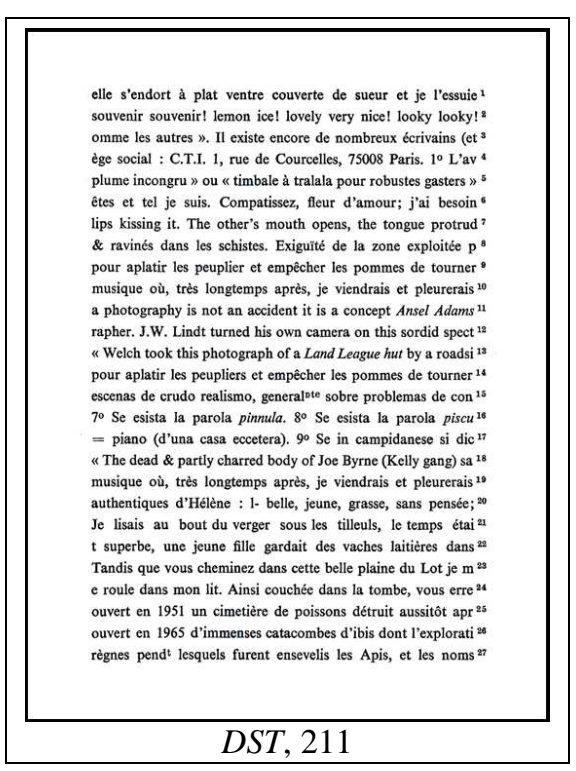
d'ailleurs ces pages comme des planches contacts, donnant aux premières et dernières lignes que délimite le cadre une importance particulière. Comme chez Cézanne la transposition concerne la « vérité » et la « réalité » des choses :

J'imaginais de piquer par milliers de piqûres successives, par dizaines de milliers de piqûres rapides et de durée semblable, la réalité des choses et des gens, mais toujours par d'autres écritures interposées, ces écritures étant des sortes de perspectives infinies mais retournées sans arrêt sur les choses ou les gens chez qui elles se trouvaient entreposées, retournées sur eux et sur elles et les commentant à ne plus en finir. (DST, 107. Nous soulignons.)

\footnotetext{
${ }^{8}$ CEZANNE, Paul, Correspondance, recueillie, annotée et préfacée par John Rewald, Paris, Grasset, 1978 : lettre à Emile Bernard du 23 octobre 1905, p. 314. Le titre choisi par Denis Roche peut aussi faire référence au livre de Jacques Derrida (La vérité en peinture, Paris, Flammarion, 1978) qui se réfère à Cézanne en mentionnant qu'il a puisé l'idée dans un livre d'Hubert Damisch (Huit thèses pour (ou contre ?) une sémiologie de la peinture, Macula, 2, 1977). Damisch qui est un ami proche de Denis Roche.

${ }^{9}$ COUTAGNe, Denis, Cézanne en vérité(s), Arles, Actes sud, 2006, p. 26.

${ }^{10}$ Ibid., p. 37.
} 
Dans les écrits de Cézanne, nous trouvons déjà les notions clefs qui caractériseront l'œuvre rochienne : l'enregistrement, l'identité, la sensation et ainsi que le terme de style qui résume les trois précédents :

Peindre c'est enregistrer ses sensations colorées.

La peinture, comme tout art, comporte une technique, une manipulation d'ouvrier, mais la justesse d'un ton et l'heureuse combinaison des effets dépendent uniquement du choix de l'artiste.

L'artiste ne perçoit pas directement tous les rapports : il les sent.

Sentir juste et réaliser pleinement donnent le style. ${ }^{11}$

Denis Roche évoque à plusieurs reprises la notion de style à propos de la photographie.

Le chapitre intitulé « Lettre à Roland Barthes sur la disparition des lucioles » explicite le choix du titre du livre et introduit la notion de style. Denis Roche a écrit cette « lettre » après la mort de Barthes et rappelle les mots de Barthes à propos du style :

Je pense surtout à ce que vous m'aviez dit, en bas de ce même escalier où j'allais, quelques semaines plus tard, apprendre votre mort, qu'au fond «la seule vraie question concernant la photographie, c'était celle du style », et vous ajoutiez : «mais c'est trop tôt pour en parler ». $(D L, 154)$

Il est intéressant que Barthes soit revenu à la fin de sa vie sur cette notion élaborée dans son premier livre de 1953, Le degré zéro de l'écriture. La notion de style chez Barthes est très complexe et ne fait pas seulement référence à un ensemble de moyens d'expression que l'auteur choisit consciemment ou inconsciemment, pour développer son œuvre. Barthes place la notion de style au-delà de la Littérature («une sorte d'opération supra-littéraire », «hors de l' $\left.\operatorname{art}^{12} »\right)$ indissociable de l'expérience personnelle de l'écrivain qu'il entoure d'une énigme en utilisant les mots : « secret », «magie », « rituel $^{13} »$ :

[...] il [le style] plonge dans le souvenir clos de la personne, il compose son opacité à partir d'une certaine expérience de la matière ; le style n'est jamais que métaphore, c'est-à-dire équation entre l'intention littéraire et la structure charnelle de l'auteur (il faut se souvenir que la structure est le dépôt d'une durée). ${ }^{14}$

\footnotetext{
${ }^{11}$ Il s'agit de pensées rapportées par le peintre et critique Émile Bernard dans son article "Paul Cézanne", publié dans la revue L'Occident, $\mathrm{n}^{\circ} 32$, juillet 1904, ainsi de pensées qu'aurait recueillies le fils de Cézanne et qu'il aurait transmises à Léo Larguier, qui les a publiées pour la première fois en 1925 dans son livre de souvenirs, Le Dimanche avec Paul Cézanne, puis à nouveau dans son essai Cézanne ou la Lutte avec l'ange de la peinture en 1947 ; fragments qui sont disponibles sur le site littératureaudio.com : http://www.litteratureaudio.com/forum?forum=5\&topic=239\&page=1 (consulté le : 04/03/2009). Nous soulignons.

${ }^{12}$ BARTHES, Roland, Le degré zéro de l'écriture suivi de Nouveaux Essais critiques, Paris, Seuil, 1953 et 1972 , p. 12-13.

${ }^{13}$ Ibid., p. 13

${ }^{14}$ Ibid. Nous soulignons pour signaler le rapport possible avec le titre du livre Dépôts de savoir \& de technique de Denis Roche.
} 
Dans Le degré zéro de l'écriture, la notion de style qui est la substance même de l'écrivain est opposée à celle de langue, code social limitatif, pour établir dans l'entredeux de ces notions celle de l'écriture, qui serait le lieu d'une liberté. L'objectif de Barthes dans cet essai est d'entamer l'histoire des rapports entre l'écriture (Signes de la Littérature) et les effets ou les changements que l'Histoire y a provoqués pour créer une nouvelle approche synthétique qui expliquerait les tendances qui se sont jouées dans la littérature depuis le romantisme jusqu'à la littérature des avant-gardes.

[...] il est donc possible de tracer une histoire du langage littéraire qui n'est ni l'histoire de la langue, ni celle des styles, mais seulement l'histoire des Signes de la Littérature, et l'on peut escompter que cette histoire formelle manifeste à sa façon, qui n'est pas la moins claire, sa liaison avec l'Histoire profonde. ${ }^{15}$

Barthes repère quatre types d'écritures possibles historiquement : l'«artisanale » et la «populiste », qui sont des échecs; l'«écriture parlée » et l'écriture «blanche » ou «neutre» constitueraient par contre le «degré zéro» des signes littéraires qui pourraient rendre compte de «l'existence d'une réalité formelle indépendante de la langue et du style ${ }^{16} »$, mais cette écriture reste pour Barthes une utopie insurpassable, car les signes de la Littérature ne peuvent pas sortir des contraintes de ces deux derniers.

Denis Roche affirme que Roland Barthes aurait également parlé de style à propos de la photographie; pourtant dans La Chambre claire Barthes rejette la notion de style en photographie en écartant la position de $« l^{\prime}$ Operator ${ }^{17} »$, du photographe. Adoptant la position du «Spectator ${ }^{18} »$, le regardant, il contemple les photos avec une approche personnelle qui ne lui fait retenir que celles qui l'affectent, qui le « pointent ${ }^{19} »$ :

[...] telle photo de Mapplethorpe m'induisait à penser que j'avais trouvé «mon» photographe ; mais non, je n'aime pas tout Mapplethorpe. Je ne pouvais donc accéder à cette notion commode, lors qu'on veut parler histoire, culture, esthétique, qu'on appelle le style d'un artiste. ${ }^{20}$

Cette position s'explique partiellement par le fait que Barthes ne considère pas la photographie comme un $\operatorname{art}^{21}$. Toutefois, il reste à jamais énigmatique ce que Roland

\footnotetext{
${ }^{15}$ BARTHES, Roland, Le degré zéro de l'écriture, p. 7. Il faut ajouter que le livre paraît dans un contexte précis, où Barthes fait référence à la fois au livre de Jean-Paul Sartre Qu'est-ce que la littérature ? et au marxisme cherchant à montrer le rapport entre les changements structurels de la société et les changements en littérature.

${ }^{16}$ BARTHES, Roland, Le degré zéro de l'écriture, p. 10.

${ }^{17}$ BARTHES, Roland, La Chambre claire, Paris, Cahiers du cinéma - Gallimard - Seuil, 1980, p. 22.

${ }^{18}$ Ibid., p. 22.

${ }^{19}$ Ibid., p. 30

${ }^{20}$ Ibid., p. 36
} 
Barthes a pu entendre plus tard par le terme de style en photographie, mais chez Denis Roche cette notion est bien présente. La photographie est particulière car elle remplit à la fois les conditions d'être un style «qui ne plonge que dans la mythologie personnelle et secrète de l'auteur ${ }^{22}$ » et un non-style, un enregistrement mécanique qui privilégie le hasard. Elle forme ainsi un paradoxe par lequel le dispositif peut atteindre un «langage universelle » qui constitue un degré zéro, elle peut atteindre l'écriture «neutre » ou «blanche » annoncé par Barthes. Chez Denis Roche tout découle de cette notion-clef de style. Dans la lettre posthume adressée à Roland Barthes, il écrit :

J'essayais de savoir où se plaçait la question du style, balançant entre l'idée d' "abîme » et celle de « réserve », et même dans l'échappée entre les deux. Je me disais que pour régler cette question du style, il faudrait pouvoir écrire un court essai. $(D L, 154)$

L'《abîme » de la photo c'est celui qui s'ouvre sur le temps et l'espace, de par l'acte photographique, et le terme de «réserve » évoque le sens de dépôt, le fait de garder pour l'avenir ce qui s'inscrit dans l'image. Les notions d'abîme et de réserve ou encore de trombe et de cumul, de mouvement centripète et centrifuge symbolisent toute la pensée rochienne sur la photographie et la littérature. C'est tout de même dans l'échappé de l'entre-deux qu'en résidera l'essence :

[...] il faut aller fourrer son nez, y voir de plus près, dans le moment où l'action a lieu, et non pas (dans) le produit de cette action, ou bien dans un hybride ambigu des deux, un multiple égaré des deux, révélateur fou baignant le vent qui passe $[\ldots] »(D L, 50$, nous soulignons).

Le produit, donc la photo n'offre qu'un leurre, mais l'acte par lequel elle est prise lui confère un ancrage spatiotemporelle. L'entre-deux implique aussi la montée des circonstances, les 30 secondes de liberté et de vol entre la mise en marche et l'actionnement final du déclencheur à retardement. Dans le chapitre «Aller et retours dans la chambre blanche », la montée des circonstances rappelle d'ailleurs les étapes de l'alchimie.

Quelle étrange traversée des chambres : d'abord la froide, qui précède le style, puis la forte, qui permet de faire le coup des épaules et de la nuque au réel ; et enfin la blanche, à l'intérieur de laquelle nous sommes souriants et amusés, conscients, dès que l'expérience aura été suffisamment répétée, que le lieu (c'est-à-dire ce que montre la photographie) est comme une contrepèterie du moment (autrement dit de ce qui se passe quand on prend la photo). $(D L, 18)$

\footnotetext{
${ }^{21}$ RABATE, Jean-Michel, «Introduction », Writing the image after Roland Barthes, (sous la dir. de JeanMichel Rabaté), Philapdeliphia, University of Pennsylvania Press, 1997. p. 8.

${ }^{22}$ BARTHES, Roland, Le degré zéro de l'écriture, p. 12. Le «style » annonce ainsi les «mythologies individuelles » élaboré dans les années 1960 par des artistes conceptuels. Voir sur ce sujet le chapitre «Le modèle des arts plastique - l'approche conceptuelle » à la page : 72 .
} 
L'alchimie de la photographie rayonne sur l'écriture qui s'en empare pour devenir trace de l'expérience personnelle, du style de l'auteur.

Le confinement de l'écriture maintenue à distance du sujet [...] et à distance raisonnable de moimême [...] [ces] éléments confluent comme une sorte de grand cube de signifiant : une chambre très forte où je peux enfin retrouver mon erre, mon style. $(D L, 14)$

La beauté et la gravité de la photographie consistent dans sa double caractéristique d'entre-deux, qui est à la fois révélateur, enregistrant la trace effective des êtres et des choses, et leurre, produisant une surface sans profondeur ; à la fois produit d'un hasard et d'un choix intentionnel, à la fois document neutre et aboutissement artistique.

[...] l'art photographique se joue tout entier, dans la plupart des cas et seulement dans la plupart des cas, mais c'est assez pour qu'on y tienne, dans «l'entre-deux » qui est compris entre les extrêmes précisément matériels de chaque photo qui se prend : l'appareil photo d'une part c'est-àdire l'ensemble fixe constitué par l'artiste et l'instrument de son art, et le « fond » de la photo, le décor ou le paysage qui fait son fond autrement dit la limite (matérielle) que le photographe a choisie comme extrémité de sa photo. Voilà donc un espace de fiction qui sera toujours sousentendu comme temps plus ou moins étendu, posé, plus ou moins contracté, instantané. (MS, 182)

Entre fiction et document, elle devient donc «neutre », mais elle peut aussi dépasser le principe d'écriture parce qu'elle sort même de la langue codée pour s'inscrire à la place dans une lecture plus directe, celle de la pulsion scopique du regard.

Style qui n'est rien d'autre, au mieux de la forme (répétons-le), qu'une région indécise, mais probable du désir. Région de calme fluide, où circulent les doutes, pays de voiles, de contours, d'entrecroisements, poussière et chaleur, tempo triste. (MS, 183. Nous soulignons.)

Comme nous l'avons déjà mentionné, Denis Roche soutient dans un article publié dans le numéro spécial «Roland Barthes » du Magazine littéraire ${ }^{23}$ que le plus important dans les écrits de Barthes sur la photographie serait d'avoir montré le caractère affectif du dispositif :

Il a rendu possible quelque chose qui n'était que le fait des photographes eux-mêmes, ou du milieu photographique, c'est-à-dire un discours dont la théorie soit constamment affective. Et cela me paraît une des dimensions réellement propre à la photographie $[\ldots]^{24}$

Rappelons, que c'est à cette dimension affective que renvoie la notion barthésienne du « punctum », ou le fait d'avoir trouvé le noème de la photographie grâce à une photo de sa mère, mais aussi le choix des photos insérées dans La chambre claire. Comme le note Denis Roche les photos représentent :

surtout des portraits d'homosexuels, ou d'enfants mâles, ou des photos faites par des homosexuels; les seuls femmes représentées comme sujets principaux étant, dans l'ordre : des

${ }^{23}$ ROCHE, Denis, «Un discours affectif sur l'image », Magazine littéraire, numéro Roland Barthes, $\mathrm{n}^{\circ} 314$, octobre 1993, p. 65-67.

${ }^{24}$ Ibid., p. 66. 
religieuses, des «négresses », comme vous dites, une mongolienne, la Reine Victoria «entirely uneaesthetic» (Virginia Wolf, comme par hasard), Marceline Desbordes-Valmore que vous qualifiez de «niaise »; une seule femme est épargnée : la mère de Nadar, substitut de la mère de l'auteur, puisque Nadar est, selon vous, «le plus grand photographe du monde», et que la seule femme digne de La chambre claire est votre mère, photographié dans un jardin d'hiver, et que, parce que c'est la seule digne d'être regardée, vous ne la montrerez pas. $(D L, 157)$

Le fait d'insister sur la dimension affective des images nous ramène au propos de Cézanne déjà évoqué : «Sentir juste et réaliser pleinement donnent le style ». Le but de la représentation n'est pas l'imitation de la nature, mais de faire voir et mobiliser par le sens sensible, le désir de voir et de savoir. Le sens sensible est indissociable de la photo, c'est le choc, le «punctum », son message immédiat et inconscient. Les images servent alors à communiquer une dimension incommunicable par les mots, et la particularité des photos est qu'elles sont des images muettes qui renvoient vertigineusement à la notion du désir, du temps et de la mort. Denis Roche encourage même à se taire :

[...] qu'on ne parle plus, qu'on se taise enfin pour que l'homme et l'Art enfin fassent leur apparition, comme si de rien n'était, simplement parce que c'est de ça qu'il s'agit, qu'il faut que les icônes laconiques que nous sommes, et que nous rêvons d'être, paressent et ne se perdent plus. $(D L, 152$. 


\section{VIII.3. La dimension autobiographique}

L'avant-dernier chapitre de La disparition des lucioles s'intitule : « Le surlendemain du style. La photographie est-elle un journal intime ? ». Il contient des photos prises lors d'un voyage en Egypte et la description des circonstances des prises de vues en forme de notes de journal intime publiées par ordre chronologique (23 mars, 3 avril, 4 avril 1981). Le texte qui révèle les circonstances de la prise est écrit au présent donnant l'illusion d'une immédiateté, l'effet d'un enregistrement immédiat des faits, comme le sentiment de présence qu'offre le cliché.

[...] je ressors par une porte qui est à côté de la caisse et qui donne directement sur l'ensemble des Pyramides. Il y a une échelle devant moi. J'hésite une seconde ou deux et juste à ce moment-là je vois la photo, tout est exactement comme il faut. Je cadre vite et je la prends. $(D L, 171)$

La mise en page est subtile, car le passage décrivant la prise de vue se trouve juste en dessous de la photo (voir les parties en rouge ci-dessous dans la maquette reconstituée du livre présentant les pages dans leur ordre successif).

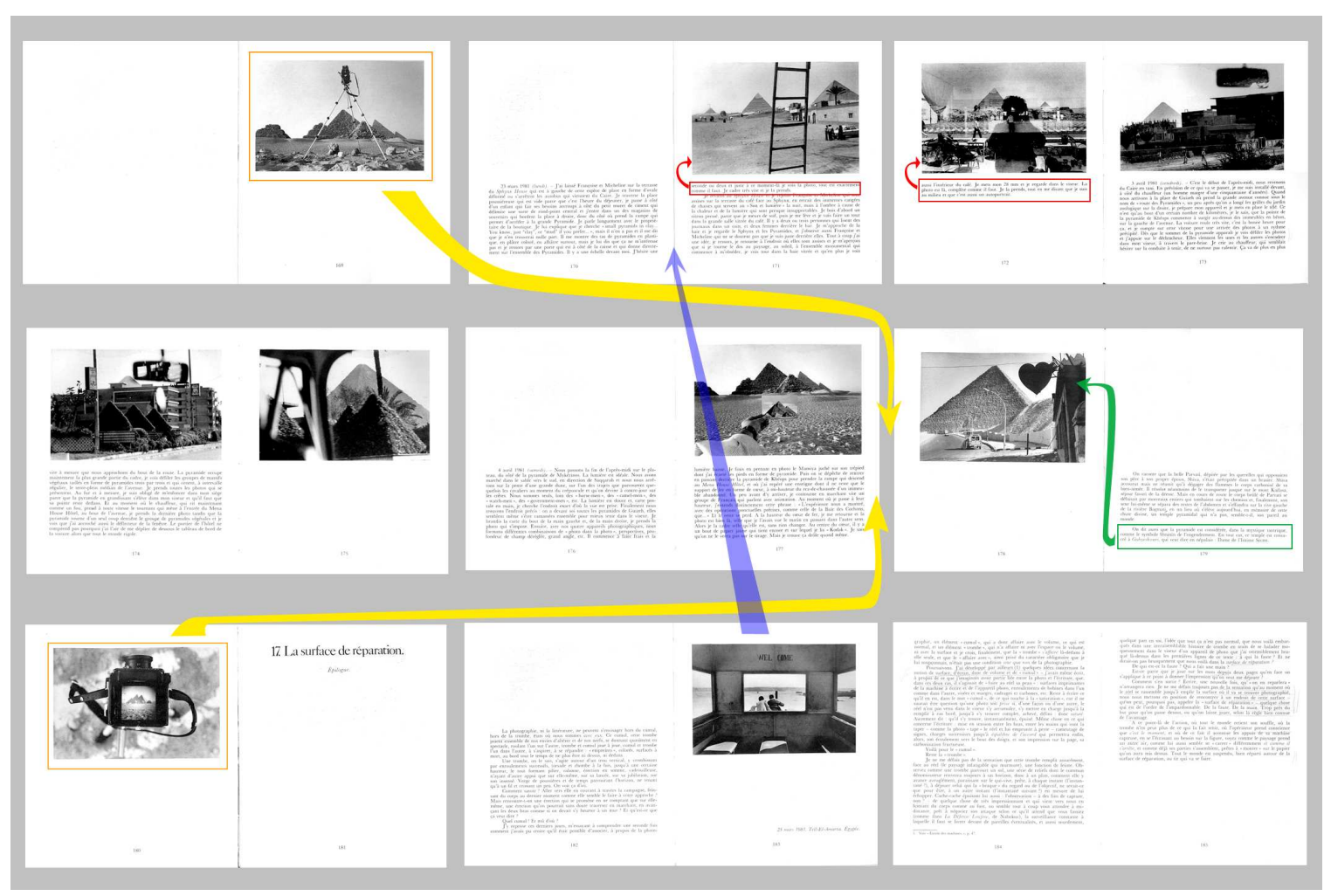

Maquette reconstituée de La disparition des lucioles, p. 170-183. 
Cependant un truchement se dévoile dans l'ensemble, car les photos ne sont pas placées par ordre chronologique comme le texte. La photo qui montre l'appareil sur le trépied est décrite comme l'avant dernière prise de vue, tandis qu'elle précède tous les textes (en jaune ci-dessus, la flèche indique sa place dans la continuité chronologique des prises de vue). Une autre photo montrant les pyramides dans le viseur de l'appareil Mamiya (qui selon le texte est prise avant celle au trépied, emplacement qu'indique la flèche en jaune ci-dessus) vient clore le récit. Les photos déplacées de la continuité logique du journal intime et placées au début et à la fin du chapitre forment un cadre ; elles mettent l'accent sur la composition et font basculer la signification de l'ensemble. L'appareil photographique devient alors l'acteur principal ou le narrateur omniscient qui prend la place de l'auteur. C'est l'appareil-écran qui met en scène la réalité, et qui permet de dépasser le style. Par ailleurs, le texte qui précède la dernière photo n'est plus un fragment de journal intime, il n'est pas daté, et il ne raconte pas une prise de vue, mais une légende indienne sur l'origine d'une pyramide (l'endroit où se défait le sexe du corps carbonisé de l'épouse de Shiva). Puis Roche ajoute :

On dit aussi que la pyramide est considérée, dans la mystique tantrique, comme le symbole féminin de l'engendrement. En tous cas, ce temple est consacré à Guhyeshwari, qui veut dire en népalais : Dame de l'Intime Secret. $(D L, 179)$

Si la photographie est un journal intime, c'est qu'elle enregistre l'histoire intime du couple, elle est un hymne à l'égard d'Éros (on peut y voir un lien possible avec le cœur sur la photo de la page précédente, qui est à l'origine, selon l'explication de la légende, une enseigne de Kodak, voir en vert ci-dessus). Dans le dernier chapitre de La disparition des lucioles, la photographie est décrite comme une «surface de réparation ». Même si l'image n'offre qu'un leurre, un écran où «le réel se rassemble jusqu'à emplir la surface où il va se trouver photographié », l'opérateur peut prendre conscience que «c'est le moment » et capter l'image. Elle s'inscrit dans le deuil d'un présent tiré vers le passé et dans la mélancolie de la perte immédiate, mais elle offre aussi la possibilité axée vers le futur d'agir dans le présent pour garder les moments d'épiphanie.

À ce point-là de l'action, où tout le monde, retient son souffle, où la trombe n'en peut plus de ce qui la fait retenir, où l'opérateur prend conscience que c'est le moment, et où de ce fait il accentue les appuis de sa machine capteuse, en se l'écrasant au besoin sur la figure, voyez comme le paysage prend un autre air, comme lui aussi semble se «carrer» différemment et comme il s'arrête, et comme déjà ses parties s'assemblent, prêtes à «monter » sur le papier qu'on aura mis dessus. Tout le monde est suspendu, bien réparti autour de la surface de réparation, au tir qui va se faire. (DL, 185. Nous soulignons) 
La photo insérée dans ce chapitre montre un cliché pris le 25 mars 1981 à Tell-ElAmarna, en Égypte, donc lors du voyage évoqué dans le chapitre précédent, et lors d'un jour qui n'est pas mentionné dans le texte du journal intime (voir le cliché ci-dessous et son emplacement dans l'ordre chronologique du texte ci-dessus en bleu). Il s'agit d'un cliché pris à partir d'une sorte de véhicule, mais qui ressemble à une chambre noire qui laisse filtrer la lumière à travers ses fenêtres-écrans ouvertes sur le monde. L'inscription à l'intérieur de la «boîte » se trouve comme par hasard découpée, elle subit le même procédé que les mots dans la poésie rochienne, et elle suggère en même temps le moment de l'arrivée et l'idée d'un seuil qui reste à franchir.

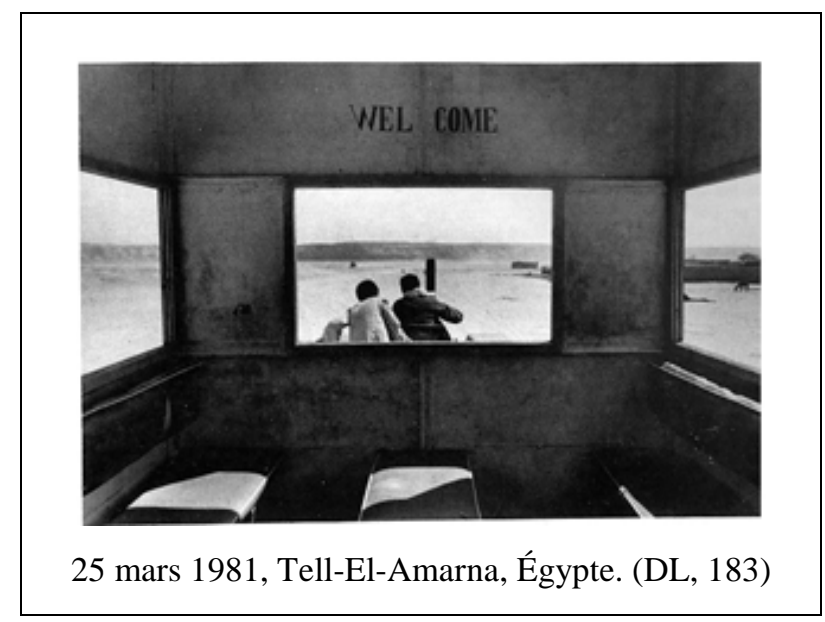

Comme chez Hervé Guibert, la photographie est suggérée être une pratique proche du journal intime, selon le chapitre de La disparition des lucioles que nous venons d'analyser, mais la publication des photos au sein des livres la rapproche d'avantage au récit autobiographique, voir à l'autofiction comme leur ordre est remanié rétrospectivement. La majorité de la production photographique de Denis Roche consiste d'ailleurs d'autoportraits ou d'autoportraits à deux avec sa femme. Ce sont des photos prises au déclencheur à retardement lors de voyages, dans des chambres d'hôtel.

Comme nous l'avons déjà évoqué, selon Denis Roche la photographie est essentiellement autobiographique, «parce que de toute façon on se photographie soimême quand on prend une photo. On photographie ce qu'on a regardé, donc on se photographie soi-même » $(D L, 73)$. La photographie est liée par l'acte photographique à 
un espace-temps précis et à un sujet précis, car derrière l'appareil se trouve toujours le photographe qui déclenche l'action'.

\section{VIII.3.a. Entrer dans le cadre}

Quand Denis Roche emprunte la technique photographique pour faire le livre Dépôt de savoir \& de technique, il transpose le principe autobiographique de l'acte photographique dans l'écriture : en fin de compte les dépôts-antéfixes qui sont censés être des portraits offrent avant tout un autoportrait de l'auteur. En effet, en lisant les antéfixes on s'aperçoit que les matériaux recueillis chez les personnes se ressemblent, les mêmes thématiques sont décelables même si le contenu varie. Ainsi nous retrouvons dans tous les antéfixes des fragments érotiques, des lieux, des dates, des noms, des chiffres (numéro de téléphone, numéros de page, numéro ISBN d'un livre ou prix), des abréviations énigmatiques, des phrases en langues étrangères. Le choix des fragments retenus renvoie bien à l'image de Denis Roche. Dans ce procédé, il y a une affaire de masque et c'est peut-être dans ce sens qu'il faut comprendre l'explication de l'auteur sur le mot « antéfixe » :

Ornement de sculpture, ordinairement en terre cuite, qui décorait le bord des toits. Sans doute d'invention étrusque, les antéfixes masquaient l'ouverture des tuiles rondes, mais devinrent rapidement de véritables statues à l'image et à la taille des hommes et des femmes du temps. (DST, 107. Nous soulignons.)

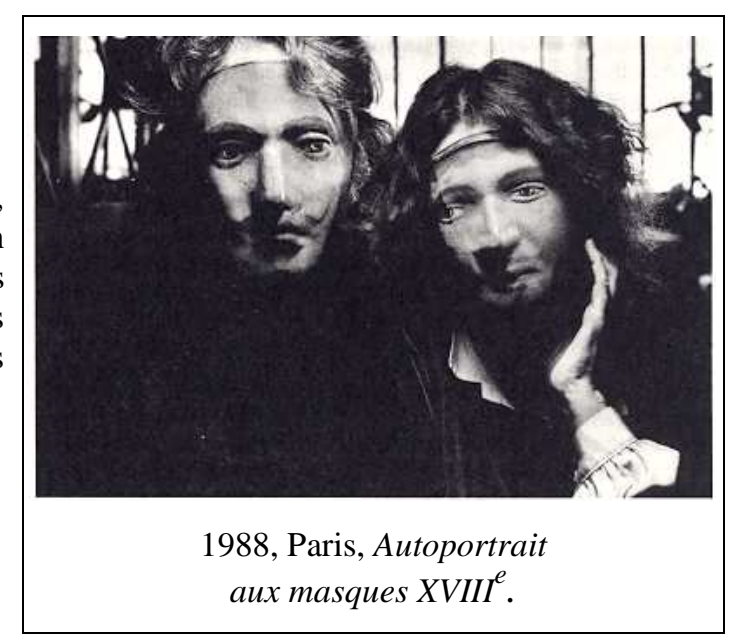

\footnotetext{
${ }^{1}$ On peut tracer un lien entre ces propos de Denis Roche avec ceux de Claude Nori et Gilles Mora dans le Manifeste photobiographique. Ce dernier prônait également l'utilisation de la photographie à des fins autobiographiques dans un dialogue de l'intime et de l'extime où le texte prend naturellement sa part. Le Manifeste a été publié à l'origine dans: MORA, Gilles; NORI, Claude, L'été dernier. Manifeste photobiographique, Paris, Étoile/Cahiers du cinéma, col. "Écrits sur l'image" 1983. Rappelons que Denis Roche a collaboré avec Gilles Mora et Claude Nori au lancement du journal Les Cahiers de la photographie. Voir a ce sujet le chapitre « Le modèle photobiographique » à la page 83.
} 
Les fragments des portraits-antéfixes viennent recouvrir le vrai visage du portraituré en y inscrivant une part d'énigme. En faisant le parallèle avec la photo publiée dans Les Cahiers de photographie ${ }^{2}$ montrant le couple portant des masques, on pourrait même se demander s'il s'agit de masques mortuaires.

Le problème se pose : où commence et où se termine la part autobiographique. Si nous postulons que toute écriture trouve son ancrage dans l'expérience personnelle de l'auteur et que par le «style » s'y inscrit le moi profond et secret, on pourrait insister sur le fait que toute écriture contient une part autobiographique. Ce serait transposer le principe autobiographique de la photographie à l'écriture, notamment le fait que ce qui est regardé et ce qui est retenu, renvoient avant tout à l'image de l'auteur ${ }^{3}$. On pourrait à ce titre interpréter le recueil de poésie Le mécrit non seulement comme le livre qui annonce une contre-écriture, mais aussi enjouant sur la prononciation phonétique du titre, il deviendrait le «je m'écri(s)» où le «m»serait le pronom réflexif de la première personne ; le texte aurait alors l'enjeu de dévoiler le spectacle de l'écriture où nécessairement un «je» écrit. Le «je» qui se reconnaît en même temps comme l'acteur et l'auteur qui fait le geste. La forme homonyme «je m'écri(s)» ferait également référence au fait de s'écrier, au cri déchirant et violent face à la mort ou au cri de la jouissance lors de l'acte sexuel.

Cependant la pratique du déclencheur à retardement va justement à l'encontre de ce principe «autobiographique », ce n'est plus l'auteur mais l'appareil qui enregistre. La photo à retardateur lui permet d'être à la fois le photographe et le photographié, celui qui se trouve «pris en photo ». C'est là qu'entre en jeu le hasard de la manière la plus évidente. C'est que le déclencheur à retardement, selon Denis Roche, paraît réduire au minimum la pose et la posture prises inévitablement devant un appareil, car « au bout des 30 secondes vous ne savez plus où vous êtes ni qui vous êtes » $(D L, 74)$.

Dans ses autoportraits Denis Roche se retire progressivement pour entrer dans le cadre : on trouve notamment des prises de vue dans des miroirs ou autres surfaces réfléchissantes, des clichés qui mettent en scène son ombre, d'autres où une partie de

\footnotetext{
${ }^{2}$ Les Cahiers de la photographie, numéro dédié à l'œuvre de Denis Roche, n²3, 1989, p. 107.

${ }^{3}$ Ce serait aussi étendre la définition de Philippe Lejeune du récit rétrospective écrite à la première personne engageant un pacte de vérité entre l'auteur et le lecteur.
} 
son corps entre dans le cadre (la mains ou les pieds) puis finalement la pratique du déclencheur à retardement qui le fait apparaître entièrement dans le cadre.

Les autoportraits semblent avoir un double rôle : ils permettent de se prendre, s'enregistrer, se voir de l'extérieur et surprendre son inconscient, mais aussi d'enregistrer pour conserver et ensuite faire dialoguer les photos par l'inconscient optique qu'elles interpellent.

Ce principe comme le remarque Denis Roche n'est pas transposable à l'écriture :

Étant écrivain, j'étais obsédé par le fait qu'on n'arrive jamais à se mettre soi-même en scène. Un écrivain ne peut jamais devenir un personnage de son œuvre; à la rigueur, il peut servir de modèle pour l'un de ses propres personnages. Mais même dans un journal intime, on n'est pas dedans. ${ }^{4}$

Les antéfixes, les essais de littérature arrêtée, ou encore les livres à deux voix (photo et texte) comme Légende de Denis Roche sont autant de tentatives de sortie de soi pour entrer dans le cadre.

Dans Légende de Denis Roche $e^{5}$ l'auteur expérimente la possibilité d'écrire une autobiographie par les images et leurs légendes. Le texte et l'image s'entrelacent dans ce projet, ce qui va dans le sens des réflexions Gabriel Bauret, qui souligne que les clichés ne peuvent avoir une fonction autobiographique sans le texte ${ }^{6}$.

Le livre est composé de photos puisées dans ses archives familiales et ses propres clichés. Dans le livre, le texte fonctionne comme une transcription littérale, donne le lieu, les circonstances de la prise de vue, précise qui a pris la photo et qui y apparaît ; de manière tautologique, il répète ce qu'on doit voir dans les photos.

L'activité d'écriture qui énonce ces rapports spatio-temporels dénonce d'un même trait combien le cliché est bâtard, anonyme, fragment qui flotte aussi longtemps qu'il ne s'encre/s'ancre pas dans la spécification du récit. ${ }^{7}$

Les études qui ont été menées sur ce livre insistent sur l'impossibilité d'écrire une autobiographie photographique. Selon Mireille Calle Gruber, la prise insistante d'un

\footnotetext{
${ }^{4}$ «Entretien avec Denis Roche », Éducation 2000, n ${ }^{\circ}$ 10, septembre 1978, p.11 cité par Jean-Marie Gleize, Poésie et figuration, Op. Cit., p. 262.

5 ROCHE, Denis, Légendes de Denis Roche, Paris, Gris banal, 1981. Par la suite nous utiliserons l'abréviation : $L D$. Luigi Magno rapporte qu'il s'agirait d'une œuvre faite sur commande (Dialectique(s), Op. cit., p. 291.), et qui se présente comme une réplique au livre Roland Barthes par Roland Barthes prouvant par l'exemple qu'il est possible de faire une autobiographie par les images.

${ }^{6}$ «La photographie ne peut à elle seule constituer un pacte autobiographique. C'est le texte, après coup, qui lui donne cette dimension » note Gabriel Bauret dans Les Cahiers de la Photographie. BAURET, Gabriel, «Autobiographie littéraire, autobiographie photographique », Les Cahiers de la Photographie, $\mathrm{n}^{\circ} 13,1984$, p. 13.

${ }^{7}$ CALLE-GRUBER, Mireille, «Écrit avec l'image, sur un essai de photo-autobiographie : Légendes de Denis Roche », Les Cahiers de la Photographie, n¹3, 1984, p. 33.
} 
même sujet (p. 15, 27, 34, 36, 51, 65, 84) ou les photos successives «sont autant d'éléments qui accentuent l'effet d'un réel inépuisable et donc insaisissable - s'effritant dans la fragmentation qu'impose sa saisie ${ }^{8} \gg$. Jan Baetens à son tour expose les deux raisons pour lesquelles le projet devient impossible. La première serait que l'autobiographie, d'après la définition de Philippe Lejeune, est censée réécrire le passé à la lumière du présent ; dans le cas de la photographie seul l'arrangement rétrospectif est possible et non la prise de vue rétrospective. Le deuxième argument serait que le pacte passé entre l'auteur et le lecteur, qui garantit la coïncidence de trois instances en principe dissociées (l'auteur extradiégétique, le narrateur diégétique, le personnage intradiégétique) est impossible à réaliser en photographie, à moins de prendre sa propre réflexion.

Si l'autobiographie photographique est problématique, l'arrangement du livre est tout de même révélateur selon Baetens. On part de photos qui ne sont pas prises par Denis Roche mais qui le prennent pour sujet, pour aller vers des photos prises par lui mais montrant d'autres personnes. Ainsi «Légendes de Denis Roche est moins une photo-autobiographie qu'il n'est une œuvre montrant le devenir photo-autobiographique du travail de Denis Roche ${ }^{9} »$. Les deux analyses s'accordent toutes les deux sur le fait que l'instance biographique dans l'œuvre ne peut se placer que dans l'écart entre l'image et l'imaginaire, dans l'intervalle qui sépare le «moi » de celui mis en scène par l'écriture du « moi » représenté par la photographie.

[...] l'idéal du style rochien serait celui de Montesquieu, qui conseillait, comme Denis Roche luimême le rappelle, de sauter les «idées intermédiaires ». Cette poétique, plus classique peut-être qu'on ne le pense (Montesquieu n'est pas le précurseur du cut-up !), est poursuivie de trois façon surtout: dans un premier temps, Denis Roche casse le vers (c'est l'amorce iconoclaste de sa carrière) ; dans un second temps, il intègre au texte, qui résiste viscéralement à la cassure (ne fûtce que parce que le lecteur s'avère capable de normaliser tout et n'importe quoi), le médium qui représente le mieux l'anti-montage : la photographie ; dans un troisième temps, il fait advenir dans le texte l'impact anti-continu de la photographie. ${ }^{10}$

La photographie inscrit le projet autobiographique dans le fragment, le discontinu et l'inachevable comme nous l'avons déjà vu dans le chapitre «L'autobiographie photolittéraire ». Pourtant, à côté de la position mélancolique, il y a toujours l'humour, la joie

\footnotetext{
${ }^{8}$ Ibid., p. 34.

9 BAETENS, Jan, «Légendes de Denis Roche : un livre "incompatible" ? », Denis Roche, l'un écrit, l'autre photographie, p. 75.

${ }^{10}$ Ibid., p. 83.
} 
de la beauté retrouvée dans l'instant et dans l'image chez Denis Roche. Sur la quatrième de couverture de Légendes de Denis Roche, il écrit :

Que veut dire l'idée qu'un homme raconte sa vie en photos, sinon qu'il s'est fait, une fois pour toutes, à cette autre idée : qu'il n'a plus désormais affaire qu'à l'incessant et admirable aller et retour que la lumière et la forme vont entreprendre, à sa place, entre la mort et la vie, c'est-à-dire entre l'oubli et Narcisse, entre le corps qu'on immerge et la Révélation ?

C'est dans le va et vient de la juxtaposition qu'il est possible de déceler la filiation. Parmi les photos qu'il puise dans ses archives familiales, plusieurs utilisent les mêmes procédés que Denis Roche lui-même dans ses propres photographies: contacts successifs, mise en scène dans le même décor à des années d'intervalle (son père avançant dans la rue, Roche à peu près au même âge que son père sur la photo, même maison, même endroit, le panneau coupé, à peine dans le cadre, indiquant un camping et le temps qui a passé p. 10), des photos prises par son père avec le même cadrage (une exposition de voiture, avec et sans hommes (p. 22), l'ombre du père visible sur la photo en train de prendre la photo (p. 29), etc.).

L'épigraphe dans le Dépôt $\mathrm{n}^{\circ} 16$ intitulé également le «Surlendemain du style » suggère aussi la possibilité de la filiation dans l'image :

Pour Ghislaine de R.

Parce que l'autre jour à la Bibliothèque nationale, j'ai regardé longuement une photo encadrées de son grand-père, et que dans le visage de cet homme d'autrefois dont tout m'aurait séparé j'ai vu monter lentement celui de sa descendante. $(D S T, 185)$

Et plus tard dans le texte du dépôt nous trouvons :

«muet », etc.) devant une photo, ou entre deux photos (une photo peut en faire parler une autre, pourquoi ?) ou face à cer-

taines qui ne sont que des « contacts » pendus la tête en bas, mais vivants, [...] $(D S T, 190)$

Sa pratique qu'il nomme les «photolalies » joue également de la continuité visuelle dans le discontinu. En dehors des légendes, en dehors de l'ancrage et du sens qu'impose le texte, deux photos juxtaposées peuvent se mettre à converser l'une avec l'autre, selon les mots de Denis Roche :

J'appelle «photolalie» cet écho muet, ce murmure de conversation tue qui surgit entre deux photographies, très au-delà du simple vis-à-vis thématique ou graphique. ${ }^{11}$

Mais le terme photolalie n'est peut-être qu'un mot plus poétique pour signifier le mouvement du va-et-vient que la simple juxtaposition de deux éléments impose, même

11 ROCHE, Denis, Photolalies, Paris, Argraphie, 1988, p. 5. Par la suite nous utiliserons l'abréviation : $P H$. 
si par son origine du mot «écholalie ${ }^{12}$ », appelle l'idée d'une parole répétée de manière mécanique, la création d'une sorte de double identique. Jean-Marie Gleize évoque à propos du terme «photolalie », un poème en langue d'oïl qui parle d'Eulalie, la vierge et martyre. Puisque c'est l'une des plus ancienne Cantilène ou Séquence que nous possédons, Gleize y voit le contrepoint du projet de Denis Roche qui annonce dans Le Mécrit que ces poèmes seraient les derniers de la langue française, la poésie étant inadmissible ${ }^{13}$.

Quelque soit son origine ou son sens concret, Denis Roche fait du terme «photolalie » une métaphore applicable à toute sa pratique photo-littéraire. Il y voit l'écho entre le texte et la photo, entre l'instant de l'acte et l'image, entre le «moi » auteur/photographe (et ses fantasmes) et le «je » narrateur, personnage/le photographié.

Je suis moi-même une «lalie » de mes photos. Mes livres d'écrivain murmurent mes livres de photographe, ils ont un flux qui se ressemble et le rêve que je fais des uns me rejette interminablement vers la rêverie des autres. Je vais des uns aux autres pris par le sentiment quadrilatère des choses qui se font et de la beauté qui a lieu, dans une rue vidée par la chaleur où l'autoportrait n'en finit pas de se recadrer et de s'inverser comme si le vide ayant rempli par la lumière, il fallait obligatoirement lui renvoyer quelque chose et que ce retour soit éternel. Et je me souviens très bien qu'au moment où le déclic allait se produire, je pensais au rocher de Zarathoustra qu'on désigne aux touristes dans l'Engadine, belle région très verte de la haute vallée de l'Inn où Nietzsche aimait, dit-on, se promener et où il rêvait, assis sur ce caillou, au mythe de l'éternel retour. Tout juste un siècle avant que je ne parle ici d'image interminable. $(P H, 44-45)$

Les photolalies assurent une certaine continuité, même si cette dernière se joue inconsciemment. En dehors du discontinu du livre Légendes de Denis Roche, une certaine filiation peut se rêver dans la juxtaposition des photos les plus diverses. L'une des dernières pages du livre montre une vue d'ensemble sur des photos étalées par terre, et la légende révèle qu'il s'agit de la maquette du livre en construction. Dans ce lieu en élaboration où les lalies se forment, les photos de la maquette font écho avec les clichés du livre achevé. Chronologiquement ce devrait être la dernière photo, mais ce n'est pas le cas : le livre se termine sur des photos montrant le couple, et inscrit ainsi la question autobiographique dans le rapport avec l'Autre.

Toutefois, lier le projet autobiographique à la fois à la photographie et à la littérature transformée par le dispositif ne fait que problématiser et nuancer l'instance du

\footnotetext{
12 Selon le dictionnaire Petit Robert, écholalie est un terme qui provient du grec êkhô «écho » et lalia «bavardage » et qui est employé en neurologie : «Répétition automatique des paroles (ou chutes de phrases) de l'interlocuteur, observée dans certaines aphasies. » Petit Robert, 2001, version électronique, (2.1).

${ }^{13}$ GLEIZE, Jean-Marie, Poésie et figuration, Op. cit., p. 248.
} 
sujet. Comme le remarque Philippe Forest dans sa monographie sur l'histoire de Tel Quel, «l'avant-garde littéraire et théorique des années soixante-dix ne s'employa pas unanimement à mettre à mort un « sujet » qu'il appartiendrait à quelques polémistes, dix ans plus tard, de glorieusement ressusciter ${ }^{14}{ }^{\prime}$. Il s'agit plutôt de remettre en question le sujet, pour en proposer une vision plus complexe, tout comme se trouve remis en cause le signifié, pour « saisir le sens au lieu même de sa naissance ${ }^{15}$ ».

${ }^{14}$ FOREST, Philippe, Histoire de "Tel Quel", 1960-1982., Op. cit., p. 463.

${ }^{15}$ Ibid., p. 464. 


\section{VIII.4. Éros et le déclic sexuel de l'obturateur}

La figure du «moi » questionnée dans l'autobiographie s'inscrit toujours dans la dialectique du regard de l'autre. Quand Denis Roche rapporte sa pratique littéraire et photographique à la pulsion érotique et à la pulsion de mort, c'est un réseau métaphorique qu'il tisse dans un ensemble complexe.

$\mathrm{Au}$ cœur de l'érotisme, selon Georges Bataille, se trouve la question de l'intégrité et de la continuité de l'être. Face à l'Autre, qui renforce l'isolement de l'être, et face à la mort qui impose sa discontinuité, l'érotisme devient le moteur d'une envie de fusion et de continuité : «[...] il semble à l'amant que seul l'être aimé peut en ce monde réaliser ce qu'interdisent nos limites, la pleine confusion de deux êtres, la continuité de deux être discontinus ${ }^{1} \gg$. Il y a dans l'acte sexuel une forme de violence, il y a «effraction», pénétration, un abandon d'identité qui provoque aussi un effondrement du moi. Il y a excès et transgression, selon Bataille, ce que l'on retrouve dans la démarche poétique de Denis Roche (dans l'excès de sens et la transgression de règles) et qui permet un premier rapprochement entre sa pratique et l'érotisme.

Denis Roche parle constamment de l'érotisme dans ses textes et ses photographies et l'on distingue dans ses propos un double mouvement, un va-et-vient entre le métaphorique et la transcription littérale. Dans ses premiers recueils, l'amour et l'acte sexuel sont évoqués symboliquement, puis la représentation métaphorique se transforme progressivement dans les écrits ultérieurs en une transcription littérale, qui devient en même temps un réseau symbolique qui envahit tout. C'est ce double mouvement que nous aimerions illustrer par les exemples qui suivent.

\section{VIII.4.a. La poésie érotisée}

Dans un poème de Liberty-grappe 2 (1962), c'est l'imagination du lecteur qui permet de saisir par une lecture latérale que derrière l'empilement discontinu des mots, il s'agit là

\footnotetext{
${ }^{1}$ BATAILLE, Georges, L'érotisme, Paris, Minuit, 1957, p. 25.

${ }^{2}$ Le poème est publié dans Récits complets (1963), le deuxième recueil de Denis Roche, (PI, p. 95).
} 
d'érotisme (voir le poème ci-dessous). Deux champs sémantiques se dessinent dans le poème celui de la violence et celui de l'amour.

La blessure au giron de la femme de l'exempt
La région profonde de saluts et de bien qui
Vient en son rouge instrument
Pire Vénus qui fuit après s'être
Prêté ces formes avantageuses
L'unisson «où par conséquent la sensibilité
Et l'action d'un individu valent pour tout"
Le monde
Notant que quelqu'un de deux directions oppo-
Sées, ou qualités, qui est capable d'ê-
Tre directement et certainement affirmé,
Vient en troupe porter l'hommage
Ne poursuivent-ils pas mêmes buts et
Oraisons que peaux séchant ou, si l'on
Veut, «mises à sécher »?
Bien sûr que si.

La violence est inscrite dans les mots que nous avons souligné en bleu, «blessure », ou «peaux séchant» (qui évoque l'image de l'écorché, mais peut aussi faire référence au langage surface), et l'acte sexuel (que nous avons souligné en rouge ${ }^{3}$ ) est évoqué par le « giron de la femme », «la région profonde de saluts et de bien », «Vénus », «l'unisson », «la sensibilité et l'action». Les deux champs, la violence et l'amour forment alors les «deux directions opposés » dont l'auteur se demande s'ils poursuivent « les mêmes buts ».

Dans Les idées Centésimales de Miss Élanize (1964), nous retrouvons l'évocation métaphorique de l'amour.

De dire à haute voix que je pense à toi calmement enfin En mon absence songe que je ne vis qu'en toi que le moins Balnéaire hôtel n'est pas si loin que je ne puisse Soulever avec bonheur le souffle régulier de tes jupes.

Dans l'extrait ci-dessus, le dernier vers «Soulever avec bonheur le souffle régulier de tes jupes», propose une description très imagée qui peut nous faire penser au film célèbre où l'on voit Marilyn Monroe au-dessus d'une bouche d'aération de métro, retenant sa jupe qui virevolte autour

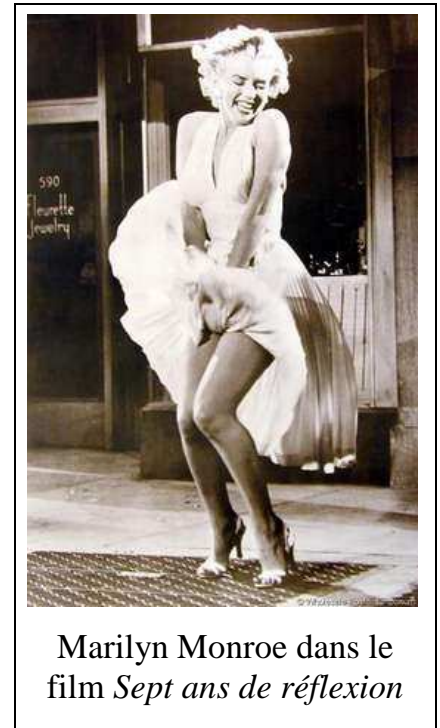

\footnotetext{
${ }^{3}$ Par la suite, nous utiliserons systématiquement la couleur rouge pour indiquer ce qui dans les poèmes se rapporte à l'amour et à l'érotisme, le bleu pour ce qui évoque la mort, et le violet pour indiquer le champ lié à la photographie.
} 
d'elle (Billy Wilder, Sept ans de réflexion, 1955, ci-contre $\left.{ }^{4}\right)$.

Dans le recueil Éros Énergumène (1968) nous notons déjà une tendance à la description littérale (voir ci-dessous).

Pareille idée de vous donner. Priée de s'ins-
Taller mais sous de si longs sleeping cars.
"Je te peins quitte de ce détournement... "
Avait été aimée en son temps d'un amour
Tout être comme abjection en général ni
Pourtant le mécanisme inversé de sa vulve
La pelletée de terre des environs de cette
Plage, parce qu'elles s'éclipsent l'une de-
Vant l'autre, épuisant par là même la moindre
Paule italienne. Rompue mais précédée de ou
D'une représentation très vive de nu, mais
De jeune femme nue, apparemment de la tren-
Taine, réinventant tous ceux qui existaient
Déjà. Il y a par conséquent des attributs
Dirigés sans qu'elle en ait conscience vers
Le double désir que j’ai d'elle mais si peu
Commode /

Les mots «pelletée de terre » et «vulve » renvoient directement à la mort et à l'acte sexuel, l'organe sexuel étant directement lié à l'excitation et au désir, au «double désir », désir de représenter la femme aimée et de voir l'irreprésentable. Dans le poème, la coupe des mots (en orange) et la coupe des vers (en vert) créent une frustration, que l'on peut par analogie comparer à l'agitation d'Éros.

Dans un des poèmes du recueil Le mécrit publié en 1972, son dernier recueil par lequel il vise à mettre à mort la poésie, nous retrouvons également l'évocation de l'érotisme.

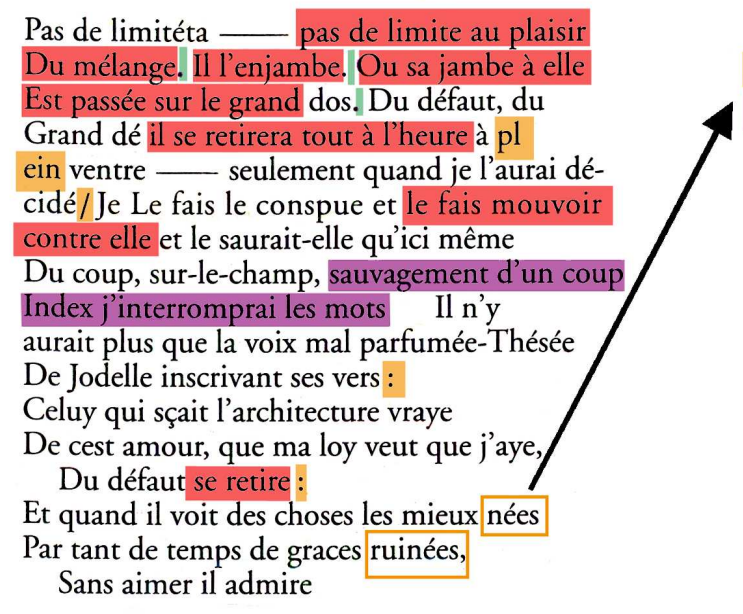

$P I, 474$.

Sans aimer il admire
Par tant de temps marchant dans des Grèces ruinées, sans aimer i'admirerai d'en sortir une lumière où je marche sur la ligne qui suit Celuy qui sçait quel toast il découvre ni quand Dans quelle demeure si ce ne sera pas pour nous Une aise, une heure d'aise, l'abondance qui Nous a si bien défigurés, tous les deux: $\mathrm{Au}$-dessus de quelques autres excellences, nous Élevons pour les cultiver toutes les trouvailles De peu d'importance la/tranquillité de l'ordre (et si c'était la guerre) n' est que saloperie. Ça tait 2.3 signes et, même alignés, on ne peut en Ceinturer ton sein qui est infranchissable et Que tu caches toujours quand je suis sur le Point d'en associer la vue au plaisir de Savoir ce quil en incombe à ton regard.

$P I, 475$.

\footnotetext{
${ }^{4}$ La photo provient du site : http://libres-expressions.sosblog.fr/Marilyn-b2/Marilyn-Monroe-b2-p11.htm (consulté le : 21/03/2009).
} 
À la suite de Bataille, c'est l'excès qui est évoqué et l'effacement du moi dans l'acte sexuel, avec les expressions «pas de limite au plaisir»; «l'abondance qui/Nous a si bien défigurés, tous les deux » qu'on pourrait rapporter au mot « ruinées » mot auquel la répétition (que nous signalons par la flèche) confère un double sens, celui de ruine / effondrement et celui de la naissance que suggère la séparation rui-/ nées. On trouve également des expressions qui rattachent le poème à la photographie, comme «sauvagement d'un coup/ Index j'interromprai les mots» ou «d'en sortir une lumière ». La vue identifiée au plaisir sexuel dans les quatre derniers vers et se trouve associée au «plaisir de savoir » et par la répétition elle est liée aussi au premier vers de la page précédente au plaisir «du mélange » que rétrospectivement nous pourrions interpréter comme un mélange entre la photographie et le texte, mélange de mots qui tissent un réseau métaphorique particulier.

Les évocations de l'acte sexuel envahissent progressivement les poèmes, si on les compare d'un recueil à l'autre, tout comme les poèmes sont submergés petit à petit par les éléments visuels, comme nous l'avons déjà indiqué, des traits, des blancs, des signes de ponctuation, des jeux du minuscule - majuscule, jusqu'à aller vers l'insertion des images ${ }^{5}$. Cet érotisme devient de plus en plus associé à la photographie.

\section{VIII.4.b. Le fantasme de la photographie}

Dans Louve Basse (1976), livre étiqueté « roman » et publié après Le mécrit, qui visait à mettre à mort la poésie, le modèle photographique est déjà très présent. Il s'agit d'un roman en forme d'informe qui frôle le théâtre absurde, la poésie sonore : on y trouve des photos intercalées dans le texte, des transcriptions d'enregistrement sur cassette, des retranscriptions ${ }^{6}$, des citations et des évocations (Bataille sous le nom de Battle et James Joyce sous le nom de Juicy Joyce, p.75) et il offre par cet amalgame, une sorte de satyre de la société. Certaines parties enregistrées sur cassette sont des transcriptions de scènes

\footnotetext{
${ }^{5}$ Voir l'annexe $n^{\circ} 5$ qui recense cette évolution iconique à la page 432.

${ }^{6}$ Par exemple la retranscription de son texte Artaud refait, tout refait, qui a été présenté au colloque de Cerisy en 1972 colloque sur intitulé «Artaud - Bataille, pour une révolution culturelle » (LB, 38-60), et dont le refus de publication a poussé l'auteur à se séparer du groupe « Tel Quel ».
} 
qui précèdent le moment de faire l'amour, la phase d'excitation (p. 25-30; p. 130-131) faisant de l'utilisation de la photographie un excitant.

Ainsi pouvons nous voir entre lignes qui font imaginer une scène où les deux protagonistes se caressent et s'excitent l'un et l'autre :

- C'est là qu'il faudrait un polaroïd ! En plus de la casette ! Tout marcherait ensemble, la cassette, les photos, tes doigts raides et moi tournant mon con autour !...

- Tu aimerais hein?

$-\ldots$

- Oui, et puis je me regarderais, et toi et mes doigts... $(L B, 28)$

À la page 131 on retrouve une scène enregistrée sur cassette qui décrit comment il (le protagoniste écrivain qu'on identifie avec l'auteur) regarde sa femme jouir pendant qu'elle prend sa douche, puis il évoque le déclic, qui déclenche l'excitation sexuelle.

- Attends un peu (je me penche vers elle et je tire le slip) attends c'est pas tout ça, mais est-ce que tu as entendu ce déclic de mon cerveau?

- Quoi ?

- J'ai dit : « aujourd'hui entendu ce déclic de mon cerveau ?» $(L B, 131)$

Il répète la phrase à la demande de sa femme mais probablement aussi pour la mettre en valeur sur l'enregistrement. Le déclic déclenche alors non seulement l'excitation sexuel mais aussi l'enregistrement mécanique de la phrase répétée qui comme une photo devient le dédoublement du moment précédent. Il se met en place dans Louve Basse un fantasme, celui de pouvoir enregistrer et dédoubler l'acte sexuel pour savoir à quoi on ressemble en faisant l'amour. L'idée est poursuivie et accomplie dans Notre Antéfixe Notre Antéfixe.

Ce dernier est d'abord publié en 1978 chez Flammarion avec une série de 40 photos et une préface intitulée «Entrée des machines ». Puis la préface et le texte sont republiés dans Dépôts de savoir et de technique en 1980, mais sans les photos, et finalement la préface toute seule, sans le texte et sans les photos, sera reprise dans $L a$ disparition des lucioles en 1982. Comme nous l'avons déjà évoqué, les antéfixes forment une sorte de portrait «mécanique » qui consiste à prélever des bribes de textes déjà existants chez les personnes portraiturées et à empiler les lignes les unes après les autres. Ces empilements créent effet de récit qui, dans le cas de l'antéfixe de l'auteur et

\footnotetext{
${ }^{7}$ Le premier Dépôt publié est celui qui a servi de préface à une exposition de Manuel Alvarez Bravo, Paris, La Photogalerie (1976), repris ensuite dans Dépôts de savoir et de technique (1980) et dans La disparition des lucioles (1982).
} 
de sa compagne, est étroitement lié à l'érotisme et à l'histoire intime du couple. Au début du livre, le lecteur est averti qu'il s'agit d'un projet intime, une sorte de cadeau pour le $10^{\text {ème }}$ anniversaire de leur rencontre.

Commencé le 15 février 1977 pour le $10^{\text {ème }}$ anniversaire de notre rencontre, et achevé le 22 mai de la même année, avec un peu de retard sur le $10^{\text {ème }}$ anniversaire de notre liaison, celle-ci ayant débuté dans la matinée du 4 mai 1967. (NA,7)

L'antéfixe-empilement est suivi de notes qui, ligne après ligne, donnent les références des lignes prélevées ${ }^{8}$. Parmi les textes sources se trouvent des notes de l'auteur et de sa compagne qui sont, comme dans Louve Basse, la transcription littérale de l'acte. Ainsi la ligne 125, que la note précise être la description d'une : «125. Éjaculation norm. mais à saccades très amples, un matin de masturbation princière ».

Dépôt

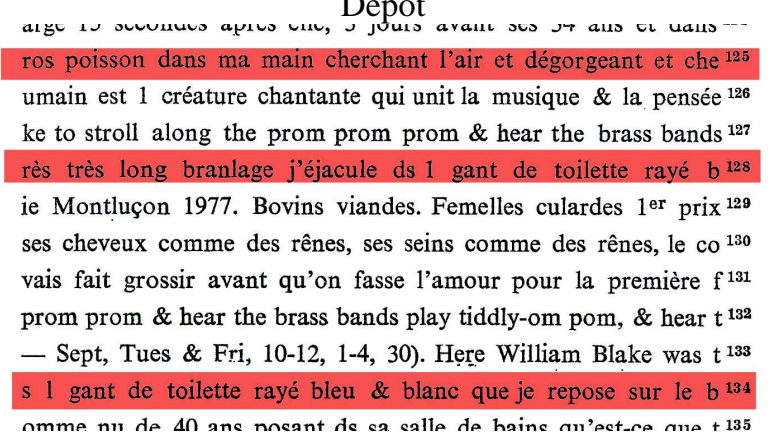

Notes

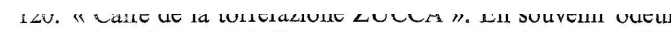
extrême de café dans Modène, rabattue sur les places chauffées à blanc par le temps lourd qui règne sur la plaine du Pô. Une ville d'appareils à torréfier Renaissance, et nous, mon cœur, au cceur de la chaleur \& de l'odeur. 19 juil. 74.

121. Restau.

122. Keats.

125. Éjaculation norm. mais à saccades très amples, un matin de masturbation princière.

Cependant la ligne 125 dans le Dépôt n'explicite pas le contenu érotique :

ros poisson dans ma main cherchant l'air et dégorgeant et che ${ }^{125}$

La suite le rend clair, mais ce n'est qu'à partir des notes qu'on peut comprendre qu'il s'agit d'une autre bribe de phrase prélevée du même texte :

rès très long branlage j'éjacule ds 1 gant de toilette rayé $\mathrm{b}^{128}$

et six lignes en dessous :

$\mathrm{s} 1$ gant de toilette rayé bleu et blanc que je repose sur le $\mathrm{b}^{134}$

La description érotique dans certaines lignes est directement liée à des photographies, par exemple dans la ligne 13 :

hoto après photo \& encore du grand cul blanc chevauchant suan ${ }^{13}$

La note précise :

\footnotetext{
${ }^{8}$ Dans l'ensemble des Dépôts de savoir \& de technique nous trouvons la retranscription des sources sous forme de Notes et commentaires seulement dans le cas de «Notre Antéfixe » et dans le cas du dernier dépôt, «Je vous dois la vérité en littérature \& je vous la dirai ». Dans le reste des dépôts la source est soit signalé en début du chapitre, mais pas référencé à chaque ligne, ou elle n’est pas du tout signalé et elle reste énigmatique comme une photo sans légende.
} 
13. Notes sur série photos prises avec retardateur, à la fin de février au moment où se mettaient en place les éléments de cette antéfixe. Pornographique et enfin satisfaisante.

Le fantasme de Louve Basse, de faire l'amour et de prendre en même temps des photos, est réalisé. Dans la publication chez Flammarion, on peut imaginer que parmi les photos publiées, celle du 6 février 1977 (ci-dessous à gauche), ou encore cet autre cliché réalisé en 1987 (ci-dessous à droite) publié dans Ellipse et Laps, correspondraient à ce jeu.

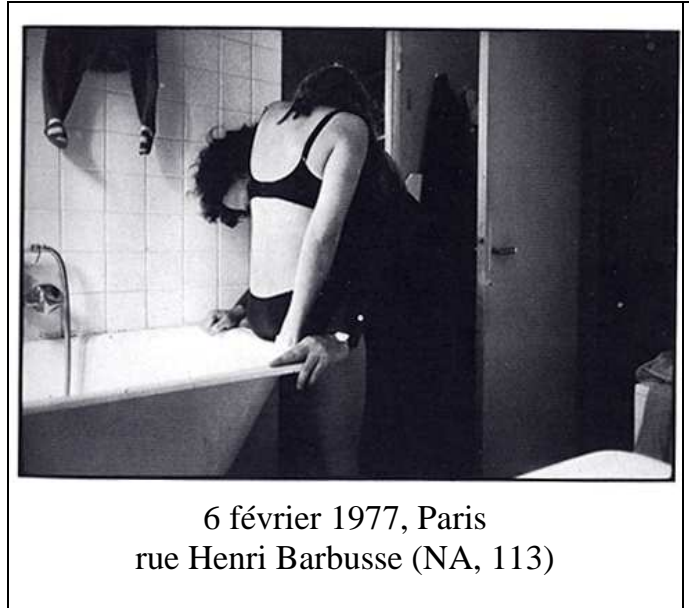

25.12.1987

Aix en Othie

Auberge de la Scierie,

chambre 26

$(\mathrm{EL}, 60)$

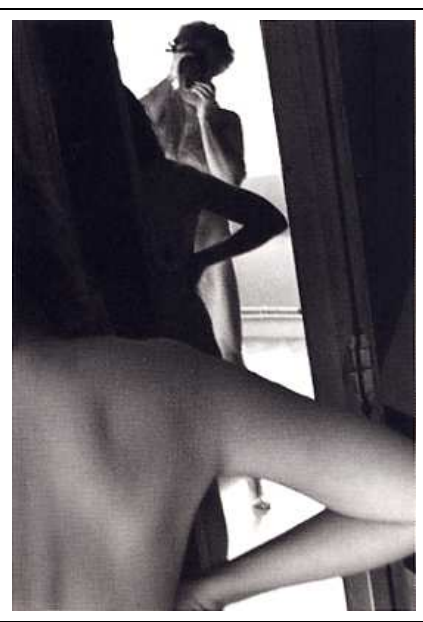

Parmi les matériaux qui servent de base à l'écriture de Notre Antéfixe (1978) nous trouvons plusieurs sources liées à la sexualité et, dans le même temps, à la photographie, sans que le texte prélevé ne révèle le caractère iconique de la source ${ }^{9}$ :

\begin{tabular}{|c|c|c|}
\hline Dépôt & & Notes \\
\hline acing this nude on a Manhattan rooftop at dusk, Michals creat ${ }^{18}$ & $\rightarrow$ & $\begin{array}{l}\text { Une légende photo de Duane Michals évoquant un } \\
\text { «nu » pioché dans Ronald H. Bailey, The } \\
\text { Photographic Illusion, 1975, (ligne 18) }\end{array}$ \\
\hline place à son cul, face aux arbres, admire les fesses qui suent ${ }^{24}$ & $\rightarrow$ & $\begin{array}{l}\text { Un roman-photo intitulé « Tiens ! Bouffe salope ! » } \\
\text { (ligne } 24 \text { repris à l'identique à la ligne 155) }\end{array}$ \\
\hline rifices de l'urètre $\&$ du vagin. Sur la femme debout le « plafo $^{51}$ & $\rightarrow$ & $\begin{array}{l}\text { G. Zwand, Le Sexe de la femme, édition illustrée } \\
\text { de 1967. (ligne 51) }\end{array}$ \\
\hline nuit. Elle pressa de la paume de sa main la touffe de cheveux ${ }^{146}$ & $\rightarrow$ & $\begin{array}{l}\text { Frederick William Rolfe, The Desire and the } \\
\text { Pursuit of the Whole (ligne 146) }\end{array}$ \\
\hline anon. photogr., c. 1890. - Thomas Eakins, c.1890. - Julien deVi ${ }^{147}$ & $\rightarrow$ & $\begin{array}{l}\text { Ovenden et Mendes, Victorian Erotic Photography } \\
\text { (ligne 147) }\end{array}$ \\
\hline
\end{tabular}

Les bribes érotiques au milieu d'autres lignes qui n'ont pas de connotation érotique influencent cependant le rapport à ces dernières, et les lignes qui n'avaient au départ aucun rapport à la sexualité s'érotisent.

${ }^{9}$ En ce qui concerne la ligne 146, Frederick William Rolfe était à la fois écrivain et photographe et un expert en photographie de nu masculin, ce qui explique la connotation érotique du fragment. Le livre de fut écrit en 1909, mais publié en 1934 à Londres (Cassel). http://en.wikipedia.org/wiki/Frederick Rolfe (consulté le: 20/03/2009). 


\begin{tabular}{|c|c|}
\hline ations aux créations, l'une recouvrant l'autre, chaque nouvel ${ }^{190}$ & dans une vieille ville des lagunes où l'anguille foisonne, le ${ }^{217}$ \\
\hline aintenant cette canaille de cagots se glissant à travers le $p^{191}$ & dans ce grand vol circu autour de la chambre 168 d'heure en $\mathrm{h}^{218}$ \\
\hline llonge entre vous, les bras en travers de vos seins, lourdeme ${ }^{192}$ & La voici en effet, fracassant les arbres, foudroyant les murs ${ }^{219}$ \\
\hline over the waterline, soaring like hawks, high, so high, myself ${ }^{193}$ & assis face à face. Je le fais jouir de mes mains et le sperme 220 \\
\hline dans une vieille ville des lagunes où l'anguille foisonne, le ${ }^{194}$ & et de Dalzon Rose, né le 11 janvier 1852 à Chandolas et décéd 221 \\
\hline dans le fait d'être à 4 pattes; la culotte tendue par les cui ${ }^{195}$ & ne te l'avais pas dit comme je t'aime comme c'était cette esp ${ }^{222}$ \\
\hline Je vous dirai donc, porc frais de mes pensées, que j'ai trava ${ }^{196}$ & place à son cul, face aux arbres, admire les fesses qui suent ${ }^{223}$ \\
\hline ent le traghetto. " Mouches » ou " hirondelles " (vaporetti del'Azi 197 & als-les-Bains, Ardèche le 23 avril 1890 épouse à Joyeuse $A n d r{ }^{224}$ \\
\hline ert, fils de Roche François et de Décade Antonia, né le 6 sep ${ }^{198}$ & a va chérie à quoi tu penses à des tas de choses tjs en colla 225 \\
\hline est le riz Basmatti. Ce riz est cultivé ds les h $\mathrm{h}^{\text {tes }}$ vallées $\mathrm{d}^{199}$ & au pied du lit, à genoux, et nous deux par terre assis face à 226 \\
\hline tembre 1903 à St-Eloy-les-Mines (Puy-de-Dôme) épouse le 21 ju 200 & ans ce marais d'êtres et de poussière et de brouillard tout ${ }^{227}$ \\
\hline vulture, " brother v ", as Con named them). But when I came ne 201 & puyée au bord du buffet, Micheline un peu de côté et moi accr 228 \\
\hline crèche kitsch animée. En ressortant je tombe amoureuse d'une ${ }^{202}$ & mmense vol de petits hérons gris se rassemblait au-dessus des 229 \\
\hline ément, moi sur Denis beaucoup, lui tournant le dos et profita 203 & ations aux créations, l'une recouvrant l'autre, chaque nouvel ${ }^{230}$ \\
\hline ui tournant le dos et profitant de lui, lui contemplant mes f ${ }^{204}$ & humain est 1 créature chantante qui unit la musique et la pen ${ }^{231}$ \\
\hline La voici en effet, fracassant les arbres, foudroyant les murs 205 & moi sur Denis beaucoup, lui tournant le dos et profitant de $1^{232}$ \\
\hline lui contemplant mes fesses découvertes, au pied du lit, à gen 206 & lui tournant le dos et profitant de lui, lui, contemplant mes ${ }^{233}$ \\
\hline ouvertes, au pied du lit, à genoux et nous deux par terre ass 207 & André, Antonie, Eugénie, Madeleine, fille de André, Arsène, L 234 \\
\hline genoux et nous deux par terre assis face à face. Je le fais $j^{208}$ & s 1 gant de toilette rayé bleu \& blanc que je repose sur le b ${ }^{235}$ \\
\hline La voici en effet, fracassant les arbres, foudroyant les murs 209 & lui, contemplant mes fesses découvertes, au pied du lit, à ge ${ }^{236}$ \\
\hline assis face à face. Je le fais jouir de mes mains et le sperme ${ }^{\mathbf{2 1 0}}$ & La voici, en effet, fracassant les arbres, foudroyant les mur ${ }^{237}$ \\
\hline et de Donnadieu Joséphine, née le 11 mai 1906,15 rue de la B 211 & mes fesses découvertes, au pied du lit, à genoux et nous deux ${ }^{238}$ \\
\hline jouir de mes mains et le sperme sort en bouillonnant de son $\mathrm{s}^{212}$ & à genoux et nous deux assis par terre face à face. Fracassant ${ }^{239}$ \\
\hline omiciliée à Montélimar, épouse à Montélimar le 20 septembre $1^{213}$ & par terre face à face. Je le fais jouir de mes mains et le sp 240 \\
\hline La voici en effet, fracassant les arbres, foudroyant les murs ${ }^{214}$ & de mes mains et le sperme sort en bouillonnant de son sexe av ${ }^{241}$ \\
\hline sort en bouillonnant de son sexe avant même qu'il s'en rende ${ }^{215}$ & maison est très belle, dans ce jardin Lucrèce redevient lisib ${ }^{242}$ \\
\hline ert, fils de Roche François et de Décade Antonia, né le 6 sep ${ }^{216}$ & son sexe av' même qu'il s'en rende compte \&c commence à jouir. ${ }^{243}$ \\
\hline 42 & 43 \\
\hline
\end{tabular}

Ainsi l'anguille devient la métaphore du pénis dans la ligne suivante ${ }^{10}$ :

dans une vielle ville des lagunes où l'anguille foisonne le (ligne 182, repris à l'identique à la ligne 194, 217 que nous avons colorié en bleu clair ci-dessus)

Plus loin une ligne figure le bruit et le déchirement de l'acte sexuel ${ }^{11}$ :

La voici en effet, fracassant les arbres, foudroyants les murs (ligne 205, 209, 214, 219, 237 que nous avons colorié en vert ci-dessus)

C'est encore le fracas que la ligne 239 met de plus en évidence, comme si les lignes 219 et 220 avaient fusionnées.

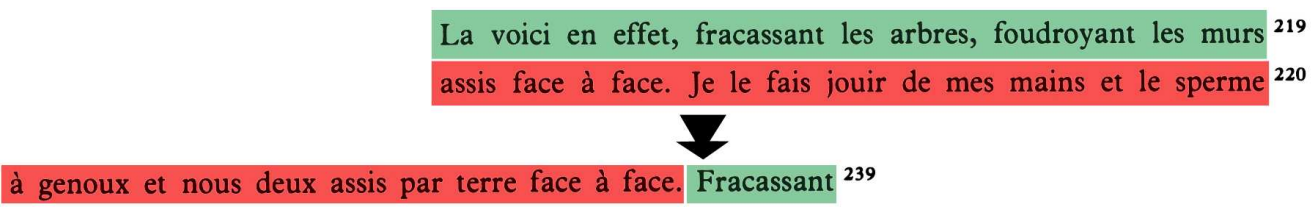

Ce fragment révèle encore une fois le caractère construit des dépôts, qui malgré le discours de l'auteur, ne sont pas de simples prélèvements et empilements, fais au hasard.

\footnotetext{
${ }^{10}$ La citation vient d'un guide de voyage Baedeker, comme l'indique la note. Ce guide de voyage du $19^{\mathrm{e}}$ siècle devint célèbre parce qu'il a révolutionné le monde du guide de voyage en développant le format "de poche" à la place des formats encyclopédiques, lourds et très coûteux. http://fr.wikipedia.org/wiki/Karl_Baedeker (consulté le: 20/03/2009).

${ }^{11}$ Selon l'analyse de Jean-Marie Gleize, les différentes variantes de cette ligne au long du dépôt, qui font s'alterner le pronom personnel (le, la, (n)ous) en début de ligne, attirent l'attention sur la problématique du sujet, et du couple. GLEIZE, Jean-Marie, Poésie et figuration, Op. cit., p. 282.
} 
Mais nous pourrions encore citer l'abréviation du nom Connie qui devient «Con » (ligne 201, en orange) dans le texte et que le contexte détourne inévitablement.

C'est par ailleurs la technique de cadrage de la photographie qui est transposée dans les effets de coupe et de retour à la ligne qui encadrent un texte légèrement décalé par rapport au fragment précédent (voir les lignes en rouge ci-dessus : 203-204; 206$208 ; 210 ; 212 ; 215 ; 220 ; 226 ; 232 ; 233 ; 236 ; 238-241 ; 243)$ et qui provoque selon Gleize un effet masturbatoire :

[...] ce qui importe c'est l'effet de récit, l'effet de figuration, et le mouvement tournant par quoi cet effet s'impose. [...] le texte se reproduit au moins de deux manières différentes, une première fois en progressant par recouvrement/élongation (selon une formule qui est à peu près celle, dans l'ordre du discours, de l'action - masturbatoire - figurée, gonflement progressive de la phrase par retours en arrière), une seconde fois, la phrase étant à peu près tendue au maximum, par soubresauts répétitifs, jusqu'à ce que le flash de la jouissance terminale achève efficacement le tout. ${ }^{12}$

Ces lignes (en rouge) qui figurent la transcription littérale de l'acte se trouvent intercalées par des lignes tirées de fiches d'état civil (en jaune) réunies par le grand père de l'auteur pour dresser l'arbre généalogique de la famille - ce qui inscrit ainsi le projet dans l'écriture autobiographique et ramène la sexualité à ses fins biologique de reproduction.

\section{VIII.4.c. La photographie comme chant d'amour}

Dans la version de Flammarion, la série de photographie vient après les textes, dans une section intitulée: «Photographies, Autoportraits au déclencheur à retardement ». Pourtant on n'y trouve aucune photo qui montrerait la pratique du va-et-vient qu'on retrouve associée à sa pratique de déclencheur à retardement dans La disparition des lucioles. Les clichés montrent plutôt des moments dans la vie du couple, des instantanés, qui font oublier qu'il s'agit d'autoportraits à deux. En tout sur les 40 photos, il y en a seulement 4 où l'on sent la pose, une sorte d'inquiétude dans le regard tourné vers la caméra. D'autres photos ne sont pas prises au déclencheur à retardement. Ainsi, 6 photos sont des photos de réflexions dans le miroir (p. 76, 96, 120, 126, 134, 140) et une montre l'ombre du couple (p. 86). La majorité des images sont des prises de

${ }^{12}$ Ibid., p. 294-295. 
vue dans des hôtels ou dans des restaurants. Les photos ne sont pas publiées par ordre chronologique et un bon nombre (14) est pris après l'achèvement du texte de Notre Antéfixe, entre le 16 et le 29 juillet 1977. Le diarogramme ${ }^{13}$ du livre révèle que plus de la moitié sont d'ailleurs prises dans l'année 1977, au moment donc où le projet s'installe.

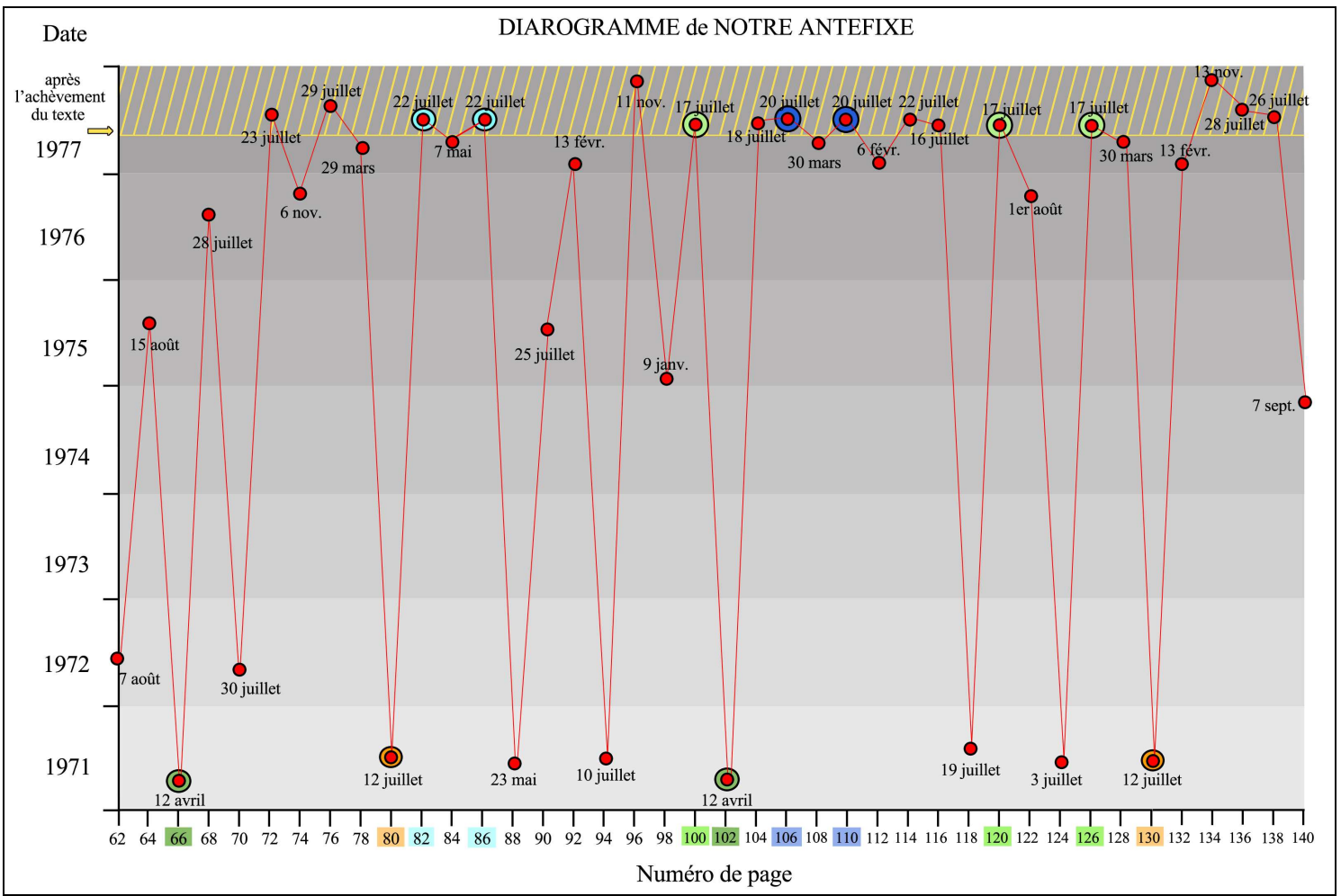

Certains clichés sont pris le même jour (signalés par les mêmes couleurs), mais ils sont séparés par la mise en page. Le diarogramme révèle encore la quasi absence des photos prises en 1973 et 1974. Certaines images sont prises le même jour et au même endroit, (p. 100, 120, 126 - vert clair) sur la terrasse de l'hôtel, à l'intérieur au reflet dans le miroir, sa femme habillée, puis déshabillée, mais elles se trouvent intercalées entre d'autre photos. Deux autres clichés sont ainsi pris le même jour, le 22 juillet 1977 (p. 82 et 86) mais l'un à Bormazo et l'autre à Norchia en Italie, deux endroits situés à une cinquantaine de kilomètre l'un de l'autre. Si l'on insiste sur la date et le lieu, c'est parce que la photographie s'appuie sur les deux dans le projet autobiographique, mais c'est

\footnotetext{
${ }^{13}$ Nous empruntons le terme et l'idée à Philippe Lejeune. Le diarogramme selon sa description rend compte de la fréquence des entrées dans un journal intime. Dans le cas de Notre Antéfixe, le diarogramme que nous avons composé dévoile la structure et le rythme particulier de l'enchaînement des dates des prises de vue.
} 
aussi ce qui s'efface dans le produit final qu'est l'image, et la mise en page non chronologique renforce cet effacement. Selon Denis Roche :

C'est aussi une façon de raconter une histoire d'amour que de se photographier à deux dans des quantités d'endroits. Car il y a l'endroit. Se photographier, c'est obligatoirement se photographier dans un endroit qui lui-même, lieu d'amour, renvoie au désir de l'appareil enregistreur photo. C'est pourquoi les légendes marquent toujours très précisément l'endroit et le jour, la date et l'espace. C'est le marquage illimité, éternel du territoire amoureux. Orphée aussi. (DL, 74-75)

En mentionnant Orphée, l'accent est mis sur l'impossibilité du retour ; mais en même temps la photographie offre tout de même la possibilité de fixer l'instant comme un souvenir qui pourra être réinvesti ultérieurement. Le territoire amoureux n'est cependant pas le territoire intime, la chambre à coucher où tous les objets racontent l'histoire du couple; il préfère au contraire les lieux anonymes que sont les hôtels ou les endroits touristiques. Ces non-lieux procurent un fond neutre dans lequel la tension, l'amour et le désir apparaissent plus intensément ${ }^{14}$.

La photo joue sur la transparence, mais il faut bien s'imaginer que la photo ci-contre $(N A, 83)$, où l'on voit le couple en train de s'embrasser dans le décor des ruines a été soigneusement préparée : la caméra a été d'abord posée à un endroit précis, la scène minutieusement cadrée, le photographe s'imaginant à l'avance dans le cadre et sur la

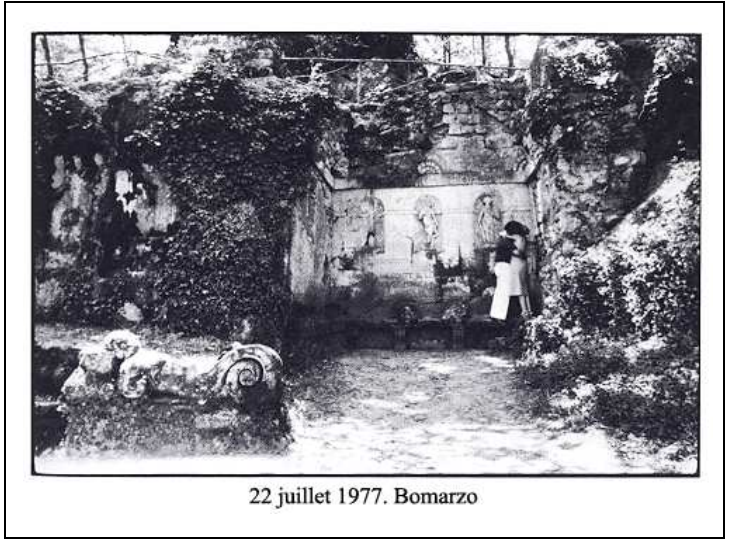
photo, puis pendant les trente secondes du déclencheur à retardement, le photographe a dû courir se placer à l'endroit, qui sur la photo paraît situé à une distance considérable, pour ensuite seulement s'abandonner au baiser. On peut penser à la série de photos de Sophie Calle intitulée La Filature (avril 1981), où les prises de vue sur lesquelles elle n'a apparemment aucune emprise sont toutefois ménagées avec soin ${ }^{15}$. L'instantanéité des photos de Denis Roche est aussi un leurre qui efface les circonstances de la prise de vue.

\footnotetext{
${ }^{14}$ Les prises de vue dans les chambres d'hôtel font penser au travail de Bernard Faucon intitulé Chambre d'amour, qui représente de manière symbolique le plaisir charnel dans la mise en scène de l'intérieur même. La série est disponible sur Internet sur le site de Bernard Faucon : http://www.bernardfaucon.net/photos/galleries/amour/index.htm (consulté le : 15/03/2009).

${ }^{15}$ Dans cette série Sophie Calle demande à sa mère d'embaucher un détective privé et de lui demander de suivre sa fille. Puisque Sophie Calle est consciente du fait qu'elle est photographiée, elle organise à l'avance ces journées en restant plus longtemps dans des endroits qu'elle veut faire marquer par le photographe.
} 
À part les photos où ils s'embrassent, on trouve des décors érectiles : menhir $(N A, 81)$, colonette $(N A, 99)$, canon $(N A, 109$ - voir ci-dessous) ; évoquant la vie érotique du couple.

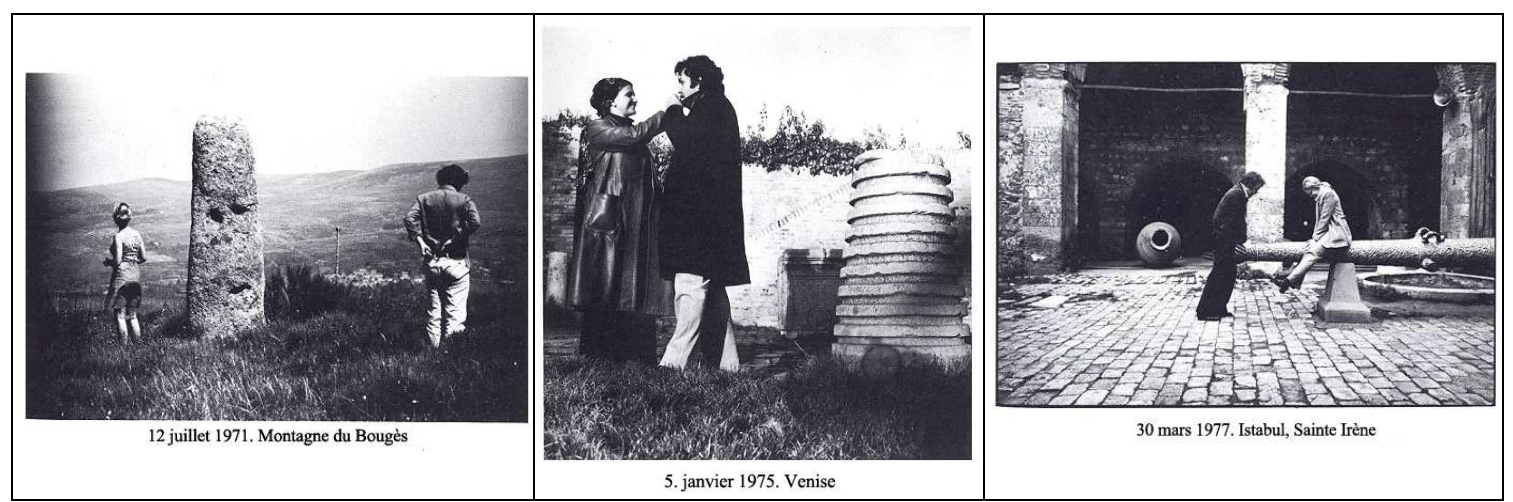

Les photographies prises dans des chambres d'hôtel, des restaurants ou des endroits touristiques ont une connotation de photo amateur, mais le flux des images au sein du livre les inscrit dans un autre régime, celui du chant poétique. Denis Roche écrit, au sujet des dépôts-antéfixes, qu'il s'agit de fixer le chant général des gens, mais les prises de vue sont également associées à un rituel chanté d'un peuple africain :

Quand un Dogon meurt, des personnages qui assistent à son enterrement improvisent un chant qui ne fait que raconter les différents endroits où est passé le mort, rien d'autre. C'est uniquement une localisation répétitive chantée. Mes photos jouent un peu comme ça. Ce ne sont jamais que des lieux. Mes légendes le disent clairement : «Tel jour, tel endroit, chambre numéro tant, tel hôtel » $(D L, 113)$

Et pourtant ce n'est pas la légende, qui indique les lieux et les dates, mais bien l'image qui rythme inconsciemment ce poème ou chant visuel. Il s'agit d'un effet inconscient, mais extrêmement construit comme dans le cas du texte-antéfixe.

\section{VIII.4.d. Analogies théorique et thématique}

Dans les écrits théoriques de Denis Roche sur la photographie, l'acte photographique est constamment comparé à l'acte sexuel :

La photographie me paraît jouer avant tout comme instantané répétitif, qui doit être immédiatement répété dès qu'il a eu lieu. Cela a un rapport immédiat avec le temps, la mort bien entendu ; et du fait de cette condamnation au répétitif, cela a rapport immédiatement avec le sexe. [...] Ce qui est le comble du malheur dans le rapport sexuel, c'est qu'il se termine et qu'il faut penser à la fois suivante. La photographie marche vraiment comme cela : plus on fait de photos, plus on s'aperçoit qu'il faut déclencher rapidement, successivement. [...] On essaye tout le temps de rattraper. Et pour rattraper ce qui est écoulé, il n'y a pas d'autre façon que de refaire exactement la même chose. L'instantané photographique c'est le coït ramené à la notion de temps. $(D L, 71$; $84)$. 
Sa pratique photographique du va-et-vient trouve ainsi son sens si on examine l'origine du mot «coït»» issu d'un verbe latin composé de ire qui signifie «marcher» ou « aller », et « co-ire » (coeo, coii, coitum) signifie alors « aller ensemble ${ }^{16} »$, et les lieux que montrent les photos, sont alors les endroits parcourus ensemble.

En plus de cette même condamnation au répétitif, la photographie est identifiée à l'acte sexuel par la montée de la tension qui précède l'acte, puis par le moment « où l'index recourbé et raide va appuyer sur le déclencheur », et finalement par le bruit de la machine et la décharge, éjaculation de lumière qui s'imprime sur le support. Dans la photographie au déclencheur à retardement, la tension et l'excitation augmentent entre le déclenchement du retardateur et la prise de la photo, tandis que dans les instantanés la tension se joue sur toute la pellicule de 36 poses, ce qui fait que la photographie devient un procédé fétichisant par excellence.

Là où c'est vraiment fascinant, c'est quand on a pris 36 fois la même chose dans les mêmes 40 secondes. On éprouve le sentiment de s'être enfin rapproché d'un lieu ultime. [...] Il faut bien dire, que c'est la prise photo elle-même qui fonctionne entièrement comme fétiche. L'appareil photographique fétichise tout [...] C'est quand même une exaltation fantastique de pouvoir fétichiser 36 fois en quelques minutes. Il n'y a rien d'autre qui donne cette sensation dans la vie. $(D L, 79,83-84)$

Non seulement Denis Roche compare la montée de tension dans l'acte photographique et dans l'acte sexuel, mais dans sa pratique photographique, la prise devient aussi l'excitant, comme nous l'avons déjà évoqué. Ainsi, dans Notre Antéfixe, certaines photos suggèrent un avant l'acte. Ce n'est pas la preuve qui compte, comme dans les photos d'Annie Ernaux et Marc Marie (L'usage de la photo), qui prises le lendemain, enregistrent la trace du rapport amoureux : chez Denis Roche, c'est la tension dans sa montée (des circonstances) qui prime.

Denis Roche fait alors fondre métaphoriquement non seulement l'acte sexuel et l'acte photographique, mais aussi l'acte d'écriture :

[...] dans la manipulation même, il y a beaucoup de choses semblable [entre la caméra et la machine à écrire], par exemple le bruit. Tout le monde sait que le bruit du déclenchement d'un appareil photographique est primordial, et on a beaucoup glosé sur la réalité sexuelle du bruit de l'appareil photographique qu'on déclenche ; [...]. C'est à la fois un bruit agressif, un bruit de déchirement du rideau... C'est le bruit violent qu'on émet soi-même simplement par une pression, qui est un bruit rassurant, exaltant, et en même temps c'est le bruit de cette espèce de réalité qui se déchire sous l'action du rideau, de l'obturateur. [...] Dans la machine à écrire c'est pareil : on est rappelé à l'ordre sans arrêt par le bruit de la frappe [...]. $(D L, 77)$

${ }^{16}$ DADOUN, Roger, L'érotisme, Paris, PUF, col. "Que sais-je ?", 2003, p. 27. 
Le bruit que fait l'appareil photo et la machine à écrire est comparé au déclic sexuel, au tilt érotique qui selon les mots de Roger Dadoun ${ }^{17}$ est l'excitation élémentaire, l'unité minimal d'Éros. Dans le rapport amoureux le déclic se produit à la vue des organes sexuels, ou d'autres parties du corps, de son substitut le vêtement, ou de n'importe quel objet dans lequel est investi un fantasme érotique. L'organe sexuel est ce qui ne peut pas être regardé, et ce qui, dans l'altérité foncière, renvoie irrévocablement à la discontinuité de l'être. Il est ce qui provoque irrévocablement le déclic, tout en étant médusant et castrateur dans la logique freudienne ${ }^{18}$. On retrouve d'ailleurs dans $L e$ Boîtier de mélancolie ${ }^{19}$, la photo du sexe féminin de Henri Maccheroni, qui pour Philippe Dubois est le correspondant visuel de l'Histoire de l'œil de Georges Bataille, où il décrit une scène où le protagoniste en apercevant le sexe de la femme est pris d'un tilt érectile mais qui s'accompagne aussitôt d'un sentiment de culpabilité castrateur.

Ensuite, je me levais et en écartant les cuisses de Simone, qui s'était couchée sur le côté, je me trouvais en face de ce que, je me figure ainsi, j'attendais depuis toujours de la même façon qu'une guillotine attend un cou à trancher. Il me semblait même que mes yeux sortaient de la tête comme s'ils étaient érectiles à force d'horreur; je vis exactement, dans le vagin velu de Simone, l'œil bleu pâle de Marcelle qui me regardait en pleurant des larmes d'urine. ${ }^{20}$

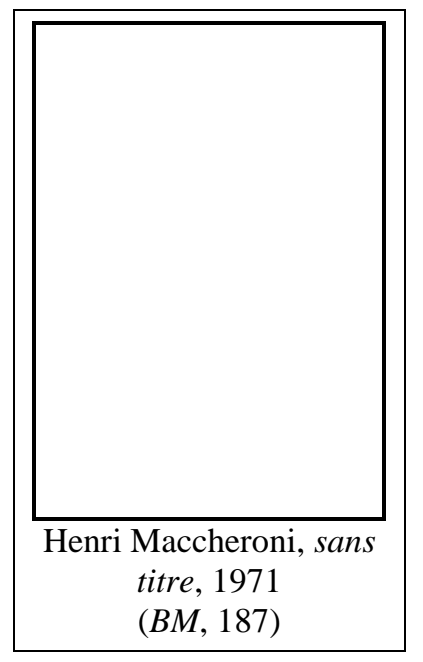

La vue de l'organe provoque le déclic, mais l'appareil photo, qui fait écran, donne à l'inverse libre cours au regard, plaçant le regardeur ${ }^{21}$ dans une bulle de protection : c'est ce regard protégé qui lui permet de jouir délibérément sans s'y perdre. L'appareil a la double fonction à la fois d'écran et d'interface où le désir est investi dans ce qui est

\footnotetext{
${ }^{17}$ Ibid., p. 11.

18 FREUD, Sigmund, «La Tête de Méduse », in Euvres complètes, (sous la direction d'André Bourguignon), tome XVI. (1921-1923), Paris, PUF, 1996, p. 163-164.

${ }^{19}$ ROCHE, Denis, Le Boîtier de mélancolie. La Photographie en 100 photographies, Paris, Hazan, 1999. Par la suite nous utiliserons l'abréviation : $B M$.

${ }^{20}$ BATAILLE, Georges, Histoire de l'œil cité par Philippe Dubois, Op. Cit., p. 141.

${ }^{21}$ Nous employons le mot « regardeur » au lieu du mot spectateur, car ce dernier implique la passivité de quelqu'un qui serait en face d'une chose à laquelle il n'a pas accès ; le terme «regarder » par contre implique le geste d'aller pour voir et d'être au milieu.
} 
regardé. Denis Roche parle ainsi d'écran à propos des photographies de touristes : (mais il s'agit là d'un écran positif, une sorte de prisme qui intensifie la choses vue :

Les touristes qui ne prennent pas de photos sont toujours horripilés quand ils voient arriver un car de touristes devant la tour de Pise, et que les gens qui descendent photographient le bâtiment avant même de le regarder. On peut penser qu'ils mettent immédiatement un écran entre ce qu'ils sont venus voir et eux. Mais je ne le crois pas. J'ai toujours eu l'impression, au contraire, qu'arrivant devant un objet pour lequel on a fait un long voyage et qu'on a grand envie de voir, le fait de le mettre d'abord en place dans cette machine capteuse qu'est l'appareil de photo, entraîne une acuité du regard qui multiplie en somme la regardabilité du monument. (DL, 82-83.)

Dans son analyse sur l'œuvre de Denis Roche, Cécile Cadu compare également l'appareil à un godemiché22, un jouet sexuel qui sert de prothèse, de substitut, et déplace le plaisir en dehors du corps. L'œil qui regarde dans le viseur se trouve modifié par l'activité photographique et «de la même façon que perdure dans le corps amputé des impressions attribuables au membre disparu, l'œil continue de vouloir répéter son activité de prélèvement alors même qu'il ne peut l'accomplir sans l'appareil ${ }^{23} »$. Par conséquent, le plaisir n'est plus identifiable à l'organe excité, mais à l'appareil, et c'est ce dernier qui décide du moment de l'interruption de la mise en tension ${ }^{24}$. Sur ses photos, on trouve souvent un appareil posé au premier plan : l'appareil dans ce cas devient l'observateur qui érotise la réalité.

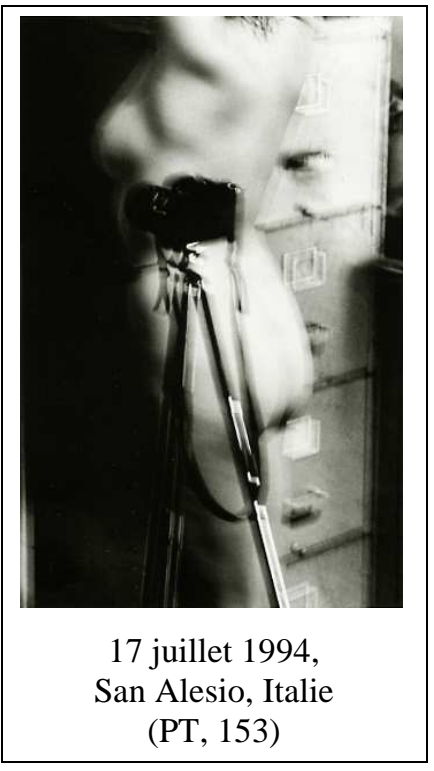

Le désir sexuel est non seulement provoqué par l'appareil et par l'acte photographique, mais il se transpose dans l'image. Notamment les photos de nu (qu'il s'agisse de pin up girl ou de nu artistique) suscitent le désir de celui qui regarde. Faire des photos de nu de la femme aimée, devient doublement érotique et par se dédoublement elle est comparé par Denis Roche à une photolalie :

La photo de nu est à elle seule une photolalie : elle capte en même temps la beauté d'un corps désiré et l'intensité de l'intérêt esthétique qu'on lui porte. C'est le combat sans fin pour la primauté, entre un désir et un regard : que l'un d'eux l'emporte et le combat cesse, et l'image s'évanouirait. $(P H, 24$.

Nous trouvons peu de photos de nus dans Notre Antéfixe, mais davantage dans les livres de cocréations qui sont publiés ensuite. Dans les photos de nu, il n'y a plus la frustration

${ }^{22}$ CADU, Cécile, «Le bras armé de l'écriture », in Denis Roche, l'un écrit, l'autre photographie, p. 219237.

${ }^{23}$ Ibid. p. 223-224.

${ }^{24}$ Ibid. 
de l'instantané et de la prise qui doit être répétée. C'est le désir permanent et le beau qui règnent. On peut déceler plusieurs influences dans les photos de nu de Denis Roche, des modèles esthétiques auxquels il se réfère d'ailleurs dans son livre Boîtier de mélancolie. Ainsi constituent un modèle, les nus d'Edward Weston ${ }^{25}$ ( $\mathrm{Nu}$ en forme de vase renversé, $1928, B M, 115)$, où les rondeurs des masses se laissent entrevoir sous la douceur de la transition entre la lumière et l'ombre, ou les photos de Bill Brandt ${ }^{26}(\mathrm{Nu}, 1953, B M$, 165) qui jouent sur la déformation-accentuation des morceaux de corps devenant lignes calligraphiques sur la page.

Dans d'autres photos l'appareil optique, comme les lunettes dans le cliché ci-contre ${ }^{27}$, focalise sur le corps érotisé, toutefois ce fétichisme ne devient pas obsédant ou excessif, car les photos de nu se trouvent toujours intercalés parmi d'autres photos dans le récit qui se forme par la mise en série au sein des livres $^{28}$.

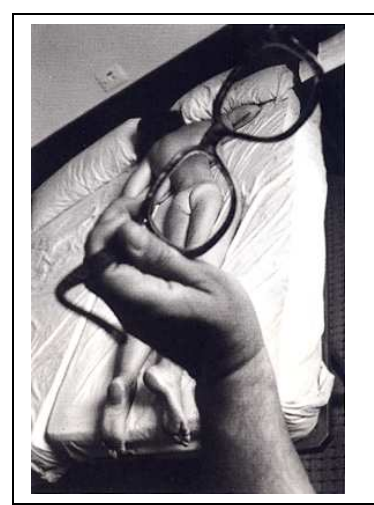

La lumière joue un rôle important dans certaines photos de nus, c'est une lumière tactile qui à la fois caresse le corps, ou y pénètre pour devenir pleinement la métaphore de la photographie : de la décharge de lumière et de l'acte érotisé.

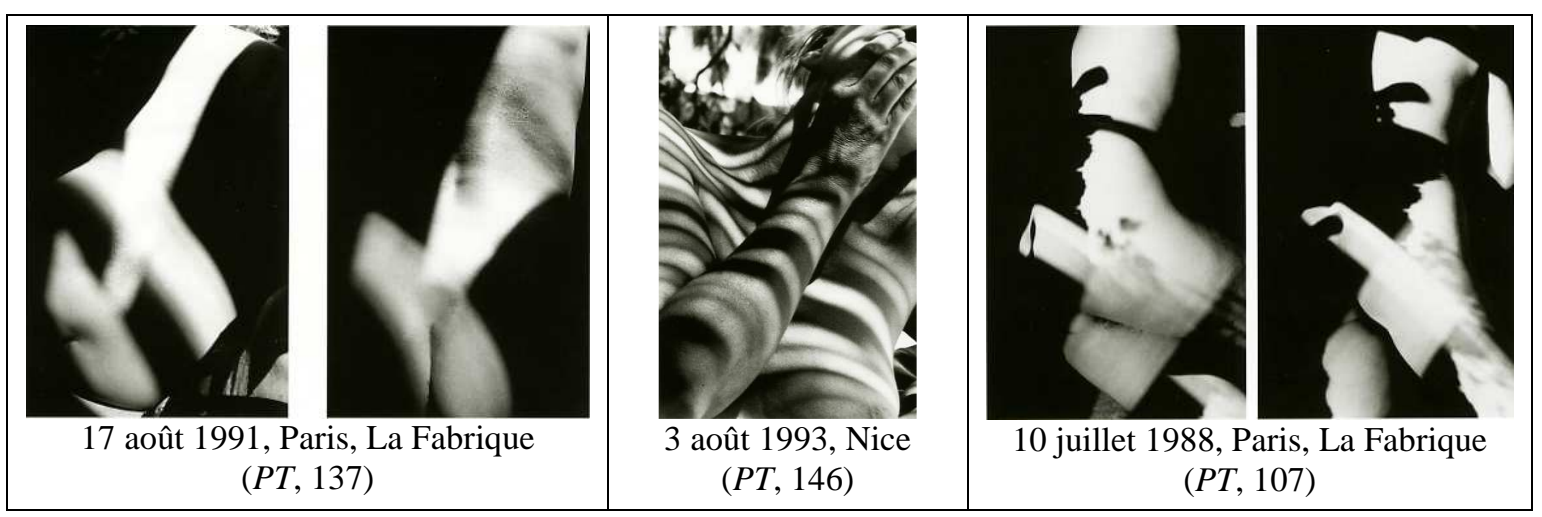

L'œuvre photographique et l'œuvre littéraire de Denis Roche s'inscrit pleinement dans la lignée de Georges Bataille quand il retrouve au fondement de toute activité humaine

\footnotetext{
${ }^{25}$ Voir quelques exemples de nu sur le site dédié à Edward Weston : http://www.edward-weston.com/edward_weston_nudes.htm (consulté le : 04/05/2009).

${ }^{26}$ Voir les images sur le site de la galerie Fahey/Klein : http://www.faheykleingallery.com/featured_artists/brandt/brandt_frames.htm (consulté le : 04/05/2009).

${ }^{27}$ Photo intitulée 21.07.1986 Ségovie, Espagne Hôtel Acueducto, ch. 216., publiée dans le catalogue d'exposition : ROCHE, Denis, Photographies 1965-1989, Espace photographique de Paris, 24 octobre 3 décembre 1989, Paris, Paris Audiovisuel, 1989 (sans pagination).

${ }^{28}$ Voir par exemple le livre Les preuves du temps.
} 
le ressort essentiel du désir, et dans la création, la seule possibilité de faire face à la béance de la mort. L'inévitable destruction de la mort est partout présente dans l'œuvre photo-littéraire, mais elle culmine avant tout dans son livre Louve basse déjà mentionné. Le livre se termine sur l'évocation par Denis Roche de sa propre mort sur un ton très neutre et scientifique qui présente la description détaillée de son propre cadavre exhumé «neuf mois et vingt-cinq jours après l'inhumation » $(L B, 227)$. La description, dans ce $13^{\text {ème }}$ et dernier chapitre, est précédée d'une série de 4 photos (une photo par page), montrant l'auteur tournant sur lui-même.

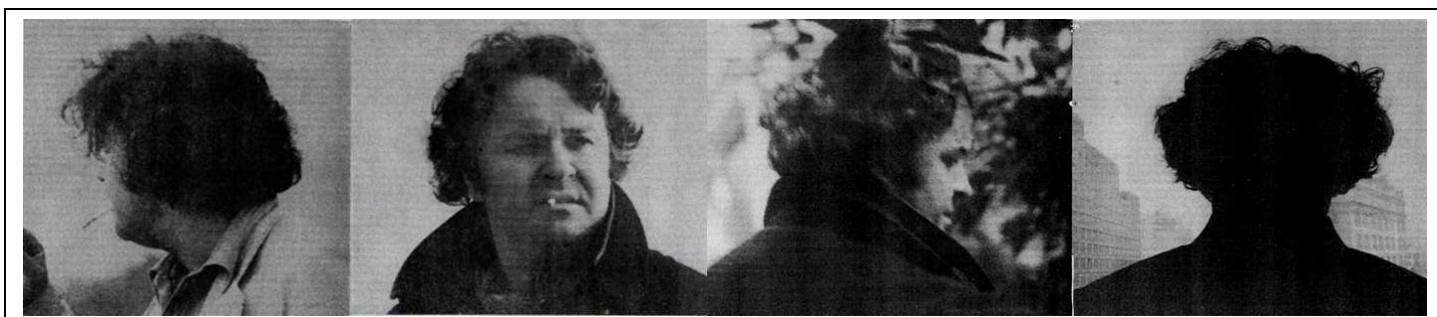

Denis Roche tournant sur lui-même, Louve basse, p. 222-224.

Les vêtements de l'auteur et l'arrière plan, montrent qu'il ne s'agit pas d'une prise de vue successive, mais nous ne trouvons aucune indication sur la date et le lieu. Selon Jean-Marie Gleize, cette série illustre l'idée que l'on tourne toujours autour de soi-même, autour de sa propre mort, et que cela est inévitable ${ }^{30}$. Mais la photo fait également référence à une série d'autoportraits de Nadar (ci-contre), dans laquelle le photographe se met aussi en scène en tournant sur lui-même.

Nadar $^{29}$, Autoportrait «tournant », ca. 1865, BNF.

La dernière photo de Denis Roche de la séquence tournant sur lui-même, le présente de dos, se fondant dans une silhouette noire. La dernière image évoque donc la mort.

Dans la théorie de la photographie de Denis Roche, se trouve également mis en parallèle la sexualité et la mort au sein du dispositif.

Dans une photo «on y passe » au sens populaire du terme, c'est-à-dire qu'on y meurt. On se signale à l'intérieur de la photo comme faisant partie du moment qui passe, qui est détruit, et donc on photographie cette destruction. La photo est un objet mortifère terrifiant. $(D L, 84)$

${ }^{29}$ Voir l'image : http://www.sceren.fr/Themadoc/niepce/images/auto.jpg (consulté le : 10/10/2009).
${ }^{30}$ GLEIZE, Jean-Marie, Poésie et figuration, Op. cit., p. 263. 
Par ce constat Denis Roche fait aussi référence à Roland Barthes, qui voyait en premier lieu dans la photographie le deuil irréparable de l'acte.

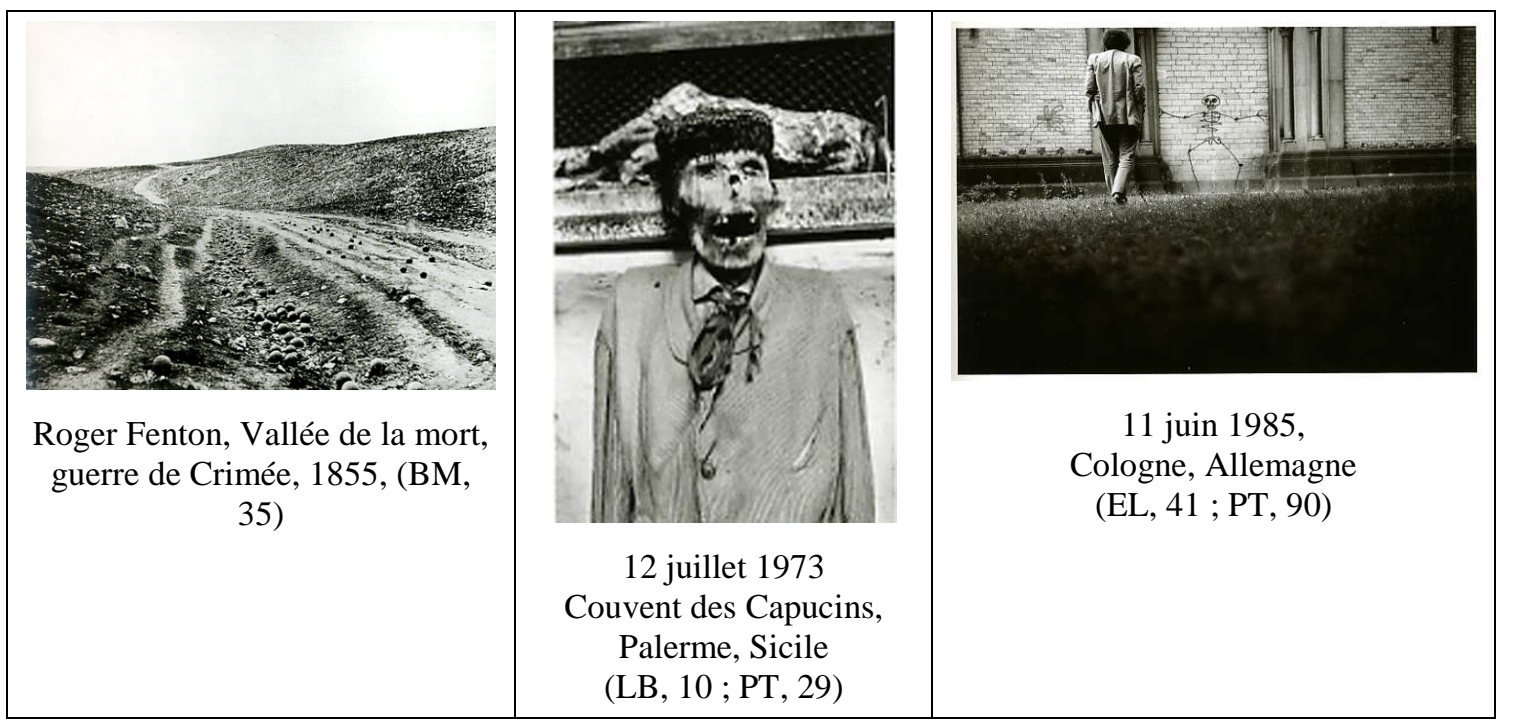

Cependant chez Denis Roche on retrouve directement le thème de la mort dans certains clichés. Dans Boîtier de mélancolie, dans le choix de photos d'autres photographes (comme celles du premier photographe de guerre Roger Fenton, ci-dessus à gauche), dans Louve Basse avec les corps momifiés (ci-dessus au milieu), ou encore avec le cliché (ci-dessus à droite) publié dans plusieurs livres, pris au déclencheur à retardement, sur lequel Denis Roche enjambe le chemin qui mène jusqu'à la mort figurée par un graffiti dessiné sur le mur. Dans Ellipse et laps à côté de ce dernier cliché, il décrit les circonstances de la prise de vue et l'angoisse irrationnelle qu'il ressent à se prêter à un jeu aussi macabre.

Je me dis : «demain j'aurai quitté cette ville et j'y reviendrai sans doute jamais. » Je me dis aussi que devant cette Mort, la seule chose que je puisse penser c'est que je suis vivant, mais que ça ne veut pas dire grande chose, et que certainement ça ne veut rien dire d'autre. ${ }^{31}$

\footnotetext{
${ }^{31}$ ROCHE, Denis, Ellipse et laps : l'œuvre photographique, Paris, Maeght, 1991, p. 39. Par la suite nous
} utiliserons l'abréviation : $E L$. 
Selon Bataille c'est la lutte contre la discontinuité de la mort qui est le motif principal de l'érotisme. Dans la fusion avec l'autre sont fantasmées la continuité et la durée. Denis Roche transpose également cet imaginaire en image. Nous retrouvons ainsi des photos où la fusion du couple est suggérée grâce aux deux faces de la vitre. L'union du couple est convoitée et

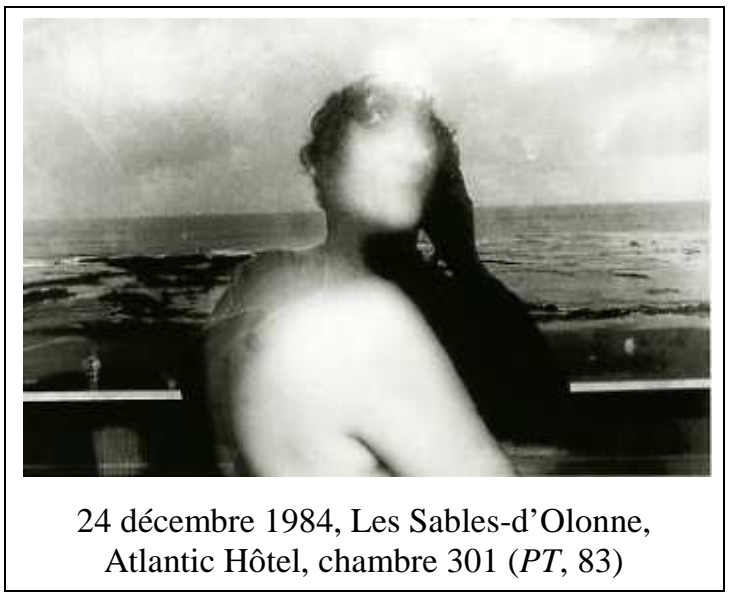
accomplie dans la photo de Légendes de Denis Roche qui montre le couple devant l'inscription Peyroche, qui fait fusionner le nom de l'auteur Denis Roche avec celui de sa compagne Françoise Peyrot, et dont la légende indique : «En langue d'Oc «Peyrot» veut dire Roche ». C'est également la fusion entre la photographie et la littérature qui s'opère dans certains clichés où l'on trouve des inscriptions, telle, dans Notre Antéfixe, la dernière photo du couple, où l'on voit sa femme de derrière et lui se reflétant dans la vitrine d'un magasin.

Le «t» dans l'inscription du magasin ALIMENTATION s'est effacée avec l'effondrement du crépi, dessinant un mot énigmatique, effacé par le temps et qui renvoie indirectement à la pratique poétique de Denis Roche visant la destruction de la poésie.

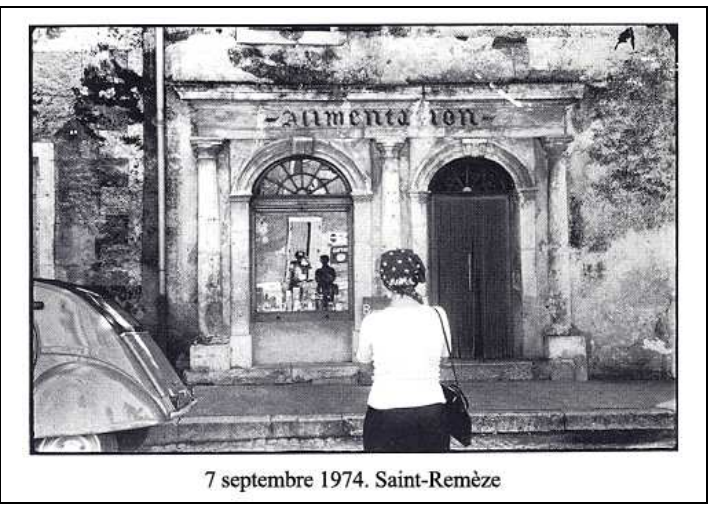

Chez Bataille la poésie permet d'accéder à la fusion et à la continuité rêvée, et c'est pour cela que la poésie devient essentiellement érotique :

La poésie mène au même point que chaque forme de l'érotisme, à l'indistinction, à la confusion des objets distincts. Elle nous mène à l'éternité, elle nous mène à la mort, et par la mort, à la continuité $[\ldots] .^{32}$

La métaphore à ce titre devient la figure érotique par excellence, car elle opère la fusion de plusieurs images. Denis Roche parle également de la métaphore comme source de jouissance :

${ }^{32}$ BATAILLE, Georges, L'érotisme, Op. cit., p. 29. 
Pendant longtemps, notamment après 68, la métaphore a été bannie du littéraire, non seulement dans la fiction mais, aussi, dans les discours théoriques. La métaphore était vraiment assimilée au diable, au diable politique. Il faudrait peut-être se demander pourquoi, et en même temps, pourquoi tellement de gens s'obstinaient à empêcher d'autres personnes de jouir, de jouir au sens littéral, d'éjaculer. [...] c'est que l'on a perdu, qu'on perd beaucoup par les tabous qui ne cessent d'être amoncelés sur notre dos, on perd vraiment de plus en plus un rapport naturel, dansé ou chanté, à notre occupation quotidienne. Dieu sait pourtant si depuis 68 on a parlé du rapport au corps et de façon vraiment hallucinante, parce que plus on parlait, moins on entendait les gens chanter, c'est absolument évident. (DL, 120-121.)

La démarche de Denis Roche, qui par le recours à la photographie, évolue vers la transcription littérale de la scène, développe en même temps un réseau métaphorique créé par les textes et les images. Dans les poèmes, on note alors si on observe l'utilisation du pronom féminin de la troisième personne du singulier « elle », qu'il peut renvoyer à la fois à la femme aimée et à la poésie. C'est le cas par exemple dans le poème déjà cité du recueil Le mécrit : «Il l'enjambe. Ou sa jambe à elle/ Est passée sur le grand dos. Du défaut, de/ Grand dé il se retirera tout à l'heure à pl/ ein ventre » $(P I$, 474, voir le poème à la page 30). « Du défaut de Grand dé » fait référence à Mallarmé et au courant poétique du $20^{\mathrm{e}}$ siècle, qui faute de pouvoir figurer l'infigurable, se retire dans le silence du blanc. C'est le courant poétique dont s'écarte Denis Roche en l'enterrant par la publication du recueil Le mécrit. L'enjambement érotique préfigure la « véhémence » par laquelle l'enjambement en fin de vers et sans tiret vient éclater le mot « $\mathrm{pl} /$ ein », transgressant les règles poétiques et linguistiques.

La jouissance de la métaphore se transpose alors dans la photographie, ce que remarque également Dominique Kunz Westerhoff :

[...] un discours de la métaphore, qui naguère contrarié par la méfiance portée sur l'institution poétique, revient par la fenêtre de l'obturateur photographique, et se déploie dans la photolittérature de Denis Roche en des analogies de l'éros, en un éros des analogies. ${ }^{33}$

${ }^{33}$ WESTERHOFF KUNZ, Dominique, «Un imaginaire objectif ou ce que devient la métaphore chez Denis Roche », in Denis Roche, l'un écrit, l'autre photographie, Op. cit., p. 134. 
La photographie est à la fois figurative et métaphorique, car dans l'instant de sa prise, l'inconscient l'investit de son imaginaire. C'est ainsi que la transcription littérale, la prise de vue machinale, l'image au déclencheur à retardement qui s'organise en faisant intervenir le hasard, peut s'inscrire dans un réseau métaphorique complexe. C'est ainsi qua la femme devient vase dans le cliché cidessus, dialoguant avec une photo d'Edward Weston déjà mentionnée, intitulée « $\mathrm{Nu}$ en forme de vase renversé » publiée dans La boîtier de mélancolie (p. 165).

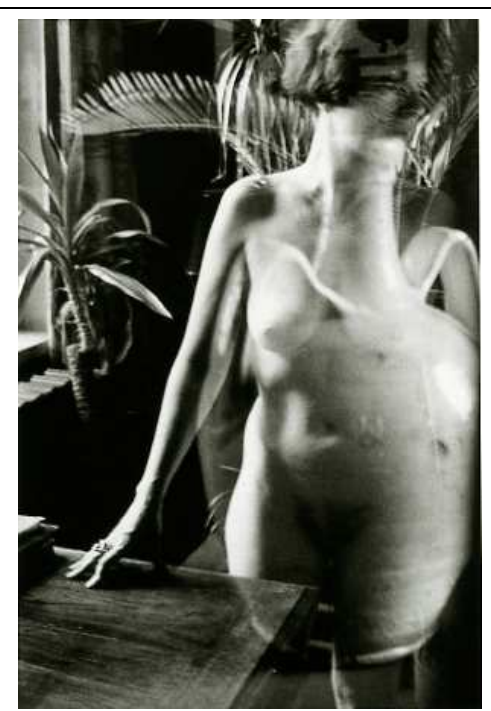

18 juin 1999, Paris, La Fabrique, $(P T, 178)$ 


\section{VIII.5. Le temps à l'épreuve}

Nous avons démontré comment l'érotisme s'inscrit dans les photos et les textes de Denis Roche pour tisser un réseau métaphorique. Selon Gilles Mora, tous les thèmes (développés par les textes et par les photos) se rapportent à la notion du Temps ${ }^{1}$. Le temps qui se trouve déployé dans l'œuvre dans ces deux étendus extrêmes : le temps instantané de l'appareil photo et le temps intérieur de chacun qui se mesure par la longueur de notre vie et dont la mort constitue l'inévitable achèvement. Le Temps est un enjeu essentiel de ses photographies et de ses écrits, c'est un concept qu'interrogent aussi bien les images que les textes.

La vie, le temps d'une vie est comparée à une course, à une lutte de plus en plus accélérée contre le temps qui passe, sans qu'on puisse l'arrêter, sans qu'on puisse revenir en arrière :

[...] enchaînant désespérément ligne après ligne, page après page, de viseur en viseur, photo après photo, comme dans cette course sans cesse retenue qui fait qu'aussitôt après avoir joui en faisant l'amour on ne pense qu'à remettre ça, déjà tendu vers ce nouveau moment où la charge, la pleine charge sera encore une fois en jeu, et où courant devant, brandissant mes machines, [...] au fur et à mesure que le rythme s'accélère et devient plus bruyant, $[\ldots]$ je crie, hors d'haleine qu'il faut s'arrêter, $[\ldots]$ qu'au besoin on revienne en arrière pour que je m'y retrouve, que je puisse améliorer le cadrage, reprendre tel ou tel mot qui n'est pas le bon, alors que je me retrouve tout à coup comme un idiot parce que je viens de me rendre compte que de toute façon le ralenti n'existe pas. $(D L, 58)$

Parmi les procédés photographiques qui explorent la tension temporelle, Gilles Mora mentionne les photos à retardateur, les clichés pris dans un même cadre à plusieurs années d'écart, les photolalies et les contacts successifs.

Dans les photos à retardateur, et plus encore quand il s'agit des prises de vue de va-et-vient, le temps s'inscrit immédiatement dans l'image en l'assimilation avec l'espace parcouru, la distance qui sépare l'appareil photo et le photographe (mais pour cela il faut aussi que le texte juxtaposé nous éclaire sur les conditions de la prise de vue).

\footnotetext{
${ }^{1}$ MORA, Gilles, «Préface », Les preuves du temps, Paris, Seuil/Maison européenne de la photographie, 2001, p. 7-17.
} 


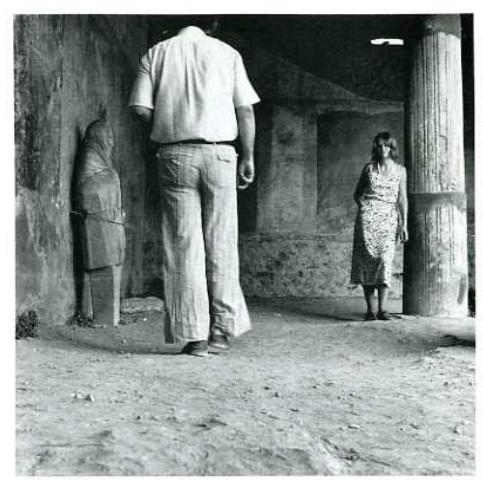

21 juillet 1979, Pompéi, Thermes des Stabies. $(D L, 21)$

Gilles Mora remarque que dans ces photos de va-etvient, le déplacement s'opère vers la femme de l'artiste, la femme qui est toujours un point fixe dans l'espace et le cadre'2. Que l'écrivain soit souvent représenté de dos, tête coupée, ou sous la forme de morceaux tronqués de corps, traduit selon Mora un déséquilibre, une instabilité dans la trajectoire qui mène vers l'élément immobile et équilibré que représente la femme/compagne. C'est la recherche de cette harmonie, «le violent désir d'équilibre » qui sous-tend la majorité des photos de Denis Roche.

Dans sa pratique des photolalies, qui consiste à dédoubler ou à juxtaposer deux clichés qui se mettent alors à dialoguer, certaines photos exploitent directement la thématique du passage du temps. Le livre Photolalie s'ouvre sur deux clichés pris à treize ans d'intervalle au cimetière de Pont-de-Montvert ( $\mathrm{Ph}, 6-7$, ci-dessous) ; elles sont suivies d'un contact successif où seuls quelques instants séparent les prises de vue montrant l'ombre de l'appareil et la main qui feint de prendre le cliché ( $P h, 9$, voir ci-contre à droite).

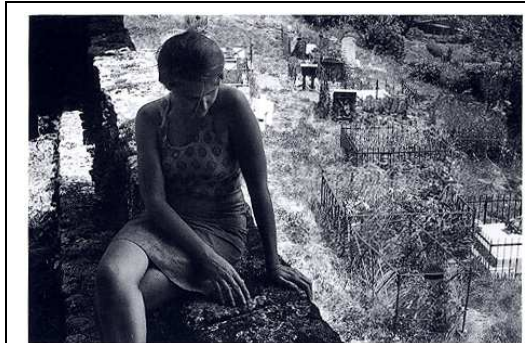

12 juillet 1971.

Pont-de-Montvert, Lozère

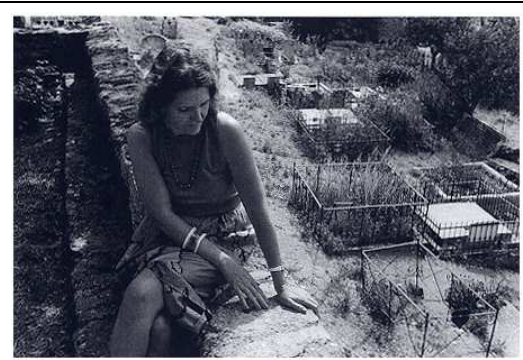

6 août 1984. Treize ans après.

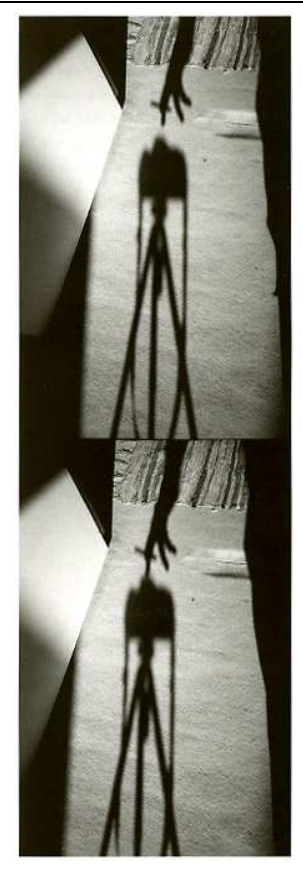

11 octobre 1987

La Fabrique, Paris.

Dans la première lalie, le temps s'inscrit dans la changement du corps représenté et du paysage ; dans la deuxième lalie, le cadre est identique et c'est la poursuite du geste qui assure la lecture du temps. Le geste cependant n' est qu'une mise en scène, car ce n'est pas l'appareil photo dont on aperçoit l'ombre qui enregistre la scène, ceci étant disposé à l'horizontal tandis que le cadre présuppose un appareil tourné verticalement. Que le

${ }^{2}$ Ibid., p. 14. 
temps puisse être à ce point comprimé entre les deux pages du livre (treize ans puis quelques secondes), entraîne le vertige et l'exclamation de l'auteur :

Salut donc au Temps, et à son ambassade de l'abîme, salut au chien qui le traînent ! $(P h, 5)$.

Ce jeu avec le temps d'écart est répété plusieurs fois : ainsi sur la tombe d'Ezra Pound les clichés sont pris à sept ans d'écart, ou ceux en Égypte, revisité plusieurs fois. La prise de vue de la cimetière de Pont-de-Montvert sera de même complétée et enrichie après sa parution dans le livre Photolalie (après 1988), complétant les deux images en une série de quatre, chaque image prise environ à dix années d'intervalle (voir la série ci-dessous tel qu'elle a été publiée en 2007 dans le livre La photographie est interminable ${ }^{3}$ ). À propos de cette série, Denis Roche dit dans une interview qu'il s'agit de faire confondre l'instantané et le perpétuel. Il relate ensuite une anecdote à propos du fait, qu'on lui aurait posé une question concernant le temps lors de l'ouverture d'une exposition et à laquelle il aurait répondu :

«Regardez ces trois photos, je photographie la femme dont je suis amoureux depuis tant d'années et évidemment elle a vieilli entre les trois photos, c'est le temps qui passe, voilà le sujet de la photo. » À ce moment-là seulement j'ai pris conscience qu'il y avait quelque chose de très particulier entre ces trois photos, elles contenaient autre chose qui était bien plus visible : c'était le cimetière qui avait changé !

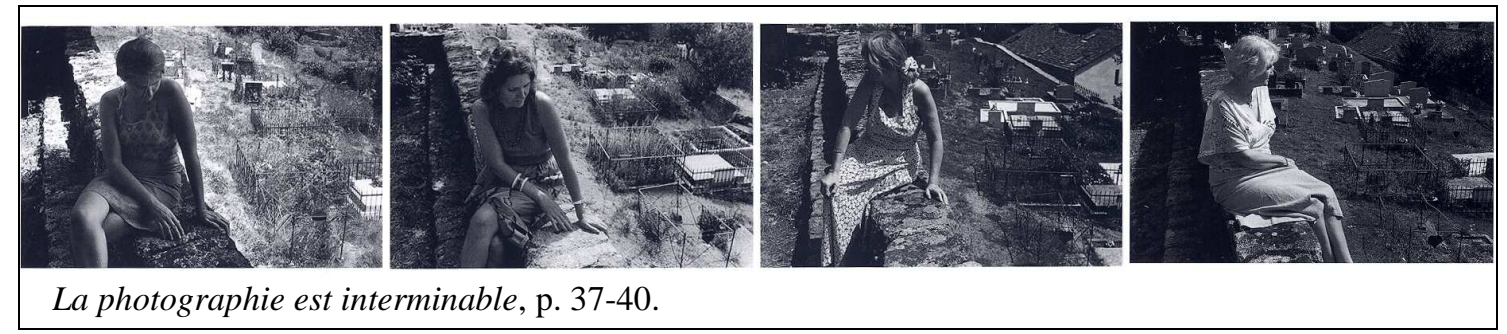

L'augmentation de la série et la publication des quatre photos va de pair avec les quatre images de Denis Roche publiées dans Louve Basse, conférant une nouvelle signification à l'ensemble. Les quatre images de Denis Roche le montraient tournant sur lui-même jusqu'à tourner le dos ; dans la série sur sa femme on trouve également un mouvement circulaire. De la contrainte d'une pose fermée et refermée sur soi-même, on passe à une certaine liberté, le modèle lève les yeux, regarde autour d'elle et s'adonne à la contemplation sereine du paysage.

\footnotetext{
${ }^{3}$ La photographie est interminable, Entretien avec Gilles Mora, Paris, Seuil, col. "Fiction \& Cie" 2007, p. 37-40.

${ }^{4}$ «Denis Roche Les temps du photographe » Entretien réalisé par Pascale Mignon et Marina Stéphanoff, La lettre de l'enfance et de l'adolescence, 2006/2 ( $\mathrm{n}^{\circ}$ 64), p. 88. Disponible sur le site de Cairn.
} 
C'est non seulement le temps chronologique qui s'inscrit dans la photo, mais aussi le temps météorologique. Il s'agit certainement d'un hasard, mais on peut trouver une correspondance métaphorique entre la qualité de la lumière et les phases de vie représentées. La première photo est baignée par une lumière vive, avec des contrastes aigus, lumière qui peut correspondre à la jeunesse où l'on ne voit les choses qu'en noir et blanc par manque d'expérience. Une ombre enveloppe le corps de la jeune femme, ce qui renforce son enfermement sur elle-même. Sur la deuxième photo, en revanche, il n'y a presque pas d'ombre grâce à la lumière diffuse : nous ne sommes plus dans la dualité de la jeunesse, mais dans la nuance et la relativité des choses. Le modèle est contraint par la pose, mais sa tête est déjà moins baissée. Sur la suivante, on retrouve une lumière et des ombres marquées, mais l'ombre cachant la femme a disparu; elle est assise de la même manière, sa main placée au même endroit, mais elle se tourne déjà pour regarder autour d'elle. Enfin, sur la dernière image, les ombres se sont allongées, la position du corps tournée vers le cimetière accorde une importance à ce dernier, mais la pose est enfin libérée, le modèle est baigné de lumière. La mise en série, tel qu'elle est publiée dans La photographie est interminable, retrace l'histoire d'un épanouissement.

La lumière joue donc un double rôle central dans la photographie : elle permet de garder la trace des choses et des êtres par la photo, mais à force d'être trop soumis à la lumière, ces mêmes traces s'évanouissent avec le temps. Le vieillissement qui permet de lire le temps écoulé sur le cliché ci-dessous rappelle la matérialité du procédé. Le cliché provient de la collection de Denis Roche : il s'agit d'un portait anonyme où l'émulsion a mangé la tête du personnage dans le cliché de gauche.

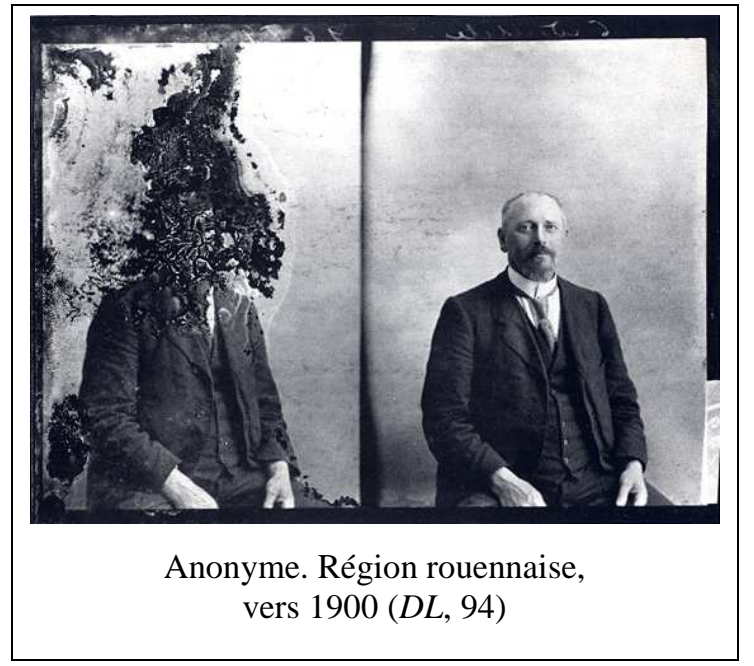


Les photos et les textes de Denis Roche jouent sur les notions d'abîmes, abîme d'espace et de temps, et sur le vertige que l'on éprouve face à une photo représentant quelqu'un qui a disparu à jamais. On retrouve cette idée dans un poème écrit en 1962 :

\author{
Et j'avais le vertige de les regarder car ils ne \\ Finissaient pas de sourire au photographe ils sont \\ Encore au silence d'une belle mixture d'ocre \\ Avalés dressés ils sont les Actes de Minutes de \\ L'existence un arbre en guise de crayon sur l'oreille \\ Du soleil qui les brûlera tous (Récits Complets, PI, 100)
}

Ce poème fait partie de la série intitulée La poésie est une question de collimateur, qui explore la temporalité de l'écriture. La suite contient dix poèmes écrits à toute vitesse. Le temps de la création est minutieusement marqué, il varie entre 6 et 24 minutes, pour des poèmes composés le 3 et le 7 février affichant la dates de leur composition comme une légende de photo. Il s'agit également d'approcher l'idéal de l'enregistrement littéral, de la saisie directe presque automatique : les poèmes suggèrent une composition accélérée, où les mots semblent refléter le flux de la pensée sans modification ultérieure. Il y a marquage du temps, mais également brouillage de repères, car les poèmes ne sont pas rangé par ordre chronologique. L'écriture de certains poèmes s'enchaîne, une minute après, mais dans le recueil on passe du 7 février au 3 février pour revenir ensuite à un poème écrit le 7 février. La reconstitution révèle aussi que le premier et le sixième poème sont rédigés de manière simultanée. Le schème de l'instantané est transposé dans l'écriture par l'accélération de la vitesse de composition, mais la mise en série témoigne de la complexité du temps.

Dès le recueil Récits complets, la question du temps est liée à la poésie (1963). Dans l'avant propos, l'auteur attire l'attention que deux temporalités se jouent dans la poésie, celle de l'écriture et celle de la lecture.

L'espace-temps du poème est avant tout celui de sa lecture, il se déroule de haut en bas de la page. [...] La lecture du poème opère le transfert d'énergie du poète au lecteur; la division en vers, à l'origine, devait correspondre à la nécessité de brisure qui est le propre de l'incantation ; $(P I, 50)$

Le changement majeur qui s'est produit depuis les origines de la poésie, est la séparation de ces deux temporalités :

[...] Si le poème traditionnel se devait de cheminer aux vitesse de la vie active avec arrêts au milieu et en bout de ligne avec cette obligation de n'avoir qu'une pensée close en fin de page, depuis longtemps déjà le poème s'est débridé, il s'est ouvert, on y a introduit une nouvelle dimension, qui est celle d'intervalle au sens où les mathématiques l'emploient; alors se sont 
déclarées de nouvelles perspectives qui font appel aux rebonds incessants qui animent notre inconscient. $(P I, 52)$

Le projet qui sera mené à terme par le biais de la photographie est donc de dévoiler les intervalles de l'écriture et de combler au mieux cette scission entre le rythme de l'écriture, celui de la vie et celui de la lecture.

Les dépôts de savoir \& de technique offrent également une lecture temporelle induite par une photographie insérée au début du livre, un cliché de l'escalier de Copán (voir ci-contre). Dans la préface du livre, l'auteur raconte de manière anecdotique comment ils se sont rendus à Copán (au Mexique) avec sa compagne pour visiter le site repéré au préalable dans un livre sur l'architecture maya et qu'il connaissait donc déjà par des photos au moment de l'écriture des dépôts. Le couple s'est donc rendu sur place, après que la majorité des dépôts furent terminés, et l'anecdote relate le choc et l'excitation qu'a provoqués la vue directe de l'escalier

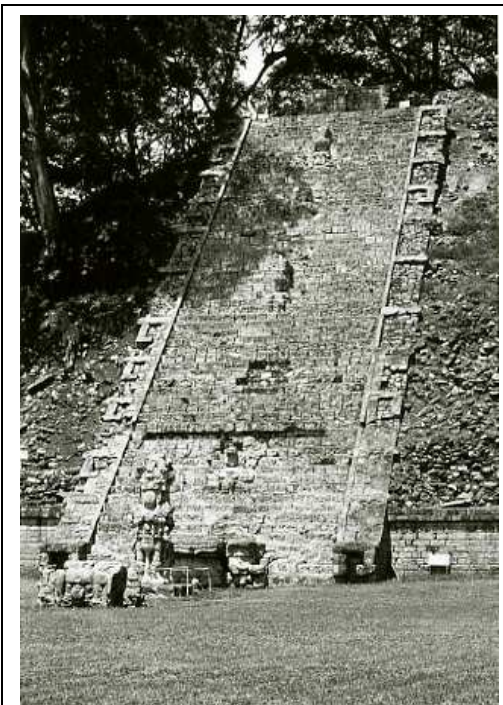

29 juillet, 1978. Copán Honduras. $(D S T, 7 ; P T, 46)$ (DST, 17-20). Il s'agit là d'un instant singulier et particulièrement dense, que l'auteur nomme «l'instant panique » dans la préface du livre Dans la maison du sphinx. C'est un moment où le sujet est en face d'une chose constamment représentée, ce qui fait que dans l'instant de la perception s'interpose inconsciemment tout l'imaginaire culturel lié au monument avec ses divers images et écrits. Pour Dominique Kunz Westerhoff, c'est un moment privilégié qui révèle comment la prise de vue est imprégnée de l'imaginaire et comment elle ouvre par un jeu de coïncidences et d'écarts un espace d'analogies, un lieu qui produit du métaphorique 5 . L'escalier de Copán est également symbolique, il figure le temps.

De l'ensemble il ne reste que l'escalier et suffisamment du sanctuaire pour qu'on voie bien à quel point de folie et de beauté inouï on a atteint là entre le $\mathrm{VI}^{\mathrm{e}}$ et le $\mathrm{VIII}^{\mathrm{e}}$ siècle de notre ère. [...] Il y a 63 marches de pierre dont les contremarches sont tout entières occupées par des hiéroglyphes mayas, dont on sait la propension fâcheuse et merveilleuse qu'ils ont à ressembler à des visages ronds de profil. Ce sont donc des textes qui sont des visages d'hommes et pourtant ils figurent en fait, des dates, des kyrielles de mots imagés trépidants qui se courent dans le dos et racontent des dates au milieu des forêts les plus denses et les plus chaudes du monde, [...] Un texte entier dont le langage, assez perdu pour qu'on ne le déchiffre jamais complètement [...]. (DST, 18-19.)

\footnotetext{
${ }^{5}$ WESTERHOFF KUNZ, Dominique, Op. cit., p. 111-134.
} 
Les textes des dépôts exploitent ligne après ligne l'écart entre les ancrages temporels, en comprimant des dates évoquées par le texte, la date de la genèse du texte originel, et la date de son dépôt dans l'antéfixe. Ce mouvement est mis en évidence dans le dernier dépôt intitulé « Je vous dois la vérité en littérature et je vous la dirai ». Il contient des « Notes et commentaires » comme le dépôt « Notre Antéfixe », mais, en plus de cela, jusqu'à la ligne 55, l'auteur indique le jour où il a «déposé » le texte. Les indications temporelles révèlent que l'écriture s'est effectuée dans un ordre chronologique (en tout cas jusqu'à la ligne 55) entre le 16 décembre 1978 et le 19 février 1979. À une journée peut correspondre une à huit ligne, et des intervalles irréguliers séparent les dates, un écart qui peut aller d'un jour à deux semaines. Une surimpression se crée alors entre les dates de création et les textes qui mentionnent des dates. C'est le cas par exemple dans la ligne 26 :

ouvert en 1951 un cimetière de poissons détruit aussitôt apr ${ }^{26}$

La note précise que la ligne est déposée le samedi 13 janvier 1979, comme celle qui la précède et celle qui la suit, mais la note renvoie aussi à un autre temps, celui de la $\mathrm{I}^{\text {re }}$ dynastie Égyptienne, puisque le texte prélevé parle d'une découverte de momies d'oiseaux datant de cette époque. La même bribe de phrase renvoie alors à des dates différentes (1951, 1979, env. 3150 av. J.-C.), comprimées et imprimées les unes sur les autres, ce qui donne du vertige si l'on imagine les intervalles de temps qu'elles supposent. Le temps devient imbriqué et l'écriture s'y oppose, comme le remarque Denis Roche : «Le Temps est un leurre. Et l'Art, qui est un doute jeté sur la Réalité, l'affronte » $(D L, 62)$. Par l'intensité de la compression du temps ${ }^{6}$ qui s'opère au fil de tout le livre, le temps et l'ancrage nécessairement autobiographique de l'acte devient ambigu et impossible à retracer :

Et mon temps à moi devenu insaisissable, comme un orvet, comme une couleur, puisqu'il est fait de tous les temps des autres, et qu'au fond je suis là quelque part $[\ldots](D S T, 16)$

Ce principe de marquage concerne d'ailleurs toute la construction du livre, car la table de matière indique également les dates de composition des 19 dépôts (du 9 novembre 1975 au 12 juillet 1979). Dans le dernier dépôt, la note de la ligne 55 précise que le fait de dater les dépôts rejoint sa pratique de marquage des photos par les légendes:

\footnotetext{
${ }^{6}$ Les notes des dépôts n'indiquent pas les lieux, mais on en trouve abondamment dans le corps du texte, ce qui provoque également une sorte de compression des références spatiales sur la page.
} 
Dans les deux cas, il s'agit d'un avertissement : sans identité, ni temps, il n'y a pas de littérature. Et pour ce qui est du choix de toutes ces lignes de textes, par un effet de compression et de peur sans doute, l'identité et le temps se retrouvent, ils sont le même poids qui écrase et terrorise l'horizon de ces feuilles, de ce chant d'amour. (DST, 228)

Toutefois, le temps ne se réduit pas simplement à la mélancolie ou à la terreur face à son écoulement et sa fin inévitable, car la note se termine sur un futur : «Cette ligne 55 concerne un site sur lequel nous nous retrouverons le lundi prochain, en fin de matinée. Dans un mois exactement » (Ibid.). La pratique de la photographie n'est pas seulement liée au présent en fuite, toujours tiré vers le passé et associé à la mélancolie du deuil, mais aussi à l'anticipation de son écoulement qui rend possible l'enregistrement de l'instant pour le conserver (même si sa signification est éphémère et énigmatique). C'est que la course se fait à rebours, car le fait de se projeter déjà sa fin, permet de fixer le présent pour en garder quelque chose, qui ne sera certainement qu'un souvenir, et non la réalité, mais la preuve d'équilibres et de beautés momentanés : «Je crois que la photographie est empreinte de profondeur [...] due à la rencontre du Temps et du $\mathrm{Beau}^{7} »$.

L'emploi du mot «postillon » à propos de la mémoire dans La disparition des lucioles contient également l'idée de projection vers l'extérieur.

Je me dis aussi que ces photos sont comme des postillons de la mémoire, un léger bombardement aérien qui précède chacun de nous dans le courant de sa phrase infinie, au-delà de la mort des autres. $(D L, 164)$

L'ancrage temporel permet d'insérer un mouvement, vers l'arrière ou vers l'avant, un intervalle qui devient un lieu de liberté et d'envol. C'est le même mouvement et la même liberté que confère la prise de vue au déclencheur à retardement ${ }^{8}$. C'est l'intervalle entre les dates des dépôts, entre les prises de vues instantanées. «C'est le maximum de liberté dans le minimum de temps ${ }^{9}$.» Il s'agit d'un mouvement imaginaire, que le lecteur doit retranscrire, mais qui se rapproche de l'effet cinématographique et du rêve de s'inscrire dans la durée.

Le cinéma est animé, les gens bougent, ils sont vivants, sur une photo ils sont morts, jeunes, beaux, bien photographiés, mais ils sont arrêtés, au cinéma ils se déplacent, ils parlent, c'est

\footnotetext{
${ }^{7}$ ROCHE, Denis, Conversation avec le Temps, Paris, Le Castor astral, 1985, p. 46.

${ }^{8}$ Dans un Entretien avec Gilles Delavaud en 1978 Denis Roche parle du «fait qu'ayant provoqué la surtension du temps et de l'espace en chargeant l'appareil, en l'armant, et en armant en plus le déclencheur à retardement, on a 30 secondes pour se reposer à l'intérieur de ça : 30 seconde de vol. » $(D L, 86)$

9 «Entretien avec Denis Roche », Prétexte 21/22. Propos recueillis par Stéphane Baquey :

http://pretexte.club.fr/revue/entretiens/entretiens fr/entretiens/denis-roche.htm (consulté le : 25/05/2007).
} 
prodigieux. Au cinéma ils sont horriblement beaux et il leur arrive des histoires magnifiques. Le seul art qui rend immortel, c'est le cinéma. Avec la photo, on montre, on fixe et on perd le temps. J'ai abandonné l'autoportrait que je pratiquais au retardateur pour me laisser le temps d'entrer dans la photo. Ce n'est plus la peine, je m'efface devant le temps, il est bien plus fort que nous. ${ }^{10}$

Entre deux photographies, entre le cliché et le texte, ou entre deux textes qui dialoguent se crée un écart temporel qui permet de reconstruire le mouvement, un non-lieu, où le temps s'efface.

La photographie est la rencontre d'un temps qui passe sans s'arrêter et d'un temps qui ne passe pas, qui ne ressemble à rien parce qu'il ne nous appartient ni de le matérialiser ni de le commenter. $(B M, 7)$

Les récits photographiques qui se mettent en place dans Notre Antéfixe, ou l'album Les preuves du Temps, s'organisent dans un ordre non-chronologique qui se rapproche du rythme de la vie avec ses accélérations et ses ralentis, mais qui reflète aussi le temps discontinu de la mémoire.

10 «Denis Roche. Les temps du photographe», entretien réalisé par Pascale Mignon et Marina Stéphanoff, $O p$. cit., p. 88. 


\section{VIII.6. Poésie et photographie en mouvance}

Les pratiques liées à la temporalité ont pour objectif d'insérer le mouvement et la durée dans le poème, mais plusieurs procédés visent à donner un effet de dynamique à l'œuvre. C'est déjà l'enjeu de la mise en série des poèmes. Comme le remarque Christian Prigent :

La série supprime l'investissement fétichiste sur le «poème» comme produit ponctuel, fini. Elle expose le procès de production, le travail, dans leur mouvance, des marques de la signifiance, leur transformation, leur disparition, leur résurgence - en somme : leur dynamique ${ }^{1}$.

La création du texte suit le mouvement de l'expérience, les techniques utilisées se mettent en place progressivement. C'est ce que souligne Jean-Marie Gleize par rapport aux Dépôts de savoir et technique :

$[\ldots]$ cette «technique » d'écriture, [...] est préparée et comme prévue dans son travail antérieur, et où d'autre part l'examen, dans leur ordre chronologique, des différents textes parus sous ce titre montrerait comment la formule s'est progressivement modifiée, définie, par étapes et découvertes successives, s'imposant dans le mouvement même de l'écrire, selon le rythme ou le vécu scandé d'une expérience. ${ }^{2}$

Suivant le flux du vécu et de l'expérience, les techniques élaborées sont non seulement reprises d'un poème à l'autre, mais transposées à partir du texte à la photographie et vice versa, ce qui provoque des effets de miroir entre les textes et les photos, comme par exemple dans les poèmes de la série «Les tentations de Francis Ponge » dans le recueil Le mécrit ${ }^{3}$ et les photos du chapitre «Comment j'ai écrit tous mes livres» dans La disparition des lucioles.

\footnotetext{
${ }^{1}$ PRIGENT, Op. Cit., p. 46.

${ }^{2}$ GLEIZE, Jean-Marie, Poésie et figuration, p. 252-253.

${ }^{3}$ Une note de la rédaction en début de la série avertit le lecteur que la disposition typographique fait référence à «L'araignée mise au mur», dans sa version dessinée par André Beaudin: «L'araignée publiée à l'intérieur de son appareil critique : F. P., ou la résolution humaine, par Georges Garampon », Paris, J. Aubier, 1952. (PI, 580)
} 


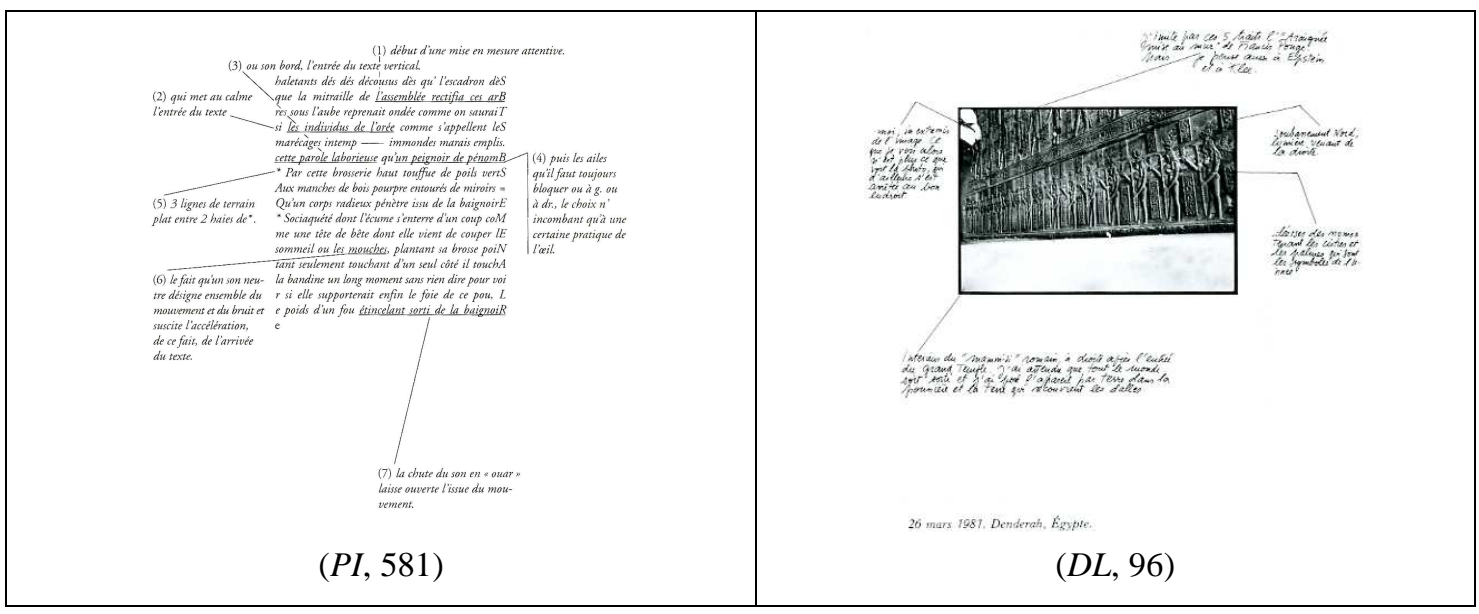

Dans le poème, les indications en marge sont des textes critiques, des explications partielles du choix de la mise en forme. Dans la photo, le texte juxtaposé retranscrit les circonstances de la prise de vue, les choix qu'a fait le photographe et le dispositif imaginaire auquel elle est liée, c'est-à-dire à quoi le photographe a pensé en prenant la photo (ou au moment d'écrire dessus le texte). Le texte constitue une aide à la compréhension de la photo. Dans le cas de la série de poèmes, l'explication devient de plus en plus obscure, jusqu'au point où l'on ne puisse plus distinguer l'explication en marge du corps du poème $(P I, 585)$. En ce qui concerne la série de photo, dans $L a$ disparition des lucioles, les textes restent plus ou moins explicatifs, mais dans des publications ultérieures, certains deviennent également énigmatiques et se chargent d'une signification précaire (par exemple, le cliché qui clôt les actes du colloque L'un écrit, l'autre photographie, p. 300). Les indications hors texte permettent également de faire basculer le mode de lecture : elles brisent en effet, les conventions de base de la lecture. Il faut tourner la page pour pouvoir lire le texte dans le bon sens (PI, 584), et il en va de même pour la photographie : pour lire l'image et le texte il faut retourner le livre de 180 degré $(D L, 93)$. Par ailleurs, plusieurs clichés qui représentent des réflexions sur des surfaces de verre, ou des flaques d'eau sont publiés à l'envers, ce qui contribue à en faire des images dérangeantes, dotée d'une touche de surréel, car le cerveau ne sait pas à première vue comment interpréter les images et elles provoquent un sentiment d'étrangeté.

Dans l'album intitulé Les preuves du temps, c'est la technique poétique utilisée dans Dépôts de savoir \& de technique qui est appliquée à l'ensemble du livre 
photographique 4 . Déjà dans Notre Antéfixe nous l'avons vu l'effet du brouillage chronologique, qui se repose sur un effet visuel inconscient. Dans Les preuves du temps, cet inconscient visuel est convoqué par le recours aux mêmes images, par les pages blanches intercalées et les images successives qui sont disloquées l'une de l'autre dans le parcours imposé de la mise en page. A première vue, la suite des clichés semble s'organiser par ordre chronologique allant du 5 mai 1970 jusqu' au 6 avril 2000, mais cet ordre chronologique est à plusieurs reprises contrarié pour laisser la place à la narrativité ou à un effet visuel, des formes se trouvant rapprochées se mettent à dialoguer. Ainsi à la page 50, 51 et 52, le temps se met à osciller du 20 avril 1979 au 19 avril, puis du 25 juillet au 21 juillet inscrivant les images du couple dans un va-et-vient temporel. Comme dans le cas des dépôts, dès qu'une continuité logique s'installe (chronologique ou narrative), elle est entrecoupée soit par une image qui déroute par son thème ou par une page blanche, soit par un cliché qui bouleverse l'ordre chronologique de l'ensemble. Les prises de vue au même endroit mais à des années d'intervalle reviennent en boucle dans le livre. Le cliché qui s'inscrit chronologiquement dans l'album, est reproduit en grand format sur une page entière, tandis que ceux qui lui font écho se situent en petit format sur la page qui précède ou qui suit (voir les légendes entourées de vert foncé, bleu turquoise, jaune et violet dans l'annexe $\left.n^{\circ} 6\right)$.

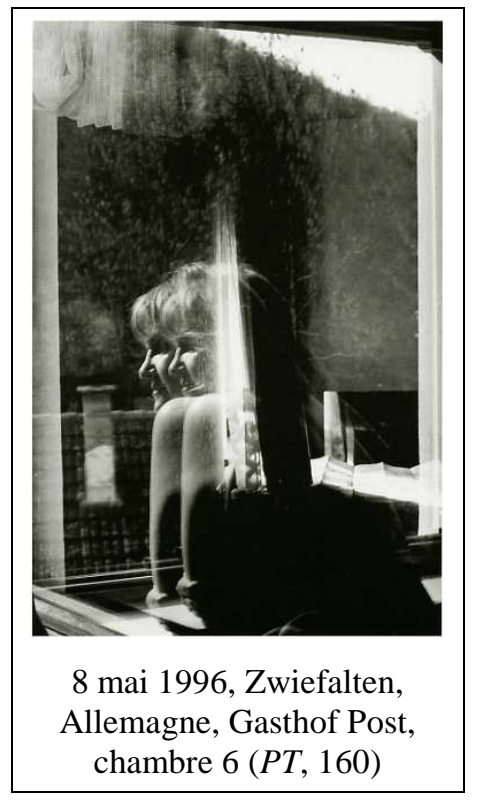

La taille du cliché varie également pour conférer une importance inconsciente à ceux qui sont de taille plus grande. Les clichés sur la couverture se retrouvent ainsi à l'intérieur du livre, en petit format (p. 93) et en grand format (p. 159-161); leur répétition et le grand format semble indiquer que le livre constitue comme une suite à Notre Antéfixe, un marquage du territoire amoureux comme un des trois clichés (ci-contre) le suggère avec la carte étalée sur le lit qui se fond dans la figure de la femme dédoublée dans le vitre de la fenêtre. D'un bout à l'autre du livre, les images se font écho (thème, forme, taille, procédé) ce qui crée un

\footnotetext{
${ }^{4}$ Voir l'annexe ${ }^{\circ} 6$ à la page 434 où les légendes sont coloriées de sorte qu'à chaque année correspond une teinte spécifique, ce qui révèle les fluctuations temporelles dans la mise en page.
} 
rythme particulier, un chant lyrique en image, qui suit le parcours et le rythme de la vie du couple.

Les techniques développées sont transposées d'une série à l'autre, d'une pratique à l'autre (de l'écriture à la photographie et vice versa), elles sont reprises dans des ouvrages ultérieurs, et un mouvement de transposition et de migration se crée dans l'ensemble de l'œuvre. Des textes réapparaissent ainsi d'une publication à l'autre. La disparition des lucioles est un livre entièrement fait d'articles déjà parus (à l'exception de trois chapitres sur les dix-sept) et remanié au sein du livre pour offrir un nouveau parcours ; mais c'est également le cas du livre Dans la maison du sphinx. Les titres migrent aussi entre les livres, s'accolant tantôt à des textes, tantôt à des photos. C'est le cas de «Dans la maison du sphinx », qui est le titre d'un livre et le titre d'un chapitre d'Ellipse et laps qui contient des photos, ou encore « Le surlendemain du style » qui est à la fois le titre du chapitre dans La disparition des lucioles où figure le journal intime construit à partir de textes et de photos, et le titre du dépôt $\mathrm{n}^{\circ} 16$ dans Dépôt de savoir \& de technique (p. 185-192).

Les photos publiées dans tel ou tel livre sont à leur tour reprises et réinsérées dans un nouveau contexte dans les nouvelles publications. C'est le cas par exemple de la série faite à Belle-Île, le $1^{\text {er }}$ juin 1979, dans le jardin d'Hubert Damisch. Initialement publiée dans le magazine «Furor » $\mathrm{n}^{\circ} 1$ en 1980 sous forme de huit clichés, puis dans $L a$ disparition des lucioles (1982), elle se réduit à quatre clichés insérés dans un chapitre intitulé «Hommage à Wittgenstein » (voir ci-dessous). Dans Ellipse et laps (1991), nous en retrouvons deux clichés dans le chapitre «Dans la maison du sphinx » (p. 130), et enfin dans Les preuves du temps (2001) figure une seule photo de la série (p. 53), mais redoublé par un contact successif pris au même endroit, vingt-deux ans plus tard (le 27 août 1997, p. 169).

La série telle qu'elle se trouve dans La disparition des lucioles constitue une mise en abîme spatiotemporelle. Les photos sont prises avec un appareil 24x36 dont l'image a une forme rectangulaire et un appareil 6x6 dont l'image a une forme carrée. Sur la première photo, prise au $6 \times 6$, nous voyons un paysage, un passage dans un hallier, les contours d'un bâtiment ou mur en pierre, et l'appareil 24x36 sur un trépied. Le format rectangulaire de la seconde photo suggère qu'elle a été prise par l'appareil qui figurait sur la première photo et elle montre le 6x6 sur un trépied à l'emplacement où la première photo a été prise, ce que suggère le décalage progressif vers l'arrière. Le jeu de 
la prise de vue de l'appareil avec lequel la photo précédente a été prise se répète encore deux fois, mais il pourrait se répéter jusqu'à l'infini. L’important est l'abîme qui s'ouvre dans l'entrelacement des photos, abîme d'espace et de temps. Abîme qui est peut être reconstitué par l'imagination du lecteur/spectateur.

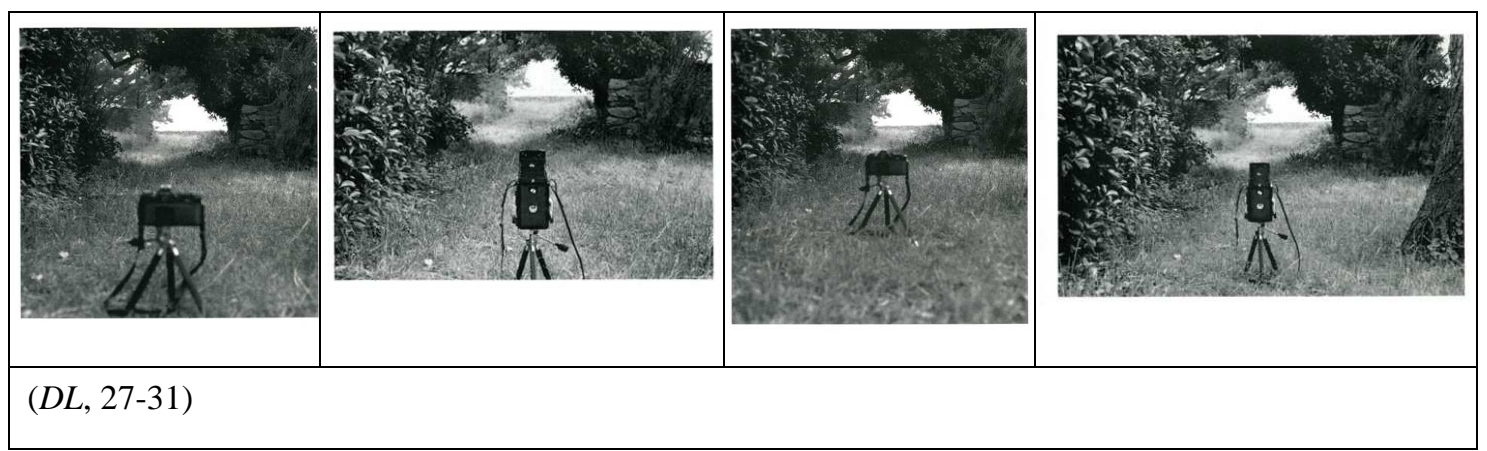

La version publiée dans Ellipse et laps consiste en deux contacts successifs pris par l'appareil 6x6 (ce qu'indique le format carré) et qui montrent le même appareil 24x36 mais déplacé dans le cadre (ci-contre).

Dans cette configuration, la circonstance de la prise de vue, telle que la suite narrative des quatre clichés le suggérait, se trouve modifiée. L'abîme de temps et d'espace se joue uniquement sur cette pellicule, provoquant une compression du temps, car le temps qu'il a fallu pour déplacer l'autre appareil ne plus être reconstitué.

Dans Les preuves du temps (voir ci-dessous à la page suivante), on retrouve à la page 53 , une photo qui provient de la série (probablement la même que la première des deux publications précédentes, mais en nouveau tirage, ce qui

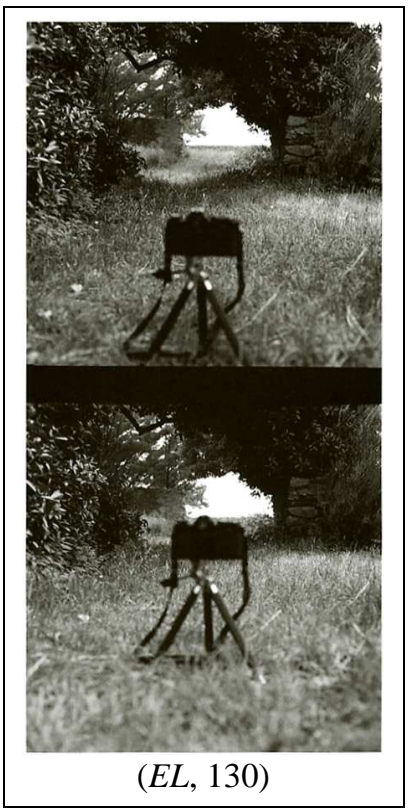
expliquerait le léger décalage), ainsi qu'à la page 169, un contact successif dont les deux clichés se reflètent en miroir inversé. L'écart de temps qui était de quelques secondes dans les séries précédentes se rallonge de vingt-deux ans (entre le premier cliché à gauche et le contact successif de droite), et plusieurs changements sont visibles sur les clichés de 1997 : l'appareil 6x6 est identique à celui qu'on voit dans $L a$ disparition des lucioles en 1979, pris par un appareil 24x36, mais les plantes ont poussées, modifiant la forme du couloir entre les haies; la technique du contact successif modifie le sens de l'image mettant l'accent non plus sur l'abîme mais sur l'image comme surface qui se prête à des jeux de forme (voir entre autres : le 
parallélogramme formé par les deux arbres ou celui dessiné au sens inverse par l'outil de jardinage).

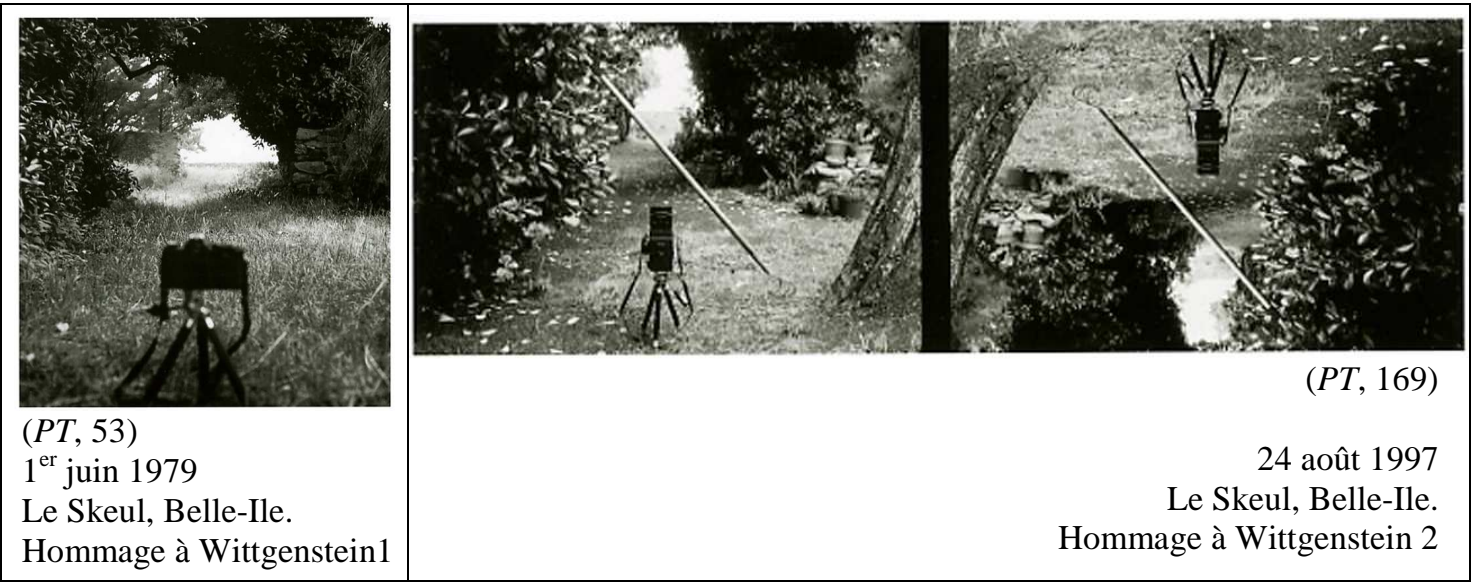

Selon Luigi Magno, le titre de la série de 1982, «Hommage à Wittgenstein », permet d'interpréter les clichés à la fois comme « un espace critique et un outil logique », où le langage est le premier visé.

Wittgenstein dans le Tractatus logico-philosophicus (1921) distinguait parmi les propositions linguistiques celles qui ont un caractère factuel, et celles qui ont une forme logique. Les propositions factuelles décrivent un état du monde, elles disent le monde non pas sur la base d'une relation au monde, mais sous une forme logique, une structure. $\mathrm{Au}$ contraire, les autres propositions sont des propositions logiques qui ne représentent pas le monde, mais représentent les qualités du langage.

Les propositions logiques montrent, donnent à voir une structure du langage que le langage même ne peut pas exprimer. Penser que le langage puisse exprimer les règles qui lui permettent de s'organiser dans des formes logiques (des structures), équivaudrait à penser que une sortie du langage hors lui-même (et plonger ainsi dans la métaphysique). Par analogie, le but de la poésie est de montrer, donner à voir une nouvelle organisation du langage (poétique), qui est à la fois son matériau et son outil. Le poème ne doit pas dire cette forme logique, il doit la montrer. ${ }^{5}$

Le sens global du monde, et la situation du sujet dans le monde ne peuvent être décrits par des propositions factuelles, ainsi «l'éthique, l'esthétique, la métaphysique ne peuvent donner matière à une expression véritable ; et philosopher, c'est finalement parvenir à reconnaître l'obligation du silence ${ }^{6} »$. Au-delà de la forme logique que la lecture de Luigi Magno souligne dans l'œuvre de Wittgenstein, il faut rappeler l'intérêt

\footnotetext{
${ }^{5}$ MAGNO, Luigi, Dialectique(s), Op. cit., p. 162.

${ }^{6}$ GRANGER, Gilles Gaston, s. v. «Ludwig Wittgenstein », Encyclopédie Universalis (consulté le : 23/03/09) : http://www.universalis-edu.com.scdbases.uhb.fr/article2.php?napp=\&nref=C030040.
} 
du philosophe pour les images. Il compare justement les propositions minimales à des images. Dans le livre intitulé Investigations philosophiques, qu'on nomme la deuxième période de la philosophie de Wittgenstein, il dépasse une première unité de signification qui résidait dans la forme logique d'une proposition atomique pour la remplacer par les règles d'usage, les actions que provoquent les signes à l'intérieur d'un jeu de langage.

Je vois, par exemple, une photographie et dis : «Il doit donc y avoir eu un siège là », ou encore : «De ce que l'on voit ici je conclus qu'il y a là un siège. »C'est une inférence ; mais pas une inférence de logique. Une inférence est le passage à une assertion : donc également au comportement qui correspond à l'assertion. «Je tire les conséquences » non pas seulement en mots, mais également en actions. ${ }^{7}$

Créer un jeu de langage pour Wittgenstein, c'est imaginer le fonctionnement d'un système symbolique fabriqué de manière artificielle, une structure qui néanmoins constitue un mode de communication complet en lui-même.

De tels jeux ne sont pas des modèles abstraits plus simples, imitant des aspects du langage naturel (à la manière dont les schémas mécaniques du physicien simplifient les phénomènes complexes). Ce sont des modes d'expression différents qui, «par comparaison», doivent «éclairer les faits du langage naturel » (Investigations philosophiques, $\S 130){ }^{8}$

Dans la seconde partie des Investigations, ajoutée par les éditeurs, Wittgenstein analyse des problèmes relatifs à la perception et met l'accent sur l'expérience.

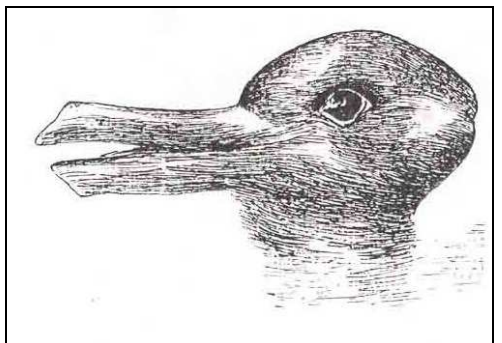

En s'intéressant comme il le fait aux aspects (voir une figure tantôt comme un lapin, tantôt comme un canard, par exemple), à l'expression ou aux «expériences» dont les mots, voire la signification, sont apparemment l'objet, Wittgenstein s'attaque à des questions qui lui permettent d'étendre les analyses consacrées aux règles ou au rôle des règles. ${ }^{9}$

La perception est liée aux expériences, quand on voit quelque chose on le voit toujours comme quelque chose, déjà intégré dans une interprétation. Dans le cas de l'illusion optique, on voit l'image tantôt comme une chose, tantôt comme une autre. Dans le cas des photographies, on perçoit déjà ce qui est représenté comme l'objet lui-même.

[...] nous regardons la photographie, le tableau sur notre mur comme l'objet lui-même (homme, paysage, etc.) qui est représenté sur eux (Wittgenstein, 1961, § 486). ${ }^{10}$

${ }^{7}$ WITTGENSTEIN, Ludwig, Tractatus logico-philosophicus, suivi de : Investigations Philosophiques, Paris, Gallimard, 1961. [trad. fr. J. Klossowski] § 486.

${ }^{8}$ http://www.universalis-edu.com.scdbases.uhb.fr/article2.php?napp=\&nref=C030040.

${ }_{9}^{9}$ GRANGER, Gilles Gaston, s.v. «Wittgenstein », Encyclopédie Universalis, Op. cit. L'image provient du site : http://www.illusions-optique.fr/illusions-optique-canard-lapin.html (consulté le : 24/03/09).

10 Cité par Evelyne ROGUE dans son article: «La représentation ou l'ambiguïté du voir chez Wittgenstein » (p.6) publié sur Internet : http://www.univ-rouen.fr/arobase/v6/rogue.pdf (consulté le : 24/03/09). 
La représentation devient créatrice de sens lié à l'expérience.

La question de savoir s'il s'agit d'un voir ou d'un interpréter apparaît par le fait qu'une interprétation devient l'expression de l'expérience. Et l'interprétation n'est pas une expression indirecte, mais son expression première. (Wittgenstein, 1989, § 20). ${ }^{11}$

Les photos de Denis Roche, par leur republication dans de nouveaux contextes, dans de nouveaux livres, créent à l'instar du modèle wittgensteinien un système symbolique dont l'interprétation est liée à l'expérience.

La recontextualisation est inhérente au principe de la photographie, qui à partir d'un réel unique crée des interprétations singulières. Elle peut se répéter à l'infini, fabriquant alors du sens à l'infini :

[...] un appareil photographique ne crée pas une situation ou un geste ou un objet donnés, mais, les « cadrant », il les oblige, comme lors d'une répétition, à exister à nouveau et, ce faisant, à dire sans doute quelque chose de nettement différent de ce qu'ils disaient avant l'irruption d'en face de l'appareil capteur qui, pourtant, ne met en scène qu'un seul réel. $(D L, 55)$

C'est ce principe de la photographie qui est transposé dans les Dépôts de savoir \& de technique, ce que Denis Roche signale par les mots suivants :

Répéter à l'infini, en étant libre de m'arrêter à n'importe quel moment, une même longueur de texte - non pas un même texte, mais un même nombre de signes, une même longueur d'écriture déjà faite. $(D L, 55)$,

et que nous retrouvons dans le texte du dépôt de Notre Antéfixe ${ }^{12}$ :

ations aux créations, l'une recouvrant l'autre, chaque nouvel ${ }^{190}$

Le même principe gouverne les clichés photographiques qui migrent d'un livre à l'autre, fonctionnant comme des textes, non seulement par leur légende, mais par l'entité iconique et la signification précaire qu'elles prennent en charge. L'objectif est de faire voir des choses que l'on reconnaît déjà, comme le signale la citation empruntée à Jean Paulhan qui figure dans Ellipse et laps : «Comment parvenir à voir du premier coup les choses pour la deuxième fois ? » $(E L, 34)$ il s'agit aussi de transmettre à la fois le principe de sa réalisation et ce qui est intraduisible au niveau verbal. Il se crée ainsi un réseau complexe et métaphorique, un jeu de langage où textes et images dialoguent sans cesse.

\footnotetext{
${ }^{11}$ Ibid., p. 7.

${ }^{12}$ Voir les lignes marquées en violet dans le fragment de Notre Antéfixe inséré à la page 399.
} 


\section{VIII.7.Denis Roche - Conclusion}

Le réseau métaphorique qui constitue un «jeu de langage » autour de la photographie concerne les thèmes que nous avons étudié au cours des chapitres: le sujet et son rapport au monde, éros et le désir comme fondement de l'être, la pulsion de mort et son rapport au temps, l'espace de la représentation et le rôle des machines.

Le dépôt intitulé «Pour saluer Manuel Alvarez Bravo" $»$ pourrait résumer l'activité photo-littéraire de l'auteur car il constitue un microsystème qui rend compte de l'ensemble des enjeux et des thèmes liés à la photographie ainsi que de la construction métaphorique de l'ensemble de l'œuvre.

Les planches du dépôt sont précédées par l'indication de la provenance des textes découpés. Ces textes primaires sont - selon les mots de Denis Roche « défaits », dépouillés de leur linéarité et de leur sens premier, pour qu'ensuite le sens interne de la photographie puisse se révéler sous les mots.

Dès qu'on veut "parler photo", l'écriture se doit d'être défaite de quelque chose qu'il faut envoyer au bain. $(D L, 34)$.

Les trois planches ont tous la même forme carrée d'une photo $6 \times 6$ et comme dans le cas des autres dépôts déjà analysés, les résonances internes, la sonorité, la découpe au milieu des mots, la répétition servent à révéler qu'il s'agit d'un montage, pour créer un rythme accéléré et inquiétant, une danse macabre, qui dans sa forme, sa démarche, son sens déconstruit la signification de la photographie. S'y déploient les principaux thèmes rochiens concernant la photographie: le temps, la mort, le sujet, la machine, éros et la représentation ${ }^{2}$. dans les 3 premiers mois de 1927 la région des Altos et de elles dessinent le fleuve humain, Brecht à propos de 1871. 177, E.J. Bellocq ; 103, E. Erwitt ; 60, Anon., c. 1870 ; Les Kri aul Strand mort hier (les Révoltés d'Alvarado, Mexico 193 Même année, même combat : “ L'ouvrier mort ”, 1934 oui 1934 ! ue le monde est petit " - "Le jour des morts ", 1933 - " Cimet combat, les federales (chapeaux, souliers, couteaux et le miettes de pain dur les enfants pleurent de faim de fatigu famille avec un espace de $3 \mathrm{~m}$ où elle faisait la cuisine o cartouche de 30-30 déjà rare et 15 centavos celle de mause pièce. Qui va payer le prix de la guerre? Malheur aux rich Weston, Arbus, Evans, Bravo, Strand, anon., portr posthume entrée de vagin sun picture calotype victorien anonyme mai de vagin d'ouvrière mauvais tirage cahier Delacroix mais i "L'ouvrier mort ", daté 1934, l'année où Paul Strand tourne ravo! Faut ré-enmatérialiser l'coup d'la photo : casser l't reviens, mon amour, reviens à ce "Portrait posthume " gloir $1^{\text {cr }}$ prix du concours de la fabrique de ciment "La Tolteca " alon de la Plastique Mexicaine. La Eastman House, Rocheste hotographies sera augmentée en 1967 par l'achat de 30 photo " autodidacte en photographie depuis 1923 ", dit l'ambassade.

\footnotetext{
${ }^{1}$ Manuel Alvarez Bravo était un photographe mexicain, dont l'œuvre se rattache au surréalisme. Ce premier dépôt publié a été réalisé à la demande de Georges Bardawill pour l'exposition de Manuel Alvarez Bravo à Paris à la Photogalerie en 1976. (La photographie est interminable, Entretien avec Gilles Mora, Op. cit., p. 25.)

${ }^{2}$ Nous marquons les thèmes de la manière suivante :
} 
Les thèmes évoqués se répètent tout au long des trois poème-images, avec la répétition de certains raccords entre les lignes :

réveil de l'oiseau-tonnerre dans un tintamarre de volcans " Artaud monté c/o les Tarahumaras vers août 1936 pour s'y r "C'est c'que j'nai jamais vu avant que j'reconnais " D. Arbu Photo cadavre de Diane Arbus suicidée le 26 juillet 1971 ovembre 74 : Bravo expose à la surexpo de la Mort au Musée " avandières implicites " - " Échelle d'échelles ", 1931 - " Le "Les accroupis ", 1934 mais faudrait traduire autrement dit 10, D.O. Hill, c. 1845 ; 138, P. Barchan, c. 1925 ; surtout Bech hotography at mid-century ", " La Familia del Hombre ", " The Contretype de " La renommée endormie " pour moi, souviens-to egardons à nouveau, mon amour, la photo de cette femme nue "il ne s'agit pas d'entrer mais de sortir des choses ". Arta ud - mais oui, dans la haute montagne mexicaine août 1936 “Ciguri mourrait s'il n'avait pas moi " - 2000 cristeros re tranchés sur les montagnes de la Colima, mais ça échoue et VIENS MON AMOUR ÉGALE L'CIL DJ PHOTOGRAPHE VIENS MON AMOU he Photographer's Eye, Great Photographers, 100 Photograph $s$ of the Museum of Modern Art of New York, etc. 1975, édit ion, par Friedlander-Wolf, New York, d'un volume in-folio avec 15 photographies. C'est la fin de la page photocopiée " autodidacte en photographie depuis 1923 ", dit l'ambassade.

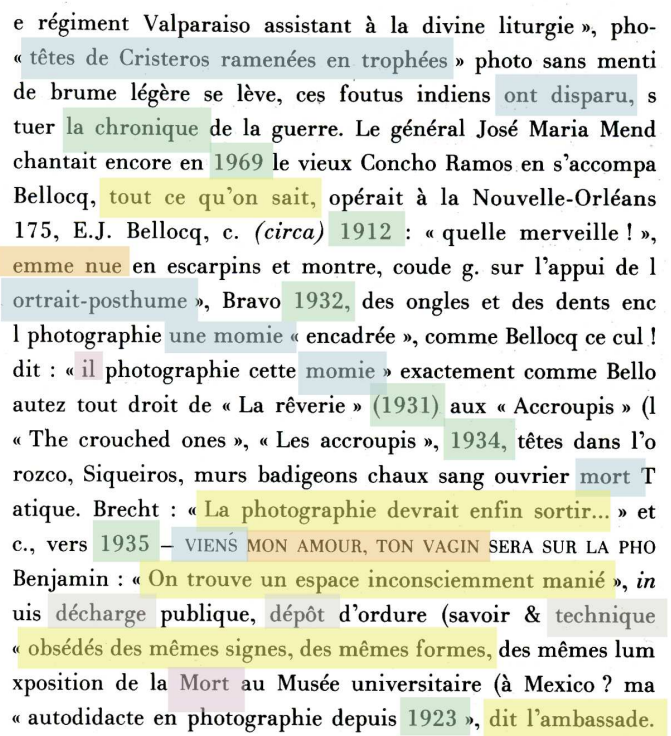

e régiment Valparaiso assistant à la divine liturgie ", pho" têtes de Cristeros ramenées en trophées " photo sans menti de brume légère se lève, ces foutus indiens ont disparu, s tuer la chronique de la guerre. Le général José Maria Mend chantait encore en 1969 le vieux Concho Ramos en s'accompa Bellocq, tout ce qu'on sait, opérait à la Nouvelle-Orléans 175, E.J. Bellocq, c. (circa) 1912 : “quelle merveille!", emme nue en escarpins et montre, coude g. sur l'appui de 1 ortrait-posthume ", Bravo 1932, des ongles et des dents enc l photographie une momie " encadrée ", comme Bellocq ce cul ! dit : " il photographie cette momie " exactement comme Bello autez tout droit de "La rêverie " (1931) aux " Accroupis " (1 "The crouched ones ", "Les accroupis ", 1934, têtes dans l'o rozco, Siqueiros, murs badigeons chaux sang ouvrier mort $\mathrm{T}$ atique. Brecht : "La photographie devrait enfin sortir... " et c., vers 1935 - VIENŚS MON AMOUR, TON VAGIN SERA SUR LA PHO Benjamin : "On trouve un espace inconsciemment manié ", in uis décharge publique, dépôt d'ordure (savoir \& technique " obsédés des mêmes signes, des mêmes formes, des mêmes lum xposition de la Mort au Musée universitaire (à Mexico ? ma " autodidacte en photographie depuis 1923 ", dit l'ambassade.

$(D L, 35-37)$

Selon le poème, la photographie forme un espace «inconsciemment manié », une «obsession » et une technique du désir, où toute signification se défait et se relie pour être recontextualisée («C'est c'que j'nai jamais vu avant que je reconnais »), qui s'inscrit nécessairement dans un dialogue intertextuel et interpictural et, en fin de compte, où l'écriture littéraire fonde le cadre du dispositif qui permet de «sortir des choses ».

C'est encore avec un jeu de mot que Denis Roche désigne l'«appareil» photographique comme «nonpareille» dans le livre Ellipse et Laps. L'expression «nonpareille» comme nom dévoile un «merveilleux fourre-tout» sémantique qui rappelle la précarité de la photo. Le mot «nonpareille» est à la fois un éponyme et un adjectif qui «seul ne veut rien dire ». En fin de compte, ce mot désigne le caractère unique du dispositif : «Comme est inégalable la photographie, comme est sans pareil l'appareil photographique » $(E L, 160)$. La photographie est donc unique dans le sens qu'elle s'ouvre dans une fraction de seconde sur l'infini des combinaisons possibles. 
L'œuvre photographique de Denis Roche permet de reconsidérer son œuvre poétique par des allers et retours. Son geste qui visait la mise à mort de la poésie semble alors comme une action qui assurait en même temps la continuité de la poésie, en dehors du langage et plus proche de la vie. 
ANNEXE $n^{\circ} 5$ : L'évolution vers l'iconicité de recueil en recueil

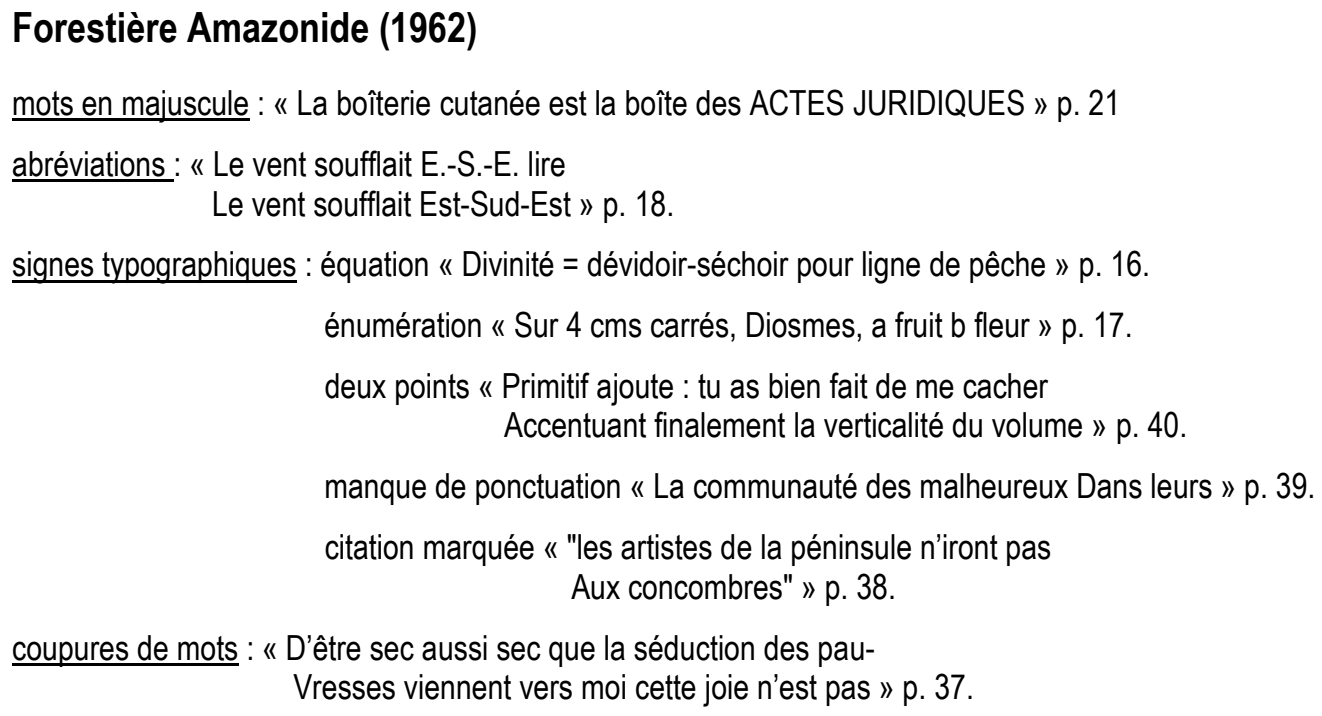

\section{Récits complets (1963)}

signes typographiques : marque de l'inachèvement «Éveille la nature (que deux mois dans le grenier N'aient été que brumes et qu'espaces...) » p. 77.

coupures de mots en fin de ligne : co- Nifère (p. 58); mono- Tonie (p.58); ser- Rées (p. 62); fenê- Tre (p. 75);

coupure définitive : «-grément de la sensation devient ce qu'il avait

Toujours été des prêtres guéris de musique la vertu » p. 136.

énumération énigmatique : "Puis elle commence de sa voix basse :

$$
\begin{aligned}
& \text { "80. } \\
& 100 . \\
& 100 . \\
& 50 . \text { à Zurich pendant l'hiver } \\
& \text { 100." } \\
& \text { Puis elle se dit qu'il était vraiment diffi- } \\
& \text { Cile d'avoir un sentiment social » p. } 89 .
\end{aligned}
$$

abréviation : « "malheureusement dit madame R qui était assise

Sur le siège à côté de monsieur $M$, il découvrit

Des yeux bleus très doux" apparemment la première ॥ $\mathrm{p} .126$.

blanc en début de ligne : "Dieu soit loué de ce que je ne saisis pas très bien pourquoi » p.102.

\section{Les idées centésimales de Miss Élanize (1964)}

poèmes en italiques : toute la série qui porte le même nom que le recueil et qui contient 33 poèmes numérotés (p. 171-203)

coupures de mots en fin de ligne sans continuation dans la ligne suivante :

"De leur cruauté et de leurs sauvagerie se hâta de leur sif-

Préciosité qui se traduisait par un soin extrême des détails » p. 176.

avec jeu sur la sonorité :

«Manquent au moins la volute de leur coquille et l'abon-

La bonde qui a été faite en couleurs par l'ingénieur » p. 186.

coupures de mots qui autorisent une double lecture : der- Nier (259)

abréviation ou faute de frappe : «Qu'il et moi, courbé souci de pudeur (l'r de pudeur) ... à rire aux éclats » (p. 256) 


\section{Éros énergumène (1968)}

traits énigmatiques:

« \qui m’amène en ce lieu qui eut peur a / » p. 293.

« Hors d'elle à lui retourner en dedans l'âme il demande aux passions des seins l'oubli ! » p. 295.

coupures de mots qui autorisent une double lecture :

re- Monte (294) ; im- Portance (297) ; tumul- Tueusement (298) lité- rature (306) ; ef- Face (308) ; pa- Vois (323) ; crépus- Cule (329)

coupure de mot avec le signalement d'un double signifiant possible

«Loin des crues, mais c'est la farce que l'on

Voit mal (les lecteurs) que je vois préc-

Précisément (précocement) les fleurs tumul-

Tueusement en dérive de notre violence. Sensibilité » (p. 298)

la phrase soulignée utilisée comme cadre : p. 320-324

les calligrammes dans « Mémoires méconnaissables » (351-355)

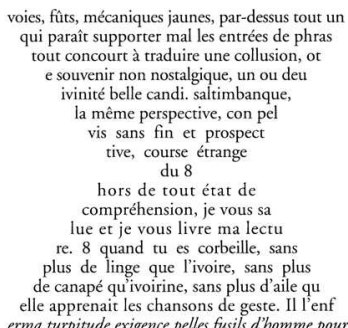

voies, futts, mécaniques jaunes, par-dessus tout un

qui parât supporter mal les entrées de phras

tout concourt a traduire une collusion, of

ivinité belle candi. savien

la même perspective, con pel

vis sans fin et prospect

tive, course érrange

du 8

hors de tout état de

comprehension, je vous sa
lue et je vous livre ma lectr

re. 8 quand tu es corbeille, sans

plus de linge que livoire, sans plus

de canapé qu ivoirine, sans plus d aile qu

elle apprenait les chansons de geste. Ill enf

erma turpitude exigence pelles fusils d'homme pour
les fesses de tourbe de femme. Il n $n^{2}$ paraitra plus...

p.353.

\section{Dialogues du paradoxe et de la barre à mine (1968)}

Poème qui tout au long de la série prend la forme d'une plaque photographique, constitué de mots, de lignes et de blancs :

p. 444. 


\section{Le Mécrit (1972)}

Saint juste ou la précipitation des actions p. 527-539.

Pourtant plus fluides les mots s'enferment étroitement dans le moule et je lui ordonnais chaque fois qu'elle avait la main posée le $t$ itre d'archange de la terreur (sans $\mathrm{T}$, la t ypograpgie va-t-elle aussi se mettre à parle)

Quarte textes p. 543-547.
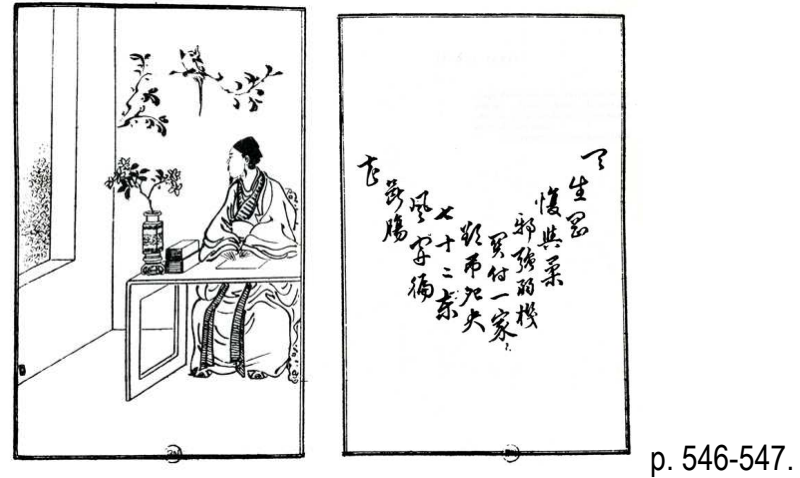

Les tentations de Francis Ponge p. 580-586.

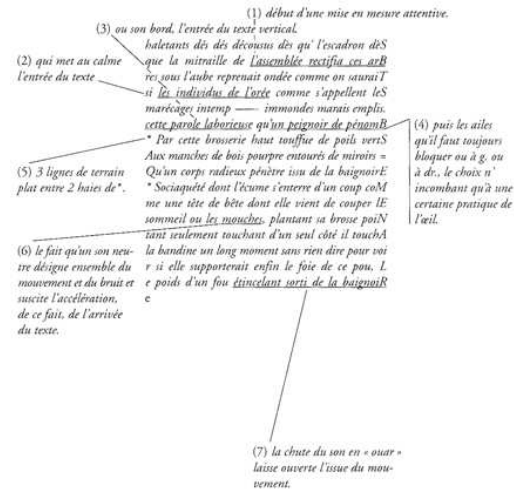

p.581.

Le mécrit p. 589-597.

Inscription 1

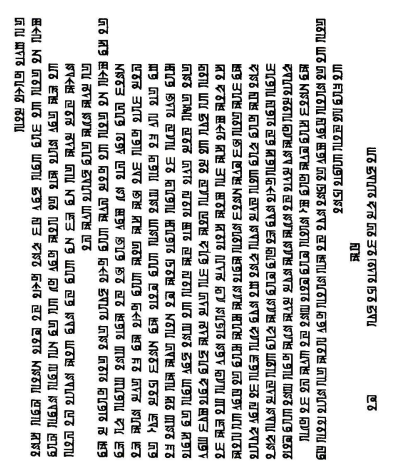

Texte 2

Sans avoir vu écrit, sans un bas de plus\& I leût donné beaucoup pour un pré de plus \& $n$ cill \& quif ait Pangle avec la forte tour lance une $t E$ te a a trait bouffi de colere: imposted pleure \& $T$ endre evidemment 5 fasse a fare heur-queue impO sante les 2 me voient andis que la forme chis $\mathrm{P}$ lus (umposinte tandis quici moim aim te sur l'enceinte je pris les 2 cheveux d'EL par! bride \& meronnant quen fin de journee of il es le con soient là mépiant me voletant autoU $\frac{1}{\mathrm{rde}}$ cette forte tour \& pieu retirant quelque col isero du paysage que je hais $\&$ o loir love o couil leuse le haut de ta jambe vers le con vers tor jE tais.

ove/queue \& a liangle enfilons la forte toU $\mathrm{E}$. 
Pal, Gyöngyi. Le dispositif photo-littéraire en France dans la seconde moitie du XXe siècle Analyse de l'oeuvre de François-Marie Banier, Jean-Loup Trassard, Lorand Gaspar et Denis Roche - 2010 
ANNEXE n ${ }^{\circ}$ : Structure temporelle du livre Les Preuves du Temps
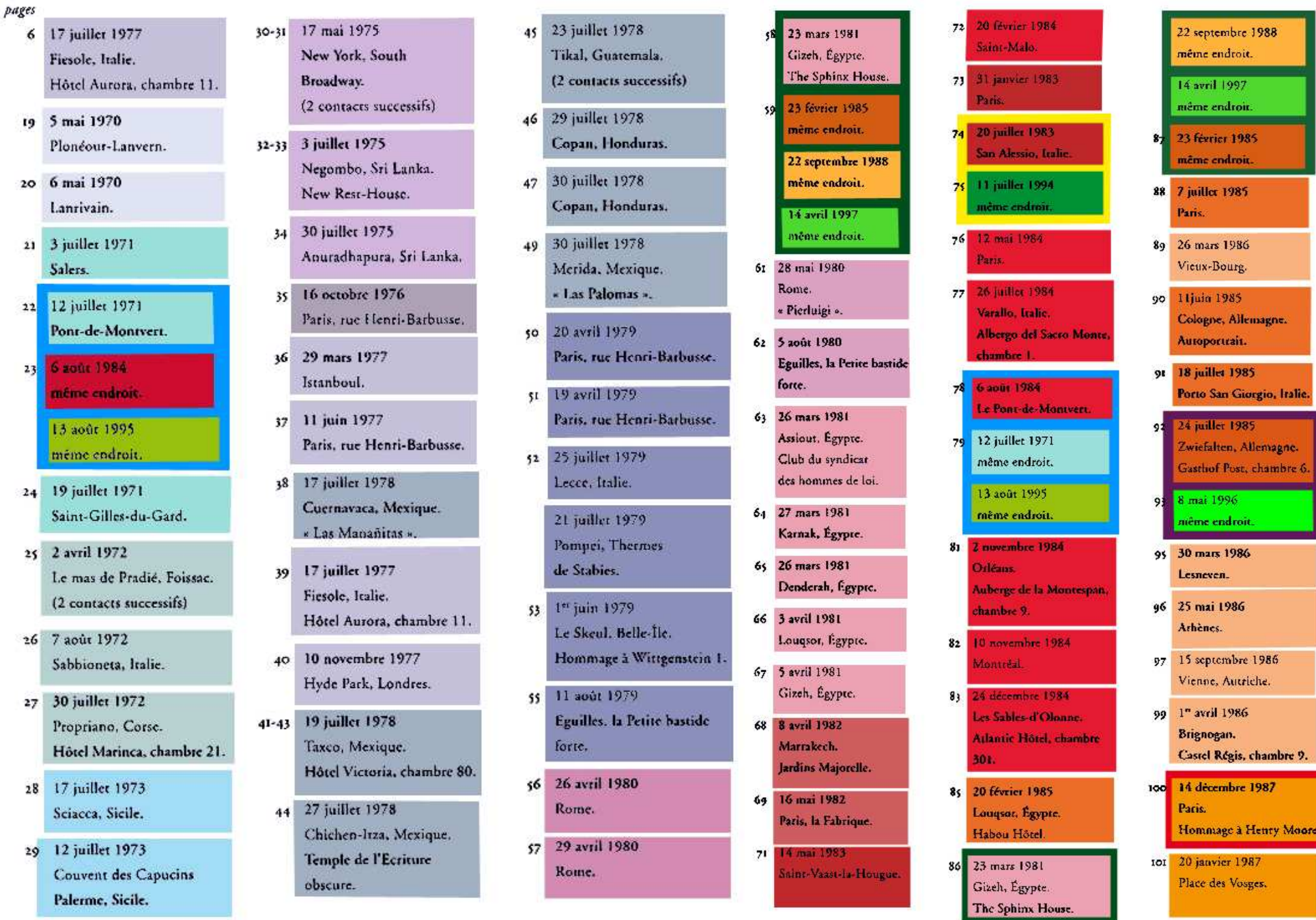

Paris.

8926 mars 1986

11 juin 1985
Cologine, Allemagne. Auroportasi.

9r 18 juilles 1985

Pocio San Giongio, Iralice.

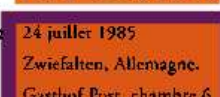

Gasthof Pust, chambre 6 .

8 mai 1996

mième endreit

95 30 mars 1986

Lesnever.

9625 mai 1986

Athènes.

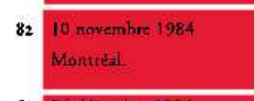

9715 seppermbre 1986

Vienns, Autriclice.

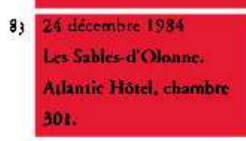

92 1" awril 1986

Brignogan.

Cossel Regis, chambre 9.

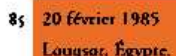

Louquas, Egypre.
Habeu Höel.

100 11 dickembre 1987

Paris

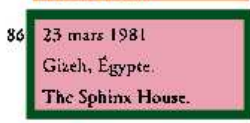

Homnage a Hetry Moore.

10120 jastrice 1987

Place des Vouges.

*Chaque année correspond à une couleur et les photos reprises à l'identique sont entourées d'une deuxième couleur 


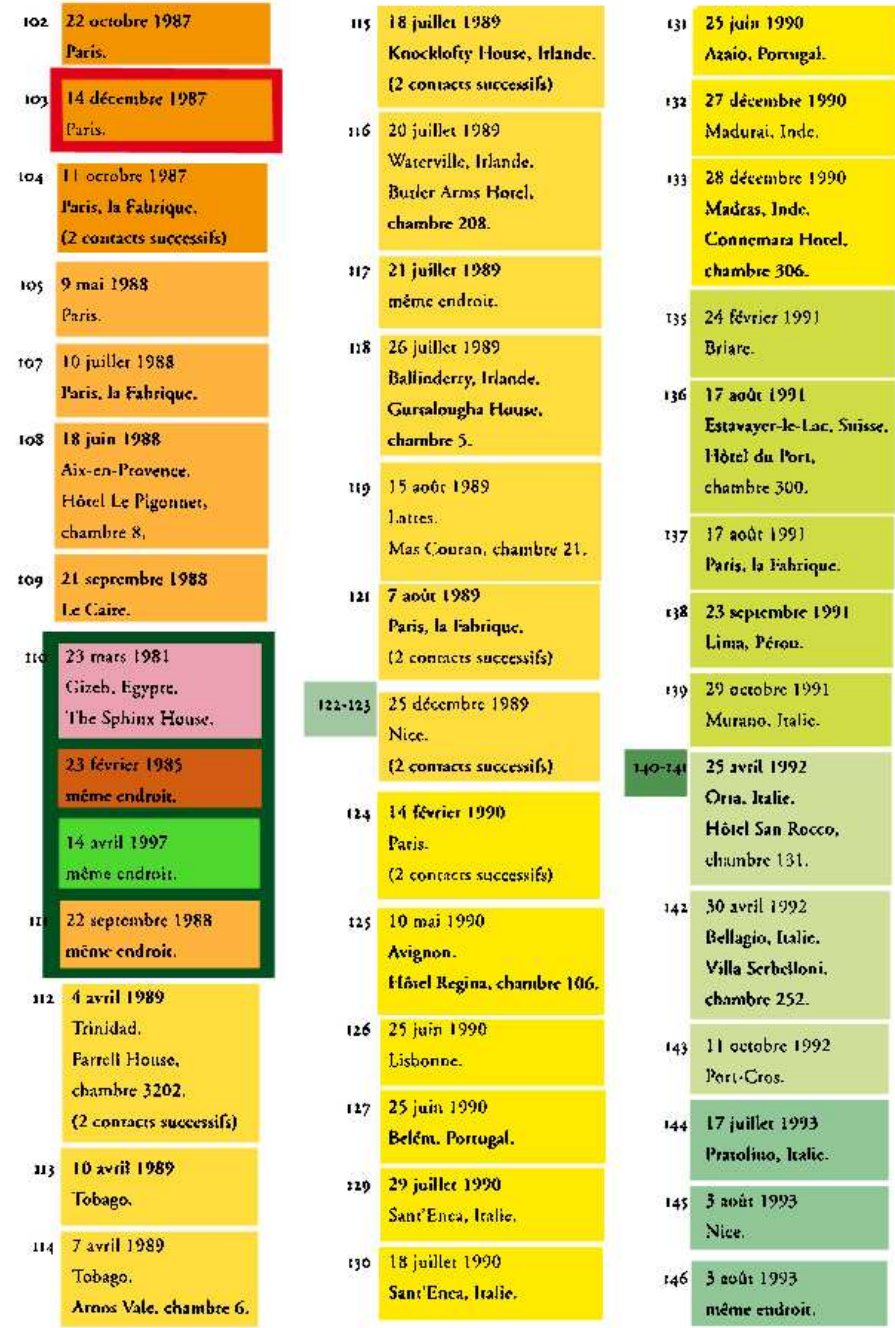
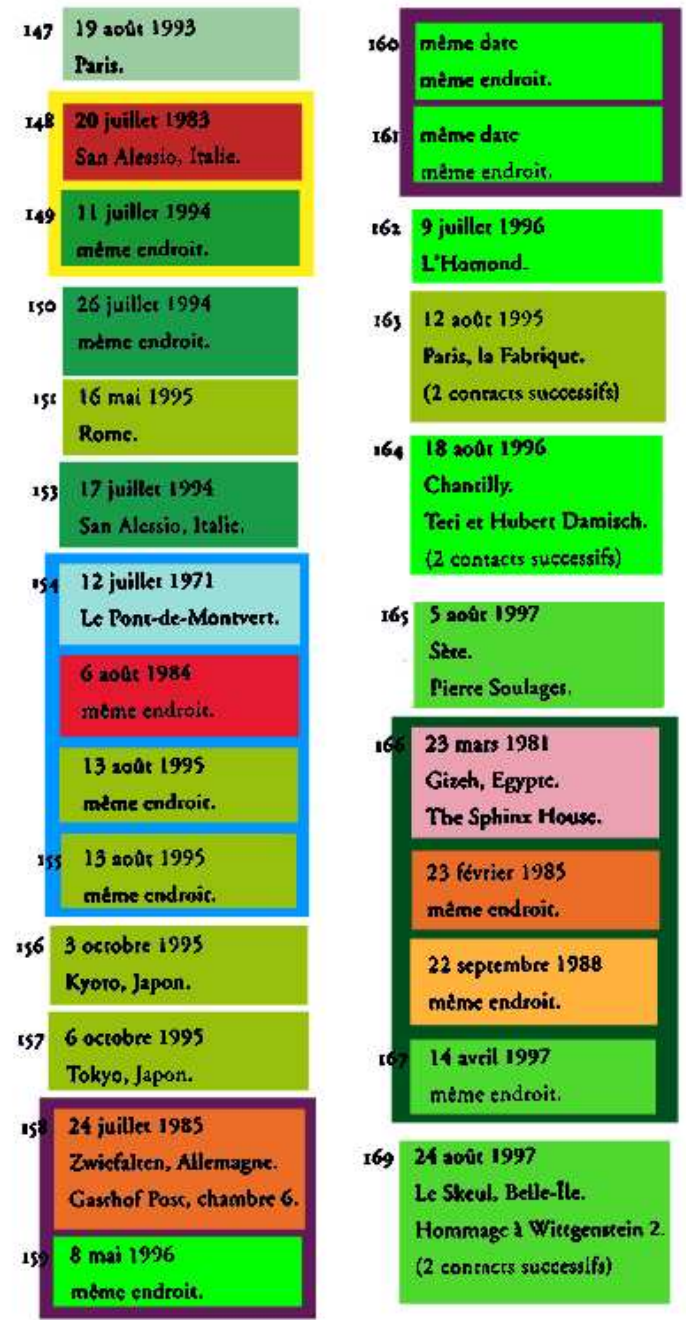

662 9 juiller 1996 L'Hamond.

1631220061995 Paris, lo Fabrique. (2 conraces sucoessifa)

\section{2004 1996}

Chancilly.

Teci et Hubert Damisch.

(2 contaces suecessifis)

16:5 5 aû́r 1997

Stere.

Pierre Soulages

\begin{tabular}{|c|}
\hline $\begin{array}{l}23 \text { mars } 1981 \\
\text { Gizeh, Egypre. } \\
\text { The Sphinx House. }\end{array}$ \\
\hline $\begin{array}{l}23 \text { février } 1985 \\
\text { même endroic. }\end{array}$ \\
\hline $\begin{array}{l}22 \text { septembre } 1988 \\
\text { menxe endroit. }\end{array}$ \\
\hline $\begin{array}{l}14 \text { avril } 1997 \\
\text { mème endroit. }\end{array}$ \\
\hline
\end{tabular}

169 24 soût 1997

Le Skeul, Belle-lle.

Hommage d Wittgenuein 2

(2 conencrs successifis)
17027 decembre 1997

S2ior-Troper.

(2 contacts suecessily)

I71 12 janvier 1998 Paris, lo Fabrique. (2 contracts successifs)

$1 7 2 \longdiv { 9 \text { aril } 1 9 9 8 }$

Paris, la Fabrique.

17) 2 msi 1998

Paris, le Fabrique.

174 15 mai 1998

Paris, la Fabrique.

(2 contacts suecessifs)

175 23 mai 1998

Paris, la Fabrique.

$1 7 6 \longdiv { 2 3 \text { mal } 1 9 9 8 }$

mème endroil.

(2 contacts suocestifis)

17731 mai 1998

Pasis, la Fabrique.

$\begin{array}{ll}178 & 18 \text { juin } 1999\end{array}$

Paris, la Fabrique.

179 1" juillet 1998

Bergerac.

180-183 26 decembre 1999

Villiers.

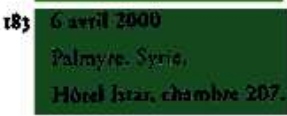




\section{La convergence dans les pratiques des écrivains photographes}

Après avoir étudié l'œuvre des quatre écrivains photographes, François-Marie Banier, Jean-Loup Trassard, Lorand Gaspar et Denis Roche, il se dévoile que malgré les dissemblances de leurs pratiques et de leurs références, leurs œuvres montrent plusieurs points communs.

On trouve tout d'abord chez eux un intérêt général pour l'image, ce qui se manifeste dans la collaboration avec des artistes qui ne sont pas photographes, ou dans l'écriture de préfaces à des expositions ou catalogues d'autres artistes. Ainsi peut-on mentionner chez Banier la préface écrite à Andy Warhol ${ }^{1}$, chez Trassard la collaboration avec des illustrateurs dans ses livres destinés à la jeunesse ${ }^{2}$ et ses livres d'artistes réalisés avec Odile Levigoureux ${ }^{3}$. Chez Lorand Gaspar on peut citer ses livres d'artistes ainsi que ses lectures d'images ${ }^{4}$ dont certains servaient aussi de préfaces. Denis Roche écrit aussi volontiers des préfaces ${ }^{5}$ et des lectures de photographies ${ }^{6}$, mais certains de ses Dépôts de savoir \& de technique dresse aussi le portrait mécanique de peintres (Claude Viallat et Bernard Dufour).

À part cet intérêt pour l'image et l'intérêt particulier pour la photographie, les œuvres photo-littéraires de tous ces quatre auteurs montrent un rapport avec l'autobiographie, même si ce lien est différent chez chaque auteur. François-Marie Banier par sa galerie de portraits d'écrivains et d'artistes fonde ainsi une seconde famille, une famille de pensée à la place d'une famille en chair qu'il ne cesse de critiquer dans tous ses romans. Photographier devient chez lui une pratique pour

\footnotetext{
${ }^{1}$ La préface est disponible sur le site personnel de Banier (consulté le : 10/10/2009) : http://www.fmbanier.com/tx_010 that_little laugh_andy had_0

${ }^{2}$ Il a travaillé notamment avec les illustrateurs suivants : Bernard Jeunet, Florence Euvremer, Patrice Roy, Lise Cour, Thierry Dalby et John Howe. Pour les titres voir dans la bibliographie la section sur les livres pour enfant chez Trassard.

${ }^{3}$ TRASSARD, Jean-Loup, LEVIGOUREUX, Odile, Lettre à la prêle, Cognac, Le Temps qu'il fait, 2006, et Lettre au lin, Cognac, Le Temps qu'il fait, 2006. Voir la présentation de l'éditeur (consulté le : 10/10/2009) : http://www.letempsquilfait.com/Pages/Vitrine/vitrine7.html

${ }^{4}$ Voir l'analyse de ses livres dans le chapitre «Les livres d'artistes et les lectures d'images » à la page 339 .

5 Voir sa préface à John Heartfield (Photomontages antinazis, Le Chêne, 1978 republié dans La disparition des lucioles, Op. cit., p. 123-131) ou à Bernard Pagès (Pagès, surgeons et acrobates, Paris, Galerie Lelong, 1999).

6 ROCHE, Denis, Écrits momentanés, Chroniques Photo du Magazine, City, 1984-1987, Paris Audiovisuel, 1988 ; ROCHE, Denis, Le Boîtier de mélancolie. La Photographie en 100 photographies, Paris, Hazan, 1999.
} 
transcrire le roman que chaque être porte en soi, et cet usage est motivé par une envie très forte de retenir et de conserver les choses, de conserver une trace, un souvenir qui pourra être revisité. «Photographes tous ceux pour qui le souvenir est à penser, à étudier, à revivre ${ }^{7} \gg-$ écrit-il. Dans la quête de l'autre, dans l'amour de la vie, la photographie devient chez lui une manière de vivre.

Chez Jean-Loup Trassard, on ne trouve pas de portrait, pourtant son œuvre s'obstine également à conserver une trace de son milieu natal, pour remémorer le bocage de la Mayenne, l'univers de son enfance, les fermes désormais en voie de disparition suite aux nouveaux modes d'agriculture. Il insiste pourtant sur le fait, que la réalité échappe nos moyens de représentation et que la photographie autant que l'écriture ne conserve qu'une trace lacunaire. La photographie sert plutôt chez Trassard à « taquiner le sens de l'espace chez le spectateur ${ }^{8} »$. Elle joue avec l'illusion de pouvoir remonter le temps, ou entre dans un jeu d'échos multiples et raffinés avec le texte.

Les photographies de Lorand Gaspar sont des clichés pris lors de ces voyages, et témoignent toujours d'un lieu «habité », investi par le poète. Mais au lieu de chercher à garder des souvenirs de ces lieux, il s'agit plutôt d'une quête de l'éternel dans sa poésie tout comme dans sa photographie. C'est la recherche d'un moment de lucidité, d'une vision, d'une beauté qui naît au contact des choses, « dans un moment d'inattention [où] le cristallin se glisse ${ }^{9} \gg$.

On pourrait avancer que l'œuvre photo-littéraire de Denis Roche est plus explicitement lié à l'autobiographie puisqu'il tourne sa caméra vers lui-même et sa compagne dans ses autoportraits à deux, ainsi qu'il publie le livre Légende de Denis Roche, une tentative d'autobiographie en image. Son œuvre, comme celles énumérées dans la partie d'introduction sur «l'autobiographie photo-littéraire », dévoile pourtant l'échec inévitable du projet autobiographique, car elle ne peut que momentanément refléter l'identité dynamique et constamment changeante d'une personne. La photographie se poétise alors en changeant - par son ancrage spatiotemporel - en des fragments visuels d'un chant d'amour qui raconte la vie du couple.

\footnotetext{
7 «La vie de la photo », Rétrospective de 2003, François-Marie Banier, (catalogue de l'exposition, Paris, Maison européenne de la photographie, 26 mars-15 juin 2003), Paris, Gallimard, 2003, p. 334.

8 «Entretien avec Arlette Bouloumié », in L'écriture du bocage : sur les chemins de Jean-Loup Trassard, textes réunis et entretien par Arlette Bouloumié, Angers, Presses de l'Université d'Angers, 2000, p. 597.

${ }^{9}$ «Entretien sur la photographie avec Georges Monti », in Lorand Gaspar (2004), p. 161.
} 
L'œuvre photographique montre donc un rapport étroit avec la vie de chaque auteur, mais cet ancrage se manifeste par des univers visuels distincts. On trouve une dissemblance aussi dans l'image de l'auteur, contrôlée et mise en scène à divers degrés.

Chez François-Marie Banier on trouve une image maîtrisée, le montrant soit invisible comme un reporter photographe qui s'efface de la scène, soit posant - beau, souriant et affectif. On trouve aussi des clichés de lui le mettant en scène dans son travail, en train de photographier, de peindre ou d'écrire sur ses photos ${ }^{10}$, contribuant de la sorte à son propre mythe comme Roland Barthes se met en scène en tant qu'écrivain à la fin de la séquence photographique dans son livre Roland Barthes par Roland Barthes. On peut ajouter que Banier contrôle non seulement son image, mais aussi son œuvre grâce à son site Internet.

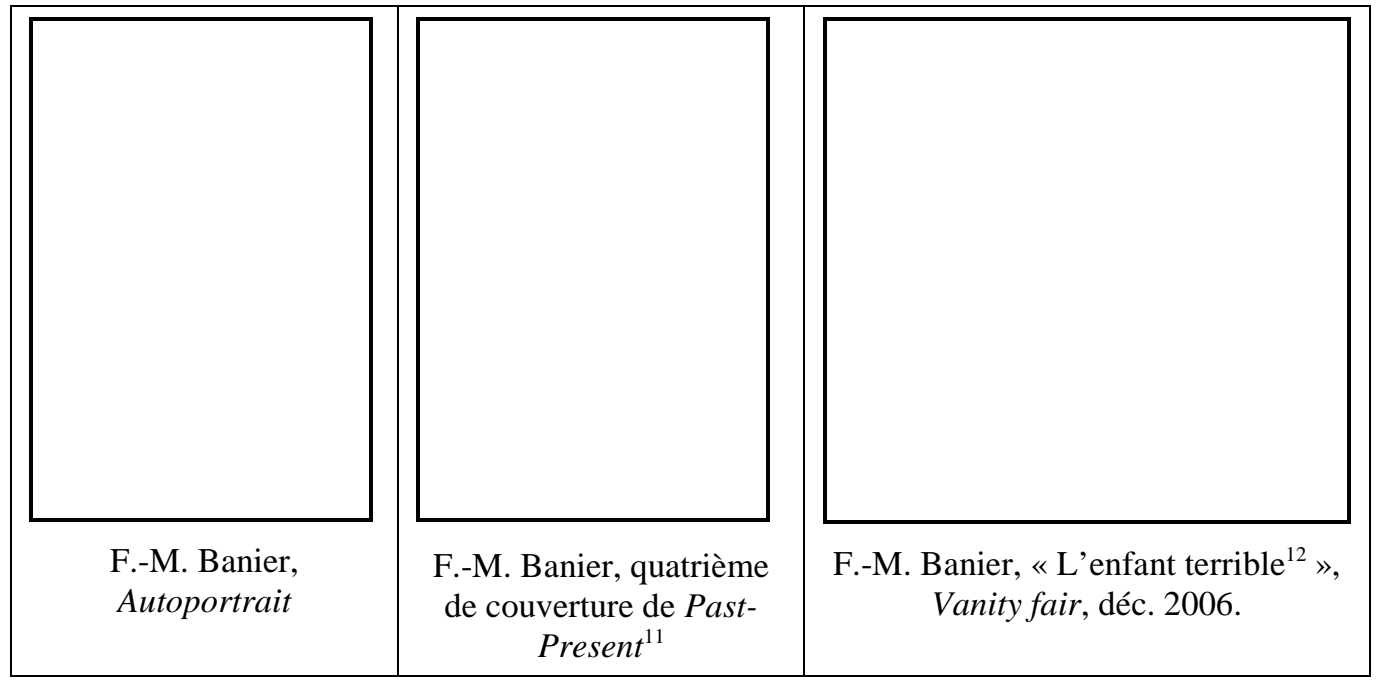

Comme nous l'avons vu, les autoportraits de Denis Roche font partie intégrante de son œuvre photo-littéraire. On trouve chez lui des autoportraits sous forme d'ombre, de réflexion, ou pris à l'aide d'un déclencheur à retardement. Il se met lui aussi en scène en train d'écrire ou en train de photographier. Cependant ses images floues ou «mal cadrées » donnent l'impression qu'il s'agit là de clichés pris au hasard par

\footnotetext{
${ }^{10}$ Voir notamment l'article «L'enfant terrible » qui lui est consacré dans Vanity Fair, décembre 2006 : http://www.fmbanier.com/content/presse/pdf/PDF-PresseUSA/PDF-VanityFair/VanityFair0612.pdf ou encore la campagne publicitaire Diane von Fürstenberg réalisée en 2008 (consulté le : 25/10/2009) http://www.dvfprojects.com/archive/\#/studio/.

${ }^{11}$ BANIER, F-M., Past-Present, New York, William Morrow, 1996. Voir l'image sur le site de l'auteur : http://www.fmbanier.com/past_present_new_york_william_morrow_1996_3 (consulté le : 25/10/2009).

12 Voir l'image sur le site de l'auteur : http://www.fmbanier.com/content/presse/pdf/PDFPresseUSA/PDF-VanityFair/VanityFair0612.pdf (consulté le : 25/10/2009).
} 
l'automatisme de l'appareil. Pourtant le choix du cliché retenu révèle une image contrôlée qui insiste autant que ses poèmes sur le fait de tourner sur soi-même.

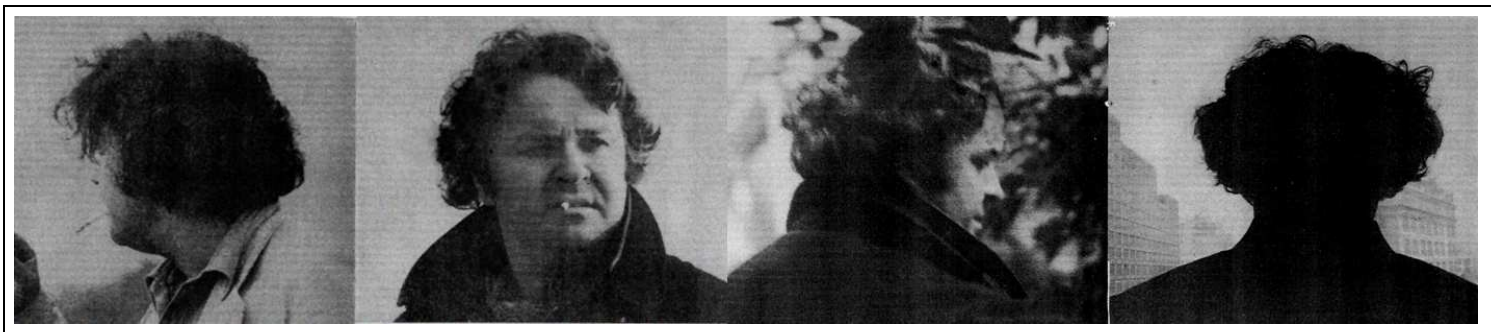

Denis Roche, Louve basse, p. 222-224.

À l'opposé de François-Marie Banier ou de Denis Roche, les portraits photographiques de Lorand Gaspar se placent en marge de son œuvre photo-littéraire. On en trouve dans des actes de colloque ou dans des revues littéraires (des numéros spécialisés sur son œuvre). Ces clichés ne le montrent pourtant ni en train d'écrire, ni en train de photographier, mais dans le désert, dans sa maison ou dans son activité de chirurgien.

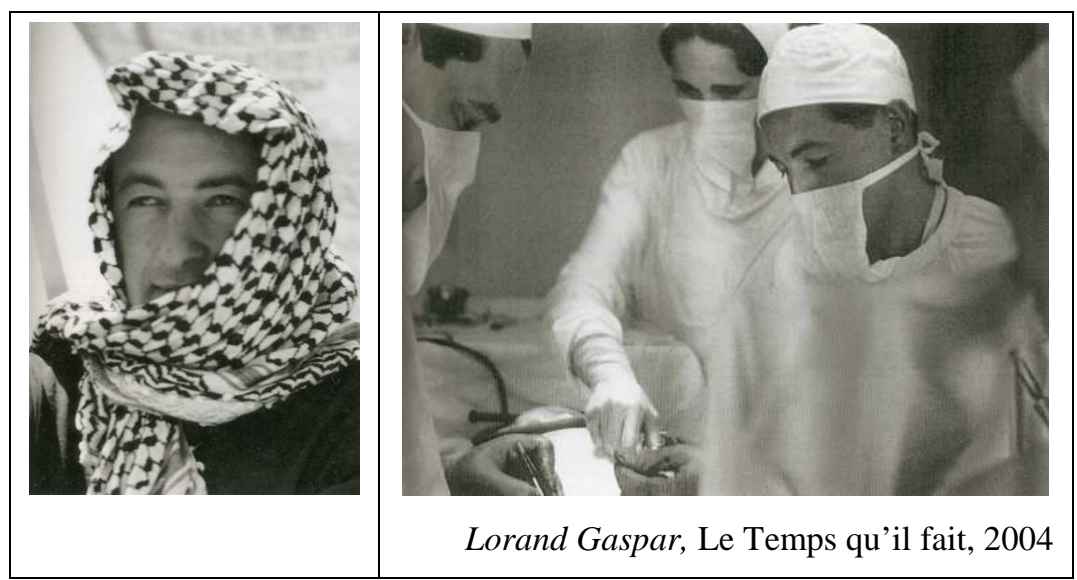

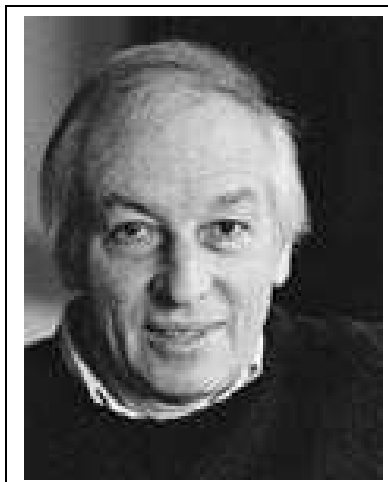

J-L Trassard, portrait sur le site de l'éditeur «Le Temps qu'il fait ${ }^{13} \gg$
Parmi les quatre auteurs, Jean-Loup Trassard est celui dont le moins de portraits furent publiés. À ce jour, une photo est visible sur le dos de l'acte de colloque consacré à son œuvre et une autre sur le site de son éditeur «Le Temps qu'il fait». Cependant, comme il le note : «pour leur site les éditeurs font ce qu'il veulent ${ }^{14} \gg$. Il envisage toutefois de faire un site personnel et d'y publier des photos, mais ces images resteront donc en marge de l'œuvre.

13 Voir l'image sur le site : http://www.letempsquilfait.com/Pages/Auteurs/Trassard/trassard.html (consulté le : 10/10/2009).

${ }^{14}$ Voir le questionnaire ci-joint à la page 294. 
Dans l'utilisation et le contrôle de leur propre image, Trassard serait donc proche de Gaspar, et Roche proche de Banier, mais certaines de leurs pratiques photo-littéraires les rapprochent également. Ainsi trouve-t-on chez Banier et chez Roche l'utilisation des inscriptions sur les photographies. On retrouve d'ailleurs cette pratique chez beaucoup de photographe - on l'avait vu chez Robert Frank ${ }^{15}$, mais il faudrait encore ajouter Edward Weston ${ }^{16}$, Bernard Faucon ${ }^{17}$ ou Edouard Levé ${ }^{18}$.

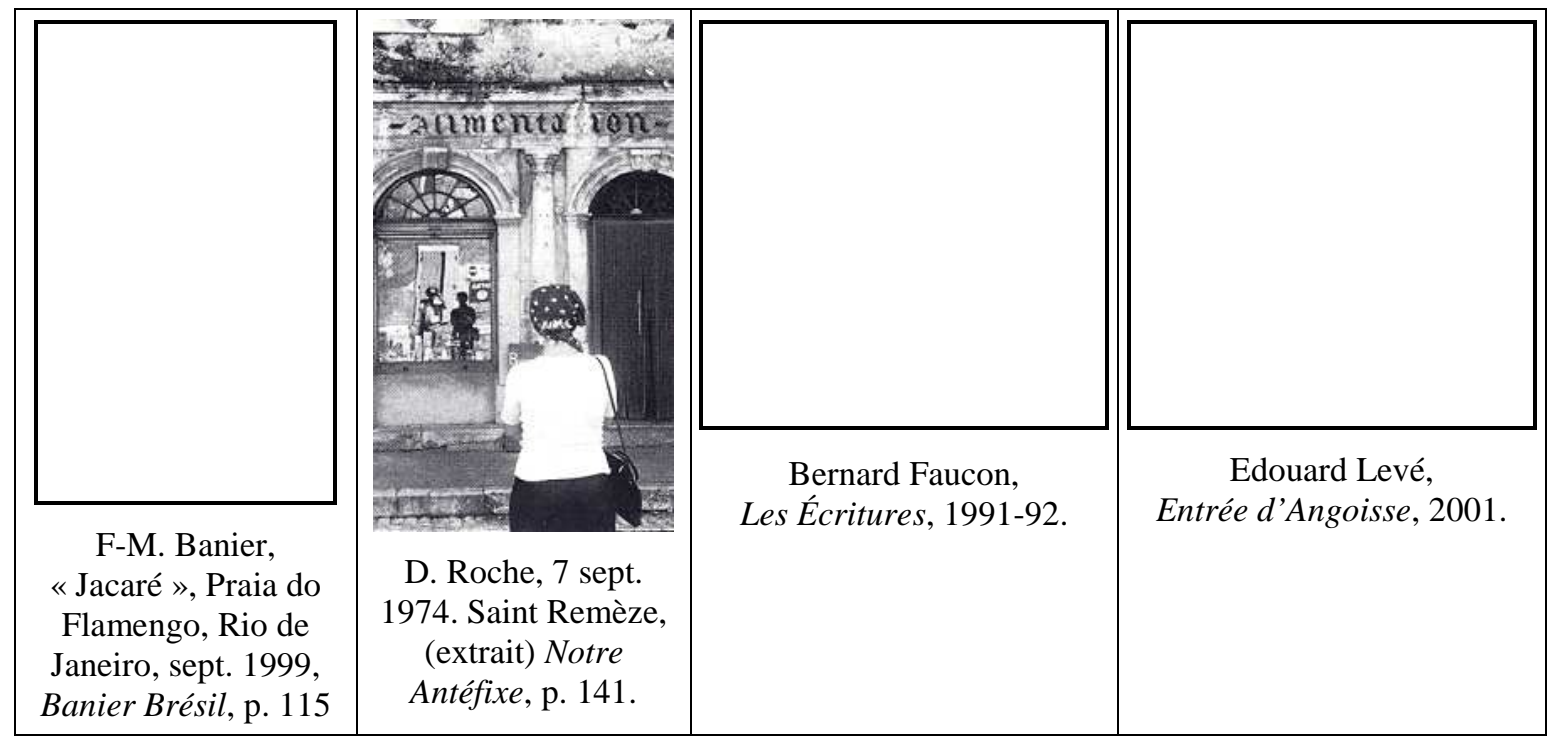

Cette pratique de cadrage de textes remet en cause la hiérarchie qui découlerait de la genèse successive de la photo et du texte. Dans ce cas, on ne peut plus distinguer quel médium influence le sens de l'autre.

À part les inscriptions sur les photos, un autre principe relie également les œuvres de Banier et de Roche : l'utilisation de la vitesse dans la composition des œuvres. Rappelons, que Banier peint volontiers à toute allure et avec les deux mains,

\footnotetext{
${ }^{15}$ Voir à la page 92.

16 Voir l'image sur: http://www.ilove80.be/blog/2009/01/05/walker-evans-penny-picture-displaysavannah-1936/ Voir aussi à ce sujet l'étude de Jay Bochner «Textes vus chez Walker Evans », in Littérature et photographie, (sous la dir. de Jean-Pierre Montier; Liliane Louvel ; Danièle Méaux ; Philippe Ortel) Rennes, PUR, 2008, p. 441-457.

${ }^{17}$ Voir la série Les Écritures sur le site du photographe : http://www.bernardfaucon.net/photos/index.htm (consulté le : 28/10/2009). Cette série est assez particulière, car Bernard Faucon dispose des lettres écrites à la main découpées et enveloppées de papier aluminium sur des bâtons devant un paysage. L'écriture s'affiche alors au moment de la prise de vue grâce à la lumière provoquée par le flash et sa réflexion sur le papier aluminium.

18 Voir la série Angoisse sur le site de la galerie Loevenbruck: (consulté le : 31/08/2009) http://www.loevenbruck.com/image.php?id=leve\&image=6.
} 
tandis que Roche se pose comme contrainte d'écrire des poèmes à toute vitesse dans la série intitulée La poésie est une question de collimateur ${ }^{19}$. La série de photographies de Roche prises à partir d'un taxi en Egypte entre dans la même logique. Il demande au chauffeur de foncer à toute vitesse tandis qu'il prend des photos de la pyramide qui devient de plus en plus grande dans le cadre de l'optique ${ }^{20}$.

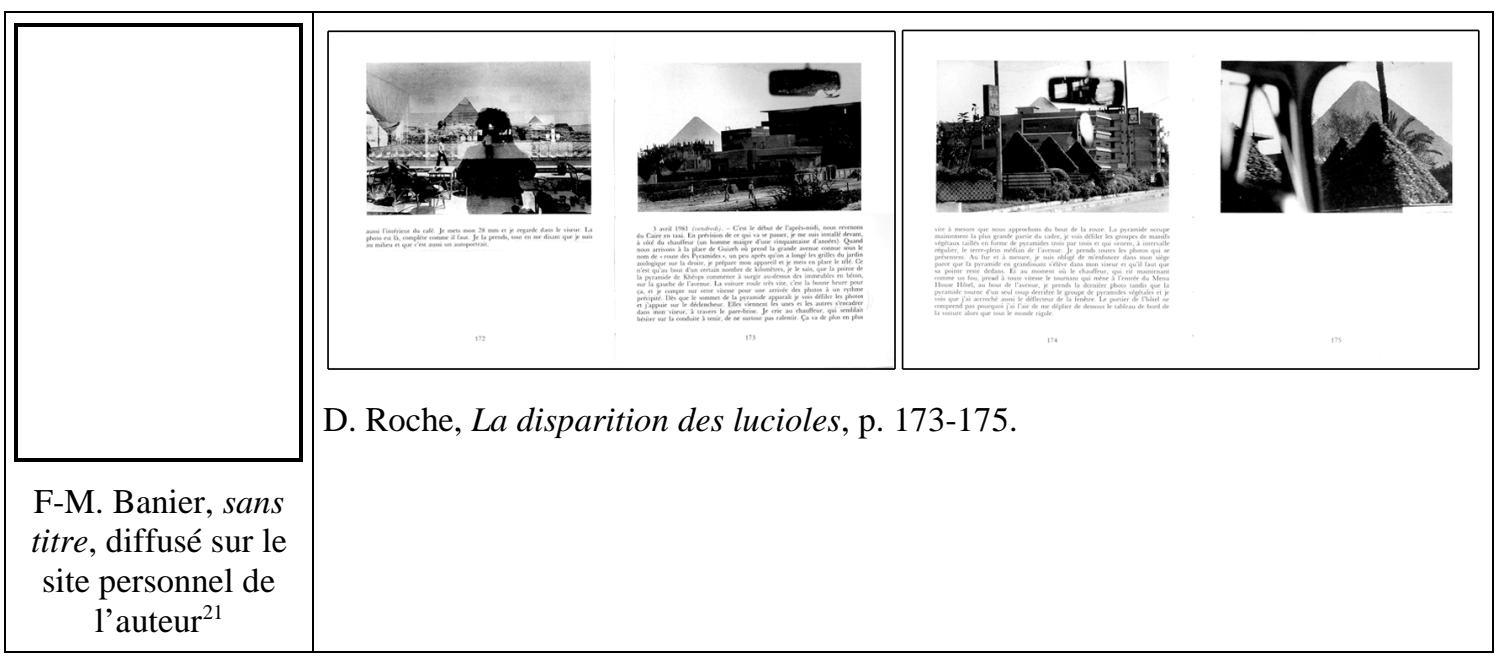

En ce qui concerne l'œuvre de Jean-Loup Trassard et celle de Lorand Gaspar, leur connivence se montre dans l'affinité pour les photographies de paysage et dans le thème de la transhumance photographié par tous les deux auteurs.

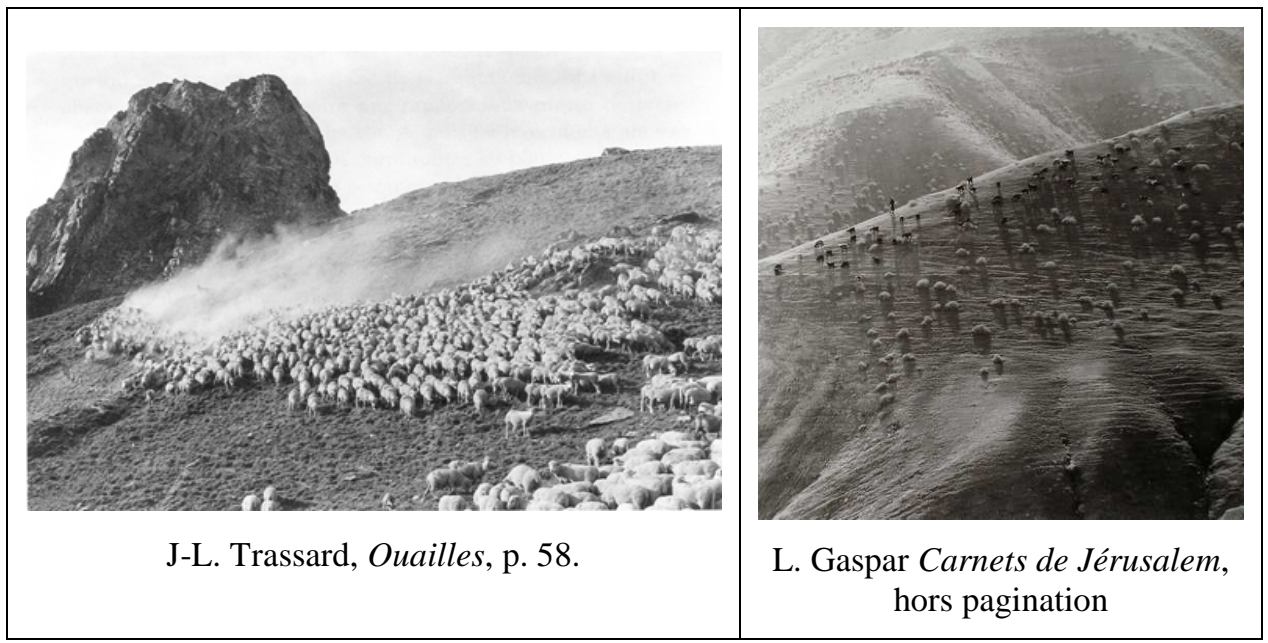

19 «La poésie est une question de collimateur », La poésie est inadmissible, œuvres poétiques complètes, Paris, Seuil, 1995, p. 97-108.

${ }^{20}$ ROCHE, Denis, La disparition des lucioles (réflexion sur l'acte photographique), Paris, Étoile, 1982, p. 173-175.

${ }^{21}$ L'image est publiée sur le site Internet de l'auteur sans légende. http://www.fmbanier.com/node/2353 (consulté le : 16/05/2009). 
Outre ce thème en commun, on découvre chez eux, tout comme chez Denis Roche, un penchant pour les compositions abstraites. Cela demande aussi lors de la prise de vue d'anticiper l'image comme surface dépourvue de dimension.

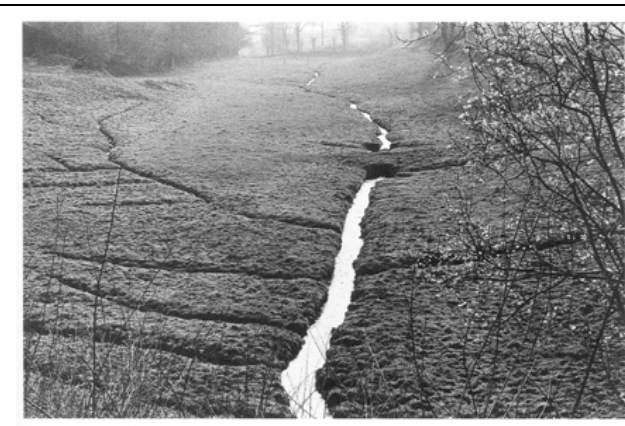

J-L. Trassard, Territoire, sans pagination

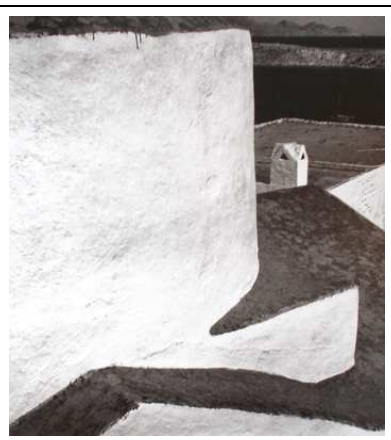

L. Gaspar, Carnet de Patmos, sans pagination

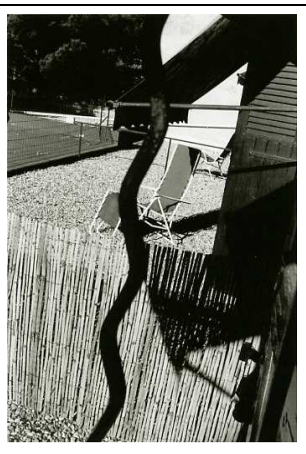

D. Roche, 18 juin 1988, Aix-en

Provence, Hôtel Le Pigonnet ch. 8, (PT, 108)

La platitude de l'image est également utilisée dans un second temps par Banier dans ses photographies écrites ou peintes et par Roche dans ses contacts successifs.

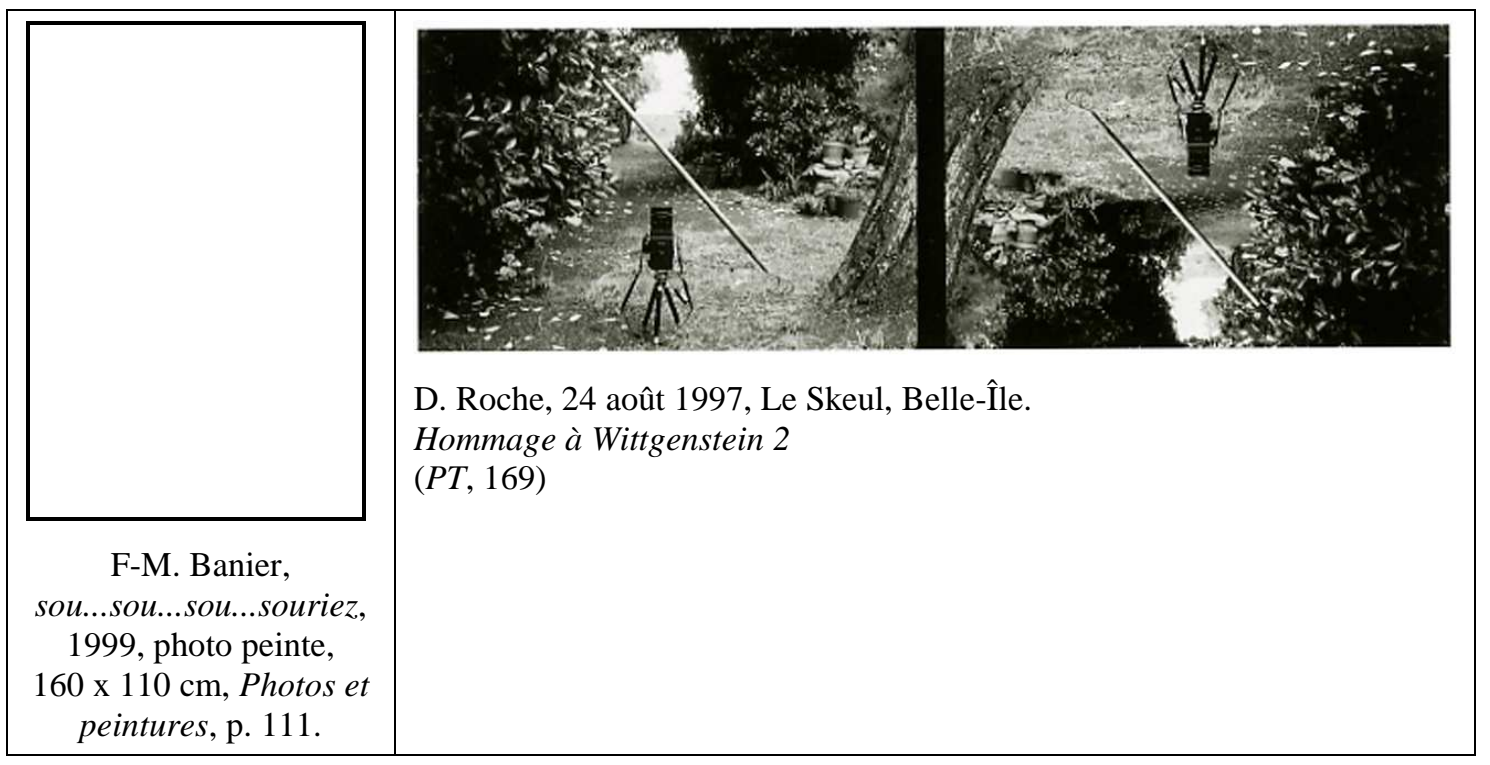

Mais ces raccords thématiques ou visuels et le lien dans l'utilisation autobiographique de la photographie qui rapprocheraient l'œuvre des quatre écrivains photographes, ne doivent pas faire oublier qu'il y a tout autant d'aspects qui séparent leurs œuvres et témoignent de la richesse du domaine photo-littéraire. 
Pal, Gyöngyi. Le dispositif photo-littéraire en France dans la seconde moitie du XXe siècle le l'oeuvre de Francois-Marie Banier, Jean-Loup Trassard, Lorand Gaspar et Denis Roche - 2010 
Les causes de la réfutation de l'hypothèse de départ

Dans notre hypothèse de départ, nous avions identifié un problème mineur : l'instabilité du référent dans la relation du texte et de la photographie, mais cette question initiale s'est élargie au fil de nos recherches, elle est devenue un indicateur de transformations essentielles dans la société et dans la littérature. À l'opposé de ce que notait Michel Tournier en 1974 sur les écrivains photographes, il paraît désormais que « l'oiseau n'est pas rare » et que le changement dans le statut de la photographie aurait influencé la visibilité des œuvres photo-littéraires. L'œuvre des écrivains photographes (Banier, Trassard, Gaspar et Roche) évolue, accordant une place plus grande à la photographie au fil du temps et c'est d'une manière de plus en plus consciente qu'ils mêlent les photos à leurs œuvres. Le statut de la photographie amateur change également à la même période, et les œuvres photographiques de certains auteurs tels Claude Simon ou Georges Simenon ont été réévaluées dans les années 1990.

La photographie amateur apparaît d'ailleurs comme une utopie, celle de l'automatisme et de l'objectivité, dans la photographie contemporaine. Une utopie, car l'objectivité est remise en cause par les théoriciens, ainsi que par les différentes usages que peuvent faire de la photographie plasticiens, reporters et artistes photographes, écrivains, etc. L'introduction des notions peirciennes dans la théorie de la photographie reflète aussi ce changement. Dans les années 1980, les termes d'icône et d'index supposaient encore l'objectivité du médium et soulignaient son caractère analogique et ontologique, tandis que dans les années 1990 les notions d'empreinte, de trace ou du dispositif comprennent déjà le système dynamique du signe de Peirce. Cette instabilité ou précarité de la signification rejoint la définition du mythe de Roland Barthes, et la photographie semble alors renouer avec une forme archaïque de communication qui précédait l'ère de l'écrit.

Quand Michel Tournier note que le texte modifie le sens de la photographie, l'on pense justement à sa pratique d'écriture palimpsestique par laquelle il cherche à réactualiser les mythes (entre autres celui de Robinson Crusoé ou de Barberousse). Tournier réutilise même ses propres textes pour les juxtaposer à des photographies dans 
ses œuvres hybrides ou dans ses préfaces à ses amis photographes. Ainsi un passage du Roi des Aulnes sur les fesses peut s'insérer dans Vues de dos ${ }^{1}$ et accompagner une photo d'enfants se baignant nus; ailleurs, dans la préface de l'album de Roiter Fulvio², c'est un passage du roman Les météores ${ }^{3}$ qui est repris à l'identique. De cette pratique découle évidemment la contestation de la stabilité du sens de la photographie, tout autant que celle de l'écriture.

\section{En dehors du langage}

Toutefois la précarité du signe ne semble plus poser de problème, car la signification s'est déplacée en dehors de l'œuvre. Selon la notion du dispositif, elle inclut en amont les stratégies éditoriales et le support sur lequel l'œuvre est diffusée et en aval l'effet de sens que provoque l'œuvre chez le lecteur ou le regardeur. Ce déplacement entraîne aussi l'apparition de nouveaux concepts dans le rapport texte/image. Ainsi les nouveaux termes - l'iconotexte, l'œuvre construite sur l'entre-deux, l'œuvre hybride ou hétérogène - acceptent désormais l'idée que l'œuvre puisse construire un effet de sens en dehors du langage.

La photographie ajoute ainsi une dimension sensible aux œuvres hybrides, en même temps qu'elle problématise la représentation par son statut à la fois documentaire et fictionnel. Nous avons vu alors, que la juxtaposition des textes et des clichés remet en question non seulement la valeur de vérité de l'image mais, par un effet de renversement, celle du texte aussi. La situation paradoxale de la photographie dans les récits autobiographiques, soulève de manière plus générale, le problème de l'identité même. On peut supposer alors que les changements qui se sont opérés dans la prise en considération de la photographie aient pu exercer une influence sur l'apparition de la notion d'autofiction dans la littérature. Ce nouveau terme questionne la valeur de vérité des récits autobiographiques, car la réalité est très complexe et la narration ne peut en rendre compte qu'enfermée dans le langage. En même temps l'autofiction remet en cause l'irréalité de la fiction, des élaborations imaginaires, des rêves ou de l'inconscient.

\footnotetext{
${ }^{1}$ TOURNIER, Michel, Vues de dos, Paris, Gallimard, 1981, (photos d'Edouard Boubat).

${ }^{2}$ ROITER, Fulvio, Venise hier et demain, Paris, Chêne, 1973, préface de Tournier : «Venise ou la tête coupée », p. 7-12.

${ }^{3}$ TOURNIER, Michel, Les météores, Paris, Gallimard, collection Folio nº5, 1975.
} 
La mythologie réapparaît là aussi comme modèle chez les artistes et les écrivains $\mathrm{du} \mathrm{XX}^{\mathrm{e}}$ siècle, comme le montre Magali Nachtergael dans sa thèse. Il semble toutefois que tout un chacun rêve de pouvoir créer sa propre «mythologie individuelle » par l'utilisation contrôlée de l'image et du texte sur les programmes d'échange comme Facebook ou Myspace.

Une interdépendance semble se profiler entre les technologies que l'homme s'invente et l'image par laquelle il se représente le monde et soi-même. La conscience du dynamisme du signe ou du changement constant de l'identité rappelle la mise à jour permanente des ordinateurs. La linéarité, l'ordre et la structure sont remplacés par le désordre, le réseau, l'informel du blob, ou encore la notion du dispositif qui ouvre sur la conjecture. C'est que les données, les images produites par les nouvelles technologies nous dépassent tout autant que la réalité environnante, qu'elles devaient initialement aider à comprendre et à maîtriser. C'est ainsi que Philippe de Jonckheere parle de son jeu de Memory programmé de manière aléatoire à partir de 50 autres jeux, comme d'un dispositif qui laisse au hasard un nombre de réalisations possibles dépassant l'imagination et les «limites de l'univers connu ${ }^{4} »$.

\section{Les nouvelles pratiques photo-littéraires}

Nous avons pu traiter des pratiques photo-littéraires très dissemblables au cours de notre recherche qui dévoile que la photographie influence la littérature en premier lieu par sa dimension spatio-temporelle. C'est notre appréhension du temps et de l'espace qui a changé grâce à la photographie qui fut la première image technologique. C'est la spatiotemporalité qui est à la base des transformations de nos modes de représentation, ou de notre image de soi.

Mais dans le rapport de la photographie et du temps, il faut faire la différence entre la position du regardeur qui contemple l'image photographique et la position de l'«Operator », du photographe qui prend les images.

\footnotetext{
${ }^{4}$ Voir les jeux de Memory sur le site du désordre: http://www.desordre.net/memory/page002.htm (consulté le : 10/10/2009).
} 


\section{Le présent}

Pour le regardeur, comme l'insinue Roland Barthes, la photographie instaure une illusion temporelle et spatiale, une «conjonction illogique entre l'ici et l'autrefois ${ }^{5} »$. Il s'agit avant tout des clichés iconiques qui se basent sur l'analogie entre l'image et la scène. Grâce à l'analogie, le regardeur se projette dans l'image et ressent l'évènement passé et lointain comme du présent. C'est la même idée qu'on retrouve chez Walter Benjamin, quand il écrit : «qu'est-ce au fond que l'aura? Un singulier entrelacs d'espace et de temps : unique apparition d'un lointain, aussi proche soit-il ${ }^{6} \gg$. Si l'image photographique paraît abolir l'aura des objets, c'est parce qu'elle crée une illusion spatiotemporelle.

On retrouve alors dans les œuvres photo-littéraires l'exploitation de cette qualité de la photographie. La présence illusoire entretient ainsi des liens divers avec la temporalité et la spatialité du texte. La série Juste absente, les livres Le voyageur à l'échelle et Les derniers paysans de Jean-Loup Trassard jouent sur cet effet trompeur. Denis Roche cherche lui aussi à rendre visible le temps, le changement qui s'insinue dans les vues prises au même endroit avec le même cadrage, mais à plusieurs années d'écart. Le fait de pouvoir juxtaposer deux clichés pris à quelques secondes ou à une dizaine d'années d'intervalle entraîne le vertige, selon lui, et ouvre la voie à une connaissance métaphysique du monde où se confondent l'instantané et le perpétuel. Les albums photos se livrent en général à cette réduction du temps, même ceux qui comprennent 14500 pages comme c'est le cas des 130 albums de Jacques-Henri Lartigue $^{7}$. Ils ne peuvent que rester fragmentaires et incomplets, et le pouvoir de mémoire de la photographie s'en trouve diminué et remis en question, tout comme son rôle dans les récits autobiographiques, qui imiteront dans leur forme ce morcellement. La linéarité du texte et de l'écriture s'en trouve même troublée, et l'ordre instauré par les règles intrinsèques du langage parait laisser la place au désordre. Le lecteur digital,

\footnotetext{
5 BARTHES, Roland, «Rhétorique de l'image », Euvres complètes, t. 1, 1942-1965, édition présentée par Éric Marty, Seuil, 1993, p. 1420. Le texte est également accessible sur Internet: http://www.oasisfle.com/doc_pdf/roland_barthes_rhetorique_image.pdf (consulté : le 06/10/2009).

${ }^{6}$ BENJAMIN, Walter, «Petite histoire de la photographie », Études photographiques, ${ }^{\circ} 1$, novembre 1996, p. 20. Le texte est disponible sur Internet : http://www.lhivic.org/sources/divers/benjamin-1931.pdf (consulté le : 10/07/2009).

${ }^{7}$ Voir le site dédié au photographe : http://www.lartigue.org/index.html (consulté le : 21/10/2009).
} 
selon Maryanne Wolf ${ }^{8}$, ne serait d'ailleurs qu'un consommateur d'information. À long terme, il risque de devenir une enveloppe vide qui cliquant sur Internet de page en page, n'aurait plus le temps d'intégrer les informations, de les ordonner ou de les prolonger selon son imaginaire. En fin de compte, la montée de la communication visuelle provoquerait, selon elle, une perte d'individualisme. Mais à l'opposé de ce pronostic, on pourrait aussi voir dans la lecture digitale une liberté qui s'offrirait à chacun de composer son propre chemin de lecture, en allant tout droit par les moteurs de recherche aux informations souhaitées, en transformant ou annotant le texte à sa guise.

\title{
Le passé
}

La photographie, définie comme acte et non comme image, tire aussi le présent dans deux directions opposées. L'acte suggère, en accord avec le fragment d'Héraclite qui dit qu' « on ne peut pas se baigner deux fois dans le même fleuve ${ }^{9}$ », que le présent tend toujours irrévocablement vers le passé. Par conséquent, le «noème » de la photographie serait le fameux «ça a été ${ }^{10}$ », qui place le médium dans le deuil et dans la perte insupportable, à l'image de ce que ressent Barthes face à la perte de sa mère. Le présent vécu et senti comme du déjà passé entraîne la remise en cause de la valeur de vérité de l'image. Rappelons les mots de Zaki Laïdi à ce propos :

\begin{abstract}
Dans cette nasse de présent, la vérité n'a de sens que dans l'ici et maintenant, un peu à l'image des marchés financiers où la valeur des choses ne fait sens qu'aujourd'hui. Non seulement la vérité n'a de sens que dans l'ici et maintenant, mais elle est toujours susceptible d'être révisée par une perception ultérieure car la vérité d'aujourd'hui ne court pas le danger d'être probablement démentie demain ; en effet, elle sera devenue la vérité d'hier et c'est le fait d'être une vérité d'hier qui la rend inexorablement obsolète aujourd'hui. Autrement dit, le sens et la valeur de la vérité ne se trouve que dans le seul présent. ${ }^{11}$
\end{abstract}

C'est le présent vécu comme du passé qui provoque en fin de compte l'instabilité du signe.

\section{Le futur}

Mais le photographe, comme nous l'avons déjà évoqué, n'est pas tourné vers le deuil et le temps irréversible. L'acte est plutôt senti comme une possibilité d'agir sur le monde

\footnotetext{
${ }^{8}$ WOLF, Maryanne, Proust and the Squib, New York, Harper, 2007.

9 Les fragments d'Héraclite sont accessibles sur plusieurs site, voir notamment: http://agora.qc.ca/mot.nsf/Dossiers/Heraclite (consulté le : 21/10/2009)

${ }^{10}$ BARTHES, Roland, La Chambre claire, Paris, Cahiers du cinéma, Gallimard, Le Seuil, 1980, p. 176.

${ }^{11}$ LAÏDI, Zaki, «Le sacre du présent », in Figures du temps (sous la dir. de Spyros, Théodorou), Paris, Parenthèse, 2003, p. 94-95.
} 
et une manière de l'habiter. La photographie fonctionnerait alors sur le mode du futur antérieur en anticipant la perte, comme le note François-Marie Banier : «photographier parce que ce ne sera plus jamais comme ça ${ }^{12}$ », ou Raymond Depardon : «ce n'est pas seulement une nostalgie, c'est aussi du présent. Il faut photographier ${ }^{13} \gg$. En regardant dans le viseur, en appuyant sur le déclencheur, en développant ou non une photo, en la considérant réussie ou ratée, en lui conférant une importance particulière sur les autres, le moment vécu et le cliché qui en porte la trace reçoivent une seconde chance d'exister, «c'est du déjà vécu qui veut se faire revivre ${ }^{14}$ ». Certes sa signification ne sera plus la même, car le regardeur réinvestit toujours l'image par le vécu, l'expérience, le savoir acquis entre-temps ${ }^{15}$, mais le premier geste est le vecteur du second.

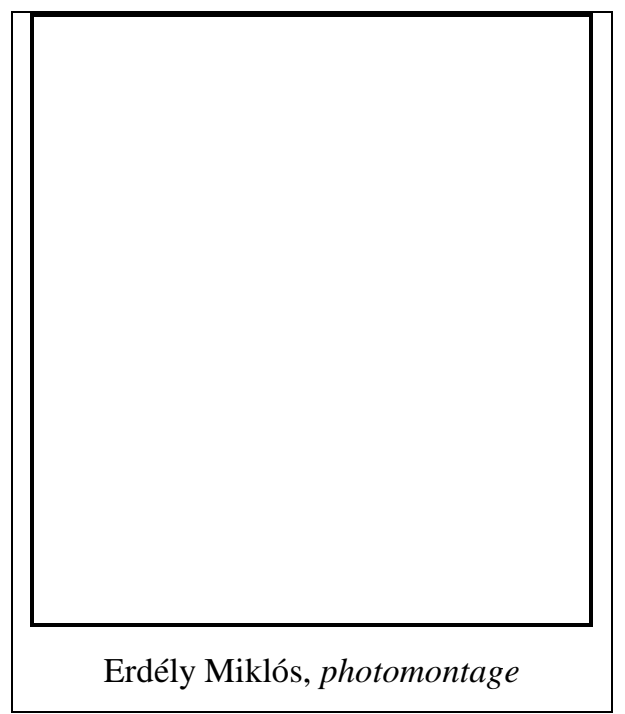

Un artiste hongrois Erdély Miklós transpose cet imaginaire en image, et suggère que les différentes tranches de temps peuvent communiquer l'une avec l'autre. Il met ainsi en scène des rencontres avec soi-même à différents âges de la vie à l'aide de photomontages. Dans le cliché ci-contre, le photographe âgé semble mettre en garde son Moi jeune sur son avenir en lui murmurant des conseils à l'oreille, tandis que le second l'accueille dans son rêve. Dans d'autres photomontages, le photographe âgé revient en arrière pour revisiter son enfance, comme le permettent les souvenirs.

Aussi retrouve-t-on le caractère prospectif de la photographie transposé en image dans le livre de Bernard Faucon, intitulé Été 2550, (Arles, Actes Sud, 2009).

12 BANIER, François-Marie, «La vie de la photo », paru dans plusieurs catalogues d'exposition mais le texte est disponible également sur le site de l'auteur: http://www.fmbanier.com/la_vie_de_la_photo (consulté le : 15/05/2009).

${ }^{13}$ DEPARDON, Raymond, L'être photographe, entretiens avec Christian Caujolle, Paris, L'Aube, 2007, p. 62.

${ }^{14}$ VALÉRY, Paul, «Mes théâtres » (1942) repris in CEuvres, t. I, édition de Jean Hytier, Pléiade, 1957, p. 1838. (Nous soulignons.)

${ }^{15}$ On retrouve cette idée également chez François-Marie Banier, qui écrit dans La vie de la photo : "Tout ce que l'on découvre à chaque fois que l'on regarde une photo n'appartient qu'à vous. Le temps est arrêté, décrit, les faits sont là et dans un léger flottement, la photo tout à coup déborde. On y ajoute tout ce qu'on ignorait du personnage et de soi-même : nous avons vécu entre-temps. La photo vit, nourrie de cette vie supplémentaire qu'elle nous suggère, et que nous lui imposons. » BANIER, François-Marie, « La vie de la photo », Op. cit., p. 337. 
Dans ce dispositif le photographe juxtapose des clichés et des fragments qui rappellent les entrées d'un journal.

Il s'agit d'une méditation sur la vieillesse, sur le temps, et sur le monde qui continue après notre mort : «Ce qui est troublant quand on se projette dans le grand inconnu de l'avenir, c'est la fatale permanence des sensations et des choses, car tout sera un peu pareil tant qu'il y aura du Monde »- écrit-il sur la quatrième de couverture. Ses vues à la fois banales, mais belles rejoignent la tendance de la photographie contemporaine à représenter des images neutres, où il ne se passe rien. Ces clichés, par

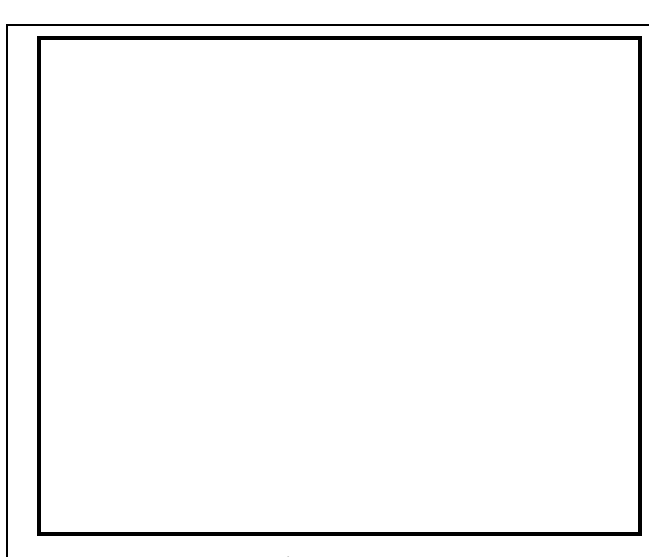
Bernard Faucon, Été 2550, sans pagination ${ }^{16}$ leur caractère banal et en même temps élémentaire - on y trouve des images du feu, de l'eau ou du vent -, ouvrent sur l'éternité et l'infini. Ils rejoignent en cela les propos de Lorand Gaspar pour qui l'implication de la lumière dans le procédé est révélatrice d'une unité profonde du Monde dans la multiplicité de ses apparences.

Le geste de photographier ouvre donc sur l'avenir, sur la possibilité qu'une fois l'image revisitée, ce qu'elle désigne puisse faire sens à nouveau. Ce caractère prospectif apparente le boîtier dans la main des photographes à un journal intime visuel discontinu et fragmentaire. L'image photographique semble en plus être une interface qui mobilise le photographe dans les deux directions opposées, vers l'intérieur et l'extérieur. L'appareil pousse le photographe à explorer le monde en faisant appel à sa sensibilité et à sa personnalité, il mobilise ainsi sa conscience et son inconscient. Mais son acte agit en même temps sur le monde, car il tire les choses photographiées vers l'existence, au même titre que l'acte de nommer.

\section{La photographie comme surface}

La photographie est une interface qui mobilise vers l'extérieur et l'intérieur, mais aussi un écran, une surface qui s'interposerait entre l'homme et le Monde, ne créant qu'une

\footnotetext{
${ }^{16}$ Voir l'image sur le site d'artnet: http://www.artnet.fr/magazine fr/livres/caujolle/faucon detail.asp (consulté le : 28/10/2009).
} 
nouvelle couche illusoire et chimérique à l'image des ombres de la caverne de Platon. Mais le cliché en tant que surface influence aussi la littérature. On peut penser aux Dépôts de savoir et de technique de Denis Roche, où les lignes de texte prélevées sont disposées en bloc comme les photos sur une planche-contact. Mais le caractère plat de la photo est aussi visible dans les clichés de Trassard, de Gaspar ou de Roche qui se transforment en lignes ou formes abstraites, ou encore dans la manière qu'à Banier de recouvrir l'image de dessins ou d'écritures, ainsi que dans les contacts successifs de Roche.

La juxtaposition de la photographie et du texte au sein d'un même livre joue également sur la spatialité de ce dernier. Cette spatialisation de la littérature rejoint alors une tendance visible dans la poésie du $\mathrm{XX}^{\mathrm{e}}$ siècle qui va de Mallarmé jusqu'à la poésie concrète, et qui considère la page comme un espace structurant. La mise en page des œuvres hybrides évoque ainsi le modèle des compositions musicales, si elle n'intègre pas carrément des partitions comme chez Denis Roche ${ }^{17}$ ou Lorand Gaspar ${ }^{18}$. Les fragments et les images sont traités comme des unités génératrices d'interstice et sont disposés de manière à créer une rythmique visuelle. Mais l'image provoque aussi un arrêt dans la lecture. Le livre hybride ou hétérogène donne d'ailleurs la possibilité de feuilleter d'abord les images - en commençant du début ou par la fin - ; le livre n'est donc plus obligatoirement parcouru de manière linéaire. Une plus grande place est laissée au hasard et à l'effet de sens qui se forme entre l'image et le texte ou, comme on l'a vu sur le site du désordre, entre n'importe quel fragment hétérogène juxtaposé.

\section{$\underline{\text { L'interstice et le vide }}$}

La dimension spatio-temporelle de la photographie ouvre en fin de compte sur un vide. Dès l'apparition du médium, l'enjeu fut de réduire le temps de pose pour que le gens, puis tout ce qui bouge et ce qui est vivant puissent apparaître nettement sur le cliché. Malgré l'évolution technique, entre l'infiniment petit dans espace ou dans le temps, il reste toujours un interstice. On retrouve d'ailleurs l'interstice, qui ouvre sur le vide dans

\footnotetext{
${ }^{17}$ Voir le dernier Dépôts de savoir \& de technique intitulé «Je vous dois la vérité en littérature et je vous la dirai », p. 215-216.

${ }^{18}$ GASPAR, Lorand, Journaux de voyages, Paris, Le Calligraphe, 1985.
} 
les livres photo-littéraires de Roland Barthes, ou dans la poésie de Lorand Gaspar et de Denis Roche. Dans l'œuvre rochienne, le vide, rythmé par les allers-retours du tempo automatique de l'appareil, devient une liberté, un envol, un « révélateur fou baignant le vent qui passe» $(D L, 50)$. Tandis que le vide gasparien «laisse pressentir la force jaillissante du spirituel ${ }^{19}{ }$ et rend visible la « respiration » du poème sur la page. Ce vide métaphysique s'inspire de la philosophie extrême-orientale, du $m u$ japonais qui signifie le « vide » et du satori - la « perte du sens » chez Roland Barthes ${ }^{20}$. Il est ce qui relie le Ciel et la Terre - symbolique qu'imite le blanc de la page ou du parchemin dans la peinture et l'écriture chinoise.

C'est d'ailleurs un photographe japonais, Hiroshi Sugimoto $^{21}$, qui démontre que la succession des images d'un film entier ouvre sur le vide ou le blanc. Il laisse ouvert l'obturateur de l'appareil durant toute la séance d'une projection cinématographique et sur l'image obtenue tout disparaît de l'écran. Il ne reste plus aucune trace du film projeté ou des spectateur, seulement la salle vide. Tout s'efface par la durée

Hiroshi Sugimoto, Stanley, New Jersey, 1993. comme sur les premiers clichés de Daguerre.

L'espace-temps singulier qu'inaugure la photographique, tout comme l'évolution du signe vers le modèle dynamique de sa signification, paraît alors renouer avec la philosophie extrême-orientale. Lors d'une conférence intitulée «Les fins du livre $^{22} \gg$, François Cheng oppose ainsi le livre occidental et oriental. Le premier trouve son origine dans la matière de la pierre, et veut conserver l'écriture inchangée, comme les Tables de la Loi de la Bible; tandis que le parchemin du livre oriental est de nature organique et sa valeur ne fait qu'augmenter avec les ajouts et annotations des lecteurs successifs.

${ }^{19}$ ALLAIRE, Suzanne, «Poésie et lumière », in Lorand Gaspar, Cognac, Le Temps qu'il fait, 2004, p. 246.

${ }^{20}$ BARTHES, Roland, L'Empire des signes, Paris, Flammarion, 1970. Voir à ce sujet le chapitre consacré à Roland Barthes à la page 121.

21 Voir l'image sur le site de la galerie Fraenkel à San Francisco (consulté le : 20/10/2009): http://www.fraenkelgallery.com/index.php\#mi $=2 \& p t=1 \& p i=10000 \& s=7 \& a=26 \& p=0 \& a t=1$

${ }^{22}$ CHENG, François, Les fins du livre [Enregistrement sonore]. «Le livre, une expérience chinoise » : conférence du 22 mai 1997. Reproduction numérisée, Paris, Bibliothèque nationale de France, 1999. 
Le développement des nouvelles technologies, comme la photographie digitale, Internet, les livres électroniques, les programmes comme Myspace et Facebook qui jouent sur le dynamisme et l'hétérogénéité de l'identité, renouerait alors avec des anciennes formes comme le livre oriental ou le «mythe » occidental qui précédait l'ère de l'écrit. On peut alors se demander si le vide du sens de l'image, comme l'entend Baudrillard, n'est pas paradoxalement un plein, du moment où sa multiplicité déborde les limites de nos connaissances et de ce qu'on peut exprimer par le langage. 


\section{Théorie de la photographie :}

AGAMBEN, Giorgio, Qu'est-ce qu'un dispositif ?, Paris, Rivage poche, 2007.

BARTHES, Roland, «Le message photographique », Euvres complètes, t. 1, 19421965, édition présentée par Éric Marty, Paris, Seuil, 1993, p. 938-948.

BARTHES, Roland, La Chambre claire, Paris, Cahiers du cinéma/Gallimard/Seuil, 1980.

BARTHES, Roland, «Rhétorique de l'image », Euvres complètes, t. 1, 1942-1965, édition présentée par Éric Marty, Paris, Seuil, 1993, p. 1417-1429.

BAUDELAIRE, Charles, «Le public modern et la photographie », Euvres complètes, (textes présentés et annotés par Claude Pichois) Paris, Gallimard, col. "La Pléiade", 1976, p. 614-619.

BAZIN, André, «Ontologie de l'image photographique », Qu'est-ce que le cinéma?, Paris, Cerf, 2002.

BENJAMIN, Walter, «Petite histoire de la photographie », (Die Literarische Welt, $\mathrm{n}^{\circ}$ 38, 1931), traduit en français en 1971 par Maurice de Gandillac, parue en édition spéciale dans Études photographiques, n ${ }^{\circ}$, novembre 1996.

BENJAMIN, Walter, L'œuvre d'art à l'époque de sa reproductibilité technique, traduit de l'allemand par Maurice de Gandillac, Paris, Allia, 2006.

BOURDIEU, P. ; BOLTANSKI, L. CASTEL, R.; CHAMBOREDON, J.-C., Un art moyen, essai sur les usages sociaux de la photographie, Paris, Minuit, col. "Le sens commun", 1965.

CHEROUX Clément, Fautographie. Petite histoire de l'erreur photographique, Paris, Yellow Now, 2003.

DAGBERT, Anne, Jean Le Gac, Paris, Fall édition, 1998.

DENOYELLE, Françoise, Le marché de la photographie, 1919-1939, Paris, l'Harmattan, 1997.

DUBOIS, Philippe, L'Acte photographique, Paris- Bruxelles, Nathan \& Labor, 1983.

ECO, Umberto, « Le hasard », L'Arc : la photographie, printemps 1963, p. 74- 81.

ELKINS, James (dir.), Photography Theory, New York, Routledge, 2007.

FLUSSER, Vilém, Pour une philosophie de la photographie, Saulxures, Circé, 2004. 
FREUND, Gisèle, Photographie et société, Paris, Seuil, 1974.

FRIZOT, Michel - DELPIRE, Robert, Histoire de voir. I-III., Paris, Nathan, col. "Photo Poche" n40, n41, n42, 2001.

GATTINONI, Christian - VIGOUROUX, Yannick, La photographie contemporaine, Paris, Scala, 2005.

GATTIONI, Christian, Les mots de la photographie, Paris, Belin, 2004.

KEMP, Wolfgang, Theorie der Fotografie, Band I-IV 1839-1995, München, Schrimer/Mosel, 2006.

KRAUSS, Rosalind, Le photographique, Paris, Macula, 1990.

LINDENKENS, René, Essai de sémiotique visuelle, Paris, Kliensieck, 1976.

MARTIN, Jean-Clet, Le corps de l'empreinte, Paris, Kimé, col. "Le collège en acte", 2004.

MORVAN, Yan, Photojournalisme, Paris, Victoires, 2007.

POINSOT, Jean-Marc (dir.), Une Scène parisienne, 1968-1972, Rennes, Archives de la critique d'art, Centre d'histoire de l'art contemporain, 1991.

POIVERT, Michel, La photographie contemporaine, Paris, Flammarion, 2002.

RABATE, Jean-Michel (dir.), Writing the image after Roland Barthes, Philadelphia, University of Pennsylvania Press, 1997.

ROCHE, Denis, «Un discours affectif sur l'image », Magazine littéraire, numéro Roland Barthes, ${ }^{\circ} 314$, octobre 1993, p. 65-67.

ROEGIERS, Patrick, Écoutez voir. Neuf entretiens avec des photographes, Paris, Paris Audiovisuel, 1989.

ROUILLÉ, André, La photographie, Paris, Gallimard, 2005.

SCHAEFFER, Jean-Marie, L'image précaire. Du dispositif photographique. Paris, Seuil, 1987.

SONTAG, Susan, Sur la photographie, Paris, Seuil, 1983.

SOULAGES, François, Esthétique de la photographie, Paris, Nathan, 1998.

STEPAN, Peter, Icons of photography, London, Prestel, 2005.

SZILÁGYI Gábor, elemi KÉPTAN elemei. Az álló és mozgó fényről, (Les éléments d'une science élémentaire de l'image) Budapest, Magyar filmintézet, 1999.

TISSERON, Serge, Le mystère de la chambre claire. Photographie et inconscient, Paris, Les Belles Lettres, 1996. 
TOURNIER, Michel, «Création et prédation », Les Cahiers de la photographie, édition du colloque de Paris I - Panthéon Sorbonne, 1982, p. 84-90.

VAN-LIER, Henri, Philosophie de la photographie, Paris - Bruxelles, Les Impressions Nouvelles, 1983.

\section{$\underline{\text { Sur Internet: }}$}

«L'image, le sensible et le photographique », colloque organisé le 19 et 20 mai 2009, voir l'annonce du colloque sur Fabula :

http://www.fabula.org/actualites/article24158.php, ainsi que le programme détaillé : http://www.univ-mlv.fr/lisaa/actualites/Colloque-19_et_20_mai_Programme.pdf (consulté le : 09/10/2009).

BARTHES, Roland, « Rhétorique de l'image », paru initialement dans la revue Communications en novembre $\mathrm{n}^{\circ} 4,1964$, p. 40-51:

http://www.oasisfle.com/doc_pdf/roland_barthes_rhetorique_image.pdf (consulté : le 06/10/2009).

BENJAMIN, Walter, «Petite histoire de la photographie », (Die Literarische Welt, $\mathrm{n}^{\circ}$ 38, 1931), traduit en français en 1971 par Maurice de Gandillac, parue en édition spéciale dans Études photographiques, n 1 , novembre 1996 :

http://etudesphotographiques.revues.org/index99.html (consulté le : 10/07/2009).

BLASER, Jean-Christophe, «Sur les traces de l'icône : vers un nouveau concept critique ? », Art architecture en Suisse (Revue de la Société de l'histoire de l'art en Suisse), $\mathrm{n}^{\circ}$ 4, hiver 2000, disponible sur le site web du Musée de l'Elysée de Lausanne, Suisse : http://www.elysee.ch/index.php?id=120\&tx ttnews[pS]=1232373229\&tx ttne ws[tt_news]=20\&tx ttnews[backPid] $=119 \& \mathrm{cHash}=644 \mathrm{~d} 62 \mathrm{fdd} 0$ (consulté le : 19/01/2009).

Blog personnel de Serge Tisseron : http://squiggle.be/serge-tisseron/nouveaux-reseauxle-danger.html (consulté le : 13/07/2009).

Dossier pédagogique sur l'œuvre de Sophie Calle sur le site du Centre Georges Pompidou : http://www.centrepompidou.fr/education/ressources/ENScalle/popup02.html (consulté le : 12/06/2009).

Études photographiques http://etudesphotographiques.revues.org/ (consulté le : $10 / 10 / 2009)$

GEIMER, Peter, «L'autorité de la photographie, Révélation d'un suaire », Études photographiques, $\mathrm{n}^{\circ} 6$, mai 1999, p. 67-99:

http://etudesphotographiques.revues.org/index189.html (consulté le : 03/03/2009).

HÉTU, Julie, Voyage entre les genres, l'entre-deux de Claude Cahun : (consulté le : 13/07/2009) http://www.chass.utoronto.ca/french/SESDEF/entredeux/juliehetu.htm. 
La fin de l'information?, Entretien avec Bernard Poulet et Vincent Giret par Thierry Pech, 18-04-2008, http://www.laviedesidees.fr/La-fin-de-l-information.html (consulté le : 03/03/2009).

Le magazine Life : $\underline{w w w . l i f e . c o m}$ (consulté le 03/03/2009).

MARTY, Robert, La dimension perdue de Roland Barthes :

http://robert.marty.perso.cegetel.net/semiotique/dimension-perdue.pdf (consulté le : 11/07/2009).

MONTIER, Jean-Pierre, La photographie « ... dans le Temps. » De Proust à Barthes et réciproquement. Mis en ligne le 20 avril 2003.

http://pierre.campion2.free.fr/montier_proustbarthes.htm (consulté le : 01/08/2009).

MORAT, Florence, Tendances de la photographie contemporaine, (dossier pédagogique de la page web du Centre Georges Pompidou),

http://www.centrepompidou.fr/education/ressources/ENS-photocontemporaine/ENS-

PhotoContemporaine.htm\#artistes (consulté le : 03/03/2005).

PUFF, Jean-François, «L'écriture photographique de Quelque chose noir », Les

Cahiers de La Licorne, Les Cahiers Roubaud, Cahiers $n^{\circ} 1,2007$. Disponible en ligne : http://edel.univ-poitiers.fr/licorne/document.php?id=3956 (consulté le : 01/08/2009).

RABATE, Jean-Michel, «Introduction », Writing the image after Roland Barthes, Philadelphia, University of Pennsylvania Press, 1997 (consulté le : 10/09/09) :

http://books.google.com/books?id=2V_4eBK6klMC\&lpg=PP1\&dq=writing\%20the\%20 image\%20after\%20roland\%20barthes $\&$ hl=fr\&pg=PP1\#v=onepage \&q=\&f=false.

Sur l'histoire du groupe Art\&Language «Blurting in Art \& Language » : http://blurtingin.zkm.de/e/home (consulté le : 03/06/2009).

\section{Albums de photographies et catalogues d'exposition}

BARBIERI, Gian Paolo, Madagascar, préface de Michel Tournier «La substance grise de Madagascar », Paris, édition Assouline, 1995.

BARBIERI, Gian Paolo, Tahiti Tatoos, préface de Michel Tournier «Quand la peau parle », Cologne, éd. Taschen, 1998.

BÉLÉGOU, Jean-Claude, Visages suivi de Les Amants, Les Cahiers de la photographie, n 26, ACCP, 1992.

CARTIER-BRESSON, Henri, Portraits par Henri Cartier-Bresson, publié à l'occasion de l' exposition Le Silence intérieur d'une victime consentante à la Fondation Henri Cartier Bresson à Paris entre le 18 janvier et 9 avril 2006, Paris, Thames \& Hudson, 2006. 
Double vie, double vue, catalogue d'exposition, Paris, Actes Sud, Fondation HenriCartier Bresson, 1996.

FRANK, Robert, Les Américains, Paris, Delpire, 1958.

FRANK, Robert, The Lines of my hand, Zurich/New York, Alltag/Parkett, 1989.

AUBENAS, Sylvie (dir.); BIROLEAU, Anne (dir), Portraits/Visages 1853-2003, Bibliothèque nationale de France/Gallimard, 2003.

LARTIGUE, Jacques-Henri, Instants de ma vie, Paris, Sté Nlle des Éditions du Chêne, 1973.

LARTIGUE, Jacques-Henri, Un album de famille de la belle époque, Lausanne, Ami Guichard Editeur et Edita S.A., 1966.

MATHON Catherine (dir.), Duchenne de Boulogne, Paris, Ecole nationale supérieure des beaux-arts, 1999.

MICHALS, Duane, Vraies Rêves, Histoires photographiques de Duane Michals, Chêne, Paris, 1977.

PARR, Martin, Signs of the Times, Manchester, Cornerhouse, 1992.

PARR, Martin, Small world, London, Dewi Lewis Publishing, 1995.

PLANTUREUX, Chantal-Meyer, La photographie de Théâtre ou la mémoire de l'éphémère, Paris, Paris Audiovisuel, 1992.

PLOSSU, Bernard, Surbanalisme, séquences photographiques de Bernard Plossu, préface de Sergio Leone, Paris, Chêne, 1972.

Réels, fictions, virtuel, catalogue publié à l'occasion des Rencontres internationales de la Photographie d'Arles, Actes Sud, 1996.

SIMON, Claude, Photographie 1937-1970 (avec une préface de Denis Roche), Paris, Maeght, 1992.

TADIE, Jean-Yves (dir), Marcel Proust, l'écriture et les arts, Paris, Gallimard/Bibliothèque nationale de France/Réunion des musées nationaux, 1999.

$\underline{\text { Sur Internet - sites personnels de photographes et galeries photographiques : }}$

Bernard Faucon : http://www.bernardfaucon.net (consulté le : 28/10/2009).

Bernard Plossu : http://www.documentsdartistes.org/artistes/plossu/repro.html (consulté le : 13/07/2009).

Bill Brandt à la galerie Fahey/Klein :

http://www.faheykleingallery.com/featured_artists/brandt/brandt_frames.htm (consulté le : 04/05/2009). 
Cindy Sherman : http://www.cindysherman.com/ (consulté le : 13/07/2009).

Claude Cahun : http://www.connectotel.com/cahun/(consulté le : 13/07/2009).

Constance Villeroy : http://www.constancevilleroy.com/ (consulté le : 01/08/2009).

Duane Michals chez Christies :

http://www.christies.com/LotFinder/ZoomImage.aspx?image=/LotFinderImages/D5165

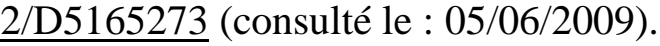

Duane Michals, à la galerie Fahey/Klein consulté le : 04/08/2009) :

http://www.faheykleingallery.com/featured_artists/michals/michals_frames1.htm

Edward Weston : http://www.edward-weston.com/edward_weston_nudes.htm (consulté le : 04/05/2009).

Evgen Bavčar : http://www.zonezero.com/exposiciones/fotografos/bavcar/index.html (consulté le : 09/10/2009).

François-Marie Banier : http://www.fmbanier.com (consulté entre 2007 - 2009).

Georges Rousse : http://www.georgesrousse.com/ (consulté le : 14/09/2009).

Hans Georg Berger - photos d'Hervé Guibert :

http://www.hansgeorgberger.de/page/herve/herve_photo.html (consulté le : 08/08/2009).

Hervé Guibert : http://www.herveguibert.net (consulté le : 08/08/2009).

Jean-Claude Bélégou http://www.belegou.org (consulté le : 28/07/2009).

La Donation Jacques Henri Lartigue : http://www.lartigue.org/index.html (consulté le : 20/08/2009).

La galerie Agathe Gaillard http://www.agathegaillard.com/ (consulté le : 10/10/2009).

La galerie municipale du Château d'eau à Toulouse http://www.galeriechateaudeau.org/ (consulté le : 10/10/2009).

La Maison Européenne de la Photographie http://www.mep-fr.org/default_test_ok.htm (consulté le : 10/10/2009).

Larry Clark : http://www.mep-fr.org/actu/lc.htm\# (consulté le : 13/07/2009).

Le musée Nicéphore Niepce de Chalon-sur-Saône : http://www.museeniepce.com/ (consulté le : 10/10/2009).

Les archives Yves Klein : http://www.yveskleinarchives.org/works/works1_fr.html (consulté le : 03/03/2009).

Louise Merzeau : http://www.merzeau.net/photo/gal/jour/0009.html (consulté le : 10/08/2009). 
Michel Séméniako : http://www.michel-semeniako.com/ (consulté le : 09/10/2009).

Miwa Nishimura : http://www.miwanishimura.com/ (consulté le : 16/07/2009).

Nan Goldin : http://www.centrepompidou.fr/expositions/nangoldin/ (consulté le : 13/07/2009).

Nicolas Bouvier http://www.peregrin-genevois.net/1bouvier/expobouvier.html (consulté le : 13/07/2009).

Philippe de Jonckheere : http://www.desordre.net (consulté le : 13/08/2009).

Pierre Molinier à la galerie Ubu à New York :

http://www.ubugallery.com/phpwcms/?id=34,149,0,0,1,0 (consulté le : 13/07/2009).

Robert Mapplethorpe : http://www.mapplethorpe.org/ (consulté le : 13/07/2009).

Sophie Calle à la Galerie Perrotin : http://www.galerieperrotin.com/artiste-

Sophie_Calle-18.html\# (consulté le : 07/06/2009).

Tate Galery à Londre :

http://www.tate.org.uk/modern/exhibitions/ubsphotography/left.shtm (consulté le : 25/05/2009).

Valéry Jouve: http://www.valeriejouve.com/\# (consulté le : 25/05/2009).

William Eggleston : http://www.egglestontrust.com/ (consulté le : 25/05/2009).

Yves Trémorin http://tremorin.wunderblock.com (consulté le : 28/07/2009).

\section{$\underline{\text { Films }}$}

«Sophie Calle », Contacts, DVD, volume 2, Réalisation : Jean-Pierre Krief, Arte, 19922000 .

CALLE, Sophie, Double - Blind, [1992] Paris, CNC, DVD, 2007.

DEPARDON, Raymond, Profils paysans I-III, Palmeraie et désert/Canal+ 2008.

DEPARDON, Raymond, Reporters, produit en 1981 et reproduit par SEPT Vidéo, 1993.

DEPARDON, Raymond, Numéros zéro naissance d'un journal, reproduit par ARTE France, 2007.

GUIBERT, Hervé, La Pudeur ou l'Impudeur, vidéo, diffusé sur TF1, 30 Jan. 1992. 


\section{Théorie photo-littéraire}

ALBERS, Irene, Claude Simon, Moments photographiques, Villeneuve d'Asq, Presses Universitaire de Septentrion, 2007.

ARROUYE, Jean, (dir.) La Photographie au pied de la lettre, Provence, Publications de l'Université de Provence, Collection " Hors champ ", 2005.

BAURET, Gabriel, « Autobiographie littéraire et autobiographie photographique », Les Cahiers de la Photographie, «Photobiographie », n 13, 1984, p. 13 - 27.

CALLE-GRUBER, Mireille, Claude Simon, chemins de la mémoire, Grenoble, PUG, 1993.

EDWARDS, Paul, Soleil Noir. Photographie et Littérature des origines au surréalisme, France \& Royaume-Uni, Rennes, PUR, 2008.

GARAT, Anne-Marie, Photos de famille, Paris, Seuil, 1994.

GROJNOWSKI, Daniel, Photographie et langage, Paris, José Corti, 2002.

HAMON, Philippe, Imageries. Littérature et image au XIX siècle, Paris, José Corti, 2001.

JOPECK, Sylvie, La photographie et l'(auto)biographie, Anthologie et lecture accompagnée, Paris, Gallimard, 2004.

Les Cahiers de la photographie, «Littérature et photographie », n², 1981.

Les Cahiers de la Photographie, «Photobiographie », n 13, 1984.

MÉAUX, Danièle - VRAY, Jean-Bernard (dir.), Traces photographiques, traces autobiographiques, Saint-Étienne, Publications de l'Université de Saint-Étienne, 2004.

MÉAUX, Danièle (dir.), Études romanesques, Photographie et romanesque, $\mathrm{n}^{\circ} 10$, CAEN, Lettres modernes minard, 2006.

MÉAUX, Danièle, La photographie et le temps. Le déroulement temporel dans l'image photographique, Aix-en-Provence, Université de Provence, 1997.

MONTIER, Jean-Pierre ; LOUVEL, Liliane ; MEAUX, Danièle ; ORTEL, Philippe (dir.), Littérature et photographie, Rennes, PUR, 2008.

MORA, Gilles ; NORI, Claude, L'été dernier. Manifeste photobiographique, Paris, Étoile/Cahiers du cinéma, col. "Écrits sur l'image" 1983.

NACHTERGAEL, Magali, Esthétiques des mythologies individuelles, thèse sous la direction d'Eric Marty soutenue à l'Université Paris 7 en 2008.

ORTEL, Philippe, La Littérature à l'ère de la photographie, Nîmes, Jacqueline Chambon, 2002. 
PEETERS, Benoît, Écrire l'image, Paris, Les impressions nouvelles, 2009.

PIRET, Pierre, La littérature à l'ère de la reproductibilité technique. Réponses littéraires au nouveau dispositif représentatif crée par les médias modernes. Penser la représentation I., Paris, L’Harmattan, col. "Champs visuels", 2007.

RABB, Jane M. (dir.), Literature and photography. Interactions 1840-1990. A critical anthology, Albuquerque, University of New Mexico Press, 1995.

THÉLOT, Jérôme, Les inventions littéraires de la photographie, Paris, PUF, 2003.

\section{$\underline{\text { Sur Internet : }}$}

ALBERS, Irene, Claude Simon, Moments photographiques, Villeneuve d'Asq, Presses Universitaire de Septentrion, 2007. Disponible partiellement sur Google books : http://books.google.com/books? id=qOKOvWozKGgC\&printsec=frontcover\&hl=fr\#v=0 nepage \&q=\&f=false (consulté le 03/09/2009).

DULONG, Annie, Le geste créateur, 2003, http://www.unites.uqam.ca/grep/AnnieDulong.pdf (consulté le : 08/08/2008).

GENON, Arnaud ; ERTAUD, Guillaume, « Entre textes et photographies : L'autofiction chez Hervé Guibert », Image [\&] Narrative, n ${ }^{\circ}$ 19, 2007. Journal électronique disponible en ligne sur :

http://www.imageandnarrative.be/autofiction/genon_ertaud.htm (consulté le : 08/08/2009).

La poésie au carrefour des arts - le site du groupe de recherche «Poésie et médias » à Paris IV - Sorbonne : http://poesie-arts.paris-sorbonne.fr/ (consulté le : 03/06/2008).

LOUVEL, Liliane, « Photography as Critical Idiom and Intermedial Criticism », Poetics Today, Spring 2008 : http://poeticstoday.dukejournals.org/cgi/reprint/29/1/31.pdf (consulté le : 20/09/2009).

MEIZEL, Laureline, La métalepse révélée au prisme du Mauvais œil, un roman-photo de Benoît Peeters et Marie-Françoise Plissart. Image [\&] Narrative journal électronique, vol. X, issue 2, 2009. Disponible sur Internet:

http://www.imageandnarrative.be/1_auteur_et_son_imaginaire/meizel.htm (consulté le : 28/08/2009).

MONTEMONT, Véronique, «Anny Duperey, Le Voile noir », mis en ligne le 19 janvier 2007. Disponible sur : http://www.item.ens.fr/index.php?id=27105 (consulté le : 03/08/2009)

MOULINIER, Didier, La poésie visuelle au XX $X^{e}$ siècle : http://www.la-poesieelementaire.net/poetique/poetique_poesie-visuelle.htm (consulté le : 20/10/2008).

PERIN, Emel Yavuz, « Photographie, séquence et texte. Le Narrative art aux confins d'une temporalité féconde », Image and narrative, n`23 nov. 2008, disponible sur le 
site : http://www.imageandnarrative.be/Timeandphotography/yavuz.html (consulté le : 13/07/2009).

POINAT, Frédérique, «" Un certain chaos résolu " : les derniers choix photographiques et littéraires d'Hervé Guibert », La Chouette, 2001 (consulté le : 03/08/2009) : http://www.bbk.ac.uk/lachouette/chou32/Poinat32.PDF.

Zones de photolittérature : http://photolitterature.hautetfort.com/ (consulté le : 08/06/2009).

\section{Textes photo-littéraires}

BARTHES, Roland, L'Empire des signes, Genève, Skira, col. "Les sentiers de la créations", 1970 (réédition en livre de poche, Flammarion, 1980).

BARTHES, Roland, Roland Barthes par Roland Barthes, Paris, Seuil, col. "Écrivains de toujours", 1976.

BOUBAT, Edouard, Miroirs autoportraits, (préface de Michel Tournier), Paris, Denoël, 1973.

BRETON, André, Nadja, Paris, Gallimard, 1928 (rééd. en Le livre de Poche), 1964.

CALLE, Sophie, Des histoires vraies + dix, Arles, Actes sud, 2002.

CALLE, Sophie, Disparitions, Arles, Actes Sud, 2000.

CALLE, Sophie, Doubles-jeux, Arles, Actes sud, 1998.

CALLE, Sophie, Douleur exquise, Arles, Actes sud, 2003.

CALLE, Sophie, Fantômes, Arles, Actes Sud, 2000.

CALLE, Sophie, L'Érouve de Jérusalem, Arles, Actes sud, 2002.

CALLE, Sophie, L'Hôtel, Paris, Étoile, col. "Écrit sur l'image", 1984.

CALLE, Sophie, Les dormeurs, Arles, Actes sud, 2000.

CALLE, Sophie, Prenez soins de vous, Arles, Actes sud, 2007.

CALLE, Sophie, Souvenirs de Berlin-Est, Arles, Actes sud, 1999.

CALLE, Sophie. Suite Vénitienne suivi de BAUDRILLARD, Jean. «Please follow me », Paris, L'Étoile, col. "Écrit sur l'image", 1983. 
COUPRIE, Katy; LOUCHARD, Antonin, Tout un monde, Paris, Thierry Magnier, 2000.

CREWDSON, Gregory, Hover, San Francisco, Artspace Books, 1998.

DEPARDON, Raymond, Correspondance new-yorkaise, (textes et photographies). BERGALA, Alain, Les absences du photographe, Paris, Étoile/Cahiers du cinéma, col. "Écrits sur l'image", 1986.

DEPARDON, Raymond, Errance, Paris, Seuil, 2003.

DEPARDON, Raymond, La Ferme du Garet, Arles, Actes Sud, 1997.

DEPARDON, Raymond, La solitude heureuse du voyageur. Précédé de Notes, Paris, Points, 2006.

DEPARDON, Raymond, Notes, Paris, Arfuyen, 1979.

DOISNEAU, Robert, 1,2,3,4,5, Lausanne, édition Clairefontaine, 1955.

DUPEREY, Anny, Le voile noir, Paris, Seuil, 1992.

ERNAUX, Annie, MARIE, Marc, L’usage de la photo, Paris, Gallimard, 2005.

GUIBERT, Hervé, L’image fantôme, Paris, Minuit, 1981.

GUIBERT, Hervé, La photo inéluctablement, Paris, Gallimard, 1999.

GUIBERT, Hervé, Suzanne et Louise (Roman-photo), Paris, Hallier, 1980.

GUIBERT, LEFEVRE, LEMERCIER, Le Photographe, Paris, Dupuis, tome 1-3, 20032006.

HOBAN, Tana, Les couleurs et des choses, Paris, L'école des loisirs, 1994.

HOBAN, Tana, Que vois-tu ?, Paris, Kaléidoscope, 2003.

HÖCH, Hannah, Bilderbuch, Berlin, The Green Box, 2008 (réédition à partir du livre de 1945).

LACHMAN, Edward; LEVINE, Elieba, Chausse-trappe, (Préface d'Alain RobbeGrillet) Paris, Minuit, 1981.

MACE, Gérard, La mémoire aime chasser dans le noir, Paris, Gallimard, 1993.

MACE, Gérard, La photographie sans appareil, Cognac, Le Temps qu'il fait, 2000.

PEETERS, Benoît ; PLISSART, Marie-Françoise Fugues, Paris, Minuit, 1983.

PEETERS, Benoît; PLISSART, Marie-Françoise Plissart, Droit de regards, Paris, Minuit, 1985 (suivi d'une lecture de Jacques Derrida).

PEETERS, Benoît ; PLISSART, Marie-Françoise, Le mauvais ail, Paris, Minuit, 1986. 
PEETERS, Benoît ; PLISSART, Marie-Françoise, Prague, Paris, Autrement, 1985.

RODENBACH, Georges, Bruges-la-morte, Paris, Flammarion, (1892) 1998.

ROUBAUD, Jacques, Quelque chose noir, Paris, Gallimard, 1986.

SEMENIAKO, Michel, Exil, textes de Louise L. Lambrichs, Paris, Éd. Trans Photographic Press, 2004.

TOURNIER, Michel, «Les suaires de Véronique », Le Coq de bruyère, Paris, Gallimard, 1978.

TOURNIER, Michel, Le Crépuscule des masques : photos et photographes, Paris, Hoëbeke, 1992.

VILLEROY, Constance (photographe) ; PREMIEL, Gérard (écrivain), Petits trésors restés dehors, Paris, Factory Editions, 2005.

WILLEMS, Sandrine ; PLISSART, Marie-Françoise, Élégie à Michel-Ange, Bruxelles, Les Impressions Nouvelles, 2005.

WILLIAMSON, Janice, Crybaby!, Edmonton, Ne West, 1998.

\section{$\underline{\text { Sur Internet : }}$}

RODENBACH, Georges, Bruges-la-morte, Paris, Flammarion, 1892 : http://users.skynet.be/fa007429/brutxt.htm (consulté le : 23/07/2009).

Romans-photos en ligne sur le site de Villabar : http://www.art-villabar.org/ (consulté le : 13/08/2009).

VILLEROY Constance, (photographe) ; PREMIEL Gérard, (écrivain), Petits trésors restés dehors, Paris, Factory Editions, 2005. (Voir un extrait sur le site de l'éditeur : http://www.linternaute.com/sortir/livre/beaux-livres/petits-tresors-restesdehors/diaporama/1.shtml (consulté le : 01/08/2009).

Voir la liste des ouvrages photo-littéraires chez Fatamorgana :

http://www.fatamorgana.fr/collections/grande-collection-hotel-du-grand-miroir (consulté le : 13/08/2009).

Voir la liste des ouvrages photo-littéraires chez l'éditeur «Le Grand Os », spécialisé dans l'édition de livres d'artiste et de livres mêlant la poésie et la photographie: http://www.legrandos.com/htm_france/catalogue.htm\# (consulté le : 13/08/2009).

Voir la liste des ouvrages photo-littéraires chez publie.net :

http://www.publie.net/tnc/spip.php?mot9 (consulté le : 13/08/2009).

WILLEMS, Sandrine ; PLISSART, Marie-Françoise, Élégie à Michel-Ange, Bruxelles, Les Impressions Nouvelles, 2005. Voir un extrait sur le site de l'éditeur : http://www.lesimpressionsnouvelles.com/extraits/Michelangeextrait.pdf (consulté le : 28/08/2009). 


\section{Sur la relation texte/image :}

BAUDRILLARD, Jean, Simulacres et simulations, Paris, Galilée, 1981.

BELTING, Hans, Pour une anthropologie des images, Paris, Gallimard, 2004.

BUTOR, Michel, Les mots dans la peinture, Genève, Paris, Albert Skira, Flammarion, 1967.

DELEUZE, Gilles, L’image-mouvement, Paris, Minuit, 1983.

DÉSIRAT, Dominique, «Préface », in DU BOS, Réflexions critiques sur la poésie et sur la peinture, Paris, École Nationale Supérieure des Beaux-Arts, 1993, p. 10 -14.

DIDI HUBERMAN, Georges, La ressemblance par contact, Paris, Minuit, 2008.

ISER, Wolfgang, L'acte de lecture, théorie de l'effet esthétique, Bruxelles, Pierre Madraga, (traduit de l'allemand par Sznycer Evelyne) 1976.

KIBÉDI VARGA, Áron, Discours, récit, image, Liège - Bruxelles, Pierre Mardaga, 1989.

LOUVEL, Lilian, L'œil du texte, Presses Universitaire de Toulouse-Le Mirail, 1998.

LOUVEL, Liliane, SCEPI, Henri (dir.) Textes/Images : nouveaux problèmes, Rennes, PUR, 2005.

MAUNET, Isabelle, La Poésie à la lettre et à la question : Du coup de dés aux poésies concrète et visuelle, thèse soutenue en 2000 à l'Université François Rabelais (Tours) sous la dir. de Jean-Claude Lieber.

MONTANDON, Alain (dir.), Iconotextes, Paris, Ophrys, 1990.

PANOFSKY, Ervin, Essais d'iconologie, Oxford, Oxford University Press, 1967.

PRUDON, Montserrat (dir.), Peinture et écriture 3. Frontières éclatées, Paris, La Différence, 2000.

VINCINGUERRA, Lorenzo, «Le sens de l'image », Magazine littéraire, $\mathrm{n}^{\circ}$ 370, novembre 1998 .

WEISSTEIN, Ulrich, " Comparing Literature and Art », in Proceedings of the IX. Congress of International Comparative Literature Association, Innsbruck, University Press, 1979, p. $24-47$.

\section{$\underline{\text { Sur Internet : }}$}

La revue Image and Narrative: http://www.imageandnarrative.be/ (consulté le: 03/02/2008). 
La revue Texte/image: http://www.revue-textimage.com/actualite.htm (consulté le : 03/02/2008).

MICHAUX, Henri, Lecture de huit lithographies de Zao Wou-ki, in Euvres de Michaux, Paris, Gallimard, Bibliothèque de la Pléiade, vol. II, 2001. Cité sur le site de Jean-Michel Maulpoix : http://www.maulpoix.net/zao.html (consulté le : 24/10/2008).

MONTANDON, Alain, «iconotexte » Dictionnaire International des Termes Littéraires : http://www.ditl.info/arttest/art2202.php (consulté le 08/12/07).

Site de l'Équipe de Recherche Interdisciplinaire sur Elsa Triolet et Louis Aragon : http://www.robertalessi.net/vigier/ERITA/spip.php?article87 (consulté le : 16/05/2009).

SOUCHIER, Emmanuel, «L'image du texte, pour une théorie de l'énonciation éditoriale », Les Cahiers de médiologie, 6 (1998), 137-145.

http://www.mediologie.org/collection/06_mediologues/souchier.pdf (consulté le : 10/09/2009).

UBU web : http://www.ubu.com/ (consulté le : 03/02/2008).

\section{Théorie littéraire}

BACHELARD, Gaston, La poétique de l'espace, Paris, PUF, (1957) 1998.

BARTHES, Roland, «La mort de l'auteur » repris dans : Le bruissement de la langue, Paris, Seuil, 1984, p. 61-67.

BARTHES, Roland, Sade, Fourier, Loyola, Euvres complètes, éd. revue, corrigée et présentée par Éric Marty, t. 3, Paris, Seuil, 2002.

BLANCHOT, Maurice, L’espace littéraire, Paris, Gallimard, 1992.

COLLOT, Michel, (dir.), Espace et poésie, Paris, ENS, 1987.

COLLOT, Michel, «La syntaxe nominale dans la poésie française », Ellipses, blancs, silences, actes du colloque du CICADA, 6-8 décembre 1990, textes réunis par Bertrand Rougé, Pau, Université de Pau, 1992, p. 105-114.

COLLOT, Michel, Francis Ponge entre mots et choses, Seyssel, Champ Vallon, 1991.

FOREST, Philippe, Histoire de "Tel Quel", Paris, Seuil, 1995.

HERSCHBERG-PIERROT, Anne, La stylistique de la prose, Paris, Belin, 1993.

HUBERT, Marie-Claude, Le théâtre, Paris, Armand Colin, 2008.

JOURDE, Pierre, TORTONESE, Paolo, Visages du double, Paris, Nathan, 1996. 
LECARME Jacques, LECARME-TABONE, Éliance, L'autobiographie, Paris, Armand Colin, 1997, rééd. 2004.

LEJEUNE, Philippe, Le Pacte autobiographique, Paris, Seuil, 1975.

MURA-BRUNEL, A. ; SCHUEREWEGEN, F. (dir.), L'Extime/L'Intime, CRIN (Cahiers de Recherches des Instituts Néerlandais de Langue et Littérature Française), 41, Amsterdam - New York, 2002.

RICEUR, Paul, La métaphore vive, Paris, Le Seuil, Point essais, 1975.

RICOEUR, Paul, Temps et Récits, «Le Temps raconté », t. 3. Paris, Seuil 1985.

ROEGIERS, Patrick (dir.), L’ère du double, Paris, Marval, 1998.

TOURET, Michèle (dir.), Histoire de la littérature française du XX siècle, t. 2, Rennes, PUR, 2008.

TOURNIER, Michel, Journal extime, Paris, La Musardine, 2002.

VANOOSTHUYSE, François, «Dispositif et temporalité », in Fiction et vues imageantes : typologies et fonctionnalités, sous la dir. de Bérengère Voisin, (Actes du colloque qui s'est tenu à Tartu le 4 et 5 avril 2008, publiés dans Studia Romanica Tartuensia VII.)

\section{$\underline{\text { Sur Internet : }}$}

« L'autoportrait » $T D C \mathrm{n}^{\circ} 853$, avril 2003. Disponible en ligne :

http://www.sceren.fr/RevueTDC/853-65992.htm (consulté le : 08/08/2009)

Actes du colloque « Fiction et vues imageantes » à Tartu (Estonie) 4-5 avril 2008.

http://www.fl.ut.ee/orb.aw/class=file/action=preview/id=445799/SRT+VII+-

+Vues+imageantes.pdf (consulté le : 20/09/2009).

BLANKCEMAN, Bruno, « Nouvelle et Autofiction : le cas Guibert », in La nouvelle aux frontières des autres genres, du Moyen-Âge à nos jours (Tome II, sous la direction de V. Engel et M. Guissart, Academia Bruylant, Bruxelles, 2001) disponible sur www.herveguibert.net (consulté le : 09/06/2008).

BON, François : http://www.tierslivre.net/spip/ (consulté le : 03/08/2009).

BRAUDEAU, Michel, « Ecrire contre la mort », Le Monde, 2 mars 1990 : http://www.herveguibert.net/index.php?2006/05/13/21-litterature-a-lami-qui-ne-ma-passauve-la-vie (consulté le : 10/08/2009).

Le site de Philippe Lejeune : http://www.autopacte.org/pacte_autobiographique.html (consulté le : 18/07/2009). 
Le site Internet de l'équipe de recherche de l'Université de Toulouse :

http://galatea.univ-tlse2.fr/pictura/UtpicturaServeur/AideRecherche.php?numero=15 (consulté le : 03/03/2009).

MAULPOIX, Jean-Michel, La poésie française depuis 1950, http://www.maulpoix.net, (consulté le : 26/11/2008).

PEETERS, Heidi. «The Networked Self : Autofiction on MySpace. » (Le « je » du réseau : autofiction sur Myspace), Image [\&] Narrative, ${ }^{\circ} 19$ (2007). Journal électronique disponible sur : http://www.imageandnarrative.be/autofiction/peeters.htm (consulté le : 30/05/2009).

Sur l'autofiction : http://www.autofiction.org (consulté le : 13/07/2009).

\section{Francois-Marie Banier ${ }^{1}$ :}

\section{$\underline{\text { Roman et prose }}$}

Les résidences secondaires, Paris, Grasset, 1969 / Gallimard Folio nº 2444, 1993.

Le Passé composé, Paris, Grasset 1971 / Gallimard Folio n² 2564, 1994.

La tête la première, Paris, Grasset, 1972 / Gallimard Folio n² 2715, 1995.

Balthazar, fils de famille, Paris, Gallimard, 1985 / Gallimard Folio n¹828, 1987.

Sur un air de fête, Paris, Gallimard, 1990 / Gallimard Folio n 3283, 1999.

Les femmes du métro Pompe, Paris, Gallimard, 2006 / Gallimard Folio n 4976, 2008.

Johnny Dasolo, Gallimard, Paris, 2008.

\section{Théâtre}

Hôtel du Lac, Gallimard, Paris, 1975.

Nous ne connaissons pas la même personne, Grasset, Paris, 1978.

Je ne t'ai jamais aimé, Gallimard, Paris, 2000.

\footnotetext{
${ }^{1}$ Pour la bibliographie complète voir le site personnel de Banier : http://www.fmbanier.com (consulté le : 10/10/2006). Pour une meilleure visibilité du parcours de l'écrivain nous présentons ses œuvres en ordre chronologique.
} 


\section{Préface}

BANIER François-Marie, « That little laugh Andy had » Préface du catalogue d'exposition Red Books, Pace MacGill Gallery, New York, Steidl, Göttingen, 2004 : Pour le texte : http://www.fmbanier.com/tx_010_that_little_laugh_andy_had_0 ; et les polaroïds pris par Andy Warhol sur Banier :

http://www.fmbanier.com/book_warhol_red_books_cat_pace_macgill_gallery_new_yor k_2004 (consulté le : 26/10/2009).

\section{$\underline{\text { Photographies }}$}

Photographies, Gallimard / Denoël, Paris, 1991.

Past-Present, New-York, William Morrow, 1996.

Private Heroes, cat. Stuttgart, Württembergischer Kunstverein, Cantz, 1998.

Vivre, cat. São Paulo, Pinacoteca do Estado; Rio de Janeiro, Museu de Arte Moderna, 1999.

François-Marie Banier. Fotos y pinturas (Photos et peintures), catalogue d'exposition qui a eu lieu à Buenos Aires au Centre Culturel Recoleta du 17 avril au 21 mai 2000, Paris, Gallimard, 2000.

Banier Brésil, Paris, Gallimard, 2001.

François-Marie Banier, exposition rétrospective, Paris, Maison européenne de la photographie, 26 mars-15 juin 2003, Paris, Gallimard, 2003.

On the Edge, Museum House Lange, Krefeld, 2004.

Perdre la tête, Martin d'Orgeval (éd.), cat. Rome, Académie de France à Rome, Villa Medici; Nice, Théâtre de la Photographie et de l'image, Gallimard/Steidl, 2005-2006.

Ouvrages critiques (repris en majorité sur le site de F-M. Banier)

APPELT, Dieter, « Principe, fonction, forme et réalité subjective dans les photographies de François-Marie Banier » préface au catalogue de l'exposition qui a eu lieu au Gagosian Gallery, Beverly Hills, Villa Oppenheim, Berlin, 2007 :

http://www.fmbanier.com/node/1990 (consulté le : 16/05/2009).

BANIER, François-Marie, «Entretien réalisé par Martin d'Orgeval », Perdre la tête, Martin d'Orgeval (éd.), cat. Rome, Académie de France à Rome, Villa Medici; Nice, Théâtre de la Photographie et de l'image, Gallimard/Steidl, 2005-2006 : http://www.fmbanier.com/martin_d_orgeval_3 (consulté le : 16/05/2009). 
D'ORGEVAL, Martin, «L'autre éternel », François-Marie Banier, rétrospective de 2003, Paris, Maison européenne de la photographie, 26 mars-15 juin 2003, Paris, Gallimard, $2003:$ http://www.fmbanier.com/martin_d_orgeval_4 (consulté le : 16/05/2005).

D'ORGEVAL, Martin, Notes sur le travail, Perdre la tête, Martin d'Orgeval (éd.), cat. Rome, Académie de France à Rome, Villa Medici; Nice, Théâtre de la Photographie et de l'image, Gallimard/Steidl, 2005-2006 :

http://www.fmbanier.com/martin_d_orgeval_6 (consulté le : 12/10/2009).

MATTHIEUSSENT, Brice, «Une peinture sans début ni fin », in BANIER, FrançoisMarie, Fotos y pinturas (Photos et peintures), catalogue d'exposition, Buenos Aires, Centre Culturel Recoleta, 17 avril - 21 mai 2000, publié à Paris, Gallimard, 2000.

Michel Tournier, « François-Marie Banier et la création photographique », On the Edge, Museum House Lange, Krefeld, 2004 : http://www.fmbanier.com/michel_tournier (consulté le : 13/05/2009).

ROEGIERS, Patrick, «Le roman photographique de François-Marie Banier », in François-Marie Banier, (catalogue de l'exposition, Paris, Maison européenne de la photographie, 26 mars-15 juin 2003), Paris, Gallimard, 2003 : http://www.fmbanier.com/patrick_roegiers_1 (consulté le : 15/05/2009).

ROEGIERS, Patrick, Un classique de la modernité, catalogue d'exposition FrançoisMarie Banier, Tokyo Metropolitan Museum of Photography, Asahi Shimbun, 2000 : http://www.fmbanier.com/patrick_roegiers_2 (consulté le : 15/05/2009).

SANTANA, Raúl, «Un entretien avec François-Marie Banier », in BANIER, FrançoisMarie, Fotos y pinturas (Photos et peintures), catalogue d'exposition, Buenos Aires, Centre Culturel Recoleta, 17 avril - 21 mai 2000, publié à Paris, Gallimard, 2000, http://www.fmbanier.com/raul_santana (consulté le : 15/05/2009).

SZEGÖ, György, «Szelíd paparazzo, vad festő » (Paparazzo tempéré, peintre effréné), Fotómüvészet (L'art photographique) 2001, n¹/2. 


\section{Jean-Loup Trassard ${ }^{2}$ :}

\section{$\underline{\text { Roman et prose }}$}

L'amitié des abeilles (Nouvelles), Paris, Gallimard, 1961 et Cognac, Le Temps qu'il fait, 1985.

L'érosion intérieure, Paris, Gallimard, 1965.

L'ancolie, Paris, Gallimard, 1975.

Des cours d'eau peu considérables, Paris, Gallimard, 1981.

La Mayenne des chemins creux : 70 circuits de petite randonnée pédestre, Association départementale de la randonnée pédestre de la Mayenne - A.D.R.P.M., 1985.

Tardifs instantanés, Paris, Gallimard, 1987.

Paroles de laine, Paris, Gallimard, 1989.

Ligature, illustré par Daniel Nadaud, Plancoët, Hôtel continental, 1990.

Campagnes de Russie, Paris, Gallimard, 1992.

L'espace antérieur, Paris, Gallimard, 1993.

Dormance, Paris, Gallimard, 2000.

La Déménagerie, Paris, Gallimard, 2004.

Conversation avec le taupier, Cognac, Le Temps qu'il fait, 2007.

\section{$\underline{\text { Livres pour enfants }}$}

Les Graines d'homme, illustré par Florence Euvremer, Paris, Flammarion, 1971.

L'ours fariné, raconté en images par Thierry Dalby, Paris, L’École des loisirs, 1974.

Trois Noëls en forêt, illustré par Michel Gay, Paris, l'École des loisirs, 1981.

Histoires fraîches, illustré par Patrice Roy, Paris, l’École des loisirs, 1981.

\footnotetext{
${ }^{2}$ Une bibliographie détaillée est disponible sur le site du « Fond Jean-Loup Trassard » de l'Université d'Angers : http://bu.univ-angers.fr/index.php?S_file=archives/fiche.php\&ref_archive=13\#bibliographie (consulté le : 03/10/2006).

Pour une meilleure visibilité du parcours de l'écrivain nous présentons ses œuvres en ordre chronologique.
} 
Une Classe de neige, Paris, l'École des loisirs, 1982.

Une Classe de nature ou Comment repiquer les petits citadins en pleine terre, illustré par Bernard Jeunet, Paris, l'École des loisirs, 1984.

Rana, la menthe, illustré par John Howe, Moulins, Ipomée, 1984.

Bleue bergère, illustré par Bernard Jeunet, Paris, l'École des loisirs, 1985.

\section{$\underline{\text { Livres d'artiste }}$}

Lettre à la prêle, en collaboration avec Odile Levigoureux, Cognac, Le Temps qu'il fait, 2006.

Lettre au lin, en collaboration avec Odile Levigoureux, Cognac, Le Temps qu'il fait, 2006.

\section{Photographie}

Territoire (Textes et photographies), Cognac, Le Temps qu'il fait, 1989.

Images de la terre russe (Textes et photographies), Cognac, Le Temps qu'il fait, 1990.

Ouailles (Textes et photographies), Cognac, Le Temps qu'il fait, 1991.

Archéologie des feux (Textes et photographies), Cognac, Le Temps qu'il fait, 1993.

Inventaire des outils à main dans une ferme (Textes et photographies), Cognac, Le Temps qu'il fait, 1995.

Objets de grande utilité (Textes et photographies), Cognac, Le Temps qu'il fait, 1995.

Tumulus (Photographies de J.-Ph. Reverdot), Cognac, Le Temps qu'il fait, 1996.

Les derniers paysans (Textes et photographies), Cognac, le Temps qu'il fait, 2000.

La Composition du jardin (Textes et photographies), Cognac, Le Temps qu'il fait, 2003.

Nuisibles (Textes et photographies), Cognac, Le Temps qu'il fait, 2005.

Le voyageur à l'échelle, (Textes et photographies), Cognac, Le Temps qu'il fait, 2006.

Sanzaki (Textes et photographies), Cognac, Le Temps qu'il fait, 2008. 
$\underline{\text { Ouvrages critiques }}$

ANTOINE, Philippe, «Voyages photobiographiques », in Traces photographiques, traces autobiographiques, (sous la dir. de Danièle Méaux et Jean-Bernard Vray), SaintÉtienne, Publications de l'Université de Saint-Étienne, 2004, p. 249-259.

ARROUYE, Jean, «Voir venir. Fonctionnement symbolique de la photographie dans Inventaire des outils à main dans une ferme », in L'écriture du bocage, sur les chemins de Jean-Loup Trassard / textes réunis et entretien par Arlette Bouloumié, Angers, Presses de l'Université d'Angers, 2000, p. 467-483.

BOULOUMIÉ, Arlette, «Photographie et Jeux d'illusion : Jean-Loup Trassard, Lucien Clergue et Bernard Faucon », L'art français et francophone depuis 1980, (sous la dir. de Michel Bishop et Christopher Elson), Amsterdam/New York, Rodopi, 2005, p. 31-38.

DUPOUY, Christine, «Un roman néolithique », Critique, $\mathrm{n}^{\circ}$ 655, décembre 2001, p. $942-954$.

FAHEY, Joseph, «Le grain de l'expérience : le rôle de l'image photographique dans les œuvres de Jean-Loup Trassard », in L'écriture du bocage, p.485-498.

GUICHARD, Jean-Paul, «La photographie est un jeu d'enfant », in L'écriture du bocage, p. 498-519.

«Entretien avec Arlette Bouloumié », in L'écriture du bocage, p. 567-602.

LAMARCHE-VADEL, Bernard, «Jean-Loup Trassard, un site pour son œuvre », in Ligne de mire, Paris, Editions Marval, 1995.

LE DANTEC, Denise, «Entretien avec Jean-Loup Trassard », L'École des Lettres, ${ }^{\circ} 8$, 15 février 1994, p. $57-60$.

PARA, Jean-Baptiste, «La langue et la terre : rencontre avec Jean-Loup Trassard », Europe, $\mathrm{n}^{\circ} 787-88,1994$, p. $191-196$.

RANNOU, Pascal, «Un mayennais au souffle cosmique : Jean-Loup Trassard », Voix d'ouest en Europe, souffles d'Europe en Ouest, Actes du colloque International d'Angers 21-24 mai 1992, textes réunis par Georges Cesbron, Angers, Presses Universitaire d'Angers, 1993, p. 559-572.

RICHARD, Jean-Pierre, L'état des choses. Études sur huit écrivains d'aujourd'hui, Paris, Gallimard, NRF, col. "Essais", 1990, p. 149-169.

TRASSARD, Jean-Loup, «Sous les nuages d'argent», in Prospectus des éditions du Temps qu'il fait, $\mathrm{n}^{\circ}$ 39, octobre 1994.

VAUGEOIS, Dominique, «Statut de la fiction et écriture du passé : le roman divinatoire de Jean-Loup Trassard », Roman 20 - 50, n 32, décembre 2001, p. 113-129.

VRAY, Jean-Bernard, «Jean-Loup Trassard: la dormance et la trace », in Traces photographiques, traces autobiographiques, p. 261-272. 
$\underline{\text { Sur Internet : }}$

ARROUYE, Jean, Intérieur de manoir, http://mucri-photographie.univparis1.fr/article.php?id=20 (consulté le : 21/07/2008).

CAMPION, Pierre, Composition à la française, Compte rendu du livre La Composition du jardin (Texte et photographies de Jean-Loup Trassard, aux éditions Le Temps qu'il fait, 2003) http://pierre.campion2.free.fr/trassard2.htm\#FN2 (consulté le : 07/05/2007

CAMPION, Pierre, Délicates images, compte rendu du livre Sanzaki (Textes et photographies de Jean-Loup Trassard, Cognac, Le Temps qu'il fait, 2008) : http://pierre.campion2.free.fr/trassard_sanzaki.htm (consulté le : 2009/04/05).

CAMPION, Pierre, Des blaireaux et des hommes, Compte rendu du livre Nuisibles (Textes et photographies de Jean-Loup Trassard, Cognac, Le Temps qu'il fait, 2005) http://pierre.campion2.free.fr/trassard_nuisibles.htm (consulté le : 07/07/2008).

\section{$\underline{\text { Lorand Gaspar }}$ :}

$\underline{\text { Poésie }}$

Amandiers, (huit estampilles d'Étienne Hajdú) Fata Morgana, 1980.

Egée suivi de Judée, Paris, Gallimard, 1980.

Sol absolu et autres textes, Paris, Gallimard, 1982.

Genèse, [aquatintes de] Zao Wou-Ki, Losne, Paris, Lacourière et Frélaut, 1982.

Patmos et autres poèmes, Paris, Gallimard, 2001.

\section{$\underline{\text { Prose }}$}

Gisements, Paris, Flammarion, 1968.

Approche de la parole suivi de Apprentissage, Paris, Gallimard, (1978) 2004.

«De la poétique de Saint-John Perse. De la conception de l'art en Chine ancienne. Rapport imaginés - », Bulletin de la société Paul Claudel, $\mathrm{N}^{\circ}$ 87, $3^{\mathrm{e}}$ trimestre, 1982, p. 5-16.

Journaux de voyages, Paris, Le Calligraphe, 1985.

\footnotetext{
${ }^{3}$ Une bibliographie très détaillée établie par Daniel Lançon se trouve à la fin des actes du colloque sur Lorand Gaspar (Cognac, Le Temps qu'il fait, 2004), p. 356-412.
} 
Feuilles d'observation, Paris, Gallimard, 1986.

Approches d'un désert vivant, Villeneuve-lès-Avignon, encres de Claude Garanjoud, 1999.

GASPAR, Lorand, PERROS, Georges, Correspondance 1966-1978, éd. établie et annotée par Thierry Gillyboeuf, Rennes, la Part commune, 2001.

KOICHIRO, Kurita, Le mouvement du monde (photographies : Koïchiro Kurita ; textes : Lorand Gaspar), Paris, Galerie Camera obscura, 2001.

\section{$\underline{\text { Photographie }^{4}}$}

Espaces. Catalogue de l'exposition à la BM de Marseille, décembre 1984-janvier 1985.

Exposition de Lorand Gaspar, (16 juin - 10 septembre) Châlons-sur-Saône, Musée Nicéphore Niepce, 1989.

Carnet de Patmos (Textes et photographies), Cognac, Le Temps qu'il fait, 1991.

Carnets de Jérusalem, (Textes et photographies), Cognac, Le Temps qu'il fait, 1997.

SACRE, James, Mouvementé de Mots et de couleurs, Cognac, Le Temps qu'il fait, 2003 (illustré par les photographies de Lorand Gaspar).

\section{Ouvrages critiques}

« Dossier Lorand Gaspar », Europe, n 918, octobre 2005, p. 15 - 68.

ALLAIRE, Suzanne, «Poésie et lumière », in Lorand Gaspar, Daniel Lançon (dir.), Cognac, Le Temps qu'il fait/Cahier seize, 2004, p. 246.

ALLAIRE, Suzanne, La parole de poésie. Lorand Gaspar, Jean Grosjean, Eugène Guillevic, Philippe Jaccottet, Rennes, Presses universitaires de Rennes, 2005.

CAMELIN, Colette, «Approches de la lumière : Einstein et Gaspar », in Lorand Gaspar (2004), p. 197-209.

CANADAS, Serge, «Du paysage au poème », in Poétique et poésie, colloque international, 25-27 mai 1987, sous la dir. de Yves-Alain Favre, Pau, Université de Pau, 1989, p. 409-427.

\footnotetext{
${ }^{4}$ Nous indiquons ici les principaux livres hybrides analysés dans la thèse. Pour la publication dans les revues et actes de colloque voir l'annexe $n^{\circ} 4$ à la page 359 .
} 
COMBE, Dominique, "Poétique et poésie », in Lorand Gaspar Transhumance et connaissance, (colloque organisé à Cerisy en 1994) textes réunis par Madeleine Renouard, Paris, Jean-Michel Place, 1995, p. 67-80.

CONSTANDULAKI-CHANTZOU, Ioanna, "Silence et poésie », in Poétique et poésie, p. 245-257.

DEBREUILLE, Jean-Yves, Lorand Gaspar, Paris, Seghers, 2007.

DEL FIOL, Maxime, «Présentation », in Un poète près de la mer, (Textes réunis par Maxime Del Fiol et Moncef Khémiri), Tunis, Sud, 2004, p. 12-17.

DEL FIOL, Maxime, «Sens vivant de l'image », in Un poète près de la mer, p. 81-93.

Égée-Judée, Le Revest-Les-Eaux, Aporie, 1988.

Espaces de Lorans Gaspar, Marseille, Sud, 1983.

FAVRIAUD, Michel, «La poétique de Lorand Gaspar » : entre ponctuation noire et ponctuation blanche, in Lorand Gaspar (2004), p. 223-242.

FLANAGAN, Anne, «Lorand Gaspar et ses livres d'art », in Poétique et poésie, p. 175184.

Genesis, n. 8, juillet 1995 Tenter d'y voir plus clair. Entretien de Madeleine Renouard avec Lorand Gaspar.

KASSAB-CHARFI, Samia, «À l'ombre d'une si calme catastrophe ou l'écriture du paradoxe dans Judée de Lorand Gaspar », in Un poète près de la mer, p. 105-122.

LEDOUX, Michel, «La création, de Spinoza aux neurosciences », Europe, $\mathrm{n}^{\circ}$ 918, octobre 2005, p. 127.

LEDOUX, Michel, «Lorand Gaspar, une rencontre », in Lorand Gaspar (2004), p. 3435 .

LITLLE, Roger, «Représentation et imaginaire de l'espace », in Transhumance et connaissance, p. 113-129.

LITTLE, Roger, «Respirations de Lorand Gaspar », in Poétique et poésie, p. 141-149.

MADOU, Jean-Pol, «La chair, mise en abîme de la lumière », in Transhumance et connaissance, p.53-66.

MARZOUKI, Afifa, «Approche de la parole poétique de Lorand Gaspar », in Un poète près de la mer, p. 35-43.

PECHAR, Jǐrí, «Réflexions sur l'articulation vie/désert», in Transhumance et connaissance, p. 22-32.

REBEYROL, Philippe, «Lorand et Spinoza », in Lorand Gaspar (2004), p. 205-219. 
VANHESE, Gisèle, «L'espace autobiographique dans l'œuvre de L. Gaspar» in Poétique et poésie, p. 151-163.

\section{Sur Internet}

KLAPKA, Ronald, «Lorand Gaspar, la musique secrète de la vie commune », sur le site remue.net : http://remue.net/spip.php?article1061 (consulté le : 16/11/2008).

MONTEMONT, Véronique, «Lorand Gaspar : genèse des Carnets de Patmos », (mis en ligne le : 15 février 2007.) http://www.item.ens.fr/index.php?id=27103 (consulté le : 03/03/2008).

\section{$\underline{\text { Denis Roche }^{5} \text { : }}$}

\section{$\underline{\text { Poésie }}$}

Forestière Amazonide, Écrire 11, Paris, Seuil, 1962.

Récits complets, Paris, Seuil, collection "Tel Quel", 1963.

Les Idées centésimales de Miss Elanize, Paris, Seuil, collection "Tel Quel", 1964.

Eros énergumène, Paris, Seuil, collection "Tel Quel", 1968.

3 Pourrissements poétiques, Paris, l'Herne, 1972.

Le Mécrit, Paris, Seuil, collection "Tel Quel", 1972.

La poésie est inadmissible, œuvres poétiques complètes, Paris, Seuil, 1995.

\section{$\underline{\text { Prose }}$}

Dans la maison du sphinx, essais sur la matière littéraire, Paris, Seuil, 1992.

\footnotetext{
${ }^{5}$ Une bibliographie très détaillée établie par Luigi Magno se trouve au début des actes du colloque sur Denis Roche (L'un écrit, l'autre photographie, Lyon, ENS, 2007).
} 
$\underline{\text { Texte et photographie }}$

Louve basse, Paris, Seuil, col. "Tel Quel", 1972.

Notre Antéfixe, Paris, Flammarion, 1978.

Dépôts de savoir \& de technique, Paris, Seuil, collection "Fiction \& Cie ", 1980.

Légendes de Denis Roche, Paris, Gris banal, 1981.

La disparition des lucioles(réflexions sur l'acte photographique), Paris, Étoile, 1982.

Carnac, ou les mésaventures de la narration, Paris, Pauvert, 1985.

Conversations avec le temps, Paris, Le Castor astral, 1985.

Photolalies, Paris, Argraphie, 1988.

Écrits momentanés, Chroniques Photo du Magazine, City, 1984-1987, Paris Audiovisuel, 1988.

Ellipse et laps : l'œuvre photographique, Paris, Maeght, 1991.

Le Boîtier de mélancolie. La Photographie en 100 photographies, Paris, Hazan, 1999.

$\underline{\text { Photographie }}$

Photographies 1965-1989, Espace photographique de Paris, 24 octobre-3 décembre 1989, Paris, Paris audiovisuel, 1989.

Les preuves du temps, Paris, Seuil/Maison européenne de la photographie, 2001.

\section{Préface à des photographes et des artistes}

«Vers la table de montage », préface à John Heartfield (Photomontages antinazis, Le Chêne, 1978 republié dans La disparition des lucioles, p. 123-131.

«Dépôt de savoir et de technique », préface à une exposition de Manuel Alvarez Bravo, Paris, La Photogalerie ; repris dans La disparition des lucioles (1982) sous le titre «Pour saluer Manuel Alvarez Bravo», et sous le titre «Au-delà du principe d'écriture », Tel Quel, n 67 p. 25-37, repris dans Dépôts de savoir \& de technique, 1980.

Bernard Plossu, Paysages intermédiaires, préface de Denis Roche, Paris, Contrejour, 1988, p. 6-11.

«Incendie significatif », Les Cahiers de la photographie, Ralph Gibson, ${ }^{\circ}$ 22, 1988, p. 14-22. 
« De la ténèbre inverse », préface à Claude Simon, Photographie, Paris, Maeght, 1992, p. 5-13.

«Le partage des eaux », préface à Jacques Damez, Vue de l'esprit, Toulouse, Belle Page, 1997, p. 13-25.

PAGES, Bernard, Pagès, surgeons et acrobates, préface de Denis Roche, Paris, Galerie Lelong, 1999 p. 4-7.

\section{$\underline{\text { Ouvrages critiques }}$}

«Denis Roche. Les temps du photographe » Entretien réalisé par Pascale Mignon et Marina Stéphanoff, La lettre de l'enfance et de l'adolescence, 2006/2 ( $\mathrm{n}^{\circ}$ 64), p. 88.

BAETENS, Jan, «Légendes de Denis Roche : un livre "incompatible" ? », Denis Roche, l'un écrit, l'autre photographie, p. 69-83.

BAQUET, Stéphane, Le primitivisme de Denis Roche. Lyrique amazonide, Paris, éd. des archives contemporains, 2008.

CADU, Cécile, «Le bras armé de l'écriture», in Denis Roche, l'un écrit, l'autre photographie, p. 219-237.

CALLE-GRUBER, Mireille, «Écrit avec l'image, sur un essai de photoautobiographie : Légendes de Denis Roche », Les Cahiers de la Photographie, $\mathrm{n}^{\circ} 13$, 1984, p. 29-42.

DUBOIS, Philippe, «Le caillou et le précipice », L'Acte photographique, ParisBruxelles, Nathan \& Labor, 1983, p. 287-301.

GLEIZE, Jean-Marie, «Préface. J'écris donc je photographie », in L'un écrit, l'autre photographie, p. 226-297.

GLEIZE, Jean-Marie, Poésie et figuration, Paris, Seuil, 1983.

Les Cahiers de photographie, numéro dédié à l'œuvre de Denis Roche, n²3, 1989.

MAGNO Luigi (dir.), Denis Roche. L'un écrit, l'autre photographie, Lyon, ENS, 2007.

MAGNO, Luigi, «Blobs momentanés », in L'un écrit, l'autre photographie, p. 273291.

MAGNO, Luigi, Dialectique(s) de l'écrit et de l'image chez Denis Roche, thèse soutenue sous la direction de Jean-Marie Gleize et Jacqueline Risset à Lyon en 2006.

MORA, Gilles, La photographie est interminable, entretien avec Denis Roche, Paris, Seuil, 2007. 
PRIGENT, Christian, Denis Roche, Paris, Seghers, col. "Poètes d'aujourd'hui", 1977.

REGIS, Durand, «L'aller-retour photographique », Art Press, hors série, n¹3, p. 7781.

ROUBAUD, Jacques, «Le mètre énergumène », in La vieillesse d'Alexandre, Paris, Ramsay, (1978 pour la première édition) 1988, p. 163-177.

WESTERHOFF KUNZ, Dominique, «Un imaginaire objectif ou ce que devient la métaphore chez Denis Roche », in L'un écrit, l'autre photographie, p. 111-134.

\section{$\underline{\text { Sur Internet }}$}

Biographie et bibliographie sur le site de la galerie Le Reverbère :

http://www.artmag.com/galeries/c_frs/reverber/roche.html (consulté le : 27/03/06).

Articles : ARGAND Catherine, «Entretien avec Denis Roche », Lire, mai 2001, http://www.lire.fr/entretien.asp?idC $=37086 \& \mathrm{idR}=201 \& \mathrm{idTC}=4 \& \mathrm{idG}=$ (consulté le : 27/03/06).

BAQUEY, Stéphane, «Entretien avec Denis Roche », Prétexte 21/22, http://pretexte.club.fr/revue/entretiens/entretiens_fr/entretiens/denis-roche.htm, (consulté le : 27/03/06).

BAQUEY, Stéphane, «Denis Roche. La rage de l'expression ou le dernier des mohicans », Prétexte, http://pretexte.club.fr/revue/critique/articles_fr/articles/roche_larage-de-l-expression-ou-le-dernier-des-mohicans.htm, (consulté le : 27/03/06).

\section{Autres}

ALLETON, Viviane, L'écriture chinoise, Paris, PUF, 1970.

ARAGON, Louis, Le Paysan de Paris, Paris, Gallimard, 1926.

ARAGON, Louis, Les collages, Paris, Hermann, 1980.

ARAGON, Louis, Traité du style, Paris, Gallimard, col. "L’imaginaire", 1928.

BARTHES, Roland, Le degré zéro de l'écriture suivi de Nouveaux Essais critiques, Paris, Seuil, 1953.

BARTHES, Roland, Le Plaisir du texte, Paris, Seuil, 1973.

BARTHES, Roland, Mythologies, Paris, Seuil, 1957.

BATAILLE, Georges, L'érotisme, Paris, Minuit, 1957. 
BOLTANSKI Christian, Recherche et présentation de tout ce qui reste de mon enfance, 1944-1950, livre d'artiste, 1969.

CEZANNE, Paul, Correspondance, recueillie, annotée et préfacée par John Rewald, Paris, Grasset, 1978.

CHENG, François, Vide et plein, Le langage pictural chinois, Paris, Seuil, 1991.

DADOUN, Roger, L'érotisme, Paris, PUF, col. "Que sais-je ?", 2003.

DELEUZE, Gilles, «Qu'est-ce qu'un dispositif ? », 1988, réédité dans : Deux régimes de fous. Textes et entretiens 1975-1995, éd. par D. Lapoujade, Paris, Minuit, 2003.

DELEUZE, Gilles, Spinoza Philosophie pratique, Paris, Minuit, 1981.

DEPARDON, Raymond, L'être photographe, entretiens avec Christian Caujolle, Paris, L'Aube, 2007.

DOTREMONT, Christian, Des logogrammes, Rennes, Ubacs, 1991.

ECO, Umberto, L’ouvre ouverte, Paris, Seuil, 1965.

FREUD, Sigmund, «La Tête de Méduse », in CEuvres complètes, (sous la direction d'André Bourguignon), tome XVI. (1921-1923), Paris, PUF, 1996.

GOURHAN, Leroi, L'homme et la matière, Paris, Albin Michel, 1943 et 1971.

GUIBERT, Hervé ; BERGER, Hans Georg, L'Image de soi, ou l'injonction de son beau moment, Bordeaux, William Blake \& Co., 1988.

GUIBERT, Hervé, À l'ami qui ne m’a pas sauvé la vie, Paris, Gallimard, 1990.

GUIBERT, Hervé, La mort propagande, Paris, Régine Deforges, 1977.

J. P. MATthiEU, A. KASTlER, P. FLEURY, Dictionnaire de physique, Paris, Masson-Eyerolles, 1991.

KLEE, Paul, Théorie de l'art modern, Paris, Denoël-Gonthier, 1980.

LAÏDI, Zaki, «Le sacre du présent », in Figures du temps (sous la dir. de Spyros, Théodorou), Paris, Parenthèse, 2003.

LEBRUN, Charles, Expression des Passions de l'Âme (edit 1727), Paris/Lille, Aux Amateurs de Livres/Bibliothèque Interuniversitaire de Lille, 1990.

MICHAUX, Henri, Idéogrammes en Chine, Fata Morgana, 1975.

ORTEL, Philippe, RYKNER, Arnaud (dir.), Discours, image, dispositif, Paris, L'Harmattan, 2008.

PEIRCE, Charles Sanders, Écrits sur le signe, Paris, Seuil, col. "L'ordre Philosophique", 1978. 
Radioscopie de Jacques Chancel avec Michel Tournier, diffusée sur France-Inter le 11/02/1981.

SAGAN, Françoise, Euvres, Paris, Robert Laffont, 1993.

SARRAUTE, Nathalie, L'ère du soupçon, Paris, Gallimard, 1956.

SARRAUTE, Nathalie, «Roman et réalité », Euvres complètes, Paris, Gallimard, 1996.

SHUSTERMAN, Richard, L'art à l'état vif : la pensée pragmatiste et l'esthétique populaire, traduit de l'américain par Christine Noille, Paris, Minuit, 1991.

TOURNIER, Michel, Le Roi des Aulnes, Paris, Gallimard, collection Folio n656, 1970.

TOURNIER, Michel, Le Tabor et le Sinaï, Paris, Belfond, 1988.

TOURNIER, Michel, Les météores, Paris, Gallimard, collection Folio n905, 1975.

TOURNIER, Michel, Vendredi ou les limbes du Pacifique, Paris, Gallimard, collection Folio plus n²12, 1967.

VALÉRY, Paul, «Mes théâtres » (1942) repris dans Euvres, t. 1, édition de Jean Hytier, Pléiade, 1957.

WITTGENSTEIN, Ludwig, Tractatus logico-philosophicus, suivi de: Investigations Philosophiques, (trad. fr. J. Klossowski), Paris, Gallimard, 1961.

WOLF, Maryanne, Proust and the Squib, New York, Harper, 2007.

Sur Internet :

ADAM Project : http://www.adamproject.net/ (consulté le : 03/08/2009).

BARTHES, Roland, La Chambre claire, « la photo d'Alexander Gardner sur un condamné à mort » : http://www.desordre.net/textes/bibliotheque/barthes.html (consulté le : 13/07/2009).

BARTHES, Roland, La Chambre claire, « la photo de Mapplethorpe » : http://www.nd.edu/ jmontgom/ti/GraphicArchive/Scans/Original\%20Files/Ch9PicTheoryPhoto/RMapplethorpe.jpg (consulté le : 13/07/2009).

BÉLÉGOU, Jean-Claude, Auto entretien, (consulté le : 28/07/2009) :

http://www.belegou.org/PDF\%20LIBRES/BELEGOU\%20ECRITS\%20SUR\%20LA\% 20PHOTO.pdf

BOURDIEU, P. ; BOLTANSKI, L. CASTEL, R. ; CHAMBOREDON, J.-C., Un art moyen, essai sur les usages sociaux de la photographie, Paris, Minuit, col. "Le sens commun", 1965. Les images analysées dans le livre de Bourdieu sont disponibles sur Flicrk : http://www.flickr.com/photos/gunthert/sets/72157615403627432/detail/ (consulté le : 17/07/2009). 
Cézanne ou la Lutte avec l'ange de la peinture en 1947 ; fragments disponibles sur le site littératureaudio.com :

http://www.litteratureaudio.com/forum?forum=5\&topic=239\&page=1 (consulté le : 04/03/2009).

CHAN, Jenny, Entre corps et pensée. L'idéogramme comme théâtre de l'originaire : la clinique du signifiant dans l'écriture de l'archaïque, Lyon, Université Lumière, (thèse) sous la direction de Alain Ferrant, http://demeter.univlyon2.fr/sdx/theses/lyon2/2006/chan_i

GAU, Olivier, «Jean-Claude Bélégou : intime conviction », L'opinion indépendante, Toulouse, 22/1/99 :

http://www.belegou.org/PDF\%20LIBRES/FORTUNE\%20CRITIQUE.pdf (consulté le : 28/07/2009)

GAULEJAC, Vincent de, «L'ego Sociologicus », Cahiers internationaux de sociologie, $\mathrm{n}^{\circ} 113,2002$. Disponible sur Cairn : http://www.cairn.info/revue-cahiersinternationaux-de-sociologie-2002-2-page-347.htm (consulté le : 18/07/2009).

GRANGER, Gilles Gaston, s. v. «Ludwig Wittgenstein », Encyclopédie Universalis, http://www.universalis-edu.com.scdbases.uhb.fr/article2.php?napp $=\& n r e f=C 030040$ (consulté le : 23/03/09).

FLUSSER, Vilem, La civilisation des médias, Paris, Circé, 2006. Le texte est disponible en hongrois sur Internet : http://www.artpool.hu/Flusser/Univerzum/00.html (consulté le : 20/10/2009).

HUITOREL, Jean-Marc, Nous Autres, (sur Yves Trémorin) http://tremorin.wunderblock.com/Pages/NousAutres.htm (consulté le : 28/07/2009).

Photonouvelles, $\mathrm{n}^{\circ} 11$, Mars-Avril 2001, Claude Nori « La rencontre : Jean-Claude Bélégou » (consulté le : 28/07/2009) : http://www.belegou.org/PDF\%20LIBRES/FORTUNE\%20CRITIQUE.pdf

ROGUE, Evelyne, «La représentation ou l'ambiguïté du voir chez Wittgenstein » publié sur Internet : http://www.univ-rouen.fr/arobase/v6/rogue.pdf (consulté le : 24/03/09).

Sites consacrés à la photo-thérapie : Patrick Wecksteen et Gérard Machot http://phototherapie.fr/ et un site anglais: http://www.phototherapy-centre.com/home.htm (consulté le : 31/07/2009)

Sur Cézanne et les jeux de représentation des surfaces sur le site Figures ambiguë : http://figuresambigues.free.fr/SommairesJeux/jeuarts.html (consulté le : 03/03/2009).

Sur la loi Hadopi : http://www.laquadrature.net/ (consulté le : 13/07/2009).

Sur le vide dans l'art occidental :

http://www.centrepompidou.fr/education/ressources/ENS-klein-EN/ENS-klein-EN.htm (consulté le : 03/08/2009). 
WHITFORD, David, « The most famoust story we never told », Fortune, 19 sept. 2005 : http://money.cnn.com/magazines/fortune/fortune_archive/2005/09/19/8272885/index.ht m (consulté le : 13/07/2009).

\section{$\underline{\text { Sur Wikipédia }}$}

Autofiction : http://fr.wikipedia.org/wiki/Autofiction (consulté le : 13/07/2009).

Baudrillard : http://fr.wikipedia.org/wiki/Jean_Baudrillard\#.C5.92uvres (en français) et (en anglais) http://en.wikipedia.org/wiki/Simulacra_and_Simulation (consulté le : 30/05/2009).

Clostera anachoreta : http://fr.wikipedia.org/wiki/Anachor\%C3\%A8te_ (papillon) (consulté le : 10/11/2009).

Dénotation et connotation : http://fr.wikipedia.org/wiki/Dénotation_et_connotation (consulté le : 10/09/09).

Dorothea Lange : http://fr.wikipedia.org/wiki/Dorothea_Lange (consulté le : 03/03/2009).

Frederick William Rolfe : http://en.wikipedia.org/wiki/Frederick_Rolfe (consulté le : 20/03/2009).

Georges Perec, Je me souviens :

http://fr.wikipedia.org/wiki/Je_me_souviens_\%28livre\%29 (consulté le : 10/09/2009).

Guide de voyage Baedeker : http://fr.wikipedia.org/wiki/Karl_Baedeker (consulté le : 20/03/2009).

Hippolyte Bayard : http://fr.wikipedia.org/wiki/Hippolyte_Bayard (consulté le : 27/05/08).

Idéogramme : http://fr.wikipedia.org/wiki/Idéogramme (consulté le : 24/10/2008).

Jacques Lacan : http://fr.wikipedia.org/wiki/Jacques_Lacan\#L.27inconscient_est_struct ur.C3.A9_comme_un_langage (consulté le : 13/07/2009).

James Agee, Walker Evans, Let us Now Praise famous Men:

http://en.wikipedia.org/wiki/Let_Us_Now_Praise_Famous_Men (consulté le : 13/07/2009).

L'écriture chinoise : http://en.wikipedia.org/wiki/Chinese_character (consulté le : 24/10/2008).

Stade du miroir : http://fr.wikipedia.org/wiki/Stade_du_miroir (consulté le : 13/07/2009).

Visual culture : http://en.wikipedia.org/wiki/Visual_culture (consulté le : 07/11/2009). 
$\underline{\text { Introduction }}$

LALOUX, René, La planète sauvage :

http://www.strimoo.com/video/16271272/Plantastic-Fanet-Vimeo.html (consulté le : 06/06/2009).

JONCKHEERE, Philippe de, Surimpression médiatique, http://www.desordre.net/photographie/numerique/campagne/surexpose/index.htm (consulté le : 06/06/2009).

L'évolution de la théorie de la photographie - la vérité en question

ZOLA, Emile, autoportrait avec ses enfants et Jeanne Rozerot :

http://fr.wikipedia.org/wiki/Fichier:ZOLA Jeanne_Enfants.jpg (consulté le :

13/07/2009).

CAPA, Robert, Mort d'un milicien, 1936 : http://expositions.bnf.fr/capa/grand/002.htm (consulté le : 13/07/2009).

FRITH, Francis, Luxor, 1856 :

http://www.shafe.co.uk/crystal/images/lshafe/Frith_Luxor_Egypt_1856.jpg (consulté le : 13/07/2009).

LANGE, Dorothea, Migrant Mother (Mère migrante), 1936 :

http://fr.wikipedia.org/wiki/Dorothea_Lange (consulté le : 03/03/2009).

SANDER, August, Lackierer, (fixeur de laque) 1936. La photo provient du site espagnol : http://www.elangelcaido.org/fotografos/sander/asander06.html (consulté le : 03/03/2009).

MOHOLY-NAGY, László, Mains et pinceaux, photogramme, 1926 :

http://exponto.spavia.com/2008/08/20/moholy-nagy-ratapint/ (consulté le : 03/03/2009).

EDGERTON, Harold E., Photographie d'une goutte de lait, 1936 :

http://www.akg.hu/fotoalkoto/foto/csepp/h_e_csepp/edgerton.htm (consulté le :

03/03/2009).

NEUSSÜS, Floris M., Nudogram, 1964 : Voir sur le site des éditions Lumas :

http://eu.lumas.com/?id=1305\&artist=71\&wid=40\&version=3\&ed= $($ consulté le : 03/03/2009).

SNOW, Michael, Authorization, 1969, Musée des Beaux Arts du Canada. http://cybermuse.gallery.ca/cybermuse/search/artwork_e.jsp?mkey=7852 (consulté le 03/03/2009). 
JAAR, Alfredo, Real Pictures, 1994

http://www.mocp.org/collections/permanent/jaar_alfredo.php (consulté le : 03/03/2009)

BRANDT, Bill, Micheldever, 1948 :

http://www.artnet.com/Galleries/Artists_detail.asp?gid=480\&aid=2968 (consulté le : 16/07/2009).

HILLIARD, John, Off screen, 2002 : http://www.staedtische-galerie-

erlangen.de/seiten/6_sammlung/bilder/diverse/hilliard_off_screen.jpg (consulté le : 16/07/2009).

NISHIMURA, Miwa, Lost paradise, society, 2005 : http://www.miwanishimura.com/ (consulté le : 16/07/2009).

TALBOT, Henri Fox, Empreinte d'une plante, 1844, planche VII :

http://www.cs.waikato.ac.nz/oldcontent/cbeardon/dcollage/collage2/images/FoxTalbot/ photogenic.jpg (consulté le : 03/03/2009).

KLEIN, Yves, Empreinte ANT, nº3, 1960 :

http://www.laboratoiredugeste.com/spip.php?article28 (consulté le : 03/03/2009).

ROUAN, François, Épreuve négative III, 45, 1998-2000. La galerie Daniel Templon, sous le nom de l'artiste et parmi les expositions de 2003 :

http://www.danieltemplon.com/ (consulté le : 03/03/2009).

SCHAEFFER, Jean-Marie, tableau sur l'indicialité et l'iconicité de la photographie dans ses divers fonctions communicationnelles dans : L'image précaire. Du dispositif photographique, Paris, Seuil, 1987, p. 139.

CALLE, Sophie, Les aveugles, 1986. Au centre Georges Pompidou http://www.centrepompidou.fr/education/ressources/ENS-calle/popup07.html et sur le blog de Magali Nachtergael : http://viperenoire.free.fr/oeuvresC.htm (consulté le 13/07/2009).

Anonyme, «K. Dauthendey et sa fiancée », insérée dans Petite histoire de la photographie, p. 8. http://www.lhivic.org/sources/divers/benjamin-1931.pdf (consulté le : 10/07/2009).

BAVČAR, Evgen, Nude with hands :

http://www.zonezero.com/exposiciones/fotografos/bavcar/bavcar21.html (consulté le : 09/10/2009).

\section{$\underline{\text { L'autobiographie photo-littéraire }}$}

KOSUTH, Josef, Une et trois chaises, 1965, 200x271x44 cm, MNAM, Paris. Voir l'image sur le site du Centre Georges Pompidou (consulté le : 03/06/2009) : http://www.centrepompidou.fr/education/ressources/ENS-ArtConcept/image03.htm.

BOLTANSKI, Christian, Vitrine de référence, 1971 (consulté le : 03/06/2009) : http://www.centrepompidou.fr/education/ressources/ENS-boltanski/popup01.html. 
LE GAC, Jean, Les Cahiers, 1970 la galerie Daniel Templon :

http://www.danieltemplon.com/ (consulté le : 13/07/2009).

LE GAC, Jean, Le peintre, 1973. L'image est reproduite dans le livre d'Anne Dagbert (Paris, Fall édition, 1998), p. 14-15.

LE GAC, Jean, Impression d'Afrique, $70 \times 50 \mathrm{~cm}, 1989$.

http://www.aresarts.com/catalog/impressiondafrique-pi-

1331.html?osCsid=722869cae8bb1cfe500f7e7a (consulté le : 06/06/2009).

LE GAC, Jean, reproduit sans titre : http://www.artpointfrance.org/Diffusion/legac.htm (consulté le : 06/06/2009).

CALLE, Sophie, Douleur Exquise, p. 224-225 (consulté le : 13/07/2009) :

http://thematique.wordpress.com/2009/05/20/douleur-exquise-adaptee-au-theatre-fta/.

CALLE, Sophie, Disparitions, p. 62-63.

CALLE, Sophie, Fantômes, p. 24-25.

CALLE, Sophie, L'Erouve de Jérusalem, p. 30-31.

BAYARD, Hippolyte Autoportrait en noyé, 1840 :

http://fr.wikipedia.org/wiki/Hippolyte_Bayard (consulté le : 27/05/08).

MICHALS, Duane, Things are queer, 1973 :

http://www.momentism.com/processthis/DM-Queer-ProcessTHIS.pdf (consulté le:

04/08/2009).

MICHALS, Duane, A letter of my father, 1975 :

http://www.flickr.com/photos/christopheducamp/3436725523/ (consulté le :

21/07/2009).

FRANK, Robert, New Year's Day, Mabou, 1981, (consulté le : 27/07/2009).

http://www.desordre.net/photographie/photographes/robert_frank/be_happy.html.

FRANK, Robert, Sick of good bys, 1978 :

http://www.desordre.net/photographie/photographes/robert_frank/sick_of_goodbyes.ht $\underline{\text { ml }}$ (consulté le : 27/07/2009).

DEPARDON, Raymond, Notes, 1979, p. 22.

DEPARDON, Raymond, Correspondance new-yorkaise, 1981, p. 38.

http://www.magnumphotos.com/Archive/C.aspx?VP3=ViewBox\&ALID=2TYRYD1K

0FR4\&IT=ThumbImage01_VForm\&CT=Album (consulté le : 27/07/2009).

DEPARDON, Raymond, La ferme du Garet, p. 317. Voir les images de Depardon sur le site de Magnum photos :

http://www.magnumphotos.com/Archive/c.aspx?VP=XSpecific_MAG.BookDetail_VP age\&pid=2K7O3R180FIW (consulté le : 27/07/2009). 
1er manifeste de Noir Limite :

http://www.belegou.org/PDF\%20LIBRES/MANIFESTESNL.pdf (consulté le : 28/07/2009).

TREMORIN, Yves, D'Ar Ger, 1999 :

http://tremorin.wunderblock.com/Pages/1992_1995.htm (consulté le : 28/07/2009).

BELEGOU, Jean-Claude, Visages, 1989/90 :

http://www.belegou.org/francais/GALERIES\%20WEB/VISAGES\%20GALERIE\%20

WEB/index.htm (consulté le : 28/07/2009).

BELEGOU, Jean-Claude, De tous les jours, 1999 :

http://www.belegou.org/francais/GALERIES\%20WEB/DTLJ\%20GALERIE\%20WEB/ index.htm\#18 (consulté le : 28/07/2009).

WIORA, Melanie, Stream, 2002 : http://www.melaniewiora.de/e/eye1_10.htm (consulté le : 29/07/2009).

SEMENIAKO, Michel, Hôpital psychiatrique de Poissy, 1983.

SEMENIAKO, Michel, Identité / Activité, autoportraits d'agents EDF, 1991 : Voir les images sur le site du photographe : http://www.michel-semeniako.com/gal_5.html (consulté le : 31/07/2009).

PARR, Martin, Italie, 1990. Voir sur le site de Magnum :

http://www.magnumphotos.com/Archive/C.aspx?VP3=ViewBox\&ALID=29YL53G7R T3\&IT=ThumbImage01_VForm\&CT=Album (consulté le : 17/07/2009).

PARR, Martin, Signs of the Times, Manchester, Cornerhouse, 1992. Voir sur le site de Magnum :

http://www.magnumphotos.com/Archive/c.aspx?VP=XSpecific_MAG.BookDetail_VP age\&pid=29YL53GUDGH (consulté le : 17/07/2009).

SCHMIDT, Joachim, Reloaded, 2008 : http://schmid.wordpress.com/works/2008reload/ (consulté le : 03/08/2009).

BARTHES, Roland, L'Empire des signes, p. 73.

BARTHES, Roland, L'Empire des signes, Op. cit., p. 64-65. Corridor de Shikidai Château Nijo, Kyoto, construit en 1603 :

http://www.eternalnetwork.org/jcl/index.php?art=790 (consulté le : 10/09/2009).

BARTHES, Roland, L'Empire des signes, L'acteur Kazuo Funaki p. 6 et 147.

BARTHES, Roland, Roland Barthes par Roland Barthes, «l'ennui » http://3.bp.blogspot.com/_7y8Jhm8GiGw/RtNZROT5P4I/AAAAAAAAALI/jvIMBDD SPE0/s1600-h/Panic+boredom.JPG (consulté le : 10/08/09).

GUIBERT, Hervé, Suzanne et Louise, (consulté le : 08/08/2009) : http://www.intexte.net/docenligne/suzannelousie_interieur.jpg. 
GUIBERT, Hervé, L'ami : http://www.intexte.net/docenligne/guibert_1_ami_zoom.jpg (consulté le : 08/08/2009).

JONCKHEERE, Philippe de, la page d'accueil du désordre :

http://www.desordre.net/labyrinthe/versions/versions_du_desordre_entier.html (consulté le : 03/08/2009).

JONCKHEERE, Philippe de, négatifs en verre d'Oscar De Jonckheere : http://www.desordre.net/memory/Memoryoscar.html (consulté le : 03/08/2009).

JONCKHEERE, Philippe de, autoportraits numériques de Philippe de Jonckheere : http://www.desordre.net/memory/Memoryautos.html (consulté le : 03/08/2009).

JONCKHEERE, Philippe de, l'ultime et cinquante et unième jeu de Memory : http://www.desordre.net/memory/MemoryRandom.html (consulté le : 03/08/2009).

JONCKHEERE, Philippe de, Autoportrait au carré :

http://www.desordre.net/photographie/numerique/autoportrait_carre/index.htm (consulté le : 03/08/2009).

$\underline{\text { Photographie et fiction - la pluralité et la dissolution des frontières }}$

RODENBACH, Georges, Bruges-la-morte, p. 9 :

http://sebald.files.wordpress.com/2007/08/bruges-canal.jpg (consulté le : 23/07/2009).

MORISE, Max ; DUHAMEL, Marcel ; RAY, Man, Les tribulations de Monsieur Wzzz..., 1928.

GUIBERT, LEFEVRE, LEMERCIER Le Photographe, tome 1 p. 5 et tome 3 p. 1 et 4 http://lephotographe.dupuis.com/didierlefevre.html (consulté le : 31/08/2009).

\section{$\underline{\text { François-Marie Banier }}$}

BANIER, François-Marie, Louis Aragon, Paris, juin 1979. Pour l'écriture : ca. 1990, encre sur photographie, 50x60 Rétrospective de 2003.

BANIER, François-Marie, Nicoll Flemming, 11 mai 1995, 57 x 77 cm : http://www.fmbanier.com/dessins_010_1 (consulté le : 10/10/2009).

BANIER, François-Marie, Françoise Sagan, 1999, encre sur photographie, 160x110 cm Rétrospective de 2003.

BANIER, François-Marie, Nathalie Sarraute, Oxford, juin 1991, Rétrospective de 2003 ; Photos et peintures p. 73 ; Past present p. 110 :

http://www.fmbanier.com/photos_portraits_001_3 (consulté le : 15/04/2009).

BANIER, François-Marie, Michel Tournier, Perdre la tête, p. 165.

BANIER, François-Marie, Salvador Dalí, Paris, mai 1968, Rétrospective 2003. 
BANIER, François-Marie, Andy Warhol, Paris, décembre 1981, Rétrospective 2003.

BANIER, François-Marie, Alex Katz, Paris, mai 2003, Perdre la tête, p. 91.

BANIER, François-Marie, Daniel Emilfork, Paris octobre 2004, Perdre la tête, p. 3-8, les photos insérées (p. 6-8) proviennent du site suivant : $\underline{w w w . t p i-}$ nice.org/expo/banier/index_banier.htm (consulté le : 06/12/2007).

BANIER, François-Marie, Anonyme, Place Victor et Hélène Basch, Paris novembre 2005 et figurent dans Perdre la tête, p. 196-201. Une série semblable est accessible sur le site d'artnet : http://www.artnet.com/artwork/425085601/412/place-pigalle-paris-mai2005.html (consulté le : 15/05/2009).

BANIER, François-Marie, Samuel Beckett, Paris, septembre 1989 : http://www.fmbanier.com/beckett_004_3 (consulté : le 10/10/2009).

BANIER, François-Marie, Anonyme, Paris, avril 2004, Perdre la tête, p. 213.

LEBRUN, Charles, Expression des Passions de l'Âme (edit 1727), Paris/Lille, Aux Amateurs de Livres/Bibliothèque Interuniversitaire de Lille, 1990, planche 4 Admiration avec étonnement.

MATHON, Catherine (dir.), Duchenne de Boulogne, Paris, École Nationale Supérieure des Beaux-arts, 1999, p. 87.

BANIER, François-Marie, Anonyme, Montmartre, Paris mai 2005, Perdre la tête, p. 194.

BANIER, François-Marie, Anonyme, Boulevard Raspail, Paris, janvier 2005, Perdre la tête, p. 11. http://relationsmedia.photographie.com/?evtid=109784 (consulté le : 16/05/2009).

BANIER, François-Marie, Anonyme, Pont Royal, Paris, mai 2005, Perdre la tête, p. 149. http://relationsmedia.photographie.com/?evtid=109784 (consulté le : 16/05/2009).

BANIER, François-Marie, Anonyme, Jardin des Tuileries, Paris, juin 2005, Perdre la tête, p. 21. http://www.fmbanier.com/anonymes_021_1 (consulté le : 16/05/2009).

BANIER, François-Marie, Trois piquets dans la neige à Saint-Pétersbourg, SaintPétersbourg, 1991, encre sur photographie, 30x40cm, Rétrospective de 2003. http://www.fmbanier.com/files/active/1/2383 large.jpg (consulté le : 16/05/2009).

BANIER, François-Marie, La femme aux perroquets, Paris, décembre 1988, encre sur photographie, 1991, 40x30 cm, Photos et peintures, p. 37.

BANIER, François-Marie, Anonyme, Rue Visconti, ca. 1990, encre sur photographie, $60 \times 50 \mathrm{~cm}$, Rétrospective de 2003 : http://www.fmbanier.com/node/2398 (consulté le : 16/05/2009).

BANIER, François-Marie, Le tricycle, 3 août 2002, encre sur photographie, $60 \times 50 \mathrm{~cm}$, Rétrospective de 2003 : http://www.fmbanier.com/node/2399 (consulté le : 16/05/2009). 
BANIER, François-Marie, http://www.fmbanier.com/node/2393 L'image est publiée sur le site Internet de l'auteur sans légende (consulté le : 16/05/2009).

BANIER, François-Marie, Lucinda Childs, 2 juillet 1998, encre sur photographie, 110x160 cm, Rétrospective de 2003 : http://www.fmbanier.com/node/2359 (consulté le : 16/05/2005).

BANIER, François-Marie, « extrait » d'Autoportrait, 13 avril 1998, encre et huile sur photographie, 160x110 cm, Rétrospective de 2003.

BANIER, François-Marie, « extrait »d'Un lavabo chez les Noailles à Fontainebleau, Août 2002, encre sur photographie, 50x60 cm, Rétrospective de 2003. Reproduit sur le site personnel de l'auteur : http://www.fmbanier.com/node/2400 (consulté le : 17/05/2009).

BANIER, François-Marie, Cabourg, 3-4 mars 1999, encre sur photographie, 110x160 cm, Rétrospective de 2003.

BANIER, François-Marie, Héricy, la maison de mes parents, 13 août 2002, encre sur photographie, 60x50 cm, Rétrospective de 2003.

BANIER, François-Marie, C'est mon masque, 1999, photographie peinte, 160x110 cm, Photos et peintures, p. 156.

BANIER, François-Marie, I am only an eye, 8 mars 2001, encre sur photographie, $30 \times 40 \mathrm{~cm}$, Rétrospective de 2003 : http://www.fmbanier.com/node/2345 (consulté le : 16/05/2005).

BANIER, François-Marie, «extrait» de Villandry I., 1998, photographie peinte, $120 \times 85 \mathrm{~cm}$ collection particulière, Photos et peintures, p. 115.

BANIER, François-Marie, «extrait» de Nicole Kidman, 28 juillet 2002, encre sur photographie, $50 \times 60 \mathrm{~cm}$, Rétrospective de 2003.

BANIER, François-Marie, http://www.fmbanier.com/node/2353 L'image est publiée sur le site Internet de l'auteur sans légende (consulté le : 16/05/2009).

BANIER, François-Marie, Tournesol I. 1999, photographie peinte, 160 x110 cm, Photos et peintures, p. 124.

BANIER, François-Marie, Fauteuil, 1999, photographie peinte, 160 x110 cm, Photos et peintures, p. 159.

BANIER, François-Marie, Ne lui faites pas de mâle II, 1998, photographie peinte, 160x110 cm, Photos et peintures, p. 141.

BANIER, François-Marie, Atelier Massaro, rue de la Paix, 2007 et Atelier Lemarié, Faubourg Saint-Denis, Paris, 2007. Les images proviennent de la série : «Embellishing Chanel », The New Yorker, 19/03/07.

http://www.newyorker.com/online/2007/03/19/slideshow_070319_Chanel (consulté le : 24/12/2007). 
BANIER, François-Marie, «Jacaré », Praia do Flamengo, Rio de Janeiro, septembre 1999, in Banier Brésil, Paris, Gallimard, 2001, p. 115.

BANIER, François-Marie, Salvador, Bahia, juin 1999, in Banier Brésil, Paris, Gallimard, 2001, p. 116.

BANIER, François-Marie, Anonymes, Perdre la tête, p. 54-60.

BANIER, François-Marie, Barbara, Paris, novembre 1998, Rétrospective de 2003.

BANIER, François-Marie, Anonyme, Salvador, Bahia, Juin 1999, Rétrospective de 2003.

BANIER, François-Marie, Salvador Dalí, Hôtel Meurice, Paris, mai 1968, Photos et peintures, p. 74.

BANIER, François-Marie, La Reine Élisabeth II, Paris, juin 1992, Photos et peintures, p. 75 .

BANIER, François-Marie, Le temps retrouvé, Cabourg, février 1999, Photos et peintures, p. 76.

BANIER, François-Marie, Marcello Mazzarella, Cabourg, février 1999, Photos et peintures, p. 77.

BANIER, François-Marie, Andy Warhol, Paris, décembre 1981, Photos et peintures, p. 85 .

BANIER, François-Marie, Yves Saint-Laurent, Paris, décembre 1982, Photos et peintures, p. 84.

Pages de garde dans Perdre la tête.

BANIER, François-Marie, couverture de l'édition Folio du livre Les résidences secondaires ou La vie distraite :

http://www.fmbanier.com/rt_residences_secondaires001 (consulté le : 16/05/2009).

BANIER, François-Marie, couverture de l'édition Folio du livre Le passé composé : http://www.fmbanier.com/passecompose001 (consulté le : 16/05/2009).

BANIER, François-Marie, couverture de l'édition Folio du livre La tête la première : http://www.fmbanier.com/rt_la tete_la_premiere (consulté le : 17/05/2007).

BANIER, François-Marie, couverture de l'édition Folio du livre Sur un air de fête : http://www.fmbanier.com/sur_un_air_de_fete_editions_gallimard_version_folio_1999 (consulté le : 17/05/2007).

BANIER, François-Marie, couverture de l'édition Folio du livre Les femmes du métro Pompe : http://www.fmbanier.com/femmes_metro004 (consulté le : 17/10/2009). 
BANIER, François-Marie, Jardin du Luxembourg, Paris, 1979, encre sur photographie, 40x30 cm, 1991, Photos et peintures, p. 27 : http://www.fmbanier.com/node/2397 (consulté le : 17/10/2009).

BANIER, François-Marie, Les jumeaux, 1997, encre sur photographie, 160x110 cm, collection particulière Photos et peintures, p. 29.

BANIER, François-Marie, sou...sou...sou...souriez, 1999, photographie peinte, 160 x $110 \mathrm{~cm}$, Photos et peintures, p. 111.

BANIER, François-Marie, Vladimir Horowitz and Wanda Toscanini Horowitz, Paris, May 1985, Past present, p. 110-111.

BANIER, François-Marie, Marie Laure de Noailles at home, Paris, juin 1968, Past present, p. 38-39.

\section{$\underline{\text { Jean-Loup Trassard }}$}

TRASSARD, Jean-Loup, Juste absente planches III, II et IV in MÉAUX, Danièle; VRAY, Jean-Bernard (dir.), Traces photographiques, traces autobiographiques, SaintÉtienne, Publications de l'Université de Saint-Étienne, 2004.

FAUCON, Bernard, Les Grandes vacances, http://www.bernardfaucon.net/photos/index.htm (consulté le : 04/06/08).

TRASSARD, Jean-Loup, Les derniers paysans (Photographies), Cognac, le Temps qu'il fait, 2000 : p. 25 , p. 29 et p. 49.

TRASSARD, Jean-Loup, Images de la terre russe (Textes et photographies), Cognac, Le Temps qu'il fait, 1990 : p. 45, p. 32, p. 34, p. 40, photo de la couverture, p. 55, p. 17.

TRASSARD, Jean-Loup, Le voyageur à l'échelle, (Textes et photographies), Cognac, Le Temps qu'il fait, 2006 : p. 49, p. 33 «extrait», p. 43 «extrait», p. 45 «extrait», p. 37 , p. 47 , p. 39 , p. 51, p. 55 , p. $41 \ll$ extrait», p. 53.

ROUSSE, Georges, Cassablanca, 2003 :

http://www.stanislasurbietorbi.com/actualites/reportages/rousse/rousse.html (consulté le : 14/09/2009).

TRASSARD, Jean-Loup, Objets de grande utilité (Textes et photographies), Cognac, Le Temps qu'il fait, 1995 : p. 51, p. 59, p. 65, p. 71.

TRASSARD, Jean-Loup, Inventaire des outils à main dans une ferme (Textes et photographies), Cognac, Le Temps qu'il fait, 1995 : «extrait» de p. 41 et la photo de couverture.

TRASSARD, Jean-Loup, Territoire (Textes et photographies), Cognac, Le Temps qu'il fait, 1989 : 6 clichés hors pagination.

TRASSARD, Jean-Loup, Ouailles (Textes et photographies), Cognac, Le Temps qu'il fait, 1991 : p. 31, p. 83, p. 95 , p. 58, p. 49, p. 51, p. 53. 
Barta Zsolt Peter, « codeX », Mains (1993), Planète crâne (1999), Méandre (2000) http://www.digibodies.org/barta.html (consulté le : 21/07/2008).

TRASSARD, Jean-Loup, Nuisibles (Textes et photographies), Cognac, Le Temps qu'il fait, $2005:$ p. 6, p. 32, p. 56, couverture, page de titre et l'achevé d'imprimer.

TRASSARD, Jean-Loup, La Composition du jardin (Textes et photographies), Cognac, Le temps qu'il fait, $2003:$ p. 28. http://mucri-photographie.univparis1.fr/image.php?id=25 (consulté le : 21/07/2008).

TRASSARD, Jean-Loup, Sanzaki (Textes et photographies), Cognac, Le Temps qu'il fait, 2008 : p. 4, p. 23, p. 59.

Lorand Gaspar (puisque les clichés sont sans titre et hors pagination nous insérons les photos concernées)

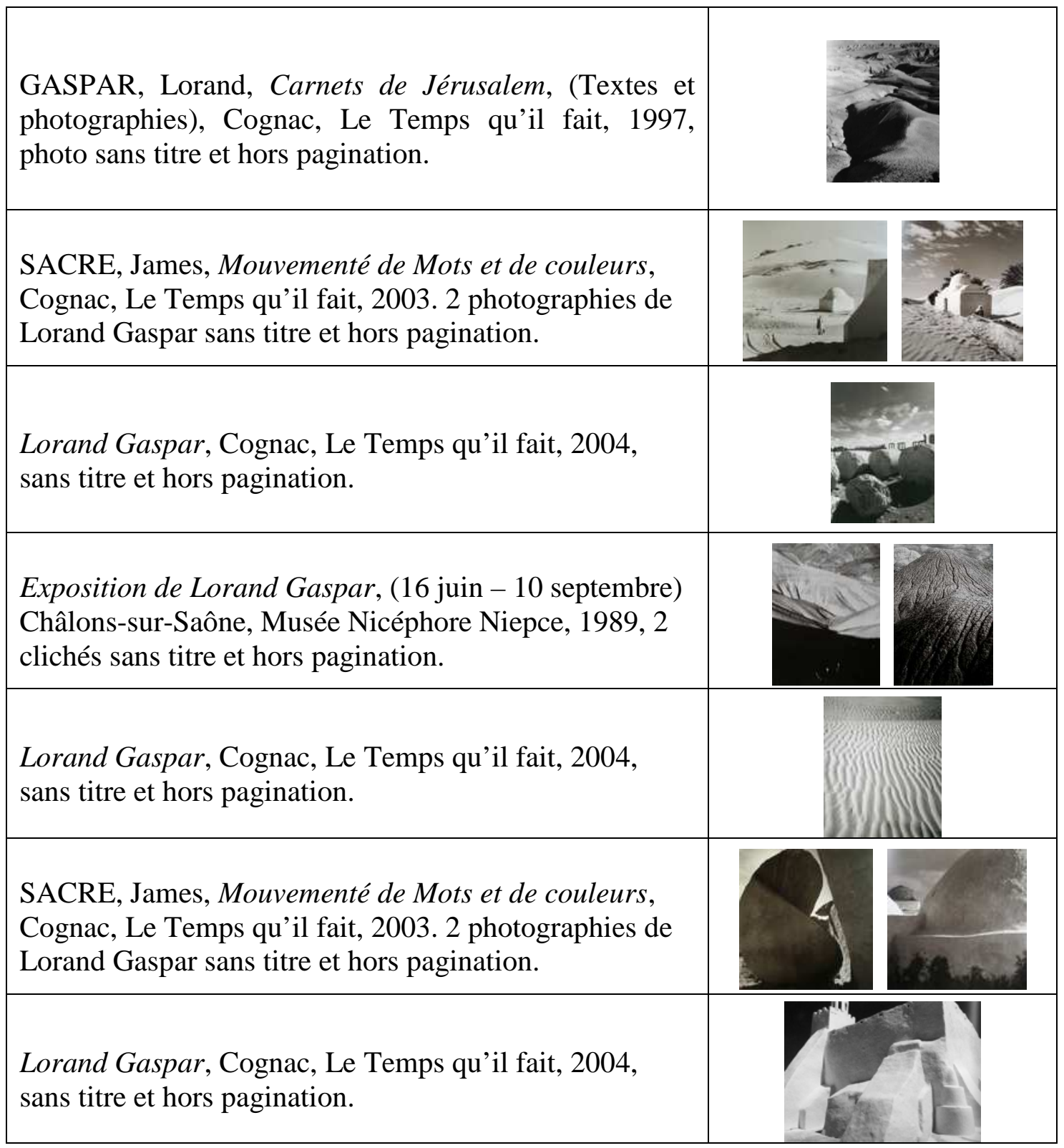




\begin{tabular}{|l|l|}
\hline $\begin{array}{l}\text { GASPAR, Lorand, Carnet de Patmos (Textes et } \\
\text { photographies), Cognac, Le Temps qu'il fait, 1991, sans } \\
\text { titre et hors pagination. }\end{array}$ \\
\hline $\begin{array}{l}\text { SACRE, James, Mouvementé de Mots et de couleurs, } \\
\text { Cognac, Le Temps qu'il fait, 2003. Photographie de } \\
\text { Lorand Gaspar sans titre et hors pagination. }\end{array}$ \\
\hline $\begin{array}{l}\text { GASPAR, Lorand, Genèse, encres de Zao Wou-Ki, Fata } \\
\text { Morgana, 1981. Sur le site de la Galerie Michel Fillon : } \\
\text { http://www.michelfillion.com/detail.php?titre=zao-wou- } \\
\text { ki-genese (consulté le : 24/10/2008). }\end{array}$ \\
\hline
\end{tabular}

HAJDU, Étienne, Illustration sur le web pour la publicité d'un livre d'Étienne Hajdú Paris, MNAM, 1973, http://www.tobeart.com/Expo/Hajdu-MNAM73.htm (consulté le : 12/11/2008).

Exemple pour le papier Duchêne : http://www.moulindelarroque.com/pages/index.php (consulté le : 12/11/2008).

Couverture d'Amandiers (1996) La photo provient du site d'un atelier de reliure artisanale : http://www.libellus.fr/galerie/gaspar_amandiers/index.html (consulté le : 14/11/2008).

Encre de T'ANG avec une note manuscrite de Lorand Gaspar, catalogue de l'exposition Pierres de chant, réalisée par Tanguy Dohollau, pour le Festival Etonnants Voyageurs de Saint-Malo en 1992, présentée sur le site remue.net :

http://remue.net/spip.php?article1061 (consulté le : 16/11/2008).

SZENES, Arpad, Sefar I, 1983, grattage, 17,5 x 23,5 cm. Reproduit sur le site de la Galerie Michelle Champetier : http://www.mchampetier.com/Etching-Arpad-Szenes5074-work.html (consulté le : 22/11/2008).

SILVA, Viera da, Un été de sel, 1989, aquatinte, 20,6 x 28,8 cm. Reproduit sur le site de la Galerie Michelle Champetier. http://www.mchampetier.com/Gravure-MariaHelena-Vieira-Da-Silva-10551.html (consulté le : 22/11/2008).

VAN ROGGER, Roger, Sans titre, 1968, peinture à huile, exposition de Van Rogger «Abstraction et Mystique » du 4 octobre au 5 novembre 2000 présentée sur le site de « la Maison des Arts » à Châtillon : http://www.ville-

chatillon.fr/mda/archive_van_rogger.htm (consulté le : 22/11/2008).

WOU-KI, Zao, sans indication de titre ou de date sur le site de la Galerie BerthetAittouarès. http://www.galerie-ba.com/artistes/Zao\%20Wou\%20Ki/zao_wou_ki.htm (consulté le : 22/11/2008).

T'ANG, Haywen, sans indication de titre ou de date sur le site personnel du peintre : http://www.tanghaywen.org/index/Projet-Frame1.htm (consulté le : 22/11/2008). 
KURITA, Koïchiro, Summer grasses, Lozere, France, 1996, platinum print, 20,3 x 25,4 cm, reproduit sur le site : http://www.artnet.fr/artwork/424696597/117186/koichirokurita-summer-grasses-lozere-france.html (consulté le : 10/11/2008).

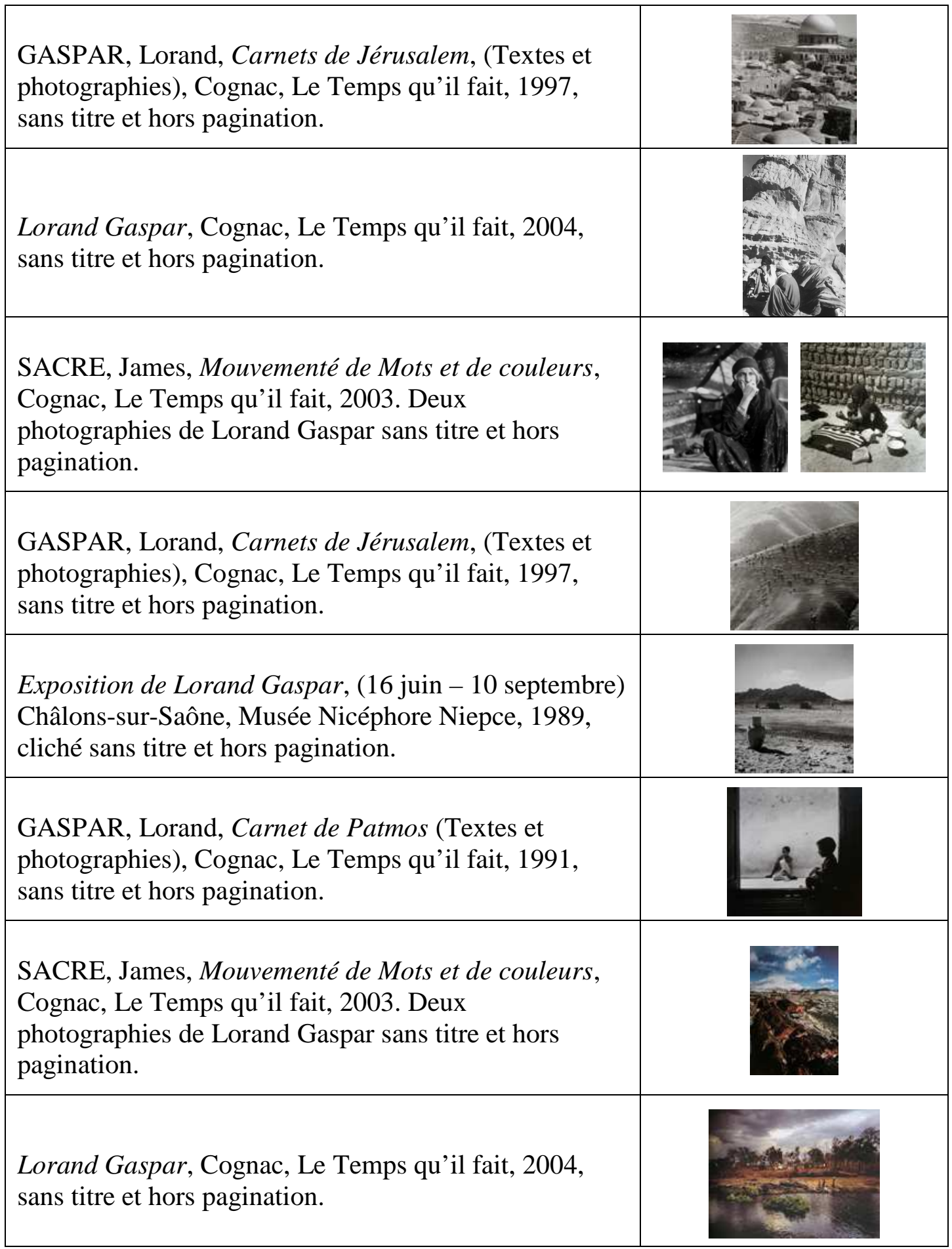

$\underline{\text { Denis Roche }}$

ROCHE, Denis, 29 mars 1977, Istanboul, Les preuves du temps, Paris, Seuil/Maison européenne de la photographie, 2001, p. 36. 
ROCHE, Denis, 18 juin 1988 Aix-en Provence, Hôtel Le Pigonnet chambre 8, Les preuves du temps, Paris, Seuil/Maison européenne de la photographie, 2001, p. 108.

Maquette reconstituée de La disparition des lucioles (réflexions sur l'acte photographique), Paris, Étoile, 1982, p. 170-183.

ROCHE, Denis, 25 mars 1981, Tell-El-Amarna, Égypte, La disparition des lucioles (réflexions sur l'acte photographique), Paris, Étoile, 1982, p. 183.

ROCHE, Denis, 1988, Paris, Autoportrait aux masques XVIII ${ }^{e}$, Les Cahiers de photographie, numéro dédié à l'œuvre de Denis Roche, n²3, 1989, p. 107.

Marilyn Monroe dans le film Sept ans de réflexion : http://libres-

expressions.sosblog.fr/Marilyn-b2/Marilyn-Monroe-b2-p11.htm (consulté le :

21/03/2009).

ROCHE, Denis, 6 février 1977, Paris rue Henri Barbusse, Notre Antéfixe, Paris, Flammarion, 1978, p. 113.

ROCHE, Denis, 25.12.1987, Aix en Othie, Auberge de la Scierie, chambre 26, Ellipse et laps : l'œuvre photographique, Paris, Maeght, 1991, p. 60.

Diarogramme de Notre Antéfixe.

ROCHE, Denis, 22 juillet 1977, Bomarzo, Notre Antéfixe, Paris, Flammarion, 1978, p. 83.

ROCHE, Denis, 12 juillet 1971, Montagne de Bougès, Notre Antéfixe, Paris, Flammarion, 1978, p. 81.

ROCHE, Denis, 5 janvier 1975, Venise, Notre Antéfixe, Paris, Flammarion, 1978, p. 99.

ROCHE, Denis, 30 mars 1977, Istanbul, Saint-Irène, Notre Antéfixe, Paris, Flammarion, 1978, p. 109.

MACCHERONI, Henri, sans titre, 1971, de la série « 2000 photographies du sexe d'une femme », Le Boîtier de mélancolie. La Photographie en 100 photographies, Paris, Hazan, 1999, p. 187.

ROCHE, Denis, 17 juillet 1994, San Alesio, Italie, Les preuves du temps, Paris, Seuil/Maison européenne de la photographie, 2001, p. 153.

ROCHE, Denis, 21.07.1986 Ségovie, Espagne Hôtel Acueducto, ch. 216., publiée dans le catalogue d'exposition : ROCHE, Denis, Photographies 1965-1989, Espace photographique de Paris, 24 octobre - 3 décembre 1989, Paris, Paris Audiovisuel, 1989 (sans pagination).

ROCHE, Denis, 17 août 1991, Paris, La Fabrique, Les preuves du temps, Paris, Seuil/Maison européenne de la photographie, 2001, p. 137.

ROCHE, Denis, 3 août 1993, Nice, Les preuves du temps, Paris, Seuil/Maison européenne de la photographie, 2001, p. 146. 
ROCHE, Denis, 10 juillet 1988, Paris, La Fabrique, Les preuves du temps, Paris, Seuil/Maison européenne de la photographie, 2001, p. 107.

ROCHE, Denis, Denis Roche tournant sur lui-même, Louve basse, Paris, Seuil, col. "Tel Quel", 1972, p. 222-224.

ROCHE, Denis, NADAR, Autoportrait «tournant » ca. 1865, BNF, http://www.sceren.fr/Themadoc/niepce/images/auto.jpg (consulté le : 10/10/2009).

FENTON, Roger, Vallée de la mort, guerre de Crimée, 1855, Le Boîtier de mélancolie. La Photographie en 100 photographies, Paris, Hazan, 1999, p. 35.

ROCHE, Denis, 12 juillet 1973 Couvent des Capucins, Palerme, Sicile, Les preuves du temps, Paris, Seuil/Maison européenne de la photographie, 2001, p. 29.

ROCHE, Denis, 11 juin 1985, Cologne, Allemagne, Les preuves du temps, Paris, Seuil/Maison européenne de la photographie, 2001, p. 90.

ROCHE, Denis, 24 décembre 1984, Les Sables-d'Olonne, Atlantic Hôtel, chambre 301, Les preuves du temps, Paris, Seuil/Maison européenne de la photographie, 2001, p. 83.

ROCHE, Denis, 7 septembre 1974, Saint-Remèze, Notre Antéfixe, Paris, Flammarion, 1978, p. 141.

ROCHE, Denis, 21 juillet 1979, Pompéi, Thermes des Stabies, La disparition des lucioles (réflexions sur l'acte photographique), Paris, Étoile, 1982, p. 21.

ROCHE, Denis, 12 juillet 1971, et 6 août 1984 (treize ans après), Pont-de-Montvert, Lozère, Photolalies, Paris, Argraphie, 1988, p. 6-7.

ROCHE, Denis, 11 octobre 1987, La Fabrique, Paris, Photolalies, Paris, Argraphie, 1988, p. 9.

ROCHE, Denis, La série de Pont-de-Montvert, Lozère, La photographie est interminable, entretien avec Denis Roche, Paris, Seuil, 2007, p. 37-40.

Anonyme. Région rouennaise, vers 1900, La disparition des lucioles (réflexions sur l'acte photographique), Paris, Étoile, 1982, p. 94.

ROCHE, Denis, 29 juillet, 1978, Copán Honduras, Dépôts de savoir \& de technique, Paris, Seuil, collection "Fiction \& Cie ", 1980, p. 7.

ROCHE, Denis, «Les tentations de Francis Ponge », La poésie est inadmissible, œuvres poétiques complètes, Paris, Seuil, 1995, p. 581.

ROCHE, Denis, «Comment j'ai écrit tous mes livres» dans La disparition des lucioles, (réflexions sur l'acte photographique), Paris, Étoile, 1982, p. 96.

ROCHE, Denis, 8 mai 1996, Zwiefalten, Allemagne, Gasthof Post, chambre 6, Les preuves du temps, Paris, Seuil/Maison européenne de la photographie, 2001, p. 160. 
ROCHE, Denis, «Hommage à Wittgenstein 1 » 1er juin 1979, Le Skeul, Belle-île La disparition des lucioles, p. 27-31 ; Ellipse et laps, p. 130 ; Les preuves du temps, p. 53.

ROCHE, Denis, «Hommage à Wittgenstein 2 », 24 août 1997, Le Skeul, Belle-île, Les preuves du temps, p. 169.

Le lapin/canard: http://www.illusions-optique.fr/illusions-optique-canard-lapin.html (consulté le : 24/03/09).

$\underline{\text { La convergence dans les pratiques des écrivains photographes }}$

BANIER, F-M., quatrième de couverture de Past-Present, New York, William Morrow, 1996. Voir l'image sur le site de l'auteur :

http://www.fmbanier.com/past_present_new_york_william_morrow_1996_3 (consulté le $: 25 / 10 / 2009$ ).

BANIER, F-M., «L'enfant terrible », Vanity fair, déc. 2006.

http://www.fmbanier.com/content/presse/pdf/PDF-PresseUSA/PDF-

VanityFair/VanityFair0612.pdf (consulté le : 25/10/2009).

GASPAR, Lorand, deux portraits sans mention de l'auteur, in Lorand Gaspar, Cognac, Le Temps qu'il fait, 2004, hors pagination.

TRASSARD, Jean-Loup, portrait sans mention de l'auteur sur le site de l'éditeur «Le Temps qu'il fait » :

http://www.letempsquilfait.com/Pages/Auteurs/Trassard/trassard.html (consulté le : 10/10/2009).

FAUCON, Bernard, Écritures, 1991-92 :

http://www.bernardfaucon.net/photos/index.htm (consulté le : 28/10/2009).

LEVE, Edouard, Entrée d'Angoisse, 2001, sur le site de la galerie Loevenbruck : http://www.loevenbruck.com/image.php?id=leve\&image=6 (consulté le : 31/08/2009).

\section{$\underline{\text { Conclusion }}$}

FAUCON, Bernard, Été 2050, sans pagination :

http://www.artnet.fr/magazine_fr/livres/caujolle/faucon_detail.asp (consulté le : 28/10/2009).

SUGIMOTO, Hiroshi, Stanley, New Jersey, 1993, sur le site de la galerie Fraenkel à San Francisco (consulté le : 20/10/2009) :

http://www.fraenkelgallery.com/index.php\#mi=2\&pt=1\&pi $=10000 \& s=7 \& a=26 \& p=0 \&$ $\underline{\mathrm{at}}=1$.

(C) Pour la reproduction des images tous droits réservés par les auteurs. 
Gyöngyi PÁL

Université de Szeged - École doctorale de théorie littéraire

Université Rennes 2 - CELAM (Centre d'études des littératures anciennes et modernes)

Résumé de la thèse en français:

Le dispositif photo-littéraire en France dans la seconde moitie du XXe siècle. Analyse de l'œuvre de François-Marie Banier, Jean-Loup Trassard, Lorand Gaspar et Denis Roche.

Au cours de la deuxième moitié du XXe siècle le statut de la photographie se trouve bouleversé : l'institutionnalisation du médium, son emploi dans les arts conceptuels, la crise du photojournalisme, l'avènement de la photographie digitale, en accord avec le passage à l'esthétique pragmatiste, influencent la reconnaissance de l'instabilité du signe et de la précarité du sens d'une œuvre. De nouveaux concepts apparaissent alors dans la définition de la photographie tels l'empreinte ou le dispositif, qui déplacent le sens de l'œuvre au delà de sa réalisation matérielle. Ce changement aura un impact sur la relation texte-image en général, ainsi que sur les œuvres photo-littéraires. Si le discours sur la photographie a toujours tourné autours de sa valeur de vérité, apposé au texte cette dernière devient problématique. La valeur documentaire paradoxale de la photo ouvre alors une multitude de possibilités de son utilisation dans les autobiographies, les autofictions ou les œuvres de fiction. La richesse des rapports texte/photo se dévoile également dans la partie qui met en parallèle des études monographiques consacrée à l'œuvre de François-Marie Banier, Jean-Loup Trassard, Lorand Gaspar et Denis Roche. Ces écrivains photographes nouent justement de différentes manières leur deux pratiques photographique et littéraire, dont l'étude nécessite aussi le développement de nouveaux outils méthodologiques. Inspiré des « cultural studies » ce travail cherche donc à comprendre l'émergence et le dépassement du problème de l'instabilité du signe dans la théorie de la photographie, dans les autobiographies photo-littéraires et dans les œuvres iconotextuelles des écrivains photographes. 
Résumé de la thèse en anglais:

The relation between photography and literature in France in the second half of the $20^{\text {th }}$ century. Study of François-Marie Banier, Jean-Loup Trassard, Lorand Gaspar and Denis Roche's work.

During the second half of the $20^{\text {th }}$ century the status of photography has changed: institutionalization of the medium, its use in conceptual art, the crisis of photojournalism, the invention of digital photography, together with the transition to more pragmatist aesthetics, have influenced the recognition of the always changing nature of signs. New concepts have appeared subsequently in the definition of photography such us the terms of "traces" and the so-called "dispositif". The limits of photography have thus extended beyond its physical manifestation. These transformations have caused a mutation in the text/image relationship in general. The possibilities of combining photos and texts are questioning the value of both mediums' truthfulness, which becomes problematic in particular in the use of photos in autobiographical writings. But once this problem was overcome a wide range of text/image combinations became possible either in autobiographical or fictional photo-literature writings. The second part of the study aims to explore these "intermedia" mixtures through a parallel monographical research on the work of François-Marie Banier, Jean-Loup Trassard, Lorand Gaspar and Denis Roche. These French artists are in fact mixing up their photographic and literary works, but each one in a different and personal way, which also requires developing new methods of analysis. This research therefore seeks to understand how the problem of the paradoxical meaning of photography appeared and was overcome in the theory of photography, in photo-literary autobiographies and in the works of writers who combine text with photography. 